\title{
LARGE-SCALE MERCURY CONTROL TECHNOLOGY TESTING FOR LIGNITE-FIRED UTILITIES - OXIDATION SYSTEMS FOR WET FGD
}

Final Report

(For the period of September 26, 2003, through March 31, 2007)

Prepared for:

AAD Document Control

U.S. Department of Energy

National Energy Technology Laboratory

3610 Collins Ferry Road, B26-269

PO Box 880, Mail Stop C04

Morgantown, WV 26507-0880

Cooperative Agreement No. DE-FC26-03NT41991

Performance Monitor: Andrew O'Palko

Prepared by:

Steven A. Benson

Michael J. Holmes

Donald P. McCollor

Jill M. Mackenzie Charlene R. Crocker

Lingbu Kong

Kevin C. Galbreath

Energy \& Environmental Research Center

University of North Dakota 15 North 23rd Street, Stop 9018

Grand Forks, ND 58202-9018

Katherine Dombrowski Carl Richardson

URS Corporation

9400 Amberglen Boulevard

Austin, TX 78729 


\section{DISCLAIMER}

This report was prepared as an account of work sponsored by an agency of the United States Government. Neither the United States Government, nor any agency thereof, nor any of their employees makes any warranty, express or implied, or assumes any legal liability or responsibility for the accuracy, completeness, or usefulness of any information, apparatus, product, or process disclosed or represents that its use would not infringe privately owned rights. Reference herein to any specific commercial product, process, or service by trade name, trademark, manufacturer, or otherwise does not necessarily constitute or imply its endorsement, recommendation, or favoring by the United States Government or any agency thereof. The views and opinions of authors expressed herein do not necessarily state or reflect those of the United States Government or any agency thereof.

This report is available to the public from the National Technical Information Service, U.S. Department of Commerce, 5285 Port Royal Road, Springfield, VA 22161; phone orders are accepted at (703) 487-4650.

\section{DOE DISCLAIMER}

This report was prepared with the support of the U.S. Department of Energy (DOE) National Energy Technology Laboratory Cooperative Agreement No. DE-FC26-03NT41991. However, any opinions, findings, conclusions, or recommendations expressed herein are those of the authors and do not necessarily reflect the views of DOE.

This report was prepared by the Energy \& Environmental Research Center (EERC), an agency of the University of North Dakota, as an account of work sponsored by DOE; Apogee; the Babcock \& Wilcox Company, Inc.; Basin Electric Power Cooperative; BNI Coal, Ltd.; Dakota Westmoreland Corporation; Electric Power Research Institute; Great River Energy; Minnkota Power Cooperative, Inc.; Montana-Dakota Utilities Co.; North American Coal Corporation; North Dakota Industrial Commission; Otter Tail Power Company; SaskPower; TXU Corporation; and URS Corporation.

\section{EERC DISCLAIMER}

LEGAL NOTICE This research report was prepared by the Energy \& Environmental Research Center (EERC), an agency of the University of North Dakota, as an account of work sponsored by U.S. Department of Energy. Because of the research nature of the work performed, neither the EERC nor any of its employees makes any warranty, express or implied, or assumes any legal liability or responsibility for the accuracy, completeness, or usefulness of any information, apparatus, product, or process disclosed or represents that its use would not infringe privately owned rights. Reference herein to any specific commercial product, process, or service by trade name, trademark, manufacturer, or otherwise does not necessarily constitute or imply its endorsement or recommendation by the EERC. 


\section{ACKNOWLEDGMENTS}

The EERC's project manager and principal investigators are grateful to the following organizations for their support, technical advice, and assistance in completing this draft final report:

- U.S. Department of Energy National Energy Technology Laboratory

- Apogee

- Babcock \& Wilcox Company, Inc.

- Basin Electric Power Cooperative

- BNI Coal, Ltd.

- Dakota Westmoreland Corporation

- Electric Power Research Institute

- Great River Energy

- Minnkota Power Cooperative, Inc.

- Montana-Dakota Utilities Co.

- North American Coal Corporation

- North Dakota Industrial Commission

- Otter Tail Power Company

- SaskPower

- TXU Energy

- URS Corporation 


\title{
LARGE-SCALE MERCURY CONTROL TECHNOLOGY TESTING FOR LIGNITE-FIRED UTILITIES - OXIDATION SYSTEMS FOR WET FGD
}

\begin{abstract}
Mercury (Hg) control technologies were evaluated at Minnkota Power Cooperative's Milton R. Young (MRY) Station Unit 2, a 450-MW lignite-fired cyclone unit near Center, North Dakota, and TXU Energy's Monticello Steam Electric Station (MoSES) Unit 3, a 793-MW lignite-Powder River Basin (PRB) subbituminous coal-fired unit near Mt. Pleasant, Texas. A cold-side electrostatic precipitator (ESP) and wet flue gas desulfurization (FGD) scrubber are used at MRY and MoSES for controlling particulate and sulfur dioxide $\left(\mathrm{SO}_{2}\right)$ emissions, respectively. Several approaches for significantly and cost-effectively oxidizing elemental mercury $\left(\mathrm{Hg}^{0}\right)$ in lignite combustion flue gases, followed by capture in an ESP and/or FGD scrubber were evaluated. The project team involved in performing the technical aspects of the project included Babcock \& Wilcox, the Energy \& Environmental Research Center (EERC), the Electric Power Research Institute, and URS Corporation. Calcium bromide $\left(\mathrm{CaBr}_{2}\right)$, calcium chloride $\left(\mathrm{CaCl}_{2}\right)$, magnesium chloride $\left(\mathrm{MgCl}_{2}\right)$, and a proprietary sorbent enhancement additive (SEA), hereafter referred to as SEA2, were added to the lignite feeds to enhance $\mathrm{Hg}$ capture in the ESP and/or wet FGD. In addition, powdered activated carbon (PAC) was injected upstream of the ESP at MRY Unit 2. The work involved establishing $\mathrm{Hg}$ concentrations and removal rates across existing ESP and FGD units, determining costs associated with a given $\mathrm{Hg}$ removal efficiency, quantifying the balance-of-plant impacts of the control technologies, and facilitating technology commercialization. The primary project goal was to achieve ESP-FGD Hg removal efficiencies of $\geq 55 \%$ at MRY and MoSES for about a month.
\end{abstract}

$\mathrm{Hg}$ in the lignite coal fired in MRY Unit 2 varied from 0.05 to $0.25 \mathrm{ppm}$ and averaged $0.112 \pm 0.014 \mathrm{ppm}$ (dry coal basis). Most of the $\mathrm{Hg}$ was associated with Hg-rich (2.28 ppm) pyrite grains that ranged in concentration from about 1 to $6 \mathrm{wt} \%$ (on a dry coal basis). During routine power plant operations, total $\mathrm{Hg}$ concentrations at the ESP and FGD inlets varied from about 12 to $16 \mu \mathrm{g} / \mathrm{dNm}^{3}$, whereas at the stack, concentrations were consistently at approximately $13 \mu \mathrm{g} / \mathrm{dNm}^{3}$, indicating that the ESP and FGD were very inefficient at removing $\mathrm{Hg}$ primarily because $\mathrm{Hg}^{0}$ was dominant. $\mathrm{MgCl}_{2}$ and $\mathrm{CaCl}_{2}$ injections were relatively ineffective in promoting $\mathrm{Hg}^{0}$ oxidation and capture in an ESP-FGD. Relatively low additions of SEA2, however, significantly improved the $\mathrm{Hg}$ removal efficiency of the ESP-FGD, although the goal of $55 \% \mathrm{Hg}$ removal was not achieved using as much as 75 ppm SEA2 (dry coal basis). Most of the $\mathrm{Hg}$ removal occurred in the ESP, suggesting that SEA2 addition promoted the conversion of $\mathrm{Hg}^{0}$ to particulate-bound Hg. SEA2 addition (50-100 ppm, dry coal basis) combined with 0.15-lb/Macf $\mathrm{PAC}$ injection was performed for a month during which $\mathrm{Hg}$ removal efficiencies generally ranged from $50 \%$ to $65 \%$.

The mobility of Hg in MRY fly ashes sampled before and after PAC and SEA2 injections was evaluated using a synthetic groundwater leaching procedure augmented with long-term treatments of 30 and 60 days. $\mathrm{Hg}$ was not detected in any of the leachates, indicating that it was relatively insoluble during the test conditions. The thermal stability of $\mathrm{Hg}$ in fly ash samples collected during baseline and $\mathrm{Hg}$ control technology testing conditions was evaluated by heating 
at $25^{\circ} \mathrm{C} / \mathrm{min}$ to $750^{\circ} \mathrm{C}$. The fly ash samples collected during baseline and $\mathrm{Hg}$ control technology testing conditions at the MRY power plant released $\mathrm{Hg}$ at about $375^{\circ}$ and $400^{\circ} \mathrm{C}$, respectively. The fly ash sampled during $\mathrm{Hg}$ control technology testing also released some $\mathrm{Hg}$ at approximately $550^{\circ} \mathrm{C}$. The $\mathrm{Hg}$ captured on fly ash and PAC during SEA2 injections was thermally more stable relative to the baseline fly ash.

Economic evaluations of $\mathrm{Hg}$ control for MRY Unit 2 were performed assuming various $\mathrm{CaCl}_{2}, \mathrm{SEA} 2, \mathrm{CaCl}_{2}$ with PAC, and SEA2 with PAC injection rates. The cost for maintaining a $55 \% \mathrm{Hg}$ removal efficiency at MRY Unit 2 by using SEA2 in combination with a small amount of PAC was estimated as follows:

- Levelized annual cost: $\$ 2,121,169$

- Annual cost, $\$ / \mathrm{MWh}$ (mills $/ \mathrm{kWh}): 0.63$

- Cost of mercury removal, $\$ / \mathrm{lb}: 16,639$

MoSES Unit 3 fires a 50:50 blend of Texas lignite and subbituminous PRB coals. PRB coal $\mathrm{Hg}$ concentrations ranged from 0.04 to $0.09 \mathrm{ppm}$ (dry coal basis), and Texas lignite coal $\mathrm{Hg}$ concentrations were highly variable, ranging from 0.17 to $0.36 \mathrm{ppm}$ (dry coal basis). ESP inlet $\mathrm{Hg}$ concentrations ranged widely from 15 to $30 \mu \mathrm{g} / \mathrm{dNm}^{3}$ (at $3 \% \mathrm{O}_{2}$ ). Baseline flue gas $\mathrm{Hg}$ measurements indicated that the ESP outlet flue gas contained about $25 \% \mathrm{Hg}^{2+}$ and $75 \% \mathrm{Hg}^{0}$, with a total $\mathrm{Hg}$ concentration of about $20 \mu \mathrm{g} / \mathrm{dNm}^{3}$. Coal and ash $\mathrm{Hg}$ analysis results corroborated flue gas measurements that indicated only a small amount of $\mathrm{Hg}$ removal $(<5 \%)$ upstream of the ESP and no removal across the ESP.

Parametric tests conducted with $\mathrm{CaCl}_{2}$ and $\mathrm{CaBr}_{2}$ demonstrated that it was possible to increase the oxidation of $\mathrm{Hg}^{0}$ in the flue gas and to simultaneously increase $\mathrm{Hg}$ removal by the FGD. $\mathrm{CaCl}_{2}$ provided only nominal improvements in $\mathrm{Hg}^{0}$ oxidation even at the highest tested injection rate of $800 \mathrm{ppm} \mathrm{Cl}$ in the coal. $\mathrm{CaCl}_{2}$ injection was incapable of sustaining the $\mathrm{Hg}^{0}$ oxidation necessary for the $\mathrm{Hg}$ removal target of $55 \%$. In contrast, parametric tests with $\mathrm{CaBr}_{2}$ demonstrated up to $78 \% \mathrm{Hg}^{0}$ oxidation at an injection rate of $200 \mathrm{ppm} \mathrm{Br}$ in the coal. Based on these parametric test results, $\mathrm{CaBr}_{2}$ was selected for evaluation involving two 2-week continuous-injection tests.

The first of these tests was conducted at an average injection rate of $55 \mathrm{ppm} \mathrm{Br}$ in the coal. This injection rate achieved an average $67 \% \mathrm{Hg}^{0}$ oxidation at the scrubber inlet, and the average removal of $\mathrm{Hg}$ across the scrubber was $65 \%$. These values represent averages over a 2 -week injection test; however, it was observed with the continuous mercury monitors (CMMs) that the scrubber outlet total $\mathrm{Hg}$ concentration steadily increased over the test period. These results were confirmed with Appendix K measurements. Therefore, a higher injection rate was evaluated during the second 2-week injection test. The $\mathrm{CaBr}_{2}$ injection rate was increased to an average $113 \mathrm{ppm} \mathrm{Br}$ in the coal. During ten days at this injection rate, the Hg at the ESP inlet was on average $85 \%$ oxidized. Hg removal across the system averaged $86 \%$. With the exception of a few brief periods, an injection rate of $113 \mathrm{ppm} \mathrm{Br}$ was sufficient to consistently maintain scrubber outlet $\mathrm{Hg}$ concentrations at $<5 \mu \mathrm{g} / \mathrm{dNm}^{3}\left(\right.$ at $\left.3 \% \mathrm{O}_{2}\right)$. 
The furnace injection of $\mathrm{CaBr}_{2}$ did not significantly improve ESP $\mathrm{Hg}$ removal. The oxidized $\mathrm{Hg}$ was removed by the FGD scrubber, as expected. During baseline and the first week of each long-term injection test, $\mathrm{Hg}$ partitioned to the FGD solids; however, during the second week of each test, $\mathrm{Hg}$ transitioned to the liquor phase. At an injection rate of $113 \mathrm{ppm} \mathrm{Br}$ in the coal, $>85 \%$ of the $\mathrm{Hg}$ in the FGD by-product was contained in the liquor.

These two 2-week furnace injection tests were not long enough to evaluate the balance-ofplant effects. A unit inspection after the test program did not indicate any bromine-related corrosion; however, the test period was too short for an adequate corrosion evaluation. The effect of increased bromine concentration in the FGD liquor on FGD performance and corrosion of FGD materials of construction needs to be determined. Duct corrosion and air heater plugging also need to be evaluated in a longer-term test. Finally, the effect of increased bromine concentrations on the marketability of the coal combustion by-products must be addressed.

Economic evaluations of $\mathrm{Hg}$ control for MoSES Unit 3 were performed assuming various $\mathrm{CaBr}_{2}$ injection rates. The cost for maintaining a $\geq 55 \%$ mercury removal efficiency at MoSES Unit 3 using $\mathrm{CaBr}_{2}$ was estimated as follows:

- Levelized annual cost: $\$ 2,933,996$

- Annual cost, \$/MWh (mills/kWh): 0.50

- Cost of mercury removal, \$/lb: 7336 


\section{TABLE OF CONTENTS}

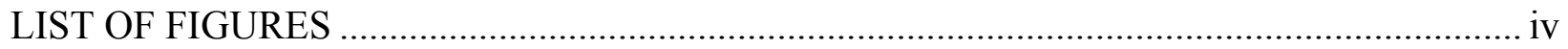

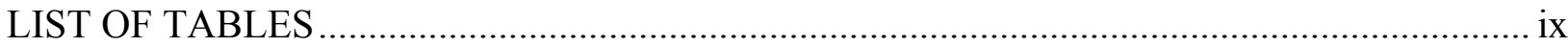

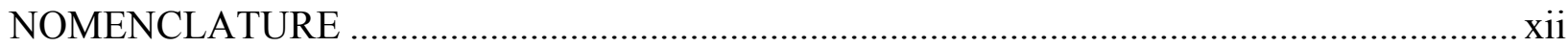

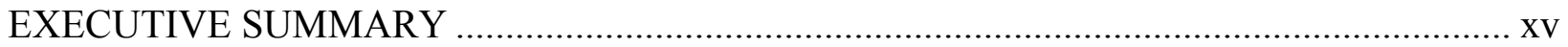

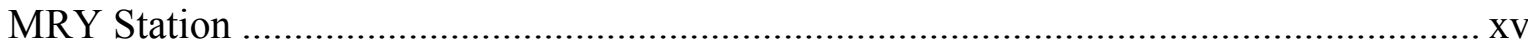

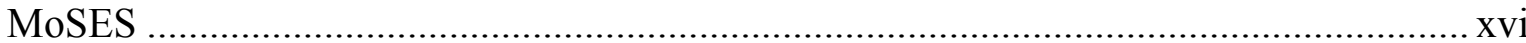

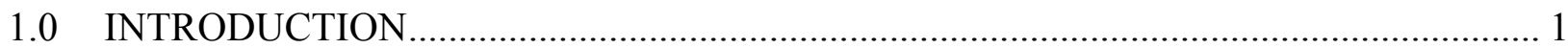

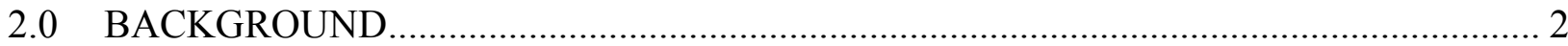

2.1 World and U.S. Mercury Emission Budget ......................................................... 2

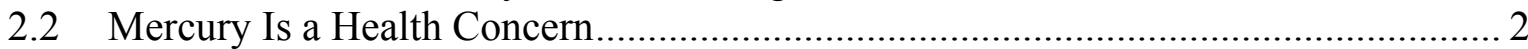

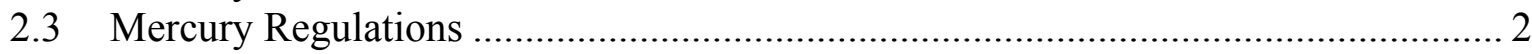

2.4 Mercury Emissions from Low-Rank Coals Will Be Difficult to Control .................... 3

2.5 Mercury Control Options..................................................................................... 4

2.5.1 Previous Results with $\mathrm{Hg}^{0}$ Oxidation Technologies...................................... 4

2.5.2 Previous Results with PAC Injection …………........................................ 5

2.5.3 Previous Results with SEAs …………………...................................... 9

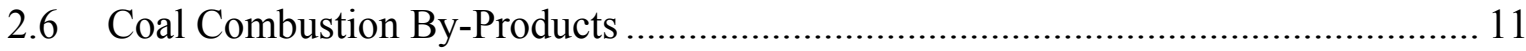

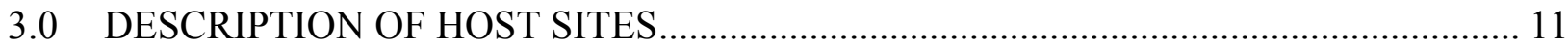

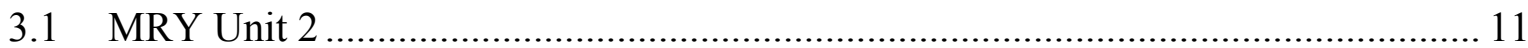

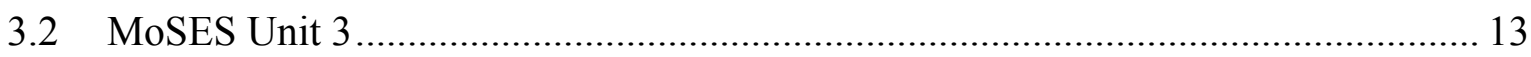

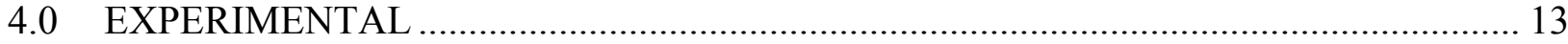

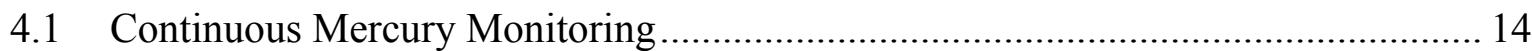

4.2 OH Flue Gas Mercury Measurements .................................................................. 15

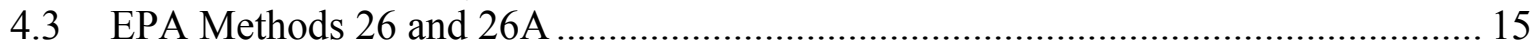

4.4 Sampling and Analysis of Coal Fly Ash............................................................... 16

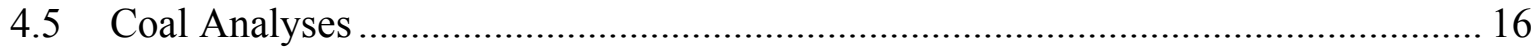

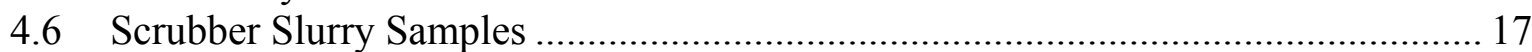

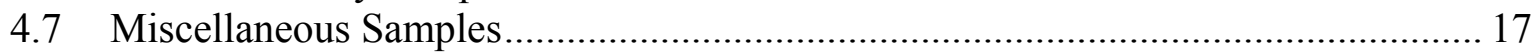

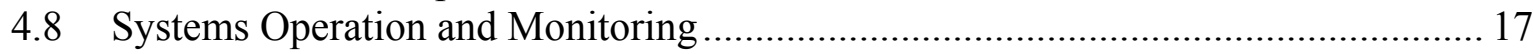

4.8.1 Aqueous $\mathrm{CaCl}_{2}, \mathrm{CaBr}_{2}, \mathrm{MgCl}_{2}$, and SEA2 Addition System....................... 17

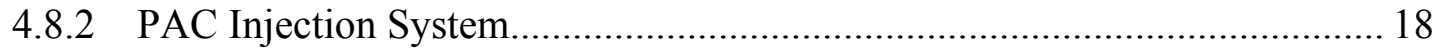

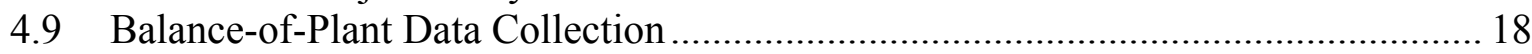

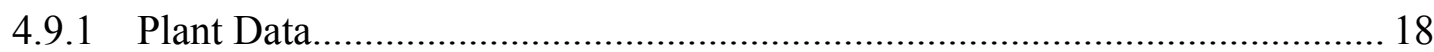

4.9.2 Corrosion/Deposition Probes......................................................................... 18

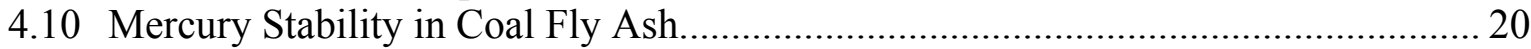

Continued. . . 


\section{TABLE OF CONTENTS (continued)}

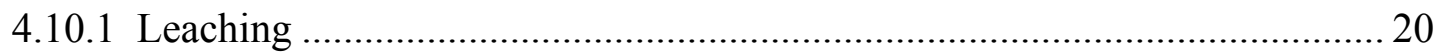

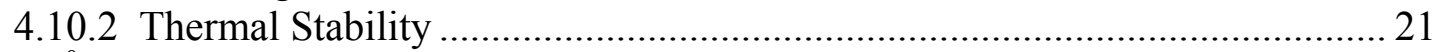

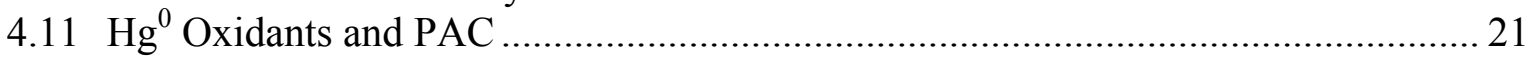

5.0 RESULTS AND DISCUSSION FOR MRY UNIT 2 TESTING ………………............. 22

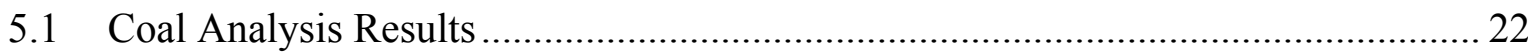

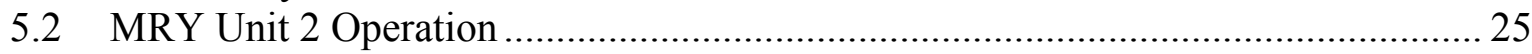

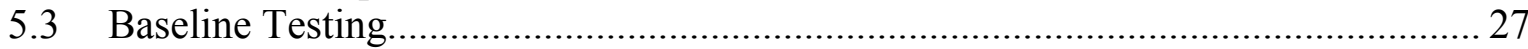

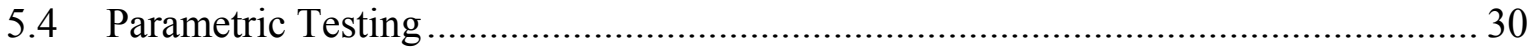

5.4.1 Effects of $\mathrm{CaCl}_{2}, \mathrm{MgCl}_{2}$, and SEA2 Additions on $\mathrm{Hg}$ Speciation and ESP-Wet FGD Capture ...................................................................................... 30

5.4.2 Effects of PAC Injection and $\mathrm{CaCl}_{2}$ and SEA2 Additions on $\mathrm{Hg}$ Speciation and ESP-Wet FGD Capture ……………………………………..... 34

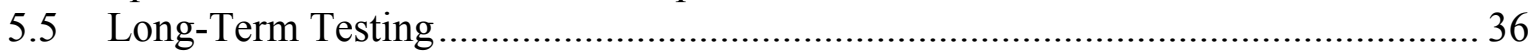

6.0 RESULTS AND DISCUSSION FOR MoSES UNIT 3 TESTING .................................... 40

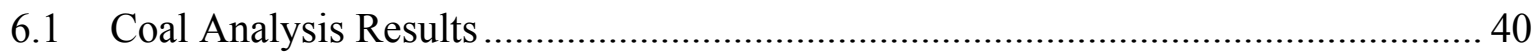

6.2 Baseline Testing............................................................................................. 44

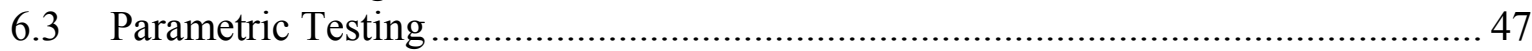

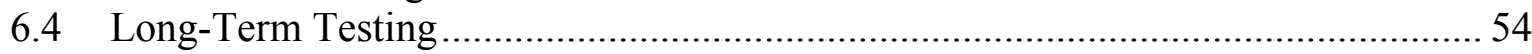

6.4.1 Evaluation of Actual $\mathrm{CaBr}_{2}$ Injection Rates ............................................... 54

6.4.2 Summary of Mercury Data from Long-Term Injection Test No. 1 ............... 58

6.4.3 Summary of Mercury Data from Long-Term Injection Test No. 2 ............... 64

7.0 BALANCE-OF-PLANT EFFECTS OF HG CONTROL TECHNOLOGIES AT

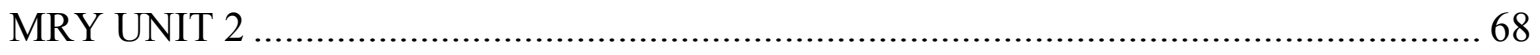

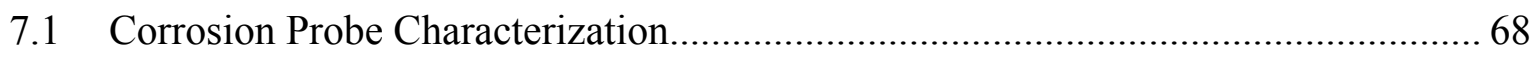

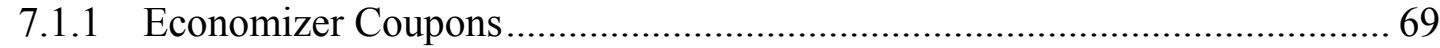

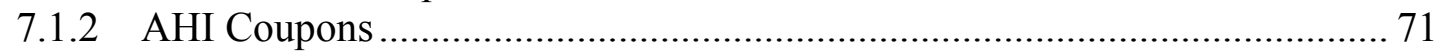

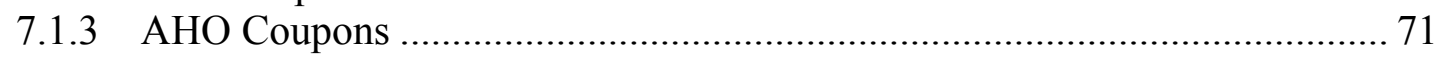

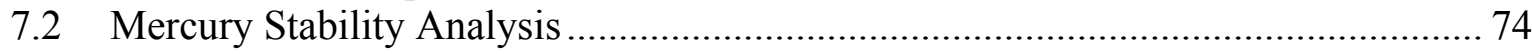

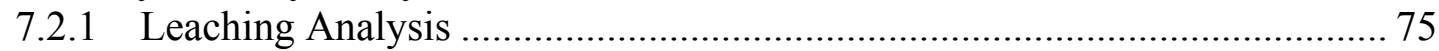

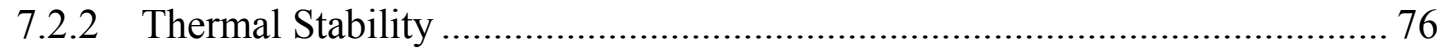

8.0 BALANCE-OF-PLANT EFFECTS OF HG CONTROL TECHNOLOGIES AT

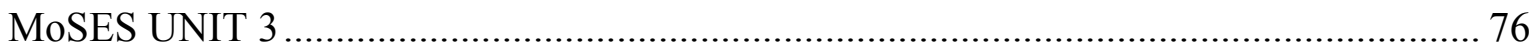

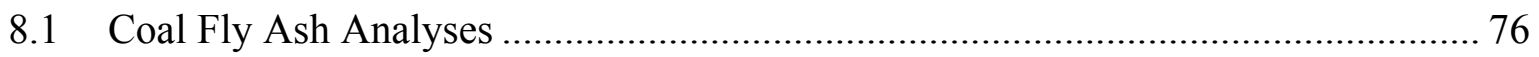

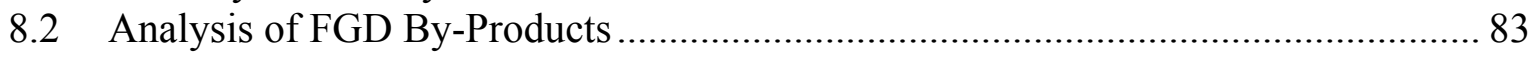

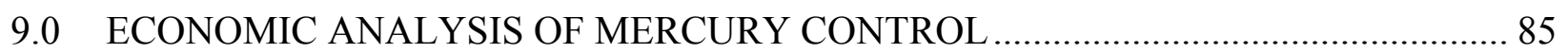

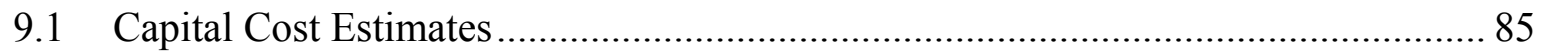

9.1.1 PAC Feeder System............................................................................. 87

Continued. . . 


\section{TABLE OF CONTENTS (continued)}

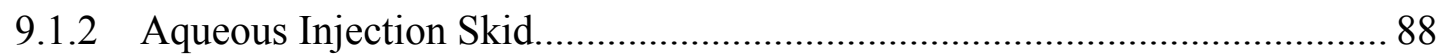

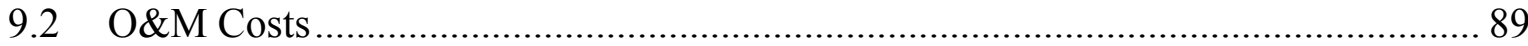

9.2.1 Maintenance and Replacement Parts .......................................................... 89

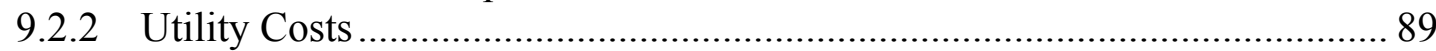

9.3 Economic Evaluation of Mercury Control at MRY Station Unit 2 ..........................90

9.4 Economic Evaluation of Mercury Control at MoSES Unit 3 ………….................... 91

10.0 COSTS OF MERCURY MEASUREMENT AND REPORTING UNDER CAMR …...... 91

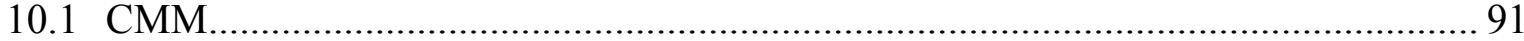

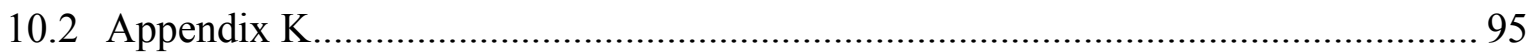

10.3 Reporting and Record-Keeping Requirements under CAMR ……...........................96

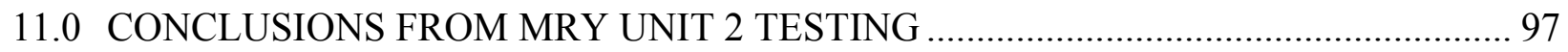

12.0 CONCLUSIONS FROM MoSES UNIT 3 TESTING ….................................................... 98

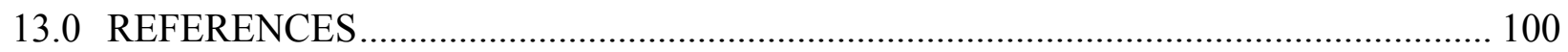

MERCURY CONTROL FIELD TESTING AT MILTON R. YOUNG STATION.....Appendix A MERCURY CONTROL FIELD TESTING AT MONTICELLO STEAM ELECTRIC STATION Appendix B 


\section{LIST OF FIGURES}

2-1 Kinetic model (Chemkin) prediction of chlorine radical concentration as a function of the temperature and residence time profile of a utility boiler ........................................... 6

2-2 Ontario Hydro (OH) $\mathrm{Hg}$ speciation results showing the effects of a coal $\mathrm{Hg}^{0}$ oxidation agent on North Dakota lignite combustion flue gas Hg speciation.

2-3 Comparison of $\mathrm{Hg}^{0}$ oxidation and $\mathrm{HCl}$ flue gas concentrations during salt injections at a North Dakota lignite-fired power plant

2-4 Pilot-scale ESP and full-scale ESP Hg removal efficiencies as a function of activated

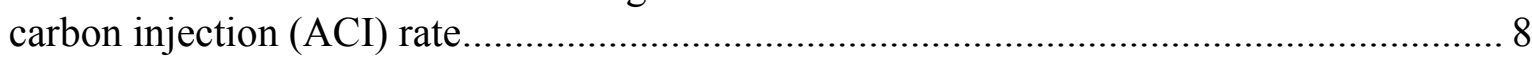

2-5 Pilot-scale ESP-FF and full-scale TOXECON and ESP Hg removal efficiencies

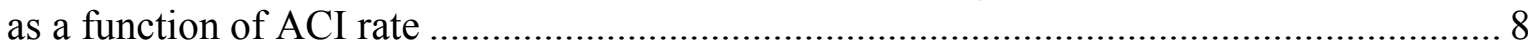

2-6 Hg emissions for PAC injection combined with additives ............................................... 10

2-7 ESP inlet and outlet total $\mathrm{Hg}$ concentrations as functions of PAC injection and SEA addition rates into North Dakota lignite combustion flue gases ......................................... 10

3-1 Schematic of MRY Unit 2 showing sampling and coal additive locations......................... 12

3-2 Average $\mathrm{OH} \mathrm{Hg}$ speciation results obtained at the ESP and wet FGD inlets and stack of

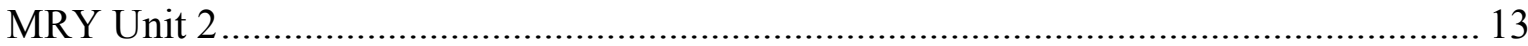

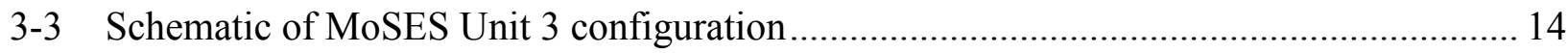

4-1 Photograph of the corrosion/deposition probe assembly ……………............................... 19

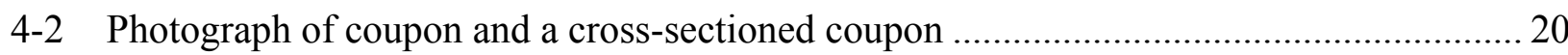

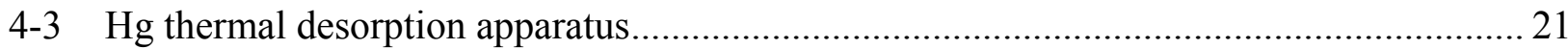

5-1 Temporal variations in MRY Unit 2 lignite Hg concentrations .........................................2

5-2 MRY Unit 2 lignite pyrite versus Hg concentrations (on a dry basis), correlation coefficient of 0.941

5-3 MRY Unit 2 lignite Hg versus $\mathrm{S}$ concentrations (on a dry basis), correlation coefficient

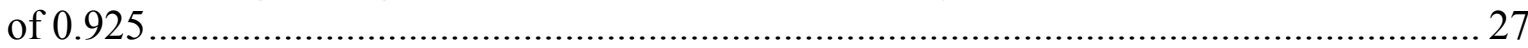

Continued. . . 


\section{LIST OF FIGURES (continued)}

5-4 Summary of MRY unit operational and emission data .............................................. 28

5-5 Baseline $\mathrm{OH} \mathrm{Hg} \mathrm{measurement} \mathrm{results..................................................................} 29$

5-6 Average $\mathrm{Hg}$ speciation results for Center lignite combustion flue gases containing

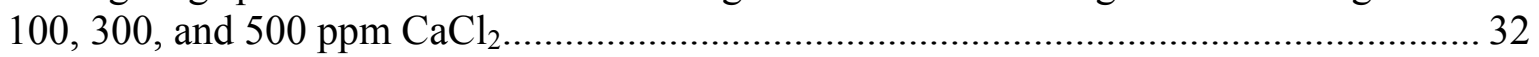

5-7 ESP-wet FGD $\mathrm{Hg}$ removal efficiencies during $\mathrm{CaCl}_{2}, \mathrm{MgCl}_{2}$, and $\mathrm{SEA} 2$ additions ......... 33

5-8 Stack CMM results before, during, and after SEA2 additions ..................................... 33

5-9 Effects of PAC injection alone and in combination with $\mathrm{CaCl}_{2}$ or SEA2 additions on

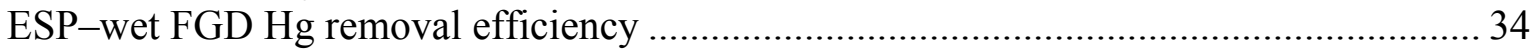

5-10 Stack CMM results obtained before, during, and after $\mathrm{PAC}$ injections and $\mathrm{CaCl}_{2}$ addition at $300 \mathrm{ppm}$

5-11 Stack CMM results obtained before, during, and after PAC injections and SEA2

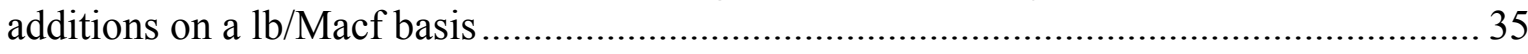

5-12 $\mathrm{OH} \mathrm{Hg} \mathrm{speciation} \mathrm{results} \mathrm{obtained} \mathrm{during} \mathrm{PAC} \mathrm{injection} \mathrm{and} \mathrm{SEA2} \mathrm{additions.................} 36$

5-13 SEA2 addition rates during the long-term testing at MRY Unit 2 .............................. 38

5-14 ESP-wet FGD Hg removal efficiencies during extended testing at MRY Unit 2 ............ 38

5-15 PAC injection rates during the long-term testing at MRY Unit 2 ................................ 39

5-16 Cumulative frequency percent plot for $\mathrm{Hg}$ removal efficiencies attained at MRY Unit 2 during (April 19 - May 18, 2005) SEA 2 (50-100 ppm, dry coal basis) and $0.15 \mathrm{lb} / \mathrm{Macf}$ PAC injections 39

6-1 Coal mercury concentrations measured during test program 43

6-2 Comparison of ESP inlet vapor-phase mercury (as measured by SCEM) to coal mercury concentration.

6-3 Baseline mercury SCEM data measured prior to parametric mercury control injection tests at MoSES Unit 3

Continued. . . 


\section{LIST OF FIGURES (continued)}

6-4 Baseline mercury SCEM data measured prior to the first set of long-term mercury control injection tests at MoSES Unit 3

6-5 Baseline mercury SCEM data measured prior to the second set of long-term mercury control injection tests at MoSES Unit 3 ........................................................................... 46

6-6 SCEM concentrations measured during $\mathrm{CaCl}_{2}$ parametric injection tests ......................... 48

6-7 SCEM concentrations measured during $\mathrm{CaBr}_{2}$ parametric injection tests .......................... 49

6-8 Percent oxidized mercury present at ESP inlet and outlet for $\mathrm{CaCl}_{2}$ parametric

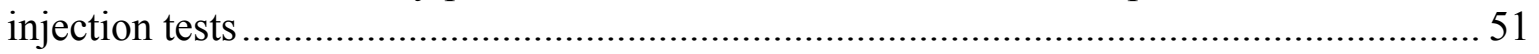

6-9 Percent oxidized mercury present at ESP inlet and outlet for $\mathrm{CaBr}_{2}$ parametric

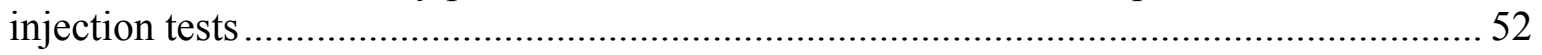

6-10 Mercury removal across the ESP and FGD for $\mathrm{CaCl}_{2}$ during parametric injection tests at MoSES

6-11 Mercury removal across the ESP and FGD for $\mathrm{CaBr}_{2}$ during parametric injection tests at MoSES.

6-12 Actual additive injection rate of $\mathrm{CaBr}_{2}$ and M26 measurements during first 2-week long-term test period at MoSES 55

6-13 Actual additive injection rate of $\mathrm{CaBr}_{2}$ and $\mathrm{M} 26$ measurements during second 2-week long-term test period at MoSES

6-14 Hourly averaged total mercury concentration from SCEM data collected during $\mathrm{CaBr}_{2}$ injection at approximately $55 \mathrm{ppm} \mathrm{Br}$ equivalent in the dry coal, first 2-week long-term test at MoSES

6-15 ESP inlet total and elemental mercury concentrations measured during $\mathrm{CaBr}_{2}$ injection at approximately $55 \mathrm{ppm} \mathrm{Br}$ equivalent in the dry coal, first 2-week long-term test at MoSES

6-16 ESP outlet total and elemental mercury concentrations measured during $\mathrm{CaBr}_{2}$ injection at approximately $55 \mathrm{ppm} \mathrm{Br}$ equivalent in the dry coal, first 2-week long-term test at MoSES

Continued. . . 


\section{LIST OF FIGURES (continued)}

6-17 FGD outlet total and elemental mercury concentrations measured during $\mathrm{CaBr}_{2}$ injection at approximately $55 \mathrm{ppm}$ Br equivalent in the dry coal, first 2-week long-term test at MoSES

6-18 Effect of coal blend on oxidation and removal of flue gas mercury during long-term test No.

6-19 Comparison of scrubber inlet elemental mercury concentration to scrubber outlet total mercury concentration during the first long-term $\mathrm{CaBr}_{2}$ injection test at MoSES

6-20 Comparison of Appendix K data with SCEM data

6-21 Hourly averaged SCEM data collected during the second long-term $\mathrm{CaBr}_{2}$ injection test at MoSES

6-22 ESP inlet total and elemental mercury concentrations measured during the second long-term $\mathrm{CaBr}_{2}$ injection test at MoSES.

6-23 ESP outlet total and elemental mercury concentrations measured during the second long-term $\mathrm{CaBr}_{2}$ injection test at MoSES

6-24 FGD outlet total and elemental mercury concentrations measured during the second long-term $\mathrm{CaBr}_{2}$ injection test at MoSES

6-25 Comparison of ESP outlet elemental mercury concentrations to scrubber outlet total mercury concentrations during the second long-term $\mathrm{CaBr}_{2}$ injection test at MoSES

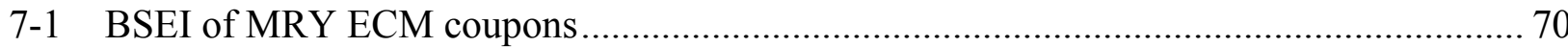

7-2 Comparison of ECM baseline and long-term coupons .............................................. 70

7-3 Comparison of additional ECM baseline and long-term coupons ................................. 71

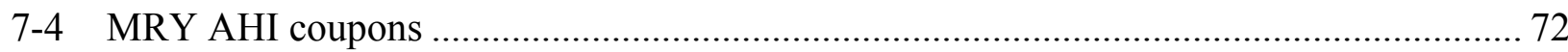

7-5 Comparison of AHI baseline and $\mathrm{Hg}$ control coupons (curved side) ............................ 72

7-6 Comparison of AHI baseline and $\mathrm{Hg}$ control coupons (flat side) ................................ 73

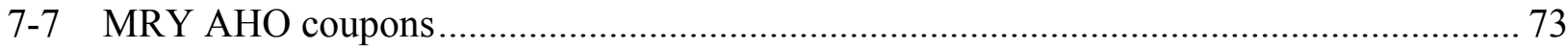

Continued. . . 


\section{LIST OF FIGURES (continued)}

7-8 Comparison of AHO baseline and long-term coupons ............................................. 74

7-9 Comparison of additional AHO baseline and long-term coupons ............................... 75

7-10 Sample 05-005 example AA mercury thermal desorption curve ................................. 77

7-11 Sample 05-017 example AA mercury thermal desorption curve ................................ 77

8-1 Mercury concentration of fly ash during baseline and first continuous-injection test....... 81

8-2 Mercury concentration of fly ash during baseline and second continuous-injection test ... 81

8-3 Ratio of mercury content in ash collected $(\mathrm{g} / \mathrm{hr})$ to mercury content in coal fired $(\mathrm{g} / \mathrm{hr}) \ldots 82$

8-4 Shift in mercury content of FGD by-product from solid to liquid phase during second

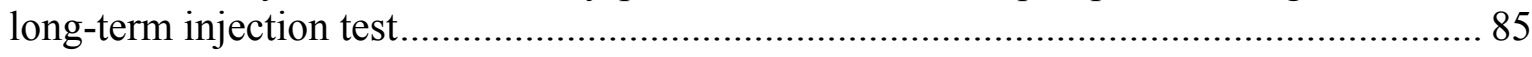

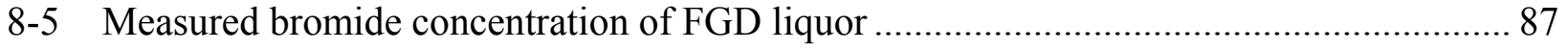




\section{LIST OF TABLES}

2-1 Average Hg Removal Efficiencies (\%) by Coal Rank and APCD Configuration ............... 5

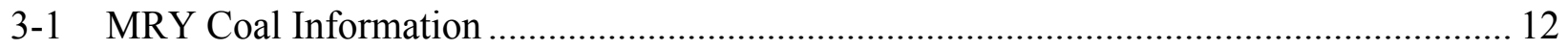

4-1 General Properties of NORIT Americas Inc. DARCO Hg ........................................... 22

5-1 Summary of MRY Unit 2 Coal Analysis Results ................................................... 23

5-2 Triplicate and Average MRY Coal Ash Elemental Oxide Compositions......................... 23

5-3 Average MRY Coal Chemical Fractionation Results ................................................ 24

5-4 Quantitative MRY Unit 2 Coal Mineral Analyses ..................................................... 24

5-5 Statistical Summary of MRY Unit 2 Coal Hg Analysis Results................................... 26

5-6 Comparison of $\mathrm{OH}$ and CMM Results $\left(\mu \mathrm{g} / \mathrm{dNm}^{3}\right)$ Obtained Concurrently During Baseline Testing Conditions (March 17 and 18, 2005).................................................. 29

5-7 Duplicate $\mathrm{Hg}, \mathrm{Br}$, and Cl Analysis Results for Fly Ashes Sampled from the ESP During Baseline Testing Conditions 30

5-8 Comparison of $\mathrm{OH}$ and CMM Results $\left(\mu \mathrm{g} / \mathrm{dNm}^{3}\right)$ Obtained Concurrently During Parametric Testing Conditions (March 18-April 1, 2005) ............................................. 31

5-9 Comparison of Average $\mathrm{OH}$ and CMM Results $\left(\mu \mathrm{g} / \mathrm{dNm}^{3}\right)$ Obtained Concurrently During Long-Term Testing Conditions (April 5-May 17, 2005) 37

5-10 Hg, Br, and Cl Analysis Results (ppm) for Fly Ashes Sampled from the ESP During

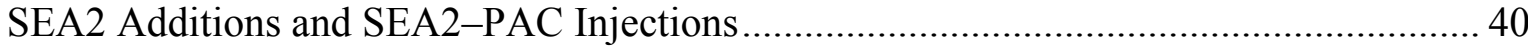

6-1 Unit 1 - Texas Lignite Coal Analyses for Long-Term Injection Test .......................... 41

6-2 Unit 1 - PRB Coal Analyses for Long-Term Injection Test ....................................... 42

6-3 Comparison of Measured Flue Gas $\mathrm{HCl}$ Concentrations to Theoretical Predictions for Parametric Tests at MoSES.

6-4 Comparison of Measured Flue Gas HBr Concentrations to Theoretical Predictions for Parametric Tests at MoSES .

Continued. . . 


\section{LIST OF TABLES (continued)}

6-5 Average Mercury Concentrations During Parametric Injection Tests at MoSES 49

6-6 Percent Oxidation of Mercury at ESP Inlet and Outlet Measured During Parametric Injection Tests

6-7 Comparison of Measured Flue Gas HBr Concentrations to Theoretical Predictions for MoSES Long-Term Tests.

6-8 Method 26A Measurement Results from the MoSES Long-Term Injection Test at $55 \mathrm{ppm}$ Br Equivalent in the Coal 57

6-9 Appendix K Measurements at Unit 3 Stack During Long-Term Test No. 1

6-10 Average FGD Outlet Mercury Concentrations Measured by SCEM During the Long-Term Injection Tests at MoSES

6-11 Ratio of Oxidized Mercury in Flue Gas to Average Coal Mercury Content During the Long-Term Injection Tests

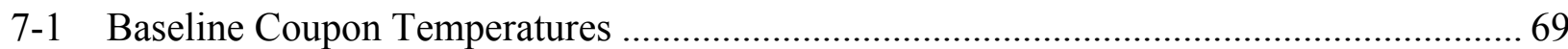

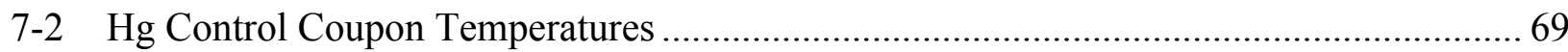

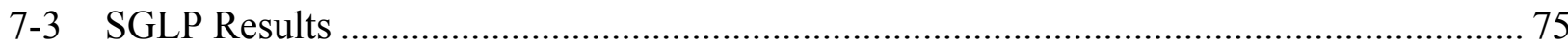

7-4 Longer-Term Fly Ash Hg Leaching Results .................................................................. 76

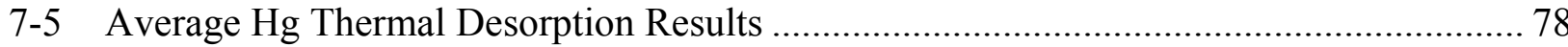

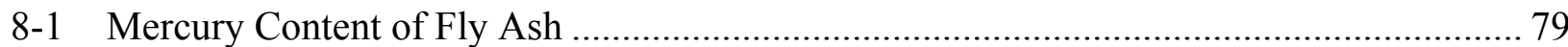

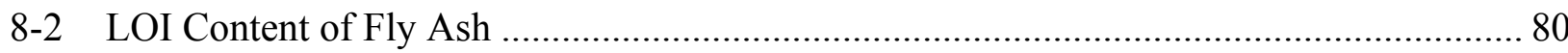

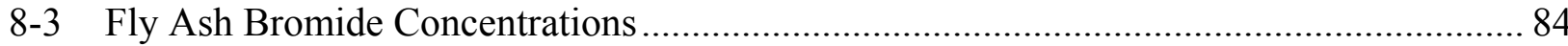

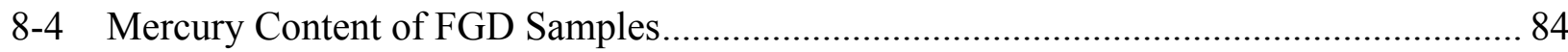

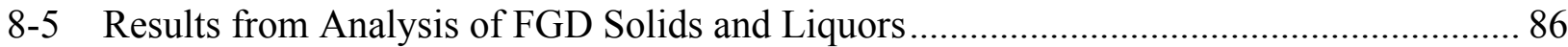

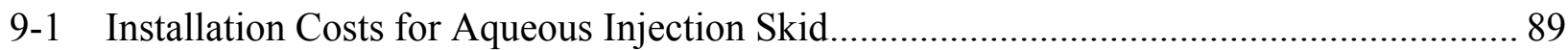

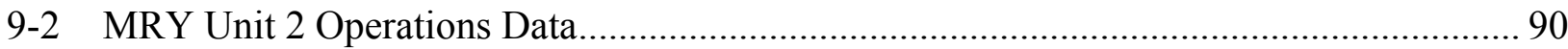

Continued. . . 


\section{LIST OF TABLES (continued)}

9-3 Summary of Costs Associated with Mercury Control at MRY Unit 2 ........................... 92

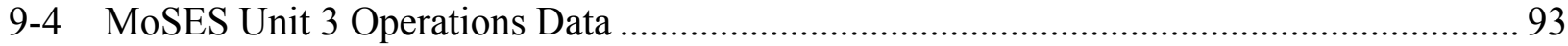

9-5 Cost Estimates Associated with Controlling Mercury at MoSES Unit 3 ....................... 93

10-1 Supplies Needed to Operate a Tekran CMM ........................................................ 95

10-2 Comparison of the Total Costs for Appendix K and CMM .......................................... 97 


\section{NOMENCLATURE}

\begin{tabular}{|c|c|}
\hline AAS & atomic absorption spectroscopy \\
\hline ACI & activated carbon injection \\
\hline AHI & air heater inlet \\
\hline AHO & air heater outlet \\
\hline APCD & air pollution control device \\
\hline Av & average \\
\hline acfm & actual cubic foot per minute \\
\hline acmm & actual cubic meter per minute \\
\hline ASTM & ASTM International (formerly American Society for Testing and Materials) \\
\hline $\mathrm{B} \& \mathrm{~W}$ & The Babcock and Wilcox Company \\
\hline BSEI & backscattered electron image \\
\hline CAIR & Clear Air Interstate Rule \\
\hline $\mathrm{CaBR}_{2}$ & calcium bromide \\
\hline $\mathrm{CaCl}_{2}$ & calcium chloride \\
\hline CAMR & Clean Air Mercury Rule \\
\hline $\mathrm{CCBs}$ & coal combustion by-products \\
\hline CCSEM & computer-controlled scanning electron microscopy \\
\hline CFR & Code of Federal Regulations \\
\hline CI & confidence interval \\
\hline $\mathrm{CMM}$ & continuous mercury monitor \\
\hline CS-ESP & cold-side electrostatic precipitator \\
\hline CVAAS & cold-vapor atomic absorption spectrometer \\
\hline CVAFS & cold-vapor atomic fluorescence spectrometry \\
\hline $\mathrm{d}$ & dry \\
\hline DF & diluted filtrate \\
\hline DMA & direct mercury analyzer \\
\hline DOE & U.S. Department of Energy \\
\hline dscm & dry standard cubic meter \\
\hline ECM & economizer \\
\hline EERC & Energy \& Environmental Research Center \\
\hline EPA & U.S. Environmental Protection Agency \\
\hline EPRI & Electric Power Research Institute \\
\hline ESP & electrostatic precipitator \\
\hline FF & fabric filter \\
\hline FGD & flue gas desulfurization \\
\hline (g) & gas \\
\hline GFE & Great River Energy \\
\hline $\mathrm{HCl}$ & hydrochloric acid \\
\hline $\mathrm{HgCl}_{2}$ & mercuric chloride \\
\hline $\mathrm{Hg}$ & mercury \\
\hline $\mathrm{Hg}^{0}$ & gaseous elemental mercury \\
\hline $\mathrm{Hg}^{2+}$ & gaseous inorganic mercuric compounds \\
\hline $\mathrm{Hg}_{\mathrm{p}}$ & particle-bound mercury \\
\hline
\end{tabular}




\begin{tabular}{|c|c|}
\hline HHV & higher heating value \\
\hline HS-ESP & hot-side electrostatic precipitator \\
\hline Total Hg & $\begin{array}{l}\text { total mercury - for Ontario Hydro method measurements it includes } \mathrm{Hg}^{0}, \mathrm{Hg}^{2+} \text {, } \\
\text { and } \mathrm{Hg}(\mathrm{p}) \text {, whereas for } \mathrm{CMM} \text { measurements, it includes } \mathrm{Hg}^{0} \text { and } \mathrm{Hg}^{2+} \text {. }\end{array}$ \\
\hline ICR & information collection request \\
\hline IGCC & integrated gasification combined cycle \\
\hline IGS & inertial gas separation \\
\hline i.d. & inside diameter \\
\hline $\mathrm{kg}$ & kilogram \\
\hline lb & pound $(0.454 \mathrm{~kg})$ \\
\hline LOI & loss on ignition \\
\hline LTL & long-term leaching \\
\hline Macf & million actual cubic feet \\
\hline $\mathrm{MgCl}_{2}$ & magnesium chloride \\
\hline MoSES & Monticello Steam Electric Station \\
\hline MRY & Milton R. Young Station \\
\hline MPC & Minnkota Power Cooperative, Inc. \\
\hline $\mathrm{NH}_{4} \mathrm{OAc}$ & ammonium acetate \\
\hline NETL & National Energy Technology Laboratory \\
\hline $\mathrm{Nm}^{3}$ & normal cubic meter $\left(20^{\circ} \mathrm{C}, 3 \% \mathrm{O}_{2}\right.$, at $\left.1 \mathrm{~atm}\right)$ \\
\hline $\mathrm{O} \& \mathrm{M}$ & operating and maintenance \\
\hline $\mathrm{OH}$ & Ontario Hydro \\
\hline PAC & powdered activated carbon \\
\hline pc & pulverized coal \\
\hline PE & purchase equipment \\
\hline ppm & parts per million \\
\hline ppmv & parts per million by volume \\
\hline PRB & Powder River Basin \\
\hline PS & particulate scrubber \\
\hline PTC & particulate test combuster \\
\hline $\mathrm{QA} / \mathrm{QC}$ & quality assurance/quality control \\
\hline RATA & relative accuracy test assessment \\
\hline RPD & relative percent difference \\
\hline RSD & relative standard deviation $(\mathrm{RSD}=$ Std. Dev. $\div$ Avg. $\times 100)$ \\
\hline SCA & specific collection areas \\
\hline $\mathrm{SCBO}$ & scrubber outlet \\
\hline SCEM & semicontinuous emission monitor \\
\hline SCR & selective catalytic reduction \\
\hline SDA & spray dryer absorber \\
\hline SEA & sorbent enhancement additive \\
\hline SEM & scanning electron microscopy \\
\hline SGLP & synthetic groundwater leaching procedure \\
\hline $\mathrm{SO}_{2}$ & sulfur dioxide \\
\hline st. dev. & standard deviation \\
\hline TCLP & toxicity characteristic leaching procedure \\
\hline
\end{tabular}




$\begin{array}{ll}\text { TOXECON }^{\circledR} & \text { An EPRI Hg control technology involving the injection of activated carbon } \\ & \text { between an ESP and FF } \\ \text { TPC } & \text { total product cost } \\ \text { TXU } & \text { Texas Utilities } \\ \mu \mathrm{g} & \text { microgram } \\ \text { UV } & \text { ultraviolet } \\ \text { WDXRF } & \text { wavelength-dispersive x-ray fluorescence }\end{array}$




\section{LARGE-SCALE MERCURY CONTROL TECHNOLOGY TESTING FOR LIGNITE-FIRED UTILITIES - OXIDATION SYSTEMS FOR WET FGD}

\section{EXECUTIVE SUMMARY}

The Energy \& Environmental Research Center (EERC) directed a consortium-based effort focused on resolving mercury $(\mathrm{Hg})$ control issues confronting the lignite industry. Specifically, the EERC team-the EERC; Apogee, Babcock \& Wilcox Company, the U.S. Department of Energy (DOE) National Energy Technology Laboratory (NETL), the Electric Power Research Institute (EPRI), the North Dakota Industrial Commission, and SaskPower, as well as a Mercury Task Force consisting of Basin Electric Power Cooperative; BNI Coal, Ltd.; Dakota Westmoreland Corporation; Great River Energy; Minnkota Power Cooperative, Inc.; MontanaDakota Utilities Co.; North American Coal Corporation; Otter Tail Power Company; and TXU Energy (TXU) - evaluated several approaches for significantly and cost-effectively oxidizing elemental mercury $\left(\mathrm{Hg}^{0}\right)$ in lignite combustion flue gases, followed by capture in an electrostatic precipitator (ESP) and/or wet flue gas desulfurization (FGD) scrubber. The project team involved in performing the technical aspects of the project included Babcock \& Wilcox, the EERC, EPRI, and URS. The two host sites were Minnkota Power Cooperative Milton R. Young (MRY) Station Unit 2 (450 MW) and TXU Monticello Steam Electric Station (MoSES) Unit 3 (793 MW). Calcium bromide $\left(\mathrm{CaBr}_{2}\right)$, calcium chloride $\left(\mathrm{CaCl}_{2}\right)$, magnesium chloride $\left(\mathrm{MgCl}_{2}\right)$, and a proprietary sorbent enhancement additive (SEA), hereafter referred to as SEA2, were added to the lignite feeds to enhance $\mathrm{Hg}$ capture in the ESP and/or wet FGD. In addition, powdered activated carbon (PAC) was injected upstream of the ESP at MRY Unit 2. The work involved establishing $\mathrm{Hg}$ concentrations and removal rates across existing ESP and FGD units, determining costs associated with those removal rates, quantifying the balance-of-plant impacts of the control technologies, and facilitating technology commercialization. The primary project goal was to achieve an ESP-FGD Hg removal efficiency of $\geq 55 \%$ at MRY and MoSES for about a month.

\section{MRY Station}

MRY Station Unit 2 is a 450-MW lignite-fired cyclone unit near Center, North Dakota. $\mathrm{CaCl}_{2}, \mathrm{MgCl}_{2}$, and a proprietary SEA, hereafter referred to as SEA2, were added to the coal feed to enhance $\mathrm{Hg}$ capture in the ESP and/or wet FGD. In addition, PAC was injected upstream of the ESP. Hg in the lignite coal fired at MRY Unit 2 varied from 0.05 to $0.25 \mathrm{ppm}$ and averaged $0.112 \pm 0.014 \mathrm{ppm}$ (dry coal basis). Most of the $\mathrm{Hg}$ was associated with $\mathrm{Hg}$-rich (average of 2.28 ppm $\mathrm{Hg}$ ) pyrite grains that ranged in concentration from about 1 to $6 \mathrm{wt} \%$ (on a dry coal basis). Baseline analyses indicated that total $\mathrm{Hg}$ concentrations at the ESP and wet FGD inlets varied from about 12 to $16 \mu \mathrm{g} / \mathrm{dNm}^{3}$, whereas at the stack concentrations were consistently at about 13 $\mu \mathrm{g} / \mathrm{dNm}^{3}$. The ESP and wet FGD were very inefficient at removing $\mathrm{Hg}$, primarily because $\mathrm{Hg}^{0}$ was dominant. $\mathrm{MgCl}_{2}$ and $\mathrm{CaCl}_{2}$ were relatively ineffective in promoting $\mathrm{Hg}^{0}$ oxidation and capture in the ESP-wet FGD. Relatively low additions of SEA2, however, significantly improved the $\mathrm{Hg}$ removal efficiency of the ESP-wet FGD, although the goal of 55\% $\mathrm{Hg}$ removal was not achieved using as much as 75 ppm SEA2 (dry coal basis). Most of the $\mathrm{Hg}$ removal occurred in the ESP, suggesting that SEA2 addition promoted the conversion of $\mathrm{Hg}^{0}$ to particulate-bound Hg. SEA2 addition (50-100 ppm, dry coal basis) combined with 
$0.15 \mathrm{lb} /$ Macf PAC injection was performed for a month during which $\mathrm{Hg}$ removals ranged from $50 \%$ to $65 \%$.

The potential corrosive effects of SEA2 and PAC injections were evaluated by installing air-cooled, stressed stainless steel, corrosion/ash deposition coupons at the economizer exit (ECM), air heater inlet (AHI), and air heater outlet (AHO) of MRY Unit 2. Two coupons for each location were fabricated by MRY personnel: a baseline coupon exposed to the normal flue gas environment for 8 weeks and a test coupon exposed to flue gas while SEA2 and PAC were being added to the coal feed for 6 weeks. Scanning electron microscopy (SEM) analyses indicated that the baseline coupons from the ECM and AHI had a smooth surface, whereas the corresponding $\mathrm{Hg}$ control coupons had a rougher surface, suggesting that corrosion was enhanced during the SEA2 and PAC injections. In contrast to the ECM and AHI coupons, steel surfaces on the AHO baseline and $\mathrm{Hg}$ control coupons were similar in appearance. Electron probe microanalyses indicated that SEA2 and PAC injections enhanced calcium sulfate deposition on the coupons.

The mobility of $\mathrm{Hg}$ in MRY fly ashes sampled before and after PAC and SEA2 injections was evaluated using a synthetic groundwater leaching procedure augmented with long-term treatments of 30 and 60 days. $\mathrm{Hg}$ was not detected in any of the leachates, indicating that it was relatively insoluble during the test conditions. The thermal stability of $\mathrm{Hg}$ in fly ash samples collected during baseline and $\mathrm{Hg}$ control technology testing conditions was evaluated by heating at $25^{\circ} \mathrm{C} / \mathrm{min}$ to $750^{\circ} \mathrm{C}$. The fly ash samples collected during baseline and $\mathrm{Hg}$ control technology testing conditions released $\mathrm{Hg}$ at about $375^{\circ}$ and $400^{\circ} \mathrm{C}$, respectively. The fly ash sampled during $\mathrm{Hg}$ control technology testing also released some $\mathrm{Hg}$ at $>550^{\circ} \mathrm{C}$. The $\mathrm{Hg}$ captured on fly ash and PAC during SEA2 injections was thermally more stable relative to the baseline fly ash.

Economic evaluations of mercury control for MRY Unit 2 were performed assuming various $\mathrm{CaCl}_{2}, \mathrm{SEA} 2, \mathrm{CaCl}_{2}$ with $\mathrm{PAC}$, and $\mathrm{SEA} 2$ with $\mathrm{PAC}$ injection rates. The cost for maintaining a 55\% mercury removal efficiency at MRY Unit 2 using SEA2 in combination with a small amount of PAC was estimated as follows:

- Levelized annual cost: $\$ 2,121,169$

- Annual cost, \$/MWh (mills/kWh): 0.63

- Cost of mercury removal, $\$ / \mathrm{lb}: 16,639$

\section{MoSES}

MoSES Unit 3 is a 793-MW unit that fires a 50-50 blend of Texas lignite and subbituminous Powder River Basin (PRB) coals. The unit is equipped with an ESP and limestone forced-oxidation spray tower FGD system for $\mathrm{SO}_{2}$ control. Baseline flue gas $\mathrm{Hg}$ measurements indicated that the ESP outlet flue gas contained about $25 \% \mathrm{Hg}^{2+}$ and $75 \% \mathrm{Hg}^{0}$, with a total $\mathrm{Hg}$ concentration of about $20 \mu \mathrm{g} / \mathrm{dNm}^{3}$.

A test program was performed at MoSES in Fall 2005 to evaluate the furnace injection of halogen materials as a means of oxidizing the flue gas $\mathrm{Hg}^{0}$ so that it could be removed in a downstream wet scrubber. The program consisted of three parts: 1) baseline measurements to quantify $\mathrm{Hg}$ concentrations and removal across the system, 2) a set of parametric tests to compare the performance of furnace injection of two halogen salts $\left(\mathrm{CaCl}_{2}\right.$ and $\left.\mathrm{CaBr}_{2}\right)$, and 
3) two 2-week continuous-injection tests to evaluate the variability and balance-of-plant impacts associated with furnace halogen injection. Flue gas $\mathrm{Hg}$ measurements were made primarily with EPRI semicontinuous emission monitors (SCEMs).

During baseline measurements, no removal of $\mathrm{Hg}$ was measured with the SCEMs and the Ontario Hydro $(\mathrm{OH})$ method across the ESP. On average for the course of the long-term test program, coal $\mathrm{Hg}$ concentrations correlated well with ESP inlet $\mathrm{Hg}$ concentrations measured by the CMM. The Hg content of the baseline fly ash represented less than $20 \%$ of the coal $\mathrm{Hg}$ content. Both the coal and ash results corroborate the flue gas determination of a small amount of $\mathrm{Hg}$ removal upstream of the ESP and no removal across the ESP. The coal $\mathrm{Hg}$ concentration of the PRB coal ranged from 0.04 to $0.09 \mathrm{ppm}$ dry. The coal $\mathrm{Hg}$ concentration of the Texas lignite was highly variable, ranging from 0.17 to $0.36 \mathrm{ppm}$ dry. Likewise, the ESP inlet $\mathrm{Hg}$ concentrations ranged widely ( 15 to $30 \mu \mathrm{g} / \mathrm{dNm}^{3}$ at $3 \% \mathrm{O}_{2}$ ) during the course of the test program. The baseline flue gas typically contained $10 \%-40 \%$ oxidized $\mathrm{Hg}$. The measured $\mathrm{Hg}^{0}$ oxidation was typical of that measured at other plants burning Texas lignite-PRB blends.

Parametric tests conducted with two halogen salts demonstrated that it was possible to increase the oxidation of $\mathrm{Hg}^{0}$ in the flue gas and to simultaneously increase $\mathrm{Hg}$ removal by the FGD scrubber. $\mathrm{CaCl}_{2}$ provided only nominal improvements in $\mathrm{Hg}^{0}$ oxidation even at the highest tested injection rate of $800 \mathrm{ppm} \mathrm{Cl}$ in the coal. $\mathrm{CaCl}_{2}$ injection was not observed to be capable of sustaining the $\mathrm{Hg}^{0}$ oxidation necessary for the project's $\mathrm{Hg}$ removal target of $55 \%$. In contrast, parametric tests with $\mathrm{CaBr}_{2}$ demonstrated up to $78 \% \mathrm{Hg}^{0}$ oxidation at an injection rate of $200 \mathrm{ppm} \mathrm{Br}$ in the coal. Based on these parametric test results, $\mathrm{CaBr}_{2}$ was selected for an evaluation in two 2-week continuous-injection tests.

The first of these tests was conducted at an average injection rate of $55 \mathrm{ppm} \mathrm{Br}$ in the coal. This injection rate achieved an average $67 \% \mathrm{Hg}^{0}$ oxidation at the scrubber inlet, and the average removal of $\mathrm{Hg}$ across the scrubber was $65 \%$. These values represent averages over a 2 -week injection test; however, it was observed with the CMMs that the scrubber outlet total $\mathrm{Hg}$ concentration steadily increased over the test period. These results were confirmed with Appendix K measurements. Therefore, a higher injection rate was evaluated in the second 2-week injection test.

For the second 2-week injection test, the $\mathrm{CaBr}_{2}$ injection rate was increased to an average $113 \mathrm{ppm} \mathrm{Br}$ in the coal. Over the course of the ten days at this injection rate, the $\mathrm{Hg}$ at the ESP inlet was on average $85 \%$ oxidized. Hg removal across the system averaged $86 \%$ for the entire test period. With the exception of a few brief periods, an injection rate of $113 \mathrm{ppm} \mathrm{Br}$ was sufficient to consistently maintain scrubber outlet $\mathrm{Hg}$ concentrations at $<5 \mu \mathrm{g} / \mathrm{dNm}^{3}$ (at $3 \% \mathrm{O}_{2}$ ).

All of the reported $\mathrm{Hg}^{0}$ oxidation and removal values were based on the average coal $\mathrm{Hg}$ concentration for the respective test periods. The scrubber inlet total $\mathrm{Hg}$ measurements made by $\mathrm{CMM}$ were biased low during $\mathrm{CaBr}_{2}$ injection, as determined from a comparison of $\mathrm{CMM}$ data to coal and ash $\mathrm{Hg}$ data. The presence of bromine in the flue gas can oxidize $\mathrm{Hg}^{0}$ in the wet solutions that pretreat the gas for the CMM. The scrubber inlet $\mathrm{Hg}^{0}$ measurements did not appear to be subject to a negative bias, as these values agreed well with the scrubber outlet total $\mathrm{Hg}$ 
concentrations. The scrubber outlet $\mathrm{Hg}$ data are not subject to the bromine bias because bromine is removed by the FGD scrubber.

The furnace injection of $\mathrm{CaBr}_{2}$ did not result in increased $\mathrm{Hg}$ removal by the fly ash. The oxidized Hg was removed by the FGD scrubber, as expected. During baseline and the first week of each long-term injection test, $\mathrm{Hg}$ partitioned to the FGD solids; however, during the second week of each test, $\mathrm{Hg}$ transitioned to the liquor phase. At an injection rate of $113 \mathrm{ppm} \mathrm{Br}$ in the coal, $>85 \%$ of the $\mathrm{Hg}$ in the FGD by-product was contained in the liquor.

These two 2-week furnace injection tests were not long enough to evaluate the balance-ofplant effects. A unit inspection conducted after the test program did not indicate any brominerelated corrosion; however, the test period was too short for an adequate corrosion evaluation. The effect of increased bromine concentration in the FGD liquor on FGD performance and corrosion of FGD materials of construction needs to be determined. Duct corrosion and air heater plugging also need to be evaluated in a longer-term test. Finally, the effect of increased bromine concentrations on the marketability of the coal combustion by-products must be addressed.

Economic evaluations of $\mathrm{Hg}$ control for MoSES Unit 3 were performed assuming various $\mathrm{CaBr}_{2}$ injection rates. The cost for maintaining a $\geq 55 \%$ mercury removal efficiency at MoSES Unit 3 using $\mathrm{CaBr}_{2}$ was estimated as follows:

- Levelized annual cost: \$2,933,996

- Annual cost, \$/MWh (mills/kWh): 0.50

- Cost of mercury removal, $\$ / 1 b: 7336$ 


\section{LARGE-SCALE MERCURY CONTROL TECHNOLOGY TESTING FOR LIGNITE-FIRED UTILITIES - OXIDATION SYSTEMS FOR WET FGD}

\subsection{INTRODUCTION}

The Energy \& Environmental Research Center (EERC) directed a consortium-based effort focused on resolving mercury $(\mathrm{Hg})$ control issues confronting the lignite industry. Specifically, the EERC team - the EERC; Apogee, Babcock \& Wilcox Company (B\&W), the U.S. Department of Energy (DOE) National Energy Technology Laboratory (NETL), the Electric Power Research Institute (EPRI), the North Dakota Industrial Commission, and SaskPower, as well as a Mercury Task Force consisting of Basin Electric Power Cooperative; BNI Coal, Ltd.; Dakota Westmoreland Corporation; Great River Energy; Minnkota Power Cooperative, Inc. (MPC); Montana-Dakota Utilities Co.; North American Coal Corporation; Otter Tail Power Company; and TXU Energy (TXU) — evaluated several approaches for significantly and costeffectively oxidizing elemental mercury $\left(\mathrm{Hg}^{0}\right)$ in lignite combustion flue gases, followed by capture in an electrostatic precipitator (ESP) and/or wet flue gas desulfurization (FGD) scrubber.

This project was developed in response to the U.S. Environmental Protection Agency (EPA) decision to regulate $\mathrm{Hg}$ from utility power plants and a DOE solicitation requesting additional data on the performance of $\mathrm{Hg}$ control technologies for lignite facilities. EPA based its decision on health effects, emissions, and scientific data. U.S. power plants burning lignite generally release greater proportions of $\mathrm{Hg}^{0}$ than those burning bituminous coals. $\mathrm{Hg}^{0}$ is the most difficult chemical species of $\mathrm{Hg}$ to remove from flue gas and, therefore, requires an innovative $\mathrm{Hg}$ control approach.

The overall project goal was to cost-effectively oxidize most of the $\mathrm{Hg}^{0}$ in lignitic combustion flue gases into a more soluble and reactive inorganic mercuric compound $\left(\mathrm{Hg}^{2+}\right)$ that could subsequently be captured in an ESP and/or wet FGD system. $\mathrm{Hg}^{0}$ oxidation processes have been demonstrated using pilot-scale and short-term full-scale tests (1-3). Longer-term full-scale testing is required to further demonstrate and optimize $\mathrm{Hg}^{0}$ oxidation technologies. The applicability of this $\mathrm{Hg}$ control approach is expected to increase with the demand for FGD systems in the United States and Canada.

MPC Milton R. Young (MRY) Station Unit 2 near Center, North Dakota, is one of two host sites for field testing as part of a project entitled Large-Scale Mercury Control Technology Testing for Lignite-Fired Utilities - Oxidation Systems for Wet FGD. The other site was TXU Monticello Steam Electric Station (MoSES) Unit 3 near Mt. Pleasant, Texas. An ESP and wet FGD are used at MRY and MoSES for controlling particulate and sulfur dioxide $\left(\mathrm{SO}_{2}\right)$ emissions, respectively. $\mathrm{Hg}$ removal technologies investigated included $\mathrm{Hg}^{0}$ oxidizing agent and sorbent enhancement additives (SEAs) and powdered activated carbon (PAC) injection. Calcium chloride $\left(\mathrm{CaCl}_{2}\right)$, calcium bromide $\left(\mathrm{CaBr}_{2}\right)$, magnesium chloride $\left(\mathrm{MgCl}_{2}\right)$, and a proprietary SEA, hereafter referred to as SEA2, were added to the coal feed to enhance $\mathrm{Hg}$ capture in the ESP and/or wet FGD. The PAC injected at MRY Unit 2 was NORIT Americas Inc. DARCO ${ }^{\circledR}$ $\mathrm{Hg}$, a lignite-based activated carbon manufactured specifically for the removal of $\mathrm{Hg}$ in coalfired utility flue gas emission streams. The EERC collaborated with Babcock \& Wilcox, EPRI, 
URS Corporation, and Apogee in performing the technical work on this project involving $\mathrm{Hg}$ measurements upstream and downstream of ESP and wet FGD units before and during $\mathrm{CaCl}_{2}$, $\mathrm{CaBr}_{2}, \mathrm{MgCl}_{2}$, and SEA2 additions and $\mathrm{PAC}$ injections; determining the $\mathrm{Hg}$ removal efficiencies of ESP and wet FGD units; quantifying the balance-of-plant impacts of the control technologies; and facilitating technology commercialization. The primary project goal was to achieve an ESPFGD $\mathrm{Hg}$ removal efficiency of $\geq 55 \%$ at MRY and MoSES for about a month.

\subsection{BACKGROUND}

\subsection{World and U.S. Mercury Emission Budget}

Trace amounts of $\mathrm{Hg}$ exist in fossil fuels such as coal, oil, and natural gas that during combustion may be released to the atmosphere. It has been estimated that the total annual worldwide atmospheric emissions of $\mathrm{Hg}$ is 4900 tons from both natural and anthropogenic sources (4). Coal-fired power plants in the United States emit approximately 48 tons of $\mathrm{Hg}$ per year, thus accounting for about $1 \%$ of the total worldwide annual $\mathrm{Hg}$ emissions (5).

\subsection{Mercury Is a Health Concern}

$\mathrm{Hg}$ is a neurological toxin that can cause impairment of mental, sensory, and motor functions in humans, particularly in developing fetuses and children. A congressionally mandated reassessment of the toxicological effects of $\mathrm{Hg}$ issued by the National Research Council (6) in August 2000 reaffirmed EPA's low Hg exposure reference dose of $0.1 \mu \mathrm{g} / \mathrm{kg}$ per day as the scientifically justifiable level for the protection of child-bearing women, based on quantifiable findings for low-dose exposure in a large study population in the Faroe Islands. Prompted by these health concerns, $\mathrm{Hg}$ is the chemical contaminant responsible, at least in part, for the issuance of approximately 2000 fish consumption advisories. Almost $68 \%$ of all advisories issued in the United States are a result of $\mathrm{Hg}$ contamination in fish and shellfish. Freshwater lake advisories have more than doubled in the last 5 years, resulting in over 40 states that have issued fish advisories because of $\mathrm{Hg}$. Furthermore, recently the Food and Drug Administration issued an advisory limiting consumption of certain ocean fish.

\subsection{Mercury Regulations}

In December 2000, EPA decided that the regulation of $\mathrm{Hg}$ from coal-fired electric utility steam-generating units was appropriate and necessary under Section 112 of the Clean Air Act. EPA determined that $\mathrm{Hg}$ emissions from power plants pose significant hazards to public health and must be reduced. The EPA Mercury Study Report to Congress (1997) (7) and the Utility Hazardous Air Pollutant Report to Congress (1998) (8) both identified coal-fired boilers as the largest single category of atmospheric $\mathrm{Hg}$ emissions in the United States, accounting for about one-third of the total anthropogenic emissions.

On March 15, 2005, EPA issued a final regulation, the Clean Air Mercury Rule (CAMR), for the control of $\mathrm{Hg}$ emissions from coal-fired power plants. This rule creates a two-phase, capand-trade regulation (Section 111 of the Clean Air Act) for both existing and new plants that is 
similar to the program in place for $\mathrm{SO}_{2}$. Phase I begins in 2010 and calls for a 38-ton nationwide cap on $\mathrm{Hg}$ emissions based on cobenefit reductions obtained with $\mathrm{SO}_{2}$ and $\mathrm{NO}_{\mathrm{x}}$ control achieved through EPA's recently issued Clean Air Interstate Rule (CAIR). Phase II of CAMR requires a $\mathrm{Hg}$ emission cap of 15 tons by 2018. Currently, the estimate of total $\mathrm{Hg}$ emitted from coal-fired power plants is 48 tons; therefore, the 2010 and 2018 reductions are $21 \%$ and $69 \%$, respectively.

With the implementation in March 2005 of CAIR to reduce emissions of $\mathrm{SO}_{2}$ and $\mathrm{NO}_{\mathrm{x}}$ in the eastern 28 states, it is expected that the initial phase of CAMR will be met as a cobenefit from the additional wet scrubbers and selective catalytic reduction (SCR) systems that will be installed. However, a cap of 15 tons will require additional $\mathrm{Hg}$-specific controls at many power plants.

For trading purposes, EPA established allocations for each state, the District of Columbia, and Indian Reservations based on their share of the total heat input from coal. These were then adjusted to reflect coal rank and existing air pollution control equipment. For allocation purposes, coals were subcategorized as bituminous, subbituminous, lignitic, integrated gasification combined cycle (IGCC), and coal refuse. The total state allocations from 2010 to 2017 are 38 tons and from 2018 and thereafter 15 tons. Each state will decide whether to participate in the trading program.

In addition to the cap-and-trade program, new coal-fired sources will have additional $\mathrm{Hg}$ requirements as part of the New Source Performance Standards. The requirements were subcategorized as follows:

- Bituminous units $-21 \times 10^{-6} \mathrm{lb} / \mathrm{MWh}$

- Subbituminous units

- Wet FGD - $42 \times 10^{-6} \mathrm{lb} / \mathrm{MWh}$

- Dry FGD - $78 \times 10^{-6} \mathrm{lb} / \mathrm{MWh}$

- Lignite units $-145 \times 10^{-6} \mathrm{lb} / \mathrm{MWh}$

- IGCC units $-20 \times 10^{-6} \mathrm{lb} / \mathrm{MWh}$

- Coal refuse units $-1.4 \times 10^{-6} \mathrm{lb} / \mathrm{MWh}$

\subsection{Mercury Emissions from Low-Rank Coals Will Be Difficult to Control}

Hg emissions from utilities burning U.S. coals were determined under EPA's information collection request (ICR), which mandated $\mathrm{Hg}$ and chlorine analyses on coal shipped to units larger than 25 MWe during 1999 and emissions testing on 84 units selected to represent different categories of air pollution control equipment and coal rank (9). Lignitic and subbituminous coals from the western United States, on average, contain significantly lower, concentrations of $\mathrm{Hg}$, chlorine, and sulfur than bituminous coals from the eastern United States, Appalachian, or interior regions. Western lignitic and subbituminous coals are also distinguished by their much higher alkaline-earth metal (i.e., magnesium and calcium) contents. Gulf Coast lignites resemble eastern bituminous coals in their high concentrations of $\mathrm{Hg}$ and iron, but are similar to western coals in regard to low chlorine and high calcium contents. These compositional differences not only affect the quantities and chemical species of $\mathrm{Hg}$ emitted from a boiler but also the effectiveness of different control technologies to remove $\mathrm{Hg}$ from flue gas. Western lignitic and 
subbituminous coals contain about half as much $\mathrm{Hg}$ on a weight basis; however, the ICR data indicate that they emit almost twice as much $\mathrm{Hg}$ on a $\mathrm{lb} /$ Btu basis because of their lower heat contents relative to bituminous coals (10).

In general, lignitic coals are characterized by their relatively high oxygen, moisture, and alkali and alkaline-earth elemental concentrations and low chlorine contents. Based on the ICR data, North Dakota and Gulf Coast lignites produce as much as $8 \mathrm{lb} \mathrm{Hg} / 10^{12}$ Btu and $12.5 \mathrm{lb} \mathrm{Hg} / 10^{12} \mathrm{Btu}$, respectively, compared to $6 \mathrm{lb} \mathrm{Hg} / 10^{12}$ Btu for subbituminous Powder River Basin (PRB) coals, $6.5 \mathrm{lb} \mathrm{Hg} / 10^{12}$ Btu for Illinois Basin bituminous coals, and $9.5 \mathrm{lb} \mathrm{Hg} / 10^{12} \mathrm{Btu}$ for Appalachian bituminous coals (9). Coal composition has a major impact on the quantity and chemical form of $\mathrm{Hg}$ in the flue gas and, as a result, the effectiveness of air pollution control devices to remove $\mathrm{Hg}$ from flue gas. Coals containing greater than about $200 \mathrm{ppm}$ chlorine produce flue gases that are dominated by the more easily removable mercuric compounds $\left(\mathrm{Hg}^{2+}\right)$, most likely mercuric chloride $\left(\mathrm{HgCl}_{2}\right)$. Appalachian and Illinois Basin bituminous coals generally have $>200 \mathrm{ppm}$ chlorine. Conversely, low-chlorine $(<50 \mathrm{ppm})$ lignite and subbituminous coal combustion flue gases contain predominantly $\mathrm{Hg}^{0}$, which is substantially more difficult to remove than $\mathrm{Hg}^{2+}(11,12)$. Additionally, the abundance of calcium in lignite and subbituminous coal fly ashes may reduce the oxidizing effect of the already low chlorine content by reactively scavenging chlorine species $\left(\mathrm{Cl}, \mathrm{HCl}\right.$, and $\left.\mathrm{Cl}_{2}\right)$ from the combustion flue gas.

\subsection{Mercury Control Options}

Options for controlling $\mathrm{Hg}$ emissions are being investigated that have the potential to attain $>90 \%$ removal of $\mathrm{Hg}$ from flue gas. ICR data and other test data of $\mathrm{Hg}$ control for lignite and subbituminous coal-fired systems indicate that low $\mathrm{Hg}^{0}$ reactivity poses technical and economic challenges and that innovative $\mathrm{Hg}^{0}$ control technologies are needed for lignite coals. $\mathrm{Hg}$ control strategies at lignite coal-fired power plants have primarily focused on enhancing existing air pollution control device (APCD) technologies. Presented in Table 2-1 is a summary of the average cobenefit $\mathrm{Hg}$ removal efficiencies for various APCD configurations and coal rank based on testing performed by EPA in 1999. Although conventional APCD technology captures some $\mathrm{Hg}$, new $\mathrm{Hg}$ control technologies will be needed to comply with the CAMR Phase II emission cap. Currently, PAC injection has shown the most promise as a near-term $\mathrm{Hg}$ control technology. PAC is typically injected downstream of a plant's air heater and upstream of a particulate control device, either an ESP or fabric filter (FF). $\mathrm{Hg}^{0}$ oxidation and sorbent enhancement technologies are also being developed to improve $\mathrm{Hg}$ capture in existing APCDs.

\subsubsection{Previous Results with $\mathrm{Hg}^{0}$ Oxidation Technologies}

The $\mathrm{Hg}^{0}$ oxidation technologies being investigated for lignites include catalysts and chemical agents. SCR catalysts for $\mathrm{NO}_{\mathrm{x}}$ reduction, noble metal-impregnated catalysts, and oxideimpregnated catalysts have been evaluated for promoting $\mathrm{Hg}^{0}$ oxidation. The chemical agents include chlorine-containing salts (chloride compounds) and cofiring fuels that contain oxidizing agents $(1,2)$. 
Table 2-1. Average Hg Removal Efficiencies (\%) by Coal Rank and APCD Configuration

\begin{tabular}{|c|c|c|c|}
\hline APCD & Bituminous & Subbituminous & Lignite \\
\hline CS-ESP ${ }^{1}$ & 36 & 3 & -4 \\
\hline HS-ESP $^{2}$ & 9 & 6 & $\mathrm{NA}^{3}$ \\
\hline $\mathrm{FF}$ & 90 & 72 & NA \\
\hline $\mathrm{PS}^{4}$ & NA & 9 & NA \\
\hline $\mathrm{SDA}^{5}-\mathrm{ESP}$ & NA & 35 & NA \\
\hline SDA-FF & 98 & 24 & 0 \\
\hline SDA-FF-SCR & 98 & NA & NA \\
\hline PS-Wet FGD & 12 & -8 & 33 \\
\hline CS-ESP-Wet FGD & 74 & 29 & 44 \\
\hline HS-ESP-Wet FGD & 50 & 29 & NA \\
\hline FF-Wet FGD & 98 & NA & NA \\
\hline
\end{tabular}

${ }^{1}$ Cold-side electrostatic precipitator.

${ }^{2}$ Hot-side electrostatic precipitator.

${ }^{3}$ Not available.

${ }^{4}$ Particulate scrubber.

${ }^{5}$ Spray dryer absorber.

Theoretically, the use of chloride compounds to oxidize $\mathrm{Hg}^{0}$ to $\mathrm{Hg}^{2+}$ makes sense. The evidence includes chemical kinetic modeling of bench-scale test results, indicating that the introduction of chloride compounds into the high-temperature furnace region will likely result in the production of atomic chlorine and/or molecular chlorine, which are generally thought to be the dominant $\mathrm{Hg}^{0}$ reactants in coal combustion flue gases (1). The formation of atomic chlorine is a key pathway involved in the chemical reaction mechanisms that result in the oxidation of $\mathrm{Hg}^{0}$ (1). Recent kinetic modeling of chlorine radical formation as a function of temperature and residence time is shown in Figure 2-1. The results indicate the importance of temperature and residence time in controlling the formation of chlorine radicals. Consistent with the modeling results in Figure 2-1, the injection of $\mathrm{HCl}$ in lower-temperature regions downstream of a furnace was ineffective in oxidizing $\mathrm{Hg}^{0}$, whereas injection into the furnace effectively transformed most of the $\mathrm{Hg}^{0}$ to $\mathrm{Hg}^{2+}(3)$.

Fuel additives for enhancing $\mathrm{Hg}^{0}$ oxidation have recently been tested in a pilot-scale system. Chloride salts promote the conversion of $\mathrm{Hg}^{0}$ to $\mathrm{Hg}^{2+}$, as shown in Figure 2-2. In addition, recent EPRI short-term testing at a $70-\mathrm{MWe}$ pulverized coal (pc)-fired North Dakota power plant indicated that chloride salt injections increased $\mathrm{Hg}^{0}$ oxidation in the flue gas (3). Approximately $70 \%$ of the $\mathrm{Hg}^{0}$ was transformed to $\mathrm{Hg}^{2+}$ at a flue gas $\mathrm{HCl}$ concentration of 110 ppm, as shown in Figure 2-3. In addition, salt injection enhanced the $\mathrm{Hg}$ removal efficiency of the SDA-FF, to $\leq 50 \%$ during short-term field testing (3).

\subsubsection{Previous Results with PAC Injection}

Many potential Hg sorbents have been evaluated. These evaluations have demonstrated that the chemical speciation of $\mathrm{Hg}$ controls its capture mechanism and ultimate environmental 


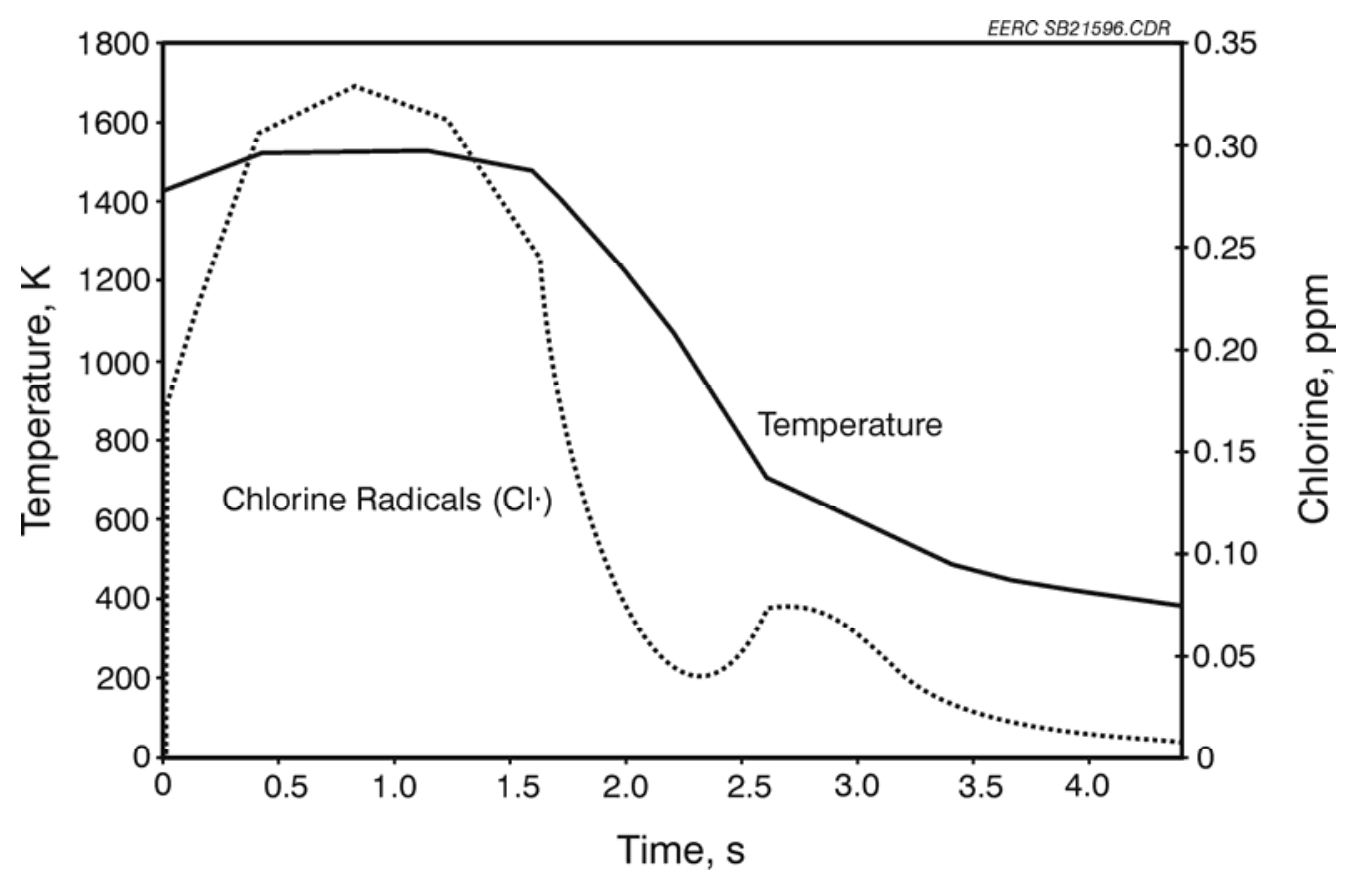

Figure 2-1. Kinetic model (Chemkin) prediction of chlorine radical concentration as a function of the temperature and residence time profile of a utility boiler.

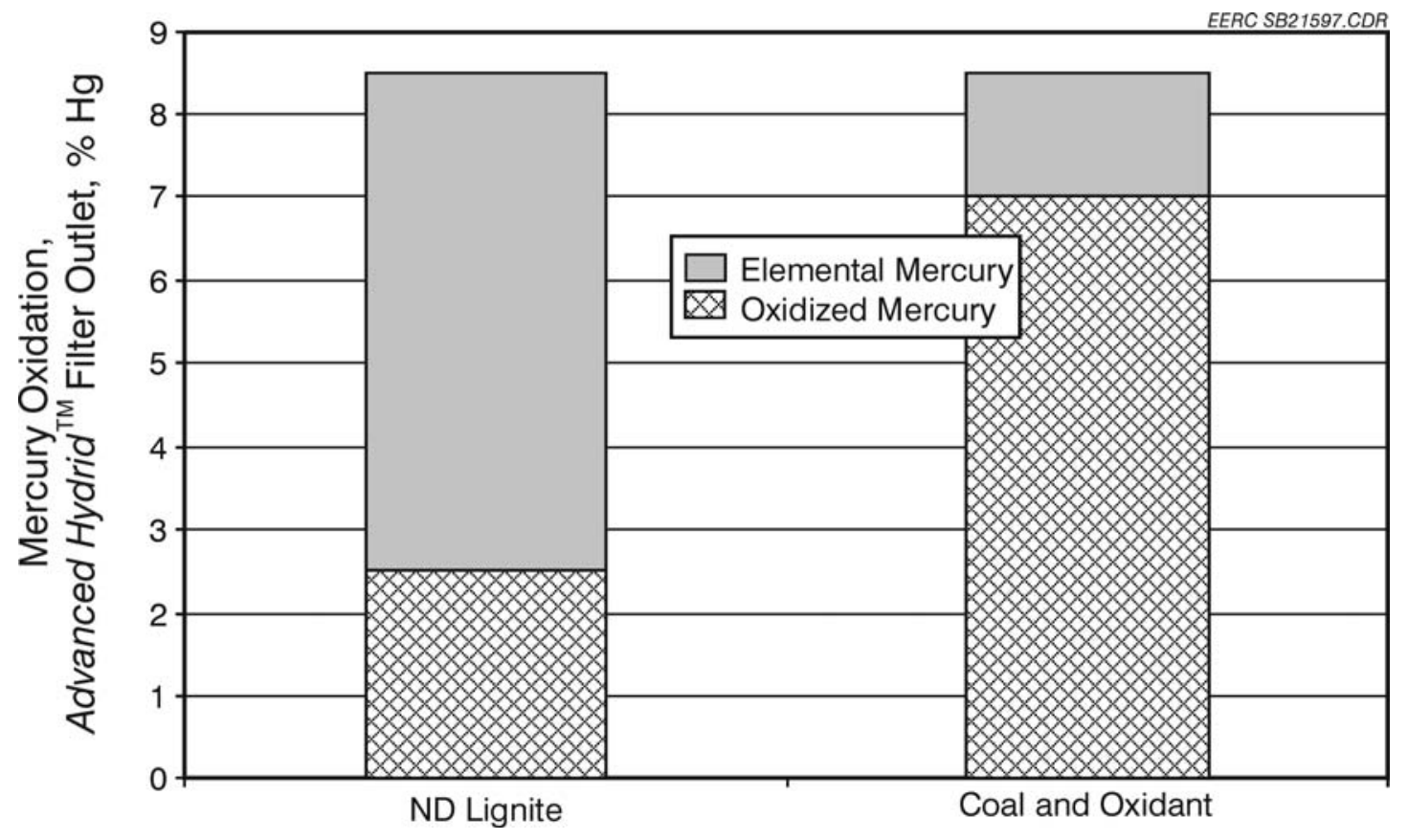

Figure 2-2. Ontario Hydro $(\mathrm{OH}) \mathrm{Hg}$ speciation results showing the effects of a coal $\mathrm{Hg}^{0}$ oxidation agent on North Dakota lignite combustion flue gas $\mathrm{Hg}$ speciation. 


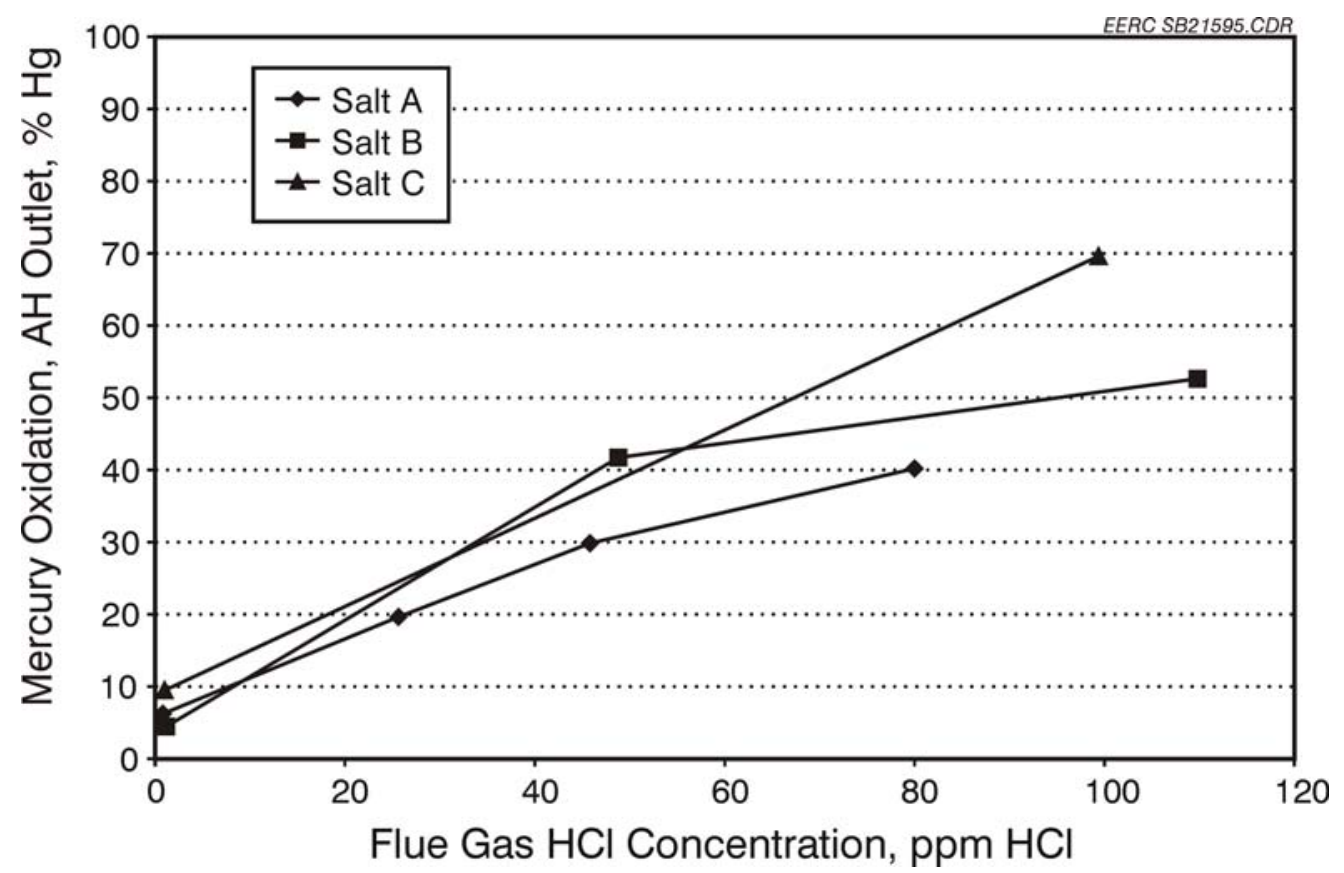

Figure 2-3. Comparison of $\mathrm{Hg}^{0}$ oxidation and $\mathrm{HCl}$ flue gas concentrations during salt injections at a North Dakota lignite-fired power plant (8).

fate. PAC injection is the most tested technology available for $\mathrm{Hg}$ control. PACs have the potential to effectively adsorb $\mathrm{Hg}^{0}$ and $\mathrm{Hg}^{2+}$, depending on the carbon characteristics and flue gas composition. Much PAC research has been performed in fixed-bed reactors that simulate relatively long-residence-time (gas-solid contact times of minutes or hours) $\mathrm{Hg}$ capture by a FF filter cake (13-15). However, it is important to investigate short-residence-time (seconds) in-flight capture of $\mathrm{Hg}^{0}$ because most of the coal-burning boilers in the United States employ cs-ESPs for controlling particulate matter emissions.

The projected annual cost for activated carbon adsorption of $\mathrm{Hg}$ in a duct injection system is significant. Based on experimental results, carbon-to-Hg weight ratios of 3000-18,000 (lb carbon injected/lb $\mathrm{Hg}$ in flue gas) were required to achieve $90 \% \mathrm{Hg}$ removal from a coal combustion flue gas containing $10 \mu \mathrm{g} / \mathrm{dNm}^{3}$ of $\mathrm{Hg}$ (16). More efficient carbon-based sorbents would enable lower carbon-to-Hg weight ratios to be used, thus reducing the costs.

EERC pilot-scale ESP and ESP-FF Hg removal efficiencies for Fort Union lignite coal combustion flue gases from Saskatchewan and North Dakota are compared in Figures 2-4 and 2-5 to those obtained at full-scale utility boilers while injecting PACs into a bituminous coal combustion flue gas upstream of a TOXECON-configured pulse-jet FF and into bituminous and PRB subbituminous coal combustion flue gases upstream of an ESP. As indicated in Figures 2-4 and 2-5, coal type (i.e., composition) was an important parameter that affected the $\mathrm{Hg}$ removal efficiency of a control device. While $\mathrm{Hg}$ removal efficiencies increased with increasing PAC injection rates, $\mathrm{Hg}$ removal efficiencies were never $>70 \%$ for the PRB subbituminous coal 


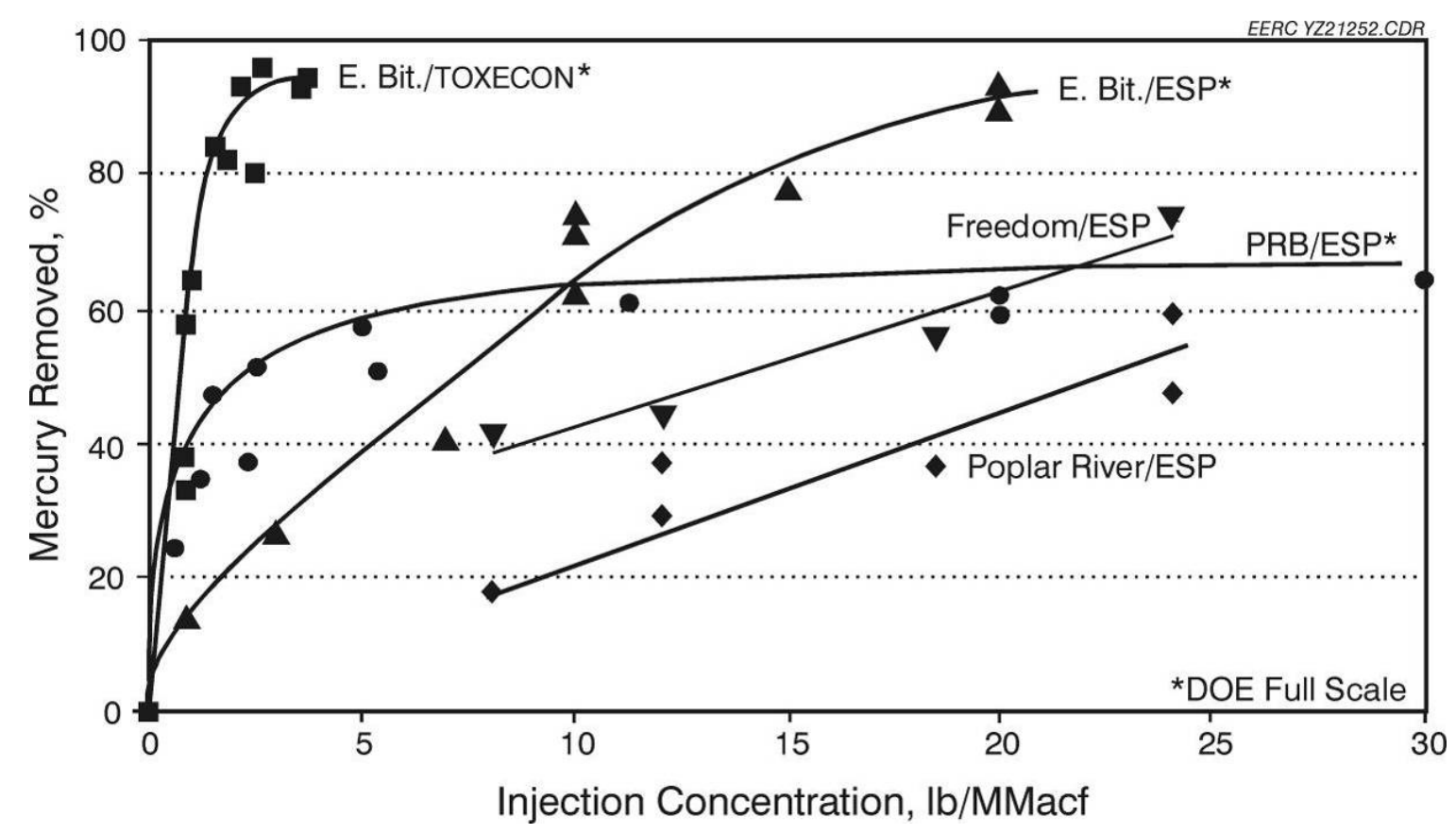

Figure 2-4. Pilot-scale ESP (12) and full-scale ESP (13) Hg removal efficiencies as a function of activated carbon injection $(\mathrm{ACI})$ rate.

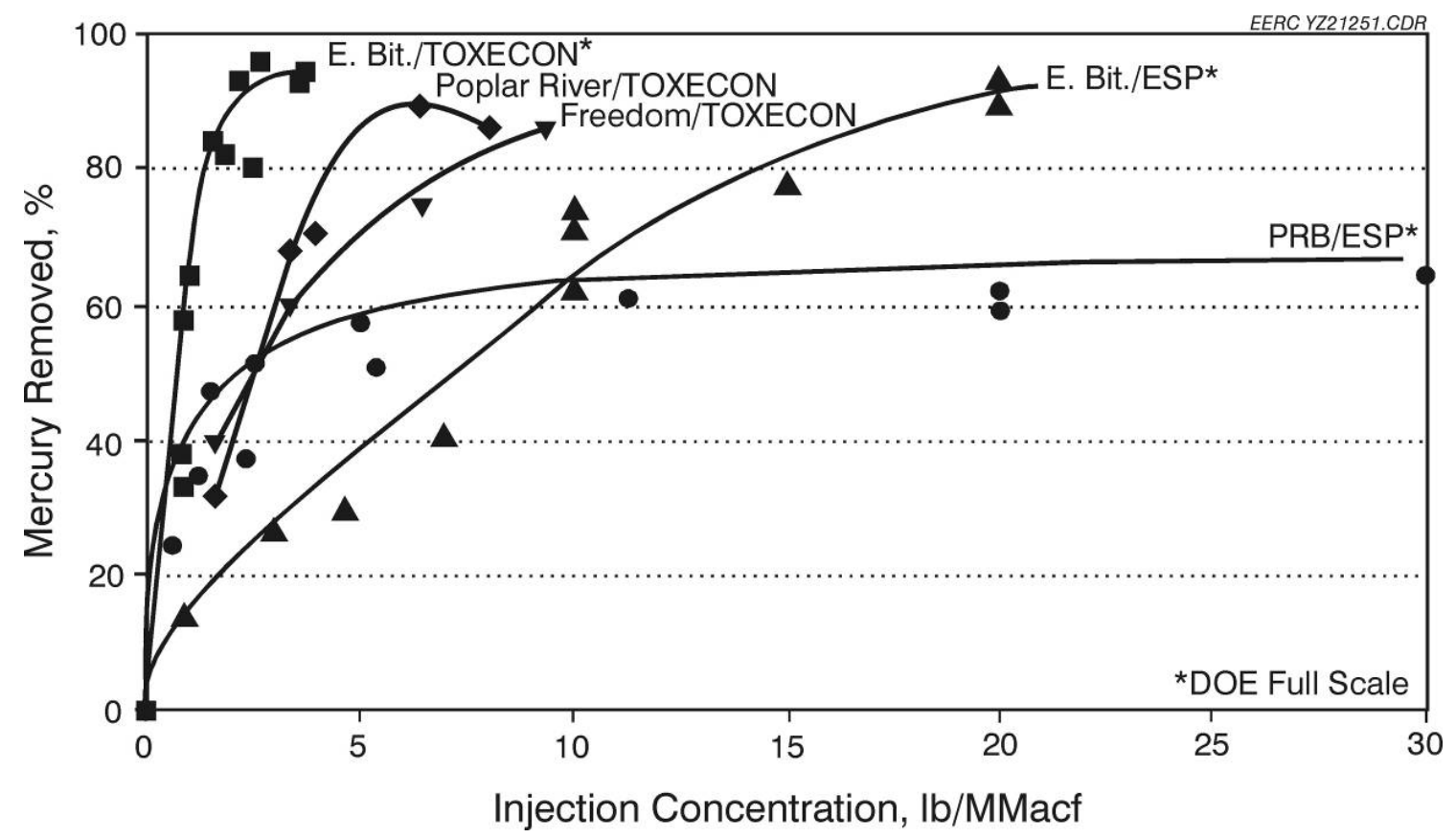

Figure 2-5. Pilot-scale ESP-FF (12) and full-scale TOXECON and ESP (13) Hg removal efficiencies as a function of ACI rate. 
combustion flue gas. This limitation may be caused by the low amount of acidic flue gas constituents, such as $\mathrm{HCl}$, that promote $\mathrm{Hg}$-activated carbon reactivity.

Testing at Great River Energy (GRE), a power plant firing Fort Union lignite and equipped with an SDA-FF, indicated that DARCO FGD and lignite-derived PACs resulted in Hg removal efficiencies of $<35 \%$ (17). The poor performance of PAC injection was thought to be the result of low-acid-gas concentrations and the high proportion of $\mathrm{Hg}^{0}$ in the flue gas. An iodine-impregnated activated carbon, however, captured approximately $90 \%$ of the $\mathrm{Hg}$.

Researchers at the EERC and elsewhere are studying the mechanisms of $\mathrm{Hg}$ species reactions on activated carbon surfaces in order to produce more efficient sorbents. Functional groups containing inorganic elements such as chlorine or sulfur may have a significant role in bonding $\mathrm{Hg}$ (18-20). Recently, detailed analyses of sorbents derived from lignites exposed to flue gas and $\mathrm{Hg}^{0}$ indicated the key species affecting oxidation and retention of $\mathrm{Hg}$ on the carbon surface were chlorine and sulfur $(21,22)$. Chlorine reacted to form organically associated chlorine on the carbon surface. The organically associated chlorine provided an important site for $\mathrm{Hg}^{2+}$ bonding.

\subsubsection{Previous Results with SEAs}

SEAs have recently been tested at the EERC. The effects of SEA additions and PAC injections on $\mathrm{Hg}$ capture in a TOXECON configuration, Advanced Hybrid filter, and ESP are illustrated in Figure 2-6. Baseline $\mathrm{Hg}$ emissions ranged from 9 to $12 \mu \mathrm{g} / \mathrm{dNm}^{3}$, with $80 \%$ to $90 \%$ of the total $\mathrm{Hg}$ as $\mathrm{Hg}^{0}$. Coal additives improved the $\mathrm{Hg}$ removal efficiencies of the TOXECON, Advanced Hybrid filter, and ESP devices to $\geq 90 \%$ removal. While using SEAs, the Hg control efficiency obtained with the ESP significantly improved compared to the previous ESP results presented in Figure 2-4. The coal additive technology also has the potential to improve SDAESP and SDA-FF Hg control efficiency.

PAC injection and SEA addition upstream of an ESP was evaluated for controlling $\mathrm{Hg}$ emissions associated with North Dakota lignite combustion. The testing was performed using the EERC's particulate test combustor (PTC) equipped with an ESP. Test results are presented in Figure 2-7. DARCO FGD injection at 3.75 and $15 \mathrm{lb} /$ Macf reduced $\mathrm{Hg}$ emissions by $50 \%$ and $60 \%$, respectively. The addition of SEA to the coal and PAC at $3.75 \mathrm{lb} / \mathrm{Macf}$ reduced $\mathrm{Hg}$ emissions by $>70 \%$.

Sorbent enhancement technologies have also been investigated by ALSTOM using a synthetic flue gas and an ESP. The sorbent preparation system enhanced sorbent performance from $68 \%$ to $>90 \% \mathrm{Hg}$ removal by changing the physical and chemical nature of the sorbent. The enhancement approach is expected to be applicable to a significant number of sorbents currently utilized for $\mathrm{Hg}$ control.

Using SEAs for the removal of $\mathrm{Hg}$ from coal-fired flue gas has the potential to create a lower-cost and more effective $\mathrm{Hg}$ removal strategy. Although the technology is in its infancy, it has great promise. 


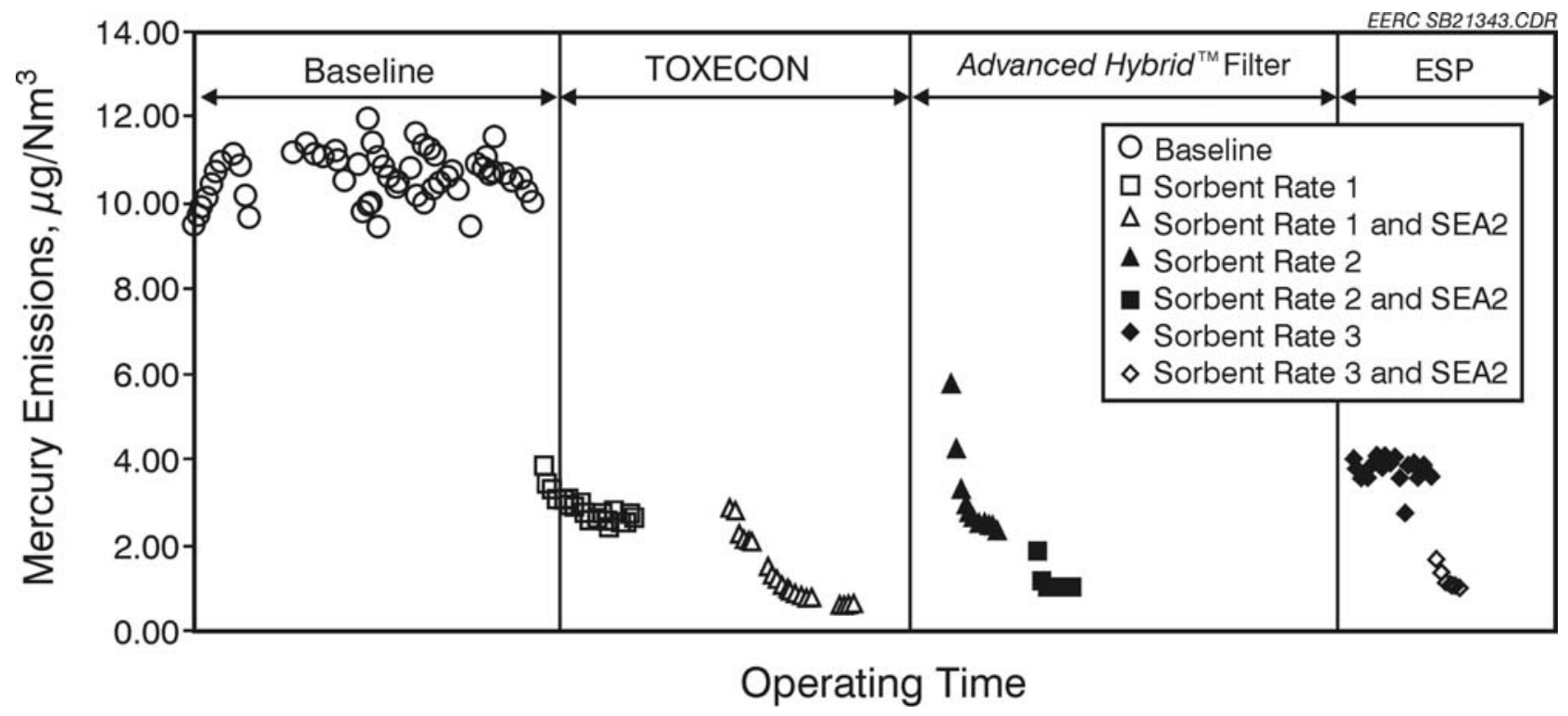

Figure 2-6. Hg emissions for PAC injection combined with additives.

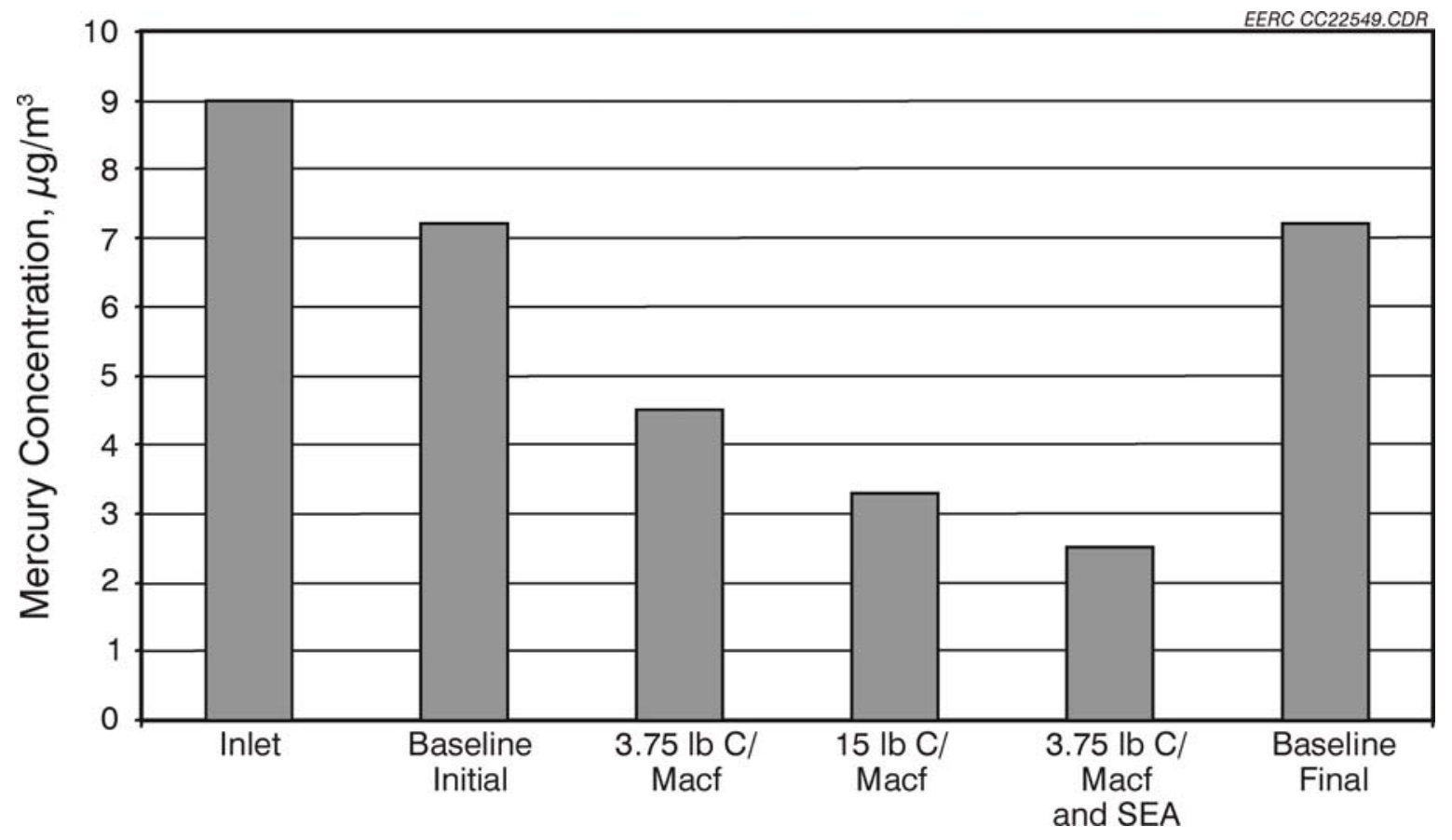

Figure 2-7. ESP inlet and outlet total $\mathrm{Hg}$ concentrations as functions of PAC injection and SEA addition rates into North Dakota lignite combustion flue gases. 


\subsection{Coal Combustion By-Products}

The Hg emission control technologies being developed for flue gases are in many cases designed to incorporate Hg into fly ash and/or FGD residue. Significant changes in the chemical composition, physical properties, and morphology of coal combustion by-products (CCBs) may occur as a result of the application of new emission controls. The stability of $\mathrm{Hg}$ associated with CCBs is being investigated at the EERC to determine if the $\mathrm{Hg}$ captured on CCBs may be released to the atmosphere or groundwater, thus negating the environmental benefit of removing $\mathrm{Hg}$ from flue gases. In addition, the physical and chemical changes that CCBs may undergo as a result of implementing $\mathrm{Hg}$ control technologies are being evaluated because they may affect how CCBs are managed.

$\mathrm{Hg}$ mobility mechanisms from $\mathrm{CCBs}$ have been identified as 1) direct leachability, 2) vapor-phase release at ambient and elevated temperatures, and 3) biologically induced leachability and vaporization. Leaching is the most likely mechanism of transport of constituents from disposed or utilized CCBs contacted by water. Leaching is typically performed on CCBs to characterize them for management purposes. Several issues have been raised by EPA's Office of Research and Development and Office of Solid Waste related to the best means of evaluating the leaching potential of CCBs. Vapor-phase release, particularly of $\mathrm{Hg}$, is important from the perspective of long-term use, storage, or disposal of CCBs. Although the $\mathrm{Hg}$ concentration in CCBs is relatively low, the large volumes of CCBs produced annually cause concern about potential $\mathrm{Hg}$ releases. Ambient and elevated-temperature studies of $\mathrm{Hg}$ mobility resulted in the development of equipment to determine $\mathrm{Hg}$ release in real time from CCBs. EERC results are presented regarding $\mathrm{Hg}$ release from $\mathrm{CCBs}$ subjected to laboratory tests designed to simulate the identified $\mathrm{Hg}$ mobility mechanisms.

\subsection{DESCRIPTION OF HOST SITES}

\subsection{MRY Unit 2}

MRY is owned and operated by MPC, with headquarters in Grand Forks, North Dakota, and a subsidiary, Square Butte Electric Cooperative. MRY is in Oliver County in western North Dakota's coal country, about 5 miles east and 3 miles south of Center, North Dakota. MRY Unit 2 is a B\&W Carolina-type radiant boiler designed to burn high-moisture North Dakota lignite. Nominally rated at 3,050,000 $\mathrm{lb} / \mathrm{hr}$, this unit is a cyclone-fired, balanced-draft, pump-assisted circulation boiler. The unit began commercial operation in May 1977 and is base-loaded at $450 \mathrm{MW}$ gross. A cold-side ESP with a specific collection area of $375 \mathrm{ft}^{2} / \mathrm{kacfm}$ and spray tower FGD system utilizing alkaline ash and lime are used for particulate and $\mathrm{SO}_{2}$ control, respectively. General information on the lignite coal burned at MRY is presented in Table 3-1.

MRY Unit 2 is ideally suited for testing $\mathrm{Hg}^{0}$ oxidation and control in an ESP-wet FGD. The high-temperature environment in the cyclone will easily vaporize and transform chlorine into the highly reactive radical species. In addition, the system has been tested for $\mathrm{Hg}$ speciation 
Table 3-1. MRY Coal Information

\begin{tabular}{lcccc}
\hline Owner and Operator & Mine & Seam Mined & Location & Mine Production, ${ }^{\text {a }}$ tons \\
\hline $\begin{array}{c}\text { BNI Coal, Ltd., a wholly } \\
\text { owned subsidiary of Allette }\end{array}$ & Center & $\begin{array}{c}\text { Kinneman Creek } \\
\text { and Hagel }\end{array}$ & $\begin{array}{c}\text { Western, northern lignite } \\
\text { basin, North Dakota }\end{array}$ & $4,522,831$ \\
\hline
\end{tabular}

${ }^{a}$ Keystone Coal Industry Manual; Mining Media: Prairieville, LA, 2004.

and control. Flue gas $\mathrm{Hg}$ sampling was performed at the ESP inlet, wet FGD inlet, and stack from October 22 through November 14, 2002. The sampling was performed using the $\mathrm{OH}$ method and continuous mercury monitors (CMMs) (23). A schematic of MRY Unit 2 showing sampling and SEA addition locations is provided in Figure 3-1.

The average $\mathrm{Hg}$ stack emissions were $95 \% \mathrm{Hg}^{0}$, as indicated in Figure 3-2. Statistical analyses of the CMM data indicated that the average total $\mathrm{Hg}$ concentration was $10.7 \pm$ $2.7 \mu \mathrm{g} / \mathrm{dNm}^{3}$ (90th percentile) at the FGD inlet and $9.3 \pm 2.2 \mu \mathrm{g} / \mathrm{dNm}^{3}$ at the stack. Fluctuations in total $\mathrm{Hg}$ concentrations resulting from coal heterogeneity and variability in plant operations were within $24 \%$ of the average values. $\mathrm{Hg}$ mass balances for MRY Unit 2 ranged from 102\% to $103 \%(10)$.

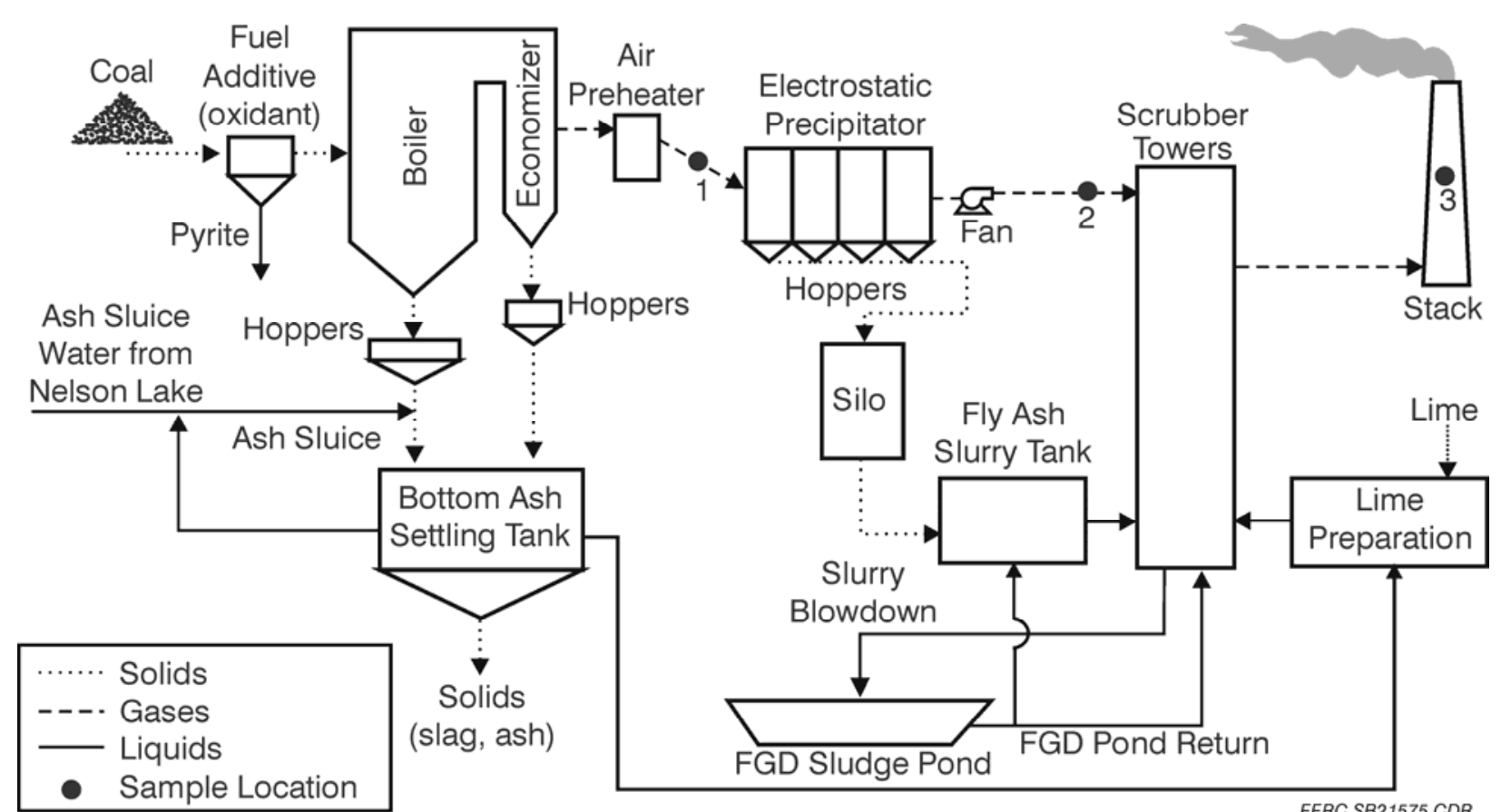

Figure 3-1.Schematic of MRY Unit 2 showing sampling and coal additive locations. 


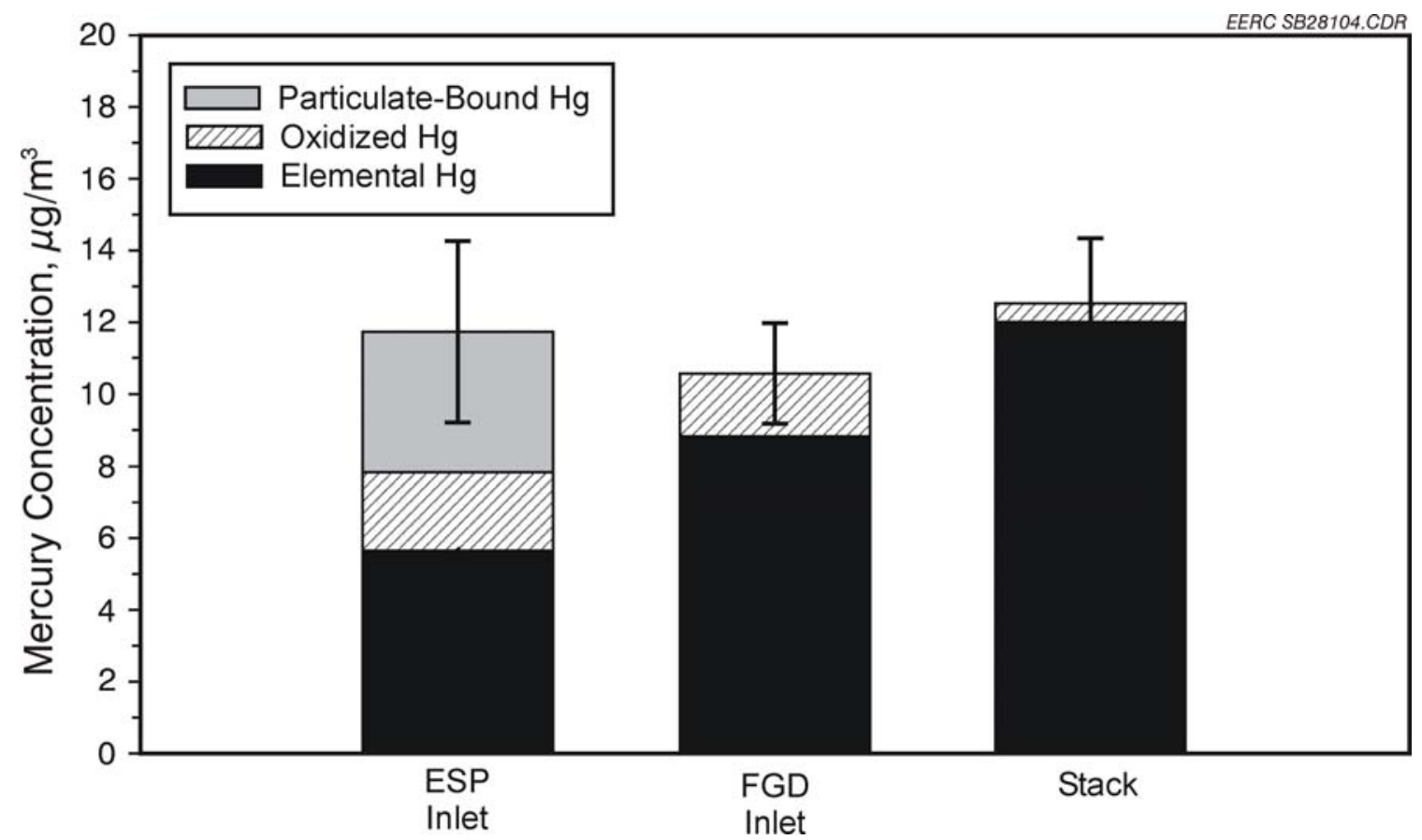

Figure 3-2. Average $\mathrm{OH} \mathrm{Hg}$ speciation results obtained at the ESP and wet FGD inlets and stack of MRY Unit 2.

\subsection{MoSES Unit 3}

TXU's MoSES Unit 3 fires a blend of approximately 50\% Texas lignite and 50\% PRB subbituminous coal and is rated at $793 \mathrm{MW}$. Figure 3-3 illustrates the Unit 3 configuration. Unit 3 has a horizontally opposed, pc boiler with low- $\mathrm{NO}_{\mathrm{x}}$ burners. A cs-ESP (design specific collection area [SCA] of $452 \mathrm{ft}^{2} / \mathrm{kacfm}$ ) is used for particulate control, and a limestone forcedoxidation spray tower FGD system is used for $\mathrm{SO}_{2}$ control. Three spray absorbers achieve about $90 \% \mathrm{SO}_{2}$ removal on the flue gas treated. About $50 \%$ of the flue gas is bypassed. The ESP outlet flue gas generally contains about $25 \% \mathrm{Hg}^{+2}$ and $75 \% \mathrm{Hg}^{0}$, with total $\mathrm{Hg}$ concentrations of about $20 \mu \mathrm{g} / \mathrm{Nm}^{3}$.

\subsection{EXPERIMENTAL}

Quality assurance and quality control (QA/QC) activities that were performed as part of the experimental activities described herein are summarized in the individual host site reports provided in Appendixes A and B. In addition, examples of calculations that were performed as part of the calibration, measurement, injection, and data reduction activities are presented in Appendixes A and B. 


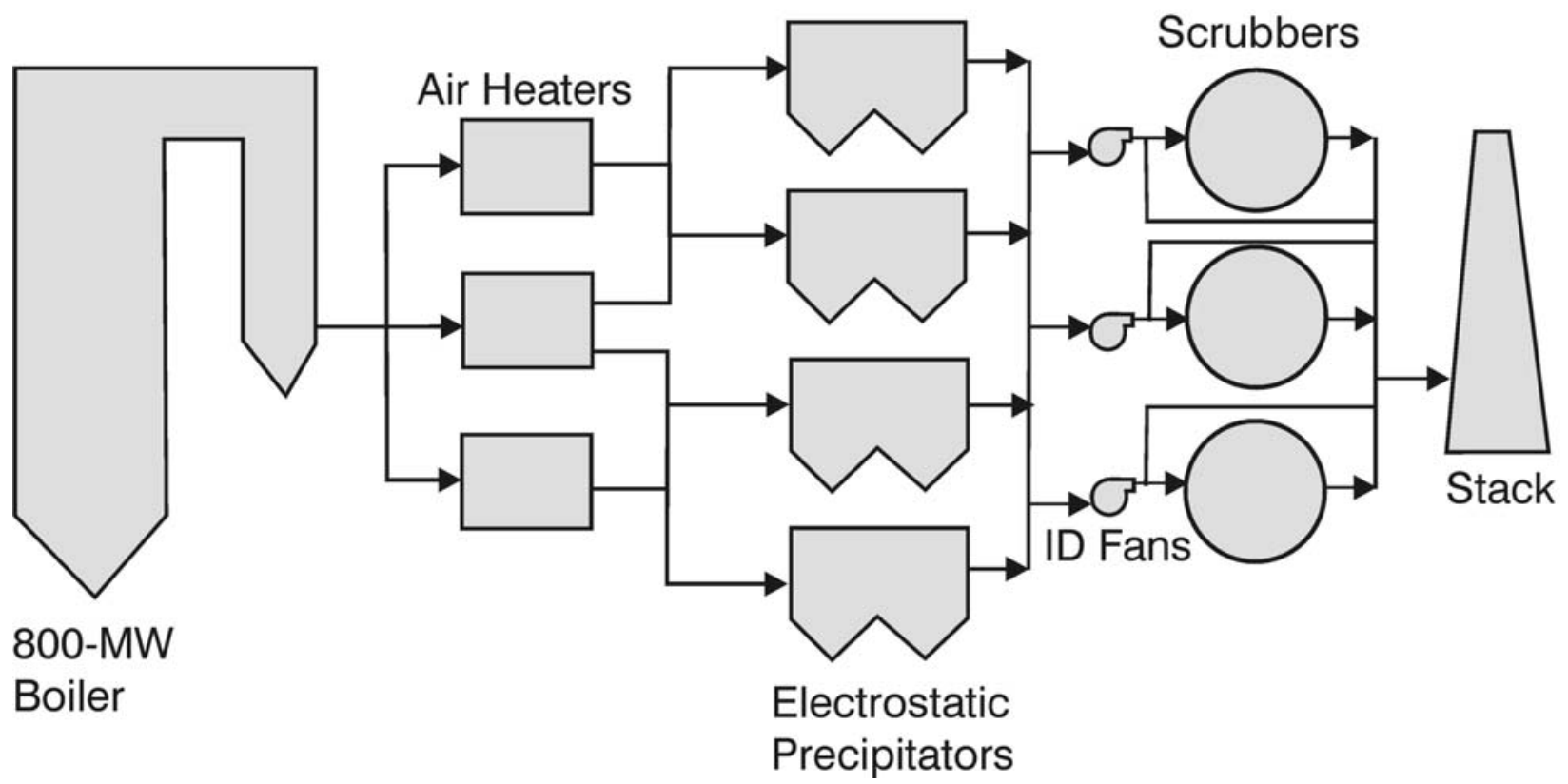

Figure 3-3. Schematic of MoSES Unit 3 configuration.

\subsection{Continuous Mercury Monitoring}

At MRY, Tekran Model 2537A atomic fluorescence-based Hg vapor analyzers were used in conjunction with PS Analytical S235C400 wet-chemistry conversion units to continuously monitor $\mathrm{Hg}^{0}$ and total gaseous $\mathrm{Hg}$ concentrations at the wet FGD inlet and stack locations. The PS Analytical uses two separate liquid flow paths, one to continuously reduce $\mathrm{Hg}^{2+}$ to $\mathrm{Hg}^{0}$, resulting in a total gas-phase $\mathrm{Hg}$ sample, and the other to continuously scrub out $\mathrm{Hg}^{2+}$, resulting in an $\mathrm{Hg}^{0}$ sample. The PS Analytical also uses a Peltier thermoelectric cooler module to cool and dry the sample gases prior to analysis.

The Tekran instrument traps the Hg vapor from the conditioned sample onto a cartridge containing an ultrapure gold sorbent. The amalgamated $\mathrm{Hg}$ is then thermally desorbed and detected using atomic fluorescence spectrometry. A dual-cartridge design enables alternate sampling and desorption, resulting in a nearly continuous measurement of the sample stream. An automatic $\mathrm{Hg}^{0}$ permeation source was used to calibrate the instrument daily. Manual $\mathrm{Hg}^{0}$ injection calibration on both cartridges was also performed for verification. The Tekran instrument measures either total $\mathrm{Hg}$ or $\mathrm{Hg}^{0}$, with an analysis occurring approximately every 2.5 minutes.

At MoSES, total gaseous $\mathrm{Hg}$ and $\mathrm{Hg}^{0}$ were measured at the ESP inlet, ESP outlet, and FGD outlet using EPRI's mercury semicontinuous emission monitor (SCEM). At each sample location, a sample of the flue gas was extracted at a single point from the duct and then drawn through an inertial gas separation (IGS) filter to remove particulate matter. This IGS filter 
consists of a heated stainless steel tube lined with sintered material. A secondary sample stream is pulled across the sintered metal filter and then is directed through the mercury analyzer at a rate of approximately 1-2 L/min, thus providing near-real-time feedback during the various test conditions. The analyzer consists of a cold-vapor atomic absorption spectrometer (CVAAS) coupled with a gold amalgamation system (Au-CVAAS). Since the Au-CVAAS measures Hg by using the distinct lines of the ultraviolet (UV) absorption characteristics of $\mathrm{Hg}^{0}$, the nonelemental fraction is converted to $\mathrm{Hg}^{0}$ prior to analysis using a chilled reduction solution of acidified stannous chloride. Several impingers containing alkaline solutions are placed downstream of the reducing impingers to remove acidic components from the flue gas; $\mathrm{Hg}^{0}$ is quantitatively transferred through these impingers. Gas exiting the impingers flows through a gold amalgamation column where the mercury in the gas is adsorbed $\left(<60^{\circ} \mathrm{C}\right)$. After adsorbing onto the gold for a fixed period of time (typically 1 to $6 \mathrm{~min}$ ), the concentrated mercury is thermally desorbed $\left(>400^{\circ} \mathrm{C}\right)$ in nitrogen or air and flows as a vapor stream to a CVAAS for analysis. The total flue gas mercury concentration is measured semicontinuously after a 1-6-minute sample time followed by a 2-min analytical period.

\subsection{OH Flue Gas Mercury Measurements}

In addition to continuous mercury monitoring, mercury speciation measurements were performed using ASTM International Method D6784-02 (Ontario Hydro Method). OH method samples were withdrawn from the flue gas stream isokinetically through a probe/filter system, maintained at $120^{\circ} \mathrm{C}$ or the flue gas temperature, whichever was greater, followed by a series of impinger solutions in an ice bath. Particle-bound mercury $\left(\mathrm{Hg}_{\mathrm{p}}\right)$ was collected on a quartz filter in the front half of the sampling train. $\mathrm{Hg}^{2+}$ was collected in impingers containing a chilled aqueous potassium chloride solution. $\mathrm{Hg}^{0}$ was collected in subsequent impingers (an impinger containing a chilled aqueous acidic solution of hydrogen peroxide and three impingers containing chilled aqueous acidic solutions of potassium permanganate). Samples were recovered and sent to the lab for analysis. The $\mathrm{OH}$ method samples were typically prepared and analyzed the same day of collection or the following day. Additional flue gas analysis results were determined as part of the $\mathrm{OH}$ method, including oxygen, carbon dioxide, moisture, and dust-loading concentrations, which were used to normalize $\mathrm{Hg}$ results. Flue gas mercury measurements were also made with the Appendix K method and a modified sorbent tube method at MoSES.

\subsection{EPA Methods 26 and 26A}

Flue gas samples were collected using EPA Method 26 (Determination of Hydrogen Halide $[\mathrm{HX}]$ and Halogen $\left[\mathrm{X}_{2}\right]$ Emissions from Stationary Sources) and EPA Method 26A (Determination of Hydrogen Halide and Halogen Emissions from Stationary Sources Isokinetic Method) during baseline, parametric, and long-term testing conditions to evaluate halogen concentrations. These measurements were made to verify the amount of halogen added to the flue gas. Flue gas samples for Method 26 were obtained at the ESP inlet location as a singlepoint measurement, nonisokinetically, and with mini-impingers. Flue gas samples for Method 26A were obtained at the FGD outlet location as an isokinetic traverse with large impingers. The impinger solutions were analyzed for halogen by ion chromatography. 
In Methods 26 and 26A, the hydrogen halides are solubilized in an acidic solution, while the halogens pass through to be captured in an alkaline solution. Methods 26 and 26A have not been validated for flue gas measurements below $20 \mathrm{ppm}$ halide; furthermore, a negative bias has been demonstrated in the quantification of the $\mathrm{X}_{2}$ (with a corresponding positive bias for the quantification of the hydrogen halide). In the presence of certain flue gas components $\left(\mathrm{SO}_{2}, \mathrm{NO}_{\mathrm{x}}\right)$, a significant fraction of the $\mathrm{X}_{2}$ is captured in the acidic solution (24). While this bias affects the halogen speciation data, it does not affect the measurement of total halogen $\left(\mathrm{HX}+\mathrm{X}_{2}\right)$ in the flue gas. Therefore, the total halogen concentration is provided for this report.

\subsection{Sampling and Analysis of Coal Fly Ash}

Selected ash samples were analyzed for Hg using ASTM Method D6414-01 (Standard Test Method for Total Mercury in Coal and Coal Combustion Residues by Acid Extraction or Wet Oxidation/Cold-Vapor Atomic Absorption). Several coal fly ashes were also analyzed for $\mathrm{Hg}$ using a Milestone direct mercury analyzer (DMA), the DMA-80. In addition, some samples were analyzed for halogens, loss-on-ignition (LOI), and carbon using standard ASTM or EPA methods.

In accordance with DOE requirements, a 5-gal composite sample was collected from MRY and MoSES ESPs three times during baseline operation and three times during the 2-month test. Again, these samples were collected concurrently with $\mathrm{OH}$ method samples. Standard 5-gal plastic buckets were filled with a representative split of the sampled ash for NETL. In addition, ash samples were collected during the baseline and long-term testing conditions for analyzing $\mathrm{Hg}$ thermal stability and aqueous mobility. A separate gallon split of these two ash samples was stored in plastic and delivered to the EERC

\subsection{Coal Analyses}

Lignite samples were collected at MRY from four of the twelve feeders that were equipped with automatic samplers and combined into a daily composite. To obtain a representative sample of coal feed, a gallon representative split of each of the daily coal samples was archived and stored in a plastic pail. This composite sample represented the coal being fed to the crushers upstream from where the $\mathrm{CaCl}_{2}, \mathrm{MgCl}_{2}$, and SEA2 were added. Proximate and ultimate analyses were conducted on the composite coal samples using ASTM Methods D3172, D5142, and D3176. A Mitsubishi Model TOX-100 total chlorine analyzer was used to perform ASTM Method D6721-01 (Standard Test Method for Determination of Chlorine in Coal by Oxidative Hydrolysis Microcoulometry). Coal Hg contents were determined in triplicate using a CVAAS according to EPA Method 245.1 and EPA SW-846 Method 7470.

The PRB and Texas lignite coals were sampled and analyzed separately. At MoSES, the only location available for segregated coal samples was at the coal belt in the coal feed yard, which is approximately 6 hours upstream of the furnace. Coal samples were collected once per day. The coal samples were analyzed in URS's Austin laboratories for mercury and halogen content. The coal was digested by ASTM 4208 and analyzed for halogens by Method 300. Coal mercury contents were determined in triplicate using ASTM 3684 digestion and CVAAS analysis. $\mathrm{Hg}$ and $\mathrm{Cl} / \mathrm{Br}$ concentrations were reported as $\mu \mathrm{g} / \mathrm{g}$ on a dry basis. The ultimate- 
proximate parameters were determined by a subcontracted laboratory (Commercial Testing and Engineering).

\subsection{Scrubber Slurry Samples}

Scrubber slurry samples were collected from MRY Unit 2 by MPC personnel from one of the recycle pumps from the scrubber downstream of the ESP involved in the testing once during baseline operation and three times during long-term testing. These were collected during the weeks that $\mathrm{OH}$ method testing was being performed. One-quart samples were stored in glass jars with plastic lids and returned to the EERC for analysis of selected samples. Similar composite scrubber slurry samples from the scrubber after the ESP not involved in the testing were collected, once during baseline operation and three times during the 2-month test. These also were collected during the weeks that $\mathrm{OH}$ method testing was being performed.

Scrubber samples were collected at MoSES Unit 3 by URS personnel from the exit of the slurry recirculation pump on the $\mathrm{C}$ scrubber module on Unit 3. The FGD sampling included a slurry to be filtered for mercury analysis of solids and liquid. The sample was filtered on-site within an hour of collection to ensure that the mercury did not repartition between the solid and liquid phases. A full set of diluted filtrates (DFs) was taken each day. DFs are used to preserve the liquid sample for analysis of $\mathrm{SO}_{3}{ }^{2-}, \mathrm{SO}_{4}{ }^{2-}, \mathrm{CO}_{3}{ }^{2-}$, halogens, $\mathrm{Ca}^{2+}, \mathrm{Mg}^{2+}$, and $\mathrm{Na}^{+}$. $\mathrm{A}$ slurry sample was taken each day and filtered off-site at URS-Austin for $\mathrm{wt} \%$ solids and cations and anions in the solids $\left(\mathrm{Ca}^{2+}, \mathrm{Mg}^{2+}, \mathrm{SO}_{3}{ }^{2-}, \mathrm{SO}_{4}{ }^{2-}\right.$, and $\left.\mathrm{CO}_{3}{ }^{2-}\right)$. All scrubber analyses were performed in URS's Austin laboratories.

The scrubber on MoSES Unit 3 was sampled during the baseline periods of operation and once per day during the long-term tests. The scrubber was not sampled during the parametric injection test periods, as these test periods were too short in comparison to the residence time of the slurry in the scrubber. Therefore, it would not have been possible to obtain representative slurry samples during the parametric tests.

\subsection{Miscellaneous Samples}

Water, limestone, and fly ash used to make wet FGD slurry as well as the slurry itself were sampled at MRY Unit 2 and MoSES Unit 3 during the baseline testing and long-term testing conditions. In addition, pyrite rejected from the coal conditioner and bottom ash settling tank solids were sampled when $\mathrm{OH}$ method measurements were being performed. All samples were stored in glass jars with plastic lids and archived for analysis.

\subsection{Systems Operation and Monitoring}

\subsubsection{Aqueous $\mathrm{CaCl}_{2}, \mathrm{CaBr}_{2}, \mathrm{MgCl}_{2}$, and $\mathrm{SEA2}$ Addition System}

The aqueous $\mathrm{CaCl}_{2}, \mathrm{CaBr}_{2}, \mathrm{MgCl}_{2}$, and SEA2 addition systems at MRY and MoSES consisted of liquid storage tanks, a metering and pumping skid, and injection lances. Detailed descriptions of the aqueous addition systems and the operating procedures that were used at 
MRY and MoSES are presented in Appendices A (Section 5.8, pp 20-24) and B (Section 3.1, pp 3-7), respectively.

\subsubsection{PAC Injection System}

A PAC injection system was supplied and installed by Apogee at MRY Unit 2 upstream of the ESP. The PAC injection system consisted of an Apogee Portapac metering skid, blower, connecting lines, and injection lances. The Portapac system includes provision for loading 900-lb supersacks of PAC, along with a discharge hopper, feed screw, blower, eductor, and discharge hose to supply carbon to the duct. PAC injection was performed at 16 locations into the ductwork upstream of the ESP. The PAC feed rate was monitored by load cells mounted on the Portapack system, with weight change and feed rate monitored by a laptop computer. Carbon was transported through a discharge hose to distribution manifolds atop the ESP inlet ducts (approximately 90 feet above the Portapack system at ground level). The carbon stream was split into two streams, with each stream then split again to feed the four ESP inlet ducts. Two more splits were made so as to feed four injection lances positioned in ports on each duct. Injection on the inboard B-side duct was on either side of the central port where the $\mathrm{OH}$ method sampling was performed. Visual inspection of the $\mathrm{OH}$ method filters showed no indication of the PAC being collected in these samples. This configuration resulted in PAC treatment of the entire flue gas stream for Unit 2. The control logic for the PAC system was configured to allow PAC addition to be set and controlled proportionally to the unit load in megawatts. Provisions were made to stop the PAC injection if the load fell below a certain MW level in the case of a plant shutdown. At the injection rates used, PAC consumption was approximately one 900-lb supersack every 2 days. No problems were encountered with the PAC injection system, except for occasional PAC stoppages because of bridging in the supersacks themselves.

\subsection{Balance-of-Plant Data Collection}

\subsubsection{Plant Data}

Plant operation data from the plant control room, such as unit temperature, load, and stack CMM data, were recorded for the duration of field testing. These data were reviewed to determine if noticeable changes in plant operation occurred during testing activities.

\subsubsection{Corrosion/Deposition Probes}

The potential corrosive effects of SEA2 and PAC injections were evaluated by installing air-cooled corrosion/deposition test probes at the economizer exit (ECM), air heater inlet (AHI), and air heater outlet (AHO) of MRY Unit 2. Two coupons for each location were fabricated by MRY personnel: a baseline coupon exposed to the normal flue gas environment for 8 weeks and a test coupon exposed to flue gas while SEA2 and PAC were being added to the coal feed for 6 weeks. No standard test method in the literature was found appropriate for corrosion testing of simulated steam tube samples in a full-scale utility boiler environment; therefore, a customized testing procedure was developed. Each corrosion/deposition probe was designed to hold an 18-in.-long, 1-in.-diameter coupon consisting of a section of stainless steel boiler tubing. To induce stress in the metal and, possibly, enhance corrosion, the tubing was flattened in a 2-in. 
section at the midpoint to produce an oval with a minimum inside diameter of 0.5 inches. The purpose of the flattening was to introduce stress in the metal to enhance potential corrosion. Actual coupon outside diameter was $111 / 16$ in., with a 0.25 -in. wall. Reducing couplings were used to join the coupons to the probes.

The corrosion probe assembly is shown in Figure 4-1, and a picture of the coupon and cross-sectioned coupon is shown in Figure 4-2. The probe was inserted into the boiler through a 4-in. threaded pipe stub attached to the boiler wall. The threaded 4-in. pipe cap supported the probe. Welded to and extending through the pipe cap was a section of 1-in. Schedule 40 pipe. Stainless steel pipe was used for all of the probes. Additional couplings and 18-in. pipe lengths were screwed on to extend the probe length, with the test coupon held at the end. The test coupons were threaded for attachment to the corrosion probe assembly and for a pipe cap to seal the opposite end. A 0.5-in. 316 stainless steel tube spans the length of the probe. Compressed air for cooling was introduced through a pipe tee and flowed down the annulus between the tubing and probe pipe and back out of the stainless steel tubing. A gate valve at the inlet was used to regulate the airflow, and a ball valve provided on/off control. Skin temperatures of the coupons were monitored with a thermocouple extending down the stainless steel tube and that pressed against the end cap. A second thermocouple monitored exit cooling-air temperature.

To preserve any ash deposit adhering to the probes, they were wrapped in plastic film and placed in cardboard tubes prior to transport. Upon arrival at the EERC, the test coupon sections of the probes were sprayed with a mixture of acetone and epoxy to affix the ash deposits during subsequent cutting. The test coupons were cross-sectioned with a metal band saw at the midpoint of the crimped area. The cutting operation was performed without lubrication to prevent contamination of the coupons. The samples were then mounted in epoxy and polished to obtain samples for scanning electron microscopy (SEM) analysis.

Six coupon samples were examined by SEM to ascertain the degree of corrosion at the metal-metal oxide-deposit interface. Line scans were performed for each sample on one of the curved sections and flat sections. Four lines were selected at each location for quantitative point analyses for $\mathrm{Na}, \mathrm{Mg}, \mathrm{Al}, \mathrm{Si}, \mathrm{P}, \mathrm{S}, \mathrm{Cl}, \mathrm{Br}, \mathrm{K}, \mathrm{Ca}, \mathrm{Ti}, \mathrm{Cr}, \mathrm{Fe}, \mathrm{Ni}, \mathrm{Mn}$, and $\mathrm{O}$. Each line was $40 \mu \mathrm{m}$ long across the metal-metal oxide-deposit interface, and 81 point analyses were performed along the line in equal intervals between points.

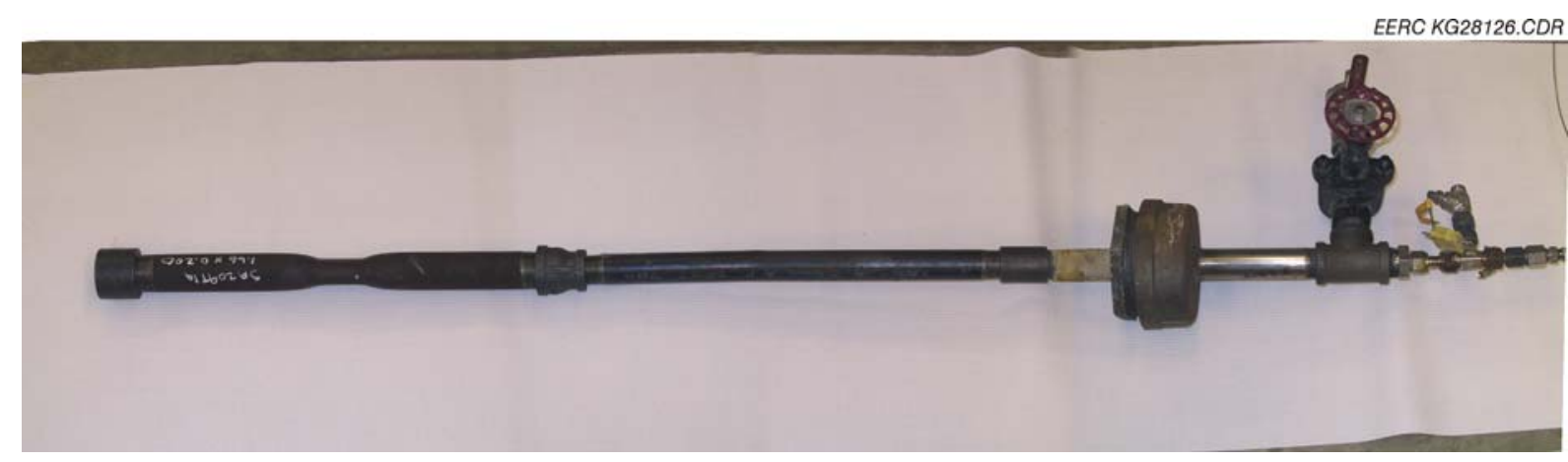

Figure 4-1. Photograph of the corrosion/deposition probe assembly. 


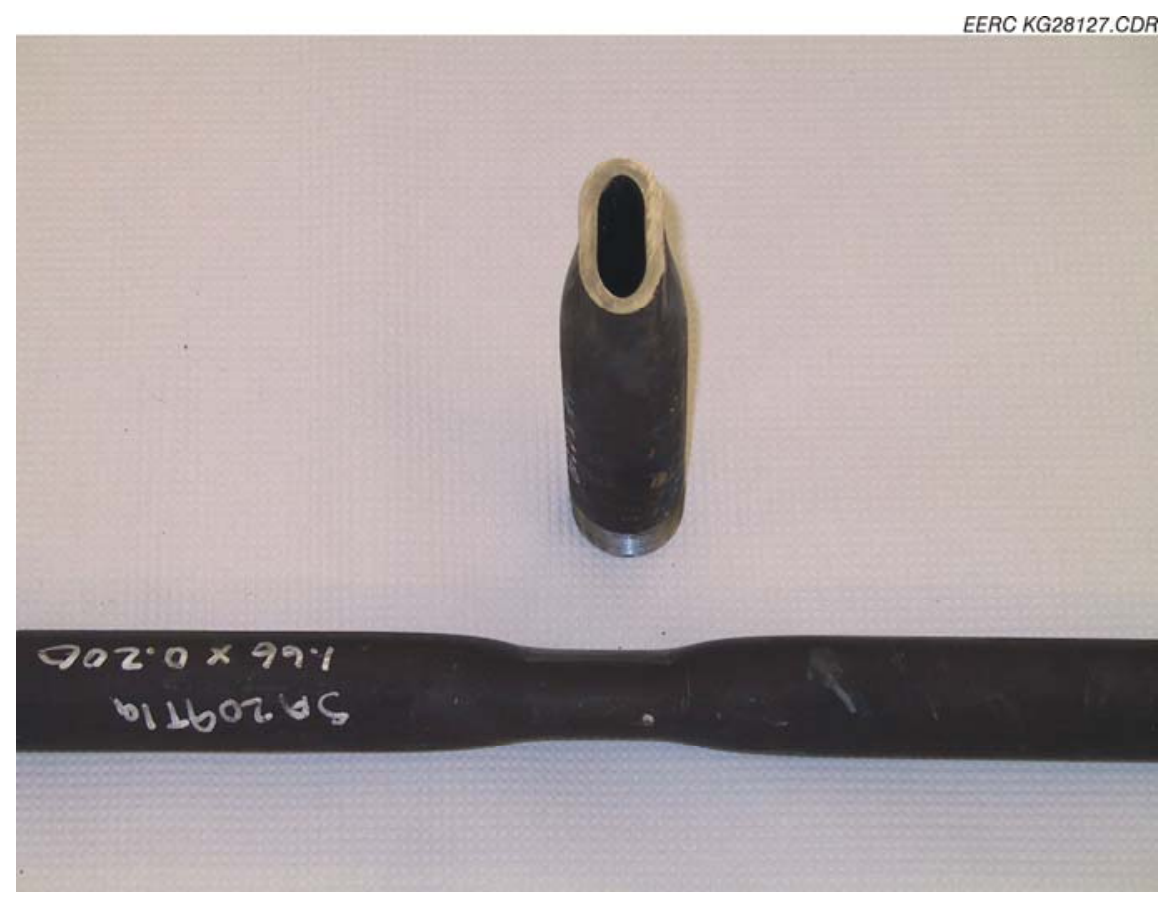

Figure 4-2. Photograph of coupon and a cross-sectioned coupon.

\subsection{Mercury Stability in Coal Fly Ash}

The stability of $\mathrm{Hg}$ in fly ashes collected from ESP hoppers during baseline and $\mathrm{Hg}$ control technology testing conditions was evaluated. Experiments were designed to assess the potential for $\mathrm{Hg}$ mobility under controlled laboratory conditions similar to those that fly ash may be exposed to in disposal and utilization environments.

\subsubsection{Leaching}

Leaching is the most likely mechanism of transport of constituents from disposed or utilized fly ashes contacted by water. Leaching is typically performed on fly ash to characterize it for management purposes. The leaching procedure used for these samples were the synthetic groundwater leaching procedure (SGLP) with long-term leaching (LTL) (25).

The SGLP batch-leaching procedure is a relatively simple test that follows many of the conditions of the toxicity characteristic leaching procedure (TCLP) (26) and ASTM D3987 (27). The test utilizes a 20:1 liquid-to-solid ratio, end-over-end agitation at approximately $30 \mathrm{rpm}$, and an 18-hour equilibration time and employs either water from the site, water that has been prepared in the lab similar to water likely to contact the ash, or distilled, deionized water. Distilled deionized water was used in this effort. For the long-term component of this procedure, multiple bottles are set up and analyzed at different time intervals. A typical SGLP and LTL test consisting of 18-hour, 30-day, and 60-day equilibration times was performed in this effort. Although 60 days is often not long enough to have achieved complete equilibrium, it is generally 
long enough to determine the concentration evolution of individual parameters. The most important factor when LTL is performed is to have at least three equilibration times to determine a true trend. Leachates were filtered through $0.45-\mu \mathrm{m}$ filter paper and analyzed for total $\mathrm{Hg} . \mathrm{Hg}$ leachate concentrations were determined using cold-vapor atomic fluorescence spectrometry (CVAFS) and CVAAS techniques.

\subsubsection{Thermal Stability}

A schematic for the controlled thermal desorption of mercury and mercury compounds was assembled and is shown in Figure 4-3. The apparatus was constructed using atomic absorption spectroscopy (AAS) for mercury detection and included a small tube furnace and temperature controller for thermal desorption. A Hewlett Packard 3395 integrator was used for data collection. Detection of thermally desorbed mercury and mercury compounds was done in an electrically heated quartz cell operated at $800^{\circ} \mathrm{C}$. The use of a heated cell allowed detection of mercury compounds by thermally decomposing compounds to form elemental mercury, which can be detected by AA. Nitrogen gas flow was maintained at $5 \mathrm{~cm}^{3} / \mathrm{min}$ through the AA. The temperature controller was ramped from ambient temperature to $750^{\circ} \mathrm{C}$ at a rate of $25^{\circ} \mathrm{C}$ per minute.

\subsection{1 $\mathrm{Hg}^{0}$ Oxidants and PAC}

The addition of inorganic chloride and bromide compounds such as $\mathrm{CaCl}_{2}, \mathrm{MgCl}_{2}$, and $\mathrm{CaBr}_{2}$ to coal may promote $\mathrm{Hg}^{0}$ oxidation after the coal combustion process. $\mathrm{CaCl}_{2}, \mathrm{MgCl}_{2}$, and

$\mathrm{CaBr}_{2}$ were selected as halogen-containing additives because the addition of small amounts of

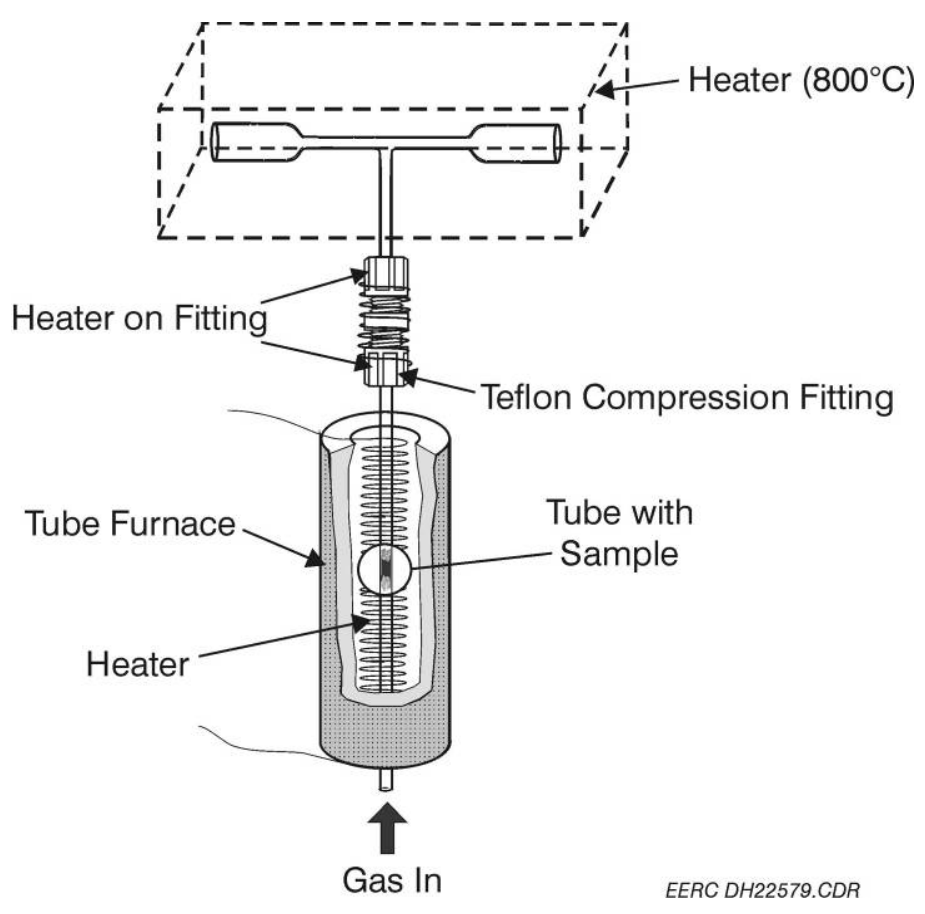

Figure 4-3. Hg thermal desorption apparatus. 
calcium and magnesium, $\leq 4 \mathrm{lb} /$ Macf, was expected to have little effect on ash slagging and fouling severity because of the inherently high alkaline-earth metal contents of the Center Mine and Texas lignite coals. SEA2 is a proprietary $\mathrm{Hg}^{0}$ oxidizing agent effective at addition rates on the order of one-tenth of those for $\mathrm{CaCl}_{2}$.

The PAC injected at MRY Unit 2 was NORIT Americas Inc. DARCO ${ }^{\circledR} \mathrm{Hg}$, a lignite-based activated carbon manufactured specifically for the removal of $\mathrm{Hg}$ in coal-fired utility flue gas emission streams. According to the manufacturer, it has been proven in numerous full-scale operating facilities to be highly effective for removing gaseous $\mathrm{Hg}$. Some of the general properties of DARCO Hg are presented in Table 4-1.

\subsection{RESULTS AND DISCUSSION FOR MRY UNIT 2 TESTING}

Most of the coal, flue gas, fly ash, and scrubber slurry sample analyses from MRY Unit 2 were replicated. However, to be concise, average results are generally presented herein. Individual analysis results are available in the MRY site report provided in Appendix A.

\subsection{Coal Analysis Results}

Coal samples were collected daily during the baseline, parametric, and long-term testing conditions. Proximate, ultimate, $\mathrm{Hg}$, and $\mathrm{Cl}$ analyses were performed on randomly selected coal samples. Average coal analysis results are summarized in Table 5-1. Even though coal samples collected downstream from the coal crushers were partially dry, they are referred to as "asreceived" in this report. Average results for the higher-moisture coals are presented in Table 5-1 for time periods corresponding to baseline, parametric, and monthlong testing conditions as well as for the entire sampling period. These coal analysis results were used to calculate theoretical $\mathrm{Hg}$ concentrations in the flue gas.

Presented in Table 5-2 are the elemental oxide compositions of three pulverized coals sampled from MRY Unit 2 during the long-term testing conditions. Even though the three coals are compositionally variable, especially their $\mathrm{SiO}_{2}, \mathrm{Al}_{2} \mathrm{O}_{3}, \mathrm{Fe}_{2} \mathrm{O}_{3}, \mathrm{CaO}, \mathrm{Na}_{2} \mathrm{O}$, and $\mathrm{SO}_{3}$ contents, they are characterized by relatively high alkaline-earth $(\mathrm{CaO}$ and $\mathrm{MgO})$ and alkali $\left(\mathrm{Na}_{2} \mathrm{O}\right)$ metal concentrations. Average chemical fractionation results for the three MRY coal samples are presented in Table 5-3. Average results are presented because the chemical fractionation results for all three samples were statistically similar with standard deviations of $<1 \%$. Certain elements

Table 4-1. General Properties of NORIT Americas Inc. DARCO Hg ${ }^{1}$

\begin{tabular}{lc}
\hline Parameter & Value \\
\hline Mesh Size, $<325$ mesh $(<45 \mu \mathrm{m})$ & $>95 \%$ \\
Iodine Number & $550 \mathrm{mg} / \mathrm{g}$ \\
Sulfur & $1.2 \mathrm{wt} \%$ \\
Bulk Density & $0.51 \mathrm{~g} / \mathrm{mL}\left(32 \mathrm{lb} / \mathrm{ft}^{3}\right)$ \\
Surface Area & $600 \mathrm{~m}^{2} / \mathrm{g}$ \\
\hline
\end{tabular}


Table 5-1. Summary of MRY Unit 2 Coal Analysis Results, as-received unless otherwise noted

\begin{tabular}{|c|c|c|c|c|c|c|c|c|}
\hline \multirow[b]{2}{*}{ Parameter, Unit } & \multicolumn{2}{|c|}{ Overall } & \multicolumn{2}{|c|}{ Baseline Testing } & \multicolumn{2}{|c|}{ Parametric Testing } & \multicolumn{2}{|c|}{ Long-Term Testing } \\
\hline & Average & St. Dev. ${ }^{1}$ & Average & St. Dev. & Average & St. Dev. & Average & St. Dev. \\
\hline Mercury, ppm (dry) & 0.112 & 0.045 & 0.112 & 0.059 & 0.063 & 0.008 & 0.117 & 0.040 \\
\hline Chlorine, ppm (dry) & 13.8 & 2.5 & 14.3 & 3.1 & 11.0 & N/A & 13.5 & 2.5 \\
\hline \multicolumn{9}{|l|}{ Proximate } \\
\hline Moisture, $w \mathrm{t} \%$ & 35.8 & 0.8 & 35.8 & 0.7 & 36.4 & $\mathrm{~N} / \mathrm{A}^{2}$ & 35.8 & 0.9 \\
\hline Volatile Matter, wt $\%$ & 27.2 & 0.8 & 28.0 & 0.5 & 28.2 & N/A & 26.8 & 0.5 \\
\hline Fixed Carbon, wt $\%$ & 29.6 & 0.9 & 28.9 & 0.9 & 28.1 & $\mathrm{~N} / \mathrm{A}$ & 29.9 & 0.7 \\
\hline Ash, wt $\%$ & 7.46 & 1.26 & 7.25 & 0.49 & 7.35 & $\mathrm{~N} / \mathrm{A}$ & 7.56 & 1.55 \\
\hline \multicolumn{9}{|l|}{ Ultimate } \\
\hline Hydrogen, wt $\%$ & 6.84 & 0.12 & 6.92 & 0.04 & 6.90 & $\mathrm{~N} / \mathrm{A}$ & 6.78 & 0.14 \\
\hline Carbon, wt $\%$ & 40.1 & 0.9 & 39.6 & 1.4 & 38.6 & $\mathrm{~N} / \mathrm{A}$ & 40.5 & 0.4 \\
\hline Nitrogen, wt $\%$ & 0.77 & 0.02 & 0.75 & 0.01 & 0.74 & $\mathrm{~N} / \mathrm{A}$ & 0.79 & 0.01 \\
\hline Sulfur, wt $\%$ & 0.95 & 0.21 & 0.79 & 0.01 & 0.78 & N/A & 1.05 & 0.22 \\
\hline Oxygen, wt $\%$ & 43.7 & 1.5 & 44.9 & 1.0 & 45.6 & $\mathrm{~N} / \mathrm{A}$ & 42.9 & 1.3 \\
\hline Heating Value, Btu/lb & 6768 & 212 & 6614 & 240 & 6445 & $\mathrm{~N} / \mathrm{A}$ & 6870 & 150 \\
\hline \multicolumn{9}{|l|}{ Calculated Parameters } \\
\hline $\mathrm{F}_{\mathrm{d}}{ }^{3}, \mathrm{dscf} / 10^{6} \mathrm{Btu}$ & 9920 & $\mathrm{NC}^{4}$ & 9982 & $\mathrm{NC}$ & 9944 & N/A & 9892 & $\mathrm{NC}$ \\
\hline Sulfur, wt $\%$ (dry) & 1.48 & 0.33 & 1.23 & 0.02 & 1.23 & $\mathrm{~N} / \mathrm{A}$ & 1.64 & 0.34 \\
\hline Heating Value, Btu/lb (dry) & 10542 & 330 & 10302 & 374 & 10134 & $\mathrm{~N} / \mathrm{A}$ & 10701 & 234 \\
\hline $\mathrm{Hg}, \mu \mathrm{g} / \mathrm{dNm}^{3}$ (flue gas basis) & 14.7 & 5.9 & 15.0 & 7.9 & 8.58 & N/A & 15.2 & 5.2 \\
\hline $\mathrm{Hg}, \mathrm{lb} / \mathrm{TBtu}$ (flue gas basis) & 10.6 & 4.3 & 10.9 & 5.7 & 6.22 & $\mathrm{~N} / \mathrm{A}$ & 10.9 & 3.7 \\
\hline
\end{tabular}

Standard deviation.

${ }^{2}$ Not applicable.

${ }^{3}$ Ratio of combustion gas volume to heat input on a dry basis.

${ }^{4}$ Not calculated.

Table 5-2. Triplicate and Average MRY Coal Ash Elemental Oxide Compositions, wt\%

\begin{tabular}{lccccc}
\hline Elemental Oxide & $4 / 12-15 / 05$ & $4 / 26-28 / 05$ & $5 / 11 / 05$ & Average & St. Dev. \\
\hline $\mathrm{SiO}_{2}$ & 20.6 & 22.0 & 32.7 & 25.1 & 6.6 \\
$\mathrm{Al}_{2} \mathrm{O}_{3}$ & 9.45 & 11.2 & 12.2 & 11.0 & 1.4 \\
$\mathrm{TiO}_{2}$ & 0.37 & 0.64 & 0.62 & 0.54 & 0.15 \\
$\mathrm{Fe}_{2} \mathrm{O}_{3}$ & 9.35 & 6.38 & 6.05 & 7.26 & 1.82 \\
$\mathrm{CaO}$ & 17.3 & 23.5 & 14.4 & 18.4 & 4.6 \\
$\mathrm{MgO}$ & 6.29 & 7.56 & 6.07 & 6.64 & 0.80 \\
$\mathrm{Na}_{2} \mathrm{O}$ & 7.39 & 5.92 & 9.24 & 7.52 & 1.66 \\
$\mathrm{~K}_{2} \mathrm{O}$ & 0.72 & 0.60 & 1.31 & 0.88 & 0.38 \\
$\mathrm{P}_{2} \mathrm{O}_{5}$ & 0.17 & 0.09 & 0.12 & 0.13 & 0.04 \\
$\mathrm{SO}_{3}$ & 27.4 & 21.2 & 16.1 & 21.6 & 5.7 \\
$\mathrm{BaO}$ & 0.56 & 0.43 & 0.77 & 0.59 & 0.17 \\
$\mathrm{Total}$ & 99.6 & 99.4 & 99.5 & 99.5 & 0.1 \\
\hline
\end{tabular}




$\begin{aligned} & \text { Table 5-3. Average MRY Coal Chemical Fractionation } \\
& \text { Results, \% removed }\end{aligned}$
\begin{tabular}{lccc}
\hline Element & $\mathrm{H}_{2} \mathrm{O}$ Soluble & $\mathrm{NH}_{4} \mathrm{OAc}$ Soluble & HCl Soluble \\
\hline $\mathrm{Fe}$ & $<5$ & $<5$ & 39 \\
$\mathrm{Ca}$ & $<5$ & 51 & 45 \\
$\mathrm{Mg}$ & 7 & 60 & 27 \\
$\mathrm{Na}$ & 17 & 81 & $<5$ \\
$\mathrm{~K}$ & $<5$ & 6 & $<5$ \\
\hline
\end{tabular}

(e.g., $\mathrm{Si}, \mathrm{Al}$, and $\mathrm{Ti}$ ) are not included in Table 5-3 because they were not removed significantly during the extraction procedure. These insoluble elements are generally associated with the aluminosilicate (e.g., mixed clays and kaolinite $\left[\mathrm{Al}_{2} \mathrm{Si}_{2} \mathrm{O}_{5}(\mathrm{OH})_{4}\right]$ ), silicate (e.g., quartz $\left[\mathrm{SiO}_{2}\right]$ ), and oxide (e.g., rutile [ $\left.\mathrm{TiO}_{2}\right]$ ) mineral components of the MRY coal. About $20 \%$ of the $\mathrm{Na}$ in MRY coal was water-soluble, suggesting that it occurs dissolved in moisture or as a salt (e.g., $\mathrm{NaCl}$ and $\mathrm{NaSO}_{4}$ ). The remaining $\mathrm{Na}$ was extracted using $\mathrm{NH}_{4} \mathrm{OAc}$, suggesting a clay and/or organic association. Essentially all of the $\mathrm{Ca}$ and $\mathrm{Mg}$ in MRY coal was extracted using $\mathrm{NH}_{4} \mathrm{OAc}$ and $\mathrm{HCl}$, implying a clay and/or organic association.

Presented in Table 5-4 are computer-controlled scanning electron microscopy (CCSEM) analysis of the coal minerals contained in six MRY Unit 2 coals sampled during baseline and long-term testing conditions. The mixed clays quantified in Table 5-4 also contain $\mathrm{Ca}$ and $\mathrm{Mg}$ that is ion-exchangeable in $\mathrm{NH}_{4} \mathrm{OAc}$. As indicated in Table 5-4, the MRY coal contains the major mineral assemblage: quartz + kaolinite + illite + mixed clays + pyrite. Hematite $\left(\mathrm{Fe}_{2} \mathrm{O}_{3}\right)$, rutile $\left(\mathrm{TiO}_{2}\right)$, calcite $\left(\mathrm{CaCO}_{3}\right)$ and/or dolomite $\left(\mathrm{CaMg}\left[\mathrm{CO}_{3}\right]_{2}\right)$, barite $\left(\mathrm{BaSO}_{4}\right)$, and gypsum

Table 5-4. Quantitative MRY Unit 2 Coal Mineral Analyses, wt \% on a mineral basis

\begin{tabular}{|c|c|c|c|c|c|c|c|c|}
\hline $\begin{array}{l}\text { Classification } \\
\text { Category }\end{array}$ & $3 / 18 / 05$ & $4 / 4 / 05$ & $4 / 8 / 05$ & $4 / 12-15 / 05$ & $4 / 26-28 / 05$ & $5 / 11 / 05$ & Av. ${ }^{1}$ & $\begin{array}{l}\text { Std. } \\
\text { Dev. }\end{array}$ \\
\hline Quartz & 10.3 & 4.3 & 11.2 & 8.8 & 13.9 & 20.5 & 11.5 & 5.4 \\
\hline Hematite & 0.8 & 0.4 & $<0.1$ & 0.3 & 0.1 & 0.7 & 0.4 & 0.3 \\
\hline Rutile & 0.3 & 0.1 & 0.3 & 0.1 & 0.2 & 0.5 & 0.2 & 0.2 \\
\hline Calcite & 0.2 & $<0.1$ & $<0.1$ & 0.2 & 0.3 & 0.8 & 0.3 & 0.3 \\
\hline Kaolinite $^{2}$ & 13.8 & 3.7 & 6.7 & 5.3 & 13.3 & 8.7 & 8.6 & 4.2 \\
\hline Illite & 5.3 & 2.9 & 3.2 & 3.6 & 4.9 & 9.0 & 4.8 & 2.3 \\
\hline Mixed Clays $^{3}$ & 15.1 & 6.4 & 8.2 & 11.7 & 12.7 & 13.6 & 11.3 & 3.3 \\
\hline Pyrite & 24.6 & 53.3 & 36.0 & 52.9 & 24.4 & 10.7 & 33.6 & 17.1 \\
\hline Barite & 0.4 & 0.6 & 0.9 & 0.2 & 0.5 & 1.4 & 0.7 & 0.4 \\
\hline Gypsum & 0.4 & 5.1 & 1.8 & $<0.1$ & 0.1 & 0.9 & 1.4 & 1.9 \\
\hline Others ${ }^{4}$ & 28.8 & 23.0 & 31.4 & 16.7 & 29.4 & 32.7 & 27.0 & 6.0 \\
\hline
\end{tabular}


$\left(\mathrm{CaSO}_{4} 2 \mathrm{H}_{2} \mathrm{O}\right)$ are present in MRY coal as accessory minerals. The mineral concentrations in these MRY coal samples are variable, which is consistent with the variability in the three coal ash compositions presented in Table 5-2.

The large variability in MRY coal pyrite $\left(\mathrm{FeS}_{2}\right)$ and, hence, sulfur contents, suggests that the $\mathrm{Hg}$ contents could also be highly variable because pyrite is generally assumed to be the dominant mineral host for $\mathrm{Hg}$ in coal. Indeed, as indicated in Figure 5-1 and statistically summarized in Table 5-5, coal Hg concentrations are very variable. As shown in Figures 5-2 and 5-3, coal pyrite and $\mathrm{Hg}$ and coal sulfur and $\mathrm{Hg}$ concentrations correlate very well with correlation coefficients of 0.941 and 0.925 , respectively. An analysis of a pyrite-rich reject sample (collected on 3/16/05) from the coal crushers indicated the presence of $2.28 \mathrm{ppm} \mathrm{Hg}$. The dominance of pyrite-associated $\mathrm{Hg}$ caused a "nugget" effect with regard to sampling coal at MRY for $\mathrm{Hg}$ analyses.

\subsection{MRY Unit 2 Operation}

MRY Unit 2 operational and stack emission data are plotted in Figure 5-4. The time lines for the three test conditions are also indicated in Figure 5-4. Total Hg measurement results are lacking during late March and early May because the CMMs were not operating then. The plant operation, especially load, remained relatively consistent during the 2 -month test period.

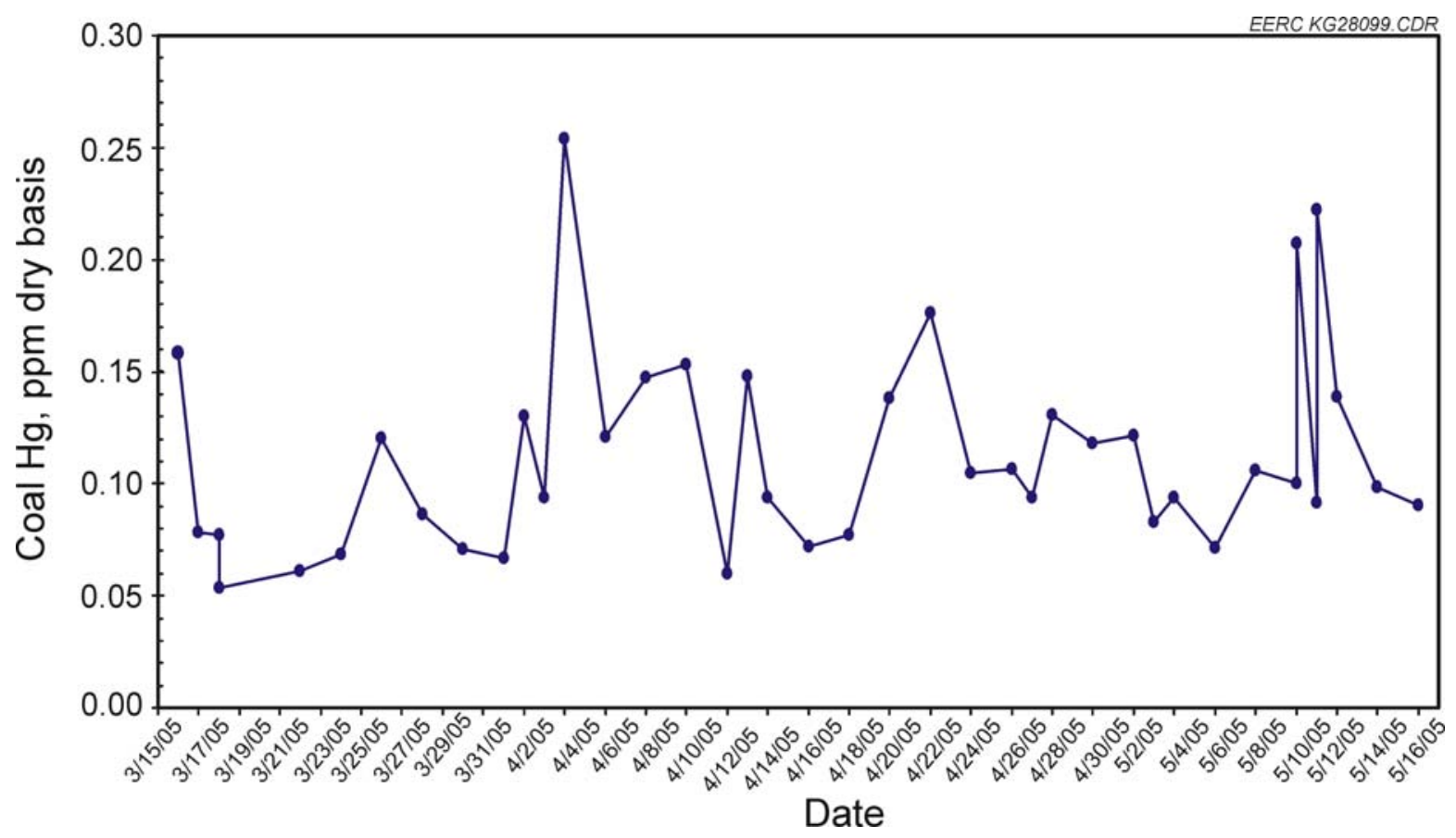

Figure 5-1. Temporal variations in MRY Unit 2 lignite Hg concentrations. 
Table 5-5. Statistical Summary of MRY Unit 2 Coal Hg Analysis Results

\begin{tabular}{lcccc}
\hline & Overall & Baseline Testing & Parametric Testing & Long-Term Testing \\
\hline Mean & 0.112 & 0.112 & 0.063 & 0.117 \\
St. Dev. & 0.045 & 0.059 & 0.008 & 0.040 \\
RSD $^{1}$ & 40.3 & 52.7 & 12.0 & 34.0 \\
95\% CI & 0.014 & 0.037 & 0.007 & 0.015 \\
$\mathrm{~N}^{3}$ & 40 & 10 & 4 & 27 \\
\hline Thelative standard deviation. & & & \\
${ }^{2}$ Confidence interval at $95 \%$. & & & \\
${ }^{3}$ Number of samples. & & &
\end{tabular}

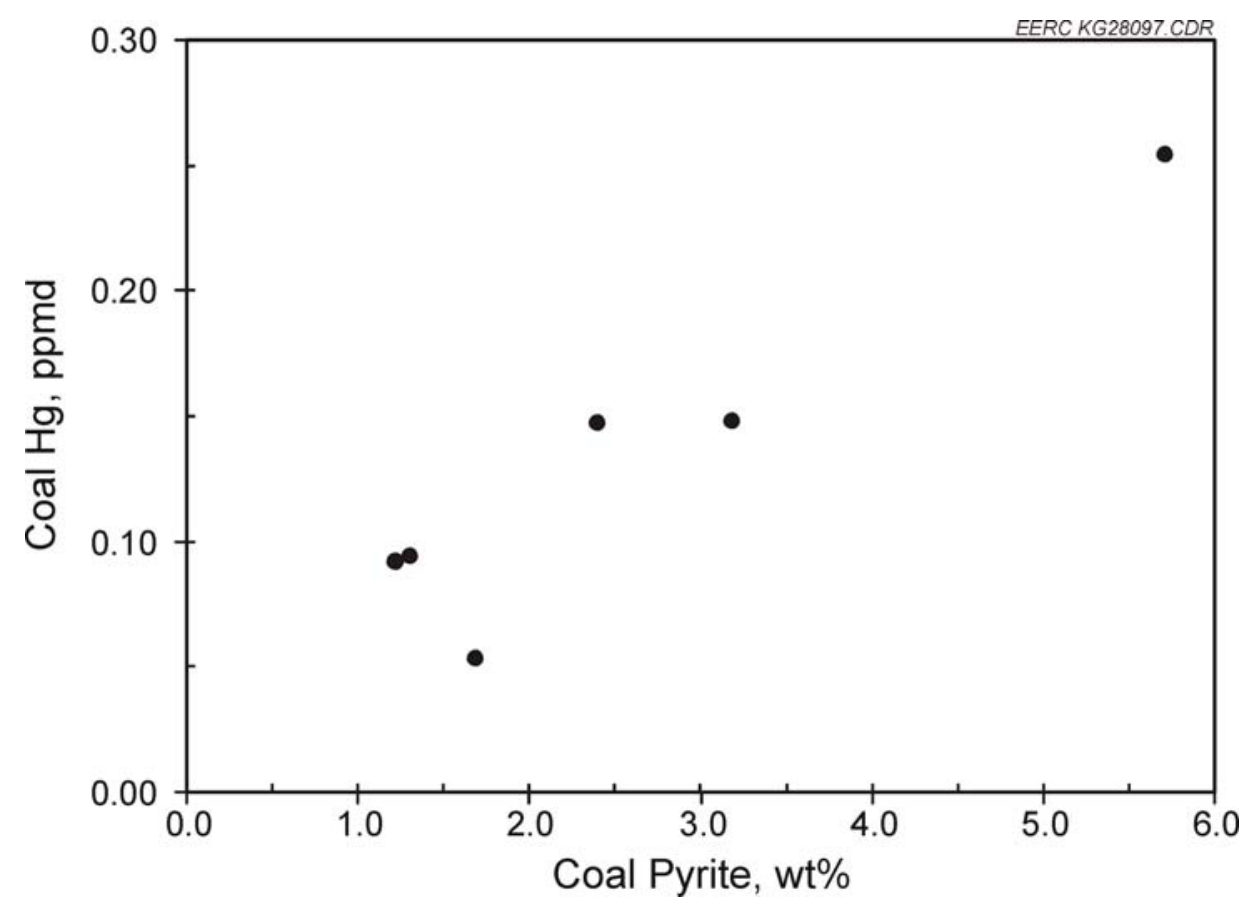

Figure 5-2. MRY Unit 2 lignite pyrite versus Hg concentrations (on a dry basis), correlation coefficient of 0.941 . 


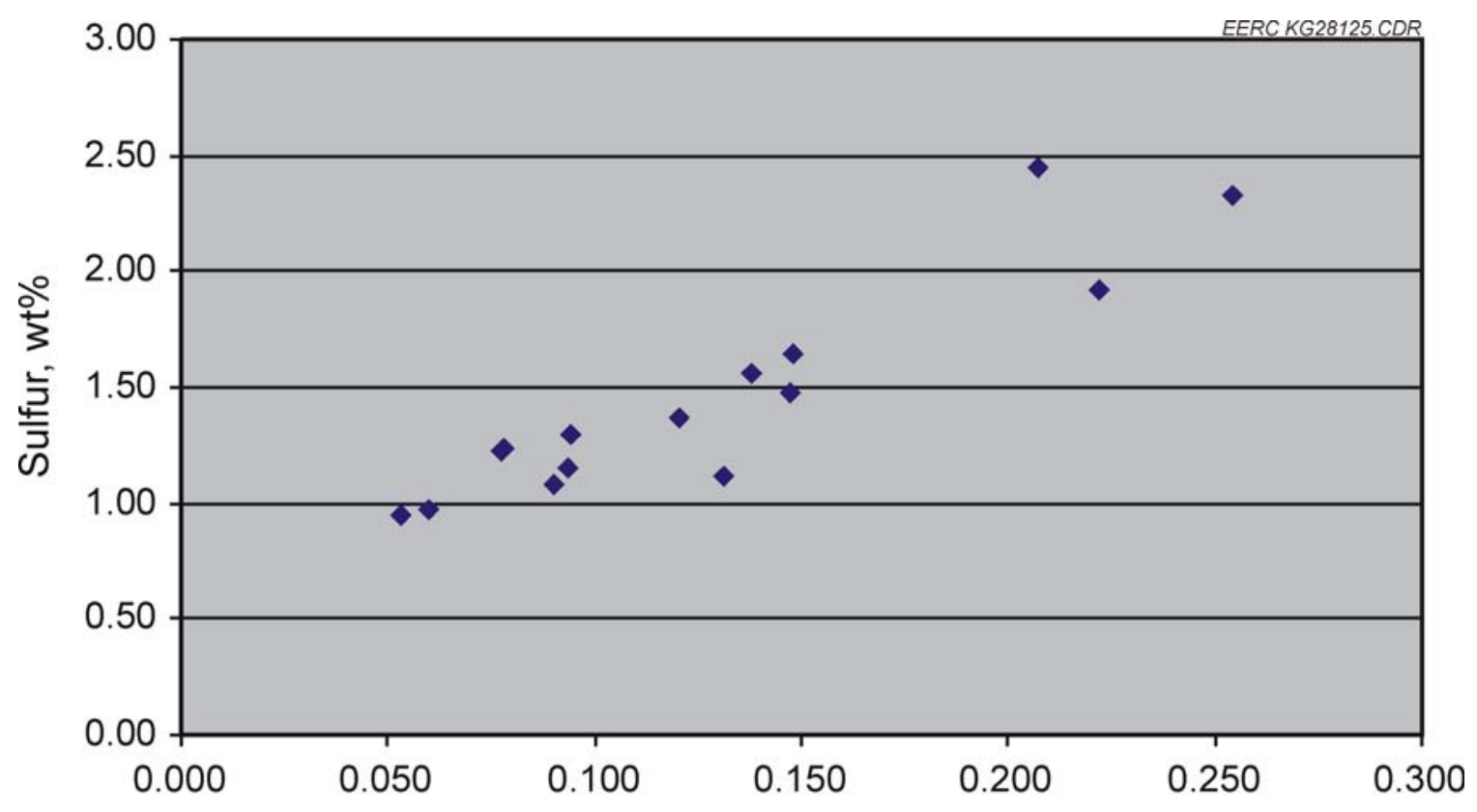

$\mathrm{Hg}, \mathrm{g} / \mathrm{g}$

Figure 5-3. MRY Unit 2 lignite Hg versus S concentrations (on a dry basis), correlation coefficient of 0.925 .

\subsection{Baseline Testing}

$\mathrm{OH}$ method $\mathrm{Hg}$ measurements were performed in triplicate to quantify baseline $\mathrm{Hg}$ concentrations at the ESP and wet FGD inlets and stack prior to any chemical additions or PAC injections. The average baseline $\mathrm{Hg}$ species measurement results are presented in Figure 5-5. The $\mathrm{Hg}$ speciation results in Figure 5-5 are very similar to those obtained in 2002 (refer to Figure 3-2). In both cases, the Hgp concentrations are significant at the ESP inlet probably because of a known measurement bias associated with the $\mathrm{OH}$ method sampling of $\mathrm{Hg}$ in the presence of relatively high fly ash concentrations. The results obtained at the wet FGD inlet and stack that indicate $\mathrm{Hg}^{0}$ as the most abundant species are probably more representative of the actual flue gas $\mathrm{Hg}$ speciation. A total $\mathrm{Hg}$ concentration in flue gas value calculated from the average coal analysis results (Table 5-1) is also plotted in Figure 5-5. The total Hg concentration measured at the ESP inlet was only $0.5 \mu \mathrm{g} / \mathrm{dNm}^{3}$ less than the theoretical value.

Compared in Table 5-6 are average $\mathrm{OH}$ method and $\mathrm{CMM}$ results that were obtained simultaneously during the baseline testing conditions. A CMM was not used at the ESP inlet because of the known $\mathrm{Hg}$ measurement interference caused by the high dust loading at such a location. The $\mathrm{OH}$ method and CMM results obtained at the FGD inlet and stack compare favorably with relative percent differences (RPDs) of $<20$. Total $\mathrm{Hg}$ concentrations at the ESP and wet FGD inlets varied from about 12 to $16 \mu \mathrm{g} / \mathrm{dNm}^{3}$, whereas at the stack concentrations were consistently at about $13 \mu \mathrm{g} / \mathrm{dNm}^{3}$, indicating that the ESP and wet FGD were very inefficient at removing $\mathrm{Hg}$ during routine power plant operations. 


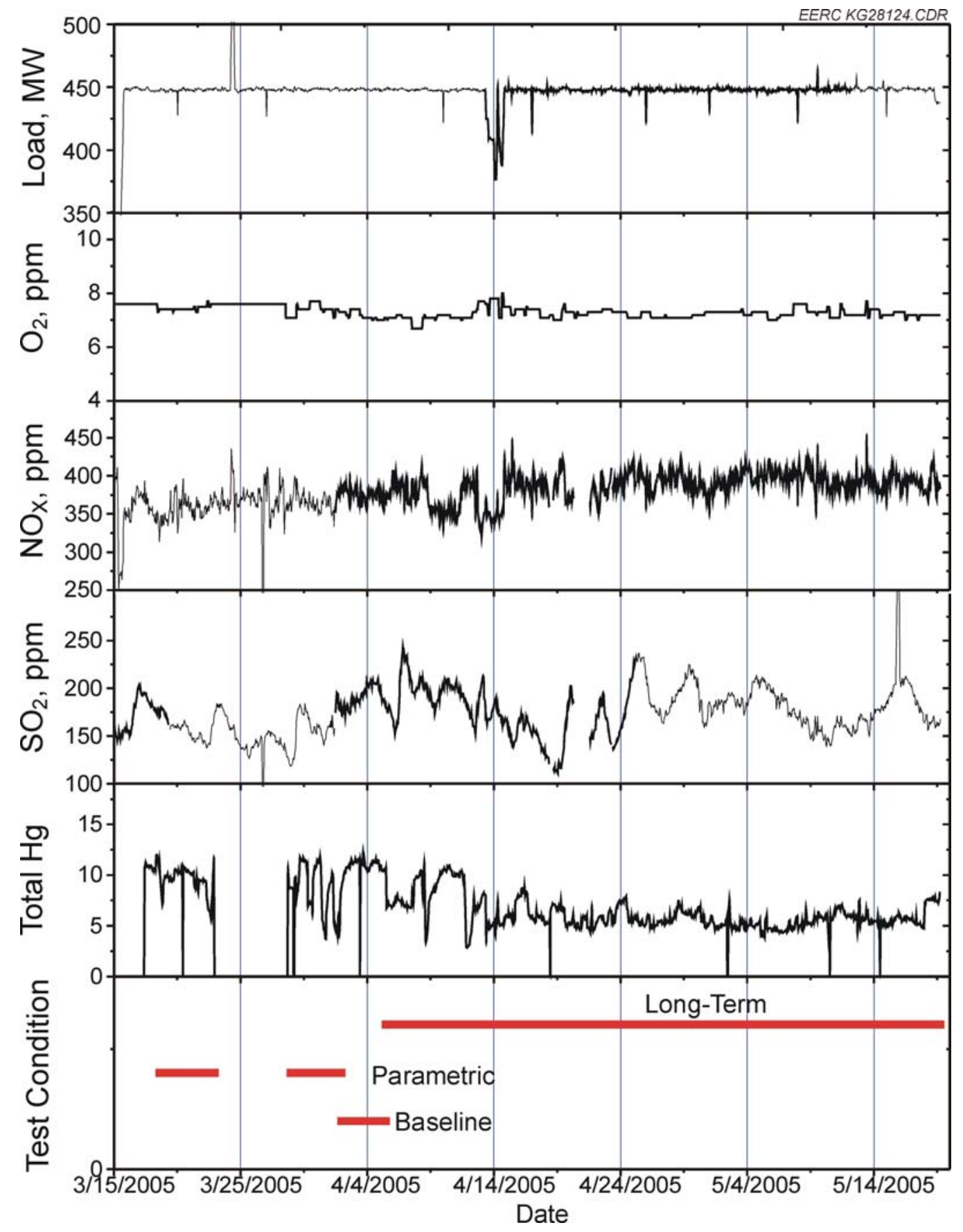

Figure 5-4. Summary of MRY unit operational and emission data. 


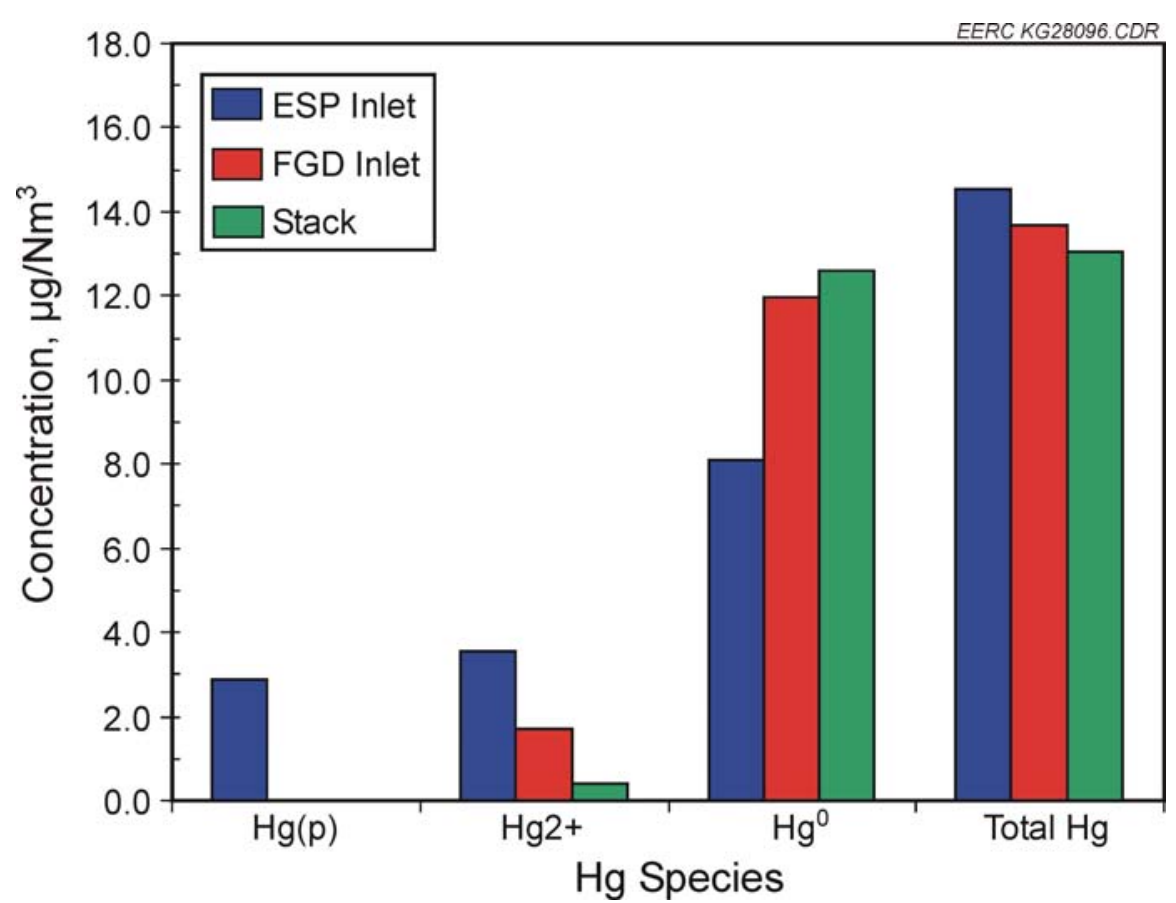

Figure 5-5. Baseline $\mathrm{OH} \mathrm{Hg} \mathrm{measurement} \mathrm{results.}$

Table 5-6. Comparison of OH and CMM Results $\left(\mu \mathrm{g} / \mathrm{dNm}^{3}\right)$ Obtained Concurrently During Baseline Testing Conditions (March 17 and 18, 2005).

\begin{tabular}{lccccccc}
\hline & \multicolumn{4}{c}{ Ontario Hydro method } & $\mathrm{CMM}^{1}$ \\
\hline \multicolumn{2}{l}{ Sampling Location } & $\mathrm{Hg}^{0}$ & $\mathrm{Hg}^{2+}$ & $\mathrm{Hg}(\mathrm{p})$ & Total $\mathrm{Hg}$ & Total Hg & $\mathrm{RPD}^{2}$ \\
\hline \multirow{2}{*}{ ESP Inlet } & Average & 8.12 & 3.55 & 2.88 & 14.5 & $\mathrm{NA}^{3}$ & $\mathrm{NA}$ \\
& St. dev. & 0.39 & 2.48 & 0.19 & 2.6 & $\mathrm{NA}$ & $\mathrm{NA}$ \\
\multirow{4}{*}{ SGD Inlet } & Average & 12.0 & 1.71 & $<0.1$ & 13.7 & 13.1 & $4.06 \%$ \\
& St. dev. & 0.5 & 0.93 & $\mathrm{NA}$ & 1.4 & 0.4 & $\mathrm{NA}$ \\
& Average & 12.6 & 0.43 & $<0.1$ & 13.0 & 11.0 & $16.6 \%$ \\
& St. dev. & 0.5 & 0.14 & $\mathrm{NA}$ & 0.6 & 0.2 & $\mathrm{NA}$ \\
\hline
\end{tabular}

${ }^{1}$ Average of two hours of CMM measurements.

${ }^{2} \mathrm{RPD}$ from the average of $\mathrm{OH}$ method and $\mathrm{CMM}$ measurement results.

${ }^{3}$ Not analyzed or not applicable.

An EPA Method 26A sampling and analysis of MRY Unit 2 flue gas at the ESP inlet indicated that $\mathrm{HCl}$ was nondetectable $(<2 \mathrm{ppmv})$. As indicated in Table 5-1, the Center lignite coal contains very low coal chlorine concentrations, consistent with the EPA Method 26A measurement result.

Presented in Table 5-7 are duplicate $\mathrm{Hg}, \mathrm{Br}$, and $\mathrm{Cl}$ analysis results for fly ash samples collected from the ESP during baseline testing conditions on March 17, 2005. The presence of about $0.3 \mathrm{ppm} \mathrm{Hg}$ on the fly ash indicates that it has some inherent $\mathrm{Hg}$ adsorption capacity. 
Table 5-7. Duplicate $\mathrm{Hg}, \mathrm{Br}$, and $\mathrm{Cl}$ Analysis Results for Fly Ashes Sampled from the ESP During Baseline Testing Conditions

\begin{tabular}{lccc}
\hline Analyte, ppm & Replicate 1 & Replicate 2 & Average \\
\hline $\mathrm{Hg}$ & 0.215 & 0.323 & 0.269 \\
$\mathrm{Br}$ & $<2$ & $<2$ & $<2$ \\
$\mathrm{Cl}$ & 26 & 26 & 26 \\
\hline
\end{tabular}

Consistent with the EPA Method 26A and coal $\mathrm{Cl}$ measurements (Table 5-1), the $\mathrm{Cl}$ content of the fly ash was very low. Br was below the quantification limit, $<2 \mathrm{ppm}$, of the ion chromatography method.

\subsection{Parametric Testing}

Parametric testing at MRY Unit 2 was performed using $\mathrm{CaCl}_{2}, \mathrm{MgCl}_{2}$, and SEA2 at varying addition rates alone and in combination with PAC injections to determine the most effective conditions for achieving $\geq 55 \% \mathrm{Hg}$ capture. Compared in Table 5-8 are average $\mathrm{OH}$ method and CMM results that were obtained simultaneously during the parametric testing conditions. During most of the tests, the $\mathrm{OH}$ method and CMM results compared favorably with RPDs of $<20$. The coal-derived $\mathrm{Hg}$ flue gas concentration of $8.58 \mu \mathrm{g} / \mathrm{dNm}^{3}$ (Table 5-1) was biased much lower relative to the $\mathrm{OH}$ method and $\mathrm{CMM}$ measurements probably because of the great variability in coal $\mathrm{Hg}$ concentrations (Figure 5-1 and Table 5-5).

\subsubsection{Effects of $\mathrm{CaCl}_{2}, \mathrm{MgCl}_{2}$, and SEA2 Additions on $\mathrm{Hg}$ Speciation and ESP- Wet FGD Capture}

Shown in Figure 5-6 are average $\mathrm{Hg}$ speciation results obtained during the combustion of Center lignite with $\mathrm{CaCl}_{2}$ added at 100,300 , and $500 \mathrm{ppm}$ on a dry coal basis. These results indicate that $\mathrm{Hg}^{2+}$ and $\mathrm{Hg}(\mathrm{p})$ concentrations only increased slightly with $\mathrm{CaCl}_{2}$ addition at $\leq 500 \mathrm{ppm}$. In contrast, when Center lignite and $\mathrm{CaCl}_{2}$ addition testing was performed in the EERC pilot-scale system, the degree of $\mathrm{Hg}^{0}$ oxidation increased dramatically with $\mathrm{CaCl}_{2}$ addition (11). Apparently, differences in combustion conditions and/or coal characteristics during the pilot- and full-scale testing affected the $\mathrm{Hg}^{0}$ chlorination reaction.

Plotted in Figure 5-7 are ESP-wet FGD $\mathrm{Hg}$ removal efficiencies as functions of $\mathrm{MgCl}_{2}$, $\mathrm{CaCl}_{2}$, and SEA2 addition rates. An example of the CMM results used to calculate total $\mathrm{Hg}$ removal efficiencies of the ESP-wet FGD is presented in Figure 5-8. Removal efficiencies were calculated based on average stack CMM measurements obtain before, during, and after the chemical additions. $\mathrm{MgCl}_{2}$ and $\mathrm{CaCl}_{2}$ were relatively ineffective in promoting $\mathrm{Hg}^{0}$ oxidation and capture in the ESP-wet FGD. Relatively low additions of SEA2, however, significantly improved the $\mathrm{Hg}$ removal efficiency of the ESP-wet FGD, although the goal of $55 \% \mathrm{Hg}$ removal was not achieved using as much as 75 ppm SEA2. Nearly all of the Hg removal occurred in the ESP, suggesting that SEA2 addition promoted the conversion of $\mathrm{Hg}^{0}$ to $\mathrm{Hg}(\mathrm{p})$ which was subsequently captured in the ESP. 
Table 5-8. Comparison of $\mathrm{OH}$ and CMM Results $\left(\mu \mathrm{g} / \mathrm{dNm}^{3}\right)$ Obtained Concurrently During Parametric Testing Conditions (March 18-April 1, 2005)

\begin{tabular}{|c|c|c|c|c|c|c|c|c|}
\hline \multirow{2}{*}{$\begin{array}{l}\text { Sampling } \\
\text { Location }\end{array}$} & \multirow[b]{2}{*}{ Date } & \multicolumn{4}{|c|}{ Ontario Hydro method } & \multicolumn{2}{|c|}{$\mathrm{CMM}^{1}$} & \multirow[b]{2}{*}{$\mathrm{RPD}^{2}$} \\
\hline & & $\mathrm{Hg}^{0}$ & $\mathrm{Hg}^{2+}$ & $\mathrm{Hg}(\mathrm{p})$ & Total $\mathrm{Hg}$ & Total $\mathrm{Hg}$ & St. Dev. & \\
\hline \multicolumn{9}{|c|}{$300 \mathrm{ppm} \mathrm{CaCl} 2$} \\
\hline ESP In & & 6.39 & 1.75 & 2.20 & 10.3 & $\mathrm{NA}^{3}$ & NA & NA \\
\hline FGD In & $3 / 19 / 05$ & 8.93 & 1.02 & $<0.1$ & 9.95 & 9.94 & 0.61 & 0.15 \\
\hline Stack & & 8.65 & 0.36 & $<0.1$ & 9.01 & 9.63 & 0.28 & 6.63 \\
\hline \multicolumn{9}{|c|}{100 ppm $\mathrm{CaCl}_{2}$} \\
\hline ESP In & & 8.79 & 2.35 & 2.19 & 13.3 & NA & NA & NA \\
\hline FGD In & $3 / 20 / 05$ & 10.2 & 0.70 & $<0.1$ & 10.9 & 11.5 & 0.4 & 4.98 \\
\hline Stack & & 10.1 & 0.47 & $<0.1$ & 10.5 & 10.5 & 0.2 & 0.75 \\
\hline \multicolumn{9}{|c|}{$500 \mathrm{ppm} \mathrm{CaCl} 2$} \\
\hline ESP In & & 7.20 & 2.97 & 2.19 & 12.4 & NA & NA & NA \\
\hline FGD In & $3 / 21 / 05$ & 10.2 & 0.86 & $<0.1$ & 11.1 & 9.71 & 0.42 & 13.0 \\
\hline Stack & & 9.30 & 0.68 & $<0.1$ & 9.99 & 8.70 & 0.27 & 13.8 \\
\hline \multicolumn{9}{|c|}{500 ppm $\mathrm{CaCl}_{2}+0.5 \mathrm{lb} / \mathrm{Macf}$ PAC } \\
\hline ESP In & & 9.63 & 1.66 & 1.99 & 13.3 & NA & NA & NA \\
\hline FGD In & $3 / 22 / 05$ & 6.62 & 0.37 & $<0.1$ & 7.00 & 7.25 & 0.58 & 3.57 \\
\hline Stack & & 7.14 & 0.12 & $<0.1$ & 7.26 & 6.49 & 0.10 & 11.2 \\
\hline \multicolumn{9}{|c|}{25 ppm SEA2 } \\
\hline ESP In & & 2.70 & 4.90 & 10.8 & 18.4 & NA & NA & NA \\
\hline FGD In & $3 / 29 / 05$ & 7.42 & 1.31 & $<0.1$ & 8.73 & 11.1 & 0.6 & 24.0 \\
\hline Stack & & 7.98 & 1.83 & $<0.1$ & 9.81 & 8.66 & 0.29 & 12.4 \\
\hline \multicolumn{9}{|c|}{50 ppm SEA2 } \\
\hline ESP In & & 3.63 & 2.22 & 3.86 & 9.71 & NA & NA & NA \\
\hline FGD In & $3 / 30 / 05$ & 8.55 & 1.19 & $<0.1$ & 9.74 & 9.34 & 0.65 & 4.20 \\
\hline Stack & & 7.37 & 2.02 & $<0.1$ & 9.39 & 7.34 & 0.16 & 24.5 \\
\hline \multicolumn{9}{|c|}{25 ppm SEA2 + 0.25 lb/Macf PAC } \\
\hline ESP In & & 5.70 & 2.78 & 3.09 & 11.6 & NA & NA & NA \\
\hline FGD In & $3 / 31 / 05$ & 5.86 & 0.70 & $<0.1$ & 6.56 & 7.01 & 0.30 & 6.56 \\
\hline Stack & & 4.95 & 1.06 & $<0.1$ & 6.00 & 5.39 & 0.18 & 10.8 \\
\hline \multicolumn{9}{|c|}{50 ppm SEA2 + 0.25 lb/Macf PAC } \\
\hline ESP In & & 2.71 & 5.91 & 4.88 & 13.5 & NA & NA & NA \\
\hline FGD In & $4 / 1 / 05$ & 5.66 & 0.99 & $<0.1$ & 6.65 & 7.46 & 1.02 & 11.4 \\
\hline Stack & & 4.40 & 1.32 & $<0.1$ & 5.72 & 4.91 & 0.27 & 15.3 \\
\hline
\end{tabular}



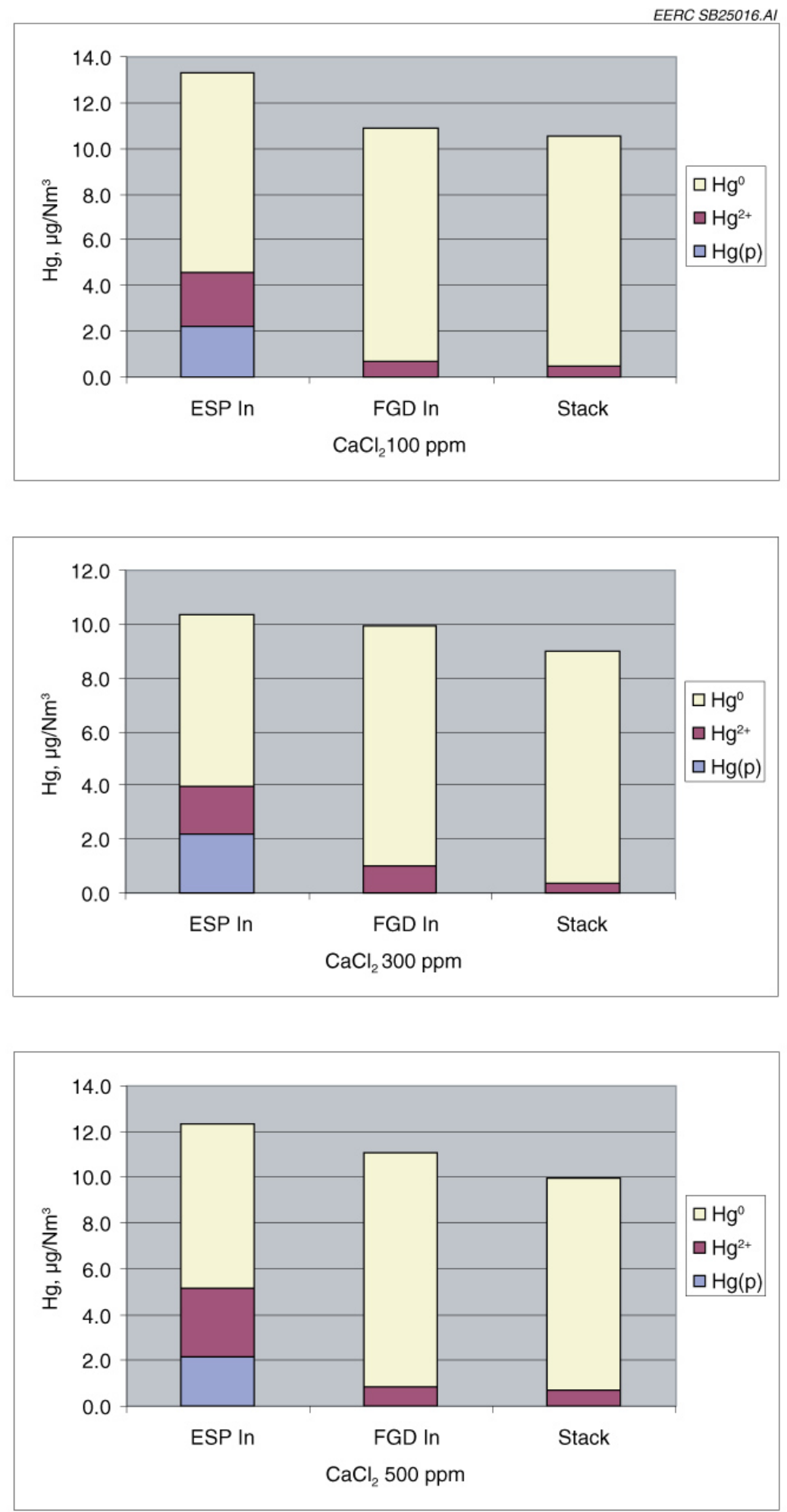

Figure 5-6. Average $\mathrm{Hg}$ speciation results for Center lignite combustion flue gases containing

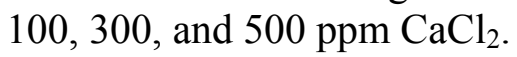




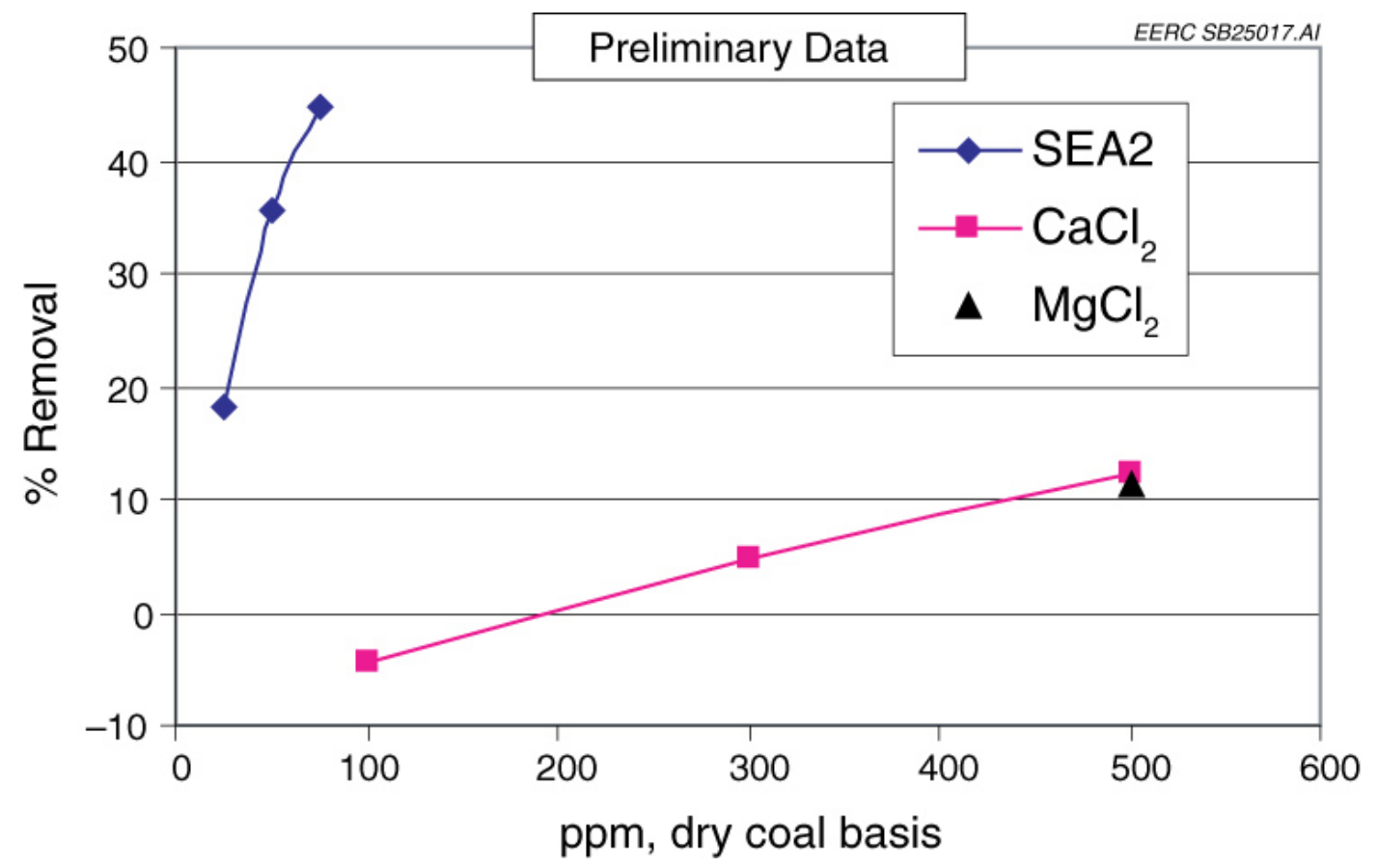

Figure 5-7. ESP-wet FGD $\mathrm{Hg}$ removal efficiencies during $\mathrm{CaCl}_{2}, \mathrm{MgCl}_{2}$, and $\mathrm{SEA} 2$ additions.

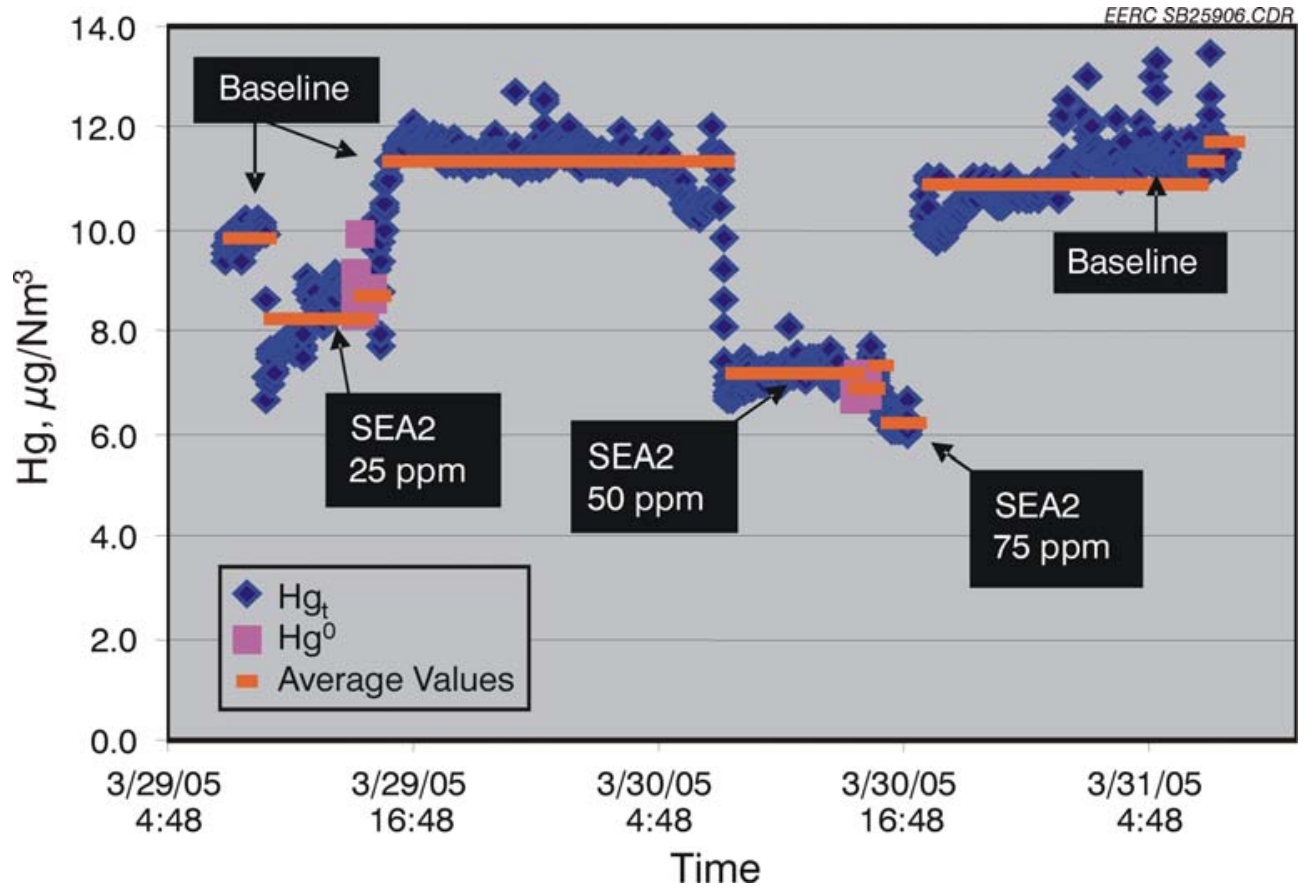

Figure 5-8. Stack CMM results before, during, and after SEA2 additions. 


\subsubsection{Effects of PAC Injection and $\mathrm{CaCl}_{2}$ and SEA2 Additions on $\mathrm{Hg}$ Speciation and ESP-Wet FGD Capture}

Presented in Figure 5-9 are total Hg removal efficiencies obtained with the ESP-wet FGD during PAC injections and $\mathrm{CaCl}_{2}$ and SEA2 additions. Presented in Figures 5-10 and 5-11 are the stack $\mathrm{CMM}$ results that were used to calculate total $\mathrm{Hg}$ removal efficiencies and construct Figure 5-9. PAC injection at a $\mathrm{lb} / \mathrm{Macf}$ resulted in an ESP-wet FGD total $\mathrm{Hg}$ removal efficiency of 35\%. Although not shown in Figure 5-9, PAC injection at $1.8 \mathrm{lb} /$ Macf resulted in a $53 \% \mathrm{Hg}$ removal efficiency, near the $55 \%$ goal, but impractical because of such a high injection rate. $\mathrm{CaCl}_{2}$ addition significantly improved $\mathrm{Hg}$ capture in the ESP-wet FGD at relatively low PAC injection rates of $0.25 \mathrm{lb} / \mathrm{Macf}$ and $0.50 \mathrm{lb} / \mathrm{Macf}$ but not at $1.0 \mathrm{lb} /$ Macf. The combination of PAC injection and SEA2 addition provided the best $\mathrm{Hg}$ capture, much better than that observed with SEA2 addition alone (Figure 5-7). As indicated by the $\mathrm{OH}$ method measurement results in Figure $5-12$, nearly all of the $\mathrm{Hg}$ removal during PAC injection and SEA2 additions occurred in the ESP, and primarily $\mathrm{Hg}^{0}$ exited the ESP and wet FGD. $\mathrm{Hg}$ removals of $50 \%$ or better were attainable with the addition of $50 \mathrm{ppm}$ SEA2 and $0.3-0.5 \mathrm{lb} /$ Macf PAC injection.

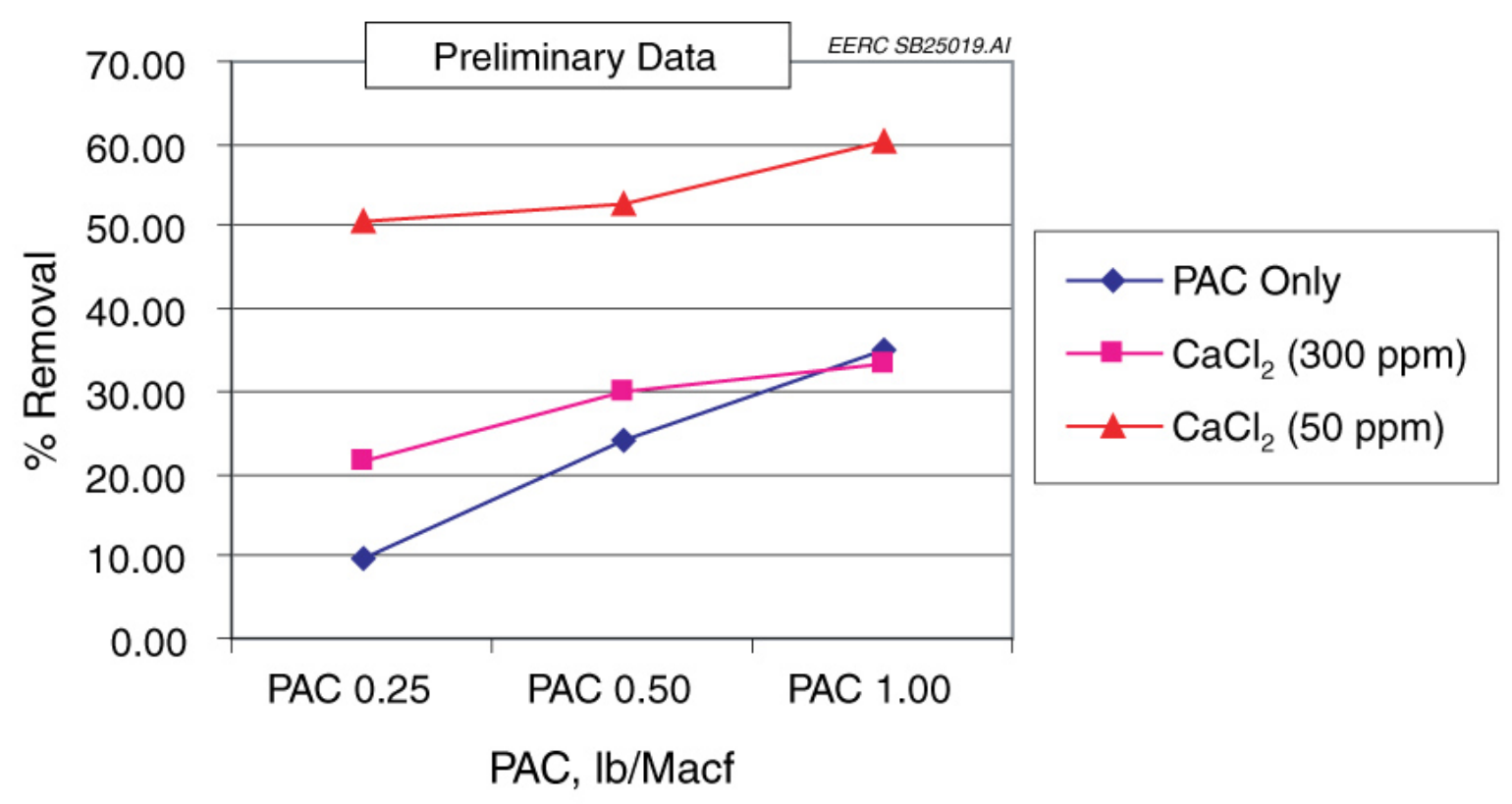

Figure 5-9. Effects of $\mathrm{PAC}$ injections alone and in combination with $\mathrm{CaCl}_{2}$ or SEA2 additions on ESP-wet FGD Hg removal efficiency. 


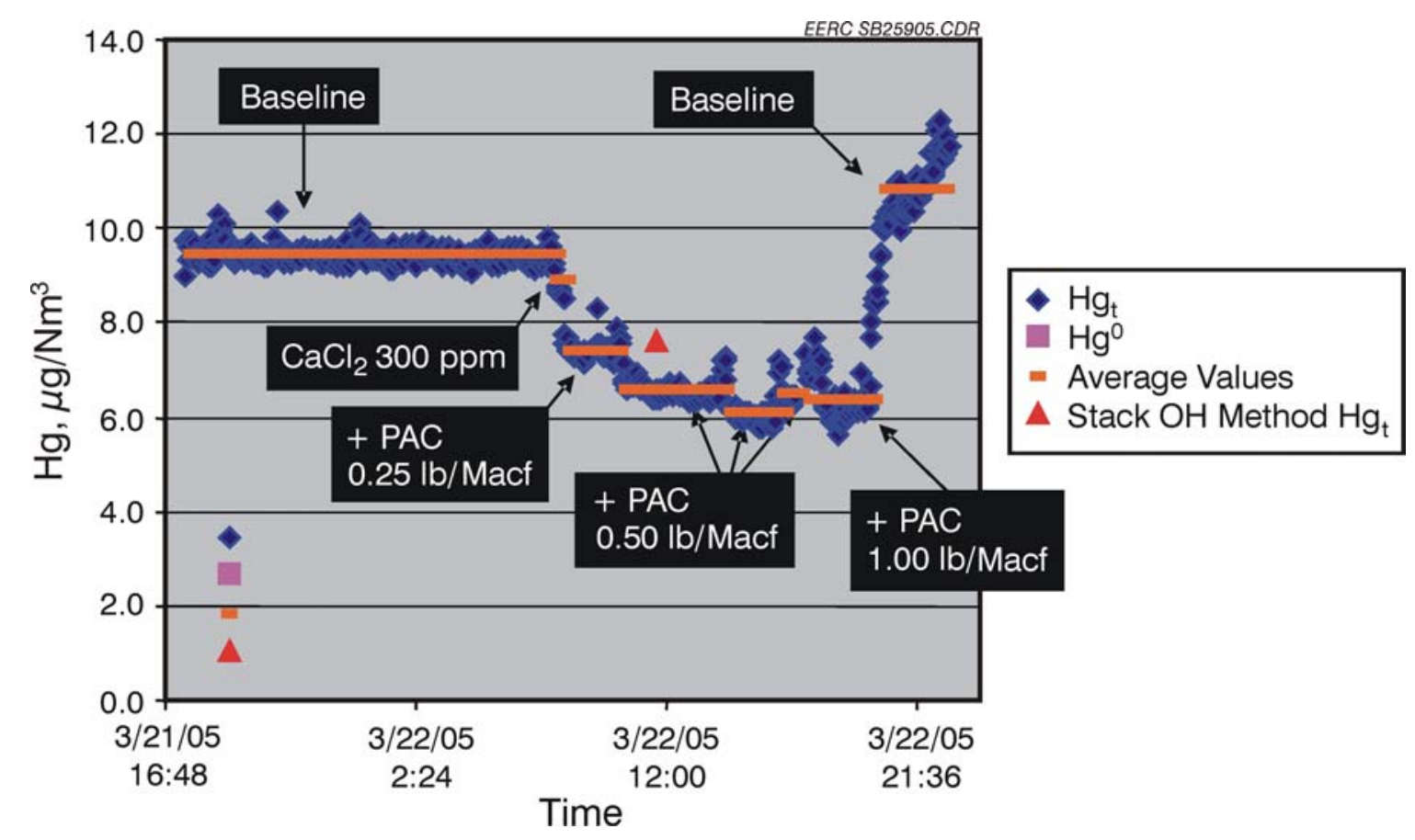

Figure 5-10. Stack CMM results obtained before, during, and after $\mathrm{PAC}$ injections and $\mathrm{CaCl}_{2}$ addition at $300 \mathrm{ppm}$.

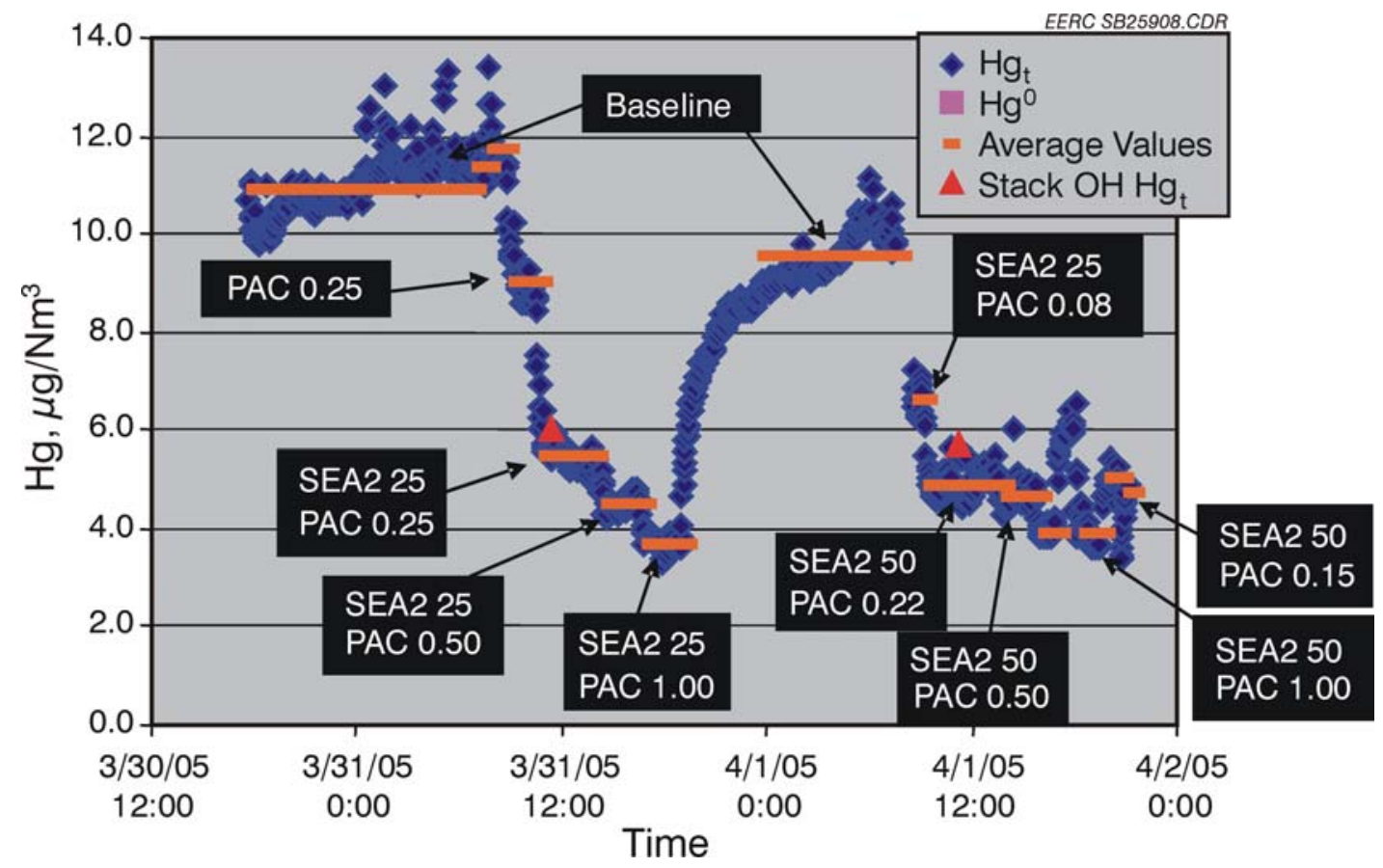

Figure 5-11. Stack CMM results obtained before, during, and after PAC injections and SEA2 additions on a lb/Macf basis. 

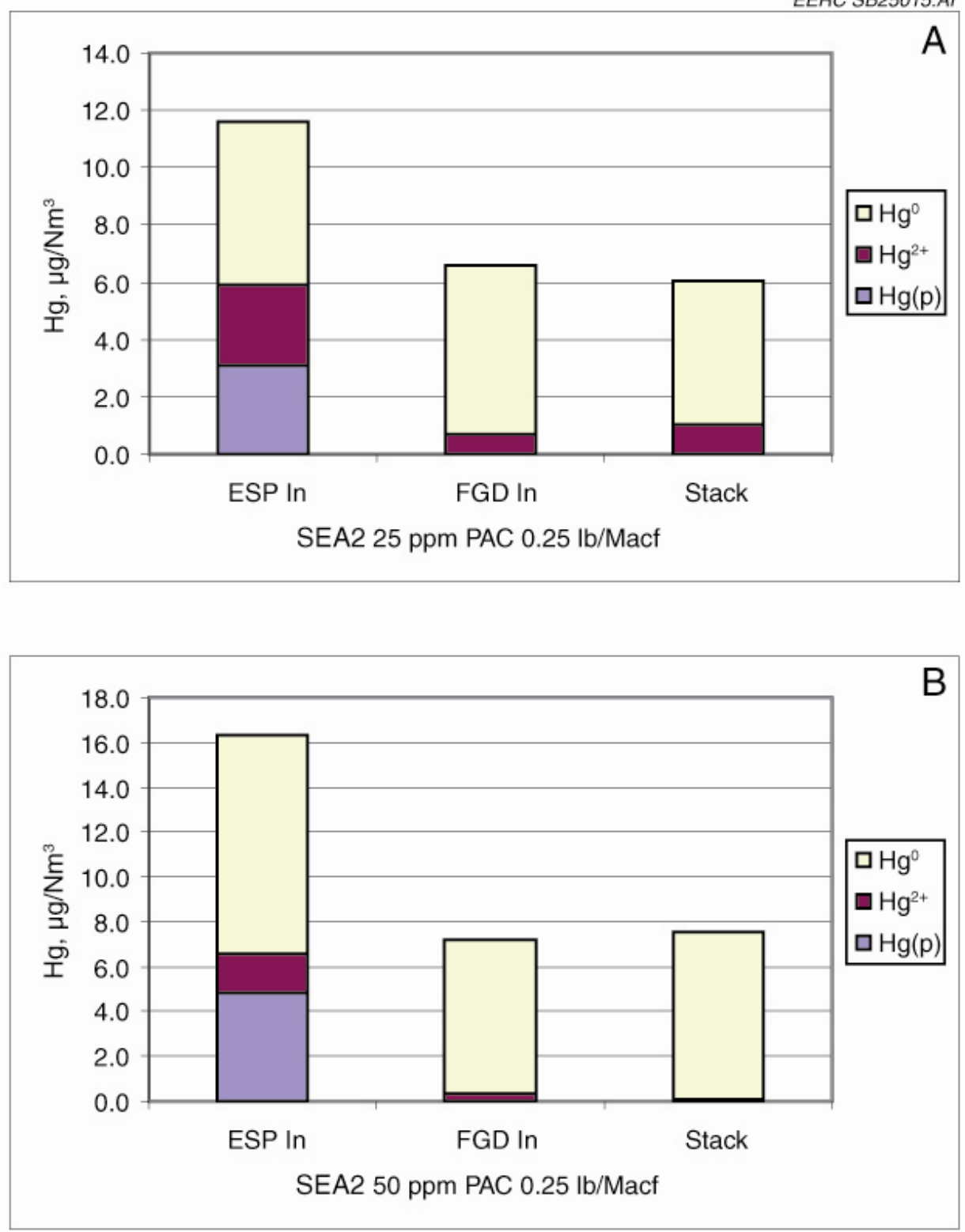

Figure 5-12. OH Hg speciation results obtained during PAC injection and SEA2 additions.

\subsection{Long-Term Testing}

Compared in Table 5-9 are average $\mathrm{OH}$ method and CMM results that were obtained simultaneously during the long-term testing conditions. Nine OH method measurements of ESP inlet total $\mathrm{Hg}$ concentrations averaged $13.0 \mu \mathrm{g} / \mathrm{dNm}^{3}$, or $86 \%$ of the $15.2 \mu \mathrm{g} / \mathrm{dNm}^{3}$ expected based on the average coal $\mathrm{Hg}$ result in Table 5-1. Early CMM measurements of FGD inlet and stack total $\mathrm{Hg}$ concentrations did not compare very well with the $\mathrm{OH}$ method results (RPDs $\approx$ 30 ), but subsequent measurements compared favorably with RPDs of $<20$. 
Table 5-9. Comparison of Average $\mathrm{OH}$ and CMM Results $\left(\mu \mathrm{gg} / \mathrm{dNm}^{3}\right)$ Obtained Concurrently During Long-Term Testing Conditions (April 5-May 17, 2005)

\begin{tabular}{|c|c|c|c|c|c|c|c|c|c|}
\hline \multirow[b]{2}{*}{$\begin{array}{l}\text { Sampling } \\
\text { Location }\end{array}$} & \multirow[b]{2}{*}{ Dates } & \multicolumn{5}{|c|}{ Ontario Hydro method $^{1}$} & \multicolumn{3}{|c|}{$\mathrm{CMM}^{2}$} \\
\hline & & $\mathrm{Hg}^{0}$ & $\mathrm{Hg}^{2+}$ & Hgp & Total Hg & St. Dev. & Total $\mathrm{Hg}$ & St. Dev. & $\mathrm{RPD}^{3}$ \\
\hline ESP In & & 3.79 & 3.17 & 4.28 & 11.2 & 0.6 & $\mathrm{NA}^{4}$ & NA & NA \\
\hline FGD In & $4 / 12-14 / 05$ & 5.56 & 4.61 & $<0.1$ & 10.2 & 1.7 & 7.11 & 0.15 & 35.4 \\
\hline Stack & & 5.41 & 1.98 & $<0.1$ & 7.40 & 1.85 & 5.66 & 0.24 & 26.6 \\
\hline ESP In & & 3.89 & 2.41 & 8.10 & 14.4 & 0.9 & NA & NA & NA \\
\hline FGD In & $4 / 26-28 / 05$ & 5.04 & 1.01 & $<0.1$ & 6.06 & 0.39 & 5.29 & 0.46 & 13.5 \\
\hline Stack & & 5.44 & 0.83 & $<0.1$ & 6.27 & 1.22 & 5.66 & 0.12 & 10.2 \\
\hline ESP In & & 4.37 & 2.09 & 6.99 & 13.4 & 2.4 & NA & NA & NA \\
\hline FGD In & $5 / 10-11 / 05$ & 4.49 & 1.17 & $<0.1$ & 5.66 & 1.52 & 5.48 & 0.75 & 3.29 \\
\hline Stack & & 5.74 & 0.56 & $<0.1$ & 6.31 & 1.11 & 5.37 & 0.34 & 16.2 \\
\hline
\end{tabular}

The Hg removal efficiencies for the extended testing were calculated from stack CMM measurements including baseline measurements performed after the parametric testing and before the long-term testing. During April 5 through April 19, 2005, problems were encountered with stratification of the diluted SEA2 solution (a concentrated $50 \mathrm{wt} \%$ SEA2 aqueous solution was diluted to a nominal $15 \mathrm{wt} / \mathrm{wt} \%$ solution for injection). Dilution was required because of pump capacity and range limitations. Additional problems were encountered because of contaminants in the SEA2 solution, including small quantities of oil, sludge, and organic debris. Significant scale formation was also encountered during the extended testing period, resulting in the plugging of filters, pumps, and flowmeters. For the SEA2-only portion of the testing, this resulted in erratic SEA2 injection rates, as indicated in Figure 5-13 and, thus, fluctuations in $\mathrm{Hg}$ removal efficiencies. Air agitation of the dilute SEA2 solution for 3 to 4 hours produced a wellmixed solution, but sludge and scale formation were a recurring problem.

The objective of the extended testing was to demonstrate that approximately $55 \% \mathrm{Hg}$ removal could be obtained over a period of a month or more. Initially, this was attempted using SEA2 addition alone at rates of 60-550 ppm (dry coal basis). The ESP-wet FGD Hg removal efficiencies for an extended period are shown in Figure 5-14. Initially, removals of $\leq 75 \%$ were attained, but only at SEA2 injection rates of 300-550 ppm. Relatively high SEA2 addition rates combined with a small quantity $(0.15 \mathrm{lb} / \mathrm{Macf})$ of PAC injection were required to consistently meet the target of 55\% Hg removal. Presented in Figure 5-15 are the PAC injection rates used during the long-term testing period. The addition of SEA2 (50-100 ppm, dry coal basis) in combination with a nominal 0.15-lb/Macf PAC injection was initiated on April 19 and continued until May 18, 2005, when the supply of SEA2 was exhausted. PAC injection continued for several hours on May 19 to empty the PAC supersack feeding the Portapac injection system. During the SEA2 and PAC injections, the $55 \% \mathrm{Hg}$ removal goal was exceeded about $25 \%$ of the time, as indicated in Figure 5-16. About half of the time, the ESP-wet FGD Hg removal rate ranged from $50 \%$ to $55 \%$. 


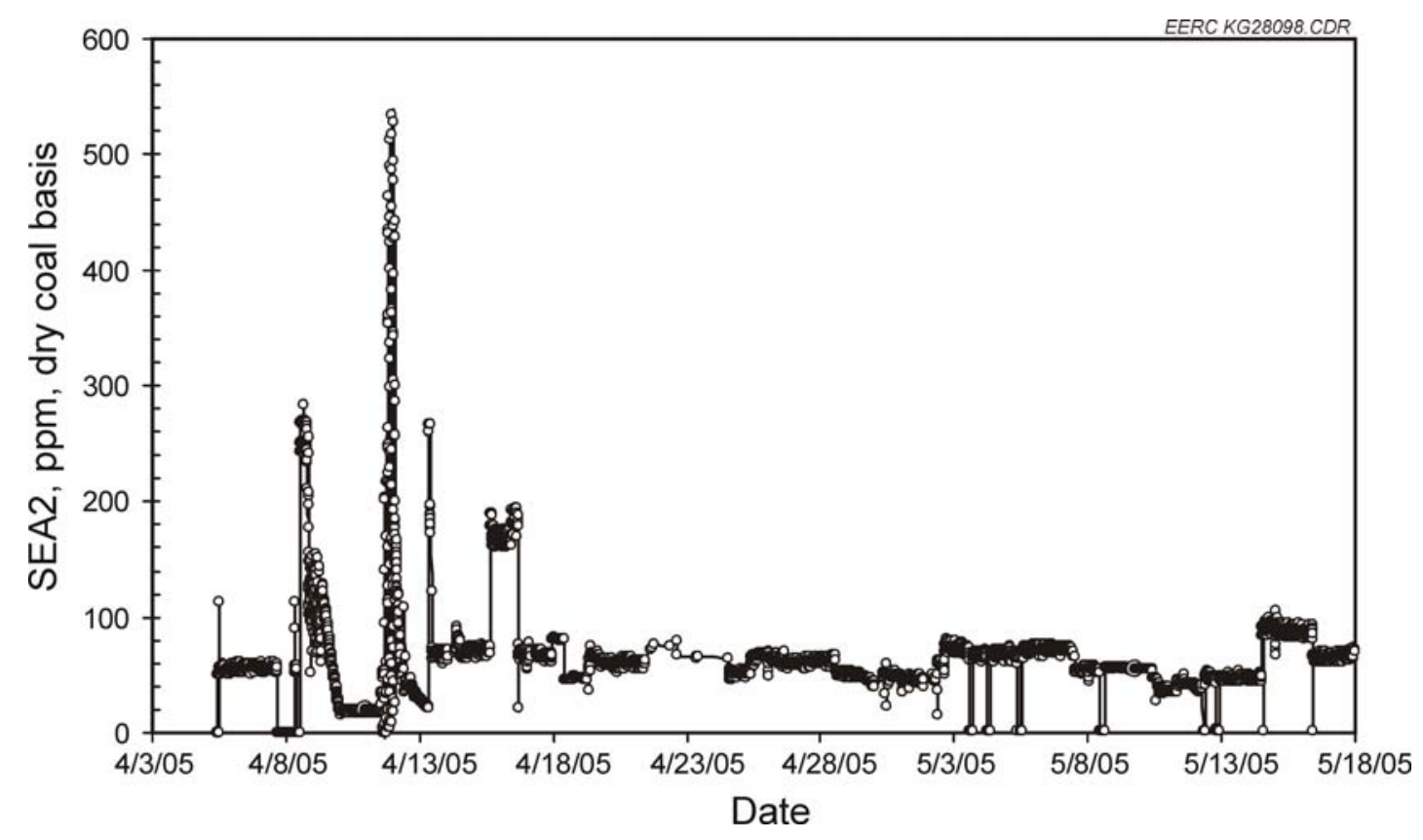

Figure 5-13. SEA2 addition rates during the long-term testing at MRY Unit 2.

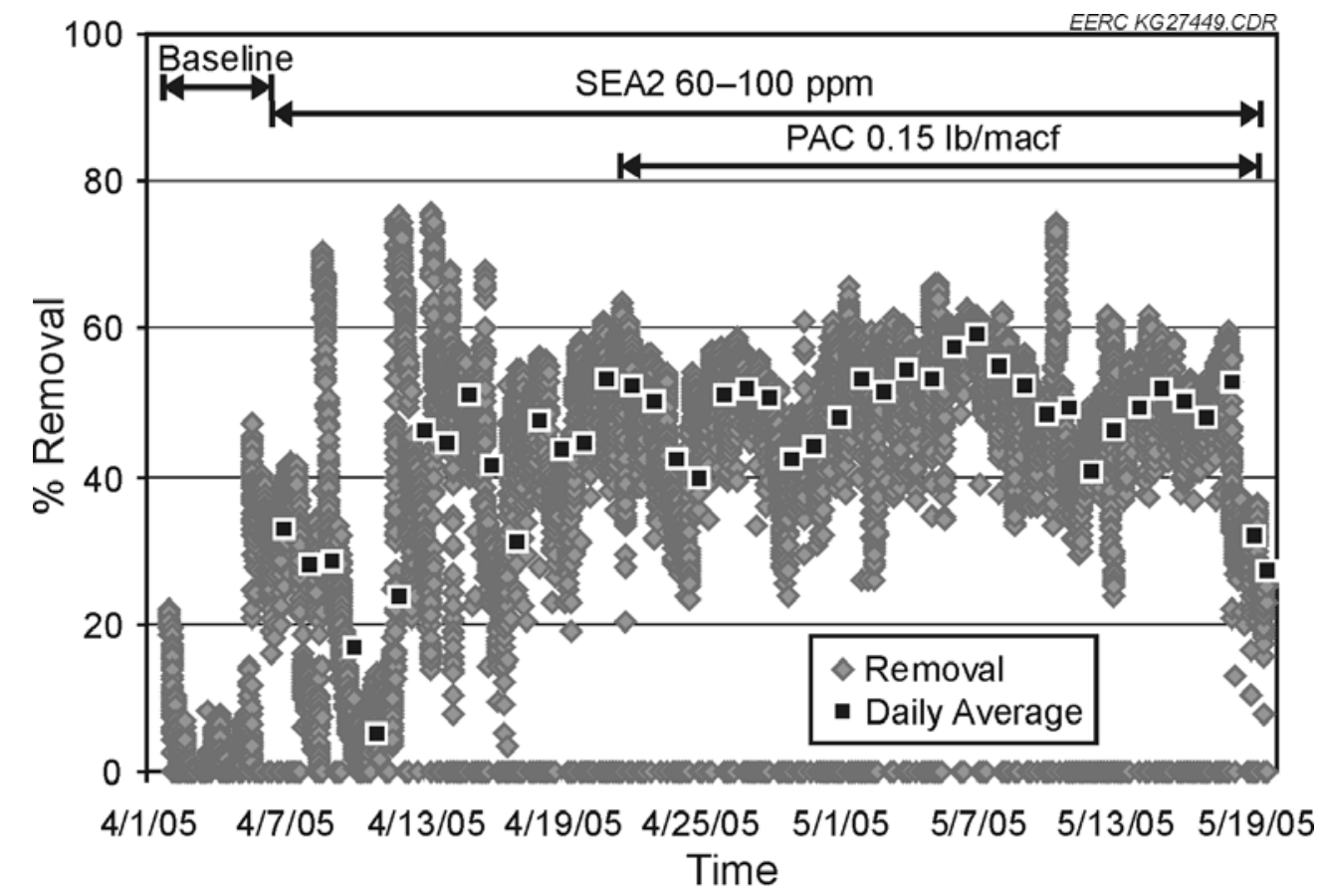

Figure 5-14. ESP-wet FGD Hg removal efficiencies during extended testing at MRY Unit 2 using SEA2 additions and SEA2 with PAC injections. 


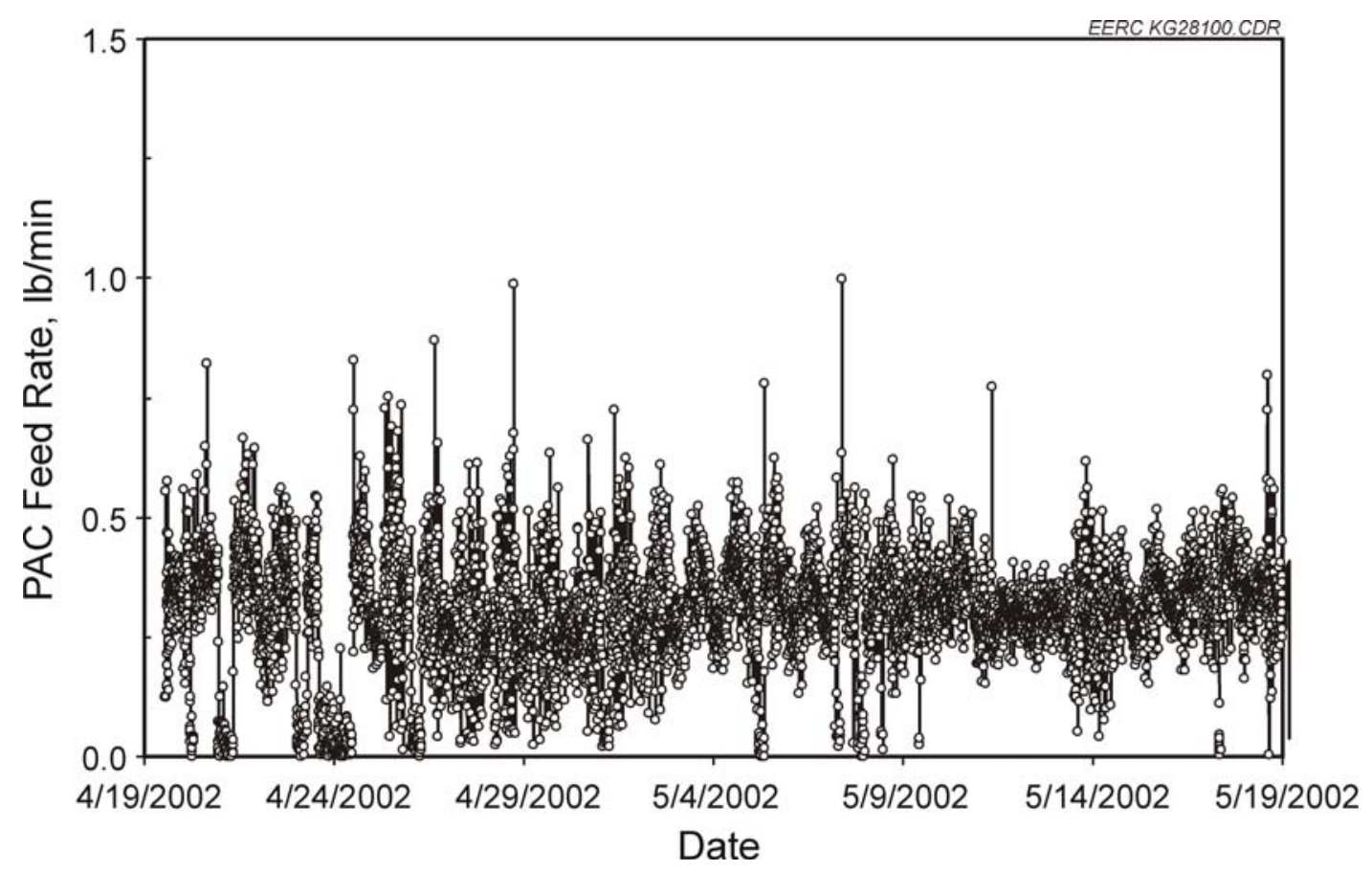

Figure 5-15. PAC injection rates during the long-term testing at MRY Unit 2.

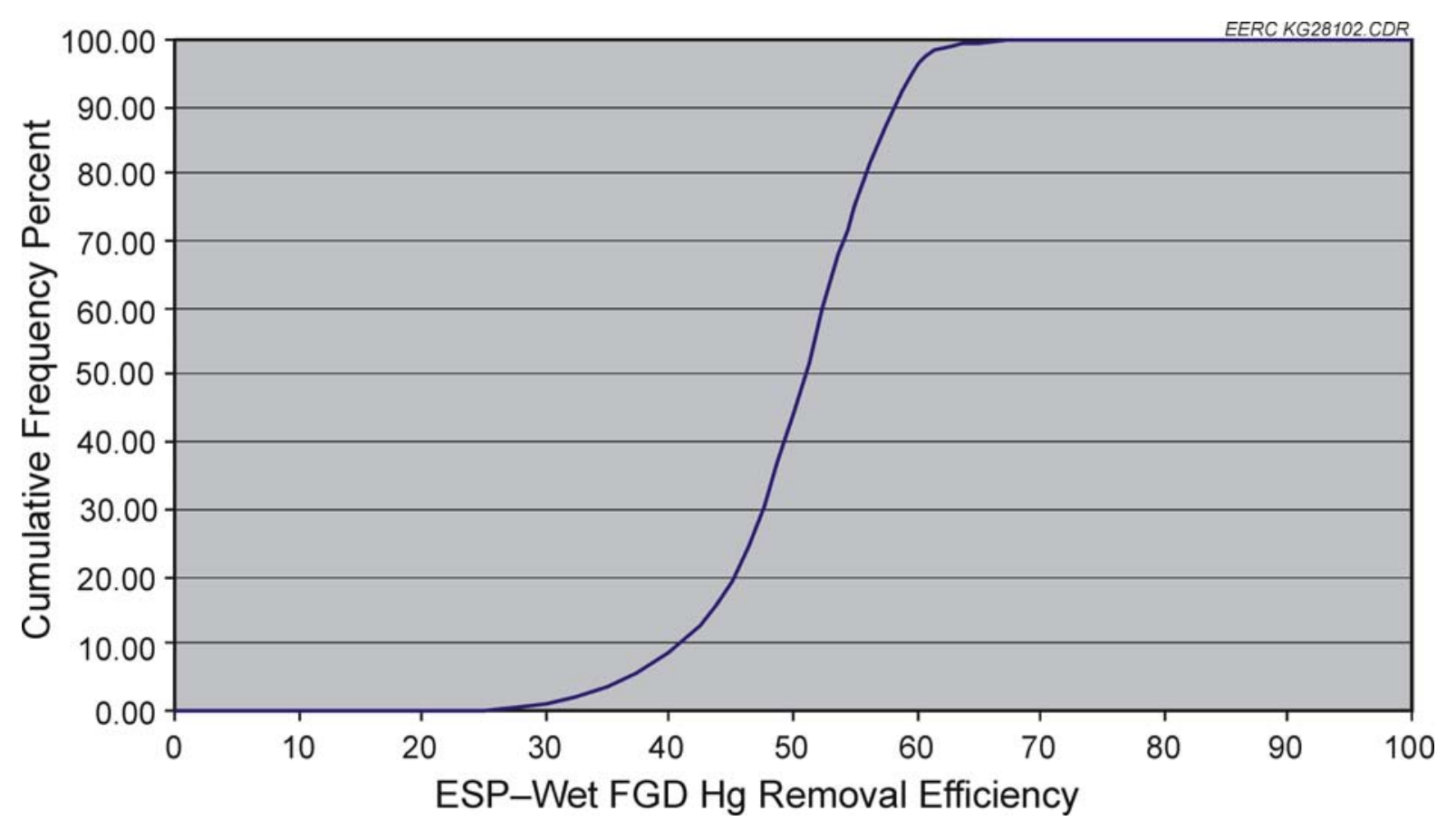

Figure 5-16. Cumulative frequency percent plot for the $\mathrm{Hg}$ removal efficiencies attained at MRY Unit 2 during (April 19 - May 18, 2005) SEA 2 (50-100 ppm, dry coal basis) and 0.15 lb/Macf PAC injections. 
Triplicate EPA Method 26A measurements indicated that $\mathrm{HCl}$ concentrations at the ESP inlet varied widely from about 2 to 25 ppmv during the monthlong $\mathrm{Hg}$ control testing. Presented in Table 5-10 are $\mathrm{Hg}, \mathrm{Br}$, and $\mathrm{Cl}$ concentrations for fly ash samples collected from Row 1 of the ESP during SEA2 additions at 60-100 ppm and SEA2 addition combined with PAC injection $(0.15 \mathrm{lb} / \mathrm{Macf})$. The Hg results in Table 5-10 are consistent with the ESP-wet FGD Hg removal efficiencies plotted in Figure 5-13 in that $\mathrm{Hg}$ is more effectively captured in the SEA2- and PACbearing fly ash relatively to the fly ash containing SEA2 only. SEA2 addition significantly increased the $\mathrm{Br}$ content, but not $\mathrm{Cl}$, of fly ash as indicated by comparing Table 5-10 fly ash $\mathrm{Br}$ concentrations with those presented in Table 5-7 for the baseline fly ashes.

\subsection{RESULTS AND DISCUSSION FOR MoSES UNIT 3 TESTING}

Most of the coal, flue gas, fly ash, and scrubber slurry sample analyses from MoSES Unit 3 were replicated. However to be concise, average results are generally presented herein. Individual analysis results are available in the MoSES site report provided in Appendix B.

\subsection{Coal Analysis Results}

Samples of the Texas lignite and PRB coal were collected daily throughout the test program. Selected coal samples were analyzed for mercury, bromide, chloride, and ultimateproximate parameters. The analysis results for the Texas lignite and PRB coals are summarized in Tables 6-1 and 6-2, respectively. The mercury content for each coal reported in Tables 6-1 and 6-2 was calculated from an average of triplicate analyses performed in URS's Austin laboratories. Figure 6-1 shows the variation in the mercury concentration of each coal. The concentration of mercury in the PRB coal was fairly consistent between 0.04 and $0.09 \mathrm{ppm}$, with the exception of a day when the mercury concentration was $0.26 \mathrm{ppm}(12 / 9 / 05)$. When this day is excluded, the average mercury concentration of the PRB coal during the test program was $0.07 \pm 0.01 \mathrm{ppm}$. The mercury concentration in the Texas lignite ranged from 0.17 to $0.71 \mathrm{ppm}$ (dry). The measured value of $0.71 \mathrm{ppm}$ was twice as high as the next highest mercury concentration measured in the Texas lignite samples. Excluding this value, the average Texas lignite mercury concentration was $0.26 \pm 0.06 \mathrm{ppm}$.

A comparison of the mercury content of the coal sampled to the flue gas mercury concentrations at the ESP inlet should provide an indication of how much mercury is removed upstream of the ESP by the fly ash. The ESP inlet vapor-phase mercury concentrations measured

Table 5-10. Hg, Br, and Cl Analysis Results (ppm) for Fly Ashes Sampled from the ESP During SEA2 Additions and SEA2-PAC Injections

\begin{tabular}{lccc}
\hline Test Condition: & SEA2 $60-100 \mathrm{ppm}$ & \multicolumn{2}{c}{ SEA2-PAC } \\
\cline { 2 - 4 } Date(s) Sampled: & $3 / 17 / 05$ & $4 / 26-28 / 05$ & $5 / 10-11 / 05$ \\
\hline $\mathrm{Hg}$ & 0.479 & 0.705 & 0.688 \\
$\mathrm{Br}$ & 176 & 451 & 464 \\
$\mathrm{Cl}$ & 10 & 17 & 20 \\
\hline
\end{tabular}


Table 6-1. Unit 1 - Texas Lignite Coal Analyses for Long-Term Injection Test

\begin{tabular}{|c|c|c|c|c|c|c|c|c|c|c|c|c|c|c|c|c|c|}
\hline Date in 2005 & $10 / 28$ & $11 / 2$ & $11 / 3$ & $11 / 4$ & $11 / 6$ & $11 / 9$ & $11 / 12$ & $11 / 13$ & 11/17 & $12 / 1$ & $12 / 2$ & $12 / 3$ & $12 / 5$ & $12 / 7$ & $12 / 9$ & $12 / 11$ & $12 / 14$ \\
\hline Sample Time & $7: 50$ & $10: 55$ & $11: 50$ & $10: 35$ & $7: 30$ & NA & NA & NA & $7: 00$ & day & day & day & $13: 20$ & $8: 00$ & NA & NA & $14: 30$ \\
\hline Coal Type & TxL & TxL & TxL & TxL & TxL & $\mathrm{TxL}$ & TxL & TxL & $\mathrm{TxL}^{1}$ & TxL & $\mathrm{TxL}^{1}$ & TxL & TxL & TxL & $\mathrm{TxL}^{1}$ & TxL & TxL \\
\hline \multicolumn{18}{|l|}{ Proximate, $\mathrm{wt} \% \mathrm{AR}^{2}$} \\
\hline Moisture & 32.44 & 29.57 & 30.25 & 31.44 & 30.37 & 31.33 & 32.14 & 31.6 & & 31.06 & & 34.22 & 33.01 & 30.93 & & 28.14 & 31.82 \\
\hline Ash & 11.21 & 17.12 & 10.37 & 12.54 & 17.99 & 16.82 & 14.33 & 14 & & 18.41 & & 7.98 & 13.53 & 15.76 & & 23.94 & 19.57 \\
\hline Volatile Matter & 28.4 & & & & 27.4 & & & 28.32 & & 27.26 & & & & & & 26.95 & \\
\hline Fixed Carbon & 27.95 & & & & 24.24 & & & 26.08 & & 23.27 & & & & & & 20.97 & \\
\hline \multicolumn{18}{|l|}{ Ultimate, wt $\%$ AR } \\
\hline Sulfur & 0.49 & 0.49 & 0.34 & 0.48 & 0.4 & 0.44 & 0.45 & 0.45 & & 0.45 & & 0.48 & 0.54 & 0.45 & & 0.42 & 0.51 \\
\hline Carbon & 40.79 & & & & 37.19 & & & 38.95 & & 36.46 & & & & & & 34.87 & \\
\hline Hydrogen & 3.03 & & & & 2.88 & & & 3.02 & & 2.88 & & & & & & 2.71 & \\
\hline Nitrogen & 0.63 & & & & 0.61 & & & 0.7 & & 0.61 & & & & & & 0.54 & \\
\hline Oxygen & 11.41 & & & & 10.56 & & & 11.28 & & 10.13 & & & & & & 9.38 & \\
\hline $\begin{array}{l}\text { Heating Value, } \mathrm{HHV}^{3} \text {, } \\
\text { Btu/lb, AR }\end{array}$ & 7011 & 6560 & 7469 & 6972 & 6424 & 6410 & 6603 & 6763 & & 6326 & & 7194 & 6638 & 6685 & & 5957 & 6012 \\
\hline $\begin{array}{l}\text { M19 F-factor, } \\
\text { dscf/MMBtu } \\
\text { at } 0 \% \mathrm{O}_{2}\end{array}$ & 9778 & & & & 9782 & & & 9722 & & 9793 & & & & & & 9941 & \\
\hline Mercury, $\mu \mathrm{g} / \mathrm{g}$, dry & 0.315 & 0.174 & 0.172 & 0.271 & 0.289 & 0.292 & 0.370 & 0.246 & & 0.168 & & 0.250 & 0.276 & 0.254 & & 0.706 & 0.361 \\
\hline Mercury, lb/TBtu & 30.35 & & 16.08 & & 31.28 & 31.26 & & 24.83 & & 18.31 & & & 27.85 & & & 85.14 & 40.97 \\
\hline Chloride, $\mu \mathrm{g} / \mathrm{g}$, dry & 27 & & $<25$ & & $<25$ & $<25$ & & 32 & & 40 & & & 54 & & & 26 & \\
\hline Bromide, $\mu \mathrm{g} / \mathrm{g}$, dry & $<10$ & & $<10$ & & $<10$ & $<10$ & & $<10$ & & $<10$ & & & $<10$ & & & $<10$ & \\
\hline
\end{tabular}

Bromide, $\mu \mathrm{g} / \mathrm{g}$, dry

$<10$

${ }^{2}$ An received.

${ }^{3}$ Higher heating value. 
Table 6-2. Unit 1 - PRB Coal Analyses for Long-Term Injection Test

\begin{tabular}{|c|c|c|c|c|c|c|c|c|c|c|c|c|c|c|c|c|c|}
\hline Date in 2005 & $10 / 28$ & $11 / 2$ & $11 / 3$ & $11 / 4$ & $11 / 6$ & $11 / 9$ & $11 / 12$ & $11 / 13$ & 11/17 & $12 / 1$ & $12 / 2$ & $12 / 3$ & $12 / 5$ & $12 / 7$ & $12 / 9$ & $12 / 11$ & $12 / 14$ \\
\hline Sample Time & $8: 40$ & $10: 55$ & $9: 15$ & $10: 35$ & $8: 50$ & NA & NA & NA & $8: 30$ & day & day & day & 1320 & $10: 00$ & NA & NA & $12: 00$ \\
\hline Coal Type & PRB & PRB & PRB & PRB & PRB & PRB & PRB & PRB & PRB & PRB & PRB & $\mathrm{PRB}^{1}$ & PRB & PRB & PRB & PRB & PRB \\
\hline \multicolumn{18}{|l|}{ Proximate, $\mathrm{wt} \% \mathrm{AR}$} \\
\hline Moisture & 30.31 & 30.14 & 29.5 & 30.79 & 31.01 & 30.54 & 30.99 & 30.45 & 30.19 & 28.23 & 29.54 & & 29.66 & 28.09 & 27.59 & 30.67 & 31.11 \\
\hline Ash & 5.94 & 5.48 & 5.48 & 4.49 & 4.95 & 4.83 & 6.03 & 4.44 & 5.01 & 4.92 & 4.69 & & 4.37 & 5.19 & 7.16 & 5.27 & 5.75 \\
\hline Volatile Matter & 29.71 & & & & 29.39 & & & 29.68 & & 31.52 & & & & & & 29.71 & \\
\hline Fixed Carbon & 34.04 & & & & 34.65 & & & 35.43 & & 35.33 & & & & & & 34.35 & \\
\hline \multicolumn{18}{|l|}{ Ultimate, $w \mathrm{t} \% \mathrm{AR}$} \\
\hline Sulfur & 0.41 & 0.33 & 0.36 & 0.31 & 0.34 & 0.35 & 0.34 & 0.28 & 0.31 & 0.37 & 0.39 & & 0.31 & 0.37 & 0.40 & 0.38 & 0.36 \\
\hline Carbon & 46.78 & & & & 46.68 & & & 47.92 & & 49.41 & & & & & & 47.05 & \\
\hline Hydrogen & 3.34 & & & & 3.35 & & & 3.42 & & 3.59 & & & & & & 3.36 & \\
\hline Nitrogen & 0.6 & & & & 0.57 & & & 0.6 & & 0.62 & & & & & & 0.61 & \\
\hline Oxygen & 12.62 & & & & 13.10 & & & 12.89 & & 12.86 & & & & & & 12.66 & \\
\hline $\begin{array}{l}\text { Heating Value, HHV, } \\
\text { Btu/lb, AR }\end{array}$ & 8084 & 8070 & 8264 & 8134 & 8046 & 8201 & 7953 & 8275 & 8187 & 8626 & 8274 & & 8363 & 8385 & 8236 & 7804 & 8043 \\
\hline Mercury, $\mu \mathrm{g} / \mathrm{g}$, dry & 0.088 & 0.046 & 0.070 & 0.053 & 0.086 & 0.063 & 0.052 & 0.054 & 0.082 & 0.078 & 0.066 & & 0.075 & 0.064 & 0.261 & 0.080 & 0.067 \\
\hline $\begin{array}{l}\text { M19 F-factor, } \\
\text { dscf/MMBtu at } \\
0 \% \mathrm{O}_{2}\end{array}$ & 9679 & & & & 9677 & & & 9677 & & 9628 & & & & & & 10084 & \\
\hline Mercury, lb/TBtu & 7.58 & & 5.93 & & 7.37 & 5.36 & & 4.56 & 6.98 & 6.45 & & & 6.33 & & & 7.12 & 5.75 \\
\hline Chloride, $\mu \mathrm{g} / \mathrm{g}$, dry & $<25$ & & $<25$ & & $<25$ & $<25$ & & $<25$ & & $<25$ & & & $<25$ & & & $<25$ & \\
\hline Bromide, $\mu \mathrm{g} / \mathrm{g}$, dry & $<10$ & & $<10$ & & $<10$ & $<10$ & & $<10$ & & $<10$ & & & $<10$ & & & $<10$ & \\
\hline
\end{tabular}

${ }^{1}$ Analysis of sample (based on heating value and ash content) revealed that it was Texas lignite, not PRB coal. 


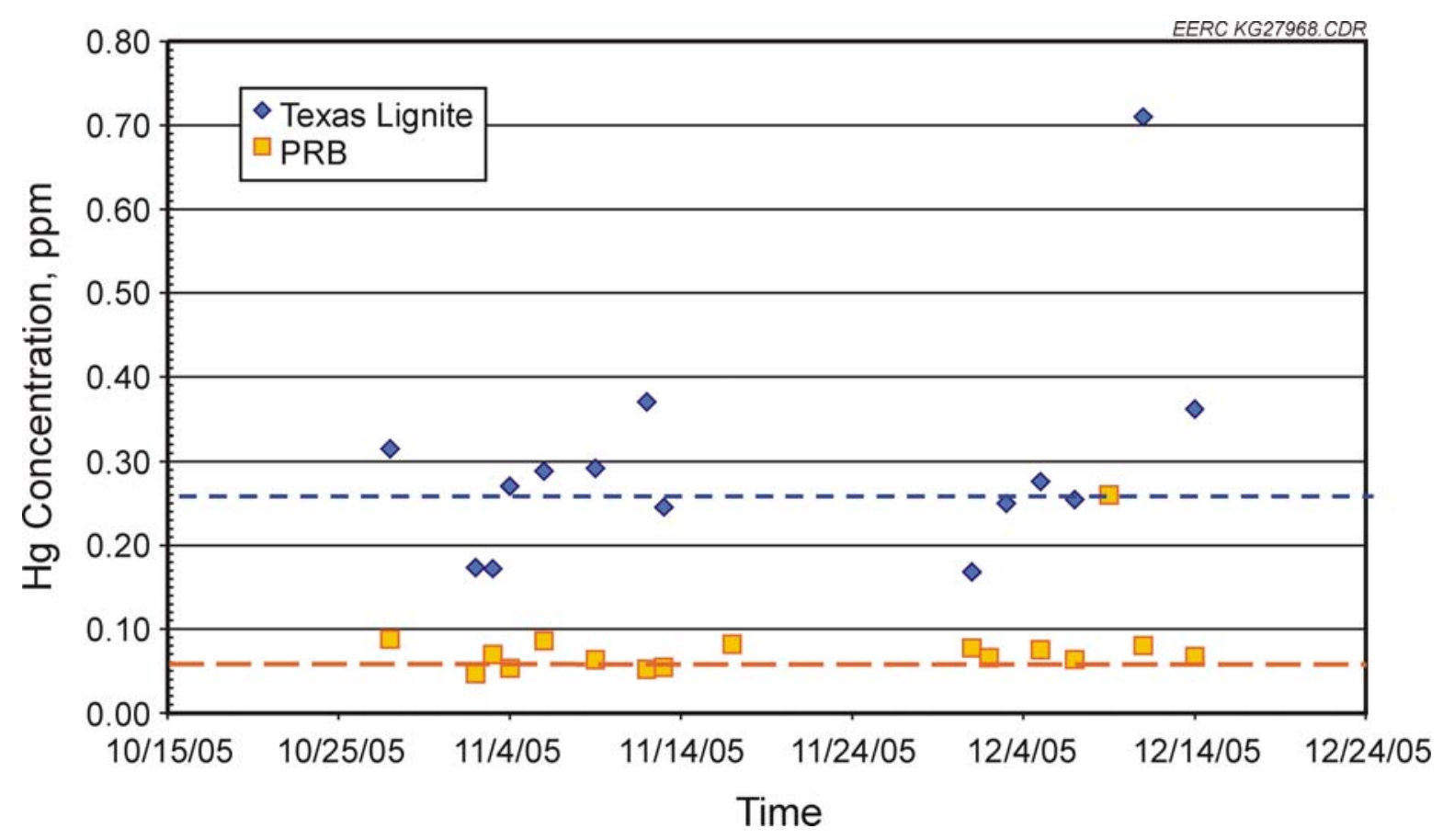

Figure 6-1. Coal mercury concentrations measured during test program.

by the SCEM were averaged for a single day. The daily coal sample mercury concentrations were combined with the coal-specific F-factors to determine the equivalent flue gas mercury concentration (expressed on the same basis as the SCEM as $\mu \mathrm{g} / \mathrm{dNm}^{3}$ at $3 \% \mathrm{O}_{2}$ ). As MoSES fires both PRB and Texas lignite coals, the coal-derived mercury concentrations were weighted based on the fraction of each coal fired. These fractions were determined from an analyzer at the plant that monitors the heating value of the coal being loaded into the bunkers and by assuming that each coal was loaded at an equal mass rate.

Figure 6-2 plots the vapor-phase ESP inlet mercury concentrations versus the coal-derived flue gas mercury concentrations. Datum points that fall along the unity line indicate little mercury removal upstream of the ESP. All five baseline days represented on this plot fall either on the unity line or slightly above it, indicating no baseline removal of mercury upstream of the ESP. Averaging these five baseline test days, the ESP inlet gas-phase mercury concentration represented $116 \%$ of the coal mercury.

Points that fall below the unity line in Figure 6-2 indicate that not all of the mercury in the coal was accounted for in the flue gas at the ESP inlet. Of the nine datum points that represent days of calcium bromide injection, only one falls on the unity line. The remaining eight points fall well below the unity line, indicating that either the calcium bromide injection caused mercury to be removed by the ash prior to the ESP or the presence of bromide in the gas caused a sampling bias with the SCEM analyzer. On average, the ESP inlet gas-phase mercury concentration represented: 


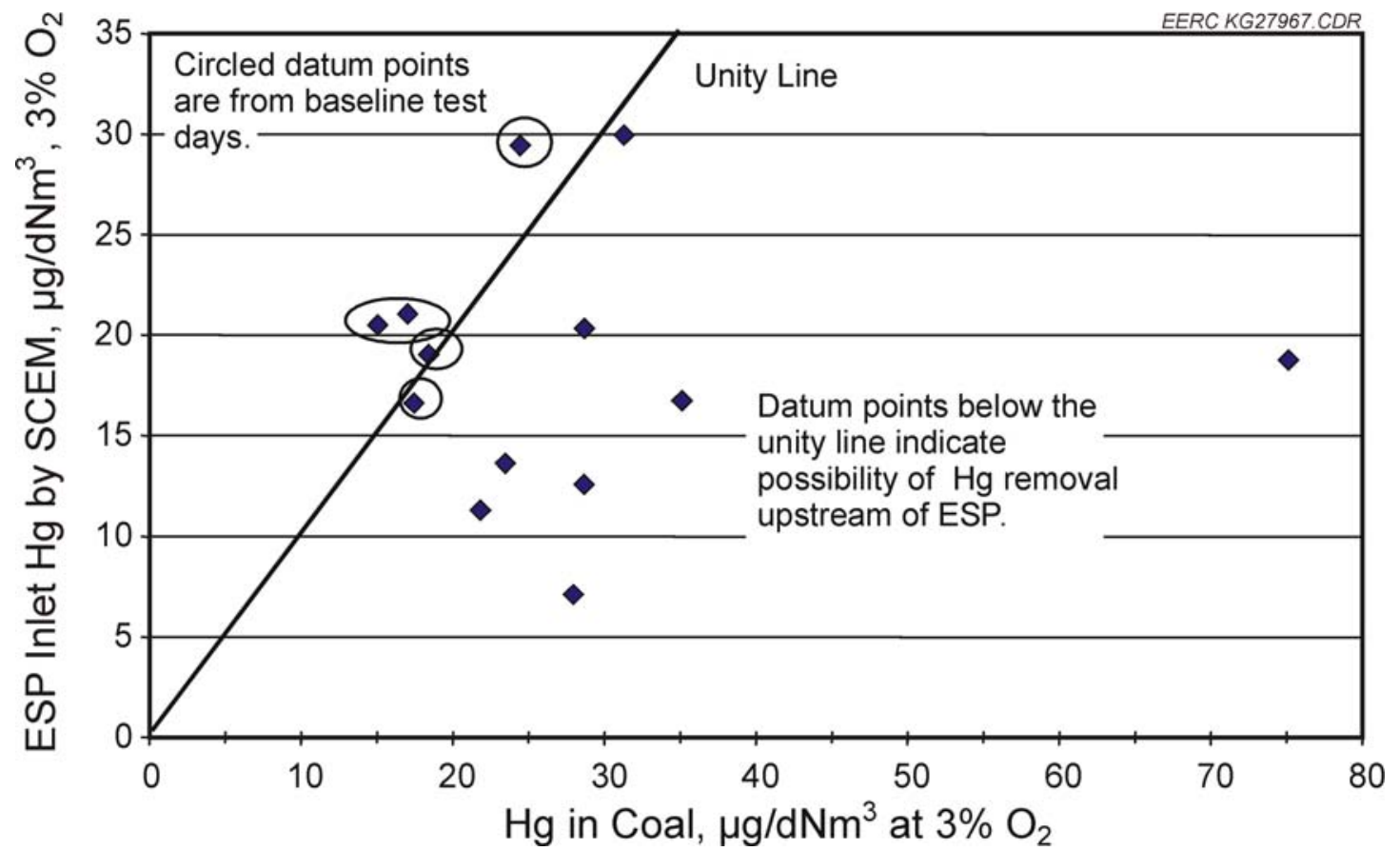

Figure 6-2. Comparison of ESP inlet vapor-phase mercury (as measured by SCEM) to coal mercury concentration.

- $54 \%$ of the coal mercury during the 55 -ppm Br test (average of 4 days).

- $36 \%$ of the coal mercury during the $113-\mathrm{ppm}$ Br test (average of 3 days).

- $96 \%$ of the coal mercury during the 330-ppm Br test (average of 1 day).

If the SCEM data are correct, then on average during the 55-ppm Br injection test, $46 \%$ of the coal mercury was removed from the flue gas upstream of the ESP. When the injection rate was increased to $113 \mathrm{ppm} \mathrm{Br}$, on average $64 \%$ of the coal mercury was removed from the flue gas upstream of the ESP. However, when the injection rate was increased to $330 \mathrm{ppm} \mathrm{Br}$, no mercury removal was observed upstream of the ESP.

\subsection{Baseline Testing}

Baseline measurements were made at MoSES Unit 3 prior to the start of each long-term testing period. Baseline flue gas mercury measurements were made during three distinct periods in the test program:

1. October 24, 19:50, through October 27, 12:55. These are the days prior to the parametric tests. Data for this time period are shown in Figure 6-3.

2. November 1, 17:00, through November 5, 12:15. These are the days prior to the first long-term injection test. Data for this time period are shown in Figure 6-4. 


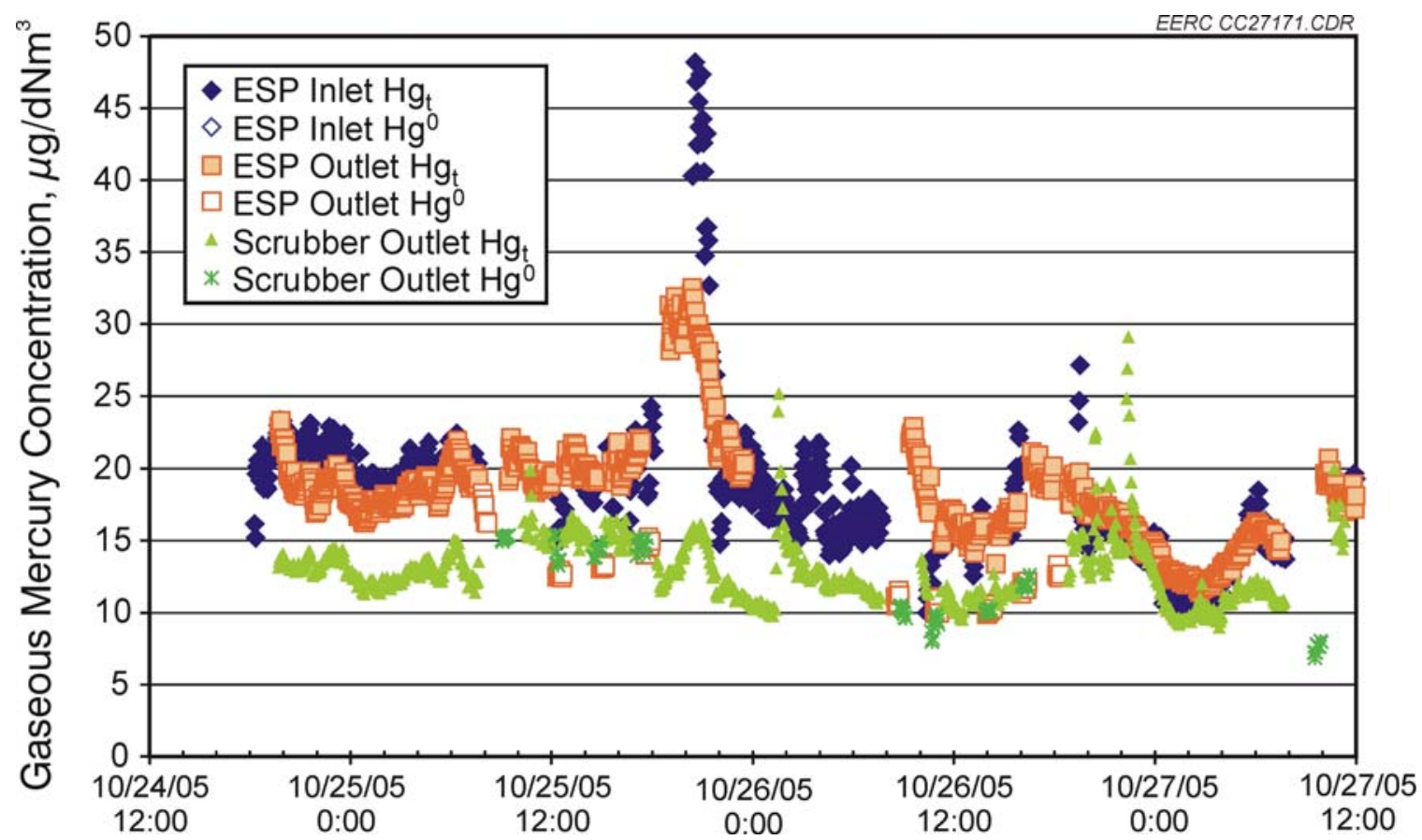

Figure 6-3. Baseline mercury SCEM data measured prior to parametric mercury control injection tests at MoSES Unit 3.

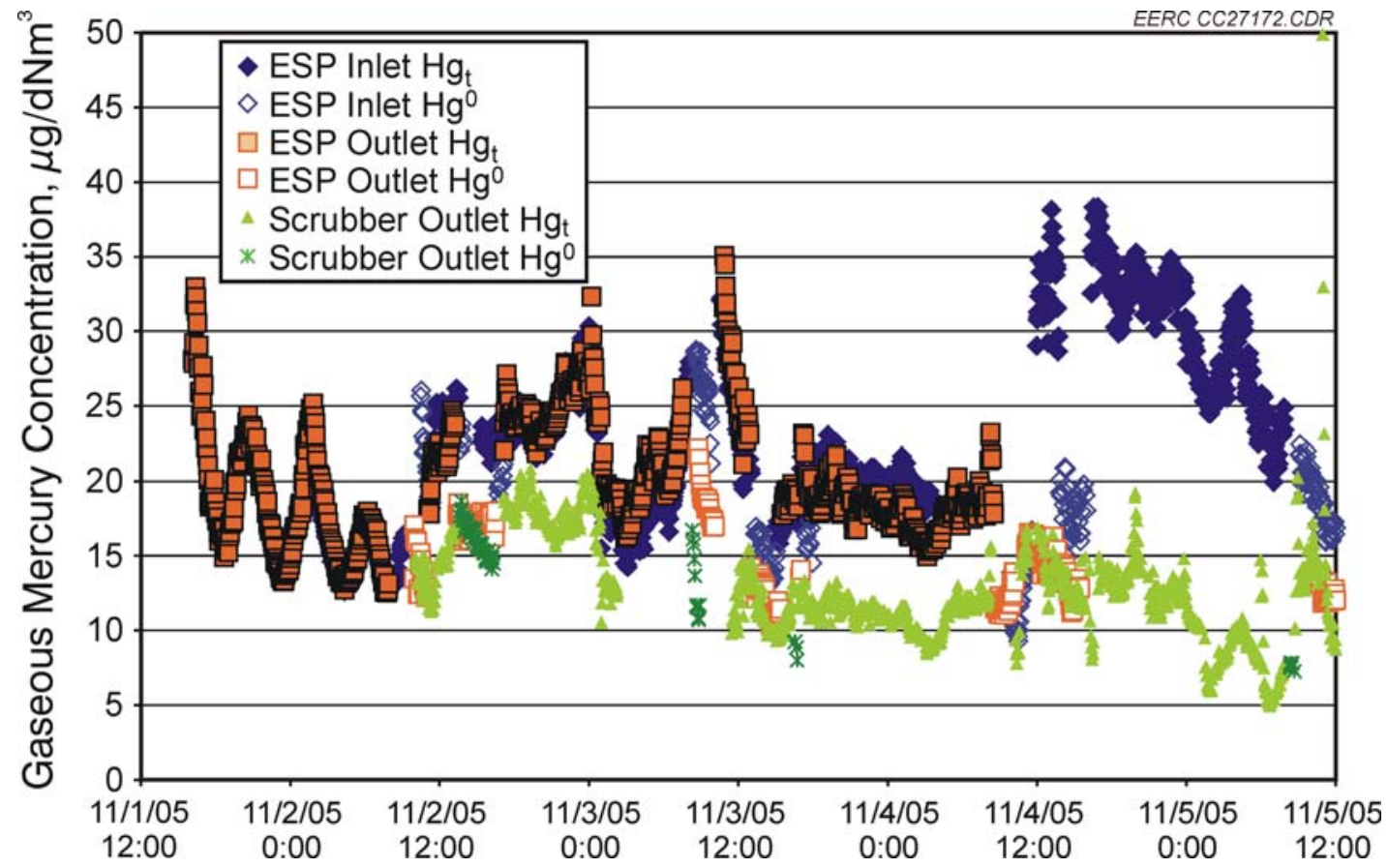

Figure 6-4. Baseline mercury SCEM data measured prior to the first set of long-term mercury control injection tests at MoSES Unit 3. 
3. November 28, 17:00, through December 2, 11:10. These are the days prior to the second long-term injection test. Data for this time period are shown in Figure 6-5.

The total gas-phase mercury concentration was highly variable at MoSES Unit 3, with the baseline ESP inlet total mercury concentration ranging between 10 and $50 \mu \mathrm{g} / \mathrm{Nm}^{3}$; however, the concentrations were typically between 15 and $30 \mu \mathrm{g} / \mathrm{Nm}^{3}$ over the course of the baseline test days. The ESP inlet and outlet mercury was typically present as $10 \%-40 \%$ oxidized mercury; however, oxidized mercury levels as high as 55\% were observed December 1-2, 2005. Calculated baseline mercury removal across the ESP ranged from $-10 \%$ to $10 \%$; therefore, removal of mercury across the ESP was negligible overall. The removal of mercury across the ESP/FGD system was equivalent to the mercury removal across the FGD since there was no mercury removal across the ESP. Mercury removal across the FGD ranged from $10 \%$ to $60 \%$ over the course of the baseline testing; however, the mercury removal across the ESP/FGD system was more typically $10 \%-40 \%$. The measured mercury removal across the FGD agreed well with the ESP outlet oxidation.

The baseline $\mathrm{HCl} / \mathrm{Cl}_{2}$ and $\mathrm{HBr} / \mathrm{Br}_{2}$ concentrations were measured with Method 26 during various baseline periods. Method 26/26A has a negative bias associated with the quantification of $\mathrm{Cl}_{2} / \mathrm{Br}_{2}$ and a correspondingly positive bias associated with $\mathrm{HCl} / \mathrm{HBr}$. Therefore, halogen concentrations are presented as total halogen, expressed as $\mathrm{HCl}$ or $\mathrm{HBr}$. The baseline $\mathrm{HCl}$ concentration ranged from 1.2 to $5.2 \mathrm{ppm}$ and averaged $3.0 \mathrm{ppm}$. The baseline $\mathrm{HBr}$ concentration averaged $0.09 \mathrm{ppm}$.

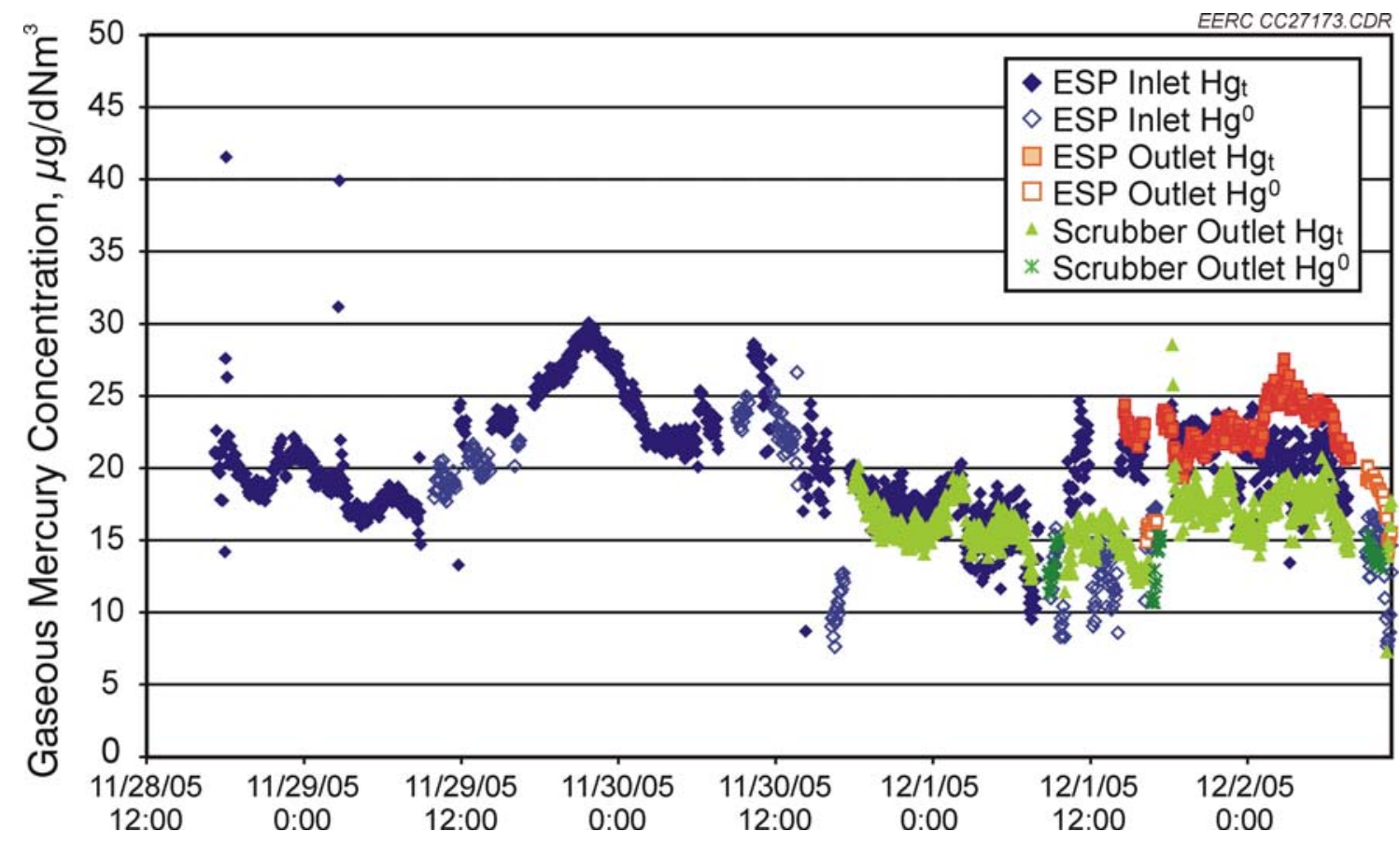

Figure 6-5. Baseline mercury SCEM data measured prior to the second set of long-term mercury control injection tests at MoSES Unit 3. 


\subsection{Parametric Testing}

Two salt solutions were evaluated in parametric tests: $\mathrm{CaCl}_{2}$ and $\mathrm{CaBr}_{2}$. Each salt solution was tested at multiple injection rates over 2-day periods. Flue gas mercury concentrations were monitored continuously with mercury SCEMs at the ESP inlet, ESP outlet, and FGD outlet. Method 26 measurements were made at the ESP inlet during each parametric test condition to verify the amount of halogen species present in the flue gas.

Tables 6-3 and 6-4 show the measured flue gas $\mathrm{HCl} / \mathrm{Cl}_{2}$ and $\mathrm{HBr} / \mathrm{Br}_{2}$ concentrations during the parametric test periods. The data presented are the average of multiple runs conducted at each test condition. The measured $\mathrm{Cl}_{2}$ and $\mathrm{Br}_{2}$ concentrations were less than the detection limits of 0.07 and $0.01 \mathrm{ppm}$, respectively.

The theoretical flue gas halogen (as HX) concentrations shown in Tables 6-3 and 6-4 were computed from the actual halogen injection rate and an estimated flue gas flow rate. The flue gas flow rate was estimated from an EPA Method 19 F-factor calculation, which agreed within $8 \%$ of the stacks CEM flow measurements. For the theoretical calculation, it was assumed that all of the injected halogen (X) converted to HX in the flue gas. The calculation of the theoretical HX concentration included the baseline measurement of HX.

Table 6-3. Comparison of Measured Flue Gas HCl Concentrations to Theoretical Predictions for Parametric Tests at MoSES

\begin{tabular}{lccc}
\hline $\begin{array}{l}\text { Average } \\
\text { Injection Rate, } \\
\text { ppm equivalent } \\
\text { in dry coal }\end{array}$ & $\begin{array}{c}\text { Average M26 } \\
\text { Measurement of } \\
\text { Flue Gas HCl, } \\
\text { ppm, dry, 3\% } \mathrm{O}_{2}\end{array}$ & $\begin{array}{c}\text { Theoretical Chloride } \\
\text { Concentration, as HCl, } \\
\text { ppm, dry, 3\% } \mathrm{O}_{2}\end{array}$ & $\begin{array}{c}\text { Measured/ } \\
\text { Theoretical, } \\
\%\end{array}$ \\
\hline 400 & 33.0 & 37 & 89 \\
600 & 52.1 & 55 & 95 \\
800 & 63.0 & 73 & 86 \\
\hline
\end{tabular}

Table 6-4. Comparison of Measured Flue Gas HBr Concentrations to Theoretical Predictions for Parametric Tests at MoSES

\begin{tabular}{lccc}
\hline $\begin{array}{l}\text { Average } \\
\text { Injection Rate, } \\
\text { ppm equivalent } \\
\text { in dry coal }\end{array}$ & $\begin{array}{c}\text { Average M26 } \\
\text { Feasurement of } \\
\text { Flue Gas HBr, } \\
\text { ppm, dry, 3\% }\end{array}$ & $\begin{array}{c}\text { Theoretical HBr } \\
\text { Concentration, } \\
\text { ppm, dry, 3\% } \mathrm{O}_{2}\end{array}$ & $\begin{array}{c}\text { Measured/ } \\
\text { Theoretical, \% }\end{array}$ \\
\hline 12.5 & $\mathrm{O}_{2}$ & 0.51 & 92 \\
50 & 0.47 & 2.03 & 94 \\
100 & 1.9 & 4.06 & 57 \\
200 & 2.3 & 8.16 & 59 \\
\hline
\end{tabular}


The measured flue gas $\mathrm{HCl}$ concentration correlates well with theoretical predictions, with the measured flue gas $\mathrm{HCl}$ concentration ranging from $86 \%$ to $95 \%$ of theoretical. For the $\mathrm{CaBr}_{2}$ tests, the measured $\mathrm{HBr}$ concentrations were closest to the theoretical concentrations at the lowest injection rates of 12.5 and $50 \mathrm{ppm} \mathrm{Br}$ equivalent in the coal (dry basis). At the higher injection rates of 100 and $200 \mathrm{ppm} \mathrm{Br}$ equivalent in the coal, the flue gas $\mathrm{HBr}$ concentration is approximately $60 \%$ of the theoretical value. This same trend of comparison between the measured to theoretical $\mathrm{HBr}$ concentrations was seen in the 2-week continuous tests.

The measured SCEM data are shown in Figures 6-6 and 6-7 for the $\mathrm{CaCl}_{2}$ and $\mathrm{CaBr}_{2}$ tests, respectively. In general, each injection rate was maintained for at least 2 hours. Once the flue gas mercury concentrations steadied out, the injection rate was changed. For each injection rate, an average of the measured steady-state mercury concentrations was taken. Table 6-5 presents these average concentrations. As can be seen in Figures 6-6 and 6-7, the total $\mathrm{Hg}$ concentrations measured at the ESP inlet and ESP outlet decreased during $\mathrm{CaBr}_{2}$ injection. This decrease in total mercury concentration was not observed during $\mathrm{CaCl}_{2}$ injection. It was later observed from the long-term test data that the presence of bromide in the flue gas likely caused a negative bias in the measurement of total mercury in the flue gas. This bias does not exist at the scrubber outlet because the scrubber removes the flue gas bromine. No biases in elemental mercury concentration measurements were observed upstream of the scrubber. The bias in total mercury concentration in the presence of bromine is explored in detail in the discussion of the long-term

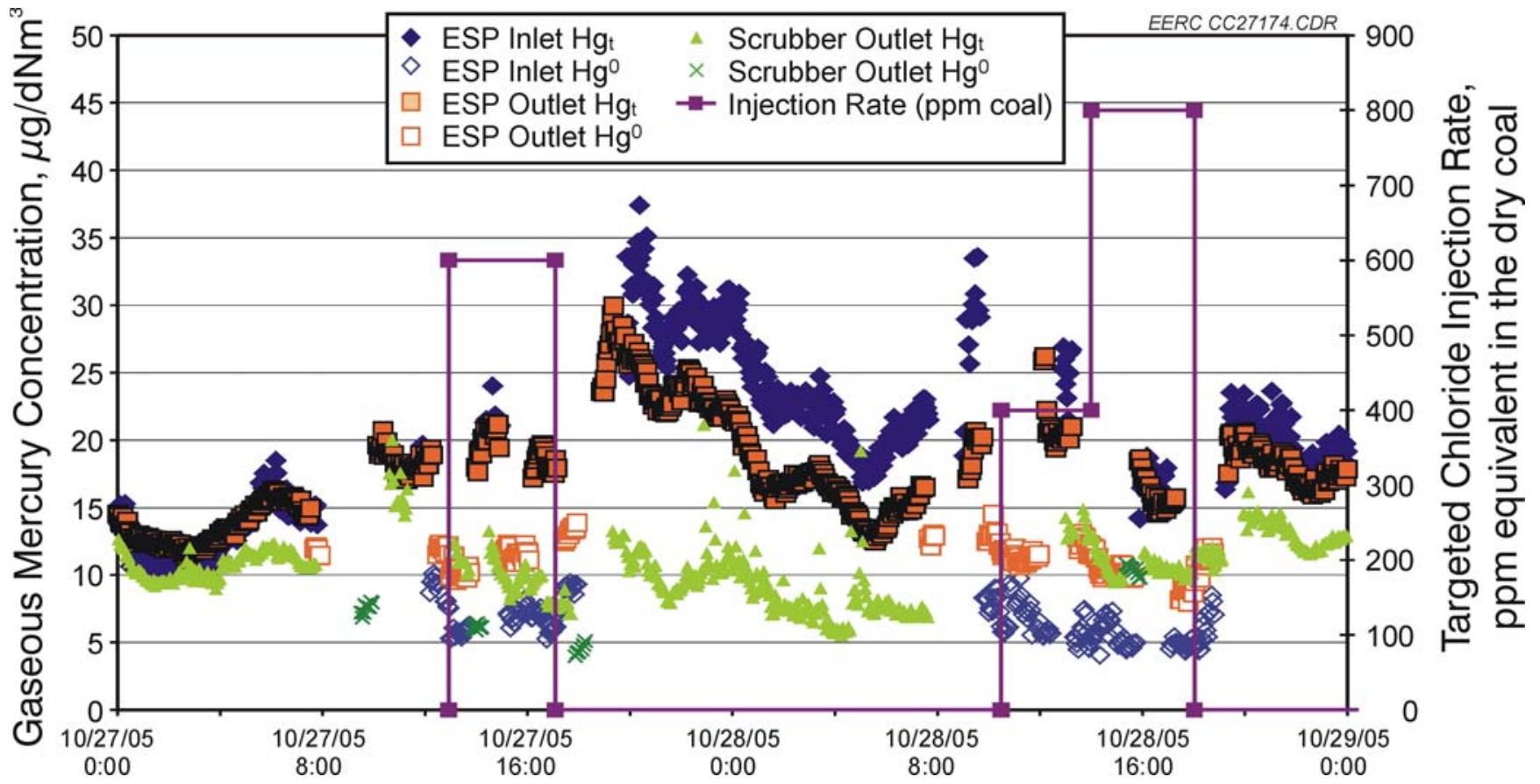

Figure 6-6. SCEM concentrations measured during $\mathrm{CaCl}_{2}$ parametric injection tests. 


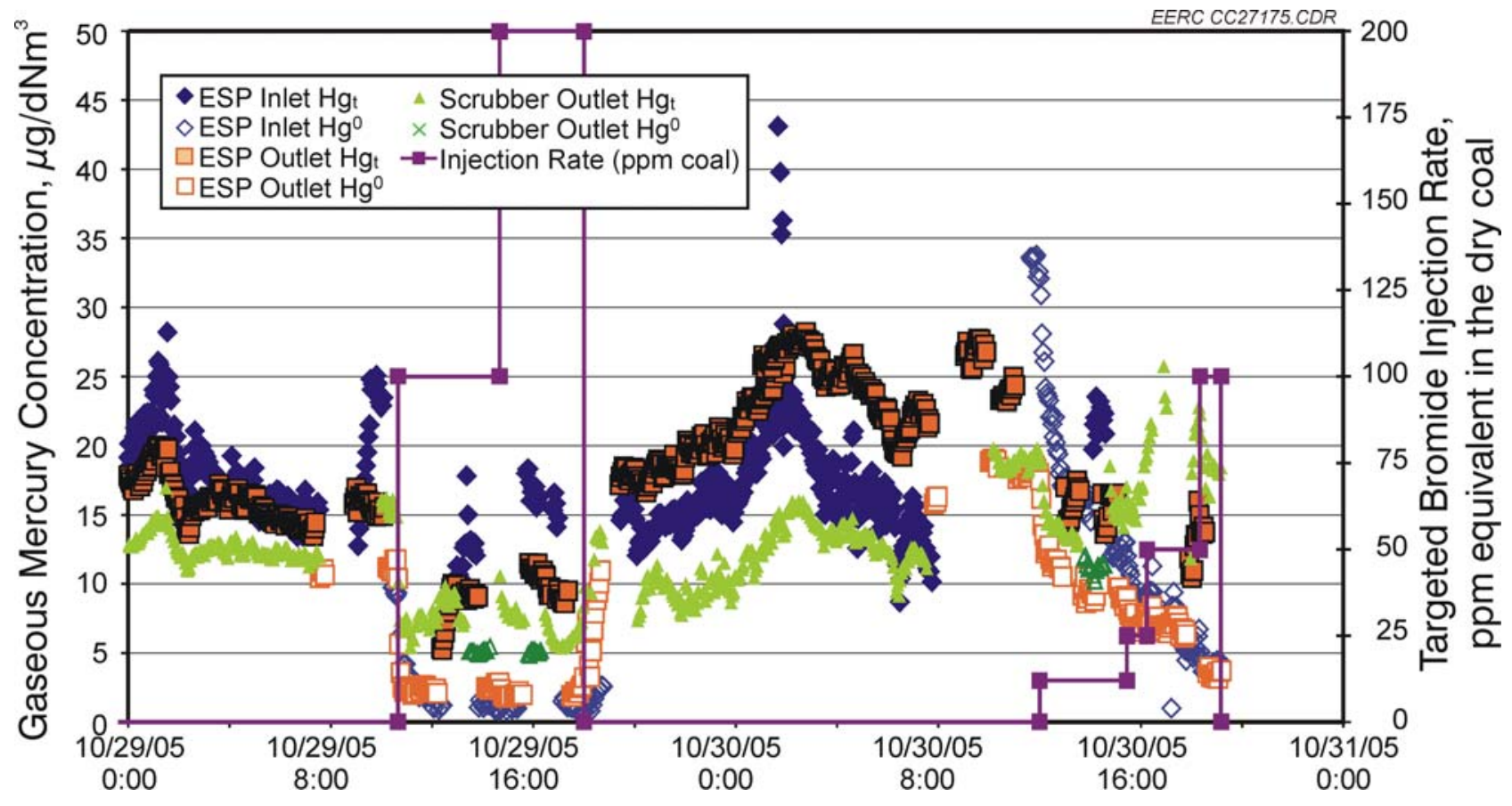

Figure 6-7. SCEM concentrations measured during $\mathrm{CaBr}_{2}$ parametric injection tests.

Table 6-5. Average Mercury Concentrations During Parametric Injection Tests at MoSES

\begin{tabular}{|c|c|c|c|c|c|c|c|}
\hline \multirow[b]{3}{*}{ Chemical } & \multirow{3}{*}{$\begin{array}{c}\text { Targeted } \\
\text { Injection Rate, } \\
\text { ppm X in coal }\end{array}$} & \multicolumn{6}{|c|}{$\begin{array}{c}\text { Gas-Phase Mercury Concentrations, } \\
\qquad \mu \mathrm{g} / \mathrm{dm}^{3}, 3 \% \mathrm{O}_{2}\end{array}$} \\
\hline & & \multicolumn{2}{|c|}{ ESP Inlet } & \multicolumn{2}{|c|}{ ESP Outlet } & \multicolumn{2}{|c|}{ Scrubber Outlet } \\
\hline & & Hg Total & $\mathrm{Hg}^{01}$ & Hg Total & $\mathrm{Hg}^{0}$ & Hg Total & $\mathrm{Hg}^{0}$ \\
\hline Baseline & 0 & 19.3 & 9.3 & 18.4 & 11.9 & 16.2 & $\mathrm{NA}$ \\
\hline $\mathrm{CaCl}_{2}$ & 600 & 21.1 & 6.8 & 19.6 & 11.0 & 10.2 & 6.2 \\
\hline Baseline & 0 & 28.2 & 7.9 & 19.3 & 12.7 & $\mathrm{NA}^{2}$ & NA \\
\hline $\mathrm{CaCl}_{2}$ & 400 & 25.0 & 7.0 & 21.0 & 11.6 & 13.6 & NA \\
\hline $\mathrm{CaCl}_{2}$ & 800 & 17.0 & 5.3 & 16.0 & 9.8 & 10.4 & 10.4 \\
\hline Baseline & 0 & 20.7 & 9.5 & 15.8 & 11.2 & 15.6 & NA \\
\hline $\mathrm{CaBr}_{2}$ & 100 & $12.0^{4}$ & 1.3 & $8.7^{4}$ & 2.4 & 8.1 & 5.1 \\
\hline $\mathrm{CaBr}_{2}$ & 200 & $16.1^{4}$ & 1.1 & $10.1^{4}$ & 2.2 & 6.3 & 5.1 \\
\hline Baseline & 0 & NA & 33.3 & 23.8 & 18.3 & 18.9 & NA \\
\hline $\mathrm{CaBr}_{2}$ & 12 & $21.9^{4}$ & 15.9 & $15.6^{4}$ & 9.9 & 14.3 & 11.2 \\
\hline $\mathrm{CaBr}_{2}$ & 50 & NA & 8.8 & NA & 7.1 & 16.9 & NA \\
\hline $\mathrm{CaBr}_{2}$ & 100 & NA & 6.4 & $12.5^{4}$ & 6.9 & $\mathrm{D}^{3}$ & NA \\
\hline $\mathrm{CaBr}_{2}$ & 200 & NA & 4.2 & NA & 3.4 & $\mathrm{D}^{3}$ & NA \\
\hline
\end{tabular}

ESP inlet $\mathrm{Hg}^{0}$ values are biased low (oxidation biased high) because of a sampling problem.

${ }^{2}$ Not available because the value either was not measured or did not pass QC.

${ }^{3}$ Deleted data because scrubber outlet probe received a slug of FGD slurry and caused increased measured mercury concentrations.

${ }^{4}$ Total Hg concentrations at ESP inlet and ESP outlet during calcium bromide injection tests may be biased low. 
injection results. In the long-term data analysis, test average coal mercury values were used in place of the scrubber inlet total vapor-phase mercury concentrations measured by the SCEMs. This option was not available for the parametric data analysis, as it was difficult to obtain single daily coal samples that were representative of the flue gas condition. Therefore, for these parametric tests, the total vapor-phase mercury concentration data are still presented for the $\mathrm{CaBr}_{2}$ injection, but they are flagged as having a possible negative bias. All mercury removal and oxidation values calculated from the total mercury concentration may likewise be biased low.

While Figure 6-7 presents all of the scrubber outlet mercury concentration data that were measured by the SCEM, only limited scrubber outlet data were used in the calculation of mercury removal for the parametric $\mathrm{CaBr}_{2}$ tests. Significant problems were initially encountered while the gas was sampled at the scrubber outlet because the only available sampling ports were directly above the scrubber exit. As the mist-laden flue gas exited the scrubber and was sampled by the mercury extraction probe, large volumes of slurry would occasionally get pulled into the extraction probe (despite having a nozzle on the probe tip that was pointed in the opposite direction of flue gas flow). As the slurry was heated by the probe, the mercury in the slurry offgassed and was sampled by the SCEM, producing a positive bias in the scrubber outlet mercury concentrations. As the test program progressed, methods were devised to minimize this positive bias. These methods included 1) the use of a dual extraction loop, 2) decreasing the heating on the extraction probe to prevent spray-drying any captured slurry, and 3) daily preventive cleaning of the extraction probe. While these methods did not eliminate the problem, they reduced the occurrence of positively biased data at the FGD outlet. However, many of these techniques were not employed until the completion of the parametric test program.

The percentage of mercury present as oxidized mercury was calculated at the ESP inlet and ESP outlet locations. Table 6-6 shows these results. Figures 6-8 and 6-9 plot the mercury oxidation results for $\mathrm{CaCl}_{2}$ and $\mathrm{CaBr}_{2}$ injection, respectively.

For the first test days during parametric testing, the oxidation of mercury at the ESP inlet was significantly higher than at the ESP outlet. At the ESP inlet, the baseline oxidation was between $54 \%$ and $71 \%$, while the ESP outlet oxidation was between $29 \%$ and $25 \%$. The ESP inlet oxidation percentages were significantly higher than what was measured during all of the other baseline measurement periods, when it was typically between $10 \%$ and $40 \%$. The IGS filter at the ESP inlet was replaced at the beginning of the fourth day of parametric testing; an increase in the elemental mercury concentration (and decrease in oxidation) measured at the ESP inlet was observed following IGS filter replacement; therefore, it is believed that the IGS filter was oxidizing a portion of the mercury in the sampled flue gas. While the oxidation values at the ESP inlet are biased high for the first three test days of parametric testing, these values do show the same performance trends as the ESP outlet data for the two halogenated chemicals.

The parametric $\mathrm{CaCl}_{2}$ tests showed only a nominal increase in mercury oxidation at the ESP inlet and ESP outlet locations. The gas-phase mercury at the ESP outlet reached a maximum of $45 \%$ oxidation at an injection rate of $400 \mathrm{ppm} \mathrm{Cl}$ equivalent in the dry coal as compared to a baseline oxidation of $35 \%$. The oxidation of mercury at both the ESP inlet and ESP outlet 
Table 6-6. Percent Oxidation of Mercury at ESP Inlet and Outlet Measured During Parametric Injection Tests

\begin{tabular}{|c|c|c|c|c|}
\hline Test Day & Chemical & $\begin{array}{c}\text { Targeted } \\
\text { Injection Rate, } \\
\text { ppm X in coal }\end{array}$ & $\begin{array}{l}\mathrm{Hg} \text { Oxidation } \\
\text { at ESP Inlet }{ }^{\mathrm{b}}, \%\end{array}$ & $\begin{array}{l}\text { Hg Oxidation } \\
\text { at ESP Outlet, \% }\end{array}$ \\
\hline \multirow[t]{2}{*}{1} & Baseline & 0 & 52 & 35 \\
\hline & $\mathrm{CaCl}_{2}$ & 600 & 68 & 44 \\
\hline \multirow[t]{3}{*}{2} & Baseline & 0 & 72 & 34 \\
\hline & $\mathrm{CaCl}_{2}$ & 400 & 72 & 45 \\
\hline & $\mathrm{CaCl}_{2}$ & 800 & 69 & 39 \\
\hline \multirow[t]{3}{*}{3} & Baseline & 0 & 54 & 29 \\
\hline & $\mathrm{CaBr}_{2}$ & 100 & $89^{c}$ & $72^{\mathrm{c}}$ \\
\hline & $\mathrm{CaBr}_{2}$ & 200 & $93^{\mathrm{c}}$ & $78^{\mathrm{c}}$ \\
\hline \multirow[t]{5}{*}{4} & Baseline & 0 & NA & 23 \\
\hline & $\mathrm{CaBr}_{2}$ & 12 & $27^{\mathrm{c}}$ & $37^{\mathrm{c}}$ \\
\hline & $\mathrm{CaBr}_{2}$ & 50 & $60^{\mathrm{a}, \mathrm{c}}$ & $50^{\mathrm{a}, \mathrm{c}}$ \\
\hline & $\mathrm{CaBr}_{2}$ & 100 & $71^{\mathrm{a}, \mathrm{c}}$ & $45^{\mathrm{c}}$ \\
\hline & $\mathrm{CaBr}_{2}$ & 200 & $81^{\mathrm{a}, \mathrm{c}}$ & $73^{\mathrm{a}, \mathrm{c}}$ \\
\hline
\end{tabular}

${ }^{\mathrm{a}}$ Total gas-phase mercury concentration was not available for these runs; therefore, percent oxidation was based on average total gas-phase mercury concentration measured during either the previous or following test.

${ }^{\mathrm{b}}$ Percent mercury oxidation at the ESP inlet may be biased high because of a problem with sampling extraction loop at ESP inlet.

${ }^{c}$ The percent oxidation measured at ESP inlet and outlet during calcium bromide injection tests may be biased low because of negative bias in measurement of total vapor-phase mercury concentrations with SCEMs in the presence of bromine.

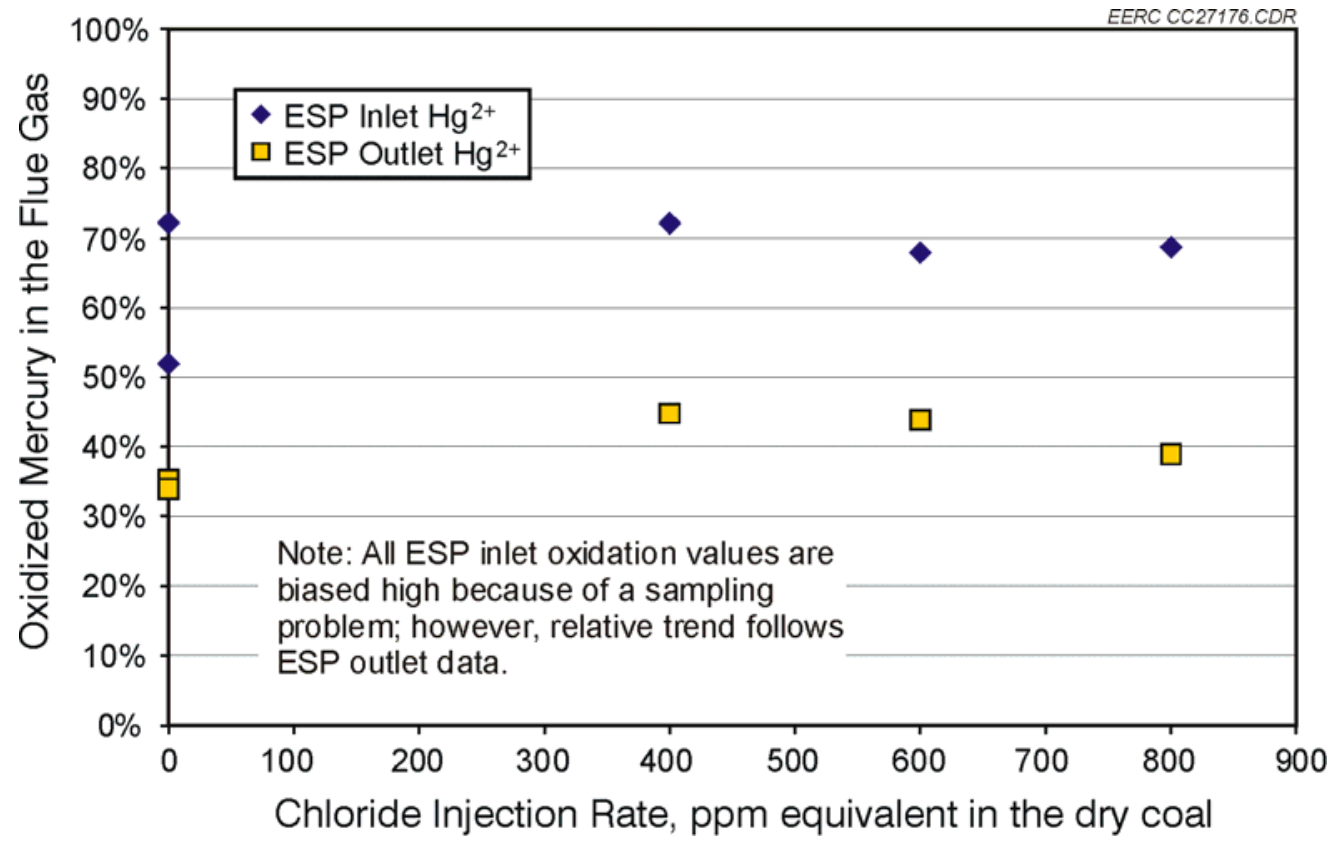

Figure 6-8. Percent oxidized mercury present at ESP inlet and outlet for $\mathrm{CaCl}_{2}$ parametric injection tests. 


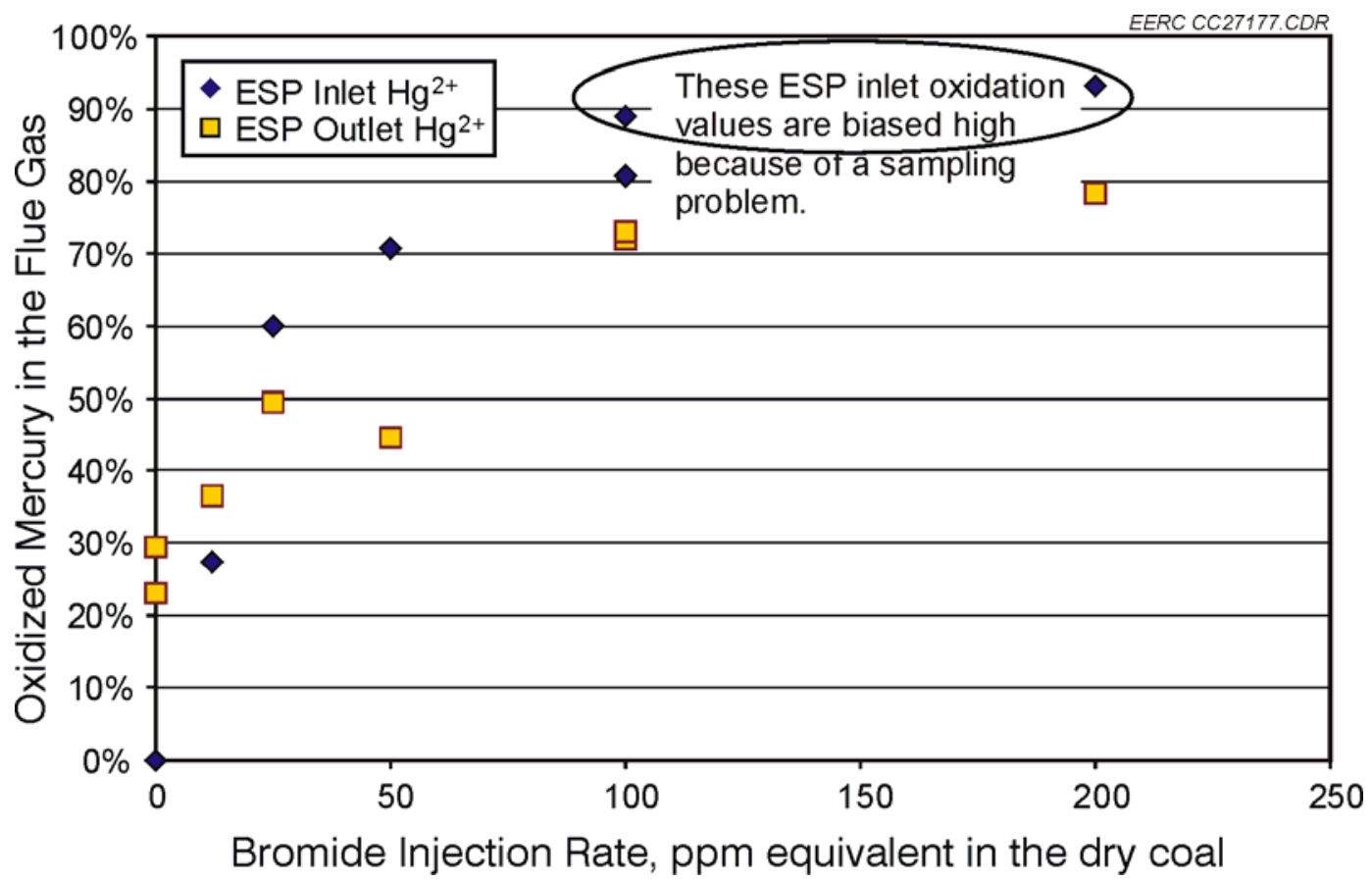

Figure 6-9. Percent oxidized mercury present at ESP inlet and outlet for $\mathrm{CaBr}_{2}$ parametric injection tests.

locations did not increase with injection rates above $400 \mathrm{ppm} \mathrm{Cl}$ equivalent in the coal. In contrast, the injection of $\mathrm{CaBr}_{2}$ resulted in up to $72 \%$ oxidation of the mercury at the ESP outlet at an injection rate of $100 \mathrm{ppm} \mathrm{Br}$ equivalent in the dry coal. The breaking point for the performance curve appears to be around $100 \mathrm{ppm} \mathrm{Br}$ equivalent in the coal. Increasing the injection rate to $200 \mathrm{ppm} \mathrm{Br}$ increased the oxidation from $72 \%$ up to only $78 \%$.

The bromide addition in this test program was limited to only two of the stock feeders. The feeders were chosen to treat both the front and back sides of the furnace, and each feeder supplied fuel pipes that spanned the width of the furnace wall. Despite these efforts to ensure that the entire flue gas was treated with bromide, the bromide concentration over the boiler flue gas might have been less evenly distributed in comparison to the addition of bromide to all of the coal feeders. Therefore, the "break point" as observed here may not be applicable to other conditions, as has been shown in some applications in which the entire coal stream was treated with bromide (5). The parametric chloride addition results from this test program may also have been impacted in a similar manner if nonuniform distribution existed.

Figures 6-10 and 6-11 show the percentage of mercury removal across the ESP and the FGD for the $\mathrm{CaCl}_{2}$ and $\mathrm{CaBr}_{2}$ injection tests, respectively. The baseline mercury removal across the ESP was approximately $20 \%$ during these test days, but was typically $0 \%$ during all other baseline periods in the test program. Neither the $\mathrm{CaCl}_{2}$ nor the $\mathrm{CaBr}_{2}$ resulted in an increase in mercury removal across the ESP. 


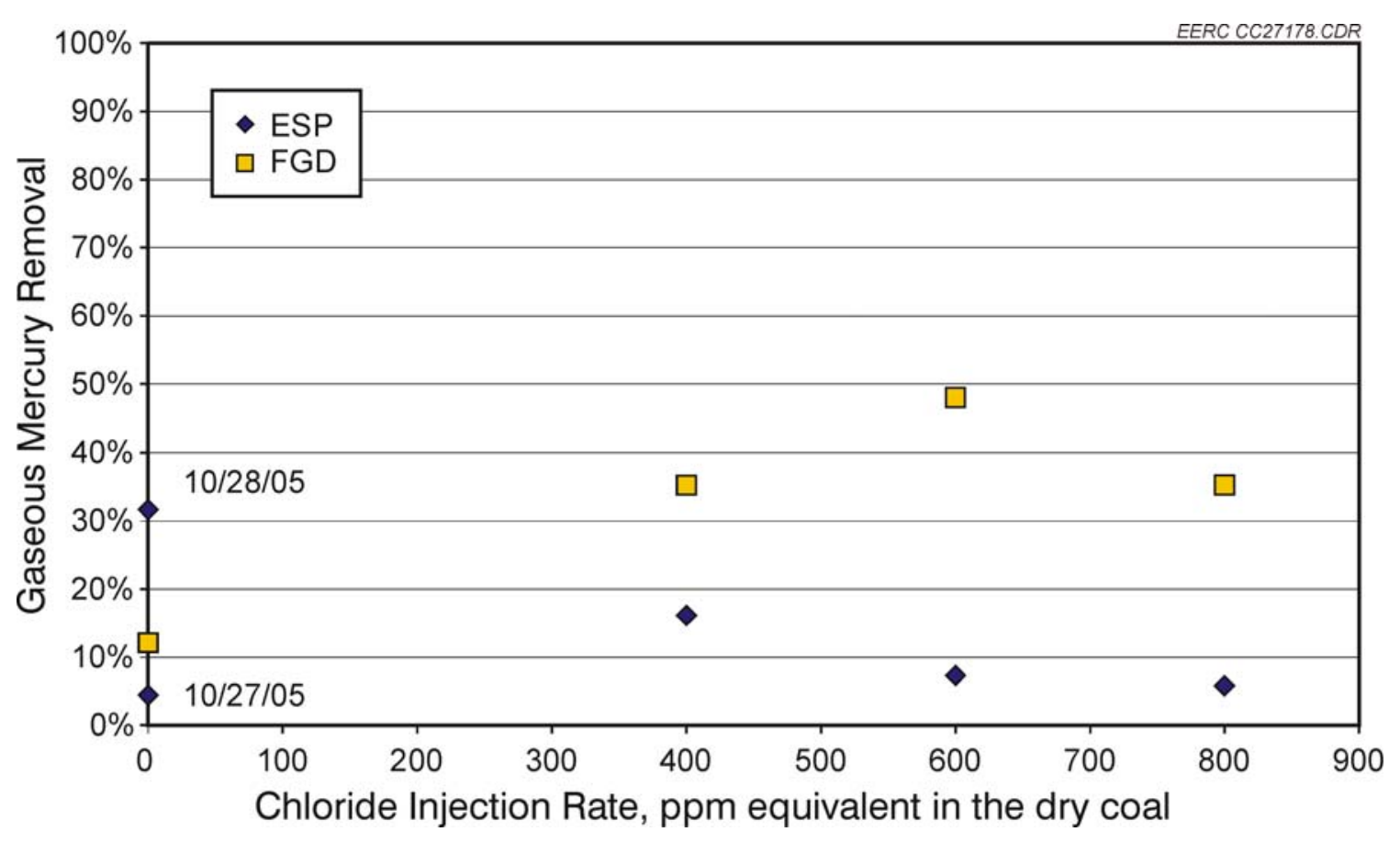

Figure 6-10. Mercury removal across the ESP and FGD for $\mathrm{CaCl}_{2}$ during parametric injection tests at MoSES.

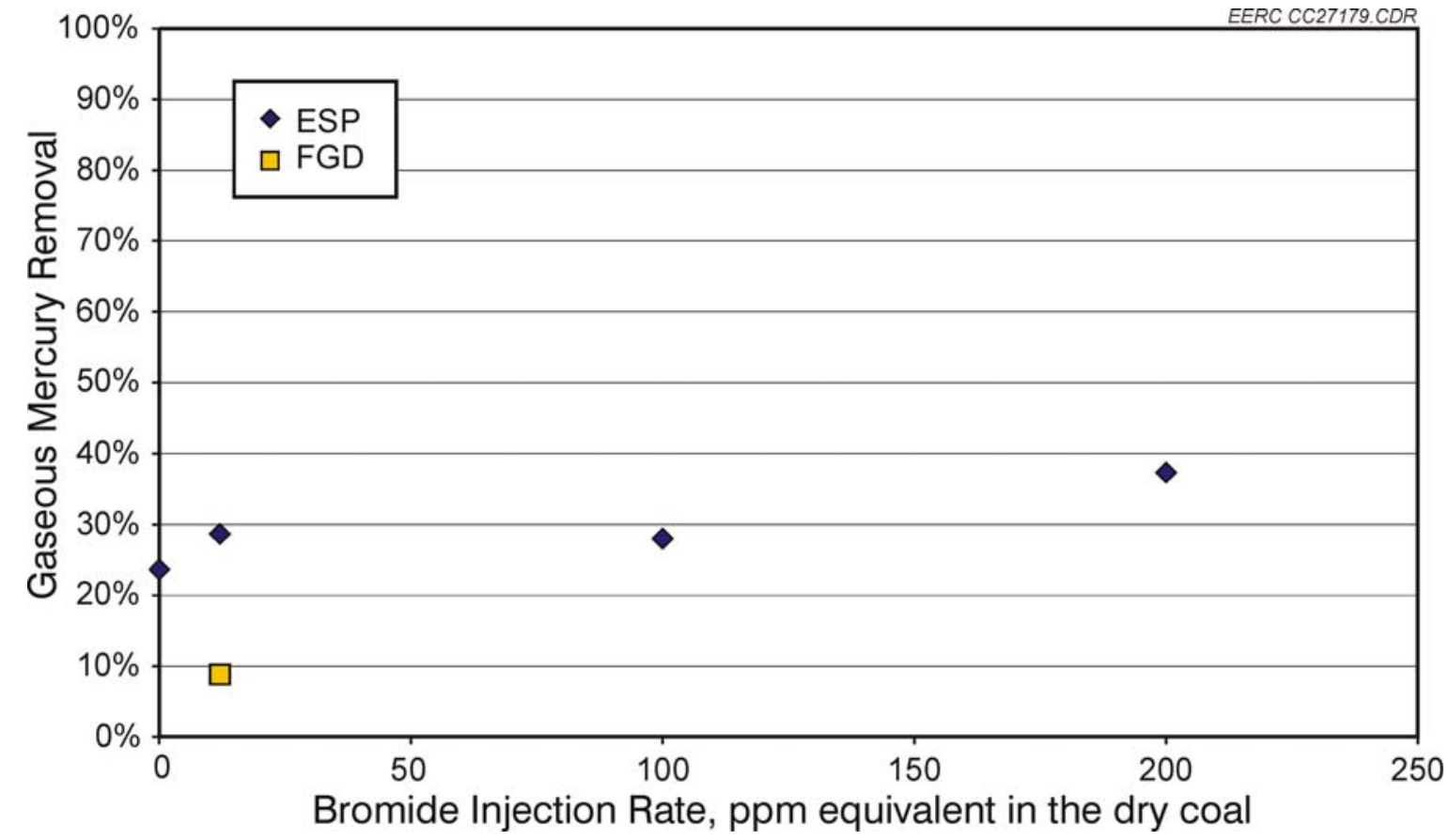

Figure 6-11. Mercury removal across the ESP and FGD for $\mathrm{CaBr}_{2}$ during parametric injection tests at MoSES. 
The mercury removal across the FGD increased from $12 \%$ at baseline to approximately $45 \%$ during the $\mathrm{CaCl}_{2}$ injection tests. These results agree well with the measured $45 \%$ oxidation of mercury at the FGD inlet (ESP outlet). Because of sampling problems (described above) at the FGD outlet during the $\mathrm{CaBr}_{2}$ parametric test days, the FGD outlet data were invalidated. Therefore, the parametric test results were inconclusive with regard to the effect of $\mathrm{CaBr}_{2}$ on mercury removal by the FGD scrubber. However, the effect of $\mathrm{CaBr}_{2}$ on mercury removal across the FGD is well documented in the long-term testing.

Because of the sampling problems at the FGD outlet during the $\mathrm{CaBr}_{2}$ injection tests, it was not possible to compare the effect of halogen identity on net flue gas mercury removal across the ESP/FGD system. The parametric tests for the $\mathrm{CaCl}_{2}$ showed that $\mathrm{CaCl}_{2}$ did not achieve the oxidation needed to meet the mercury removal target of $55 \%$ for the project. Conversely, $\mathrm{CaBr}_{2}$ was shown capable of achieving high mercury oxidation that might be sufficient to achieve the mercury removal goals for the project; therefore, $\mathrm{CaBr}_{2}$ was selected for the long-term tests. For the first 2-week continuous-injection test, an injection rate of $50 \mathrm{ppm} \mathrm{Br}$ equivalent in the coal was selected. Based on the parametric oxidation results, this injection rate appeared capable of achieving the mercury removal target of 55\%.

\subsection{Long-Term Testing}

Two longer-term, continuous-injection tests were executed as part of this test program. In the first 2-week continuous test, $\mathrm{CaBr}_{2}$ was injected at a target injection rate of $50 \mathrm{ppm} \mathrm{Br}$ equivalent in the dry coal. In the second 2-week test, $\mathrm{CaBr}_{2}$ was injected at a target injection rate of $100 \mathrm{ppm}$ Br equivalent in the coal. At the end of the second 2-week test, the injection rate was further increased in an attempt to achieve higher mercury oxidation and removal rates.

\subsubsection{Evaluation of Actual $\mathrm{CaBr}_{2}$ Injection Rates}

During the $\mathrm{CaBr}_{2}$ injection tests, the approximate targeted injection rate was maintained by monitoring the coal feed rate and the solution pump rate and by using measurements of the solution density to estimate the bromide content of the solution. The pumped $\mathrm{CaBr}_{2}$ solution was collected daily during the test program. At the conclusion of the long-term tests, these solution samples were analyzed in URS's Austin laboratory with ion chromatography for the true bromide content. The true bromide content was used in conjunction with the solution density and coal feed rate (from plant data) to calculate the actual injection rates maintained during the test program. In addition, flue gas halogen concentrations were monitored daily at the ESP inlet using Method 26.

Overall, the calculated injection rates, as presented in Figure 6-12, were slightly higher than the target injection rate of $50 \mathrm{ppm} \mathrm{Br}$ equivalent in the dry coal for the first 2-week test period. Over the course of the 2-week test period, the actual injection rate was an average $55 \mathrm{ppm} \mathrm{Br}$ equivalent in the coal. Because of fluctuations in the $\mathrm{CaBr}_{2}$ pump response to the changing load and pulverizer speeds, the injection rate temporarily reached as low as $45 \mathrm{ppm}$ and as high as 90 ppm during the test period. 


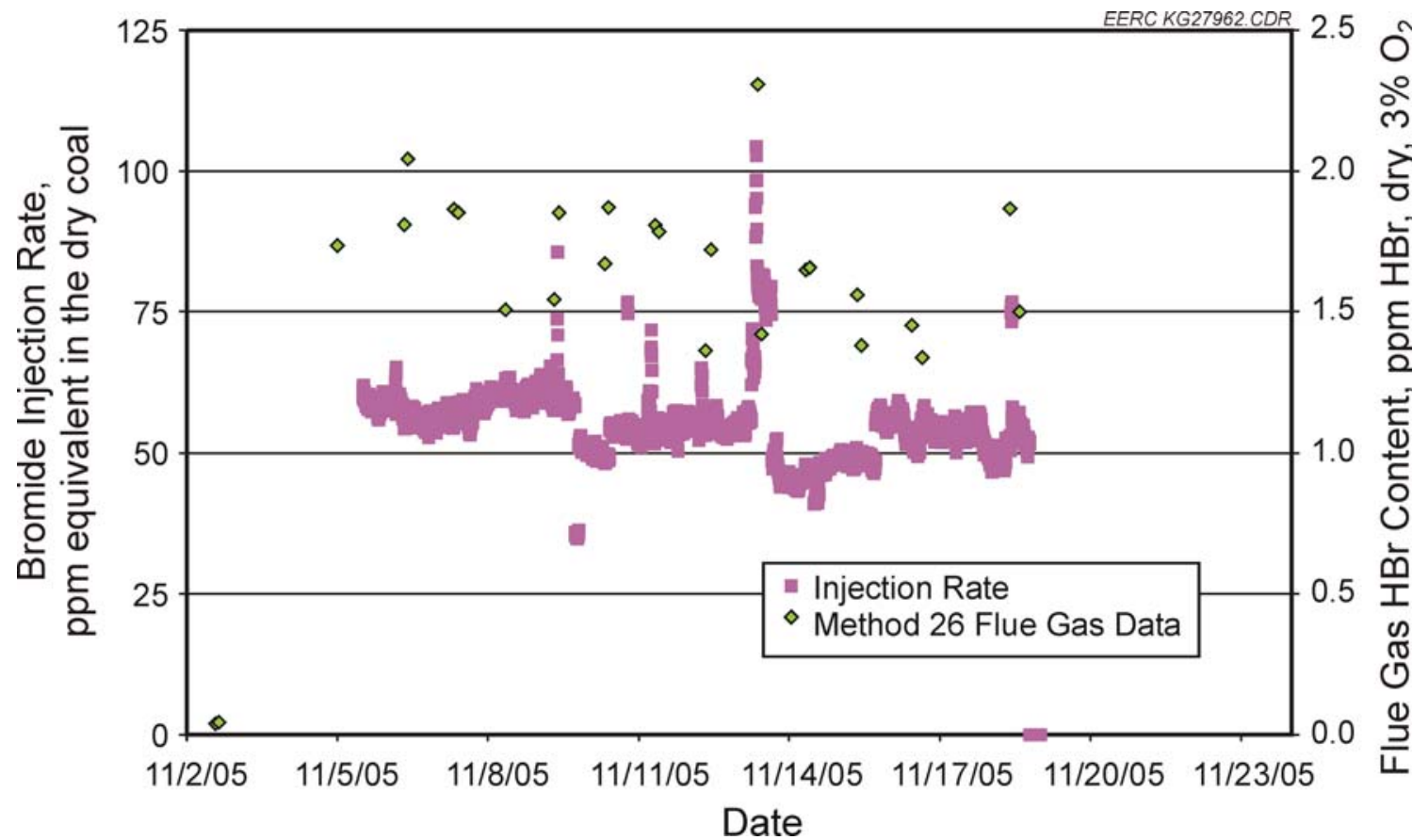

Figure 6-12. Actual additive injection rate of $\mathrm{CaBr}_{2}$ and M26 measurements during first 2-week long-term test period at MoSES.

Figure 6-12 also shows the results of daily Method 26 monitoring of flue gas bromide concentrations made daily during the test period (complete results are tabulated in Appendix C). During baseline (no $\mathrm{CaBr}_{2}$ injection), the flue gas $\mathrm{HBr}$ content was less than $0.09 \mathrm{ppm}$ (dry, $3 \% \mathrm{O}_{2}$ ). As noted in the description of $\mathrm{M} 26$, the method has a negative bias for the quantification of $\mathrm{Br}_{2}$ and a corresponding positive bias for $\mathrm{HBr}$. Results are reported for total $\mathrm{Br}$ as $\mathrm{HBr}$, but in reality some portion of the bromine may be present in flue gas as $\mathrm{Br}_{2}$. The $\mathrm{HBr}$ concentration of the flue gas averaged $1.7 \mathrm{ppm}\left(\mathrm{dry}, 3 \% \mathrm{O}_{2}\right)$ over the course of the first 2-week injection test period. Because of the fluctuations in the feed rate, the $\mathrm{HBr}$ concentration went as high as 2.3 and as low as $1.3 \mathrm{ppm}$.

The target injection rate for the second 2-week test period was initially $100 \mathrm{ppm} \mathrm{Br}$ equivalent in the coal. The injection rate was increased toward the end of the test period in an attempt to realize higher oxidation and removal rates of mercury. The actual injection rate is shown in Figure 6-13. Over the course of the 2-week test period (December 2-12, 2005), the actual injection rate averaged $113 \mathrm{ppm} \mathrm{Br}$ equivalent in the coal. The injection rate ranged from as low as $97 \mathrm{ppm}$ to as high as $158 \mathrm{ppm}$. On December 12, the injection rate was increased to $193 \mathrm{ppm} \mathrm{Br}$, and on December 13, the injection rate was further increased to an injection rate of $330 \mathrm{ppm} \mathrm{Br}$ equivalent in the coal. 


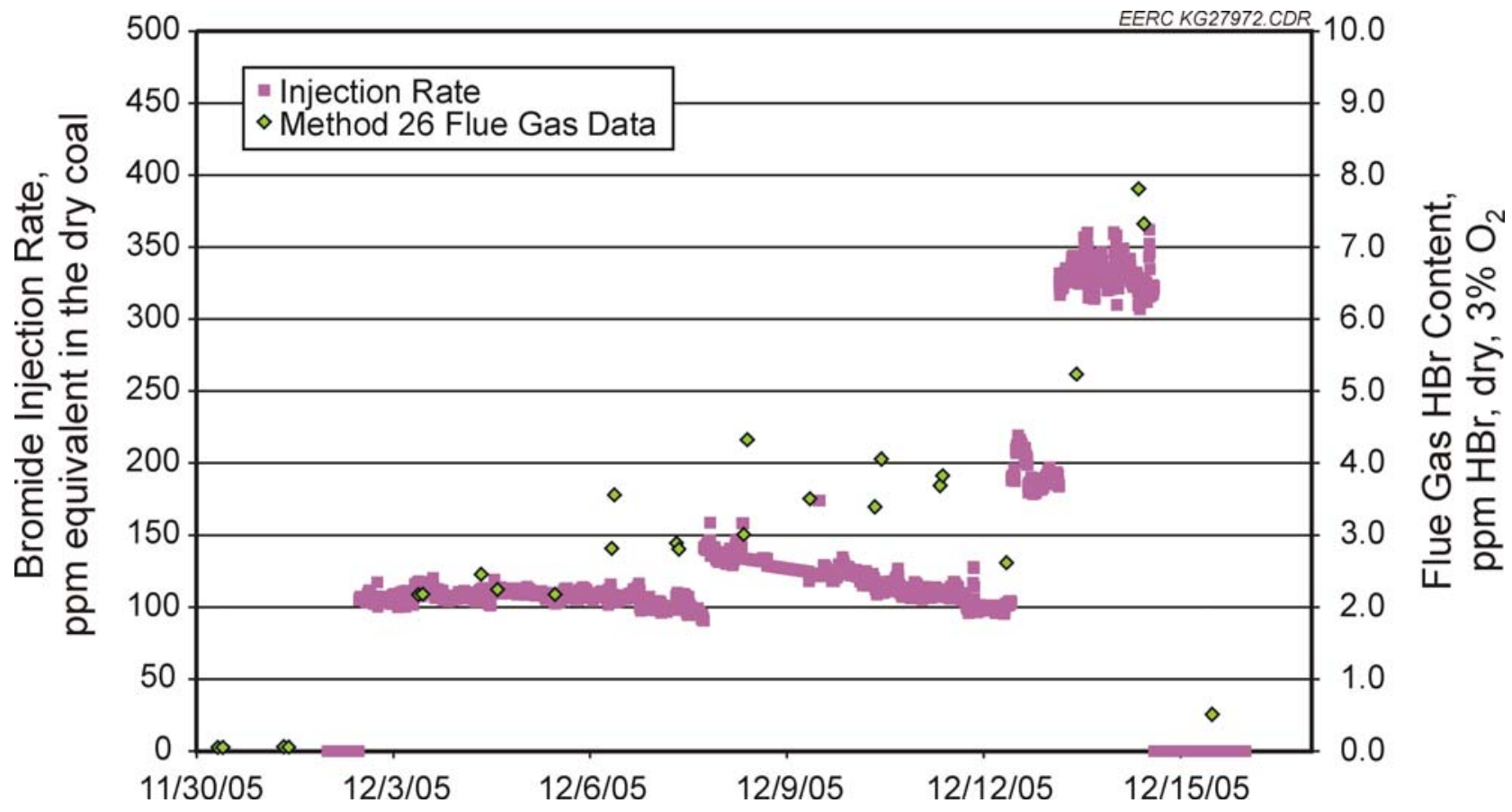

Figure 6-13. Actual additive injection rate of $\mathrm{CaBr}_{2}$ and $\mathrm{M} 26$ measurements during second 2-week long-term test period at MoSES.

Results of daily Method 26 measurements of flue gas bromide/bromine concentrations are also shown in Figure 6-13. The $\mathrm{Br}_{2}$ concentration of the flue gas was less than the detection limit of $0.02 \mathrm{ppm}$ during all of the long-term test periods. During baseline (no $\mathrm{CaBr}_{2}$ injection), the flue gas $\mathrm{HBr}$ content was less than $0.06 \mathrm{ppm}$ (dry, corrected to $3 \% \mathrm{O}_{2}$ ). The $\mathrm{HBr}$ concentration of the flue gas averaged $3.0 \mathrm{ppm}\left(\right.$ dry, $\left.3 \% \mathrm{O}_{2}\right)$ during the period when the average injection rate was $113 \mathrm{ppm} \mathrm{Br}$ equivalent in the coal. When the injection rate was increased to $193 \mathrm{ppm} \mathrm{Br}$ equivalent in the coal, the flue gas $\mathrm{HBr}$ concentration increased to $5.2 \mathrm{ppm}$; when the injection rate was further increased to $330 \mathrm{ppm} \mathrm{Br}$ equivalent in the coal, the flue gas $\mathrm{HBr}$ concentration increased to $7.6 \mathrm{ppm}$.

The theoretical flue gas $\mathrm{HBr}$ concentration was computed from the actual $\mathrm{CaBr}_{2}$ injection rate and the flue gas flow rate. The flue gas flow rate was estimated from an EPA Method 19 F-factor calculation. For the theoretical calculation, it was assumed that all of the injected bromide converts to flue gas HBr. Table 6-7 compares the average Method 26 measurement of flue gas $\mathrm{HBr}$ content to the theoretical prediction. The measured flue gas $\mathrm{HBr}$ concentration correlated relatively well with theoretical predictions. At the lowest injection rate, the measured concentration was $77 \%$ of the theoretical concentration. As the injection rate increases, the measured concentration decreased to only $57 \%$ of the theoretical concentration.

While most flue gas halogen monitoring was carried out nonisokinetically with the Method 26 mini-impinger method, one set of Method 26A samples was collected during 1 day of the 


\begin{tabular}{|c|c|c|c|}
\hline Average Injection & Average M26 & & \\
\hline $\begin{array}{l}\text { Rate, ppm } \mathrm{Br} \\
\text { equivalent in dry } \\
\text { coal }\end{array}$ & $\begin{array}{l}\text { Measurement of } \\
\text { Flue Gas } \mathrm{HBr} \text {, } \\
\text { ppm, dry, } 3 \% \mathrm{O}_{2}\end{array}$ & $\begin{array}{l}\text { Theoretical } \mathrm{HBr} \\
\text { Concentration, } \\
\text { ppm, dry, } 3 \% \mathrm{O}_{2}\end{array}$ & $\begin{array}{c}\text { Measured/Theoretical, } \\
\%\end{array}$ \\
\hline 55 & 1.7 & 2.2 & 77 \\
\hline 113 & 3.0 & 4.6 & 65 \\
\hline 193 & 5.2 & 7.8 & 66 \\
\hline 330 & 7.6 & 13.4 & 57 \\
\hline
\end{tabular}

injection test at $55 \mathrm{ppm} \mathrm{Br}$ equivalent in the coal. An isokinetic, full-traverse Method 26A was conducted at the ESP inlet, and an isokinetic, single-point Method 26A was conducted at the scrubber outlet locations. The results are summarized in Table 4-6. At the ESP inlet, the flue gas chlorine and bromine concentrations were below the detection limit of the method. The flue gas $\mathrm{HBr}$ concentration was $1.85 \mathrm{ppm} \mathrm{HBr}\left(\mathrm{dry}, 3 \% \mathrm{O}_{2}\right)$, which agreed well with the average flue gas $\mathrm{HBr}$ concentration measured with the nonisokinetic Method 26. The flue gas $\mathrm{HCl}$ concentration measured by Method 26A was $1.5 \mathrm{ppm} \mathrm{HCl}$, which was within the range of $\mathrm{HCl}$ concentrations measured with Method 26.

The Method 26A data at the scrubber outlet were problematic. The scrubber outlet Method 26A measurements were made in the same row of ports that the OH method and SCEM measurements were made. As already discussed in regard to the SCEM measurements, these ports were located directly above the scrubber exit, and FGD slurry was frequently accidentally pulled into the sample probes. Therefore, scrubber slurry contaminated the sample train at the FGD outlet, biasing the results high.

Both $\mathrm{HCl}$ and $\mathrm{HBr}$ should be scrubbed with nearly $100 \%$ efficiency by the FGD scrubber. Therefore, the expected scrubber outlet $\mathrm{HCl}$ and $\mathrm{HBr}$ concentrations should be close to zero. However, these Method 26A measurements indicated an average of $15.8 \mathrm{ppm} \mathrm{HCl}$ at the scrubber outlet, which is ten times higher than the inlet $\mathrm{HCl}$ concentration. The average Method $26 \mathrm{~A} \mathrm{HBr}$ concentration at the scrubber outlet was $0.9 \mathrm{ppm} \mathrm{HBr}$, which indicated that only $50 \%$ of the $\mathrm{HBr}$ was scrubbed. These Method 26A measurements are unrealistic; therefore, the results have been voided and are not reported in Table 6-8.

\begin{tabular}{|c|c|c|c|c|c|}
\hline Condition & $\begin{array}{l}\text { Location/ } \\
\text { Run No. }\end{array}$ & Date & Start Time & $\mathrm{HCl}$ & $\mathrm{HBr}$ \\
\hline $55 \mathrm{ppm} \mathrm{Br}$ & ESP Inlet 1 & $11 / 16 / 05$ & $8: 32$ & 1.56 & 1.84 \\
\hline $55 \mathrm{ppm} \mathrm{Br}$ & ESP Inlet 2 & $11 / 16 / 05$ & $10: 30$ & 1.40 & 1.87 \\
\hline \multirow[t]{2}{*}{$55 \mathrm{ppm} \mathrm{Br}$} & ESP Inlet 3 & $11 / 16 / 05$ & $12: 25$ & 1.46 & 1.86 \\
\hline & ESP Inlet & & Average & 1.49 & 1.86 \\
\hline
\end{tabular}




\subsubsection{Summary of Mercury Data from Long-Term Injection Test No. 1}

Figure 6-14 shows the SCEM total mercury concentrations measured at the ESP inlet, ESP outlet, and FGD outlet over the course of the first 2-week continuous injection test. Figures 6-15 through 6-17 show hourly averages of the total and elemental mercury concentrations measured at each of the three locations.

As noted in the discussion of the parametric test results, there was a negative bias in the measurement of total vapor-phase mercury upstream of the scrubber. This bias was caused by the presence of bromine in the flue gas. The bias was not confirmed until after the test program was completed and coal and ash mercury concentrations were available for data analysis. This bias is explored further at the end of this report, when the coal and ash mercury results are presented. For the long-term tests, the total vapor-phase mercury concentrations are presented in Figures 6-14, 6-15, and 6-16, with the caveat that the values are likely biased low at the scrubber inlet.

This bias does not exist at the scrubber outlet because the scrubber removes the flue gas bromine; therefore, the total mercury concentrations at the scrubber outlet should be reliable. Because the scrubber inlet elemental mercury concentrations matched well with the scrubber outlet total mercury concentrations, it is believed that the scrubber inlet elemental mercury concentrations were not subject to the measurement bias.

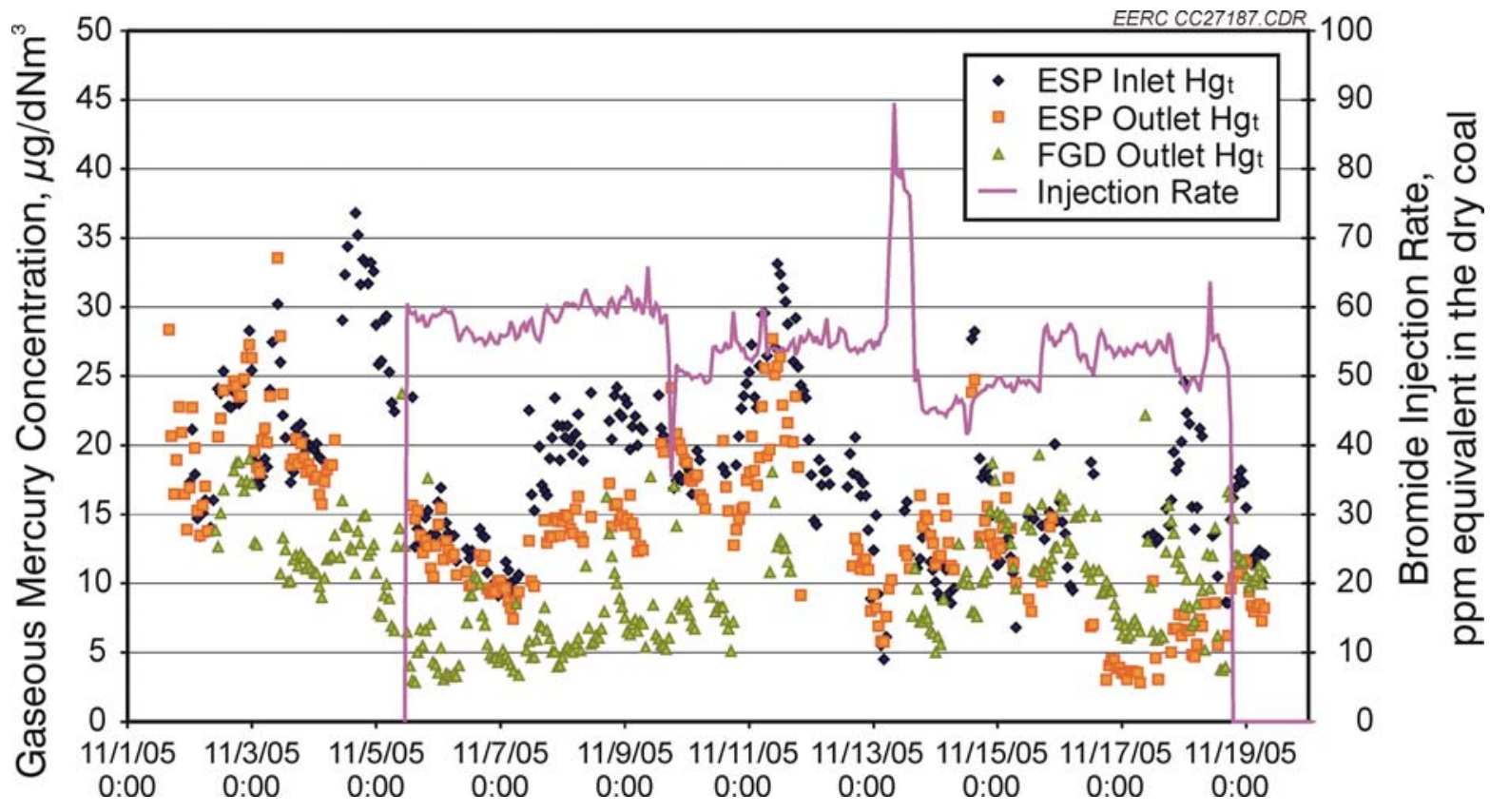

Figure 6-14. Hourly averaged total mercury concentration from SCEM data collected during $\mathrm{CaBr}_{2}$ injection at approximately $55 \mathrm{ppm} \mathrm{Br}$ equivalent in the dry coal, first 2-week long-term test at MoSES. 


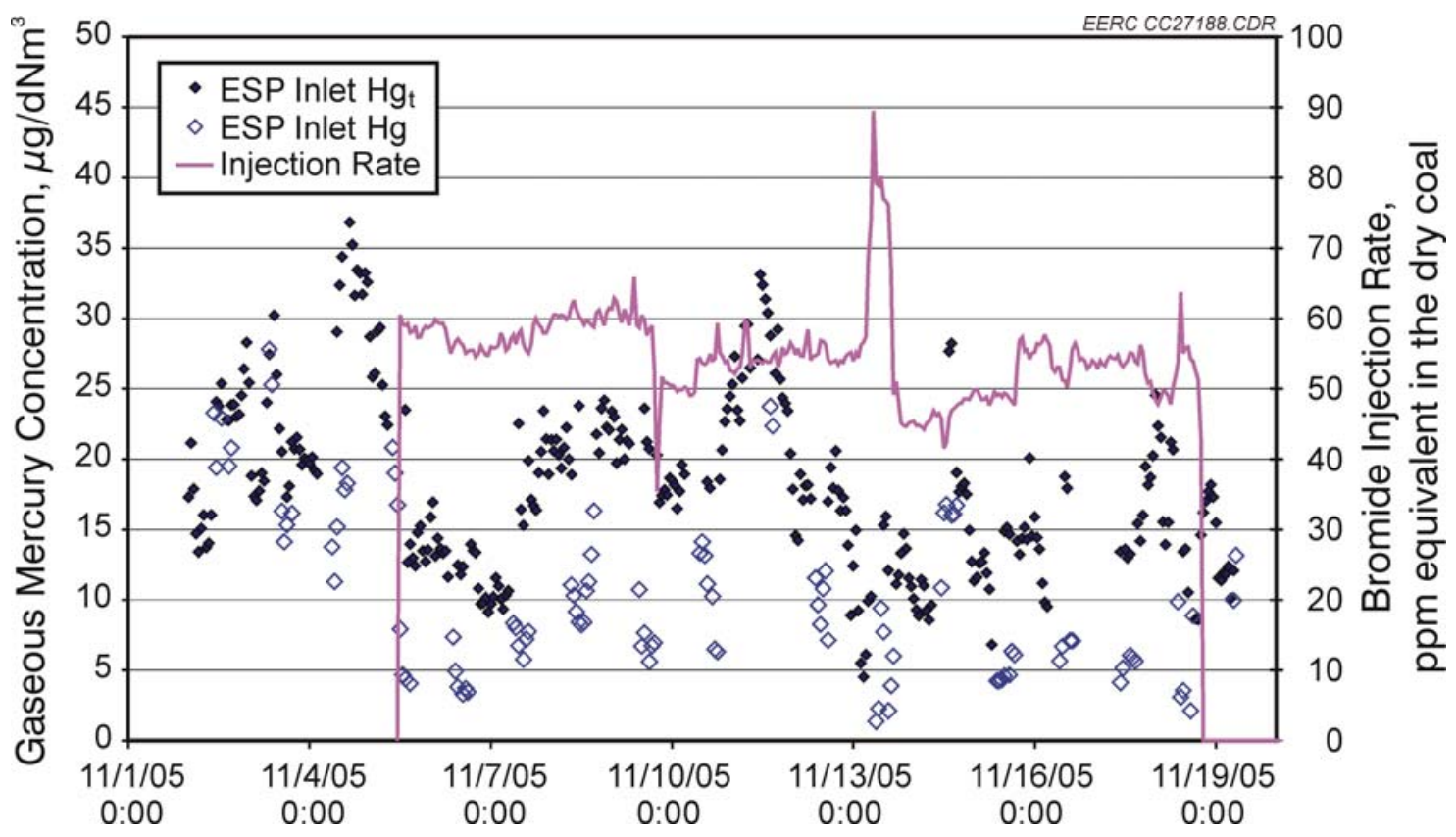

Figure 6-15. ESP inlet total and elemental mercury concentrations measured during $\mathrm{CaBr}_{2}$ injection at approximately $55 \mathrm{ppm} \mathrm{Br}$ equivalent in the dry coal, first 2-week long-term test at MoSES.

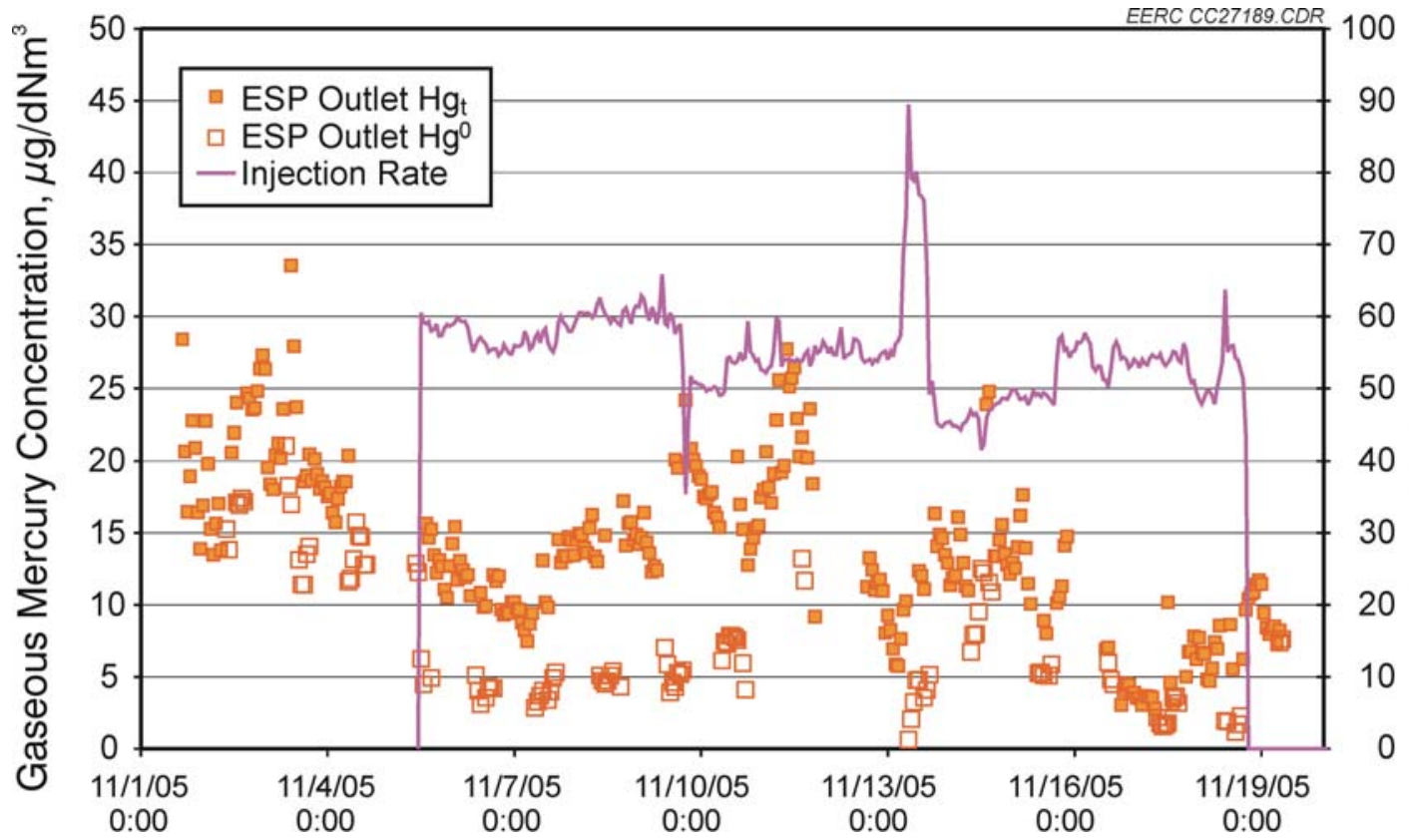

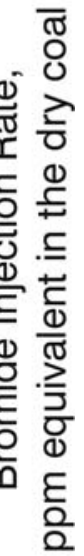

Figure 6-16. ESP outlet total and elemental mercury concentrations measured during $\mathrm{CaBr}_{2}$ injection at approximately $55 \mathrm{ppm} \mathrm{Br}$ equivalent in the dry coal, first 2-week long-term test at MoSES. 


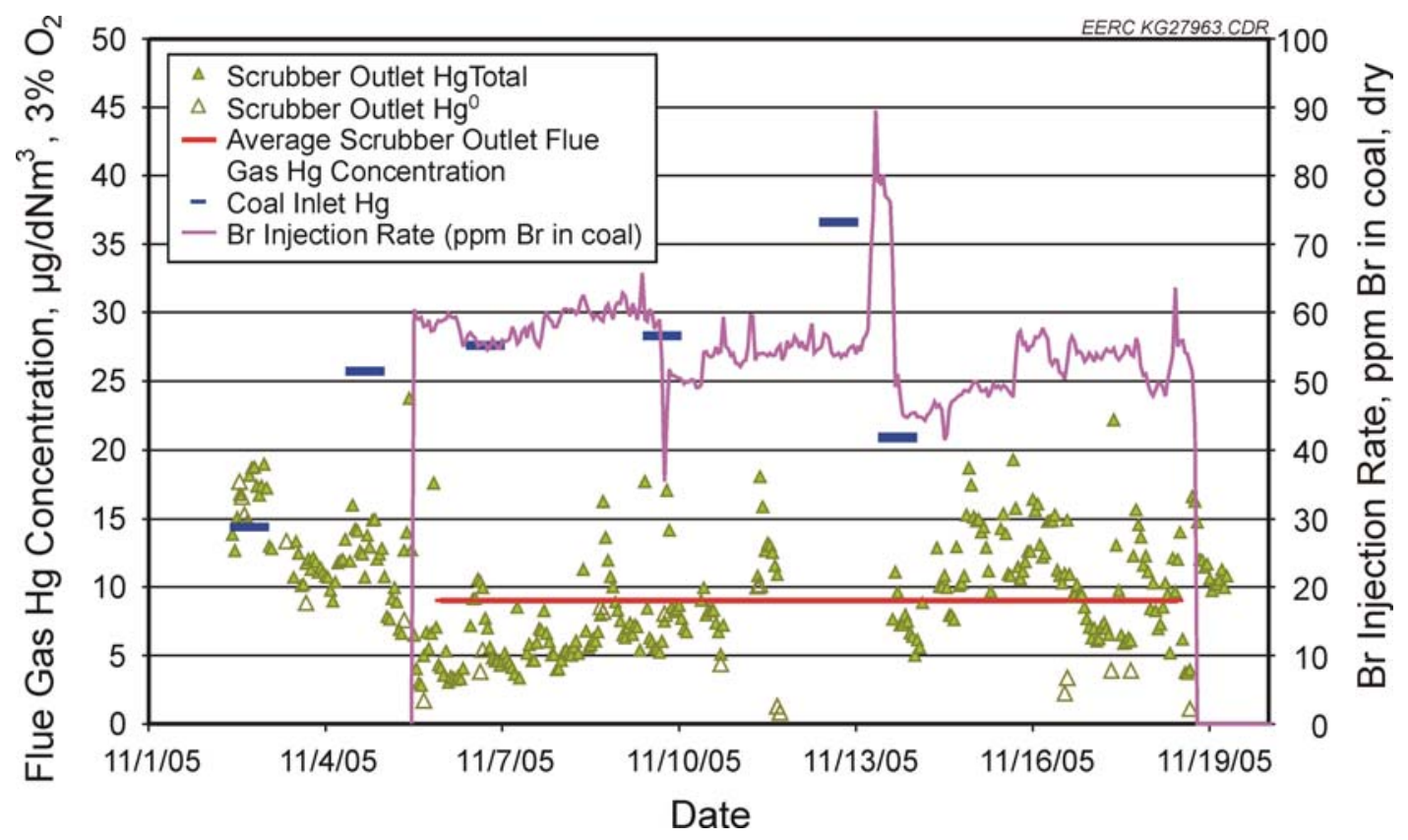

Figure 6-17. FGD outlet total and elemental mercury concentrations measured during $\mathrm{CaBr}_{2}$ injection at approximately $55 \mathrm{ppm} \mathrm{Br}$ equivalent in the dry coal, first 2-week long-term test at MoSES.

In the long-term data analysis, test average coal mercury values were used in place of the scrubber inlet total vapor-phase mercury concentrations measured by the SCEMs. The average coal mercury concentration for each entire test period was compared to the average SCEM data for the entire test period. Calculations were not made for individual days because of the difficulty in obtaining single coal samples that were representative of the flue gas mercury concentration. The coal mercury data were coupled with the inlet elemental mercury data to determine average mercury oxidation during the long-term injection test periods. Using this methodology, the vapor-phase mercury at the scrubber inlet was on average $67 \%$ oxidized at an injection rate of $55 \mathrm{ppm} \mathrm{Br}$ in the coal.

The weight fraction of Texas lignite coal fired by Unit 3 varied over the course of the first long-term test, ranging from $47 \%$ to $69 \%$. Figure 6-18 plots the percent oxidation of mercury at the ESP outlet and the percent removal of vapor-phase mercury across the FGD versus the weight fraction of Texas lignite fired. For the range of coal blends tested, there is no clear relationship between mercury oxidation/removal and the fraction of Texas lignite in the coal blend.

The average coal mercury data were coupled with the average scrubber outlet mercury concentration to quantify the overall mercury removal obtained during the long-term injection test period. Using this methodology, the vapor-phase mercury removal for the system was $65 \%$ at an injection rate of $55 \mathrm{ppm} \mathrm{Br}$ in the coal. However, over the 2-week test period at this injection rate, the scrubber outlet total mercury steadily increased, indicating that this removal rate was not sustained over the test period. 


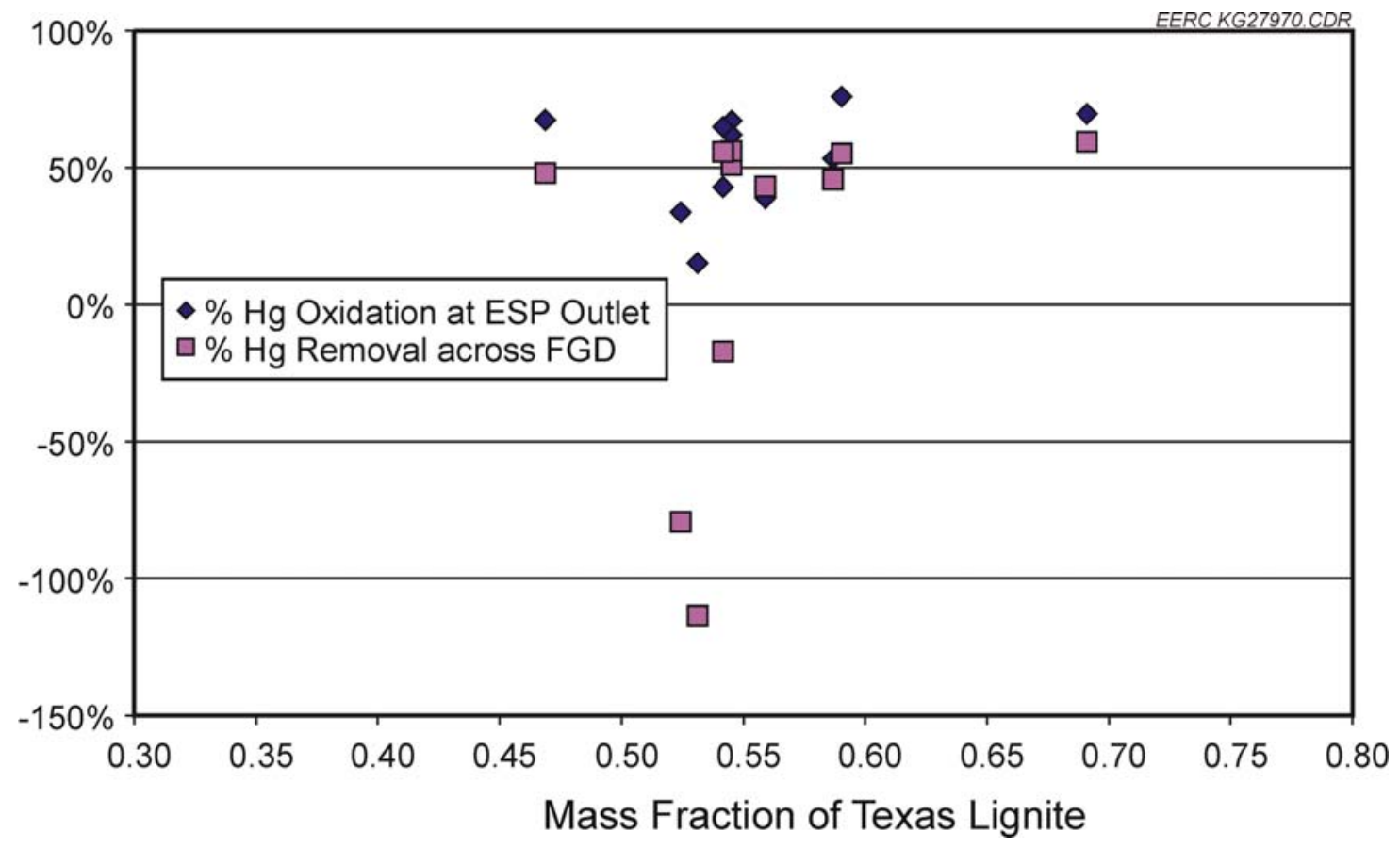

Figure 6-18. Effect of coal blend on oxidation and removal of flue gas mercury during long-term test No. 1.

Prior to the start of the injection test, the scrubber inlet elemental mercury concentration and the scrubber outlet total mercury concentration ranged from 10 to $20 \mu \mathrm{g} / \mathrm{dNm}^{3}\left(3 \% \mathrm{O}_{2}\right)$. During the first day of the injection test, the ESP inlet and ESP outlet elemental mercury concentrations decreased significantly, and the scrubber outlet mercury concentration decreased to $3-7 \mu \mathrm{g} / \mathrm{Nm}^{3}$. On the following 6 days, the scrubber outlet mercury concentration steadily increased to approximately $12 \mu \mathrm{g} / \mathrm{Nm}^{3}$; however, the ESP inlet concentration also increased during this time period. On November 11, 2005, the scrubber C module (which is the module on which SCEM measurements were being made) was taken out of service for 2 days. The scrubber $\mathrm{C}$ module was placed back in service on November 13. During the first 2 days back in service, the scrubber outlet mercury concentration steadily increased from 5 to $12 \mu \mathrm{g} / \mathrm{Nm}^{3}$. For the remainder of the test period (November 15 to 18 ), the scrubber outlet mercury concentrations remained in this range.

A possibility for this phenomenon could be a positive bias in the scrubber outlet extraction system, caused by the vaporization of mercury in the FGD slurry accidentally captured in the extraction loop. However, the scrubber outlet extraction loop was kept under constant supervision, cleaning, and maintenance during this test program. Typically, when the scrubber outlet mercury concentrations were biased high, the biased period lasted for a finite period of time on the order of a few to several hours. In this case, the elevated scrubber concentrations were maintained for several days, despite cleaning of the scrubber extraction loop. 
Figure 6-19 compares the scrubber outlet total mercury concentration to the scrubber inlet (ESP outlet) elemental mercury concentration. In a situation with complete removal of oxidized mercury and no mercury reemissions across the scrubber, these two values should be equal. Figure 6-19 shows that the values are equivalent for the baseline period prior to the injection test and for the first half of the injection test (through November 14, 2005). After that period, the scrubber outlet total mercury concentration was, at times, more than double the scrubber inlet elemental mercury concentration.

Appendix $\mathrm{K}$ measurements were made at the stack during the first long-term injection test. The results are provided in Table 6-9. The stack flue gas is composed of approximately $60 \%$ gas that is treated by the FGD scrubber and $40 \%$ gas that bypasses the FGD scrubber. To compare the SCEM data to the Appendix K data, a composite stack SCEM concentration was calculated as follows:

\section{Composite Stack SCEM Hg $=0.6 \times$ Scrubber Outlet SCEM + 0.4 $\times$ ESP Outlet Hg SCEM}

The composite stack concentration was alternatively calculated with the ESP inlet (rather than ESP outlet) mercury concentration from the SCEM. Figure 6-20 shows a comparison of both of these methodologies to the Appendix K data. All three data sets show the same trend in the concentration over the course of the test program. The composite concentration calculated from the ESP inlet data matches very well with the Appendix K data. All seven runs were within

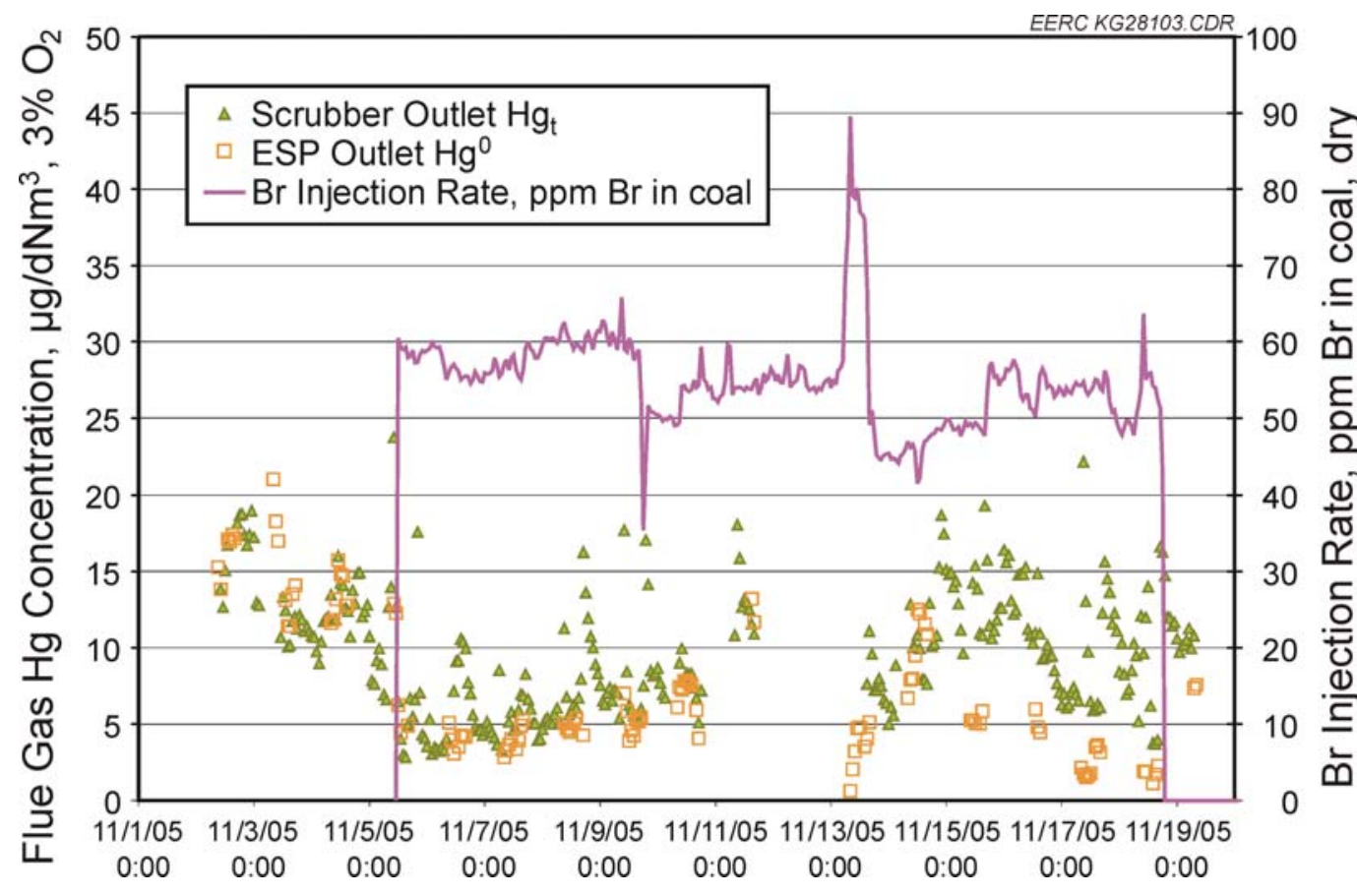

Figure 6-19. Comparison of scrubber inlet elemental mercury concentration to scrubber outlet total mercury concentration during the first long-term $\mathrm{CaBr}_{2}$ injection test at MoSES. 
Table 6-9. Appendix K Measurements at Unit 3 Stack During Long-Term Test No. 1

\begin{tabular}{lcccc}
\hline Condition & Date & Start Time & End Time & $\begin{array}{c}\text { Stack Flue Gas Hg Concentration } \\
\left(\mu \mathrm{g} / \mathrm{dNm}^{3} \text { at } 3 \% \mathrm{O}_{2}\right)^{*}\end{array}$ \\
\hline $55 \mathrm{ppm}$ & $11 / 08 / 05$ & $09: 45$ & $13: 45$ & 9.6 \\
$55 \mathrm{ppm}$ & $11 / 08 / 05$ & $09: 45$ & $13: 45$ & 9.5 \\
$55 \mathrm{ppm}$ & $11 / 09 / 05$ & $13: 06$ & $17: 06$ & 14.5 \\
$55 \mathrm{ppm}$ & $11 / 09 / 05$ & $13: 06$ & $17: 06$ & 12.6 \\
$55 \mathrm{ppm}$ & $11 / 11 / 05$ & $10: 35$ & $14: 35$ & 21.2 \\
$55 \mathrm{ppm}$ & $11 / 11 / 05$ & $10: 35$ & $14: 35$ & 18.9 \\
$55 \mathrm{ppm}$ & $11 / 14 / 05$ & $13: 50$ & $17: 50$ & 15.4 \\
$55 \mathrm{ppm}$ & $11 / 14 / 05$ & $13: 50$ & $17: 50$ & 14.8 \\
$55 \mathrm{ppm}$ & $11 / 16 / 05$ & $08: 07$ & $12: 07$ & 14.4 \\
$55 \mathrm{ppm}$ & $11 / 16 / 05$ & $08: 07$ & $12: 07$ & 13.6 \\
$55 \mathrm{ppm}$ & $11 / 16 / 05$ & $12: 41$ & $16: 41$ & 15.5 \\
$55 \mathrm{ppm}$ & $11 / 16 / 05$ & $12: 41$ & $16: 41$ & 13.9 \\
$55 \mathrm{ppm}$ & $11 / 17 / 05$ & $11: 35$ & $15: 35$ & 10.0 \\
$55 \mathrm{ppm}$ & $11 / 17 / 05$ & $11: 35$ & $15: 35$ & 9.0 \\
$55 \mathrm{ppm}$ & $11 / 18 / 05$ & $08: 28$ & $12: 28$ & 13.8 \\
$55 \mathrm{ppm}$ & $11 / 18 / 05$ & $08: 28$ & $12: 28$ & 14.6 \\
\hline
\end{tabular}

* Oxygen concentrations were not originally reported with Appendix $\mathrm{K}$ measurements. Assumed $7 \% \mathrm{O}_{2}$ concentration on the stack, based on a weighted average of $\mathrm{O}_{2}$ concentrations measured by EPRI SCEMs at the ESP outlet and FGD outlet.

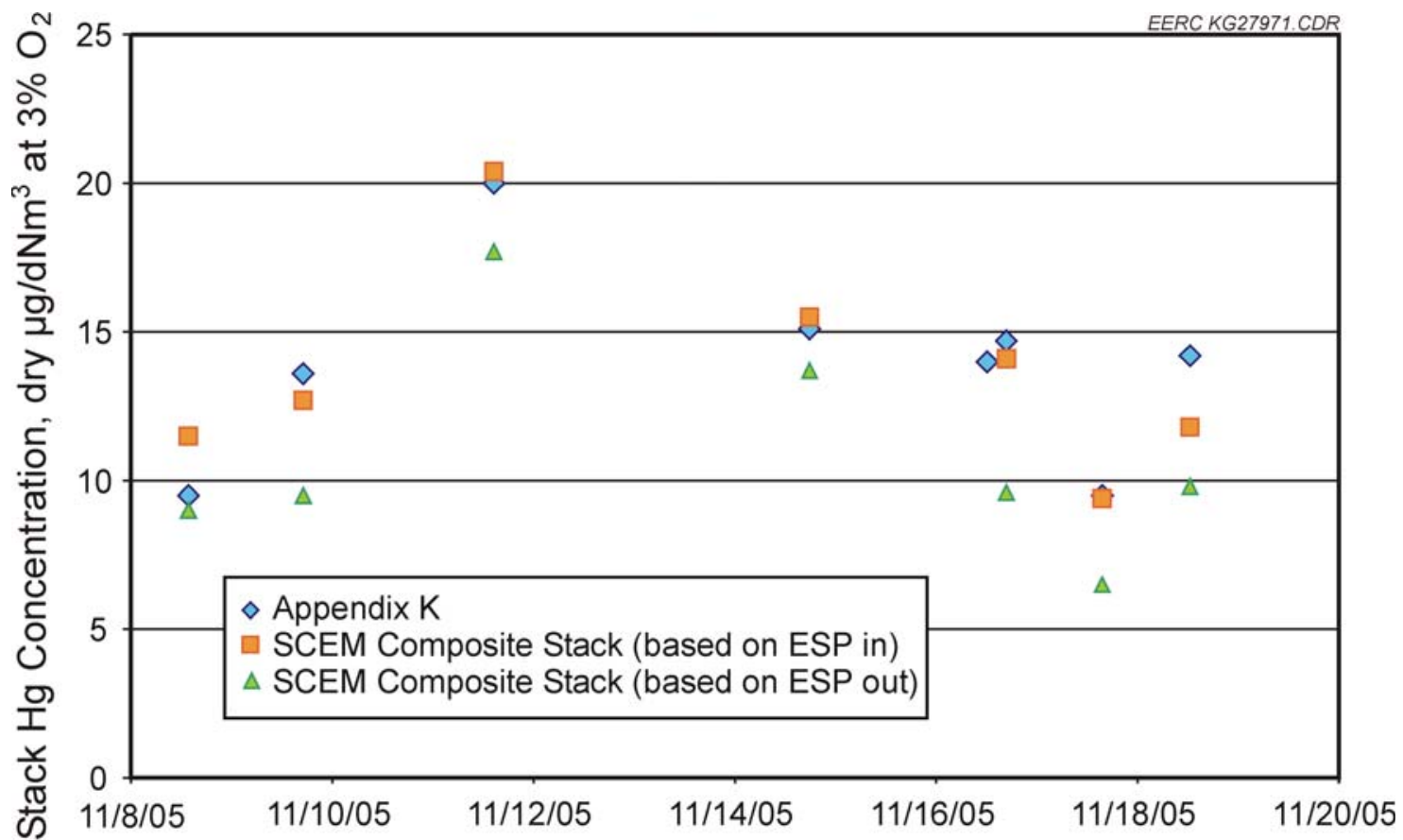

Figure 6-20. Comparison of Appendix K data with SCEM data. 
$\pm 20 \%$ of each other, with five of the seven runs within $\pm 7 \%$ of each other. When the ESP outlet SCEM data are used to calculate the composite stack concentration, the composite stack data are within $-5 \%$ to $-35 \%$ of the Appendix $\mathrm{K}$ data. The agreement between the Appendix $\mathrm{K}$ and SCEM data indicate that elevated mercury concentrations measured by the SCEM at the scrubber outlet may have been real and not the result of a sampling artifact.

Based on a preliminary evaluation of these data made immediately following the conclusion of the first 2-week injection test, the project team elected to conduct the second 2-week injection test at double the $\mathrm{CaBr}_{2}$ injection rate. The results for the second 2-week injection test are presented in the next subsection.

\subsubsection{Summary of Mercury Data from Long-Term Injection Test No. 2}

The second long-term mercury control test involved $\mathrm{CaBr}_{2}$ injection at an average $113 \mathrm{ppm}$ $\mathrm{Br}$ equivalent in dry coal. Figure 6-21 shows the hourly averages of the SCEM total mercury concentrations measured at the ESP inlet, ESP outlet, and FGD outlet over the course of the second 2-week continuous-injection test. Figures 6-22 through 6-24 show the total and elemental mercury concentrations measured at each of the three locations. As noted with the parametric and long-term tests, there was a negative bias in the measurement of total mercury concentrations at the ESP inlet and ESP outlet when bromine was present in the flue gas. The discussion of the first long-term injection test contains details on how this bias was accounted for in the presentation of the results.

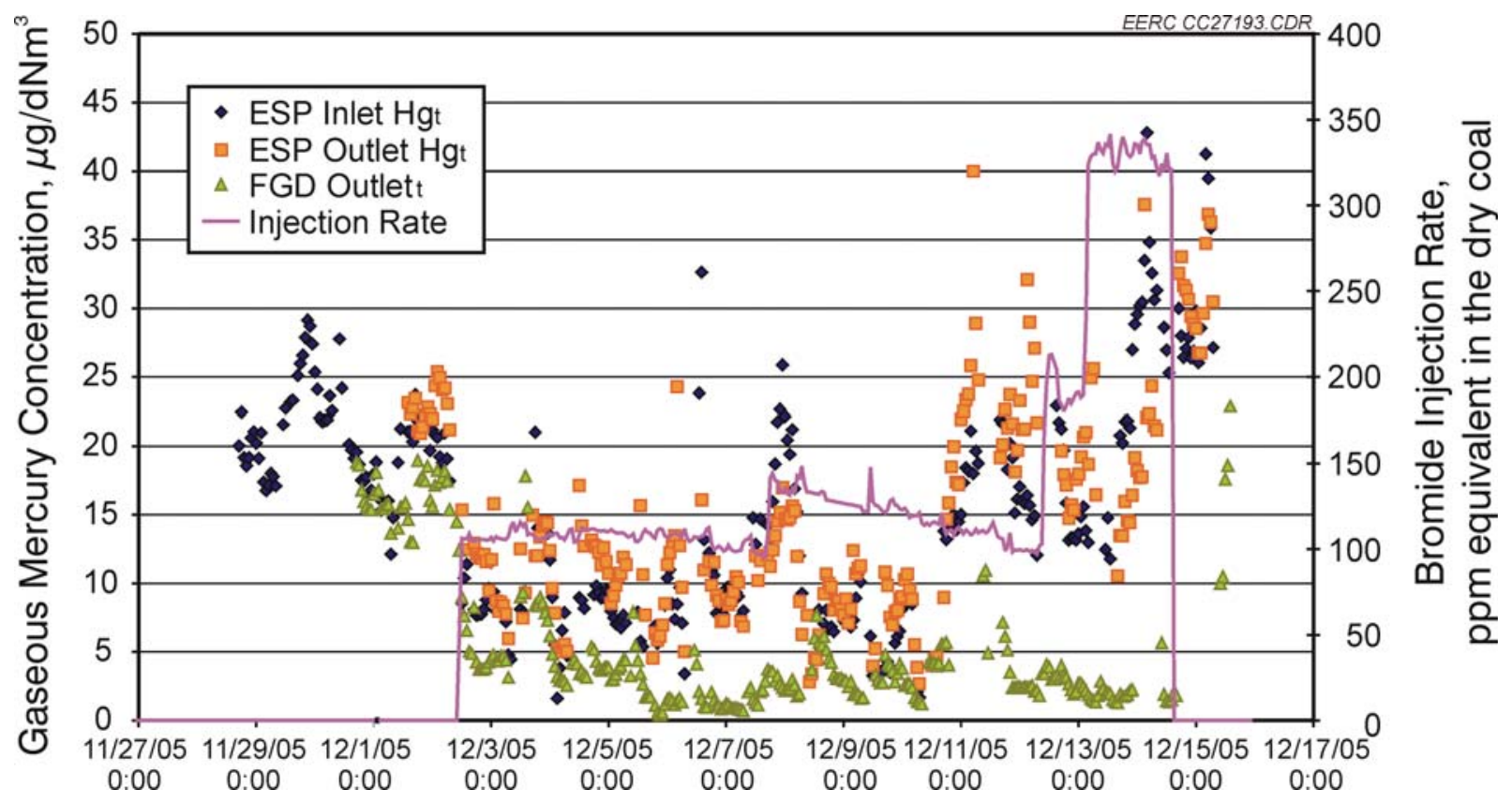

Figure 6-21. Hourly averaged SCEM data collected during the second long-term $\mathrm{CaBr}_{2}$ injection test at MoSES. 


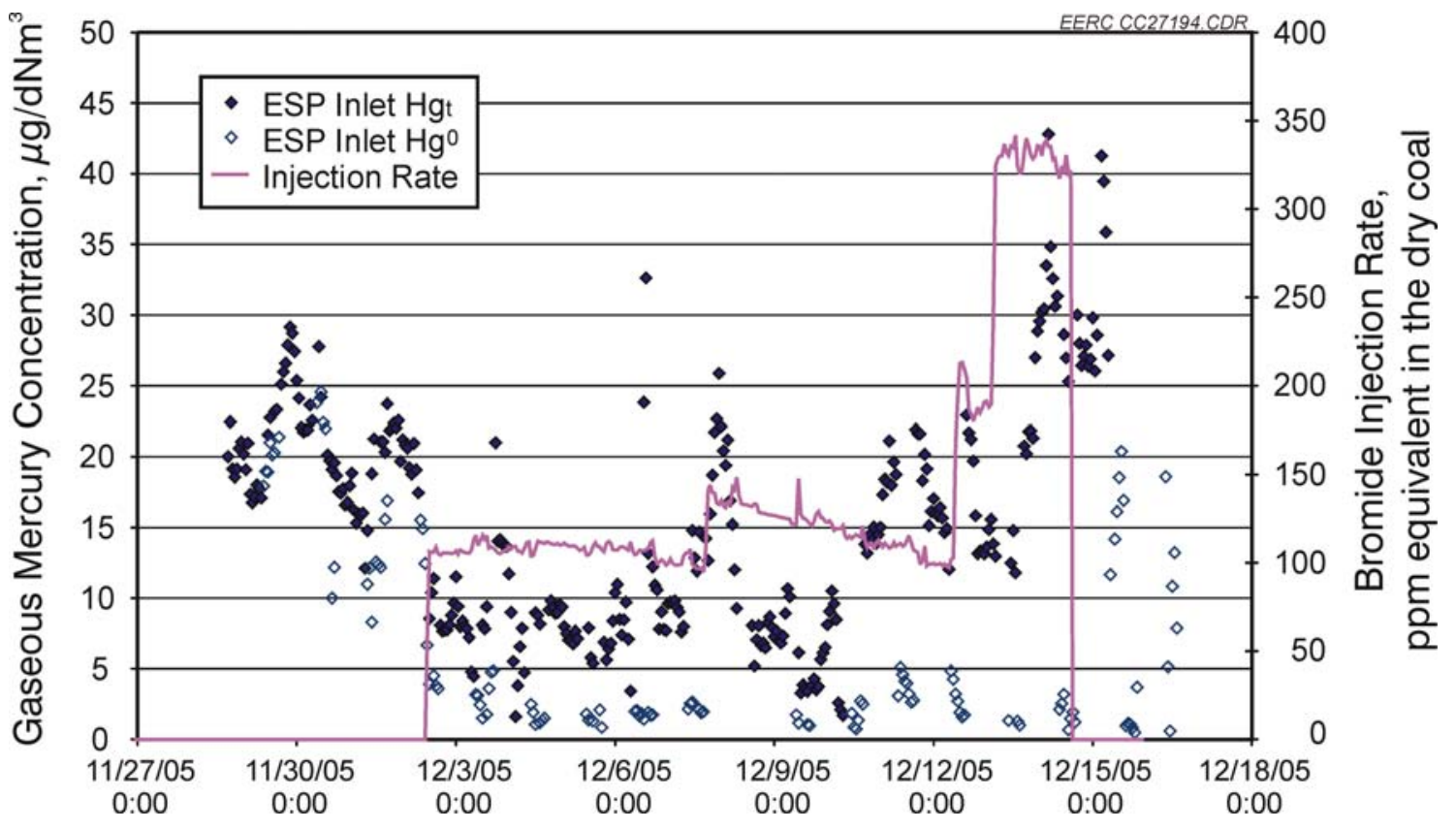

Figure 6-22. ESP inlet total and elemental mercury concentrations measured during the second long-term $\mathrm{CaBr}_{2}$ injection test at MoSES.

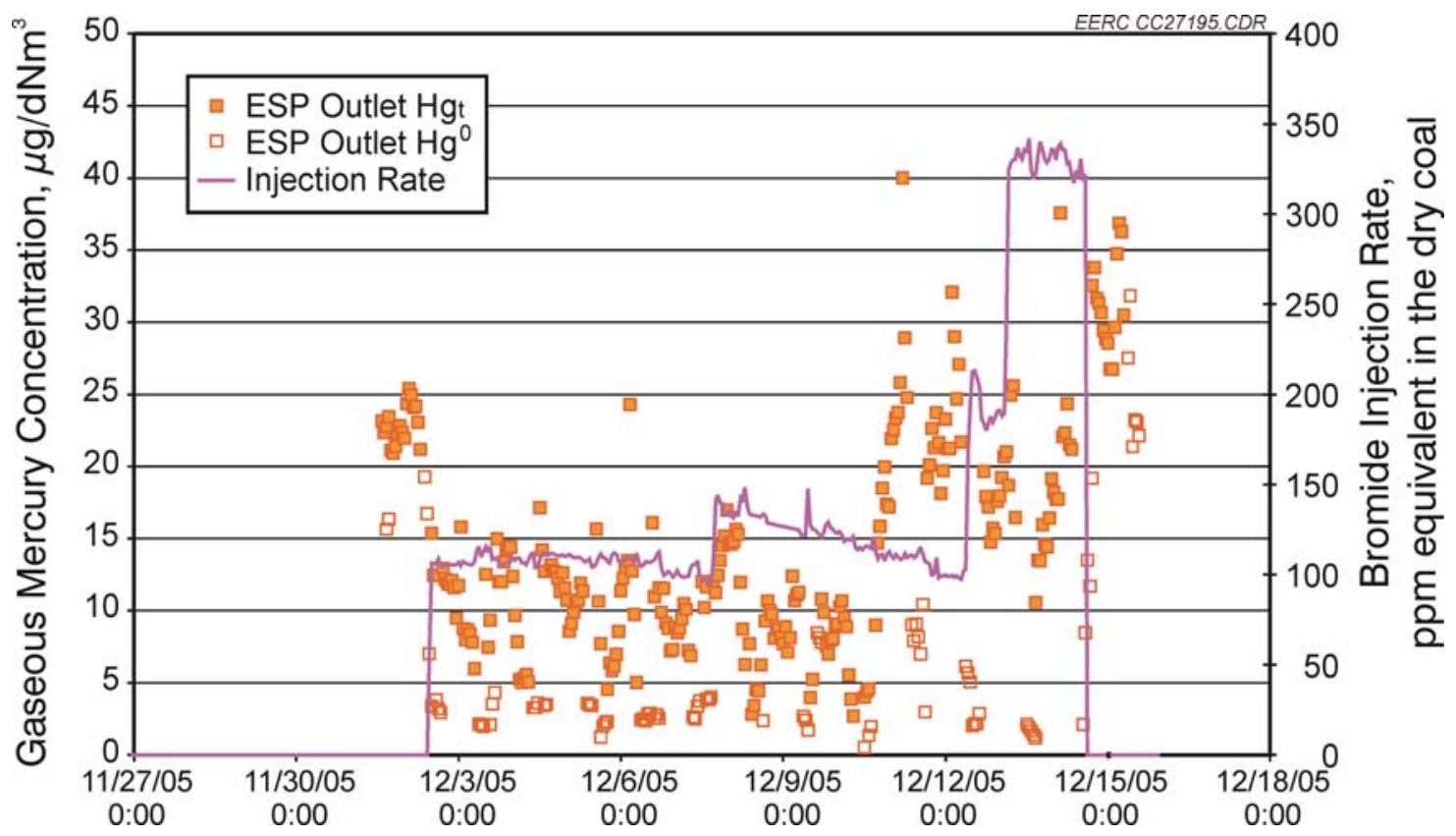

Figure 6-23. ESP outlet total and elemental mercury concentrations measured during the second long-term $\mathrm{CaBr}_{2}$ injection test at MoSES. 


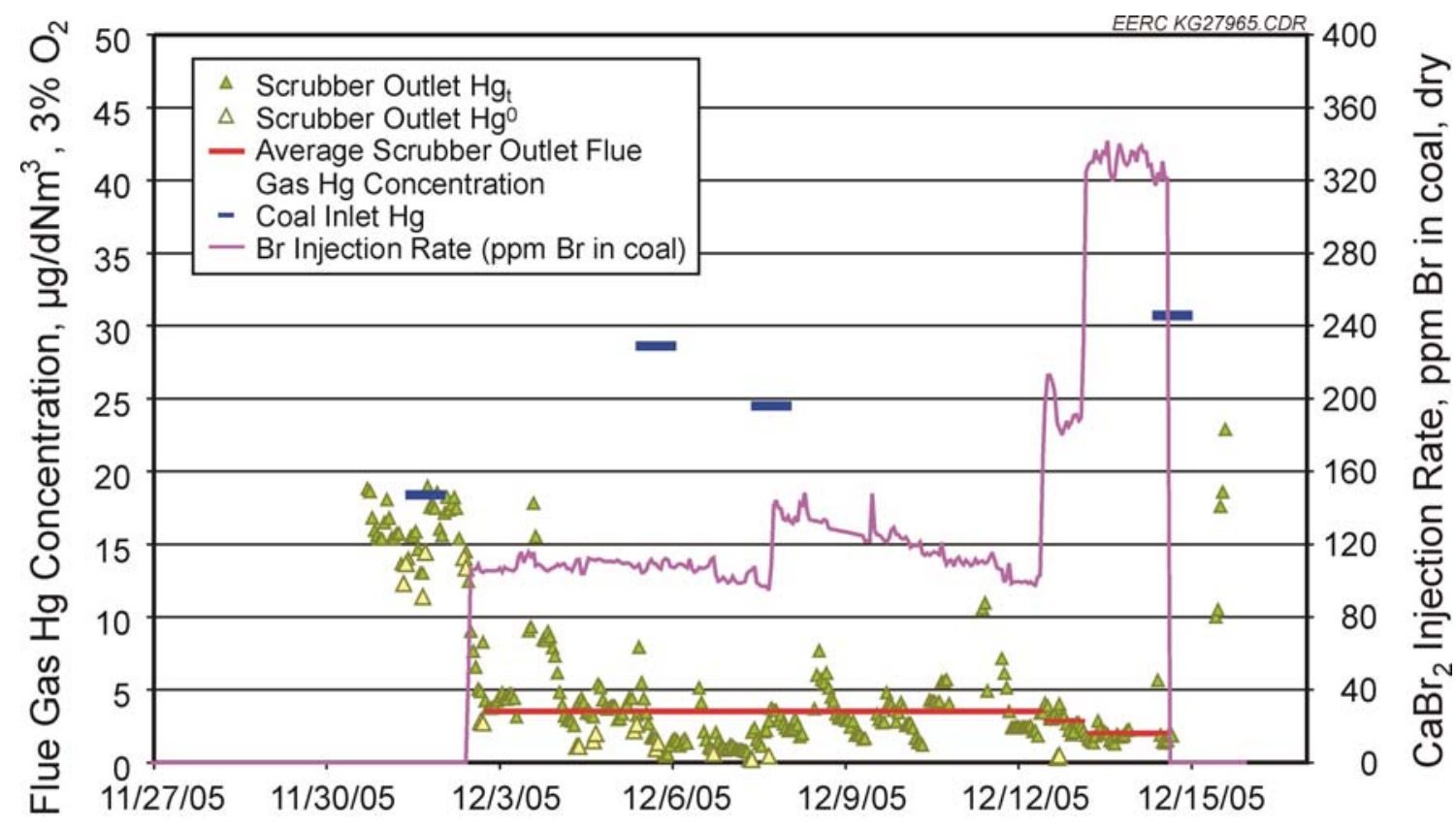

Figure 6-24. FGD outlet total and elemental mercury concentrations measured during the second long-term $\mathrm{CaBr}_{2}$ injection test at MoSES.

Prior to the start of the injection test, the ESP outlet elemental mercury concentrations and the scrubber outlet total mercury concentrations ranged from 12 to $19 \mu \mathrm{g} / \mathrm{dNm}^{3}\left(3 \% \mathrm{O}_{2}\right)$. During the first day of the injection test, the ESP inlet and ESP outlet elemental mercury concentrations decreased significantly, and the scrubber outlet mercury concentration decreased to $4 \mu \mathrm{g} / \mathrm{Nm}^{3}$. During the next 10 days of the injection test, in which the injection rate averaged $113 \mathrm{ppm} \mathrm{Br}$ equivalent in the coal, the scrubber outlet mercury concentration ranged from 0.5 to $11 \mu \mathrm{g} / \mathrm{Nm}^{3}$. However, the scrubber outlet mercury concentration was typically less than $5 \mu \mathrm{g} / \mathrm{Nm}^{3}$; only during short periods of a few hours did the scrubber outlet mercury concentration exceed $5 \mu \mathrm{g} / \mathrm{Nm}^{3}$. A 1-day test showed that increasing the injection rate to $193 \mathrm{ppm}$ Br equivalent in the coal resulted in the scrubber outlet concentration being maintained below $4 \mu \mathrm{g} / \mathrm{Nm}^{3}$. The injection rate was increased to $330 \mathrm{ppm} \mathrm{Br}$ equivalent in the coal, and the scrubber outlet mercury concentration was maintained below $3 \mu \mathrm{g} / \mathrm{Nm}^{3}$ for the 2-day duration of this injection rate. Figure 6-25 compares the scrubber outlet elemental mercury concentration to the scrubber outlet total mercury concentration. Throughout the 2-week test period, the two values are nearly equivalent, indicating little to no mercury reemissions. The average FGD outlet mercury concentrations measured during each test period are summarized in Table 6-10.

The average oxidation of mercury during each tested injection rate is shown in Table 6-11. All oxidation percentages are calculated as the oxidized mercury concentration at the scrubber inlet averaged over the test period divided by the coal mercury concentration. At an injection rate of $55 \mathrm{ppm} \mathrm{Br}$ in the coal (first long-term test), the mercury in the scrubber inlet flue gas was $67 \%$ oxidized. At an injection rate of $113 \mathrm{ppm} \mathrm{Br}$ equivalent in the coal, the oxidation of 


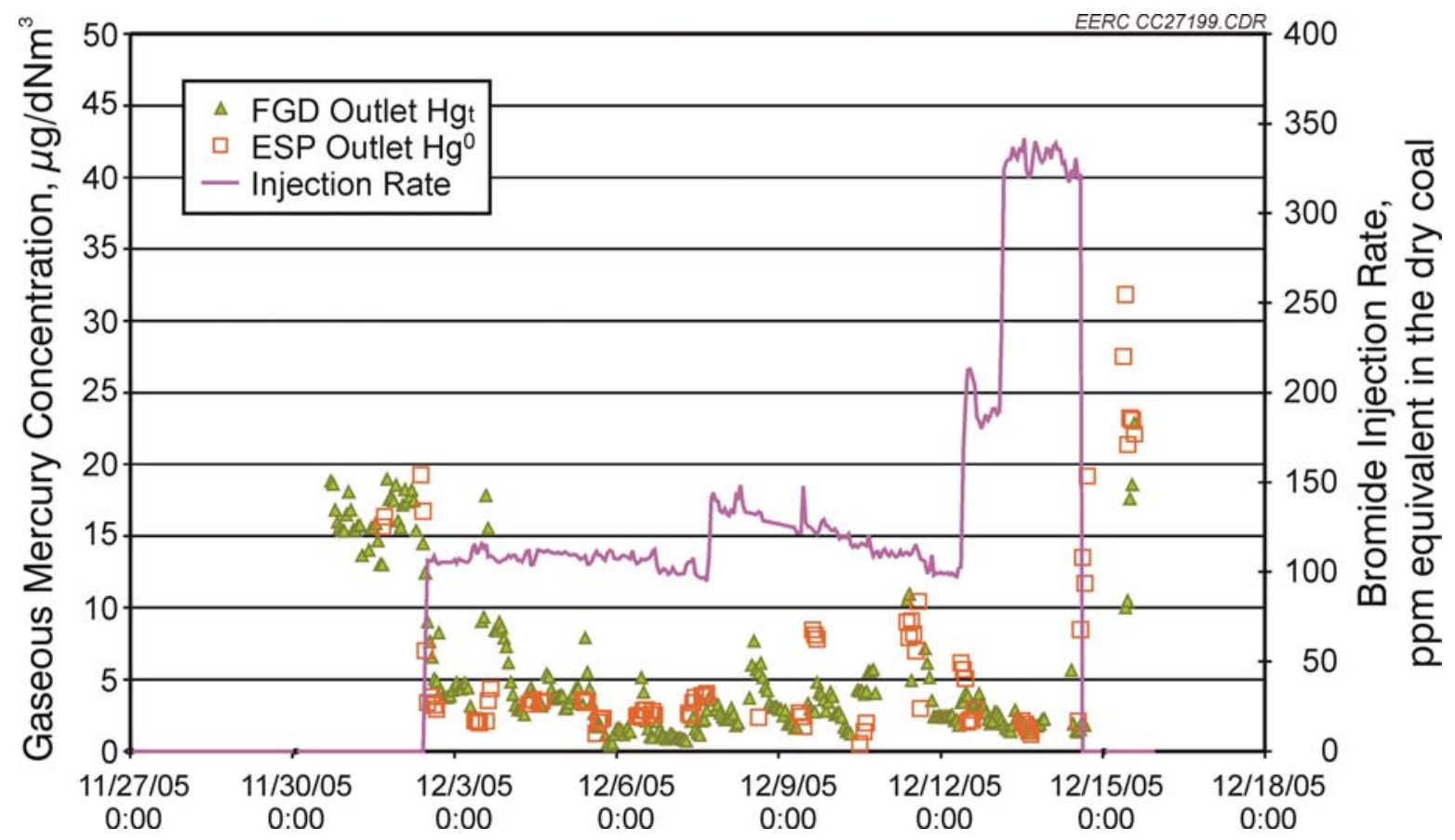

Figure 6-25. Comparison of ESP outlet elemental mercury concentrations to scrubber outlet total mercury concentrations during the second long-term $\mathrm{CaBr}_{2}$ injection test at MoSES.

Table 6-10. Average FGD Outlet Mercury Concentrations Measured by SCEM During the Long-Term Injection Tests at MoSES

\begin{tabular}{lc}
\hline $\mathrm{CaBr}_{2}$ Injection Rate, & $\begin{array}{c}\text { Average FGD Outlet } \mathrm{Hg} \\
\text { ppm, dry, }\end{array}$ \\
$3 \% \mathrm{O}_{2}$ & \begin{tabular}{c} 
Concentration, $\mu \mathrm{g} / \mathrm{dNm}^{3}, 3 \% \mathrm{O}_{2}$ \\
\hline 55
\end{tabular} \\
113 & 3.0 \\
193 & 2.9 \\
330 & 2.0 \\
\hline
\end{tabular}

Table 6-11. Ratio of Oxidized Mercury in Flue Gas to Average Coal Mercury Content During the Long-Term Injection Tests

\begin{tabular}{lcc}
\hline $\mathrm{CaBr}_{2}$ Injection Rate, & $\begin{array}{c}\text { \% Oxidation of } \\
\text { Hg at Scrubber } \\
\text { Inlet } \mathrm{Br} \text { in the coal }\end{array}$ & $\begin{array}{c}\text { \% Removal of Hg at } \\
\text { Scrubber Outlet } \\
\text { (compared to coal Hg) }\end{array}$ \\
\hline 55 & 67 & 65 \\
113 & 85 & 86 \\
193 & 91 & 89 \\
330 & 93 & 92 \\
\hline
\end{tabular}


mercury at the ESP inlet was an average $85 \%$. Increasing the injection rate to $193 \mathrm{ppm} \mathrm{Br}$ equivalent in the coal resulted in a slightly higher oxidation percentage of 91\%. Further increasing the $\mathrm{CaBr}_{2}$ injection rate to $330 \mathrm{ppm}$ in the coal did not result in significantly higher oxidation of mercury.

The removal of mercury across the system (computed as average scrubber outlet total mercury concentration compared to coal mercury concentration) is also shown in Table 6-11. The oxidation of mercury at the scrubber inlet compares very favorably with the removal of mercury across the scrubber. At an injection rate of $113 \mathrm{ppm} \mathrm{Br}$ in the coal, $86 \%$ of the coal mercury was removed by the system. Tripling the bromide injection rate resulted in mercury removals just over $90 \%$.

\subsection{BALANCE-OF-PLANT EFFECTS OF HG CONTROL TECHNOLOGIES AT MRY UNIT 2}

\subsection{Corrosion Probe Characterization}

Baseline coupons were exposed to flue gas for 8 weeks during routine power plant operating conditions. $\mathrm{Hg}$ control coupons were exposed to flue gas for 6 weeks during the chemical and PAC injection testing conditions. On installation, uncooled coupon skin temperatures were approximately $800^{\circ}$ and $775^{\circ} \mathrm{F}$ at the ECM and AHI, respectively. Cooling airflows for the ECM, AHI, and AHO coupons were established to maintain coupon skin temperatures at approximately $460^{\circ}, 485^{\circ}$, and $270^{\circ} \mathrm{F}$, respectively. Temperatures were logged with a computer at 5-minute intervals during the coupon testing. Temperatures fluctuated based on flue gas temperature because the cooling airflow was not constantly being adjusted.

The baseline coupons were in the boiler from 11/18/04 16:34 to $1 / 17 / 0513: 12$. A summary of the temperature data for the baseline coupon testing is given in Table 7-1. Some temperature information was not obtained because of problems with the data logger. During the period from $11 / 22 / 0410: 43$ to $11 / 24 / 0412: 08$, the compressed air supply to the AHO probe was apparently reduced or interrupted, because the coupon skin temperature was abnormally high and the exit cooling-air temperature was much lower. During three brief periods between 11/30/04 and $12 / 13 / 04$, both the coupon skin temperature and exiting cooling-air temperature went much lower than normal, and the coupon skin temperature approximated its cooling air temperature, indicating reduced/interrupted flue gas flow or excess cooling air to the ECM and AH probes.

The $\mathrm{Hg}$ control coupons were tested from $4 / 5 / 05$ to $5 / 17 / 05$. However, most of the temperature data were lost as a result of computer hard disk failure. Coupon temperature data were retained only for the period of 4/11/05 7:03 to 4/15/05 5:19, as summarized in Table 7-2. Coupon temperatures during this short period were relatively stable. 
Table 7-1. Baseline Coupon Temperatures, ${ }^{\circ} \mathrm{F}$

\begin{tabular}{lccccrc}
\hline & ECM & ECM & AHI & AHI Cooling & AHO & AHO \\
& Coupon & Cooling Air & Coupon & Air & Coupon & Cooling Air \\
\hline Av. & 472.2 & 235.3 & 453.3 & 250.0 & 260.9 & 158.0 \\
Min. & 66.4 & 58.7 & 66.6 & 59.1 & 55.1 & 16.3 \\
Max. & 878.3 & 353.3 & 517.5 & 307.7 & 368.7 & 209.8 \\
St. Dev. & 97.6 & 38.2 & 73.4 & 35.5 & 65.9 & 44.3 \\
\hline
\end{tabular}

Table 7-2. Hg Control Coupon Temperatures, ${ }^{\circ} \mathrm{F}$

\begin{tabular}{lcccccc}
\hline & ECM & ECM & AHI & AHI & AHO & \\
& Coupon & Cooling Air & Coupon & Cooling Air & Coupon & AHO Cooling Air \\
\hline Av. & 435.7 & 266.1 & 456.0 & 264.4 & 245.3 & 127.2 \\
Min. & 414.3 & 252.7 & 430.7 & 250.0 & 220.1 & 97.4 \\
Max. & 457.0 & 281.2 & 478.7 & 276.8 & 274.6 & 138.9 \\
St. Dev. & 8.1 & 4.9 & 8.2 & 4.7 & 11.5 & 5.0 \\
\hline
\end{tabular}

\subsubsection{Economizer Coupons}

Compared in Figure 7-1 are backscattered electron images (BSEIs) of the steel-ash deposit interface for the curved and flat sections of the ECM baseline and Hg control coupons. The brightness and contrast in a BSEI is a function of average atomic number. Consequently, the brightest feature on the right side of each picture is the steel coupon, the gray area is a deposit layer, and the darkest gray area on the left side is epoxy in which the coupon section was mounted. For both the baseline and Hg control ECM coupons, a portion of the deposit occurs as closely packed spheres. The baseline coupon has a smooth surface, whereas the $\mathrm{Hg}$ control coupon has a rougher surface, indicating more extensive corrosion. On the flat coupon sections, the baseline sample has a thicker deposit layer relative to the $\mathrm{Hg}$ control coupon.

Figures 7-2 and 7-3 show results of electron microprobe line scan analyses for $\mathrm{Fe}, \mathrm{Cr}, \mathrm{Ni}$, $\mathrm{S}, \mathrm{Na}, \mathrm{K}, \mathrm{Ca}, \mathrm{Si}$, and $\mathrm{Al}$ on the ECM coupons. $\mathrm{Al}, \mathrm{Si}$, and $\mathrm{Ca}$ are the major elements comprising the deposits on the coupons. The deposits on baseline coupons have greater Al and Si contents relative to those on the $\mathrm{Hg}$ control coupons, whereas the $\mathrm{Hg}$ control coupon deposits have much higher $\mathrm{Ca}$ contents, especially on the curved coupon section. Both the baseline and $\mathrm{Hg}$ control coupons have relatively high sulfur concentrations in the ash deposit layers. The deposit on the flat section of the $\mathrm{Hg}$ control coupon has a much higher sulfur content relative to the corresponding baseline coupon deposit. Sulfur contents for the deposits on the baseline and $\mathrm{Hg}$ control curved coupons are similar. Variations in $\mathrm{Ca}$ and $\mathrm{S}$ concentrations in Figures 7-2 and 7-3 suggest that calcium sulfate deposition increased as a result of SEA2 and PAC injections. 

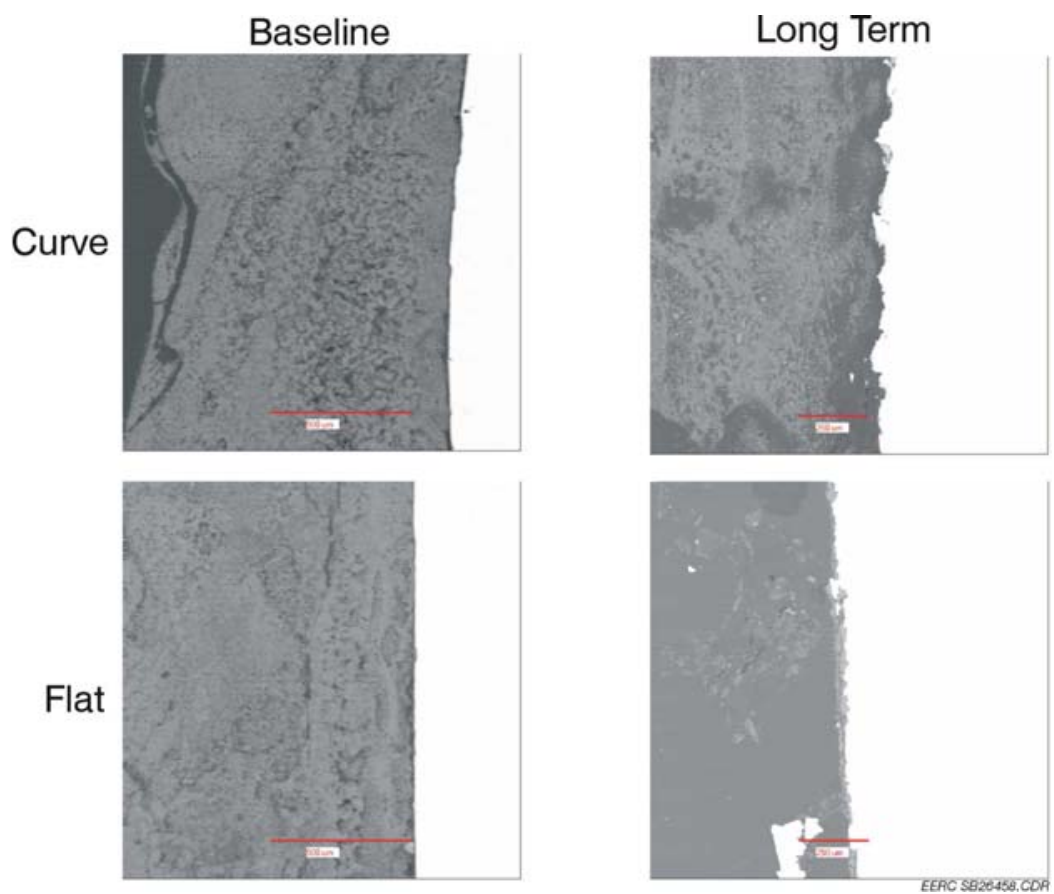

Figure 7-1. BSEI of MRY ECM coupons.
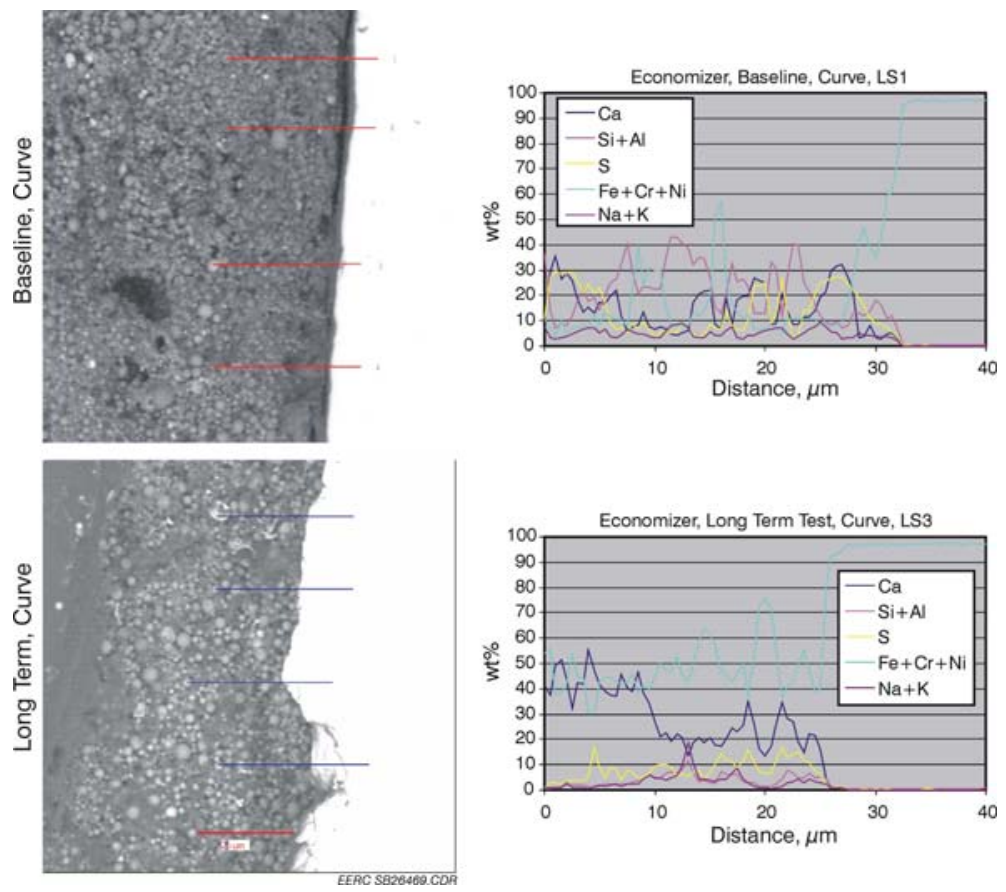

Figure 7-2. Comparison of ECM baseline and long-term coupons. 

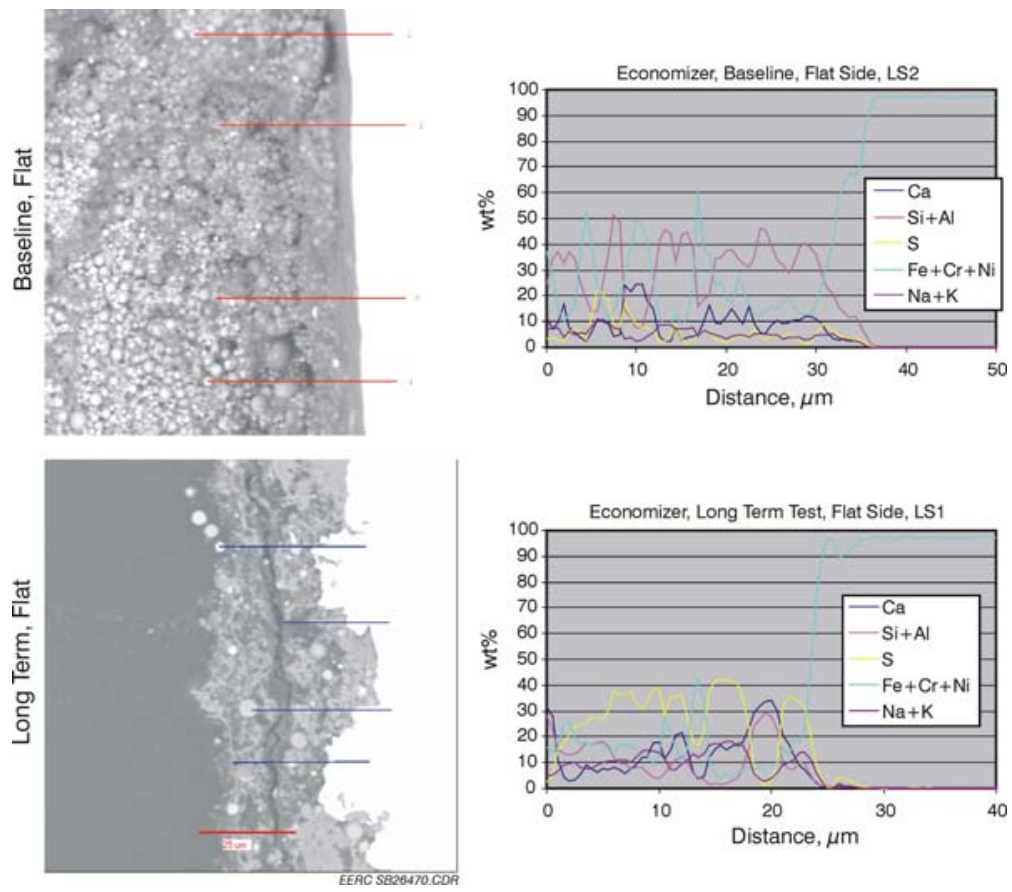

Figure 7-3. Comparison of additional ECM baseline and long-term coupons.

\subsubsection{AHI Coupons}

The AHI baseline and $\mathrm{Hg}$ control coupon cross sections are compared in Figure 7-4. The BSEIs of the AHI coupons are similar to those of the ECM coupons shown in Figure 7-1, the baseline coupons have a smooth surface, and the $\mathrm{Hg}$ control coupons have a rougher steel surface, indicating more intensive corrosion during the SEA2 and PAC injections. The deposit layers, however, are much thinner relative to those on the ECM coupons. Deposits on the $\mathrm{Hg}$ control coupons are closely packed on the steel surface, while there is a "crack" between the deposit layer and steel surface on baseline coupons.

SEM line scan analysis results for the AHI coupons are compared in Figures 7-5 and 7-6. In general, these results are similar to those for the ECM coupons. A notable difference is that the deposits on the $\mathrm{Hg}$ control coupons have much higher $\mathrm{Na}, \mathrm{K}$, and $\mathrm{S}$ concentrations. On the flat section of the $\mathrm{Hg}$ control coupon, the deposit layer comprises mostly $\mathrm{Na}, \mathrm{K}$, and $\mathrm{Ca}$ sulfates.

\subsubsection{AHO Coupons}

Figure 7-7 shows the appearance of typical areas of the steel-oxide interface for the AHO baseline and long-term coupons. The deposit layer on the baseline coupon is much thicker than that of the long-term coupon. In contrast to the ECM and AHI coupons, steel surfaces on the AHO baseline and long-term coupons are similar. The long-term coupon steel surface is not as rough as that of the ECM and AHI long-term coupons. There is no indication of more intensive corrosion of the long-term coupon than the baseline coupon. 

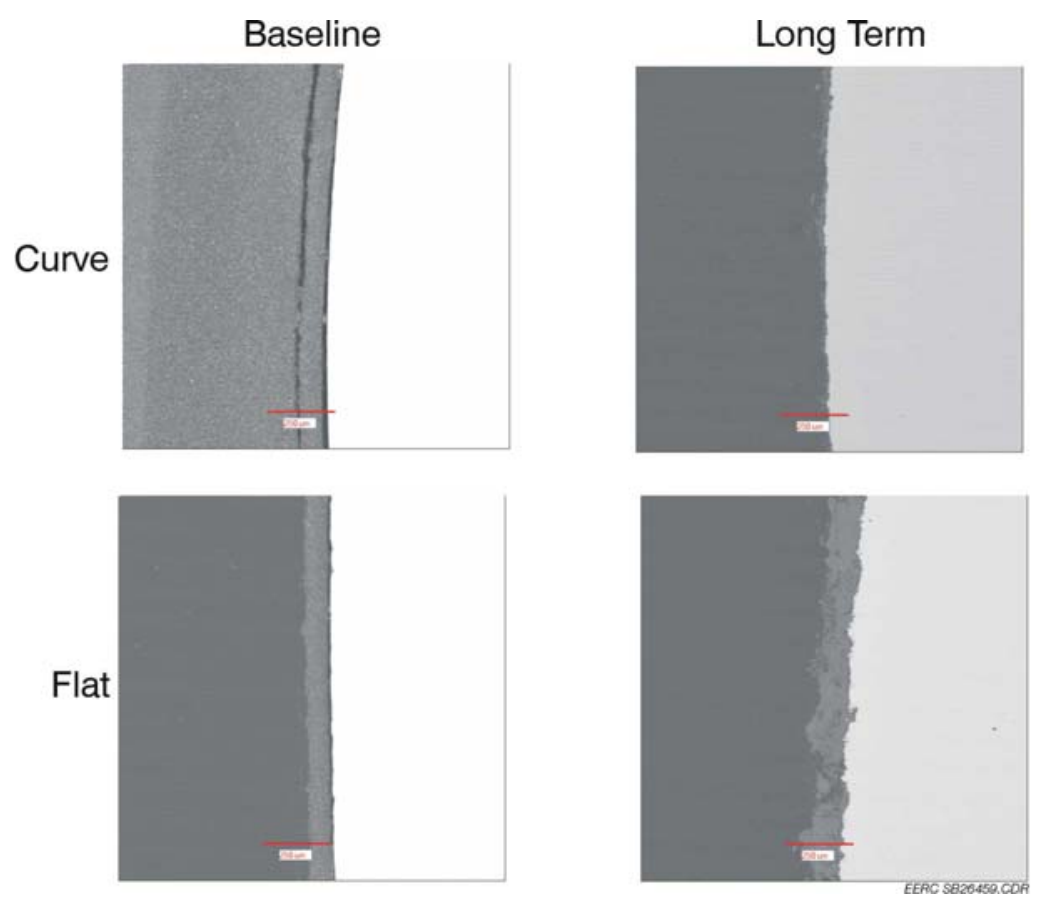

Figure 7-4. MRY AHI coupons.
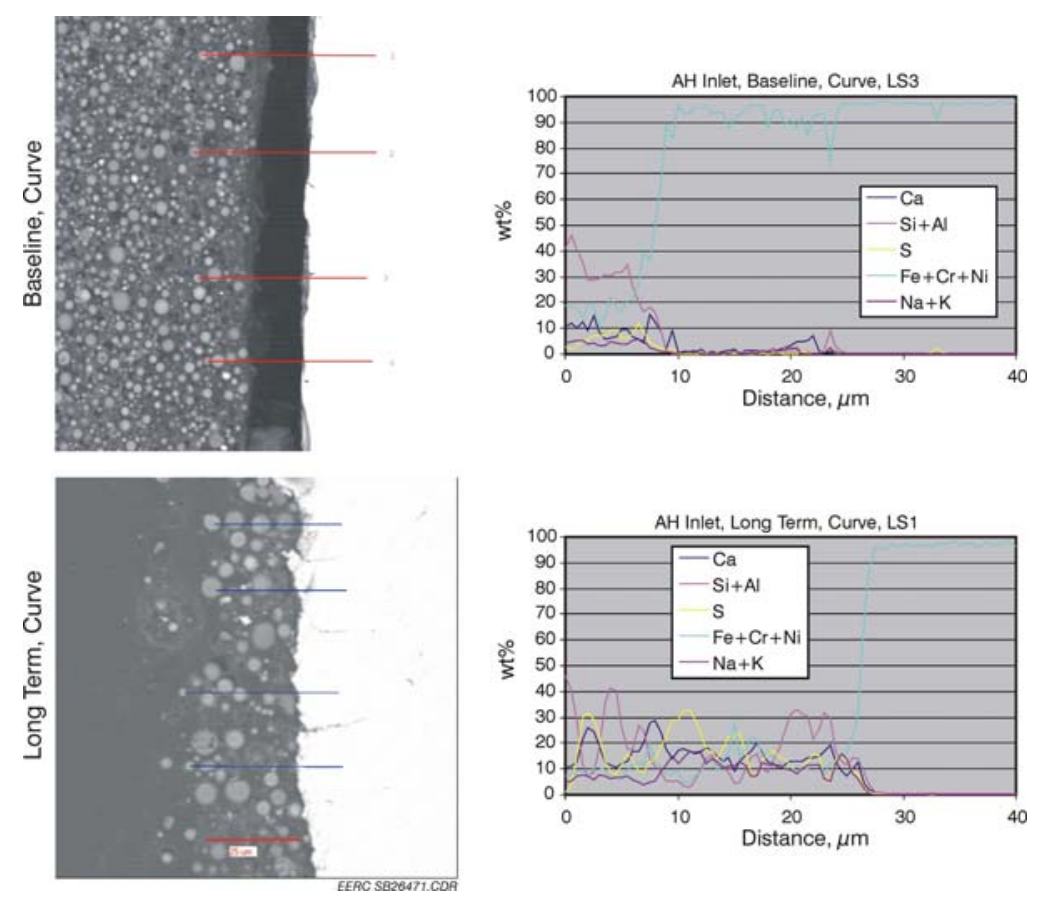

Figure 7-5. Comparison of AHI baseline and Hg control coupons (curved side). 

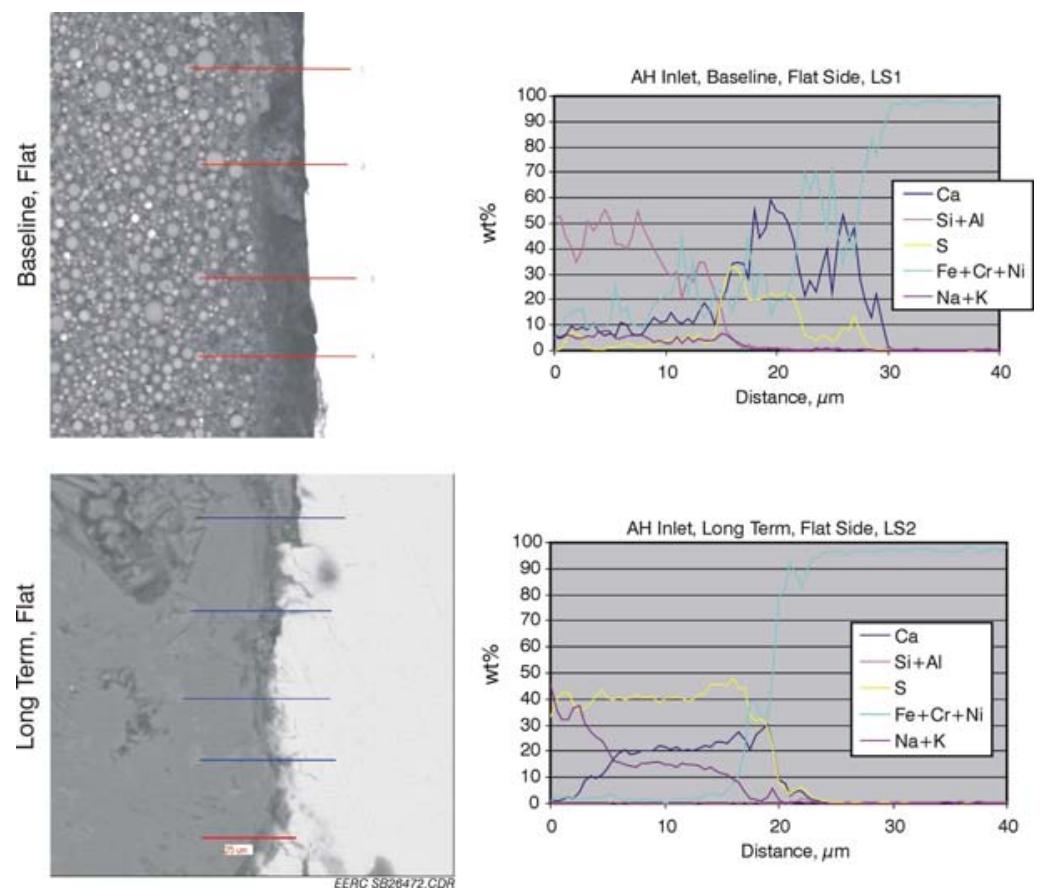

Figure 7-6. Comparison of AHI baseline and $\mathrm{Hg}$ control coupons (flat side).
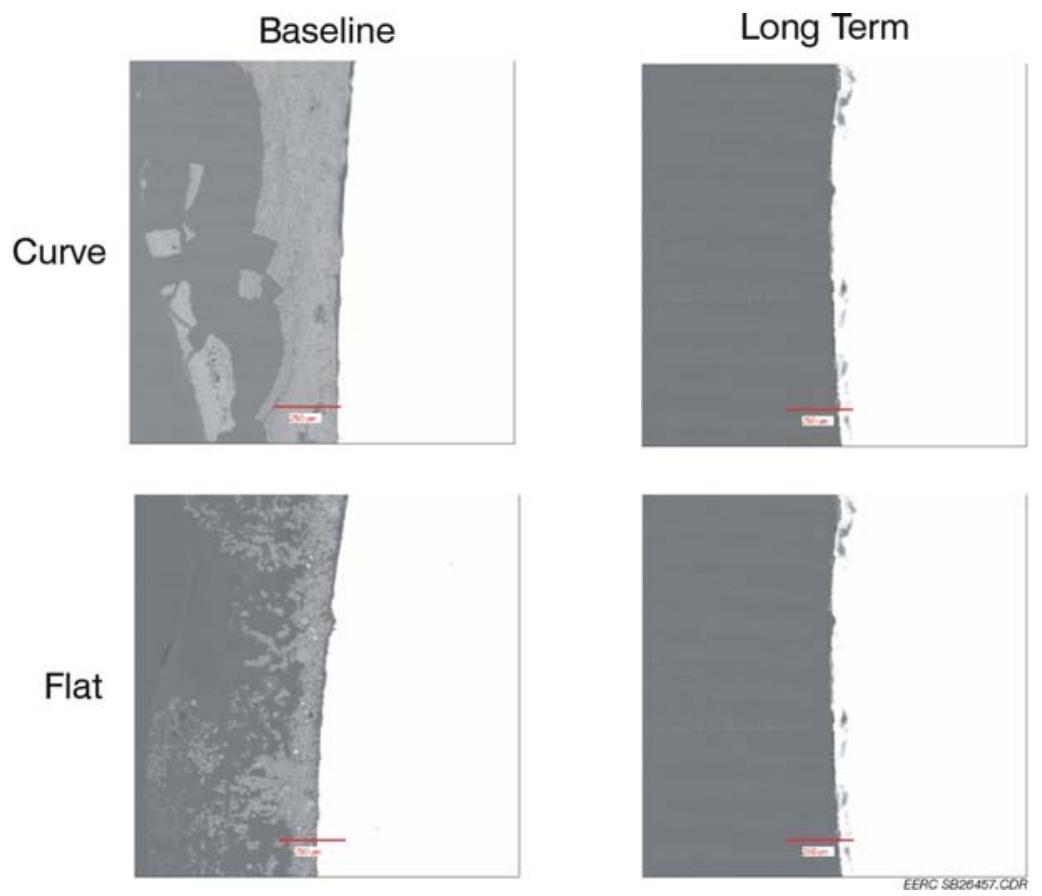

Figure 7-7. MRY AHO coupons. 
Electron microprobe line scan analyses for the AHO coupons are compared in Figures 7-8 and 7-9. The deposit layer on the curved section is different from that on the flat section of the same coupon. On the baseline coupon, although both the curve and flat sections have a deposit layer of aluminosilicate fly ash particles cemented by $\mathrm{Na}, \mathrm{K}$, and $\mathrm{Ca}$ sulfates, the fly ash particles on the curve are $\leq 2 \mu \mathrm{m}$ in diameter, whereas particles on the flat sections are much coarser, $\geq 30 \mu \mathrm{m}$ in diameter. On the long-term coupon, the deposit layer of the flat section is composed of fine aluminosilicate particles cemented with sodium, potassium, and calcium silicate, while the deposit on the curve is a thin layer of sodium, potassium, and calcium sulfates.

Chemically, these results are similar to those for the ECM and AHI coupons. The deposits produced during $\mathrm{Hg}$ control testing conditions have higher $\mathrm{Na}$, $\mathrm{K}$, and $\mathrm{S}$ concentrations and lower $\mathrm{Al}$ and $\mathrm{Si}$ concentrations relative to the baseline deposits. On the curved coupon section, the $\mathrm{Hg}$ control coupon has higher $\mathrm{Ca}$ concentrations in the deposit layer than the baseline coupon. Apparently, SEA2 and PAC injections enhance Ca sulfate deposition on the coupon.

\subsection{Mercury Stability Analysis}

Fly ash samples were collected from ESP hoppers for evaluating Hg mobility during leaching and heating experiments. Sample 05-005 was collected on March 17, 2005, during baseline testing conditions, whereas Sample 05-017 was collected on April 13, 2005, during Hg control technology testing involving SEA2 injections.
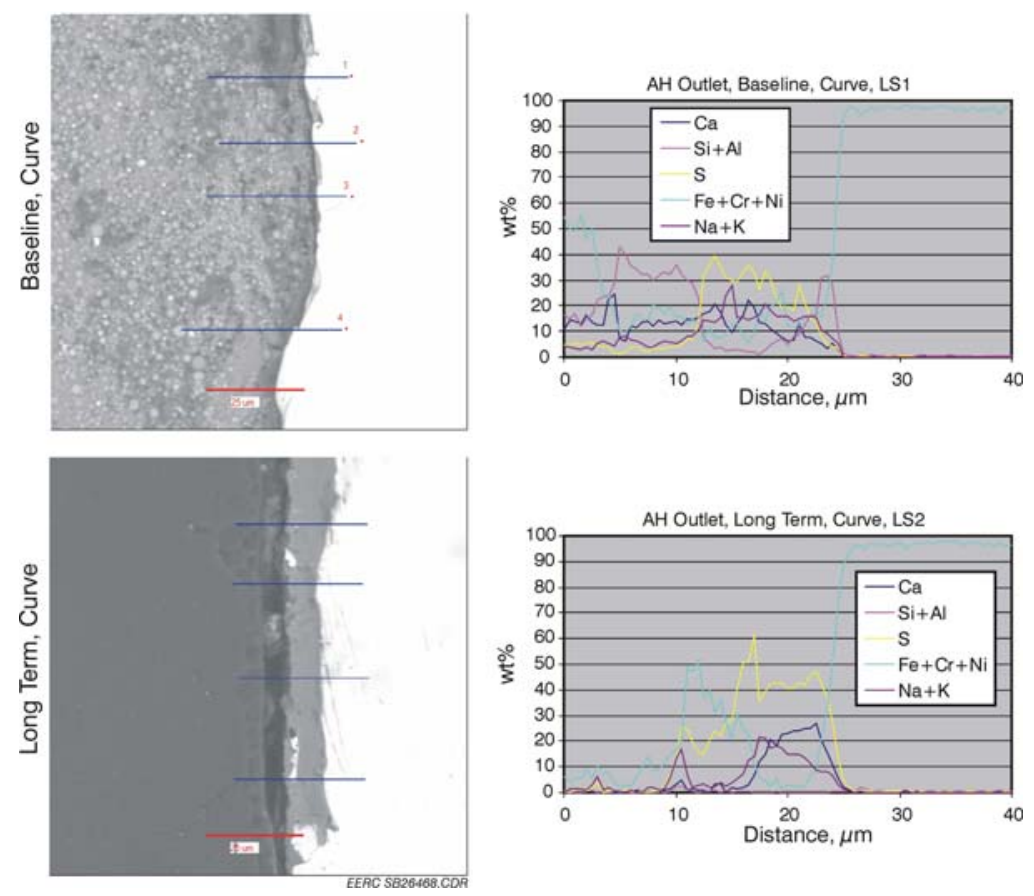

Figure 7-8. Comparison of AHO baseline and long-term coupons. 

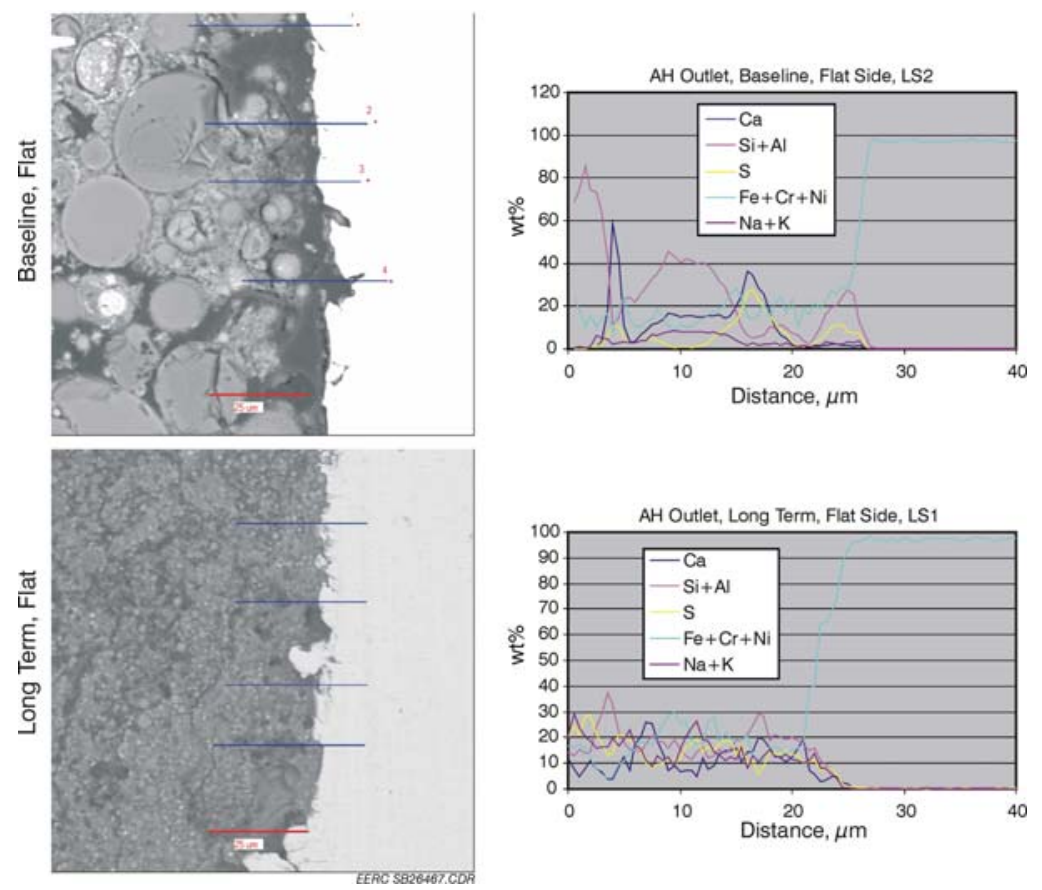

Figure 7-9. Comparison of additional AHO baseline and long-term coupons.

Before the leaching and thermal stability analyses were performed, the total $\mathrm{Hg}$ contents and $\mathrm{pH}$ of the fly ash samples were determined, as reported in Table 7-1. As expected, the total $\mathrm{Hg}$ content of the fly ash collected during $\mathrm{Hg}$ control testing is greater than the baseline sample. The $\mathrm{pH}$ of the fly ash samples was determined using distilled water after 24 hours of stirring. The $\mathrm{pH}$ of both samples was $>10$, indicating that LTL is appropriate for evaluating the leaching profile of these samples. Coal fly ashes exhibiting a high $\mathrm{pH}$ have the potential to undergo hydration reactions that can change the leaching profile with time.

\subsubsection{Leaching Analysis}

Fly ash leaching results, consisting of final leachate $\mathrm{pH}$ and $\mathrm{Hg}$ concentrations, from using SGLP and 30- and 60-day LTL tests are compared in Tables 7-3 and 7-4. Duplicate 60-day LTL analyses were performed yielding reproducible leachate $\mathrm{Hg}$ concentrations that were less than the quantification limit of the analysis method, indicating that the $\mathrm{Hg}$ in these two fly ashes was relatively insoluble.

Table 7-3. SGLP Results

\begin{tabular}{lcccc}
\hline ID No. & Testing Condition & Total $\mathrm{Hg}, \mu \mathrm{g} / \mathrm{g}$ & Initial $\mathrm{pH}$ & 24-hr $\mathrm{pH}$ \\
\hline $05-005$ & Baseline & 0.431 & 11.77 & 11.57 \\
$05-017$ & PAC and SEA2 injections & 0.717 & 12.04 & 11.77 \\
\hline
\end{tabular}


Table 7-4. Longer-Term Fly Ash Hg Leaching Results

\begin{tabular}{lcccc}
\hline ID No. & Testing Condition & Leaching Procedure & $\mathrm{Hg}, \mu \mathrm{g} / \mathrm{L}$ & Leachate $\mathrm{pH}$ \\
\hline $05-005$ & Baseline & SGLP & $<0.01$ & 11.73 \\
$05-005$ & Baseline & 30-day LTL & $<0.01$ & 11.61 \\
$05-005$ & Baseline & 60-day LTL & $<0.01$ & 11.84 \\
$05-005$ & Baseline & 60-day LTL & $<0.01$ & 11.83 \\
$05-017$ & PAC and SEA2 injections & SGLP & $<0.01$ & 11.94 \\
$05-017$ & PAC and SEA2 injections & 30-day LTL & $<0.01$ & 11.69 \\
$05-017$ & PAC and SEA2 injections & 60-day LTL & $<0.01$ & 12.01 \\
$05-017$ & PAC and SEA2 injections & 60-day LTL & $<0.01$ & 11.99 \\
\hline
\end{tabular}

\subsubsection{Thermal Stability}

The generation of $\mathrm{Hg}$ thermal desorption curves for two fly ash samples was technically challenging. Samples of fly ash collected during baseline testing conditions were evaluated asreceived and after sieving (100 mesh) to concentrate unburned carbon in a coarser fly ash fraction. Samples of fly ash collected during the PAC and SEA2 injections were also tested asreceived. Examples of $\mathrm{Hg}$ thermal desorption curves for the fly ashes sampled during baseline and long-term $\mathrm{Hg}$ control testing conditions are presented in Figures 7-10 and 7-11, respectively. Both samples generally desorbed $\mathrm{Hg}$ at a peak temperature. However, the fly ash sampled during $\mathrm{PAC}$ and SEA2 injections occasionally produced an additional minor peak at $>550^{\circ} \mathrm{C}$. The average $\mathrm{Hg}$ release peak temperatures for the samples are presented in Table 7-5. Hg release profiles similar to those presented in Figures 7-10 and 7-11 have been reported for other coal fly ashes (28). The $\mathrm{Hg}$ evolved from the sieved baseline fly ash at a lower temperature relative to the corresponding as-received sample, apparently because the $\mathrm{Hg}$ associated with the larger ash particles is more volatile. The Hg captured on fly ash during PAC and SEA2 injections was thermally more stable relative to the baseline fly ash.

$\mathrm{Hg}$ mass balance recoveries for both samples were low because a $\mathrm{Hg}$ compound had deposited on a cool area of the furnace tube $\left(\sim 200^{\circ} \mathrm{C}\right)$. $\mathrm{Hg}$ analyses of thermally desorbed samples indicated that $\mathrm{Hg}$ was below detection in the baseline fly ashes; however, a minute amount was detected in the fly ashes sampled during long-term $\mathrm{Hg}$ control testing conditions.

\subsection{BALANCE-OF-PLANT EFFECTS OF HG CONTROL TECHNOLOGIES AT MoSES UNIT 3}

\subsection{Coal Fly Ash Analyses}

The ash mercury contents were analyzed to determine if the injection of calcium bromide caused an increase in mercury partitioning to the fly ash. Ash samples were collected by hopper from the first two fields of the ESP on a daily basis. Selected ash samples were analyzed for mercury and LOI content, as summarized in Tables 8-1 and 8-2, respectively. For each day, the average mercury and LOI content was calculated for Field 1 and Field 2. 
Run No. 1219

\section{Start}

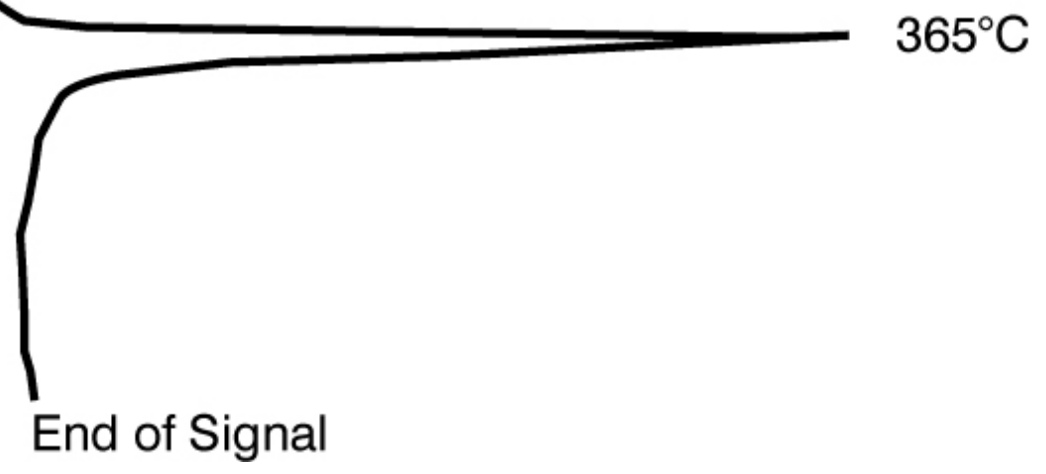

Figure 7-10. Sample 05-005 example AA mercury thermal desorption curve.

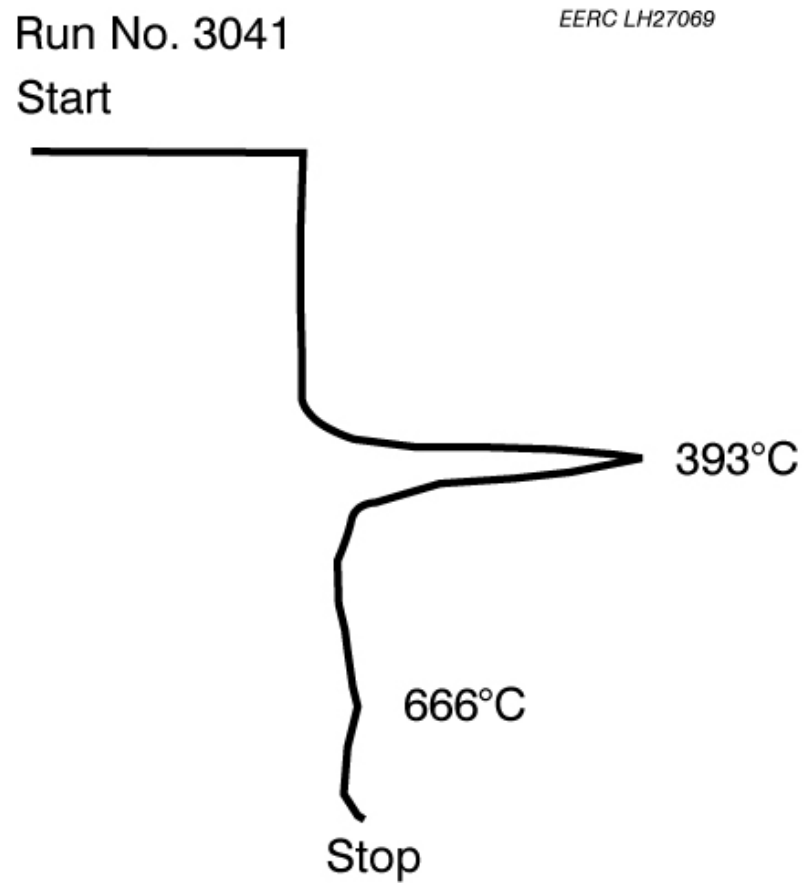

Figure 7-11. Sample 05-017 example AA mercury thermal desorption curve. 
Table 7-5. Average Hg Thermal Desorption Results

\begin{tabular}{lccccc}
\hline Sample & Averting Condition & $\begin{array}{c}\text { Average } \\
\text { Peak, }{ }^{\circ} \mathrm{C}\end{array}$ & St. Dev. & RSD, \% & $\mathrm{N}^{1}$ \\
\hline 05-005, both & Baseline & 353 & 30.4 & 8.6 & 7 \\
05-005, as-received & Baseline & 375 & 9.6 & 2.6 & 3 \\
05-005, sieved & Baseline & 336 & 29.8 & 8.9 & 4 \\
05-017, as-received & $\begin{array}{c}\text { PAC and SEA2 } \\
\text { Injections }\end{array}$ & 402 & 8.8 & 2.2 & 7 \\
\hline
\end{tabular}

${ }^{1}$ Number of analyses.

Figures 8-1 and 8-2 show the mercury concentration of the composite fly ash samples for the two long-term injection tests. Each plot shows the baseline (no injection) ash data as well as the ash mercury concentrations collected during injection. The average mercury concentration of the first field baseline ash collected during the baseline period prior to the first continuousinjection test was $0.214 \mu \mathrm{g} / \mathrm{g}$. During the first injection test (55 ppm Br in the coal), the average first field ash mercury concentration increased to $0.328 \mu \mathrm{g} / \mathrm{g}$. Likewise, the second field ash mercury concentration also increased during the calcium bromide injection test.

The average mercury concentration of the first field baseline ash collected during the baseline period prior to the second continuous-injection test $(0.230 \mu \mathrm{g} / \mathrm{g})$ was similar to the first baseline period $(0.214 \mu \mathrm{g} / \mathrm{g})$. During the second injection test (113 ppm $\mathrm{Br}$ in the coal), the average first field ash mercury concentration increased to $0.334 \mu \mathrm{g} / \mathrm{g}$. Likewise, the second field ash mercury concentration also increased during the calcium bromide injection test.

Figure 8-3 shows the ratio of the mercury leaving the system with the fly ash compared to the mercury entering the system with the coal. A value of $0 \%$ indicates no removal of mercury by the ash, and a value of $100 \%$ indicates total removal of mercury by the fly ash. For the baseline day just prior to the 55-ppm Br test, the ash mercury represented $12 \%$ of the coal mercury, indicating little native removal. During the 55-ppm Br test, 4 days of coal and ash data indicate that an average $25 \%$ of the coal mercury was removed with the fly ash. These data indicate a slight increase in mercury removal by the fly ash during calcium bromide injection; however, the ash data do not indicate as high a mercury removal as the gas-phase SCEM data, which had indicated an average of $46 \%$ mercury removal by the fly ash.

For the baseline day just prior to the 113-ppm Br test, the ash mercury represented $22 \%$ of the coal mercury. During the 113-ppm Br test, the three days of coal and ash data indicate that an average $22 \%$ of the coal mercury was removed with the fly ash. Similarly for the 330-ppm Br test, $22 \%$ of the coal mercury was removed with the fly ash. The injection of calcium bromide during this second long-term test did not result in an increase in mercury removal by the fly ash. These results contradict the flue gas data for the 113-ppm $\mathrm{Br}$ test, which showed $64 \%$ of the mercury being removed prior to the ESP. The percentage of mercury removed by the fly ash during this second long-term test is comparable to the percentage of mercury removed during the first long-term test. It is possible that the baseline ash/coal ratio of $12 \%$ measured just prior to the first long-term test is a low outlier and that, indeed, the removal of mercury by the fly ash did not increase during the 55-ppm Br injection test. 
Table 8-1. Mercury Content of Fly Ash

\begin{tabular}{|c|c|c|c|c|c|c|c|c|c|}
\hline Date & Time & Field & Row 1 & Row 2 & Row 3 & Row 4 & Row 5 & Row 6 & Average \\
\hline \multirow[t]{2}{*}{$10 / 25 / 05$} & $13: 00$ & 1 & & 0.155 & & 0.325 & 0.340 & 0.287 & 0.277 \\
\hline & & 2 & & & & 0.566 & & & 0.566 \\
\hline \multirow[t]{2}{*}{$10 / 26 / 05$} & $15: 30$ & 1 & & 0.125 & 0.162 & 0.290 & & 0.235 & 0.203 \\
\hline & & 2 & & & & 0.572 & 0.471 & 0.477 & 0.507 \\
\hline \multirow[t]{2}{*}{$11 / 04 / 05$} & $17: 00$ & 1 & 0.113 & 0.088 & & 0.217 & 0.214 & 0.174 & 0.161 \\
\hline & & 2 & & 0.215 & & 0.438 & 0.415 & 0.445 & 0.378 \\
\hline \multirow[t]{2}{*}{$11 / 06 / 05$} & $15: 00$ & 1 & 0.280 & 0.231 & & 0.493 & 0.451 & 0.430 & 0.377 \\
\hline & & 2 & & 0.444 & & 0.859 & 0.793 & 0.679 & 0.694 \\
\hline \multirow[t]{2}{*}{$11 / 09 / 05$} & $14: 30$ & 1 & 0.218 & 0.170 & & 0.405 & 0.370 & 0.370 & 0.307 \\
\hline & & 2 & 0.303 & 0.341 & & & 0.698 & 0.724 & 0.517 \\
\hline \multirow[t]{2}{*}{$11 / 11 / 05$} & $15: 30$ & 1 & 0.157 & 0.140 & & 0.264 & 0.263 & 0.246 & 0.214 \\
\hline & & 2 & 0.235 & 0.239 & & & 0.462 & 0.481 & 0.354 \\
\hline \multirow[t]{2}{*}{$11 / 12 / 05$} & $17: 00$ & 1 & 0.194 & 0.139 & & 0.380 & 0.333 & 0.357 & 0.281 \\
\hline & & 2 & 0.319 & 0.364 & & & 0.583 & 0.628 & 0.474 \\
\hline \multirow[t]{2}{*}{$11 / 13 / 05$} & $16: 45$ & 1 & 0.308 & 0.257 & & 0.482 & 0.506 & 0.441 & 0.399 \\
\hline & & 2 & 0.447 & 0.464 & & & 0.844 & 0.966 & 0.68 \\
\hline \multirow[t]{2}{*}{$11 / 15 / 05$} & 14:00 & 1 & 0.312 & 0.261 & & 0.491 & 0.462 & 0.418 & 0.389 \\
\hline & & 2 & 0.510 & 0.577 & & & 0.766 & 0.835 & 0.672 \\
\hline \multirow[t]{2}{*}{$11 / 17 / 05$} & $11: 50$ & 1 & 0.304 & 0.212 & & 0.392 & 0.379 & 0.347 & 0.327 \\
\hline & & 2 & 0.542 & 0.482 & & & 0.719 & 0.710 & 0.613 \\
\hline \multirow[t]{2}{*}{$11 / 29 / 05$} & 14:05 & 1 & 0.110 & 0.070 & & & 0.051 & & 0.077 \\
\hline & & 2 & 0.118 & 0.110 & & & 0.087 & 0.100 & 0.104 \\
\hline \multirow[t]{2}{*}{$12 / 01 / 05$} & $14: 00$ & 1 & 0.153 & 0.133 & & 0.244 & 0.233 & 0.211 & 0.195 \\
\hline & & 2 & 0.182 & 0.265 & & & 0.403 & 0.377 & 0.307 \\
\hline \multirow[t]{2}{*}{$12 / 02 / 05$} & $14: 30$ & 1 & 0.189 & 0.175 & & 0.321 & 0.317 & 0.316 & 0.264 \\
\hline & & 2 & 0.353 & 0.363 & & & 0.539 & 0.603 & 0.465 \\
\hline \multirow[t]{2}{*}{$12 / 06 / 05$} & $13: 35$ & 1 & 0.256 & 0.217 & & 0.522 & 0.510 & 0.556 & 0.412 \\
\hline & & 2 & 0.370 & 0.430 & & & 0.922 & 0.762 & 0.621 \\
\hline \multirow[t]{2}{*}{$12 / 05 / 05$} & $15: 30$ & 1 & 0.254 & 0.166 & & 0.531 & 0.493 & 0.411 & 0.371 \\
\hline & & 2 & 0.383 & 0.456 & & & 0.877 & 0.907 & 0.656 \\
\hline \multirow[t]{2}{*}{$12 / 07 / 05$} & $15: 00$ & 1 & 0.202 & 0.216 & & 0.472 & 0.482 & 0.304 & 0.335 \\
\hline & & 2 & 0.460 & 0.399 & & & 0.963 & 0.913 & 0.684 \\
\hline \multirow[t]{2}{*}{$12 / 09 / 05$} & 11:00 & 1 & 0.274 & 0.212 & & 0.306 & 0.312 & & 0.276 \\
\hline & & 2 & 0.444 & 0.414 & & & 0.546 & 0.488 & 0.473 \\
\hline \multirow[t]{2}{*}{$12 / 11 / 05$} & $11: 15$ & 1 & 0.251 & 0.203 & & 0.326 & 0.325 & & 0.276 \\
\hline & & 2 & 0.352 & 0.355 & & & 0.484 & 0.462 & 0.413 \\
\hline \multirow[t]{2}{*}{$12 / 13 / 05$} & $14: 45$ & 1 & 0.356 & 0.306 & & 0.439 & 0.452 & 0.467 & 0.404 \\
\hline & & 2 & 0.546 & 0.574 & & & 0.662 & 0.699 & 0.62 \\
\hline $12 / 14 / 05$ & $14: 25$ & 2 & 0.483 & 0.511 & & & 0.508 & 0.516 & 0.505 \\
\hline
\end{tabular}


Table 8-2. LOI Content of Fly Ash

\begin{tabular}{lccccccccc}
\hline Date & Time & Field & Row 1 & Row 2 & Row 3 & Row 4 & Row 5 & Row 6 & Average \\
\hline $10 / 25 / 05$ & $13: 00$ & 1 & & 0.34 & & 0.16 & 0.12 & 0.13 & 0.19 \\
& & 2 & & & & 0.20 & & & 0.2 \\
$10 / 26 / 05$ & $15: 30$ & 1 & & 0.38 & 0.22 & 0.22 & & 0.14 & 0.24 \\
& & 2 & & & & 0.30 & 0.23 & 0.29 & 0.27 \\
$11 / 04 / 05$ & $17: 00$ & 1 & 0.11 & 0.18 & & 0.15 & 0.12 & 0.16 & 0.14 \\
& & 2 & & 0.19 & & 0.15 & 0.21 & 0.10 & 0.16 \\
$11 / 06 / 05$ & $15: 00$ & 1 & 0.12 & 0.29 & & 0.16 & 0.32 & 0.18 & 0.21 \\
& & 2 & & 0.13 & & 0.20 & 0.19 & 0.19 & 0.18 \\
$11 / 09 / 05$ & $14: 30$ & 1 & 0.09 & 0.21 & & 0.13 & 0.25 & 0.13 & 0.16 \\
& & 2 & 0.11 & 0.12 & & & 0.13 & 0.10 & 0.12 \\
$11 / 11 / 05$ & $15: 30$ & 1 & 0.20 & 0.24 & 0.27 & 0.24 & 0.32 & 0.25 \\
& & 2 & 0.22 & 0.21 & & & 0.22 & 0.25 & 0.23 \\
$11 / 12 / 05$ & $17: 00$ & 1 & 0.18 & 0.27 & 0.16 & 0.31 & 0.13 & 0.21 \\
& & 2 & 0.17 & 0.17 & & & 0.14 & 0.11 & 0.15 \\
$11 / 13 / 05$ & $16: 45$ & 1 & 0.25 & 0.35 & 0.32 & 0.25 & 0.12 & 0.26 \\
& & 2 & 0.13 & 0.22 & & & 0.17 & 0.10 & 0.16 \\
$11 / 15 / 05$ & $14: 00$ & 1 & 0.08 & 0.20 & 0.20 & 0.29 & 0.27 & 0.21 \\
& & 2 & 0.27 & 0.22 & & & 0.16 & 0.28 & 0.23 \\
$11 / 17 / 05$ & $11: 50$ & 1 & 0.14 & 0.25 & & 0.35 & 0.19 & 0.22 & 0.23 \\
& & 2 & 0.15 & 0.22 & & & 0.15 & 0.20 & 0.18 \\
$12 / 01 / 05$ & $14: 00$ & 1 & 0.05 & 0.12 & & 0.12 & 0.07 & 0.11 & 0.09 \\
& & 2 & 0.05 & 0.14 & & & 0.11 & 0.07 & 0.09 \\
$12 / 02 / 05$ & $14: 30$ & 1 & 0.09 & 0.22 & & 0.15 & 0.25 & 0.09 & 0.16 \\
& & 2 & 0.10 & 0.10 & & & 0.11 & 0.14 & 0.11 \\
$12 / 06 / 05$ & $13: 35$ & 1 & 0.15 & 0.28 & & 0.26 & 0.20 & 0.09 & 0.2 \\
& & 2 & 0.12 & 0.14 & & & 0.17 & 0.10 & 0.13 \\
$12 / 05 / 05$ & $15: 30$ & 1 & 0.15 & 0.36 & 0.27 & 0.15 & 0.24 & 0.23 \\
& & 2 & 0.12 & 0.16 & & & 0.19 & 0.23 & 0.18 \\
$12 / 07 / 05$ & $15: 00$ & 1 & 0.10 & 0.11 & 0.13 & 0.20 & 0.10 & 0.13 \\
& & 2 & 0.09 & 0.13 & & & 0.12 & 0.09 & 0.11 \\
$12 / 09 / 05$ & $11: 00$ & 1 & 0.08 & 0.27 & 0.17 & 0.17 & & 0.17 \\
& & 2 & 0.08 & 0.13 & & & 0.13 & 0.09 & 0.11 \\
$12 / 11 / 05$ & $11: 15$ & 1 & 0.13 & 0.08 & 0.14 & 0.10 & & 0.11 \\
& & 2 & 0.09 & 0.09 & & 0.05 & 0.07 & 0.08 \\
$12 / 13 / 05$ & $14: 45$ & 1 & 0.04 & 0.16 & 0.11 & 0.11 & 0.05 & 0.09 \\
& & 2 & 0.08 & 0.07 & & & 0.05 & 0.05 & 0.06 \\
$12 / 14 / 05$ & $14: 25$ & 2 & 0.04 & 0.06 & & & 0.03 & 0.04 & 0.04 \\
\hline & & & & & & & & &
\end{tabular}




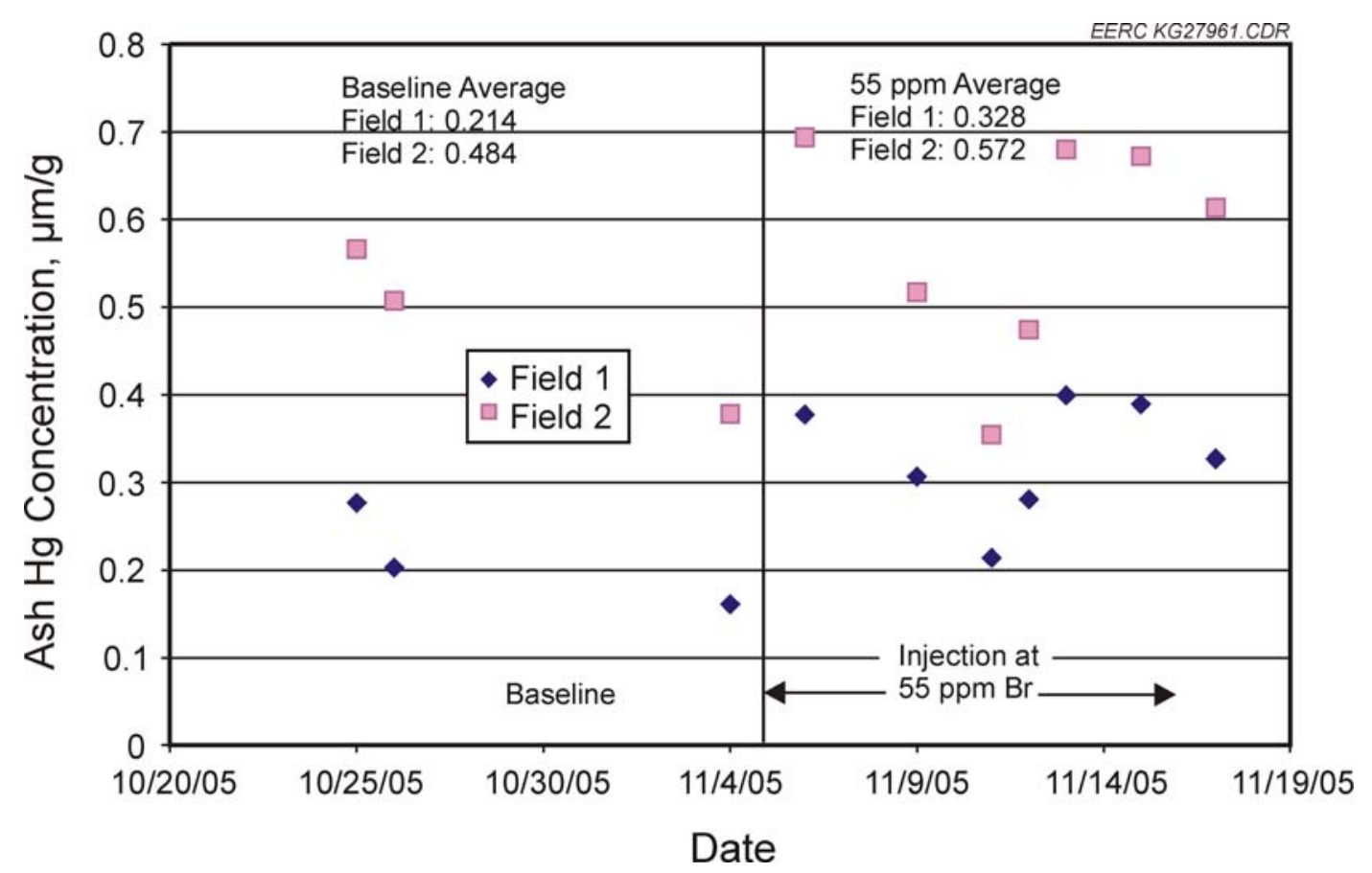

Figure 8-1. Mercury concentration of fly ash during baseline and first continuous-injection test.

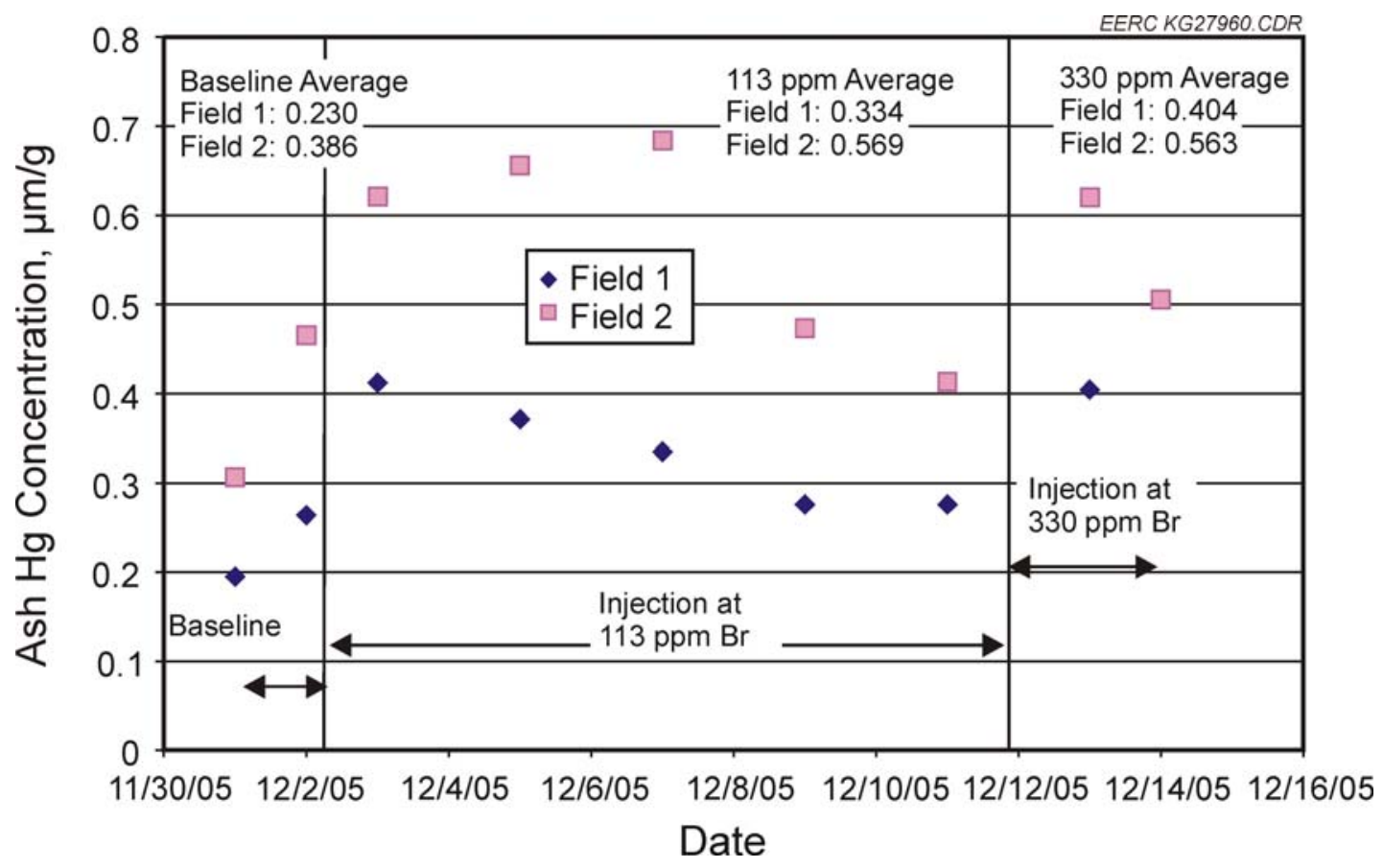

Figure 8-2. Mercury concentration of fly ash during baseline and second continuous-injection test. 


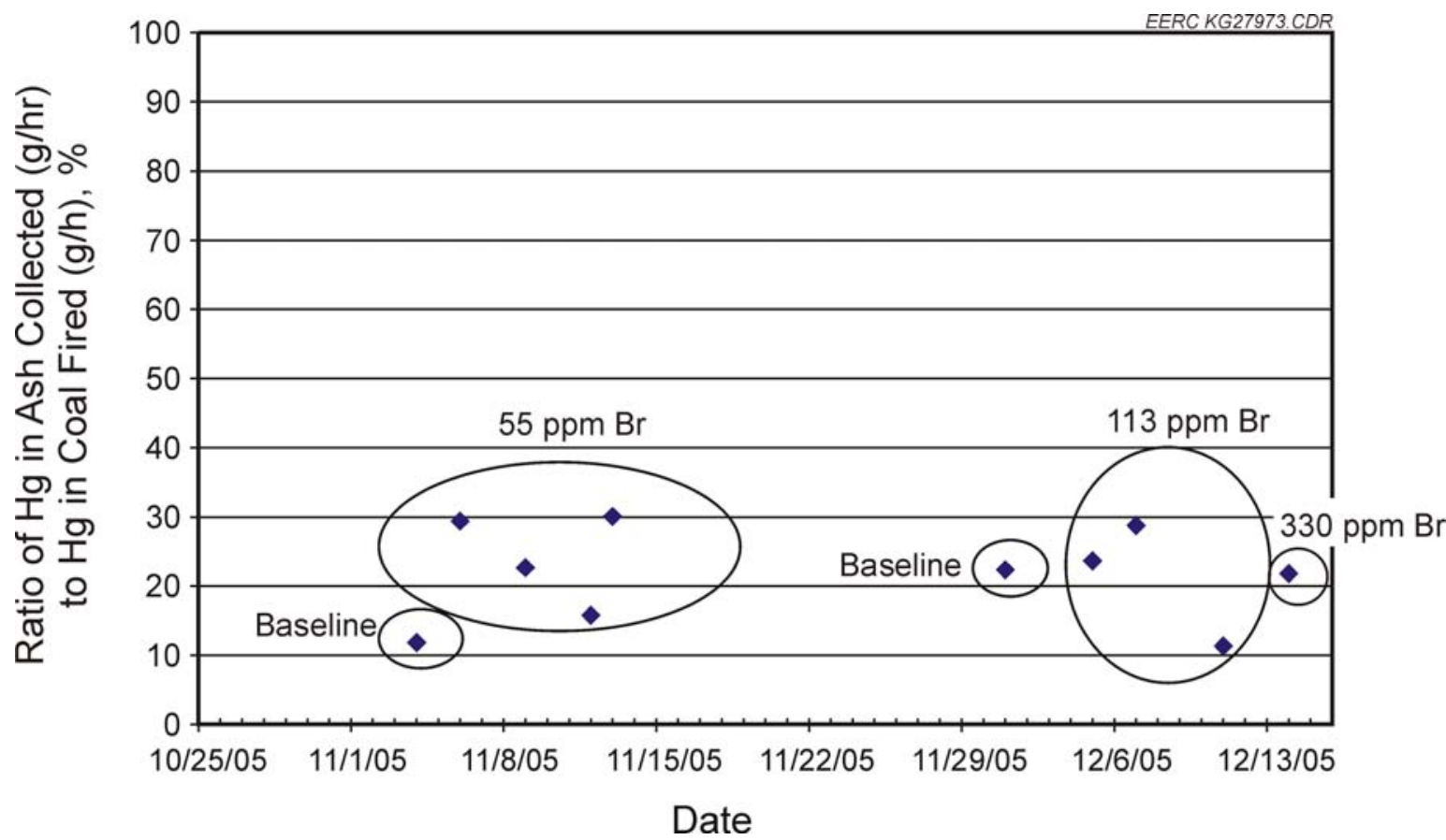

Figure 8-3. Ratio of mercury content in ash collected $(\mathrm{g} / \mathrm{hr})$ to mercury content in coal fired $(\mathrm{g} / \mathrm{hr})$.

The comparison of the ESP inlet vapor-phase data and the ash mercury data to the coal mercury data indicates a contradiction. The ESP inlet vapor-phase mercury data for the 55-ppm and 113-ppm $\mathrm{Br}$ injection tests indicate appreciable (46\% and 64\%, respectively) removal of mercury upstream of the ESP, while the ash mercury data indicate little additional removal of mercury with the bromine injection process. Kanefke et al. (29) have observed a negative measurement bias by SCEMs (such as the EPRI SCEMs in this project) using a stannous chloride solution for the reduction of oxidized mercury. Kanefke et al. (29) showed that in the presence of $6 \mathrm{ppmv} \mathrm{Br}$, the measured total vapor-phase mercury concentrations were biased by as much as $20 \%$. In the presence of $30 \mathrm{ppmv} \mathrm{Br}$, the measured total vapor-phase mercury concentrations were biased by as much as $50 \%$.

Analysis of the gas-phase mercury concentrations measured by the SCEMs and the coal and ash mercury data indicate that there was a bromine-related negative bias associated with the measurement of total vapor-phase mercury upstream of the scrubber. Such a bias does not appear to exist for the measurement of elemental mercury upstream of the scrubber, as the scrubber inlet elemental mercury concentrations agree well with the scrubber outlet total mercury concentrations. For the purposes of calculating the oxidation of mercury and the removal of mercury by the system, average coal mercury values were used in place of the SCEM total mercury data at the scrubber inlet. 
Selected ash samples were analyzed for bromine content, as summarized in Table 8-3. The bromine in the ash was extracted with the SGLP (EPA Method 1312) and analyzed with ion chromatography. During baseline, the bromine content of the ash was $<1 \mathrm{ppm}$. During the $55-\mathrm{ppm} \mathrm{Br}$ injection test, the bromine content of the fly ash was just over $3 \mathrm{ppm}$. At the $113-\mathrm{ppm}$ $\mathrm{Br}$ injection rate, the bromine content of the fly ash was measured at 3.5 and $5.0 \mathrm{ppm}$ for two different test days. The bromine content of the fly ash increased to $7.0 \mathrm{ppm}$ at the 330-ppm injection rate. For all ash samples analyzed, the bromide content of the fly ash represented less than $0.5 \%$ of the bromide injected into the furnace.

\subsection{Analysis of FGD By-Products}

A sample of the FGD slurry was filtered daily on-site and preserved for mercury analysis off-site at URS's Austin laboratories. The mercury concentrations in the FGD solids and liquors are summarized in Table 8-4. The baseline mercury concentration of the FGD solids ranged from 1.50 to $3.16 \mathrm{ppm}$, and the baseline mercury concentration of the FGD liquor was $3.22 \mathrm{ppb}$. Greater than $98 \%$ of the mercury in the FGD slurry was contained in the FGD solids.

For both the 55-ppm and 113-ppm Br injection tests, the first week of $\mathrm{CaBr}_{2}$ injection did not appear to affect either the liquor or solids mercury concentrations. In the second week of testing, the mercury concentration of the liquor increased by two orders of magnitude, while the mercury concentration of the solids decreased by one order of magnitude. These data indicate that the partitioning of the mercury in the FGD by-products shifts from the solid to the liquor phase. At the conclusion of the 55-ppm $\mathrm{Br}$ injection test, approximately half of the mercury in the FGD slurry was contained in the liquor; at the end of the 113-ppm Br test, over $85 \%$ of the mercury in the FGD slurry was contained in the liquor. The increase in mercury concentration of the liquor is a step change that occurs after approximately 1 week of injection, perhaps indicating that there is some sort of threshold that must be overcome. This sudden increase occurred after 10 days of injection at $55 \mathrm{ppm} \mathrm{Br}$ and after only 7 days of injection at $113 \mathrm{ppm}$ Br. Figure 8-4 plots the change in mercury content of the FGD solids and liquor for the long-term test at 113 ppm Br.

Table 8-5 presents the chemical analysis of the FGD liquors and solids collected during the two long-term injection tests. The sulfite concentration of the liquor was below the detection limit of $4 \mathrm{ppm}$. The chloride concentration of the liquor ranged between 2000 and $3500 \mathrm{ppm}$. Baseline bromide concentrations were much lower, ranging between 27 and $35 \mathrm{ppm}$. The bromide concentration of the liquor increased during the calcium bromide injection tests as indicated in Figure 8-5. After 2 weeks of injection at $55 \mathrm{ppm} \mathrm{Br}$ in the coal, the bromine concentration of the FGD liquor reached a steady value of $55 \mathrm{ppm}$. After approximately 10 days of injection at $113 \mathrm{ppm} \mathrm{Br}$ in the coal, the bromine concentration of the FGD liquor reached a steady $110 \mathrm{ppm}$. The increase in bromine concentration in the FGD liquor represented approximately $8 \%$ of the bromine injected into the furnace. 
Table 8-3. Fly Ash Bromide Concentrations

\begin{tabular}{lccccc}
\hline Condition & Date & Time & Composite of Hoppers & Field & $\begin{array}{c}\text { Br in Ash, } \\
\mu \mathrm{g} / \mathrm{g}\end{array}$ \\
\hline Baseline & $11 / 4 / 2005$ & $17: 00$ & $1,2,4,5,6$ & 1 & $<1$ \\
Baseline & $12 / 1 / 2005$ & $14: 00$ & $1,2,4,5,6$ & 1 & $<1$ \\
$55 \mathrm{ppm} \mathrm{Br}$ & $11 / 9 / 2005$ & $14: 30$ & $1,2,4,5,6$ & 1 & 2.25 \\
$55 \mathrm{ppm} \mathrm{Br}$ & $11 / 13 / 2005$ & $16: 45$ & $1,2,4,5,6$ & 1 & 3.10 \\
$55 \mathrm{ppm} \mathrm{Br}$ & $11 / 17 / 2005$ & $11: 50$ & $1,2,4,5,6$ & 1 & 3.20 \\
$55 \mathrm{ppm} \mathrm{Br}$ & $11 / 17 / 2005$ & $11: 50$ & $7,8,11,12$ & 2 & 4.46 \\
$113 \mathrm{ppm} \mathrm{Br}$ & $12 / 9 / 2005$ & $11: 00$ & $1,2,4,5$ & 1 & 5.03 \\
$113 \mathrm{ppm} \mathrm{Br}$ & $12 / 11 / 2005$ & $11: 15$ & $1,2,4,5$ & 1 & 3.54 \\
$113 \mathrm{ppm} \mathrm{Br}$ & $12 / 11 / 2005$ & $11: 15$ & $7,8,11,12$ & 2 & 3.71 \\
$330 \mathrm{ppm} \mathrm{Br}$ & $12 / 13 / 2005$ & $14: 45$ & $1,2,4,5,6$ & 1 & 6.98 \\
\hline
\end{tabular}

Table 8-4. Mercury Content of FGD Samples

\begin{tabular}{lcccc}
\hline Condition & Date & Time & $\begin{array}{c}\text { Hg in FGD } \\
\text { liquor, } \mu \text { g/L }\end{array}$ & $\begin{array}{c}\text { Hg in FGD } \\
\text { solid, } \mu \mathrm{g} / \mathrm{g}\end{array}$ \\
\hline Baseline & $11 / 3 / 05$ & $16: 30$ & 3.93 & 1.50 \\
Baseline & $11 / 4 / 05$ & $16: 48$ & 3.22 & 3.16 \\
$55 \mathrm{ppm} \mathrm{Br}$ & $11 / 6 / 05$ & $\mathrm{NA}$ & 2.11 & 3.24 \\
$55 \mathrm{ppm} \mathrm{Br}$ & $11 / 9 / 05$ & $14: 15$ & 4.08 & 2.51 \\
$55 \mathrm{ppm} \mathrm{Br}$ & $11 / 11 / 05$ & $15: 30$ & 2.83 & 2.83 \\
$55 \mathrm{ppm} \mathrm{Br}$ & $11 / 13 / 05$ & $16: 00$ & 3.13 & 3.61 \\
$55 \mathrm{ppm} \mathrm{Br}$ & $11 / 15 / 05$ & $11: 37$ & 111 & Not available \\
$55 \mathrm{ppm} \mathrm{Br}$ & $11 / 17 / 05$ & $15: 40$ & 163 & 1.48 \\
$\mathrm{Baseline}$ & $12 / 2 / 05$ & $10: 10$ & $50.2 *$ & 2.46 \\
$113 \mathrm{ppm} \mathrm{Br}$ & $12 / 5 / 05$ & $16: 45$ & 6.87 & 3.21 \\
$113 \mathrm{ppm} \mathrm{Br}$ & $12 / 7 / 05$ & $13: 08$ & 4.38 & 3.30 \\
$113 \mathrm{ppm} \mathrm{Br}$ & $12 / 9 / 05$ & $15: 45$ & 262 & 0.89 \\
$113 \mathrm{ppm} \mathrm{Br}$ & $12 / 11 / 05$ & $10: 20$ & 455 & 0.48 \\
$330 \mathrm{ppm} \mathrm{Br}$ & $12 / 13 / 05$ & $15: 15$ & Not available & 0.38 \\
$330 \mathrm{ppm} \mathrm{Br}$ & $12 / 14 / 05$ & $14: 40$ & 417 & 0.33 \\
\hline
\end{tabular}

* This value appears to be an outlier for baseline scrubber liquor mercury concentration.

Long-term furnace chemical injection of calcium bromide did not result in an increase in the bromine concentration of the FGD solids from baseline values. Baseline FGD solids bromine concentrations were $10 \mathrm{ppm}$ or less; the bromine concentrations of the FGD solids during chemical injection ranged from 8 to $19 \mathrm{ppm}$.

During the long-term calcium bromide injection test, the maximum bromide concentrations reached in the liquor were less than $10 \%$ of the chloride concentration; however, the bromide species is more reactive than the chloride species with respect to mercury complexation. This test program was not long enough to evaluate the effect of the elevated bromide concentration on the 


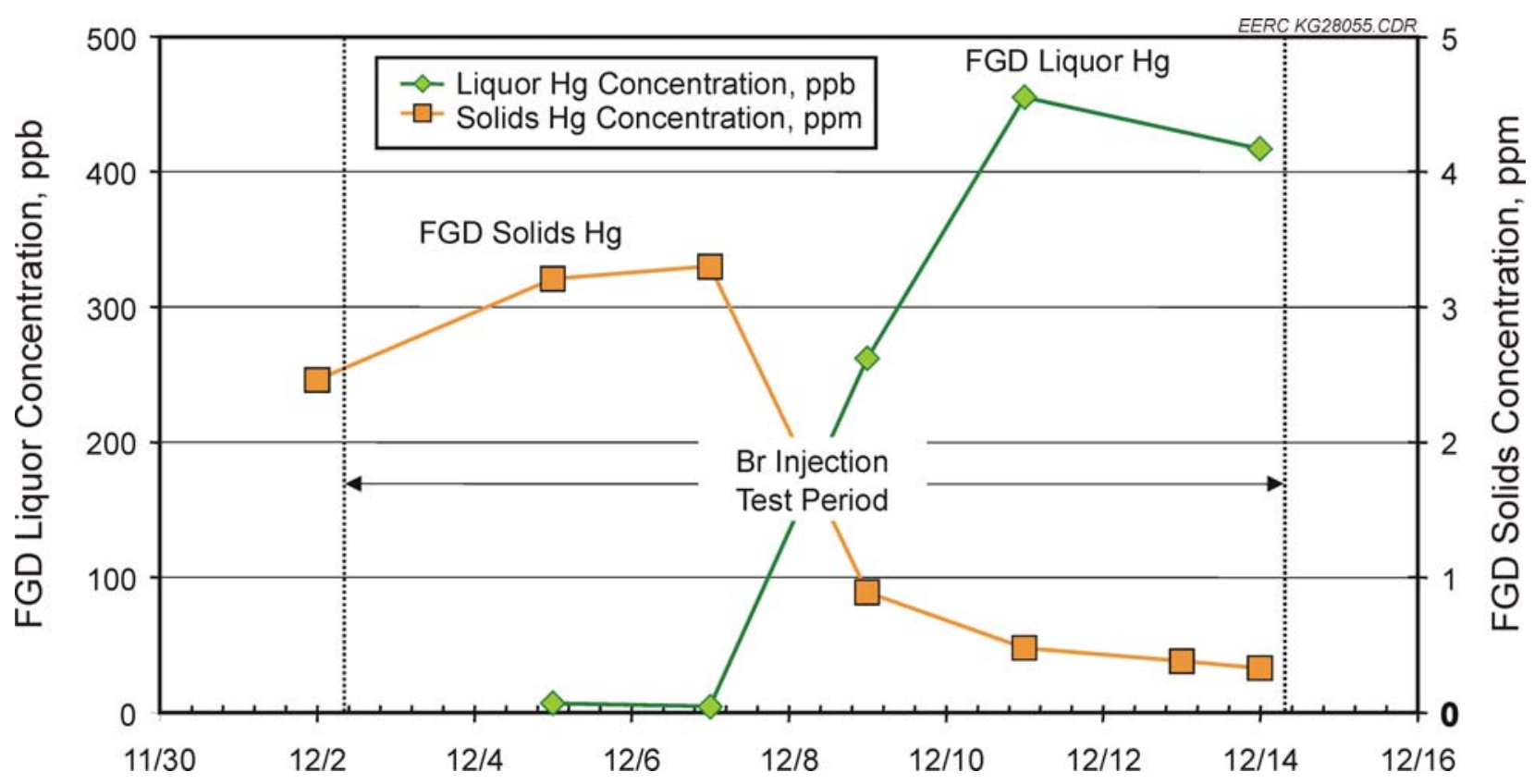

Figure 8-4. Shift in mercury content of FGD by-product from solid to liquid phase during second long-term injection test.

rate of corrosion of the materials of construction for the FGD scrubber. Monticello Unit 3 was inspected during a plant outage that followed 4 months after the long-term calcium bromide tests. There were no abnormal signs of corrosion observed.

A mass balance on the bromine does not close for this system. Of the bromine injected into the furnace, approximately $8 \%$ was found in the FGD liquor, none was found in the FGD solids, and less than $0.5 \%$ was found in the ash. It is unclear why the other $90 \%$ of the injected bromine did not show up in the FGD liquor. A possible sample bias in the measurement of bromine in the FGD liquor is being investigated.

\subsection{ECONOMIC ANALYSIS OF MERCURY CONTROL}

\subsection{Capital Cost Estimates}

Economic evaluations of mercury control for the MRY Unit 2 and MoSES Unit 3 were performed. The generation capacity of MRY Unit 2 and MoSES Unit 3 are $450 \mathrm{MW}$ and $739 \mathrm{MW}$, respectively. Because of the different size of two units, there were substantial differences in the capital costs and operating and maintenance (O\&M) costs. Economic evaluations of mercury control for MRY Unit 2 were performed assuming various $\mathrm{CaCl}_{2}, \mathrm{SEA} 2$, $\mathrm{CaCl}_{2}$ with PAC, and SEA2 with PAC injection rates. The primary capital investments were an additive injection skid and PAC feeder. The economic evaluation for MoSES Unit 3 was performed with $\mathrm{CaBr}_{2}$ injection as the mercury control technology. The primary capital 
Table 8-5. Results from Analysis of FGD Solids and Liquors

\begin{tabular}{|c|c|c|c|c|c|c|c|c|c|c|}
\hline Date: & $11 / 4 / 05$ & $11 / 9 / 05$ & $11 / 13 / 05$ & $11 / 15 / 05$ & $11 / 17 / 05$ & $12 / 2 / 05$ & $12 / 5 / 05$ & $12 / 7 / 05$ & $12 / 11 / 05$ & $12 / 14 / 05$ \\
\hline Time: & $16: 45$ & $14: 20$ & $16: 15$ & $11: 37$ & $15: 40$ & $10: 10$ & $16: 45$ & 13:08 & 10:20 & $14: 40$ \\
\hline Condition: & Baseline & $55 \mathrm{ppm} \mathrm{Br}$ & $55 \mathrm{ppm} \mathrm{Br}$ & $55 \mathrm{ppm} \mathrm{Br}$ & $55 \mathrm{ppm} \mathrm{Br}$ & Baseline & $113 \mathrm{ppm} \mathrm{Br}$ & $113 \mathrm{ppm} \mathrm{Br}$ & $113 \mathrm{ppm} \mathrm{Br}$ & $330 \mathrm{ppm} \mathrm{Br}$ \\
\hline $\mathrm{pH}$ & 5.62 & 5.72 & 5.62 & 5.76 & 5.7 & 5.6 & 5.73 & 5.79 & 5.7 & 5.74 \\
\hline Temp., ${ }^{\circ} \mathrm{C}$ & 56.2 & 60.1 & 55 & 58.9 & 53.8 & 56.8 & 57.2 & 57.2 & 57.6 & 57.8 \\
\hline \multicolumn{11}{|c|}{ Liquids Summary } \\
\hline $\mathrm{Ca}, \mathrm{mg} / \mathrm{L}$ & 667 & 651 & 676 & 736 & 674 & 646 & 641 & 644 & 674 & 642 \\
\hline $\mathrm{Mg}, \mathrm{mg} / \mathrm{L}$ & 2500 & 2569 & 2040 & 1945 & 1683 & 2293 & 2240 & 2538 & 1651 & 2037 \\
\hline $\mathrm{Na}, \mathrm{mg} / \mathrm{L}$ & 1889 & 1895 & 1540 & 1448 & 1219 & 1549 & 1591 & 1768 & 1195 & 1403 \\
\hline $\mathrm{Cl}, \mathrm{mg} / \mathrm{L}$ & 3441 & 3542 & 2815 & 2888 & 2381 & 3055 & 2775 & 3332 & 2118 & 2680 \\
\hline $\mathrm{Br}, \mathrm{mg} / \mathrm{L}$ & 35 & 37 & 41 & 55 & 55 & 27 & 72 & 102 & 109 & 145 \\
\hline $\mathrm{CO}_{3}, \mathrm{mg} / \mathrm{L}$ & 21 & 31 & 23 & 19 & 21 & 23 & 23 & 21 & 28 & 20 \\
\hline $\mathrm{SO}_{3}, \mathrm{mg} / \mathrm{L}$ & $<3$ & $<3$ & $<3$ & $<3$ & $<2$ & $<2$ & $<4$ & $<2$ & $<2$ & $<2$ \\
\hline $\mathrm{SO}_{4}, \mathrm{mg} / \mathrm{L}$ & 9960 & 10,373 & 8447 & 8383 & 7314 & 8833 & 8970 & 9748 & 6815 & 7863 \\
\hline \multicolumn{11}{|c|}{ Solids Summary } \\
\hline $\mathrm{Ca}, \mathrm{mg} / \mathrm{g}$ & 228 & 225 & 228 & 228 & 228 & 225 & 221 & 223 & 230 & 228 \\
\hline $\mathrm{Mg}, \mathrm{mg} / \mathrm{g}$ & 1.03 & 0.53 & 0.64 & 0.66 & 0.46 & 0.38 & 0.33 & 0.36 & 0.28 & 0.29 \\
\hline $\mathrm{Br}, \mathrm{mg} / \mathrm{g}$ & 13 & 8 & $<10$ & 9 & 9 & $<10$ & $<10$ & $<10$ & 19 & 13 \\
\hline $\mathrm{SO}_{3}, \mathrm{mg} / \mathrm{g}$ & 0.00 & 0.26 & 0.26 & 0.53 & 0.67 & 0.27 & 0.27 & 0.27 & 0.00 & 0.00 \\
\hline $\mathrm{SO}_{4}, \mathrm{mg} / \mathrm{g}$ & 538 & 542 & 543 & 538 & 548 & 543 & 546 & 541 & 543 & 542 \\
\hline $\mathrm{CO}_{3}, \mathrm{mg} / \mathrm{g}$ & 0.30 & 0.14 & 1.35 & 4.95 & 0.30 & 1.51 & 1.30 & 1.76 & 1.06 & 1.64 \\
\hline Inerts, wt $\%$ & 1.4 & 1.08 & 1.42 & 1.39 & 1.07 & 1 & 0.8 & 0.91 & 1.11 & 0.96 \\
\hline Solids, wt\% & 6.2 & 12.9 & 8.9 & 12.1 & 12.8 & 13.3 & 13.2 & 14.0 & 14.5 & 8.9 \\
\hline Oxidation, \% & 100 & 99.9 & 99.9 & 99.9 & 99.9 & 99.9 & 99.9 & 99.9 & 100 & 100 \\
\hline
\end{tabular}




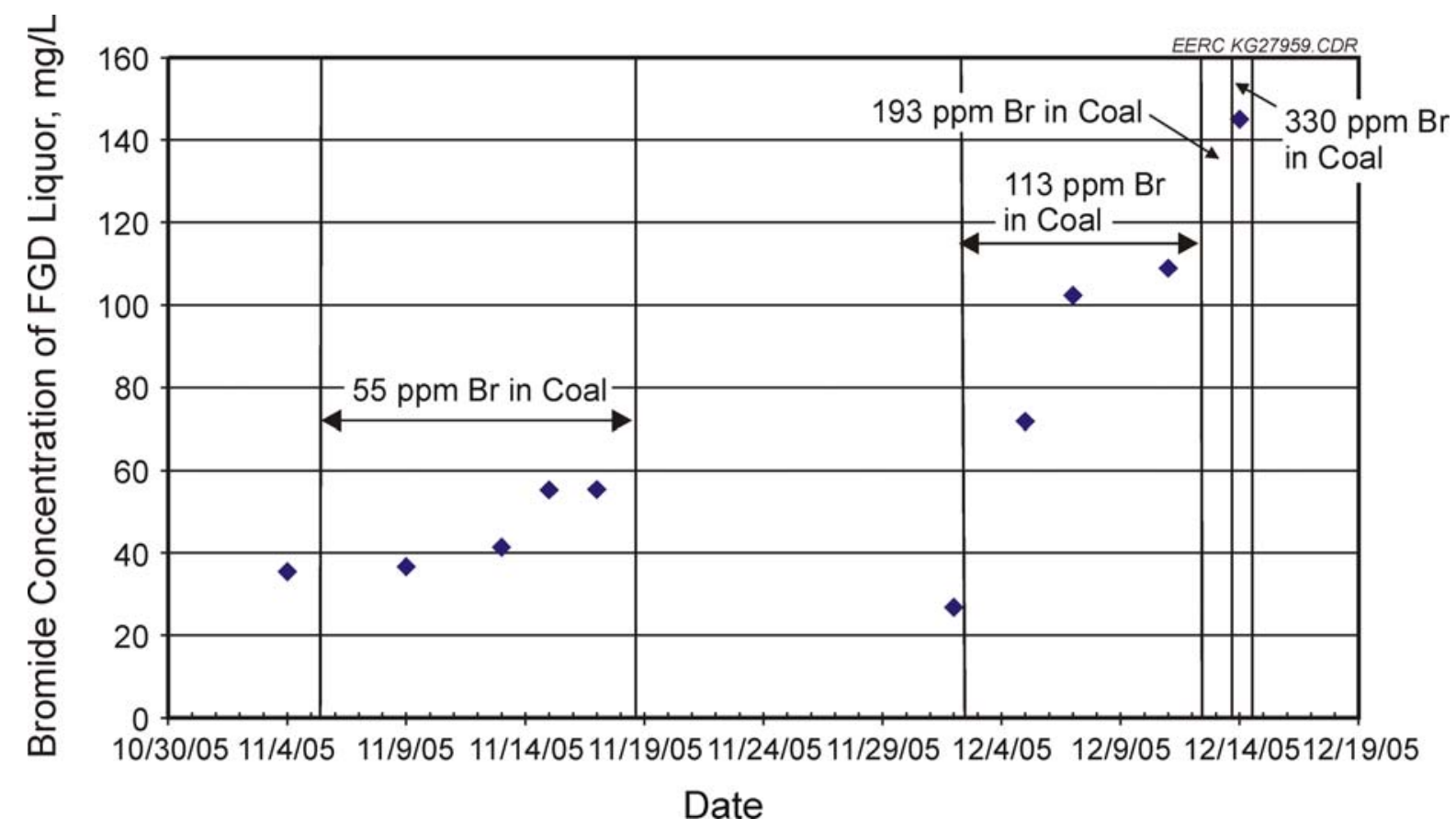

Figure 8-5. Measured bromide concentration of FGD liquor.

investment cost for MoSES was an additive injection skid. Cost estimates for these systems included the following:

- Base equipment cost

- Instrumentation and controls

- Injection lances and distribution modeling

- Shipping

- Installation costs

- Earthwork, foundation, and structural support

- Labor (general, technical, and supervisory)

- Checkout testing

- Contingency

- Taxes

\subsubsection{PAC Feeder System}

A Portapack injection system was supplied and installed by Apogee Scientific. At the injection rates used, PAC consumption was approximately a 900-lb supersack every 2 days, which was well within the maximum capacity of the PAC system. The total estimated capital cost of the delivered PAC injection system was $\$ 974,000$. The following items were included with the PAC injection system:

- PAC storage silo and all associated equipment 
- Volumetric feeder, hopper, and associated equipment for delivery lines

- Eductors and blowers

- All structural steel and piping

- Control panel and associated software and hardware

- Injection distribution system (injection lances) and flow/distribution modeling

- Field support services

In addition to capital equipment provided by a vendor, site preparation and infrastructure would be required by plant personnel. The MRY Plant was assumed to provide the following:

- Concrete foundations for the silo, feeders, and blowers

- Unloading and assembly of vendor-supplied equipment with support from the PAC vendor on-site technician

- Piping to provide dry compressed air (100 psi) to the feeder and silo

- Drainage and containment as required by the site to collect and dispose of wash-down and any other wastes generated by the PAC system

- Electrical service including single-phase $120-\mathrm{V}$ and three-phase $480-\mathrm{V}$ power

- Communication wiring to the plant process and data control system

- General lighting

- Applicable permits

\subsubsection{Aqueous Injection Skid}

$\mathrm{B} \& \mathrm{~W}$ provided a system to inject $\mathrm{CaCl}_{2}, \mathrm{MgCl}_{2}, \mathrm{SEA} 2$, and $\mathrm{CaBr}_{2}$ in an aqueous form. The system consists of four skid-mounted transfer pumps, flowmeters, and controllers to enable the injection rate of the aqueous solution to be adjusted and, if necessary, follow the load through communications with the plant data collection system. The control panel received a signal from the plant, allowing the injection rate to be set and controlled proportionally to the overall coal feed rate. Each pump had a maximum capacity of $2.2 \mathrm{gpm}$. The total capital cost of the aqueous injection system was $\$ 500,000$.

Plant-required costs to install an injection skid include site preparation, foundation installation, and piping and electrical connection. The total installation cost is calculated based on using $\$ 32 / \mathrm{hr}$ for skilled labor such as operators, technicians, and electricians; $\$ 23 / \mathrm{hr}$ for general labor; and an overhead rate plus benefit rate of $42 \%$ on labor cost. Table 9-1 presents the installation costs for the aqueous injection system. 
Table 9-1. Installation Costs for Aqueous

Injection Skid

\begin{tabular}{lcc}
\hline Item & Hours & Cost, \$ \\
\hline Skilled Labor & 300 & 9600 \\
General Labor & 80 & 1840 \\
Concrete Pad & & 5500 \\
Supplies & & 6500 \\
Overhead & 5260 \\
\hline Total & & 28,700 \\
\hline
\end{tabular}

\section{$9.2 \quad 0 \& M$ Costs}

The O\&M costs are divided into variable and fixed costs. The primary variable costs are associated with purchases of $\mathrm{CaCl}_{2}, \mathrm{SEA} 2, \mathrm{CaBr}_{2}$, and PAC. The delivered cost of PAC was $\$ 0.58 / \mathrm{lb}$. The delivered cost of $\mathrm{CaCl}_{2}$ was $\$ 0.3 / \mathrm{lb}$ compared to $\$ 2.05 / \mathrm{lb}$ for SEA2 and $\mathrm{CaBr}_{2}$.

Also included in the O\&M costs are the operating labor, maintenance labor, replacement parts, and utilities. The fixed costs for installation include taxes, capital recovery, and depreciation. Additional factors, pertinent to operational costs that were used to evaluate the economic impact of mercury capture include the following:

- Economic life, 20 years

- Discount rate, $6.5 \%$

- Escalation factor, $3.5 \%$

- Depreciation rate, $5 \%$

- Overhead and benefit rate, $42 \%$ of O\&M labor costs

\subsubsection{Maintenance and Replacement Parts}

Maintenance, both routine and unscheduled, has an impact on operational costs. Typically, maintenance activities would include routing system inspection, equipment servicing based on manufacturer specifications (i.e., lubrication, calibration), and repair of equipment failure or damage. The total labor requirement for maintenance of the PAC skid has been estimated at 80 personnel days for general labor and 40 personnel days for specialized labor. Maintenance labor for the $\mathrm{CaCl}_{2}, \mathrm{CaBr}_{2}$, and SEA2 injection system has been estimated at 40 personnel days of general labor and 20 personnel days of specialized maintenance labor. The cost for replacement parts has been based on a percentage of the total purchase cost for the skids and is set at $2 \%$ of the total product cost (TPC) on an annual basis.

\subsubsection{Utility Costs}

The overall utility cost for the PAC and aqueous injection systems is a product of feed rate. Therefore, the energy costs are based on the maximum capacity of the equipment. Each of the two process systems contains several electrical components that contribute to the overall energy 
consumption. The electrical requirements for the components of the PAC skid include the following:

- Rotary valves are driven by a $1 / 2-\mathrm{hp}, 480-\mathrm{V}$ motor.

- The volumetric feeder is driven by a 1-hp, 480-V motor.

- The blowers (two) are each 10-hp, 480-V.

- Miscellaneous process control and communication power are supplied by a $480-\mathrm{V}$ control center.

The utilities necessary to operate the aqueous injection skid are:

- Propane or natural gas at $2.5 \mathrm{~kg} / \mathrm{hr}$.

- A 7-hp, 480-V blower.

- Miscellaneous process control and communication power, likely provided through the PAC system.

- $5 \mathrm{gal} / \mathrm{min}$ of cooling water.

The total power requirement on a yearly basis for the PAC skid is $25 \mathrm{~kW}$, or $195,000 \mathrm{kWh}$. For the aqueous injection skid, the total amount of propane and natural gas is $50 \mathrm{cfh}$, or $385,000 \mathrm{cf} / \mathrm{yr}$, and the yearly power requirement is $65,600 \mathrm{kWh}$. The total cooling water is $2.3 \times 10^{6} \mathrm{gal} / \mathrm{yr}$. Utility costs used for the cost analysis include the following:

- $\$ 0.045 / \mathrm{kWh}$ for electricity

- $\$ 1.042 / \mathrm{scf}$ for natural gas

- $\$ 1.00 / 1000$ gal for water

\subsection{Economic Evaluation of Mercury Control at MRY Station Unit 2}

The economic evaluation of mercury control for MRY Unit 2 was based on the operations data presented in Table 9-2. Economic analysis results for eight different mercury control technology scenarios involving $\mathrm{CaCl}_{2}, \mathrm{SEA} 2$, and PAC injections at MRY Unit 2 are presented in Table 9-3. As indicated in Table 9-3, SEA2 and a small amount of PAC injection were more cost-effective compared to $\mathrm{CaCl}_{2}$ injection.

Table 9-2. MRY Unit 2 Operations Data

\begin{tabular}{lc}
\hline Plant Capacity, net MW & 450 \\
Capacity Factor & 0.85 \\
Flue Gas Volume, acf/min ${ }^{\mathrm{a}}$ & $1,109,585$ \\
Temperature of Flue Gas, ${ }^{\circ} \mathrm{F}$ & 181.2 \\
Net Unit Heat Rate, Btu/kWh & 10,137 \\
Fuel Burn Rate, ton $/ \mathrm{hr}$ & 337 \\
Excess $\mathrm{O}_{2}, \%$ volume dry basis & 4.16 \\
\hline
\end{tabular}

${ }^{\mathrm{a}}$ Volume is based on fuel burn rate. 


\subsection{Economic Evaluation of Mercury Control at MoSES Unit 3}

The economic evaluation of mercury control for MoSES Unit 3 was based on the operations data presented in Table 9-4. Presented in Table 9-5 are cost estimates associated with controlling mercury at MoSES Unit 3 using various $\mathrm{CaBr}_{2}$ injection rates.

\subsection{COSTS OF MERCURY MEASUREMENT AND REPORTING UNDER CAMR}

CAMR requires each utility $(>25 \mathrm{MW})$ to continuously monitor mercury and report the results to both ensure the utility is in compliance with the rule and provide data for establishing trading criteria. Two methods are outlined in the rule to measure mercury: using CMMs or sorbent traps (referred to as Appendix K). The costs are very different for these two methods. For the purposes of this report, it has been assumed that the monitor purchased will be a Tekran Model 3300. For Appendix K, it has been assumed that the traps are purchased and analyzed by Frontier Geosciences at present costs. It should be noted that for Appendix K, there are very few vendors from which to purchase sampling equipment and traps and obtain sample trap analysis. It is expected that during the next 3-5 years, the cost will decrease as new methods are developed and more vendors become equipped to support this method. The costs associated with mercury measurement and reporting are listed below:

- Capital costs for mercury measurement equipment

- If CMMs are used, costs are associated with PS 12A (instrument setup)

- If Appendix $\mathrm{K}$ is used, there are costs associated with purchasing, replacing, and analyzing sorbent traps

- Training costs

- Maintenance costs including replacement parts

- Ongoing QA/QC requirements including a yearly relative accuracy test assessment (RATA)

- Reporting costs associated with mercury measurement

- Reporting costs associated with cap-and-trade provisions of CAMR

\subsection{CMM}

Based on a recent quote from Tekran, the cost of the CMM is $\$ 122,365$. The capital costs for purchasing and installing a CMM include the following:

- Sample conditioner module

- Elemental mercury calibration unit 
Table 9-3. Summary of Costs Associated with Mercury Control at MRY Unit 2

\begin{tabular}{|c|c|c|c|c|c|c|c|c|}
\hline & Case 1 & Case 2 & Case 3 & Case 4 & Case 5 & Case 6 & Case 7 & Case 8 \\
\hline $\begin{array}{l}\text { Targeted Mercury } \\
\text { Removal }\end{array}$ & $16 \%$ & $44 \%$ & $55 \%$ & $35 \%$ & $53 \%$ & $55 \%$ & $60 \%$ & $55 \%$ \\
\hline Test Type $^{1}$ & $\mathrm{P}$ & $P$ & $\mathrm{P}$ & $\mathrm{P}$ & $P$ & $\mathrm{P}$ & $P$ & $\mathrm{~L}$ \\
\hline $\mathrm{CaCl}_{2}$ Injection Rate, ppm & 500 & - & - & 300 & - & - & & \\
\hline SEA2 Injection Rate, ppm & - & 75 & 112 & - & 50 & 50 & 50 & 100 \\
\hline PAC Injection Rate, lb/Macf & - & - & - & 1.0 & 0.49 & 0.61 & 1.03 & 0.15 \\
\hline \multicolumn{9}{|l|}{ Capital Cost, \$ } \\
\hline Purchased Equipment & 500,000 & 500,000 & 500,000 & $1,474,000$ & $1,474,000$ & $1,474,000$ & $1,474,000$ & $1,474,000$ \\
\hline Installation & 26,950 & 26,950 & 26,950 & 51,950 & 51,950 & 51,950 & 51,950 & 51,950 \\
\hline Indirect $^{2}$ & 90,000 & 90,000 & 90,000 & 90,000 & 90,000 & 90,000 & 90,000 & 90,000 \\
\hline Total Capital Cost & 616,950 & 616,950 & 616,950 & $1,615,950$ & $1,615,950$ & $1,615,950$ & $1,615,950$ & $1,615,950$ \\
\hline \multicolumn{9}{|l|}{ O\&M, \$/yr } \\
\hline Operating Labor & 16,000 & 16,000 & 16,000 & 48,000 & 48,000 & 48,000 & 48,000 & 48,000 \\
\hline Maintenance Labor & 79,800 & 79,800 & 79,800 & 98,040 & 98,040 & 98,040 & 98,040 & 98,040 \\
\hline Supervision Labor ${ }^{3}$ & 2400 & 2400 & 2400 & 7200 & 7200 & 7200 & 7200 & 7200 \\
\hline Replacement Parts ${ }^{4}$ & 10,000 & 10,000 & 10,000 & 29,480 & 29,480 & 29,480 & 29,480 & 29,480 \\
\hline Sorbents/Additives & 752,794 & 771,613 & $1,152,276$ & 806,311 & 688,180 & 730,736 & 879,682 & $1,082,013$ \\
\hline Utilities & 5252 & 5252 & 5252 & 14,027 & 14,027 & 14,027 & 14,027 & 14,027 \\
\hline Disposal & 0 & 0 & 0 & 7606 & 6849 & 7762 & 10,956 & 7385 \\
\hline Overhead $^{5}$ & 37,870 & 37,870 & 37,870 & 63,952 & 63,952 & 63,952 & 63,952 & 63,952 \\
\hline Taxes, Insurance, & 30,848 & 30,848 & 30,848 & 80,798 & 80,798 & 80,798 & 80,798 & 80,798 \\
\hline Administration $^{6}$ & & & & & & & & \\
\hline Fixed Charges & 114,602 & 114,602 & 114,602 & 300,173 & 300,173 & 300,173 & 300,173 & 300,173 \\
\hline \multicolumn{9}{|l|}{ Levelized Annual Costs, $\$^{7}$} \\
\hline Total Annual Cost, $\$ / y r$ & $1,321,980$ & $1,346,764$ & $1,848,053$ & $1,758,392$ & $1,601,830$ & $1,659,074$ & $1,859,426$ & $2,121,169$ \\
\hline Total Annual Cost, & 0.39 & 0.40 & 0.55 & 0.52 & 0.48 & 0.50 & 0.55 & 0.63 \\
\hline \$/MWh (mills/kWh) & & & & & & & & \\
\hline $\begin{array}{l}\text { Mercury Reduction, \$/lb } \\
\text { Hg Removed }\end{array}$ & 91,568 & 14,088 & 14,496 & 17,379 & 10,445 & 10,424 & 12,834 & 16,639 \\
\hline
\end{tabular}

$\mathrm{P}$ - parametric, $\mathrm{L}$ - monthlong.

Indirect charges (includes contingency) are for SEA skid only.

${ }^{3}$ Based on $15 \%$ of operating labor.

Based on $2 \%$ of purchase equipment.

${ }^{5}$ Based on $20 \%$ of labor costs.

${ }^{6}$ Based on 3\% of total capital requirements.

The sum of the levelized operating and fixed costs. 
Table 9-4. MoSES Unit 3 Operations Data

\begin{tabular}{lc}
\hline Plant Capacity, net MW & 793 \\
Capacity Factor & 0.85 \\
Flue Gas Volume, acf $/ \mathrm{min}^{\mathrm{a}}$ & $2,798,155$ \\
Temperature of Flue Gas, ${ }^{\circ} \mathrm{F}$ & 345 \\
Net Unit Heat Rate, Btu/kWh & 10,357 \\
Fuel Burn Rate, ton $/ \mathrm{hr}$ & 573 \\
Excess $\mathrm{O}_{2}, \%$ volume dry basis & $6 \%$ \\
\hline
\end{tabular}

${ }^{\mathrm{a}}$ Volume is based on fuel burn rate.

Table 9-5. Cost Estimates Associated with Controlling Mercury at MoSES Unit 3

\begin{tabular}{|c|c|c|c|}
\hline & Case 1 & Case 2 & Case 3 \\
\hline Plant Configuration & ESP-FGD & ESP-FGD & ESP-FGD \\
\hline Targeted Mercury Removal & $59 \%$ & $83 \%$ & $90 \%$ \\
\hline $\mathrm{CaBr}_{2}$ Injection Rate, ppm & 113 & 193 & 330 \\
\hline \multicolumn{4}{|l|}{ Capital Cost, \$ } \\
\hline Purchased Equipment & 500,000 & 500,000 & 500,000 \\
\hline Installation & 26,950 & 26,950 & 26,950 \\
\hline Indirect $^{1}$ & 90,000 & 90,000 & 90,000 \\
\hline Total Capital Requirement & 616,950 & 616,950 & 616,950 \\
\hline \multicolumn{4}{|l|}{ O\&M, \$/yr } \\
\hline Operating Labor & 16,000 & 16,000 & 16,000 \\
\hline Maintenance Labor & 79,800 & 79,800 & 79,800 \\
\hline Supervision Labor $^{2}$ & 2,400 & 2,400 & 2,400 \\
\hline Replacement Parts ${ }^{3}$ & 10,000 & 10,000 & 10,000 \\
\hline Raw Materials (SEA2) & $1,976,905$ & $3,376,483$ & $5,773,261$ \\
\hline Utilities & 5252 & 5252 & 5252 \\
\hline Overhead $^{4}$ & 37,870 & 37,870 & 37,870 \\
\hline Taxes, Insurance, & 30,848 & 30,848 & 30,848 \\
\hline \multicolumn{4}{|l|}{ Administration ${ }^{5}$} \\
\hline Fixed Charges & 114,602 & 114,602 & 114,602 \\
\hline \multicolumn{4}{|l|}{ Levelized Annual Costs, $\$^{6}$} \\
\hline Total Annual Cost, $\$ / y r$ & $2,933,996$ & $4,772,082$ & $7,933,368$ \\
\hline $\begin{array}{l}\text { Total Annual Cost, } \$ \text { /MWh } \\
\text { (mills/kWh) }\end{array}$ & 0.50 & 0.81 & 1.34 \\
\hline $\begin{array}{l}\text { Mercury reduction, } \$ / 1 \mathrm{~b} \mathrm{Hg} \\
\text { removed }\end{array}$ & 7336 & 6641 & 9764 \\
\hline $\begin{array}{l}{ }^{1} \text { Indirect charges (includes contin } \\
{ }^{2} \text { Based on } 15 \% \text { of operating labo } \\
{ }^{3} \text { Based on } 2 \% \text { of purchase equipr } \\
{ }^{4} \text { Based on } 20 \% \text { of labor costs. } \\
{ }^{5} \text { Based on } 3 \% \text { of total capital req }\end{array}$ & cy) are for SEA & skid only. & \\
\hline
\end{tabular}


- Inertial sampling system and probe

- Mercury analyzer

- Heated umbilical cord

- Air and water filtrations systems

- Mounting rack

- Shipping

To complete the specifications as required by PS $12 \mathrm{~A}$ and provide necessary QA/QC, a $\mathrm{CMM}$ will also require an oxidized mercury injection system. The estimated cost for the system is $\$ 35,000$ (based on projected cost for the Tekran system available in fall 2006).

As part of the purchase price, the vendor will provide an instrument technician to aid the plant in installing the CMM. Based on the EERC's experience, it is assumed that a minimum of a month of skilled labor will be required to install the CMM. Once the instrument is installed, the protocols as written in PS 12A in 40 Code of Federal Regulations (CFR) Part 60 must be completed. Although training costs are considered to be part of the O\&M costs, there is some overlap with installation costs associated with PS 12A. It is expected the vendor or hired consultants (integrators) will provide additional training and consulting support to help meet the requirements of PS 12A. The most costly part of PS 12A will be doing a complete RATA. Based on the requirements stated in CAMR, a RATA consists of completing nine valid paired sets of $\mathrm{OH}$ method samples. The relative difference between the paired trains must be less than $10 \%$. The RATA cost to complete 12 paired trains (nine required plus three contingency samples) is estimated to be $\$ 55,000$. It is possible that, in the future, an instrumental reference method may be developed that could reduce this cost.

Although not considered part of this economic analysis, another potential cost item for operating CMMs is the potential need to expand the plant's CMM complex. These instruments are fairly large and at a site with multiple stacks more space may be needed.

Once the instrument has been installed and is operating (must be completed by January 1, 2009), the plant must then obtain 12 months of valid data before it is required to begin reporting data for compliance purposes. Assuming an economic life of 10 years (although the firstgeneration compliance CMMs may be replaced earlier as it is expected that vendors will be making improvements during the first couple years of operation), the main O\&M costs associated with CMM use include the following:

- Training costs

- Utility requirements (electrical, air, argon, etc.)

- Operational and maintenance labor

- Replacement parts

- Annual RATA

- Reporting and recordkeeping

A minimum of 3 weeks of training time per person will be needed to ensure an instrument technician is able to operate and perform the required maintenance and troubleshoot these instruments. A utility will need to have at least two people able to operate these instruments. 
Therefore, training costs will include 30 days of instrument technician time and the cost of the training, which is expected to cost $\$ 100 / \mathrm{hr}$, resulting in a total training cost of $\$ 24,000$.

It is expected, especially during the first year, that a minimum of $2 \mathrm{hr} /$ day of an instrument technician's time will be needed to ensure the instrument is running properly. Further, it has been assumed that replacement part costs are $10 \%$ of purchased equipment cost, equal to $\$ 15,375$ a year.

For a CMM, the utilities required are electrical power (both to operate the instrument and to ensure the heat-traced umbilical sample line remains hot), compressed air (70-100 psi), argon (two cylinders/month), and deionized water. Table 10-1 provides the required utilities and cost to operate a Tekran with a 500-foot sampling line.

\subsection{Appendix K}

The capital costs for Appendix K sampling include the cost associated with purchasing the sampling box and probe. Based on a quote from Apex, the cost of a load-following unit will be $\$ 25,000$ for a dual-train box. This quote includes the following:

- One consol containing duplicate sampling systems

- A dual-trap heated probe and connections

- A 25-foot umbilical cord and connections

- A chiller

- Software

A plant would also need to purchase a second unit so that when maintenance and calibration of the consol are being done, mercury sampling can continue. Therefore, the total capital cost would be $\$ 50,000$.

In addition to the capital costs of the equipment, it is required that the sampling system be load-following; therefore, the sampling system must be tied into the plant process control and data acquisition system. This will allow the Appendix $\mathrm{K}$ controller to adjust the sample flow proportionate to the plant load. Based on discussions with Apex, it is expected that 40 hours of skilled labor (electrician) will be necessary to install and shake down the system, and $\$ 5000$ of materials will be needed. It is assumed that once installation is complete, switching out sampling consoles will be relatively simple and would be associated with the O\&M costs of switching the sorbent traps.

Table 10-1. Supplies Needed to Operate a Tekran CMM

\begin{tabular}{lccc}
\hline Utility & Required & Cost $/$ Unit & Cost, $\$$ \\
\hline Electrical & $53,340 \mathrm{kWh}$ & $\$ 0.045 / \mathrm{kWh}$ & 2400 \\
Argon & two cylinders $/$ month & $\$ 240 /$ cylinder & 5760 \\
Compressed Air & $80 \mathrm{psi}$ & $\$ 1250 / \mathrm{yr}$ & 1250 \\
Deionized Water & $1 \mathrm{gal} /$ day & $\$ 250 / 1000 \mathrm{gal}$ & 100 \\
\hline Total Cost & & & 9510 \\
\hline
\end{tabular}


The O\&M costs associated with Appendix K, assuming an economic life of 5 years, are as follows:

- Spiked sorbent traps and analyses

- Electrical requirements

- Training costs

- Labor to change the sorbent traps on a weekly basis

- Maintenance

- Annual RATA

- Reporting and recordkeeping

Based on the most current quote from Frontier Geosciences, the cost per spiked trap and analysis is $\$ 200(2 / 20 / 06)$. It will take one person about 8 hours a week to remove and change the traps, bag and ship them, and record the data once they are obtained. There are very few data available regarding maintenance requirements for the Appendix K sampling system, but based on previous work at the EERC with the similar EPA Method 5 systems, it is expected that, with calibration, a total of $80 \mathrm{hr}$ a year will be needed. It is assumed that replacement part costs are $10 \%$ of capital cost, or $\$ 5000$ a year. The power requirement is approximately $3 \mathrm{~kW}$, or $22,860 \mathrm{kWh}$.

Although an initial RATA certification is not necessary, Appendix K does have annual RATA requirements similar to these for a CMM installation. The cost of doing the RATA is estimated to be $\$ 55,000$.

\subsection{Reporting and Record-Keeping Requirements under CAMR}

There are essentially three types of mercury reporting required under CAMR. The first is mercury-monitoring certification reporting. As part of this reporting, a mercury representative must designate and complete a certification application for each monitoring system. In addition, as part of the certification, PS 12A must be met for each monitoring system.

For ongoing mercury-monitoring reporting requirements, monthly reports must be filed electronically. These reports must include all mercury measurement data and a data assessment report based on CAMR requirements. The mercury representative must also report any exceedences as required under $40 \mathrm{CFR} \S 60.7(\mathrm{a})$ and maintain records needed to demonstrate compliance with CAMR.

As part of the cap-and-trade provisions of CAMR, a legally binding and federally enforceable written document (Title V) must be completed. This document must be issued by a permitting authority and must specify the mercury budget-trading requirements for each source. The plant must, therefore, provide any documentation required by the permitting authority. The mercury measurement data must be provided in such a manner that would document trading allowances.

It is expected that utilities will require a full-time person at the corporate level especially during the early part of the rule to support PS 12A documentation completion. The representative 
must also directly work with the state to determine proper allowances based on the mercury budgets established for North Dakota. Finally, a recordkeeping system must be established that meets the requirements under CAMR. Basin Electric has eight units that would be required to share in this cost. The estimated costs for the two mercury-monitoring methods are compared in Table 10-2.

\subsection{CONCLUSIONS FROM MRY UNIT 2 TESTING}

$\mathrm{Hg}$ in the lignite coal fired in MRY Unit 2 varied from 0.05 to $0.25 \mathrm{ppm}$ and averaged $0.112 \pm 0.014 \mathrm{ppm}$ (dry coal basis). Most of the $\mathrm{Hg}$ was associated with $\mathrm{Hg}$-rich (2.28 ppm) pyrite grains that ranged in concentration from about 1 to $6 \mathrm{wt} \%$ (on a coal basis). During routine power plant operations, total $\mathrm{Hg}$ concentrations at the ESP and wet FGD inlets varied from about 12 to $16 \mu \mathrm{g} / \mathrm{dNm}^{3}$, whereas at the stack, concentrations were consistently at approximately $13 \mu \mathrm{g} / \mathrm{dNm}^{3}$, indicating that the ESP and wet FGD were very inefficient at removing $\mathrm{Hg}$, primarily because $\mathrm{Hg}^{0}$ was dominant. $\mathrm{MgCl}_{2}$ and $\mathrm{CaCl}_{2}$ were relatively ineffective in promoting $\mathrm{Hg}^{0}$ oxidation and capture in an ESP-wet FGD. Relatively low additions of SEA2, however, significantly improved the $\mathrm{Hg}$ removal efficiency of the ESP-wet FGD, although the goal of

Table 10-2. Comparison of the Total Costs for Appendix K and CMM

\begin{tabular}{lrr}
\hline & Appendix K & CMM \\
\hline Capital Cost, \$ & & \\
Purchased Equipment (PE) & & \\
$\quad$ Instrument/Console & 50,000 & $\$ 122,365$ \\
Calibration Unit & 0 & 35,000 \\
Installation & 2280 & \\
Labor & 5000 & 12,500 \\
Materials & 500 & 5000 \\
Overhead & 0 & 2500 \\
PS 12A & 57,780 & 55,000 \\
\hline Total Capital Requirement & & 232,365 \\
\hline O\&M, \$/yr & 6400 & \\
Training & 18,100 & 24,000 \\
Sorbent Traps and Analyses & 20,800 & 0 \\
Operating Labor & 4560 & 31,025 \\
Maintenance Labor & 1268 & 5600 \\
Supervision Labor (5\% of labor) & 5000 & 1831 \\
Replacement Parts (10\% of PE) & 1715 & 15,735 \\
Utilities & 5000 & 9510 \\
Depreciation & 5325 & 15,735 \\
Overhead (20\% of labor) & 55,000 & 7691 \\
RATA & 17,700 & 55,000 \\
Reporting and Recordkeeping & 140,868 & 17,700 \\
\hline Total Annual O\&M Costs & & 183,827 \\
\hline
\end{tabular}


$55 \% \mathrm{Hg}$ removal was not achieved using as much as 75 ppm SEA2 (dry coal basis). Most of the $\mathrm{Hg}$ removal occurred in the ESP, suggesting that SEA2 addition promoted the conversion of $\mathrm{Hg}^{0}$ to particulate-bound $\mathrm{Hg}$. SEA2 addition (50-100 ppm, dry coal basis) combined with 0.15-lb/Macf PAC injection was performed for a month during which $\mathrm{Hg}$ removal efficiencies generally ranged from $50 \%$ to $65 \%$.

SGLP and LTL analyses of fly ash samples collected during baseline and Hg control testing conditions indicated that $\mathrm{Hg}$ was relatively insoluble. The fly ash samples collected during baseline and $\mathrm{Hg}$ control technology testing conditions at the MRY power plant released $\mathrm{Hg}$ at about $375^{\circ}$ and $400^{\circ} \mathrm{C}$, respectively. The fly ash sampled during $\mathrm{Hg}$ control technology testing also released some $\mathrm{Hg}$ at approximately $550^{\circ} \mathrm{C}$. The $\mathrm{Hg}$ captured on fly ash and PAC during SEA2 injections was thermally more stable relative to the baseline fly ash.

Economic evaluations of mercury control for MRY Unit 2 were performed assuming various $\mathrm{CaCl}_{2}, \mathrm{SEA} 2, \mathrm{CaCl}_{2}$ with $\mathrm{PAC}$, and $\mathrm{SEA} 2$ with $\mathrm{PAC}$ injection rates. The cost for maintaining a 55\% mercury removal efficiency at MRY Unit 2 using SEA2 in combination with a small amount of PAC was estimated as follows:

- Levelized annual cost: $\$ 2,121,169$

- Annual cost, $\$ / \mathrm{MWh}$ (mills $/ \mathrm{kWh}): 0.63$

- Cost of mercury removal, $\$ / \mathrm{lb}: 16,639$

\subsection{CONCLUSIONS FROM MoSES UNIT 3 TESTING}

TXU's MoSES Unit 3 was one of two units to be tested as part of a project primarily funded by DOE entitled "Large-Scale Mercury Control Technology Testing for Lignite-Fired Utilities - Oxidation Systems for Wet FGD." The overall project goal was to cost-effectively oxidize most of the $\mathrm{Hg}^{0}$ in lignitic combustion flue gases into a more soluble and reactive inorganic mercuric compound $\left(\mathrm{Hg}^{2+}\right)$ that could subsequently be captured in an ESP and/or wet FGD system. MoSES Unit 3 is a 793-MW unit that fires a 50-50 blend of Texas lignite and PRB coals. The unit is equipped with an ESP and limestone forced-oxidation spray tower FGD system for $\mathrm{SO}_{2}$ control. Baseline flue gas mercury measurements indicated that the ESP outlet flue gas typically contains about $25 \% \mathrm{Hg}^{2+}$ and $75 \% \mathrm{Hg}^{0}$, with a total $\mathrm{Hg}$ concentration of about $20 \mu \mathrm{g} / \mathrm{dNm}^{3}$.

A test program was carried out at MoSES in Fall 2005 to evaluate the furnace injection of halogen materials as a means of oxidizing the flue gas mercury so that it could be removed in a downstream wet scrubber. The program consisted of three parts: 1) baseline measurements to quantify the mercury concentrations and mercury removal across the system, 2) a set of parametric tests to compare the performance of furnace injection of two halogen salts $\left(\mathrm{CaCl}_{2}\right.$ and $\mathrm{CaBr}_{2}$ ), and 3) two 2-week continuous-injection tests to evaluate the variability and balance-ofplant impacts associated with furnace halogen injection. Flue gas mercury measurements were made primarily with EPRI SCEMs. 
During baseline measurements, no removal of mercury was measured with the SCEMs and the $\mathrm{OH}$ method across the ESP. On average for the course of the long-term test program, coal mercury concentrations correlated well with ESP inlet mercury concentrations measured by the CMM. The mercury content of the baseline fly ash represented less than $20 \%$ of the coal mercury content. Both the coal and ash results corroborate the flue gas determination of a small amount of mercury removal upstream of the ESP and no removal across the ESP. The coal mercury concentration of the PRB coal ranged from 0.04 to $0.09 \mathrm{ppm}$ dry. The coal mercury concentration of the Texas lignite was highly variable, ranging from 0.17 to $0.36 \mathrm{ppm}$ dry. Likewise, the ESP inlet mercury concentrations ranged over a wide span (15 to $30 \mu \mathrm{g} / \mathrm{dNm}^{3}$ at $3 \% \mathrm{O}_{2}$ ) during the course of the test program. The baseline flue gas typically contained $10 \%-40 \%$ oxidized mercury. The measured mercury oxidation was typical of that measured at other plants burning Texas lignite-PRB blends.

Parametric tests conducted with two halogen salts demonstrated that it was possible to increase the oxidation of mercury in the flue gas and to simultaneously increase mercury removal by the FGD scrubber. Calcium chloride provided only nominal improvements in mercury oxidation even at the highest tested injection rate of $800 \mathrm{ppm} \mathrm{Cl}$ in the coal. The calcium chloride was not observed to be capable of sustaining the mercury oxidation necessary for the project's mercury removal target of $55 \%$. In contrast, parametric tests with calcium bromide demonstrated up to $78 \%$ oxidation at an injection rate of $200 \mathrm{ppm} \mathrm{Br}$ in the coal. Based on these parametric test results, calcium bromide was selected for an evaluation in two 2-week continuous-injection tests.

The first of these tests was conducted at an average injection rate of $55 \mathrm{ppm} \mathrm{Br}$ in the coal. This injection rate achieved an average $67 \%$ mercury oxidation at the scrubber inlet, and the average removal of mercury across the scrubber was $65 \%$. These values represent averages over a 2-week injection test; however, it was observed with the SCEMs that the scrubber outlet total mercury concentration steadily increased over the test period. These results were confirmed with Appendix $\mathrm{K}$ measurements. Therefore, a higher injection rate was evaluated in the second 2-week injection test.

For the second 2-week injection test, the calcium bromide injection rate was increased to an average $113 \mathrm{ppm} \mathrm{Br}$ in the coal. Over the course of the 10 days at this injection rate, the mercury at the ESP inlet was on average $85 \%$ oxidized. The removal of vapor-phase mercury across the system averaged $86 \%$ for the entire test period. With the exception of a few brief periods, an injection rate of $113 \mathrm{ppm} \mathrm{Br}$ was sufficient to consistently maintain scrubber outlet mercury concentrations below $5 \mu \mathrm{g} / \mathrm{dNm}^{3}$ (at $3 \% \mathrm{O}_{2}$ ).

It should be noted that all of the reported mercury oxidation and removal values were based on the average coal mercury concentration for the respective test periods. The scrubber inlet total vapor-phase mercury measurements made by SCEM were biased low during bromide injection, as determined from a comparison of SCEM data to coal and ash mercury data. The presence of bromine in the flue gas can oxidize mercury in the wet solutions that pretreat the gas for the SCEM. The scrubber inlet elemental mercury measurements did not appear to be subject to a negative bias, as these values agreed well with the scrubber outlet total mercury 
concentrations. The scrubber outlet mercury data are not subject to the bromine bias because bromine is removed by the FGD scrubber.

The furnace injection of calcium bromide did not result in increased mercury removal by the fly ash. The oxidized mercury was removed by the FGD scrubber, as expected. During baseline and the first week of each long-term injection test, the mercury partitioned to the FGD solids; however, during the second week of each test, the mercury transitioned to the liquor phase. At an injection rate of $113 \mathrm{ppm} \mathrm{Br}$ in the coal, over $85 \%$ of the mercury in the FGD by-product was contained in the liquor.

These two 2-week furnace injection tests were not long enough to evaluate the balance-ofplant effects. A unit inspection conducted after the test program did not indicate any brominerelated corrosion; however, the test period was too short for an adequate corrosion evaluation. The effect of increased bromine concentration in the FGD liquor on FGD performance and corrosion of FGD materials of construction needs to be determined. Duct corrosion and air heater plugging also need to be evaluated in a longer-term test. Finally, the effect of increased bromine concentrations on the marketability of the CCBS must be addressed.

Economic evaluations of mercury control for MoSES Unit 3 were performed assuming various $\mathrm{CaBr}_{2}$ injection rates. The cost for maintaining a $\geq 55 \%$ mercury removal efficiency at MoSES Unit 3 using $\mathrm{CaBr}_{2}$ was estimated as follows:

- Levelized annual cost: $\$ 2,933,996$

- Annual cost, \$/MWh (mills/kWh): 0.50

- Cost of mercury removal, $\$ / 1 b: 7336$

\subsection{REFERENCES}

1. Pavlish, J.H.; Sondreal, E.A.; Mann, M.D.; Olson, E.S.; Galbreath, K.C.; Laudal, D.L.; Benson, S.A. Status Review of Mercury Control Options for Coal-Fired Power Plants. Fuel Process. Technol. 2003, 82 (2, 3), 89-165.

2. Sjostrom, S.; Richardson, C.; Chang, R. Evaluation of Mercury Emissions and Control Options for Great River Energy; Final Report for North Dakota Industrial Commission; June 2001.

3. Chang, R.; StrOH methodfus, M. The Evaluation of Chemical Additives for Mercury Emission Control at Great River Energy; Final Report for the North Dakota Industrial Commission; Jan 2003.

4. Global Mercury Assessment. United Nations Environment Program (UNEP) Chemicals: Geneva, Switzerland; Dec 2002.

5. Kilgroe, J.; Sedman, C.; Srivastava, R.; Ryan, J.; Lee, C.; Thorneloe, S. Control of Mercury Emissions from Coal-Fired Electric Utility Boilers: Interim Report Including Errata; Dated 
March 21, 2002; EPA-600/R-01-109; U.S. Environmental Protection Agency: Washington, DC, April 2002.

6. National Research Council. Toxicological Effects of Methylmercury; Report for U.S. Environmental Protection Agency; National Academy Press: Washington, DC, Aug 2000.

7. U.S. Environmental Protection Agency. Mercury Study Report to Congress Volume I: Executive Summary; EPA-452/R-97-003; Office of Air Quality Planning and Standards and Office of Research and Development: Dec 1997.

8. U.S. Environmental Protection Agency. A Study of Hazardous Air Pollutant Emissions from Electric Utility Steam Generating Units: Final Report to Congress; EPA-453/R-98-004a; U.S. EPA Office of Air Quality Planning and Standards, U.S. Government Printing Office: Washington, DC, Feb 1998.

9. U.S. Environmental Protection Agency. Information Collection Request; 1999.

10. Pavlish, J.H.; Holmes, M.J. Mercury Control for Lignite-Fired Power Plants Poses a Challenge. Center for Air Toxic Metals Newsletter 2002, 8 (1), 6.

11. Pavlish, J.H.; Sondreal, E.A.; Mann, M.D.; Olson, E.S.; Galbreath, K.C.; Laudal, D.L.; Benson, S.A. Status Review of Mercury Control Options for Coal-Fired Power Plants. Fuel Process. Technol. 2003, 82 (2-3), 89-165.

12. Carey, T.R.; Hargrove, O.W.; Richardson, C.F.; Chang, R.; Meserole, F.B. Factors Affecting Mercury Control in Utility Flue Gas Using Activated Carbon. J. Air Waste Manage. Assoc. 1998, 48, 1166-1174.

13. Dunham, G.E.; Olson, E.S.; Miller, S.J. Impact of Flue Gas Constituents on Carbon Sorbents. In Proceedings of the Air Quality II: Mercury, Trace Elements, and Particulate Matter Conference; McLean, VA, Sept 19-21, 2000; Paper A4-3.

14. Olson, E.S.; Sharma, R.K.; Miller, S.J.; Dunham, G.E. Identification of the Breakthrough Oxidized Mercury Species from Sorbents in Flue Gas. In Proceedings of the Specialty Conference on Mercury in the Environment; Minneapolis, MN, Sept 15-17, 1999; pp 121126.

15. Pavlish, J.H.; Holmes, M.J.; Benson, S.A.; Crocker, C.R.; Galbreath, K.C. Mercury Control Technologies for Utilities Burning Lignite Coal, In Proceedings of Air Quality III, Mercury, Trace Elements, and Particulate Matter Conference, Sept 9-12, 2002.

16. Bustard, J.; Durham, M.; Starns, T.; Lindsey, C.; Martin, C., Schlager, R.; Bladrey, K. FullScale Evaluation of Sorbent Injection for Mercury Control on Coal-Fired Power Plants. In Proceedings of Air Quality III: Mercury, Trace Elements, and Particulate Matter Conference; Sept 9-12, 2002. 
17. Sjostrom, S.; Richardson, C.; Chang, R. Evaluation of Mercury Emissions and Control Options for Great River Energy; Final Report for North Dakota Industrial Commission, June 2001.

18. Liu, W.; Vidic, R.D.; Brown, T.D. Optimization of Sulfur Impregnation Protocol for FixedBed Application of Activated Carbon-Based Sorbents for Gas-Phase Mercury Removal. Environ. Sci. Technol. 1998, 32, 531-538.

19. Ghorishi, S.B.; Kenney, R.M.; Serre, S.D.; Gullett, B.K.; Jozewicz, W.S. Development of a Cl-Impregnated Carbon for Entrained-Flow Capture of Elemental Mercury. Environ. Sci. Technol. 2002, 36, 4454-4459.

20. Dunham, G.E.; Miller, S.J.; Laudal, D.L. Investigation of Sorbent Injection for Mercury Control in Coal-Fired Boilers; Final Report for EPRI and DOE; Energy \& Environmental Research Center: Grand Forks, ND, Sept 1998.

21. Laumb, J.D.; Benson, S.A.; Olson, E. S. X-Ray Photoelectron Spectroscopy Analysis of Mercury Sorbent Surface Chemistry. In Proceedings of the Air Quality III: Mercury, Trace Elements, and Particulate Matter Conference; Arlington, VA, Sept 9-12, 2002; Energy \& Environmental Research Center: Grand Forks, ND, 2002.

22. Benson, S.A.; Olson, E.; Crocker, C.; Pavlish, J.; Holmes, M. Mercury Sorbent Testing in Simulated Low-Rank Coal Flue Gases. In Proceedings of the 6th Electric Utilities Environmental Conference; Jan 27-30, 2003.

23. Thompson, J.S.; Holmes, M.J.; Laudal, D.L. Long-Term Monitoring at North Dakota Power Plants; Final Report for the North Dakota Industrial Commission; March 2003.

24. Sun, J.Q.; Crocker, C.R.; Lillemoen, C.M. The Effect of Coal Combustion Flue Gas Components on Low-Level Chlorine Speciation Using EPA Method 26A. J. Air Waste Manage. Assoc. 2000, 50, 936-940.

25. Hassett, D.J. Synthetic Groundwater Leaching Procedure. In Encyclopedia of Environmental Analysis and Remediation; JOH methodn Wiley \& Sons, Inc., 1998; pp 4797-4803.

26. U.S. Environmental Protection Agency. Method 1311, Toxicity Characteristic Leaching Procedure, Test Methods for Evaluating Solid Waste, Physical/Chemical Methods; EPA Publication SW-846, Third Edition, as amended by Updates I, II, IIB, and III, finalized in the Federal Register, June 13, 1997.

27. ASTM International. Standard Method for Shake Extraction of Solid Waste with Water. In Annual Book of ASTM Standards; Section 11: Water and Environmental Technology, ASTM D3987-85, 1989. 
28. Hassett, D.J.; Heebink, L.V.; Pflughoeft-Hassett, D.F.; Zacher, E.J.; Buckley, T.D.; Eylands, K.E. Mercury and Air Toxic Element Impacts of Coal Combustion By-Product Disposal and Utilization; Final Year 2 Annual Report for U.S. Department of Energy National Energy Technology Laboratory Cooperative Agreement No. DE-FC2602NT41727; EERC Publication 2005-EERC-06-09; Energy \& Environmental Research Center: Grand Forks, ND, Jun 2005.

29. Kanefke, R. Rauchgasreinigung - Abscheidung von Quecksilber und sonstigen Schwermetallen, Aerosolen, Dioxinen und Furanen Haus der Technik, 09 February 2006. 
APPENDIX A

\section{MERCURY CONTROL FIELD TESTING AT MILTON R. YOUNG STATION}




\section{MERCURY CONTROL FIELD TESTING AT MILTON R. YOUNG STATION}

Site Report

Prepared for:

Minnkota Power Cooperative, Inc.

Prepared by:

Steven A. Benson

Michael J. Holmes

Donald P. McCollor

Jill M. Mackenzie

Charlene R. Crocker

Kevin C. Galbreath

Lingbu Kong

Energy \& Environmental Research Center

University of North Dakota

PO Box 9018

Grand Forks, ND 58202-9018 


\section{DOE DISCLAIMER}

This report was prepared as an account of work sponsored by an agency of the United States Government. Neither the United States Government, nor any agency thereof, nor any of their employees makes any warranty, express or implied, or assumes any legal liability or responsibility for the accuracy, completeness, or usefulness of any information, apparatus, product, or process disclosed or represents that its use would not infringe privately owned rights. Reference herein to any specific commercial product, process, or service by trade name, trademark, manufacturer, or otherwise does not necessarily constitute or imply its endorsement, recommendation, or favoring by the United States Government or any agency thereof. The views and opinions of authors expressed herein do not necessarily state or reflect those of the United States Government or any agency thereof.

This report is available to the public from the National Technical Information Service, U.S. Department of Commerce, 5285 Port Royal Road, Springfield, VA 22161; phone orders accepted at (703) 487-4650.

\section{DISCLAIMERS}

This report was prepared with the support of the U.S. Department of Energy (DOE) National Energy Technology Laboratory Cooperative Agreement No. DE-FC26-03NT41991. However, any opinions, findings, conclusions, or recommendations expressed herein are those of the authors and do not necessarily reflect the views of DOE.

This report was prepared by the Energy \& Environmental Research Center (EERC), an agency of the University of North Dakota, as an account of work sponsored by DOE; Apogee; The Babcock \& Wilcox Company (B\&W), Inc.; Basin Electric Power Cooperative; BNI Coal, Ltd.; Dakota Westmoreland Corporation; EPRI; Great River Energy; Minnkota Power Cooperative; Montana-Dakota Utilities Company; North American Coal Corporation; North Dakota Industrial Commission; Otter Tail Power Company; SaskPower; TXU Corporation; and URS Corporation.

\section{ACKNOWLEDGMENTS}

The EERC's project manager and principal investigators are grateful to the following organizations for their support, technical advice, and assistance in completing this draft site report:

- DOE National Energy Technology Laboratory

- Apogee

- Babcock \& Wilcox (B\&W)

- Basin Electric Power Cooperative

- BNI Coal, Ltd.

- Dakota Westmoreland Corporation

- Electric Power Research Institute

- Great River Energy

- Minnkota Power Cooperative, Inc.
- Montana-Dakota Utilities Company

- North American Coal Corporation

- North Dakota Industrial Commission (NDIC)

- Otter Tail Power Company

- SaskPower

- TXU Energy (TXU)

- URS Corporation (URS) 


\title{
MERCURY CONTROL FIELD TESTING AT MILTON R. YOUNG STATION
}

\begin{abstract}
Mercury $(\mathrm{Hg})$ control technologies were evaluated at Minnkota Power Cooperative's Milton R. Young (MRY) Station Unit 2, a 450-MW lignite-fired cyclone unit near Center, North Dakota. A cold-side electrostatic precipitator (ESP) and wet flue gas desulfurization (FGD) are used at MRY for controlling particulate and sulfur dioxide $\left(\mathrm{SO}_{2}\right)$ emissions, respectively. Calcium chloride $\left(\mathrm{CaCl}_{2}\right)$, magnesium chloride $\left(\mathrm{MgCl}_{2}\right)$, and a proprietary sorbent enhancement additive, hereafter referred to as SEA2, were added to the coal feed to enhance $\mathrm{Hg}$ capture in the ESP and/or wet FGD. In addition, powdered activated carbon (PAC) was injected upstream of the ESP. Hg in the lignite coal fired at MRY Unit 2 varied from 0.05 to $0.25 \mathrm{ppm}$ and averaged $0.112 \pm 0.014$ ppm (dry coal basis). Most of the $\mathrm{Hg}$ was associated with $\mathrm{Hg}$-rich (average of $2.28 \mathrm{ppm} \mathrm{Hg}$ ) pyrite grains that ranged in concentration from about 1 to $6 \mathrm{wt} \%$ (on a dry coal basis). Baseline analyses indicated that total $\mathrm{Hg}$ concentrations at the ESP and wet FGD inlets varied from about 12 to $16 \mu \mathrm{g} / \mathrm{dNm}^{3}$, whereas at the stack concentrations were consistently at about $13 \mu \mathrm{g} / \mathrm{dNm}^{3}$. The ESP and wet FGD were very inefficient at removing $\mathrm{Hg}$ primarily because $\mathrm{Hg}^{0}$ was dominant. $\mathrm{MgCl}_{2}$ and $\mathrm{CaCl}_{2}$ were relatively ineffective in promoting $\mathrm{Hg}^{0}$ oxidation and capture in the ESP-wet FGD. Relatively low additions of SEA2, however, significantly improved the $\mathrm{Hg}$ removal efficiency of the ESP-wet FGD, although the goal of $55 \% \mathrm{Hg}$ removal was not achieved using as much as $75 \mathrm{ppm}$ SEA2 (dry coal basis). Most of the $\mathrm{Hg}$ removal occurred in the ESP, suggesting that SEA2 addition promoted the conversion of $\mathrm{Hg}^{0}$ to particulate-bound $\mathrm{Hg}$. SEA2 addition (50-100 ppm, dry coal basis) combined with $0.15 \mathrm{lb} /$ Macf PAC injection was performed for a month during which $\mathrm{Hg}$ removals ranged from $50 \%$ to $65 \%$.
\end{abstract}

The potential corrosive effects of SEA2 and PAC injections were evaluated by installing air-cooled, stressed stainless steel, corrosion/ash deposition coupons at the economizer exit (ECM), air heater inlet (AHI), and air heater outlet (AHO) of MRY Unit 2. Two coupons for each location were fabricated by MRY personnel: a baseline coupon exposed to the normal flue gas environment for 8 weeks and a test coupon exposed to flue gas while SEA2 and PAC were being added to the coal feed for 6 weeks. Scanning electron microscopy analyses indicated that the baseline coupons from the ECM and AHI had a smooth surface, whereas the corresponding $\mathrm{Hg}$ control coupons had a rougher surface, suggesting that corrosion was enhanced during the SEA2 and PAC injections. In contrast to the ECM and AHI coupons, steel surfaces on the AHO baseline and $\mathrm{Hg}$ control coupons were similar in appearance. Electron probe microanalyses indicated that SEA2 and PAC injections enhanced calcium sulfate deposition on the coupons.

The mobility of Hg in MRY fly ashes sampled before and after PAC and SEA2 injections was evaluated using a synthetic groundwater leaching procedure augmented with long-term treatments of 30 and 60 days. $\mathrm{Hg}$ was not detected in any of the leachates, indicating that it was relatively insoluble during the test conditions. The thermal stability of $\mathrm{Hg}$ in fly ash samples collected during baseline and $\mathrm{Hg}$ control technology testing conditions was evaluated by heating at $25^{\circ} \mathrm{C} / \mathrm{min}$ to $750^{\circ} \mathrm{C}$. The fly ash samples collected during baseline and $\mathrm{Hg}$ control technology testing conditions released $\mathrm{Hg}$ at about $375^{\circ}$ and $400^{\circ} \mathrm{C}$, respectively. The fly ash sampled during $\mathrm{Hg}$ control technology testing also released some $\mathrm{Hg}$ at $>550^{\circ} \mathrm{C}$. The $\mathrm{Hg}$ captured on fly ash and PAC during SEA2 injections was thermally more stable relative to the baseline fly ash. 
Economic evaluations of mercury control for MRY Unit 2 were performed assuming various $\mathrm{CaCl}_{2}, \mathrm{SEA} 2, \mathrm{CaCl}_{2}$ with $\mathrm{PAC}$, and $\mathrm{SEA} 2$ with $\mathrm{PAC}$ injection rates. The cost for maintaining a 55\% mercury removal efficiency at MRY Unit 2 using SEA2 in combination with a small amount of PAC was estimated as follows:

- Levelized annual cost: $\$ 2,121,169$

- Annual cost, $\$ / \mathrm{MWh}$ (mills $/ \mathrm{kWh}): 0.63$

- Cost of Mercury removal, $\$$ / lb: 16,639 


\section{TABLE OF CONTENTS}

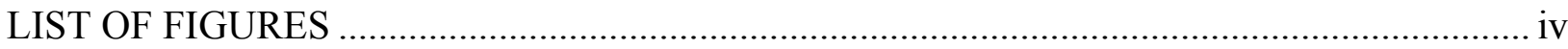

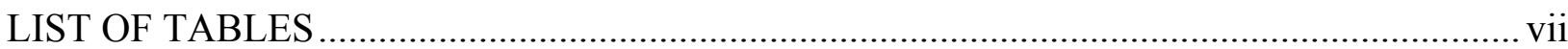

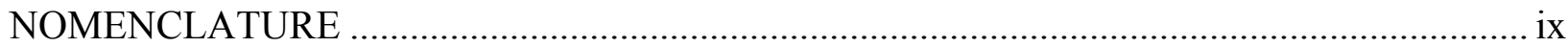

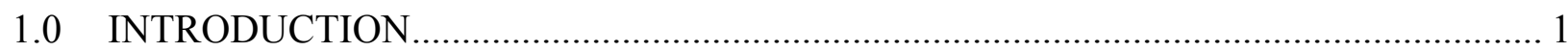

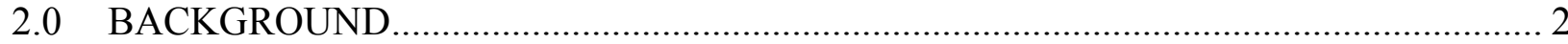

$2.1 \quad$ World and U.S. Mercury Emissions Budget ……………....................................... 2

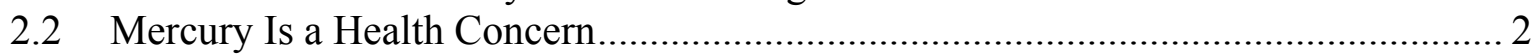

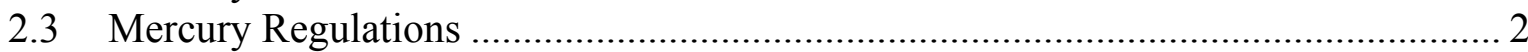

2.4 Mercury Emissions from Low-Rank Coals Will Be Difficult to Control .................... 3

2.5 Mercury Control Options..................................................................................... 4

2.5.1 Previous Results with $\mathrm{Hg}^{0}$ Oxidation Technologies....................................... 4

2.5.2 Previous Results with Powdered Activated Carbon Injection .......................... 5

2.5.3 Previous Results with Sorbent Enhancement Additives................................. 9

2.6 Coal Combustion By-Products ............................................................................ 10

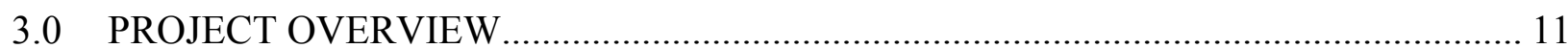

$3.1 \quad$ Goals and Objectives .................................................................................... 11

3.2 Approach/Work Plan .......................................................................................... 12

4.0 DESCRIPTION OF MILTON R. YOUNG (MRY) UNIT 2 ………………………...... 15

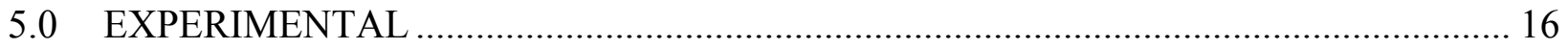

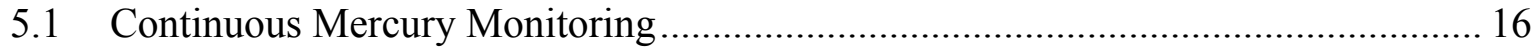

5.2 Ontario Hydro Flue Gas Mercury Measurements .................................................... 18

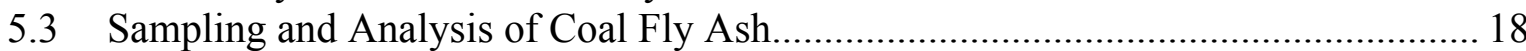

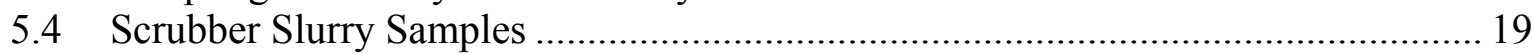

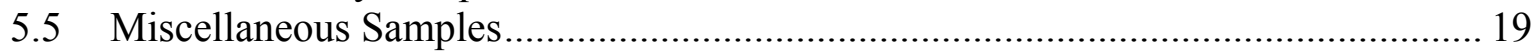

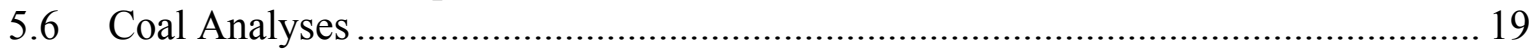

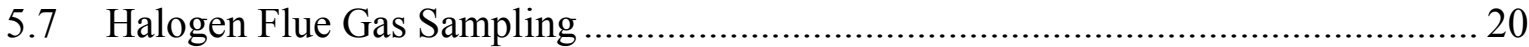

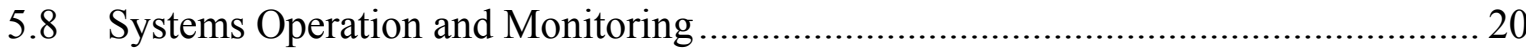

5.8.1 Aqueous $\mathrm{CaCl}_{2}, \mathrm{MgCl}_{2}$, and SEA2 Addition System................................. 20

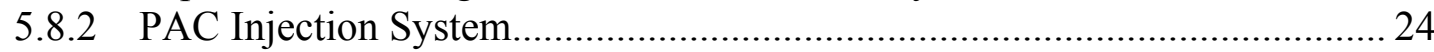

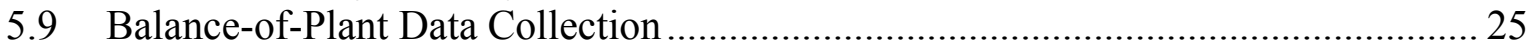

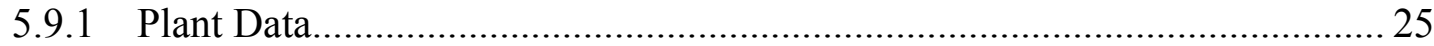

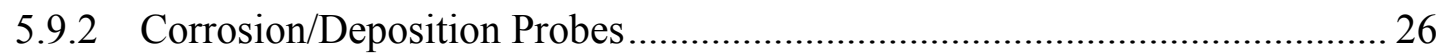

5.10 Mercury Stability in Coal Fly Ash................................................................... 27

Continued ... 


\section{TABLE OF CONTENTS (continued)}

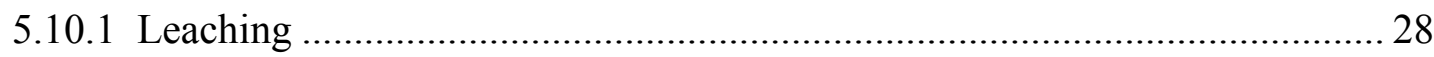

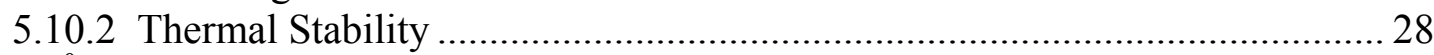

$5.11 \mathrm{Hg}^{0}$ Oxidants and Powdered Activated Carbon....................................................... 28

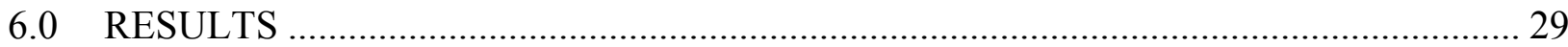

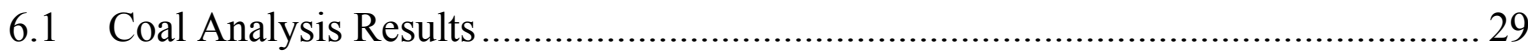

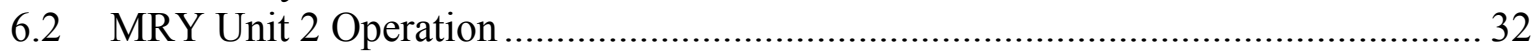

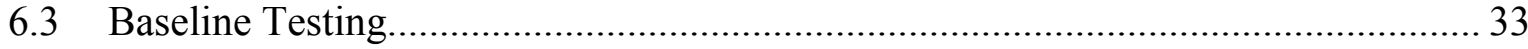

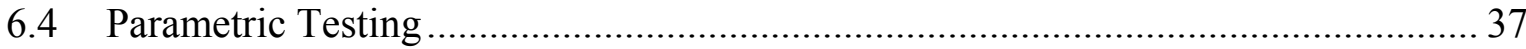

6.4.1 Effects of $\mathrm{CaCl}_{2}, \mathrm{MgCl}_{2}$, and SEA2 Additions on $\mathrm{Hg}$ Speciation

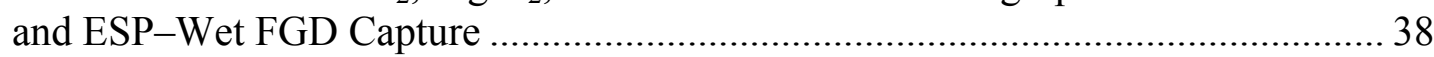

6.4.2 Effects of PAC Injection and $\mathrm{CaCl}_{2}$ and SEA2 Additions on Hg Speciation and ESP-Wet FGD Capture........................................................ 40

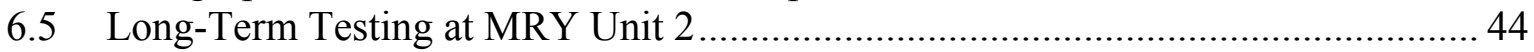

7.0 BALANCE-OF-PLANT EFFECTS OF HG CONTROL TECHNOLOGIES ................... 48

7.1 Corrosion Probe Characterization...................................................................... 48

7.1.1 Economizer Coupons.............................................................................. 49

7.1.2 Air Heater Inlet Coupons.......................................................................... 51

7.1.3 Air Heater Outlet Coupons ……………………...................................... 51

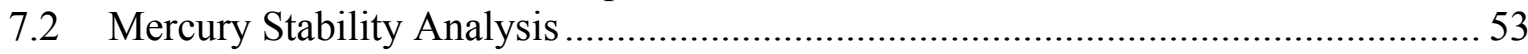

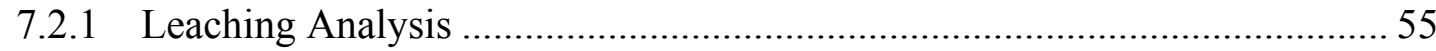

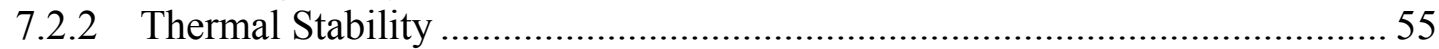

7.3 Fly Ash Particle-Size Distribution......................................................................... 57

8.0 ECONOMIC ANALYSIS OF MERCURY CONTROL ……..................................... 57

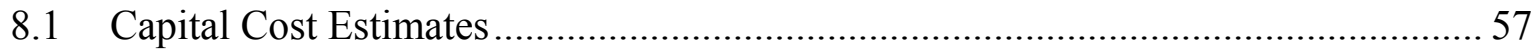

8.1.1 PAC Feeder System .............................................................................5 58

8.1.2 Aqueous Injection Skid............................................................................. 58

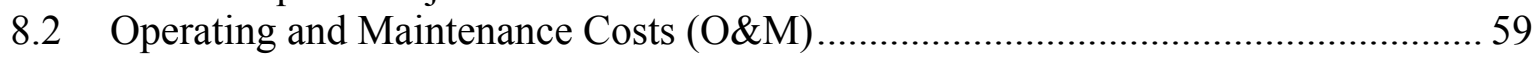

8.2.1 Maintenance and Replacement Parts .......................................................... 59

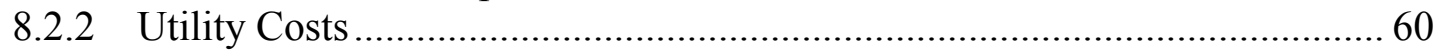

8.3 Economic Evaluation of Mercury Control at MRY Station Unit 2 ........................... 60

9.0 COSTS OF MERCURY MEASUREMENT AND REPORTING UNDER CAMR .......... 61

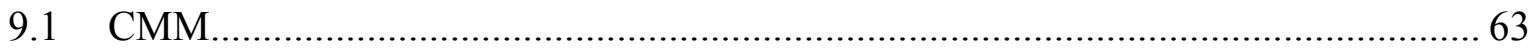

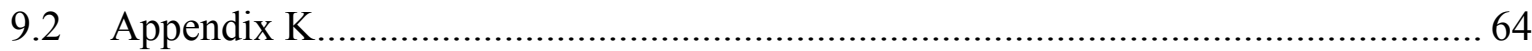

9.3 Reporting and Recordkeeping Requirements under CAMR ………………….......... 65

Continued ... 


\section{TABLE OF CONTENTS (continued)}

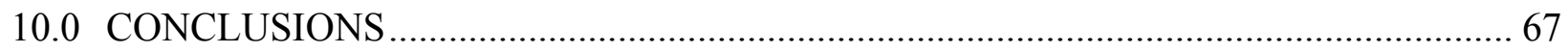

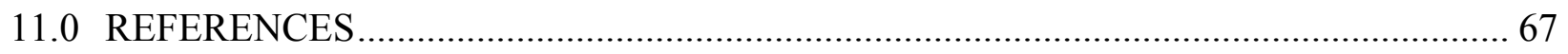

QUALITY ASSURANCE/QUALITY CONTROL FOR PILOT-SCALE TESTS ......Appendix A SAMPLE CALCULATIONS .......................................................................... Appendix B

STANDARD OPERATING PROCEDURE FOR COAL/ASH MINERAL ANALYSIS

BY COMPUTER-CONTROLLED SCANNING ELECTRON MICROSCOPY ........ Appendix C

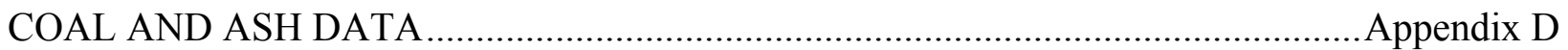




\section{LIST OF FIGURES}

2-1 Kinetic model (Chemkin) prediction of chlorine radical concentration as a function of the temperature and residence time profile of a utility boiler........................................... 6

2-2 Ontario Hydro $(\mathrm{OH}) \mathrm{Hg}$ speciation results showing the effects of a coal $\mathrm{Hg}^{0}$ oxidation agent on North Dakota lignite combustion flue gas $\mathrm{Hg}$ speciation

2-3 Comparison of $\mathrm{Hg}^{0}$ oxidation and $\mathrm{HCl}$ flue gas concentrations during salt injections at a North Dakota lignite-fired power plant

2-4 Pilot-scale ESP (12) and full-scale ESP (13) Hg removal efficiencies as a function of

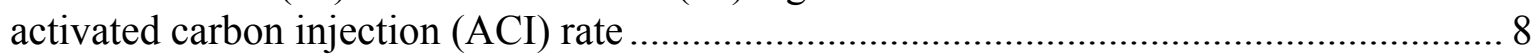

2-5 Pilot-scale ESP-FF (12) and full-scale TOXECON and ESP (13) Hg removal

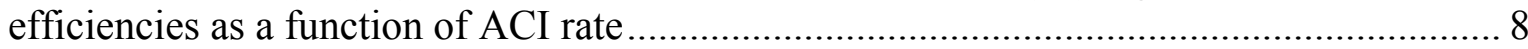

2-6 Hg emissions for PAC injection combined with additives ............................................... 9

2-7 ESP inlet and outlet total $\mathrm{Hg}$ concentrations as functions of PAC injection and SEA addition rates into North Dakota lignite combustion flue gases................................. 10

4-1 Schematic of MRY Unit 2 showing sampling and coal additive locations......................... 16

4-2 Average $\mathrm{OH} \mathrm{Hg}$ speciation results obtained at the ESP and wet FGD inlets and

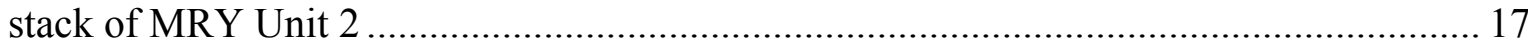

5-1 $\mathrm{OH}$ and $\mathrm{CMM}$ mercury-sampling and measurement location on the stack ……................ 17

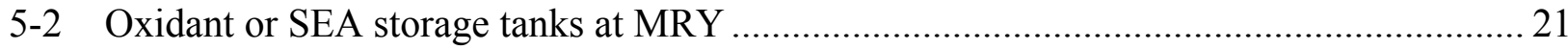

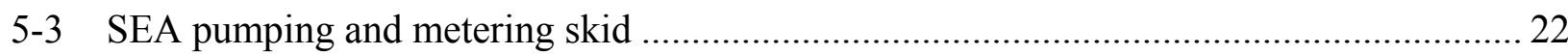

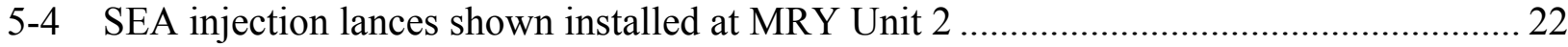

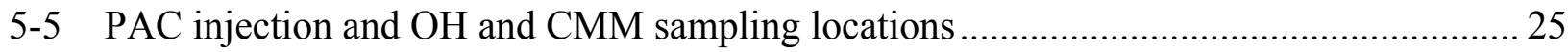

5-6 Photograph of the corrosion/deposition probe assembly ................................................... 26

5-7 Photograph of coupon and a cross-sectioned coupon .......................................................... 27

Continued ... 


\section{LIST OF FIGURES (continued)}

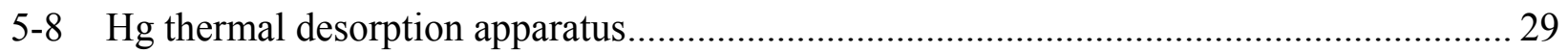

6-1 Temporal variations in MRY Unit 2 lignite Hg concentrations ............................................ 33

6-2 MRY Unit 2 lignite pyrite versus Hg concentrations (on a dry basis), correlation

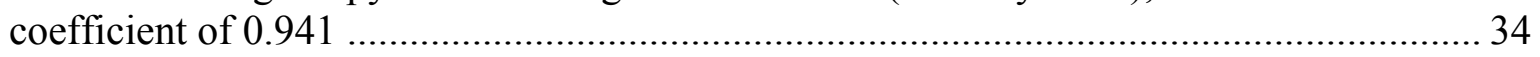

6-3 MRY Unit 2 lignite $\mathrm{Hg}$ versus $\mathrm{S}$ concentrations (on a dry basis), correlation

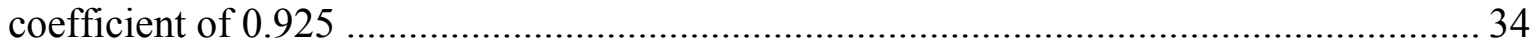

6-4 Summary of MRY unit operational and emissions data. .................................................... 35

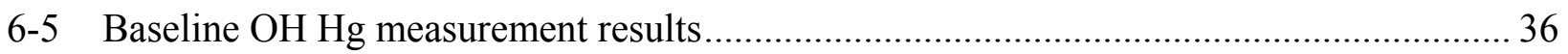

6-6 Average $\mathrm{Hg}$ speciation results for Center lignite combustion flue gases containing

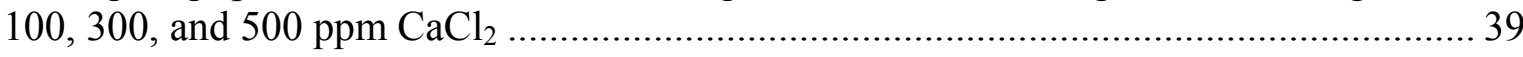

6-7 ESP-wet FGD $\mathrm{Hg}$ removal efficiencies during $\mathrm{CaCl}_{2}, \mathrm{MgCl}_{2}$, and SEA2 additions ......... 40

6-8 Stack CMM results before, during, and after SEA2 additions............................................ 41

6-9 Effects of PAC injections alone and in combination with $\mathrm{CaCl}_{2}$ or SEA2 additions on ESP-wet FGD Hg removal efficiency .......................................................... 41

6-10 Stack CMM results obtained before, during, and after PAC injections and $\mathrm{CaCl}_{2}$ addition at $300 \mathrm{ppm}$

6-11 Stack CMM results obtained before, during, and after PAC injections and SEA2 additions.

6-12 $\mathrm{OH} \mathrm{Hg}$ speciation results obtained during PAC injection and SEA2 additions.................. 43

6-13 SEA2 addition rates during the long-term testing at MRY Unit 2 ………………............. 45

6-14 ESP-wet FGD Hg removal efficiencies during extended testing at MRY Unit 2 using SEA2 additions and SEA2 with PAC injections ............................................................. 46

6-15 PAC injection rates during the long-term testing at MRY Unit 2 ....................................... 46

Continued ... 


\section{LIST OF FIGURES (continued)}

6-16 Cumulative frequency percent plot for the $\mathrm{Hg}$ removal efficiencies attained at MRY Unit 2 during (April 19 - May 18, 2005) SEA 2 (50-100 ppm, dry coal basis) and $0.15 \mathrm{lb} / \mathrm{Macf} \mathrm{PAC}$ injections

7-1 Backscattered electron image of MRY ECM coupons ................................................ 49

7-2 Comparison of ECM baseline and long-term coupons .............................................. 50

7-3 Comparison of ECM baseline and long-term coupons .............................................. 50

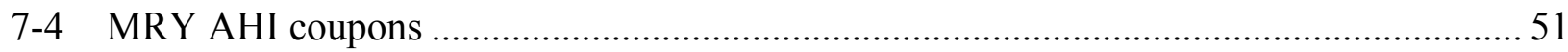

7-5 Comparison of AHI baseline and Hg-control coupons (curved side) ............................. 52

7-6 Comparison of AHI baseline and Hg-control coupons (flat side).................................5 52

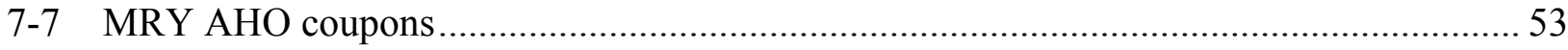

7-8 Comparison of AHO baseline and long-term coupons ................................................. 54

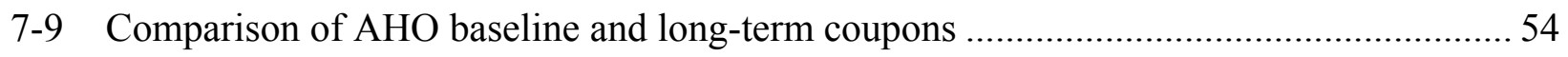

7-10 Sample 05-005 example AA mercury thermal desorption curve ...................................56

7-11 Sample 05-017 example AA mercury thermal desorption curve ...................................5 57 


\section{LIST OF TABLES}

2-1 Average Hg Removal Efficiencies (\%) by Coal Rank and APCD Configuration ............... 5

3-1 Schedule of Test Conditions, Chemical Additions, PAC Injections, and Sampling Activities Performed at MRY Unit 2 ......................................................................... 15

4-1 Coal Information for Milton R. Young Station ............................................................. 15

5-1 Chemical Fractionation Protocol............................................................................... 20

5-2 General Properties of NORIT Americas Inc. DARCO $\mathrm{Hg}^{1}$......................................... 29

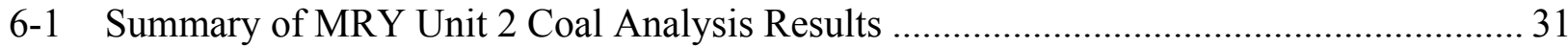

6-2 Triplicate and Average MRY Coal Ash Elemental Oxide Compositions......................... 31

6-3 Average MRY Coal Chemical Fractionation Results ................................................... 32

6-4 Quantitative MRY Unit 2 Coal Mineral Analyses ..................................................... 32

6-5 Statistical Summary of MRY Unit 2 Coal Hg Analysis Results.................................... 33

6-6 Comparison of $\mathrm{OH}$ and CMM results $\left(\mu \mathrm{g} / \mathrm{dNm}^{3}\right)$ Obtained Concurrently During Baseline Testing Conditions (March 17 and 18, 2005).................................................. 37

6-7 Duplicate $\mathrm{Hg}, \mathrm{Br}$, and $\mathrm{Cl}$ Analysis Results for Fly Ashes Sampled from the ESP During Baseline Testing Conditions ......................................................................... 37

6-8 Comparison of $\mathrm{OH}$ and CMM Results $\left(\mu \mathrm{g} / \mathrm{dNm}^{3}\right)$ Obtained Concurrently During Parametric Testing Conditions (March 18-April 1, 2005) .......................................... 38

6-9 Comparison of Average $\mathrm{OH}$ and CMM Results $\left(\mu \mathrm{g} / \mathrm{dNm}^{3}\right)$ Obtained Concurrently During Long-Term Testing Conditions (April 5-May 17, 2005)

6-10 $\mathrm{Hg}, \mathrm{Br}$, and $\mathrm{Cl}$ Analysis Results (ppm) for Fly Ashes Sampled from the ESP During SEA2 Additions and SEA2-PAC Injections ......................................................... 47

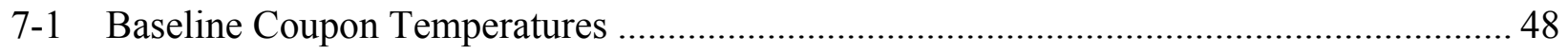

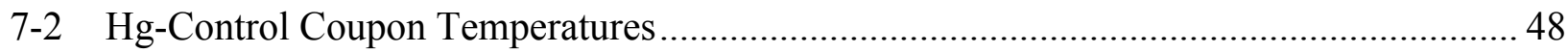

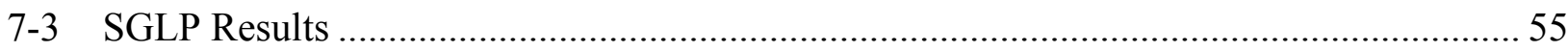

Continued ... 


\section{LIST OF TABLES (continued)}

7-4 Longer-Term Fly Ash Hg Leaching Results ............................................................ 55

7-5 Average Hg Thermal Desorption Results ..................................................................... 56

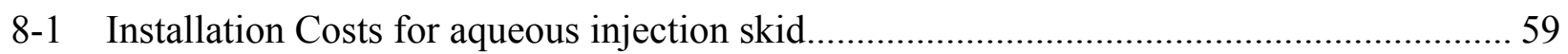

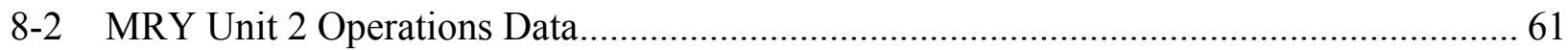

8-3 Summary of Costs Associated with Mercury Control at MRY Unit 2 .......................... 62

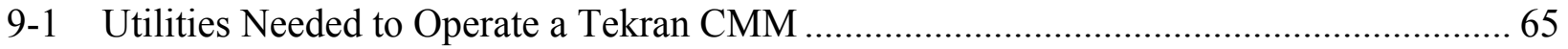

9-2 Summary Comparison of the Total Costs for Appendix K and CMMs ............................ 66 


\section{NOMENCLATURE}

\begin{tabular}{|c|c|}
\hline AAS & atomic absorption spectroscopy \\
\hline ACI & activated carbon injection \\
\hline $\mathrm{AH}$ & amine heater \\
\hline AHI & air heater inlet \\
\hline $\mathrm{AHO}$ & air heater outlet \\
\hline APCD & air pollution control device \\
\hline Av & average \\
\hline AVS & Antelope Valley Station \\
\hline acfm & actual cubic foot per minute \\
\hline acmm & actual cubic meter per minute \\
\hline AES & atomic emission spectroscopy \\
\hline ASTM & ASTM International (formerly American Society for Testing and Materials) \\
\hline $\mathrm{B} \& \mathrm{~W}$ & The Babcock and Wilcox Company \\
\hline BSEI & backscattered electron image \\
\hline CAIR & Clear Air Interstate Rule \\
\hline $\mathrm{CaCl}_{2}$ & calcium chloride \\
\hline CAMR & Clean Air Mercury Rule \\
\hline CCBs & coal combustion by-products \\
\hline CCSEM & computer-controlled scanning electron microscopy \\
\hline $\mathrm{CI}$ & confidence interval \\
\hline CMM & continuous mercury monitor \\
\hline CS-ESP & cold-side electrostatic precipitator \\
\hline CVAAS & cold-vapor atomic absorption spectroscopy \\
\hline CVAFS & cold-vapor atomic fluorescence spectrometry \\
\hline d & dry \\
\hline DMA & direct mercury analyzer \\
\hline DOE & U.S. Department of Energy \\
\hline dscm & dry standard cubic meter \\
\hline ECM & economizer \\
\hline EERC & Energy \& Environmental Research Center \\
\hline EPA & U.S. Environmental Protection Agency \\
\hline EPRI & Electric Power Research Institute \\
\hline ESP & electrostatic precipitator \\
\hline FF & fabric filter \\
\hline FGD & flue gas desulfurization \\
\hline (g) & gas \\
\hline $\mathrm{HCl}$ & hydrochloric acid \\
\hline $\mathrm{Hg}$ & mercury \\
\hline $\mathrm{Hg}^{0}$ & gaseous elemental mercury \\
\hline $\mathrm{Hg}^{2+}$ & gaseous inorganic mercuric compounds \\
\hline $\mathrm{Hg}_{\mathrm{p}}$ & particle-bound mercury \\
\hline HS-ESP & hot-side electrostatic precipitator \\
\hline
\end{tabular}




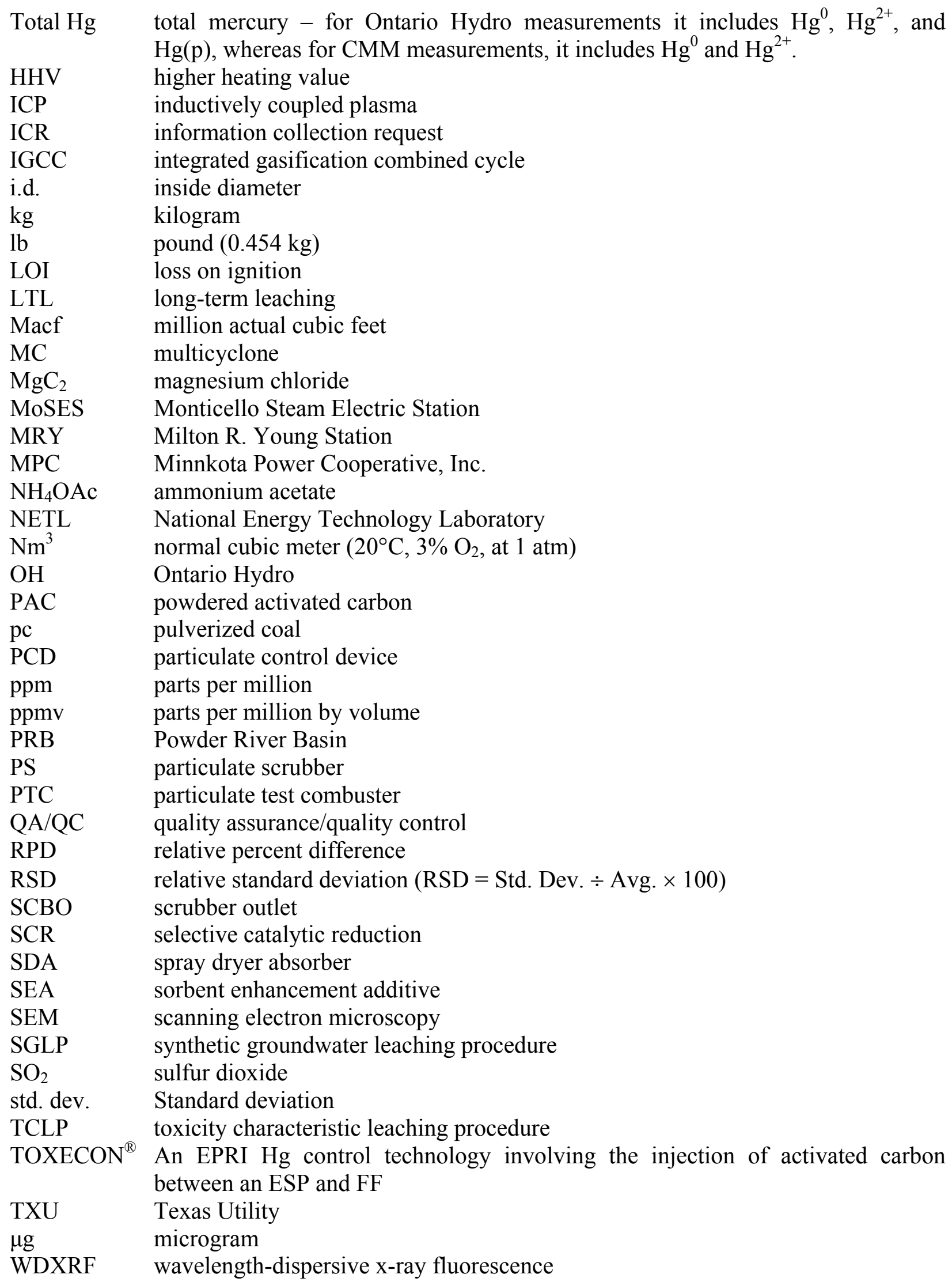




\section{MERCURY CONTROL FIELD TESTING AT MILTON R. YOUNG STATION}

\subsection{INTRODUCTION}

The Energy \& Environmental Research Center (EERC) is leading a consortium involving Apogee, Babcock \& Wilcox Company, the U.S. Department of Energy (DOE) National Energy Technology Laboratory (NETL), the Electric Power Research Institute (EPRI), North Dakota Industrial Commission, and SaskPower, as well as a Mercury Task Force consisting of Basin Electric Power Cooperative; BNI Coal, Ltd.; Dakota Westmoreland Corporation; Great River Energy; Minnkota Power Cooperative, Inc. (MPC); Montana-Dakota Utilities Co.; North American Coal Corporation; Otter Tail Power Company; and TXU Energy (TXU) to evaluate cost-effective approaches for capturing the mercury $(\mathrm{Hg})$ occurring in lignitic combustion flue gases using a cold-side electrostatic precipitator (ESP) and/or wet flue gas desulfurization (FGD) system. This project was developed in response to the U.S. Environmental Protection Agency (EPA) decision to regulate $\mathrm{Hg}$ from utility power plants and a DOE solicitation requesting additional data on the performance of $\mathrm{Hg}$ control technologies for lignite facilities. EPA based its decision on health effects, emissions, and scientific data. U.S. power plants burning lignite generally release greater proportions of elemental mercury $\left(\mathrm{Hg}^{0}\right)$ than those burning bituminous coals. $\mathrm{Hg}^{0}$ is the most difficult chemical species of $\mathrm{Hg}$ to remove from flue gas and, therefore, requires an innovative $\mathrm{Hg}$ control approach.

The overall project goal was to cost-effectively oxidize most of the $\mathrm{Hg}^{0}$ in lignitic combustion flue gases into a more soluble and reactive inorganic mercuric compound $\left(\mathrm{Hg}^{2+}\right)$ that could subsequently be captured in an ESP and/or wet FGD system. $\mathrm{Hg}^{0}$ oxidation processes have been demonstrated using pilot-scale and short-term full-scale tests (1-3). Longer-term full-scale testing is required to further demonstrate and optimize $\mathrm{Hg}^{0}$ oxidation technologies. The applicability of this $\mathrm{Hg}$ control approach is expected to increase with the demand for FGD systems in the United States and Canada.

Minnkota Power Cooperative Milton R. Young (MRY) Station Unit 2 near Center, North Dakota, is one of two host sites for field testing as part of a project entitled Large-Scale Mercury Control Technology Testing for Lignite-Fired Utilities - Oxidation Systems for Wet FGD. The other site was TXU Monticello Steam Electric Station (MoSES) Unit 3 near Mt. Pleasant, Texas. An ESP and wet FGD are used at MRY for controlling particulate and sulfur dioxide $\left(\mathrm{SO}_{2}\right)$ emissions, respectively. $\mathrm{Hg}$ removal technologies investigated at MRY included $\mathrm{Hg}^{0}$ oxidizing agent and sorbent enhancement additions (SEA) and powdered activated carbon (PAC) injection. Calcium chloride $\left(\mathrm{CaCl}_{2}\right)$, magnesium chloride $\left(\mathrm{MgCl}_{2}\right)$, and a proprietary SEA, hereafter referred to as SEA2, were added to the coal feed to enhance $\mathrm{Hg}$ capture in the ESP and/or wet FGD. The PAC injected at MRY Unit 2 was NORIT Americas Inc. DARCO ${ }^{\circledR} \mathrm{Hg}$, a lignitebased activated carbon manufactured specifically for the removal of $\mathrm{Hg}$ in coal-fired utility flue gas emission streams. The EERC collaborated with Babcock \& Wilcox, EPRI, URS, and Apogee in performing the technical work on this project involving $\mathrm{Hg}$ measurements upstream and downstream of ESP and wet FGD units before and during $\mathrm{CaCl}_{2}, \mathrm{MgCl}_{2}$, and SEA2 additions and PAC injections; determining the $\mathrm{Hg}$ removal efficiencies of ESP and wet FGD units; 
quantifying the balance-of-plant impacts of the control technologies; and facilitating technology commercialization.

\subsection{BACKGROUND}

\subsection{World and U.S. Mercury Emissions Budget}

Trace amounts of $\mathrm{Hg}$ exist in fossil fuels such as coal, oil, and natural gas that during combustion may be released to the atmosphere. It has been estimated that the total annual worldwide atmospheric emissions of $\mathrm{Hg}$ is 4900 tons from both natural and anthropogenic sources (4). Coal-fired power plants in the United States emit approximately 48 tons of $\mathrm{Hg}$ per year, thus accounting for about $1 \%$ of the total worldwide annual $\mathrm{Hg}$ emissions (5).

\subsection{Mercury Is a Health Concern}

$\mathrm{Hg}$ is a neurological toxin that can cause impairment of mental, sensory, and motor functions in humans, particularly in developing fetuses and children. A congressionally mandated reassessment of the toxicological effects of $\mathrm{Hg}$ issued by the National Research Council (6) in August 2000 reaffirmed EPA's low Hg exposure reference dose of $0.1 \mu \mathrm{g} / \mathrm{kg}$ per day as the scientifically justifiable level for the protection of child-bearing women, based on quantifiable findings for low-dose exposure in a large study population in the Faroe Islands. Prompted by these health concerns, $\mathrm{Hg}$ is the chemical contaminant responsible, at least in part, for the issuance of approximately 2000 fish consumption advisories. Almost $68 \%$ of all advisories issued in the United States are a result of $\mathrm{Hg}$ contamination in fish and shellfish. Freshwater lake advisories have more than doubled in the last 5 years, resulting in over 40 states that have issued fish advisories because of $\mathrm{Hg}$. Furthermore, recently the Food and Drug Administration issued an advisory limiting consumption of certain ocean fish.

\subsection{Mercury Regulations}

In December 2000, EPA decided that the regulation of $\mathrm{Hg}$ from coal-fired electric utility steam-generating units was appropriate and necessary under Section 112 of the Clean Air Act. EPA determined that $\mathrm{Hg}$ emissions from power plants pose significant hazards to public health and must be reduced. The EPA Mercury Study Report to Congress (1997) (7) and the Utility Hazardous Air Pollutant Report to Congress (1998) (8) both identified coal-fired boilers as the largest single category of atmospheric $\mathrm{Hg}$ emissions in the United States, accounting for about one-third of the total anthropogenic emissions.

On March 15, 2005, EPA issued a final regulation, the Clean Air Mercury Rule (CAMR), for the control of $\mathrm{Hg}$ emissions from coal-fired power plants. This rule creates a two-phase, capand-trade regulation (Section 111 of the Clean Air Act) for both existing and new plants that is similar to the program in place for $\mathrm{SO}_{2}$. Phase I begins in 2010 and calls for a 38-ton nationwide cap on $\mathrm{Hg}$ emissions based on cobenefit reductions obtained with $\mathrm{SO}_{2}$ and $\mathrm{NO}_{\mathrm{x}}$ control achieved through EPA's recently issued Clean Air Interstate Rule (CAIR). Phase II of the CAMR requires 
a $\mathrm{Hg}$ emission cap of 15 tons by 2018. Currently, the estimate of total $\mathrm{Hg}$ emitted from coal-fired power plants is 48 tons; therefore, the 2010 and 2018 reductions are $21 \%$ and $69 \%$, respectively.

With the implementation in March 2005 of CAIR to reduce emissions of $\mathrm{SO}_{2}$ and $\mathrm{NO}_{\mathrm{x}}$ in the eastern 28 states, it is expected that the initial phase of the CAMR will be met as a cobenefit from the additional wet scrubbers and selective catalytic reduction (SCR) systems that will be installed. However, a cap of 15 tons will require additional $\mathrm{Hg}$-specific controls at many power plants.

For trading purposes, EPA established allocations for each state, the District of Columbia, and Indian Reservations based on their share of the total heat input from coal. These were then adjusted to reflect coal rank and existing air pollution control equipment. For allocation purposes, coals were subcategorized as bituminous, subbituminous, lignitic, integrated gasification combined cycle (IGCC), and coal refuse. The total state allocations from 2010 to 2017 are 38 tons and from 2018 and thereafter 15 tons. Each state will decide whether to participate in the trading program.

In addition to the cap-and-trade program, new coal-fired sources will have additional $\mathrm{Hg}$ requirements as part of the New Source Performance Standards. The requirements were subcategorized as follows:

- Bituminous units $-21 \times 10^{-6} \mathrm{lb} / \mathrm{MWh}$

- Subbituminous units

- Wet FGD $-42 \times 10^{-6} \mathrm{lb} / \mathrm{MWh}$

- Dry FGD - $78 \times 10^{-6} \mathrm{lb} / \mathrm{MWh}$

- Lignite units $-145 \times 10^{-6} \mathrm{lb} / \mathrm{MWh}$

- IGCC units $-20 \times 10^{-6} \mathrm{lb} / \mathrm{MWh}$

- Coal refuse units $-1.4 \times 10^{-6} \mathrm{lb} / \mathrm{MWh}$

\subsection{Mercury Emissions from Low-Rank Coals Will Be Difficult to Control}

$\mathrm{Hg}$ emissions from utilities burning U.S. coals were determined under EPA's information collection request (ICR), which mandated $\mathrm{Hg}$ and chlorine analyses on coal shipped to units larger than $25 \mathrm{MWe}$ during 1999 and emissions testing on 84 units selected to represent different categories of air pollution control equipment and coal rank (9). Lignitic and subbituminous coals from the western United States, on average, contain significantly lower, concentrations of $\mathrm{Hg}$, chlorine, and sulfur than bituminous coals from the eastern United States, Appalachian, or interior regions. Western lignitic and subbituminous coals are also distinguished by their much higher alkaline-earth metal (i.e., magnesium and calcium) contents. Gulf Coast lignites resemble eastern bituminous coals in their high concentrations of $\mathrm{Hg}$ and iron, but are similar to western coals in regard to low chlorine and high calcium contents. These compositional differences not only affect the quantities and chemical species of $\mathrm{Hg}$ emitted from a boiler but also the effectiveness of different control technologies to remove $\mathrm{Hg}$ from flue gas. Western lignitic and subbituminous coals contain about half as much $\mathrm{Hg}$ on a weight basis; however, the ICR data indicate that they emit almost twice as much $\mathrm{Hg}$ on a $\mathrm{lb} /$ Btu basis because of their lower heat contents relative to bituminous coals (10). 
In general, lignitic coals are characterized by their relatively high oxygen, moisture, and alkali and alkaline-earth elemental concentrations and low chlorine contents. Based on the ICR data, North Dakota and Gulf Coast lignites produce as much as $8 \mathrm{lb} \mathrm{Hg} / 10^{12}$ Btu and $12.5 \mathrm{lb} \mathrm{Hg} / 10^{12} \mathrm{Btu}$, respectively, compared to $6 \mathrm{lb} \mathrm{Hg} / 10^{12}$ Btu for subbituminous Powder River Basin (PRB) coals, $6.5 \mathrm{lb} \mathrm{Hg} / 10^{12}$ Btu for Illinois Basin bituminous coals, and $9.5 \mathrm{lb} \mathrm{Hg} / 10^{12} \mathrm{Btu}$ for Appalachian bituminous coals (9). Coal composition has a major impact on the quantity and chemical form of $\mathrm{Hg}$ in the flue gas and, as a result, the effectiveness of air pollution control devices to remove $\mathrm{Hg}$ from flue gas. Coals containing greater than about $200 \mathrm{ppm}$ chlorine produce flue gases that are dominated by the more easily removable mercuric compounds $\left(\mathrm{Hg}^{2+}\right)$, most likely mercuric chloride $\left(\mathrm{HgCl}_{2}\right)$. Appalachian and Illinois Basin bituminous coals generally have $>200 \mathrm{ppm}$ chlorine. Conversely, low-chlorine $(<50 \mathrm{ppm})$ lignite and subbituminous coal combustion flue gases contain predominantly $\mathrm{Hg}^{0}$, which is substantially more difficult to remove than $\mathrm{Hg}^{2+}(11,12)$. Additionally, the abundance of calcium in lignite and subbituminous coal fly ashes may reduce the oxidizing effect of the already low chlorine content by reactively scavenging chlorine species $\left(\mathrm{Cl}, \mathrm{HCl}\right.$, and $\left.\mathrm{Cl}_{2}\right)$ from the combustion flue gas.

\subsection{Mercury Control Options}

Options for controlling $\mathrm{Hg}$ emissions are being investigated that have the potential to attain $>90 \%$ removal of $\mathrm{Hg}$ from flue gas. ICR data and other test data of $\mathrm{Hg}$ control for lignite and subbituminous coal-fired systems indicate that low $\mathrm{Hg}^{0}$ reactivity poses technical and economic challenges and that innovative $\mathrm{Hg}^{0}$ control technologies are needed for lignite coals. $\mathrm{Hg}$ control strategies at lignite coal-fired power plants have primarily focused on enhancing existing air pollution control device (APCD) technologies. Presented in Table 2-1 is a summary of the average cobenefit $\mathrm{Hg}$ removal efficiencies for various APCD configurations and coal rank based on testing performed by the EPA in 1999. Although conventional APCD technology captures some $\mathrm{Hg}$, new $\mathrm{Hg}$ control technologies will be needed to comply with the CAMR Phase II emission cap. Currently, PAC injection has shown the most promise as a near-term Hg control technology. PAC is typically injected downstream of a plant's air heater and upstream of a particulate control device, either an ESP or $\mathrm{FF}$. $\mathrm{Hg}^{0}$ oxidation and sorbent enhancement technologies are also being developed to improve $\mathrm{Hg}$ capture in existing APCDs.

\subsubsection{Previous Results with $\mathrm{Hg}^{0}$ Oxidation Technologies}

The $\mathrm{Hg}^{0}$ oxidation technologies being investigated for lignites include catalysts and chemical agents. Selective catalytic reduction catalysts for $\mathrm{NO}_{\mathrm{x}}$ reduction, noble metalimpregnated catalysts, and oxide-impregnated catalysts have been evaluated for promoting $\mathrm{Hg}^{0}$ oxidation. The chemical agents include chlorine-containing salts (chloride compounds) and cofiring fuels that contain oxidizing agents $(1,2)$.

Theoretically, the use of chloride compounds to oxidize $\mathrm{Hg}^{0}$ to $\mathrm{Hg}^{2+}$ makes sense. The evidence includes chemical kinetic modeling of bench-scale test results, indicating that the introduction of chloride compounds into the high-temperature furnace region will likely result in the production of atomic chlorine and/or molecular chlorine, which are generally thought to be 
Table 2-1. Average Hg Removal Efficiencies (\%) by Coal Rank and APCD Configuration

\begin{tabular}{lccc}
\hline APCD & Bituminous & Subbituminous & Lignite \\
\hline CS-ESP $^{1}$ & 36 & 3 & -4 \\
HS-ESP $^{2}$ & 9 & 6 & NA $^{3}$ \\
FF $^{4}$ & 90 & 72 & NA \\
PS $^{5}$ & NA & 9 & NA \\
SDA $^{6}-$ ESP & NA & 35 & NA \\
SDA-FF & 98 & 24 & 0 \\
SDA-FF-SCR & 98 & NA & NA \\
PS-Wet FGD & 12 & -8 & 33 \\
CS-ESP-Wet FGD & 74 & 29 & 44 \\
HS-ESP-Wet FGD & 50 & 29 & NA \\
FF-Wet FGD & 98 & NA & NA \\
\hline
\end{tabular}

${ }^{1}$ Cold-side electrostatic precipitator

${ }^{2}$ Hot-side electrostatic precipitator

${ }^{3}$ Not available.

${ }^{4}$ Fabric filter.

${ }_{6}^{5}$ Particulate scrubber

${ }^{6}$ Spray dryer absorber

the dominant $\mathrm{Hg}^{0}$ reactants in coal combustion flue gases (1). The formation of atomic chlorine is a key pathway involved in the chemical reaction mechanisms that result in the oxidation of $\mathrm{Hg}^{0}$ (1). Recent kinetic modeling of chlorine radical formation as a function of temperature and residence time is shown in Figure 2-1. The results indicate the importance of temperature and residence time in controlling the formation of chlorine radicals. Consistent with the modeling results in Figure 2-1, the injection of $\mathrm{HCl}$ in lower-temperature regions downstream of a furnace was ineffective in oxidizing $\mathrm{Hg}^{0}$, whereas injection into the furnace effectively transformed most of the $\mathrm{Hg}^{0}$ to $\mathrm{Hg}^{2+}(3)$.

Fuel additives for enhancing $\mathrm{Hg}^{0}$ oxidation have recently been tested in a pilot-scale system. Chloride salts promote the conversion of $\mathrm{Hg}^{0}$ to $\mathrm{Hg}^{2+}$, as shown in Figure 2-2. In addition, recent EPRI short-term testing at a $70-\mathrm{MWe}_{\mathrm{e}}$ pc-fired North Dakota power plant indicated that chloride salt injections increased $\mathrm{Hg}^{0}$ oxidation in the flue gas (3). Approximately $70 \%$ of the $\mathrm{Hg}^{0}$ was transformed to $\mathrm{Hg}^{2+}$ at a flue gas $\mathrm{HCl}$ concentration of $110 \mathrm{ppm}$, as shown in Figure 2-3. In addition, salt injection enhanced the Hg removal efficiency of the SDA-FF, to $\leq 50 \%$ during short-term field testing (3).

\subsubsection{Previous Results with Powdered Activated Carbon Injection}

Many potential $\mathrm{Hg}$ sorbents have been evaluated. These evaluations have demonstrated that the chemical speciation of $\mathrm{Hg}$ controls its capture mechanism and ultimate environmental fate. PAC injection is the most tested technology available for $\mathrm{Hg}$ control. PACs have the potential to effectively adsorb $\mathrm{Hg}^{0}$ and $\mathrm{Hg}^{2+}$, depending on the carbon characteristics and flue 


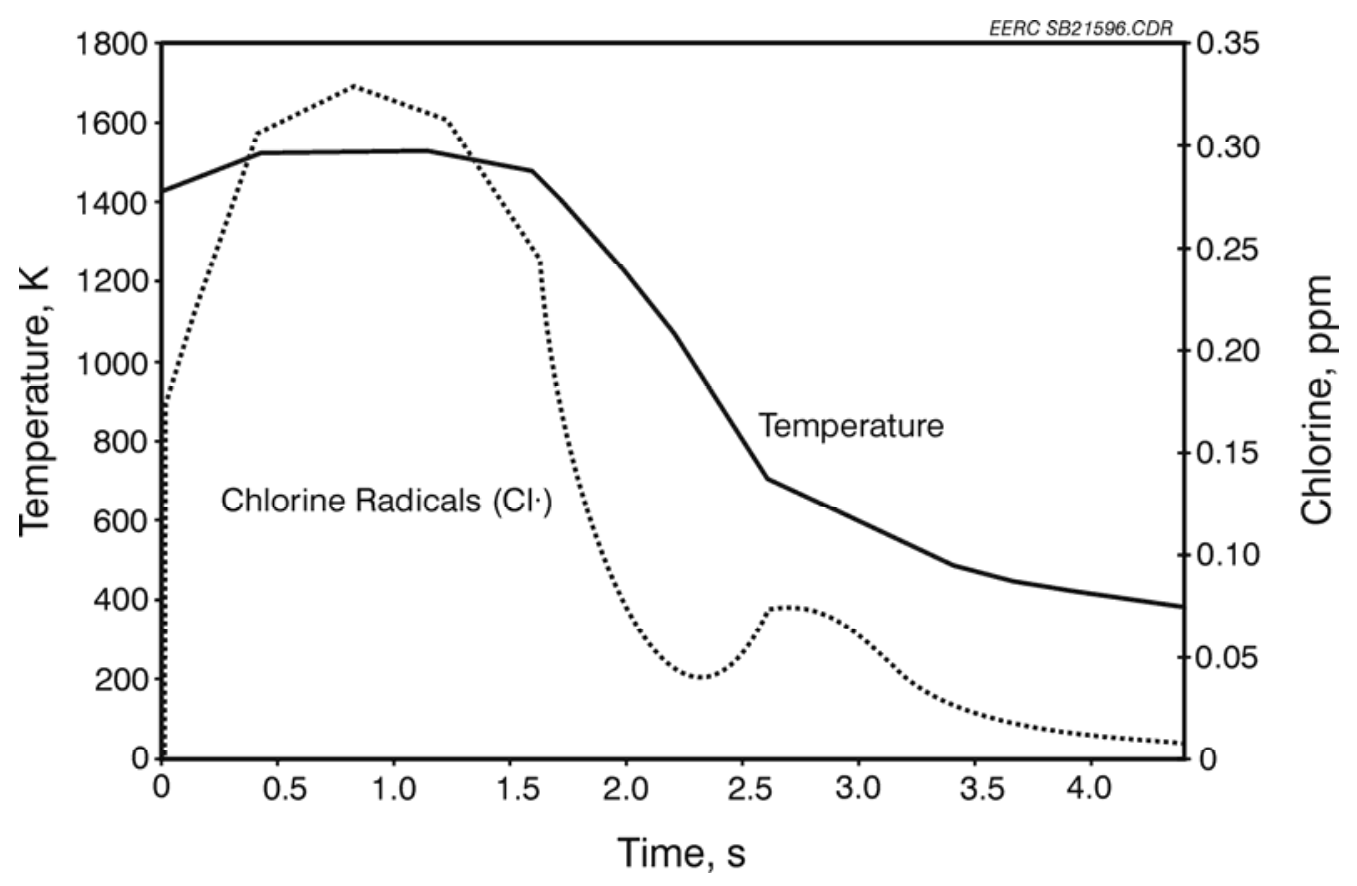

Figure 2-1. Kinetic model (Chemkin) prediction of chlorine radical concentration as a function of the temperature and residence time profile of a utility boiler.

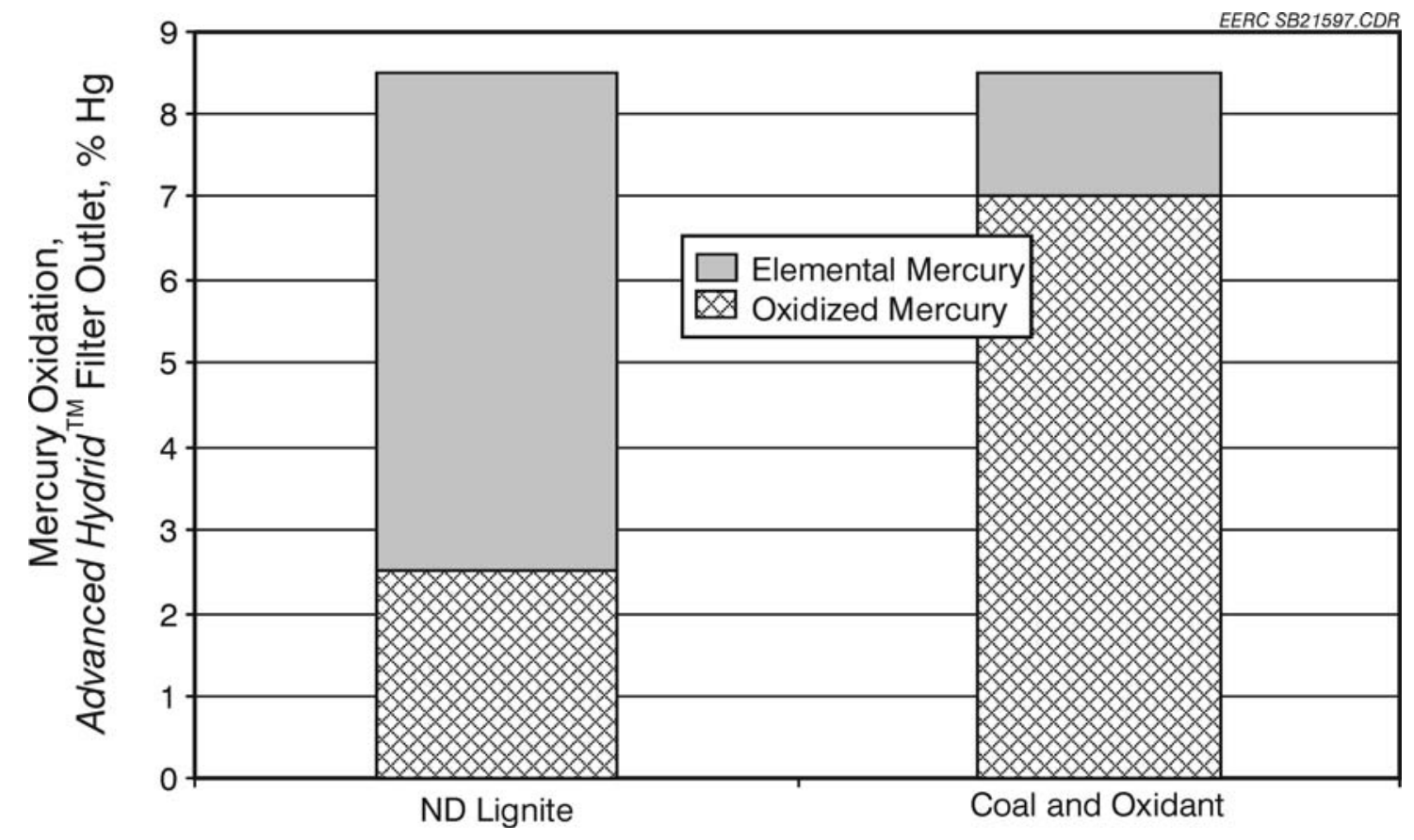

Figure 2-2. Ontario Hydro $(\mathrm{OH}) \mathrm{Hg}$ speciation results showing the effects of a coal $\mathrm{Hg}^{0}$ oxidation agent on North Dakota lignite combustion flue gas $\mathrm{Hg}$ speciation. 


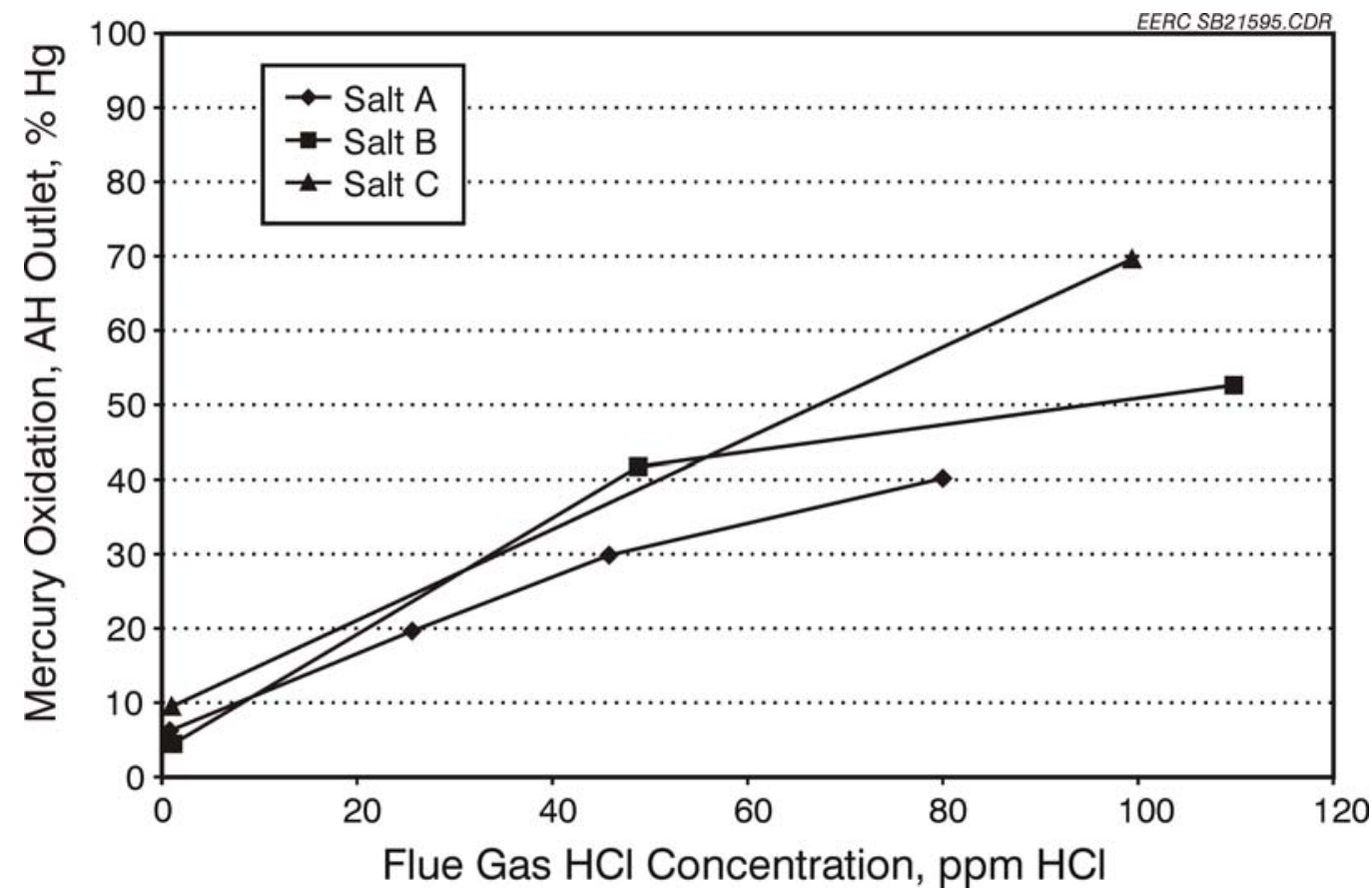

Figure 2-3. Comparison of $\mathrm{Hg}^{0}$ oxidation and $\mathrm{HCl}$ flue gas concentrations during salt injections at a North Dakota lignite-fired power plant (8).

gas composition. Much PAC research has been performed in fixed-bed reactors that simulate relatively long-residence-time (gas-solid contact times of minutes or hours) $\mathrm{Hg}$ capture by a FF filter cake (13-15). However, it is important to investigate short-residence-time (seconds) in-flight capture of $\mathrm{Hg}^{0}$ because most of the coal-burning boilers in the United States employ cold-side ESPs for controlling particulate matter emissions.

The projected annual cost for activated carbon adsorption of $\mathrm{Hg}$ in a duct injection system is significant. Based on experimental results, carbon-to-Hg weight ratios of 3000-18,000 (lb carbon injected/lb $\mathrm{Hg}$ in flue gas) were required to achieve $90 \% \mathrm{Hg}$ removal from a coal combustion flue gas containing $10 \mu \mathrm{g} / \mathrm{dNm}^{3}$ of $\mathrm{Hg}$ (16). More efficient carbon-based sorbents would enable lower carbon-to-Hg weight ratios to be used, thus reducing the costs.

EERC pilot-scale ESP and ESP-FF Hg removal efficiencies for Fort Union lignite coal combustion flue gases from Saskatchewan and North Dakota are compared in Figures 2-4 and 2-5 to those obtained at full-scale utility boilers while injecting PACs into a bituminous coal combustion flue gas upstream of a TOXECON configured pulse-jet FF and into bituminous and PRB subbituminous coal combustion flue gases upstream of an ESP. As indicated in Figures 2-4 and 2-5, coal type (i.e., composition) was an important parameter that affected the $\mathrm{Hg}$ removal efficiency of a control device. While $\mathrm{Hg}$ removal efficiencies increased with increasing PAC injection rates, $\mathrm{Hg}$ removal efficiencies were never $>70 \%$ for the PRB subbituminous coal combustion flue gas. This limitation may be caused by the low amount of acidic flue gas constituents, such as $\mathrm{HCl}$, that promote $\mathrm{Hg}$-activated carbon reactivity. 


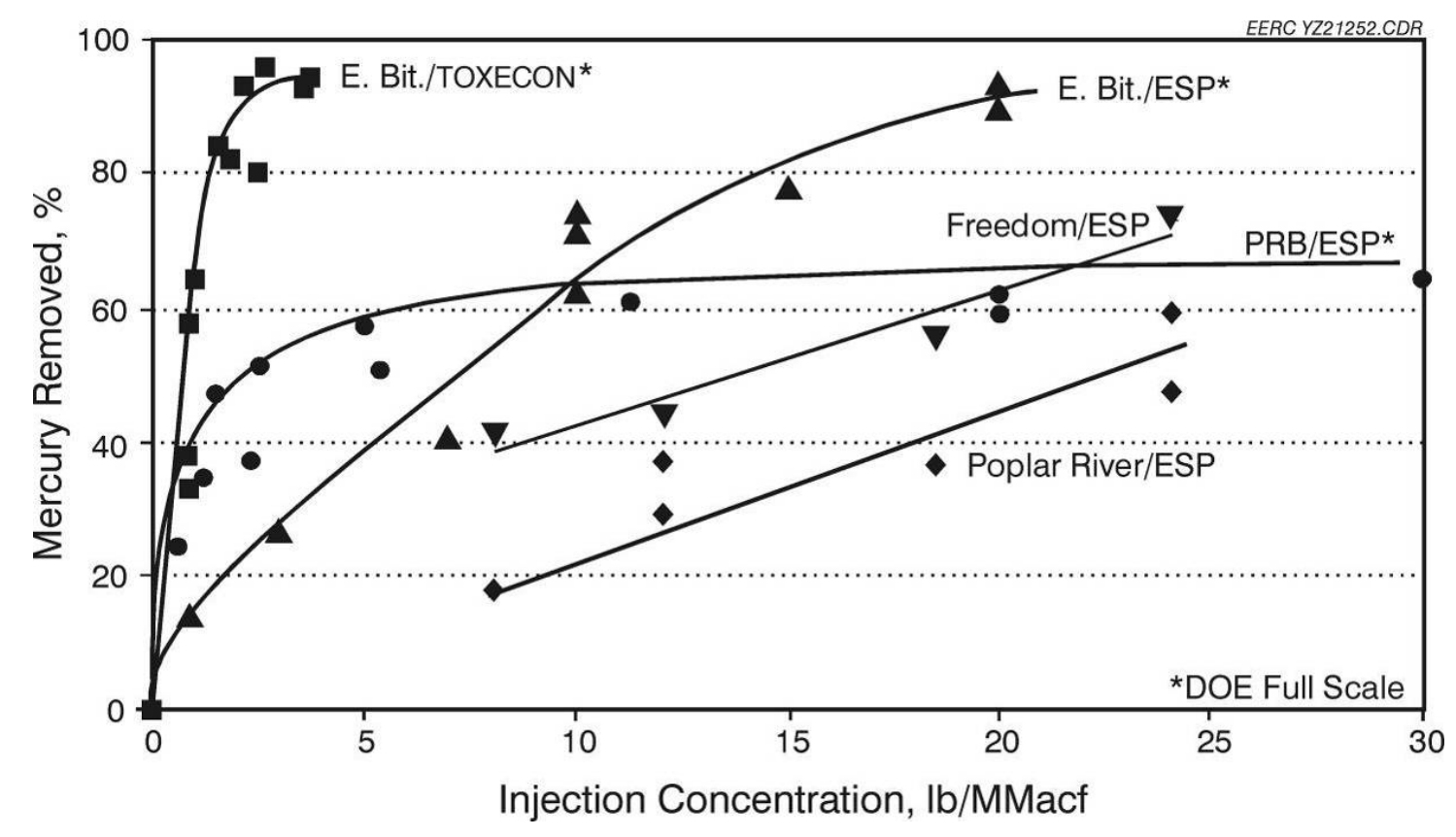

Figure 2-4. Pilot-scale ESP (12) and full-scale ESP (13) Hg removal efficiencies as a function of activated carbon injection $(\mathrm{ACI})$ rate.

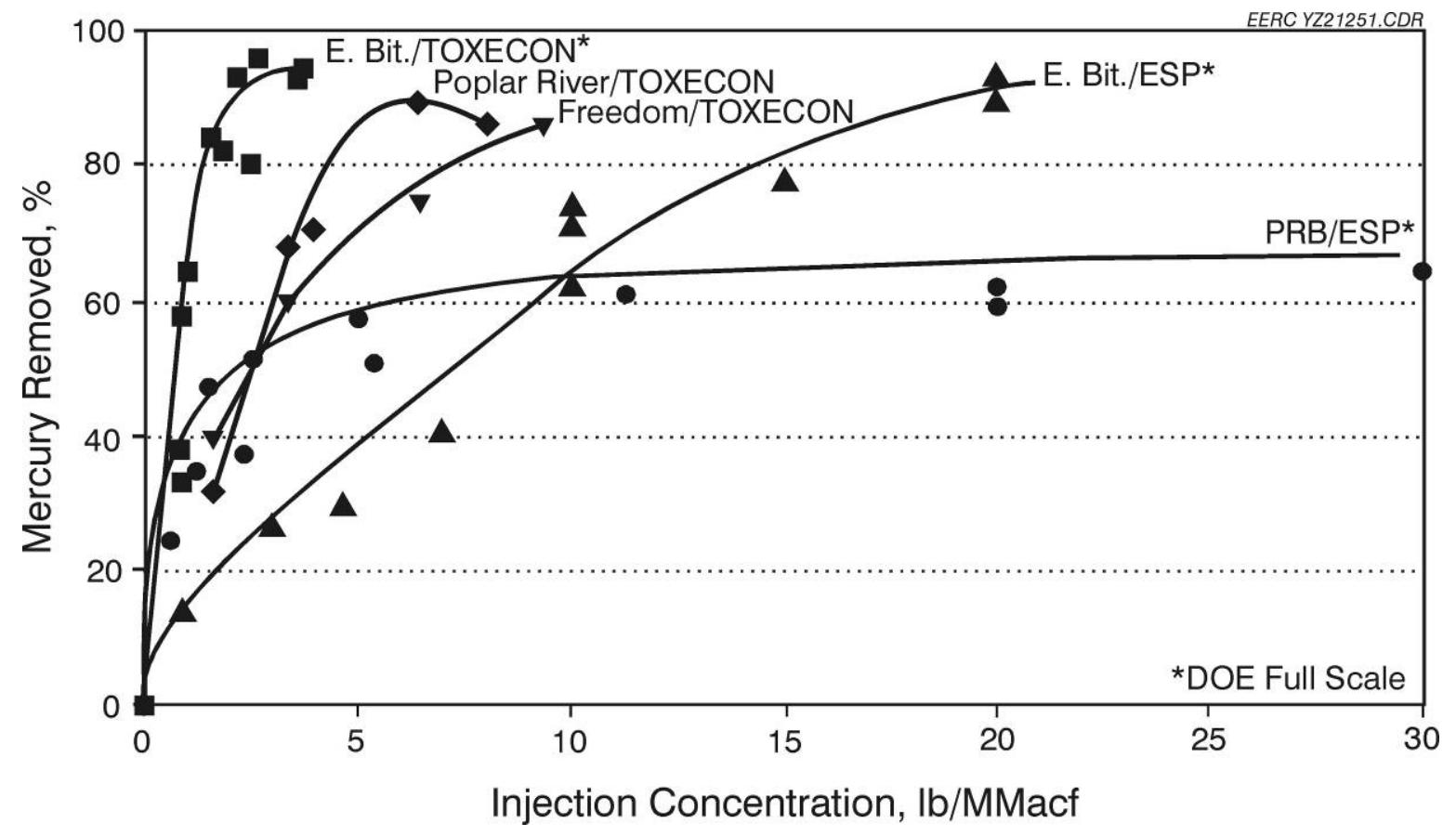

Figure 2-5. Pilot-scale ESP-FF (12) and full-scale TOXECON and ESP (13) Hg removal efficiencies as a function of ACI rate. 
Testing at GRE, a power plant firing Fort Union lignite and equipped with an SDA-FF, indicated that DARCO FGD and lignite-derived PACs resulted in $\mathrm{Hg}$ removal efficiencies of $<35 \%$ (17). The poor performance of PAC injection was thought to be the result of low-acid-gas concentrations and high proportion of $\mathrm{Hg}^{0}$ in the flue gas. An iodine-impregnated activated carbon, however, captured approximately $90 \%$ of the $\mathrm{Hg}$.

Researchers at the EERC and elsewhere are studying the mechanisms of $\mathrm{Hg}$ species reactions on activated carbon surfaces in order to produce more efficient sorbents. Functional groups containing inorganic elements such as chlorine or sulfur may have a significant role in bonding $\mathrm{Hg}(18-20)$. Recently, detailed analyses of sorbents derived from lignites exposed to flue gas and $\mathrm{Hg}^{0}$ indicated the key species affecting oxidation and retention of $\mathrm{Hg}$ on the carbon surface were chlorine and sulfur $(21,22)$. Chlorine reacted to form organically associated chlorine on the carbon surface. The organically associated chlorine provided an important site for $\mathrm{Hg}^{2+}$ bonding.

\subsubsection{Previous Results with Sorbent Enhancement Additives}

SEAs have recently been tested at the EERC. The effects of SEA additions and PAC injections on $\mathrm{Hg}$ capture in a TOXECON configuration, Advanced Hybrid filter, and ESP are illustrated in Figure 2-6. Baseline $\mathrm{Hg}$ emissions ranged from 9 to $12 \mu \mathrm{g} / \mathrm{dNm}^{3}$, with $80 \%$ to $90 \%$ of the total $\mathrm{Hg}$ as $\mathrm{Hg}^{0}$. Coal additives improved the $\mathrm{Hg}$ removal efficiencies of the TOXECON, Advanced Hybrid filter, and ESP devices to $\geq 90 \%$ removal. While using SEAs, the Hg control efficiency obtained with the ESP significantly improved compared to the previous ESP results presented in Figure 2-4. The coal additive technology also has the potential to improve SDAESP and SDA-FF Hg control efficiency.

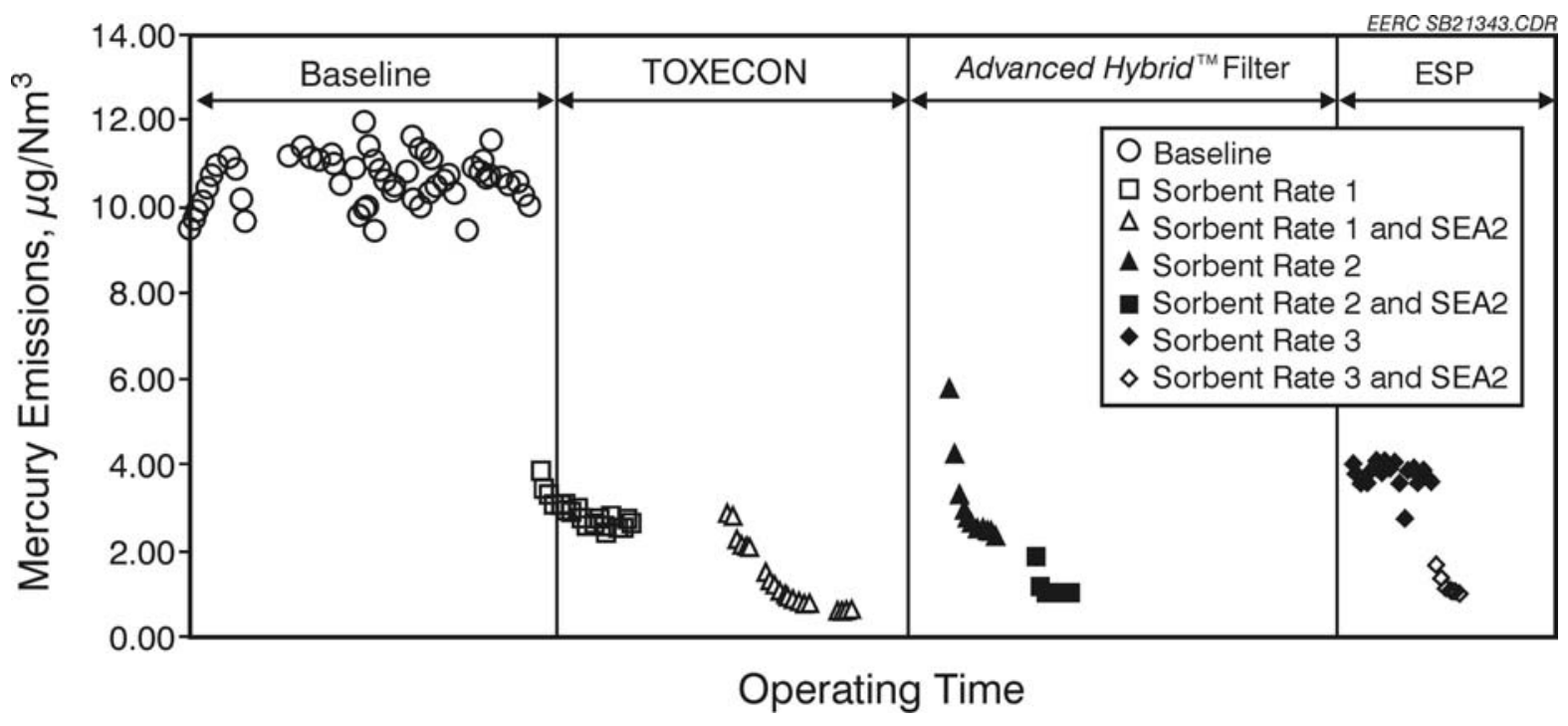

Figure 2-6. Hg emissions for PAC injection combined with additives. 
PAC injection and SEA addition upstream of an ESP was evaluated for controlling $\mathrm{Hg}$ emissions associated with North Dakota lignite combustion. The testing was performed using the EERC's particulate test combustor (PTC) equipped with an ESP. Test results are presented in Figure 2-7. DARCO FGD injection at 3.75 and $15 \mathrm{lb} / \mathrm{Macf}$ reduced $\mathrm{Hg}$ emissions by $50 \%$ and $60 \%$, respectively. The addition of SEA to the coal and PAC at $3.75 \mathrm{lb} / \mathrm{Macf}$ reduced $\mathrm{Hg}$ emissions by $>70 \%$.

Sorbent enhancement technologies have also been investigated by ALSTOM using a synthetic flue gas and an ESP. The sorbent preparation system enhanced sorbent performance from $68 \%$ to $>90 \% \mathrm{Hg}$ removal by changing the physical and chemical nature of the sorbent. The enhancement approach is expected to be applicable to a significant number of sorbents currently utilized for $\mathrm{Hg}$ control.

Using SEAs for the removal of $\mathrm{Hg}$ from coal-fired flue gas has the potential to create a lower cost and more effective $\mathrm{Hg}$ removal strategy. Although the technology is in its infancy, it has great promise.

\subsection{Coal Combustion By-Products}

The $\mathrm{Hg}$ emission control technologies being developed for flue gases are in many cases designed to incorporate $\mathrm{Hg}$ into fly ash and/or FGD residue. Significant changes in the chemical composition, physical properties, and morphology of coal combustion by-products (CCBs) may occur as a result of the application of new emission controls. The stability of $\mathrm{Hg}$ associated with

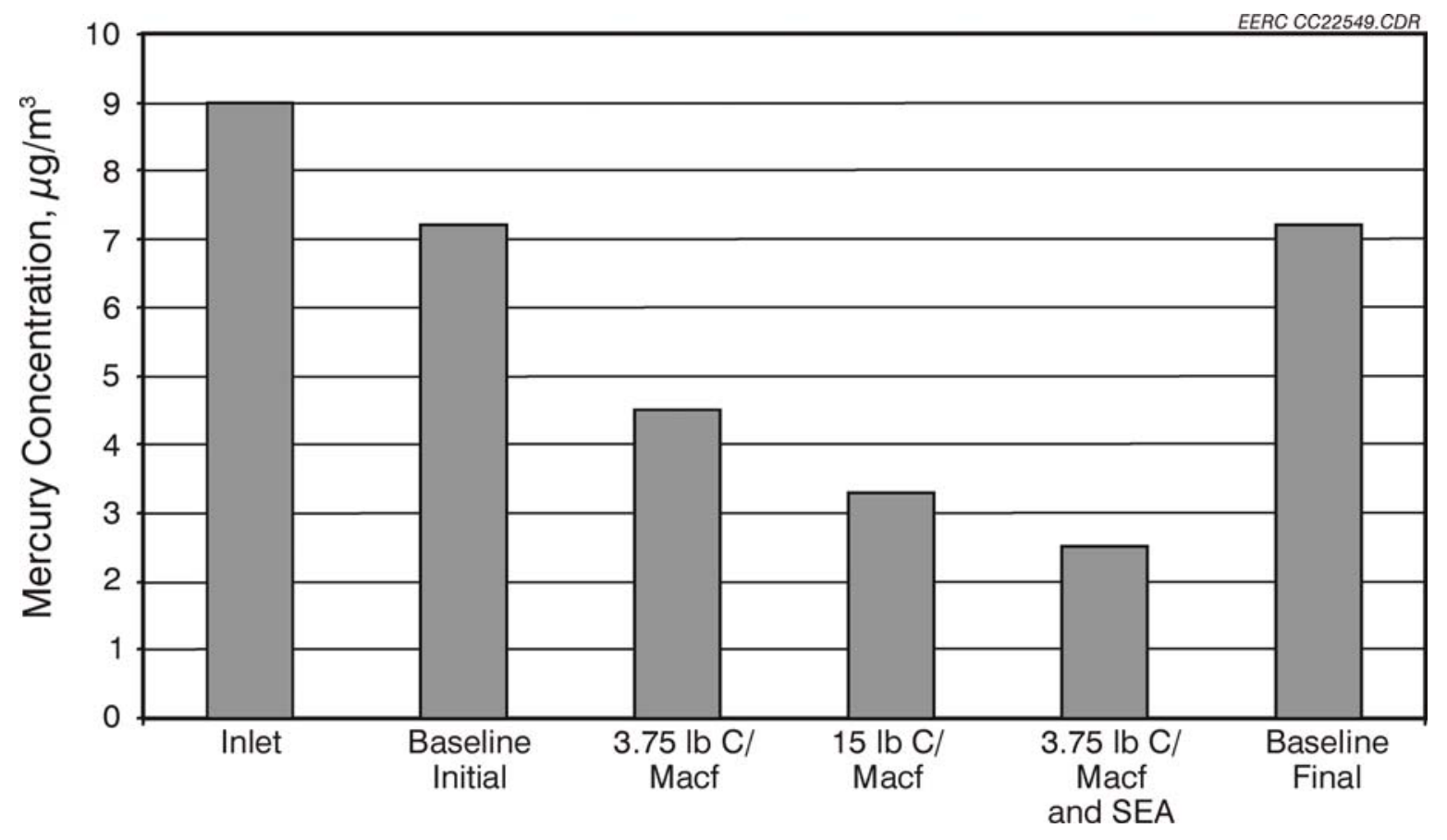

Figure 2-7. ESP inlet and outlet total $\mathrm{Hg}$ concentrations as functions of PAC injection and SEA addition rates into North Dakota lignite combustion flue gases. 
CCBs is being investigated at the EERC to determine if the $\mathrm{Hg}$ captured on CCBs may be released to the atmosphere or groundwater, thus negating the environmental benefit of removing $\mathrm{Hg}$ from flue gases. In addition, the physical and chemical changes that CCBs may undergo as a result of implementing $\mathrm{Hg}$ control technologies are being evaluated because they may affect how CCBs are managed.

$\mathrm{Hg}$ mobility mechanisms from CCBs have been identified as 1) direct leachability, 2) vapor-phase release at ambient and elevated temperatures, and 3) biologically induced leachability and vaporization. Leaching is the most likely mechanism of transport of constituents from disposed or utilized CCBs contacted by water. Leaching is typically performed on CCBs to characterize them for management purposes. Several issues have been raised by EPA's Office of Research and Development and Office of Solid Waste related to the best means of evaluating the leaching potential of CCBs. Vapor-phase release, particularly of $\mathrm{Hg}$, is important from the perspective of long-term use, storage, or disposal of CCBs. Although the $\mathrm{Hg}$ concentration in CCBs is relatively low, the large volumes of CCBs produced annually cause concern about potential $\mathrm{Hg}$ releases. Ambient and elevated-temperature studies of $\mathrm{Hg}$ mobility resulted in the development of equipment to determine $\mathrm{Hg}$ release in real time from CCBs. EERC results are presented regarding $\mathrm{Hg}$ release from $\mathrm{CCBs}$ subjected to laboratory tests designed to simulate the identified Hg mobility mechanisms.

\subsection{PROJECT OVERVIEW}

In response to a DOE solicitation calling for additional data on the performance of $\mathrm{Hg}$ control technologies for lignite facilities, a consortium was developed to perform the research described herein. The objective, therefore, was to evaluate potentially cost-effective $\mathrm{Hg}$ control technology options by using existing emission control equipment. Three primary technologies were identified for field testing: 1) in situ $\mathrm{Hg}$ sorbent enhancement of PAC, 2) injection of treated PACs, and 3) $\mathrm{Hg}^{0}$ oxidation upstream of a wet or dry scrubber. PAC injection is the most mature technology available for controlling gaseous $\mathrm{Hg}$ emissions. The technology relies on the sorption of $\mathrm{Hg}$ species by a solid sorbent injected upstream of a particulate control device (PCD) such as an ESP or FF. Flue gas contact with the sorbent in the duct provides a very short in-flight period where $\mathrm{Hg}$ can sorb to a carbon or other sorbent. Additional gas-solid contact can occur across an FF, resulting in greater $\mathrm{Hg}$ capture than similar operation with an ESP; however, both devices have captured $\mathrm{Hg}$.

\subsection{Goals and Objectives}

The primary project goal was to achieve an ESP-wet FGD Hg removal efficiency of $\geq 55 \%$ at MRY Unit 2 for about a month. The objective of MRY Unit 2 testing was to evaluate the effects of chemical additions and PAC injections on $\mathrm{Hg}$ speciation, overall $\mathrm{Hg}$ removal from the lignite combustion flue gas using an ESP and wet FGD, and deposition on and corrosion of system components. To meet this goal and objectives, the following work was performed at MRY Unit 2:

- Baseline Hg speciation and removal were measured. 
- $\mathrm{Hg}$ removal resulting from $\mathrm{CaCl}_{2}, \mathrm{MgCl}_{2}$, and $\mathrm{SEA} 2$ additions was measured.

- Hg removal was determined during PAC injections.

- $\mathrm{Hg}$ removal was determined when $\mathrm{CaCl}_{2}$ and SEA2 were added during PAC injections.

- SEA2 addition and PAC injection rates were optimized for capturing $\mathrm{Hg}$ in the ESP and wet FGD.

- A monthlong test was conducted to evaluate the potential long-term balance-of-plant effects associated with removing $\mathrm{Hg}$ using SEA2 and PAC.

- The variability of $\mathrm{Hg}$ removal and emissions was evaluated while applying the control technology.

- An economic evaluation of long-term Hg control was performed.

- The thermal stability and leachability of $\mathrm{Hg}$ in $\mathrm{CCB}$ were determined.

- The potential effects of SEA2 and PAC injections on deposition and corrosion of steel surfaces were evaluated.

\subsection{Approach/Work Plan}

Presented in Table 3-1 is a detailed schedule of test conditions, chemical additions, PAC injections, and sampling activities that were performed at MRY Unit 2 from mid-March to midMay of 2005. The schedule included a week for setup and shakedown of the chemical addition and PAC injection systems as well as installing the CMM and other sampling equipment. Baseline testing was performed to characterize the inherent $\mathrm{Hg}$ emission characteristics of MRY Unit 2 during routine power plant operations. Parametric testing was performed to identify the chemical additions and PAC injections required to achieve the targeted ESP-FGD Hg removal efficiency of 55\%. Early in the long-term testing, it was determined that the SEA2 addition rate required to achieve the $\mathrm{Hg}$ removal goal was untenable; therefore, a small amount of PAC was injected at the ESP inlet to further enhance $\mathrm{Hg}$ removal.

$\mathrm{Hg}$ sampling and speciation measurements occurred at two locations, the air heater (AH) outlet and stack, on MRY Unit 2. Sampling was performed during baseline unit operation, parametric testing, and monthlong testing. Continuous mercury monitors (CMMs) and coal $\mathrm{Hg}$ analyses were the primary sources of data for evaluating $\mathrm{Hg}$ control across the unit. Additional measurements using the ASTM International Method D6784-02 (Standard Test Method for Elemental, Oxidized, Particle-Bound, and Total Mercury in Flue Gas Generated from Coal-Fired Stationary Sources), originally referred to as the $\mathrm{OH}$ method, were performed to provide $\mathrm{Hg}$ speciation results and to verify measurements obtained with the CMMs. 
Table 3-1. Schedule of Test Conditions, Chemical Additions, PAC Injections, and Sampling Activities Performed at MRY Unit 2

\begin{tabular}{|c|c|c|c|c|c|c|}
\hline Date & Condition & Start Time & End Time & $\begin{array}{c}\text { Chemical } \\
\text { Additions, ppm } \\
\text { (dry coal basis) }\end{array}$ & $\begin{array}{c}\text { PAC Injection, } \\
\mathrm{lb} / \mathrm{min}\end{array}$ & Sampling \\
\hline $3 / 16 / 05$ & Baseline & $24: 00$ & & & & \\
\hline $3 / 16 / 05$ & Baseline & $18: 00$ & 19:00 & & & M26A $^{1}$ \\
\hline $3 / 17 / 05$ & Baseline & $10: 20$ & $12: 20$ & & & $\mathrm{OH}^{2}$ \\
\hline $3 / 17 / 05$ & Baseline & $14: 40$ & $16: 40$ & & & $\mathrm{OH}$ \\
\hline $3 / 18 / 05$ & Baseline & $10: 52$ & $11: 22$ & & & $\mathrm{OH}$ \\
\hline $3 / 18 / 05$ & Baseline & 10:04 & 12:04 & & & \\
\hline $3 / 18 / 05$ & Parametric & $15: 00$ & $16: 00$ & & & $\mathrm{MC}^{3}$ \\
\hline $3 / 18 / 05$ & Parametric & $14: 53$ & $16: 54$ & & 0.5 & \\
\hline $3 / 18 / 05$ & Parametric & $17: 03$ & $19: 20$ & & 1.0 & \\
\hline $3 / 18 / 05$ & Parametric & $19: 29$ & $21: 34$ & & 2.0 & \\
\hline $3 / 19 / 05$ & Parametric & $8: 45$ & $19: 00$ & $\mathrm{CaCl}_{2}, 300$ & & \\
\hline $3 / 19 / 05$ & Parametric & $16: 55$ & $18: 55$ & $\mathrm{CaCl}_{2}, 300$ & & $\mathrm{OH}$ \\
\hline $3 / 20 / 05$ & Parametric & $7: 51$ & $11: 00$ & $\mathrm{CaCl} 2,100$ & & \\
\hline $3 / 20 / 05$ & Parametric & $8: 52$ & $10: 52$ & $\mathrm{CaCl}_{2}, 100$ & & $\mathrm{OH}$ \\
\hline $3 / 21 / 05$ & Parametric & $8: 00$ & $12: 41$ & $\mathrm{CaCl}_{2}, 500$ & 0.5 & \\
\hline $3 / 21 / 05$ & Parametric & $10: 33$ & $12: 33$ & $\mathrm{CaCl}_{2}, 500$ & & $\mathrm{OH}$ \\
\hline $3 / 21 / 05$ & Parametric & $13: 45$ & $15: 40$ & $\mathrm{CaCl}_{2}, 300$ & & \\
\hline $3 / 21 / 05$ & Parametric & $15: 45$ & $17: 17$ & $\mathrm{MgCl}_{2}, 500$ & & \\
\hline $3 / 22 / 05$ & Parametric & $7: 45$ & $16: 15$ & $\mathrm{CaCl}_{2}, 300$ & & \\
\hline $3 / 22 / 05$ & Parametric & $8: 01$ & 10:00 & $\mathrm{CaCl}_{2}, 300$ & 0.5 & \\
\hline $3 / 22 / 05$ & Parametric & $10: 12$ & 14:01 & $\mathrm{CaCl}_{2}, 300$ & 1.0 & \\
\hline $3 / 22 / 05$ & Parametric & $11: 42$ & $13: 42$ & $\mathrm{CaCl}_{2}, 300$ & 1.0 & $\mathrm{OH}$ \\
\hline $3 / 22 / 05$ & Parametric & $14: 15$ & $14: 36$ & $\mathrm{CaCl}_{2}, 300$ & 2.0 & \\
\hline $3 / 22 / 05$ & Parametric & $14: 37$ & $16: 15$ & $\mathrm{CaCl}_{2}, 300$ & 2.1 & \\
\hline $3 / 22 / 05$ & Parametric & $16: 16$ & $17: 53$ & $\mathrm{CaCl}_{2}, 500$ & 1.0 & \\
\hline $3 / 22 / 05$ & Parametric & $19: 40$ & $19: 40$ & $\mathrm{CaCl}_{2}, 1000$ & 1.0 & \\
\hline $3 / 23 / 05$ & Baseline & 19:40 & $20: 03$ & & 1.0 & \\
\hline $3 / 24 / 05$ & Baseline & & & & & \\
\hline $3 / 25 / 05$ & Baseline & & & & & \\
\hline $3 / 26 / 05$ & Baseline & & & & & \\
\hline $3 / 27 / 05$ & Baseline & & & & & \\
\hline $3 / 28 / 05$ & Baseline & $18: 17$ & & & & \\
\hline $3 / 29 / 05$ & Parametric & $9: 20$ & $14: 56$ & SEA2, 25 & & \\
\hline $3 / 29 / 05$ & Parametric & $11: 50$ & $13: 50$ & SEA2, 25 & & $\mathrm{OH}$ \\
\hline $3 / 30 / 05$ & Parametric & $7: 35$ & $15: 25$ & SEA2, 50 & & \\
\hline $3 / 30 / 05$ & Parametric & $11: 13$ & $13: 13$ & SEA2, 50 & & $\mathrm{OH}$ \\
\hline $3 / 30 / 05$ & Parametric & $15: 25$ & $17: 00$ & SEA2, 75 & & \\
\hline $3 / 31 / 05$ & Parametric & $8: 42$ & $13: 57$ & & 0.5 & \\
\hline $3 / 31 / 05$ & Parametric & $10: 23$ & $18: 55$ & SEA2, 25 & & \\
\hline $3 / 31 / 05$ & Parametric & $11: 33$ & $13: 33$ & SEA2, 25 & 0.5 & $\mathrm{OH}$ \\
\hline $3 / 31 / 05$ & Parametric & $13: 58$ & $16: 34$ & & 1.1 & \\
\hline $3 / 31 / 05$ & Parametric & $16: 35$ & $17: 25$ & & 2.0 & \\
\hline $3 / 31 / 05$ & Parametric & $17: 26$ & 19:00 & & 2.2 & \\
\hline $4 / 1 / 05$ & Parametric & $7: 55$ & $9: 10$ & SEA2, 25 & & \\
\hline $4 / 1 / 05$ & Parametric & $8: 10$ & $9: 10$ & & 0.2 & \\
\hline $4 / 1 / 05$ & Parametric & $9: 10$ & $20: 30$ & SEA2, 50 & & \\
\hline $4 / 1 / 05$ & Parametric & 9:11 & $13: 30$ & & 0.40 & $\mathrm{OH}$ \\
\hline
\end{tabular}


Table 3-1. Schedule of Test Conditions, Chemical Additions, PAC Injections, and Sampling Activities Performed at MRY Unit 2 (continued)

\begin{tabular}{|c|c|c|c|c|c|c|}
\hline Date & Condition & Start Time & End Time & $\begin{array}{c}\text { Chemical } \\
\text { Additions, ppm } \\
\text { (dry coal basis) }\end{array}$ & $\begin{array}{c}\text { PAC Injection, } \\
\mathrm{lb} / \mathrm{min}\end{array}$ & Sampling \\
\hline $4 / 1 / 05$ & Parametric & $13: 31$ & $15: 45$ & & 1.00 & \\
\hline $4 / 1 / 05$ & Parametric & $15: 46$ & $16: 45$ & & 2.10 & \\
\hline $4 / 1 / 05$ & Parametric & $17: 58$ & $19: 30$ & & 2.20 & \\
\hline $4 / 1 / 05$ & Parametric & $19: 31$ & $20: 32$ & & 0.30 & \\
\hline $4 / 1 / 05$ & Parametric & $20: 33$ & $20: 56$ & & 3.50 & \\
\hline $4 / 1 / 05$ & Parametric & $20: 57$ & 21:07 & & 3.60 & \\
\hline $4 / 2 / 05$ & Baseline & & & & & \\
\hline $4 / 3 / 05$ & Baseline & & & & & \\
\hline $4 / 4 / 05$ & Baseline & & & & & \\
\hline $4 / 5 / 05$ & Long term & $12: 50$ & & SEA2, 45 & & \\
\hline $4 / 6 / 05$ & Long term & & & SEA2, 45 & & \\
\hline $4 / 7 / 05$ & Long term & & & SEA2, 45 & & \\
\hline $4 / 8 / 05$ & Long term & & & SEA2, 45-200 & & \\
\hline $4 / 9 / 05$ & Long term & & & SEA2, 20-80 & & \\
\hline $4 / 10 / 05$ & Long term & & & SEA2, 15 & & \\
\hline $4 / 11 / 05$ & Long term & & & SEA2, 15-400 & & \\
\hline $4 / 12 / 05$ & Long term & $14: 35$ & $16: 35$ & SEA2, 35 & & $\mathrm{OH}$ \\
\hline $4 / 13 / 05$ & Long term & $11: 50$ & $13: 50$ & SEA2, 70 & & $\mathrm{OH}$ \\
\hline $4 / 13 / 05$ & Long term & $15: 15$ & $17: 15$ & SEA2, 70 & & $\mathrm{OH}$ \\
\hline $4 / 13 / 05$ & Long term & $16: 49$ & $17: 54$ & SEA2, 65 & & M26 \\
\hline $4 / 14 / 05$ & Long term & $13: 44$ & $15: 44$ & SEA2, 65 & & $\mathrm{OH}$ \\
\hline $4 / 15 / 05$ & Long term & $11: 53$ & $13: 53$ & SEA2, 70 & & $\mathrm{OH}$ \\
\hline $4 / 16 / 05$ & Long term & & & SEA2, 65-190 & & \\
\hline $4 / 17 / 05$ & Long term & & & SEA2, 55 & & \\
\hline $4 / 18 / 05$ & Long term & & & SEA2, 50-80 & & \\
\hline $4 / 19 / 05$ & Long term & $13: 55$ & & SEA2, 55 & 0.15 & \\
\hline $4 / 20 / 05$ & Long term & & & SEA2, 60 & 0.15 & \\
\hline $4 / 21 / 05$ & Long term & & & SEA2, 60 & 0.15 & \\
\hline $4 / 22 / 05$ & Long term & & & SEA2, 75 & 0.15 & \\
\hline $4 / 23 / 05$ & Long term & & & SEA2, 65 & 0.15 & \\
\hline $4 / 24 / 05$ & Long term & & & SEA2, 50 & 0.15 & \\
\hline $4 / 25 / 05$ & Long term & & & SEA2, 60 & 0.15 & \\
\hline $4 / 26 / 05$ & Long term & $10: 13$ & $12: 13$ & SEA2, 60 & 0.15 & $\mathrm{OH}$ \\
\hline $4 / 26 / 05$ & Long term & $17: 32$ & $18: 53$ & SEA2, 60 & 0.15 & M26 \\
\hline $4 / 27 / 05$ & Long term & $10: 58$ & $12: 58$ & SEA2, 60 & 0.15 & $\mathrm{OH}$ \\
\hline $4 / 27 / 05$ & Long term & $17: 02$ & $18: 49$ & SEA2, 60 & 0.15 & $\mathrm{MC}$ \\
\hline $4 / 28 / 05$ & Long term & $10: 50$ & $12: 50$ & SEA2, 65 & 0.15 & $\mathrm{OH}$ \\
\hline $4 / 29 / 05$ & Long term & & & SEA2, 50 & 0.15 & \\
\hline $4 / 30 / 05$ & Long term & & & SEA2, 30 & 0.15 & \\
\hline $5 / 1 / 05$ & Long term & & & SEA2, 40 & 0.15 & \\
\hline $5 / 2 / 05$ & Long term & & & SEA2, 40 & 0.15 & \\
\hline $5 / 3 / 05$ & Long term & & & SEA2, 60 & 0.15 & \\
\hline $5 / 4 / 05$ & Long term & & & SEA2, 60 & 0.15 & \\
\hline $5 / 5 / 05$ & Long term & & & SEA2, 60 & 0.15 & \\
\hline $5 / 6 / 05$ & Long term & & & SEA2, 70 & 0.15 & \\
\hline $5 / 7 / 05$ & Long term & & & SEA2, 60 & 0.15 & \\
\hline $5 / 8 / 05$ & Long term & & & SEA2, 40 & 0.15 & \\
\hline
\end{tabular}

Continued ... 
Table 3-1. Schedule of Test Conditions, Chemical Additions, PAC Injections, and Sampling Activities Performed at MRY Unit 2 (continued)

\begin{tabular}{|c|c|c|c|c|c|c|}
\hline Date & Condition & Start Time & End Time & $\begin{array}{c}\text { Chemical } \\
\text { Additions, ppm } \\
\text { (dry coal basis) }\end{array}$ & $\begin{array}{l}\text { PAC Injection, } \\
\mathrm{lb} / \mathrm{min}\end{array}$ & Sampling \\
\hline $5 / 9 / 05$ & Long term & $15: 40$ & $17: 17$ & SEA2, 55 & 0.15 & M26 \\
\hline $5 / 10 / 05$ & Long term & $10: 37$ & $12: 37$ & SEA2, 45 & 0.15 & $\mathrm{OH}$ \\
\hline $5 / 10 / 05$ & Long term & $16: 00$ & 18:00 & SEA2, 40 & 0.15 & $\mathrm{OH}$ \\
\hline $5 / 11 / 05$ & Long term & $10: 55$ & $12: 55$ & SEA2, 40 & 0.15 & $\mathrm{OH}$ \\
\hline $5 / 11 / 05$ & Long term & $15: 36$ & $17: 18$ & SEA2, 40 & 0.15 & $\mathrm{MC}$ \\
\hline $5 / 12 / 05$ & Long term & & & SEA2, 35 & 0.15 & \\
\hline $5 / 13 / 05$ & Long term & & & SEA2, 50 & 0.15 & \\
\hline $5 / 14 / 05$ & Long term & & & SEA2, 65 & 0.15 & \\
\hline $5 / 15 / 05$ & Long term & & & SEA2, 90 & 0.15 & \\
\hline $5 / 16 / 05$ & Long term & & & SEA2, 75 & 0.15 & \\
\hline $5 / 17 / 05$ & Long term & & $23: 49$ & SEA2, 65 & 0.15 & \\
\hline
\end{tabular}

\subsection{DESCRIPTION OF MILTON R. YOUNG (MRY) UNIT 2}

MRY is owned and operated by Minnkota Power Cooperative (MPC) with headquarters in Grand Forks, North Dakota, and a subsidiary, Square Butte Electric Cooperative. MRY is in Oliver County in western North Dakota's coal county, about 5 miles east and 3 miles south of Center, North Dakota. MRY Unit 2 is a B\&W Carolina-type radiant boiler designed to burn high-moisture North Dakota lignite. Nominally rated at 3,050,000 lb/hr, this unit is a cyclonefired, balanced-draft, pump-assisted circulation boiler. The unit began commercial operation in May 1977 and is base-loaded at 450 MW gross. A cold-side ESP with a specific collection area of $375 \mathrm{ft}^{2} / \mathrm{kacfm}$ and spray tower FGD system utilizing alkaline ash and lime are used for particulate and $\mathrm{SO}_{2}$ control, respectively. General information on the lignite coal burned at MRY is presented in Table 4-1.

Table 4-1. Coal Information for Milton R. Young Station

\begin{tabular}{|c|c|c|c|c|}
\hline Owner and Operator & Mine & Seam Mined & Location & Mine Production, ${ }^{a}$ tons \\
\hline $\begin{array}{l}\text { BNI Coal, Ltd., a wholly } \\
\text { owned subsidiary of Allette }\end{array}$ & Center & $\begin{array}{c}\text { Kinneman Creek } \\
\text { and Hagel }\end{array}$ & $\begin{array}{l}\text { Western, northern lignite } \\
\text { basin, North Dakota }\end{array}$ & $4,522,831$ \\
\hline
\end{tabular}

MRY Unit 2 is ideally suited for testing $\mathrm{Hg}^{0}$ oxidation and control in an ESP-wet FGD. The high-temperature environment in the cyclone will easily vaporize and transform chlorine into the highly reactive radical species. In addition, the system has been tested for $\mathrm{Hg}$ speciation and control. Flue gas Hg sampling was performed at the ESP inlet, wet FGD inlet, and stack from October 22 through November 14, 2002. The sampling was performed using the $\mathrm{OH}$ method and CMMs (23). A schematic of MRY Unit 2 showing sampling and SEA addition locations is provided in Figure 4-1. 


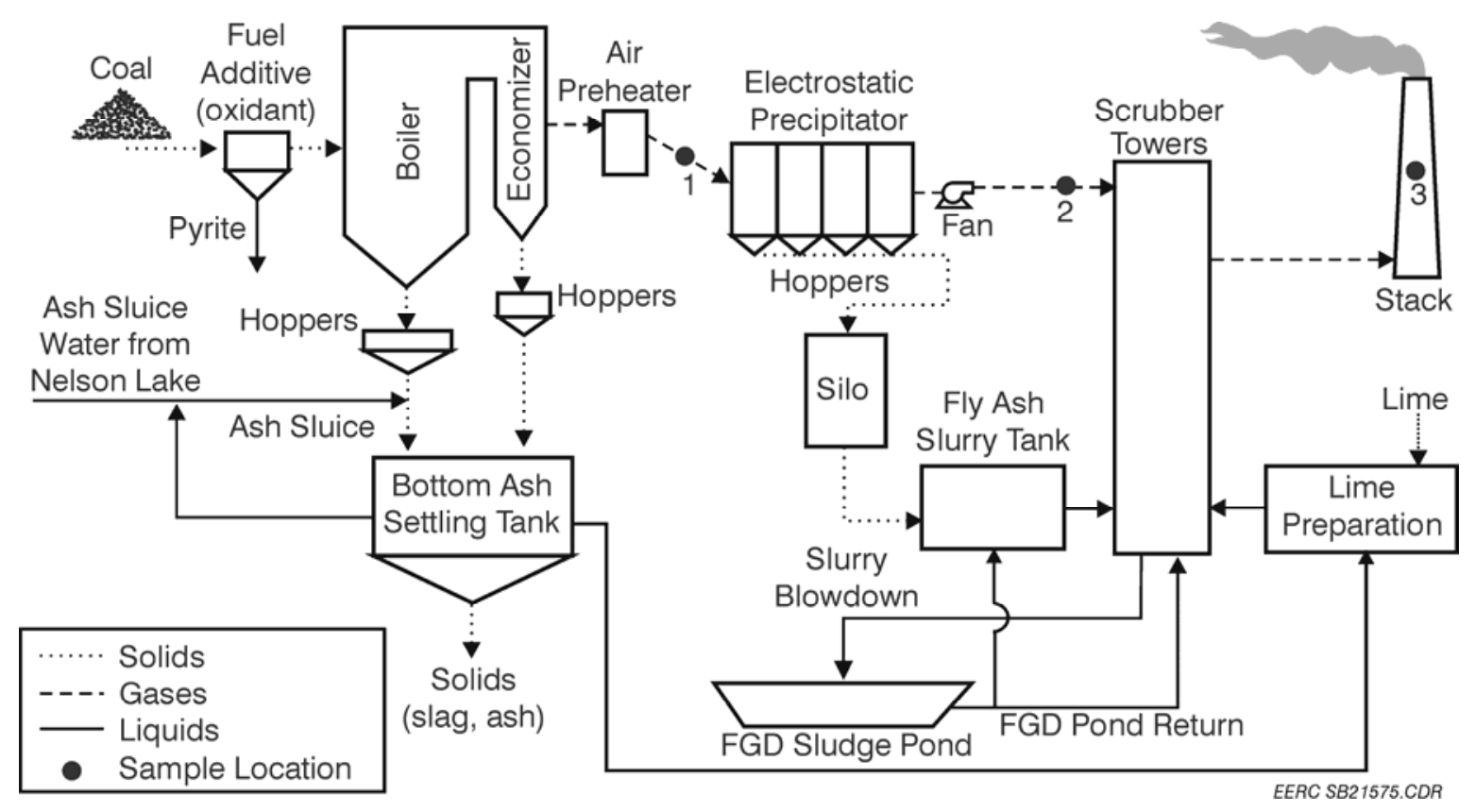

Figure 4-1. Schematic of MRY Unit 2 showing sampling and coal additive locations.

The average $\mathrm{Hg}$ stack emissions were $95 \% \mathrm{Hg}^{0}$ as indicated in Figure 4-2. Statistical analyses of the CMM data indicated that the average total $\mathrm{Hg}$ concentration was $10.7 \pm$ $2.7 \mu \mathrm{g} / \mathrm{dNm}^{3}$ (90th percentile) at the FGD inlet and $9.3 \pm 2.2 \mu \mathrm{g} / \mathrm{dNm}^{3}$ at the stack. Fluctuations in total $\mathrm{Hg}$ concentrations resulting from coal heterogeneity and variability in plant operations were within $24 \%$ of the average values. $\mathrm{Hg}$ mass balances for MRY Unit 2 ranged from $102 \%$ to $103 \%(10)$.

\subsection{EXPERIMENTAL}

Quality assurance and quality control (QA/QC) activities that were performed as part of the experimental activities described herein are summarized in Appendix A. In addition, examples of calculations that were performed as part of the calibration, measurement, injection, and data reduction activities are presented in Appendix B.

\subsection{Continuous Mercury Monitoring}

The Tekran Model 2537A atomic fluorescence-based $\mathrm{Hg}$ vapor analyzer was used in conjunction with a PS Analytical S235C400 wet-chemistry conversion unit to continuously monitor $\mathrm{Hg}^{0}$ and total $\mathrm{Hg}$ concentrations at the wet FGD inlet and stack locations. The stack location is illustrated in Figure 5-1. The PS Analytical uses two separate liquid flow paths, one to continuously reduce $\mathrm{Hg}^{2+}$ to $\mathrm{Hg}^{0}$, resulting in a total gas-phase $\mathrm{Hg}$ sample, and the other to continuously scrub out $\mathrm{Hg}^{2+}$, resulting in an $\mathrm{Hg}^{0}$ sample. The PS Analytical also uses a Peltier thermoelectric cooler module to cool and dry the sample gases prior to analysis. 


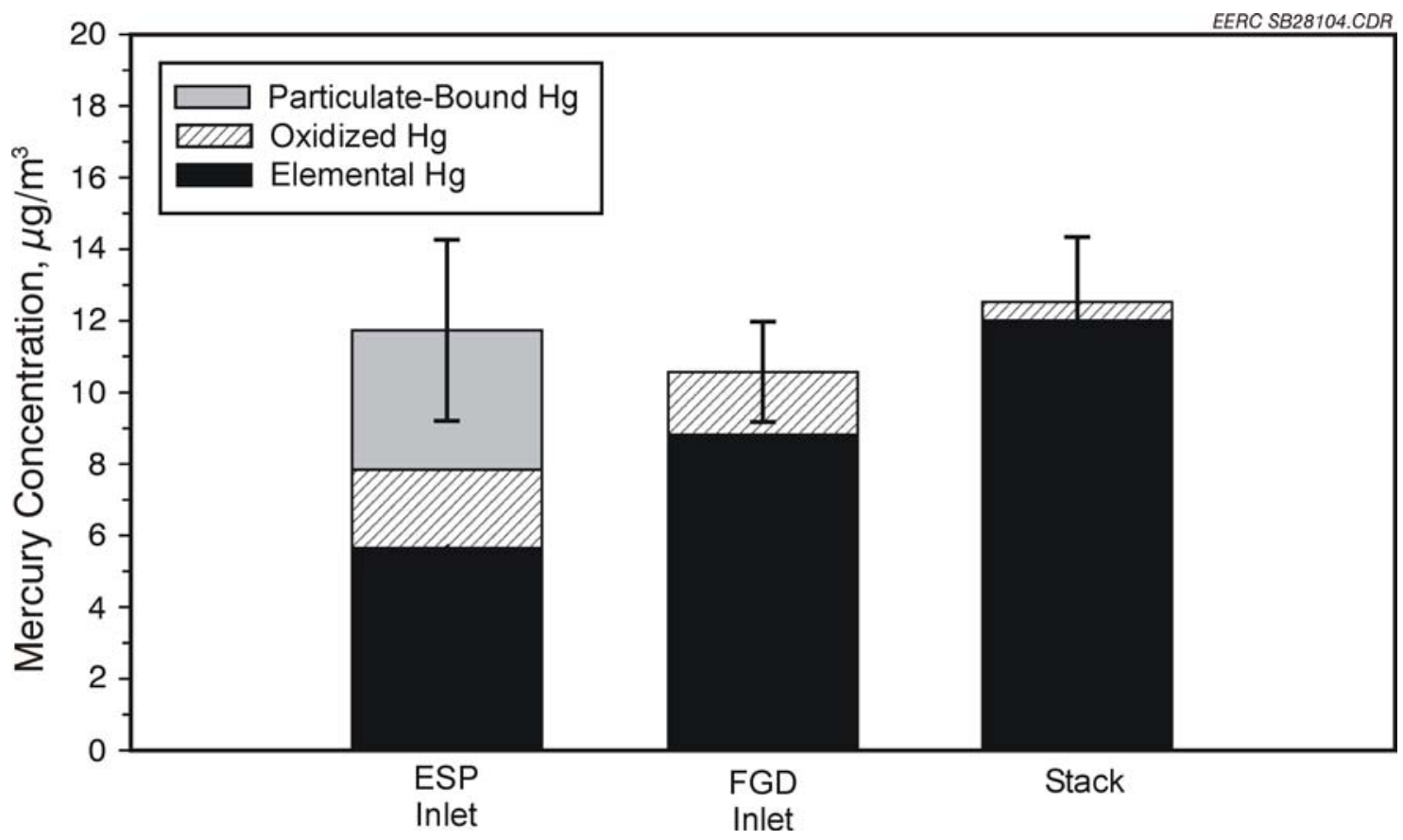

Figure 4-2. Average $\mathrm{OH} \mathrm{Hg}$ speciation results obtained at the ESP and wet FGD inlets and stack of MRY Unit 2.

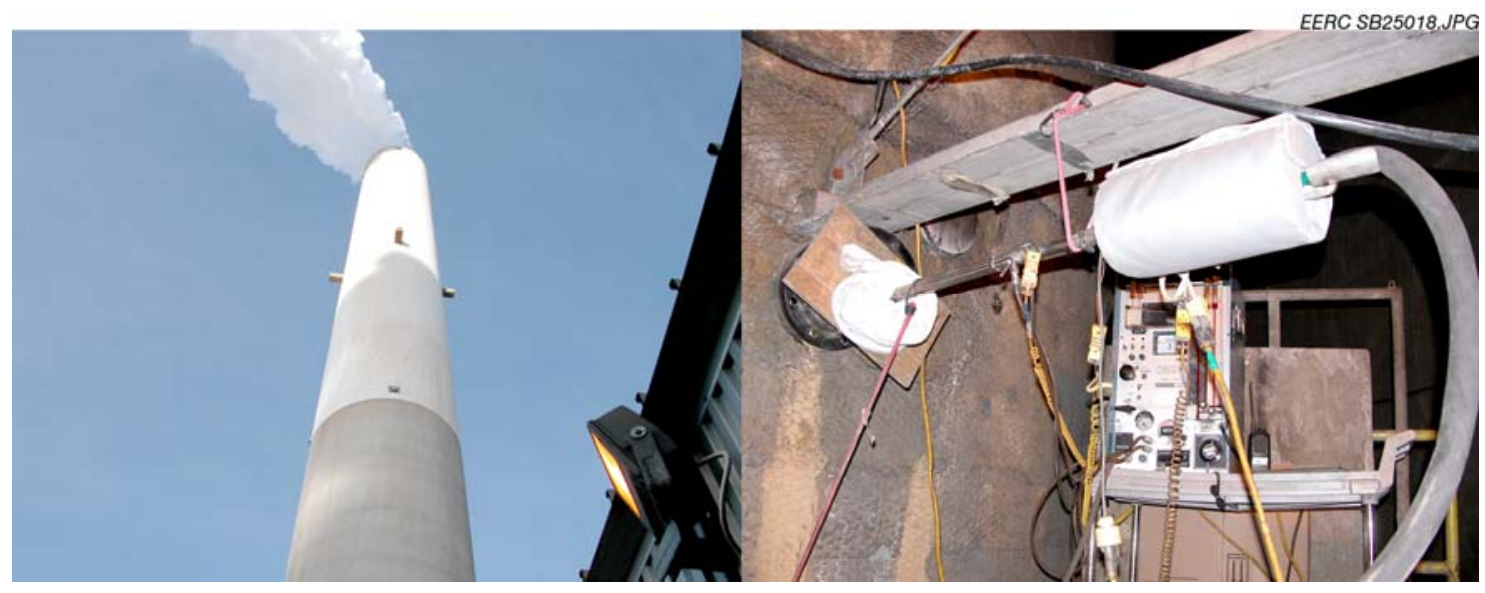

Figure 5-1. OH and CMM mercury-sampling and measurement location on the stack.

The Tekran instrument traps the $\mathrm{Hg}$ vapor from the conditioned sample onto a cartridge containing an ultrapure gold sorbent. The amalgamated $\mathrm{Hg}$ is then thermally desorbed and detected using atomic fluorescence spectrometry. A dual-cartridge design enables alternate sampling and desorption, resulting in a nearly continuous measurement of the sample stream. An automatic $\mathrm{Hg}^{0}$ permeation source was used to calibrate the instrument daily. Manual $\mathrm{Hg}^{0}$ injection calibration on both cartridges was also performed for verification. The Tekran 
instrument measures either total $\mathrm{Hg}$ or $\mathrm{Hg}^{0}$, with an analysis occurring approximately every 2.5 minutes.

\subsection{Ontario Hydro Flue Gas Mercury Measurements}

$\mathrm{OH}$ samples were withdrawn from the flue gas stream isokinetically through a probe/filter system, maintained at $120^{\circ} \mathrm{C}$ or the flue gas temperature, whichever was greater, followed by a series of impinger solutions in an ice bath. Particle-bound mercury $\left(\mathrm{Hg}_{\mathrm{p}}\right)$ was collected on a quartz filter in the front half of the sampling train. $\mathrm{Hg}^{2+}$ was collected in impingers containing a chilled aqueous potassium chloride solution. $\mathrm{Hg}^{0}$ was collected in subsequent impingers (an impinger containing a chilled aqueous acidic solution of hydrogen peroxide and three impingers containing chilled aqueous acidic solutions of potassium permanganate). Samples were recovered and sent to the lab for analysis. The $\mathrm{OH}$ samples were typically prepared and analyzed the same day of collection or the following day. $\mathrm{Hg}$ was determined by cold-vapor atomic absorption spectroscopy (CVAAS) using a CETAC M6000A automated $\mathrm{Hg}$ analyzer. Example calculations for reporting results in units of $\mu \mathrm{g} / \mathrm{dNm}^{3}$ are presented in Appendix B.

OH sampling was performed simultaneously at the ESP inlet, wet FGD inlet, and stack locations. Additional flue gas analysis results were determined as part of the $\mathrm{OH}$ method, including oxygen, carbon dioxide, moisture, and dust-loading concentrations, that were used to normalize $\mathrm{Hg}$ results.

\subsection{Sampling and Analysis of Coal Fly Ash}

Fly ash samples were collected from the eight hoppers in Row 1 of the ESP and combined into a daily composite by MPC personnel. To obtain a representative sample, a split of the collected ash was stored in a glass jar with a plastic lid and archived for the duration of the project. Similar composites from Rows 2, 3, and 4 were collected, once during baseline operation and three times during the long-term testing. These were taken during the weeks that $\mathrm{OH}$ samples were being collected. A similar composite sample from Row 1 of the ESP not involved in the testing was collected, once during baseline operation and three times during the long-term testing. These samples were collected during the weeks that $\mathrm{OH}$ testing was being performed. Selected ash samples were analyzed for $\mathrm{Hg}$ by the EERC using ASTM Method D6414-01 (Standard Test Method for Total Mercury in Coal and Coal Combustion Residues by Acid Extraction or Wet Oxidation/Cold-Vapor Atomic Absorption). Several coal fly ashes were also analyzed for $\mathrm{Hg}$ using a Milestone direct mercury analyzer, the DMA-80. In addition, some samples were analyzed for halogens, loss-on-ignition (LOI), and carbon (C) using standard ASTM or EPA methods by the EERC.

In accordance with DOE requirements, a 5-gal composite sample from Row 1 was collected three times during baseline operation and three times during the 2-month test. Again, these samples were collected concurrently with $\mathrm{OH}$ samples. Standard 5-gal plastic buckets were filled with a representative split of the sampled ash for NETL. In addition, ash samples were collected during the baseline and long-term testing conditions for analyzing $\mathrm{Hg}$ thermal stability and aqueous mobility. A separate gallon split of these two ash samples was stored in plastic and delivered to the EERC. 


\subsection{Scrubber Slurry Samples}

Scrubber slurry samples were collected by MPC personnel from one of the recycle pumps from the scrubber downstream of the ESP involved in the testing once during baseline operation and three times during the long-term testing. These were collected during the weeks that $\mathrm{OH}$ testing was being performed. One-quart samples were stored in glass jars with plastic lids and returned to the EERC for analysis of selected samples. Similar composite scrubber slurry samples from the scrubber after the ESP not involved in the testing were collected, once during baseline operation and three times during the 2-month test. These also were collected during the weeks that $\mathrm{OH}$ testing was being performed.

\subsection{Miscellaneous Samples}

Water, limestone, and fly ash used to make wet FGD slurry as well as the slurry itself were sampled during the baseline testing and long-term testing conditions. In addition, pyrite rejected from the coal conditioner and bottom-ash settling-tank solids were sampled when $\mathrm{OH}$ measurements was being performed. All samples were stored in glass jars with plastic lids and archived for analysis.

\subsection{Coal Analyses}

Coal samples were collected from four of the twelve feeders that were equipped with automatic samplers and combined into a daily composite by MPC personnel. To obtain a representative sample of coal feed, a gallon representative split of each of the daily coal samples was archived and stored in a plastic pail. This composite sample represented the coal being fed to the crushers upstream from where the $\mathrm{CaCl}_{2}, \mathrm{MgCl}_{2}$, and SEA2 were added. Proximate and ultimate analyses were conducted on the composite coal samples using ASTM Methods D3172, D5142, and D3176. A Mitsubishi Model TOX-100 total chlorine analyzer was used to perform ASTM Method D6721-01 (Standard Test Method for Determination of Chlorine in Coal by Oxidative Hydrolysis Microcoulometry). Coal $\mathrm{Hg}$ contents were determined in triplicate using CVAAS according to EPA Method 245.1 and EPA SW-846 Method 7470.

CCSEM was used to quantify coal mineralogy. Approximately 3500 mineral grains ranging from 1 to $100 \mu \mathrm{m}$ in cross-sectional diameter were analyzed in three coal samples collected from MRY Unit 2 pulverizers. A detailed description of the CCSEM method is provided in Appendix C. Coal ash elemental oxide compositions were determined using WDXRF (wavelength-dispersive $x$-ray fluorescence) spectrometry, as described in ASTM International Method D4326.

Three MRY Unit 2 coal samples were analyzed using a chemical fractionation method to evaluate elemental distributions among the various organic and inorganic components of coal. A representative 40 - to 80 -gram sample of pulverized coal was vacuum oven-dried to constant weight. A portion of each coal was analyzed for ash content and major and minor elements by WDXRF (ASTM D4326). The coals were then subjected to the successive extraction treatments summarized in Table 5-1. After each extraction, the coal mixture was filtered, and a portion of the residue was analyzed for ash content and major and minor elements by WDXRF. The 
analysis data were then utilized in mass balance calculations to determine the elemental losses, relative to the unfractionated coal, resulting from each extraction. Elements removed by $\mathrm{H}_{2} \mathrm{O}$ are primarily associated with water-soluble minerals (e.g., alkali halides). Exchangeable ions, principally elements associated with salts of organic acids and clay minerals, are removed by ammonium acetate $\left(\mathrm{NH}_{4} \mathrm{OAc}\right)$. Hydrochloric acid $(\mathrm{HCl})$ removes elements associated with acidsoluble minerals (carbonates, oxides, and metastable sulfides) and organic coordination complexes, such as carboxylate groups on coal surfaces. Elements remaining in the final residue are presumably associated with insoluble silicate and sulfide minerals.

Table 5-1. Chemical Fractionation Protocol

\begin{tabular}{lccc}
\hline Reagent & Quantity, mL & Temperature, ${ }^{\circ} \mathrm{C}$ & Duration, hr \\
\hline $\mathrm{H}_{2} \mathrm{O}$ & 100 & $\sim 25$ & 24 \\
$1 \mathrm{M} \mathrm{NH}_{4} \mathrm{OAc}^{\mathrm{a}}$ & 100 & 70 & 24 \\
$1 \mathrm{M} \mathrm{HCl}^{\mathrm{b}}$ & 100 & 70 & 24 \\
\hline $\mathrm{a}^{\mathrm{a}}$ Extraction performed in triplicate. & & \\
${ }^{\mathrm{b}}$ Extraction performed in duplicate. & &
\end{tabular}

\subsection{Halogen Flue Gas Sampling}

Flue gas samples were collected using EPA Method 26A (Determination of Hydrogen Halide and Halogen Emissions from Stationary Sources Isokinetic Method) during baseline, parametric, and long-term testing conditions to evaluate halogen concentrations. Flue gas samples were obtained at the ESP inlet. Four Method 26A samples were collected, one during the baseline testing, and one during each of the 3 weeks of long-term testing when $\mathrm{OH}$ sampling was being performed.

\subsection{Systems Operation and Monitoring}

\subsubsection{Aqueous $\mathrm{CaCl}_{2}, \mathrm{MgCl}_{2}$, and SEA2 Addition System}

The aqueous $\mathrm{CaCl}_{2}, \mathrm{MgCl}_{2}$, and SEA2 addition system consisted of liquid storage tanks, a metering and pumping skid, and injection lances. Three tanks for storage and diluting the solutions are shown in Figure 5-2. The storage capacity of each tank was 3100 gallons. The pumping and metering skid is shown in Figure 5-3. This system pumped the solutions at rates of 0.1 to $2.2 \mathrm{gal} / \mathrm{min}$ corresponding to concentrations of $\leq 500 \mathrm{ppm}$ on an as-fired coal basis. The solutions were injected into the coal pipes feeding 4 of the 12 Unit 2 cyclones $(3,4,9,10)$. Two injection lances are shown in Figure 5-4. The original B\&W design had 1-in. pipes semipermanently mounted in the coal pipes. These had been installed during a January outage. When removed for inspection during an early March unscheduled scheduled outage, it was found that extensive erosion had occurred. Replacement pipes with additional hard facing were then installed. Because of concerns about plugging and erosion of the injectors, the original design was modified. New injectors were fabricated of 3/8-in. stainless steel tubing, which slid through 
the original 1-in. ball valve, with a compression fitting forming a gas-tight seal above the valve when the injector was inserted. Thus the original 1-in. pipe formed a shield around the new injector to prevent erosion, and the injector could be removed for cleaning and replaced online (the original injectors mounted to 6-in. flanges installed on the feed pipes and could only be removed during a plant outage). The new injectors functioned flawlessly, with no plugging or erosion.

Having only two skid pumps available, a manifold on the skid was used to split the liquid stream as evenly as possible into four $1 / 2$-in.-i.d. rubber hoses of equal length (approximately 200 feet each) leading to the four injectors. Rotometers on each line gave an indication of flow, which could be roughly balanced with flow valves. As these were ball valves installed with the intention of providing on/off control only, the flow to each injector was not precisely regulated, although the total flow from the upstream pump remained constant. No change was observed in SEA effectiveness regardless of the distribution of flow between the four injectors.

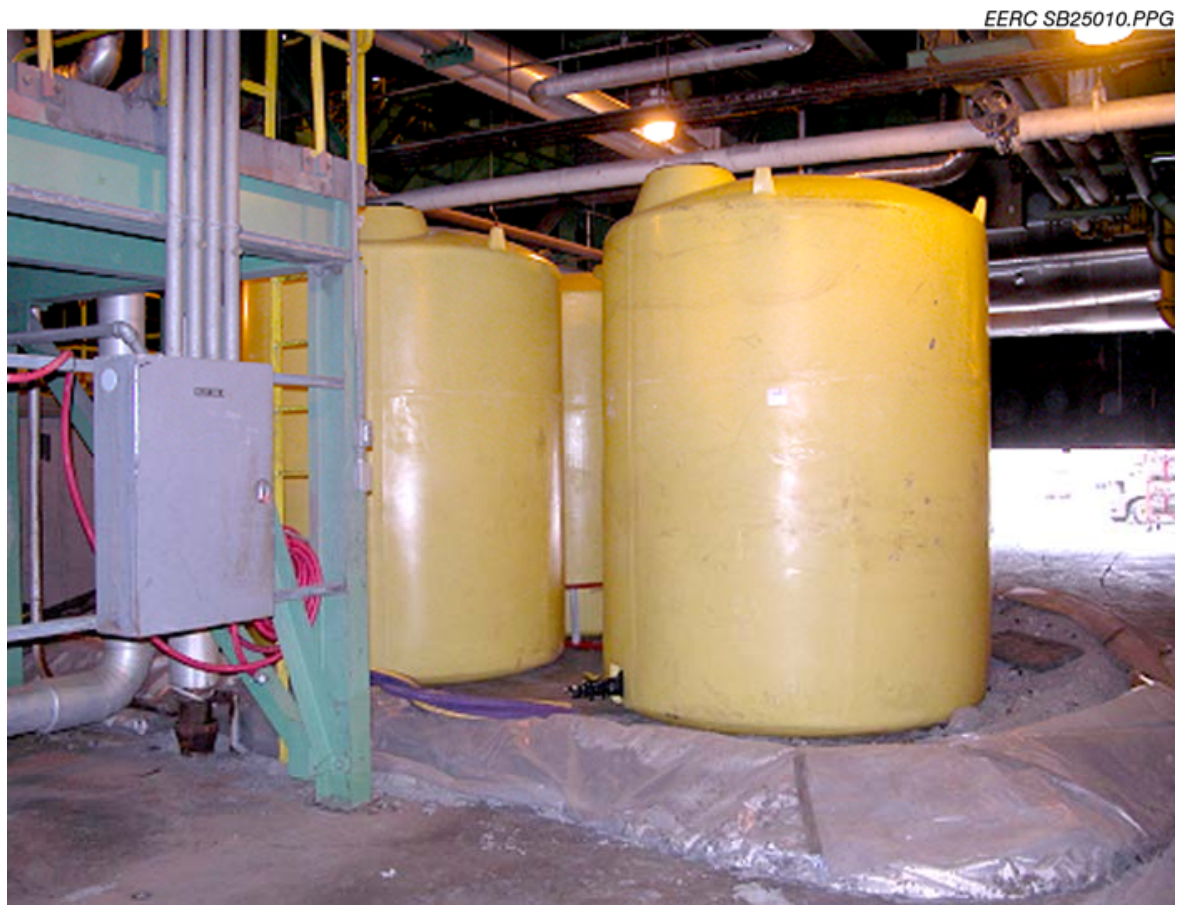

Figure 5-2. Oxidant or SEA storage tanks at MRY. 


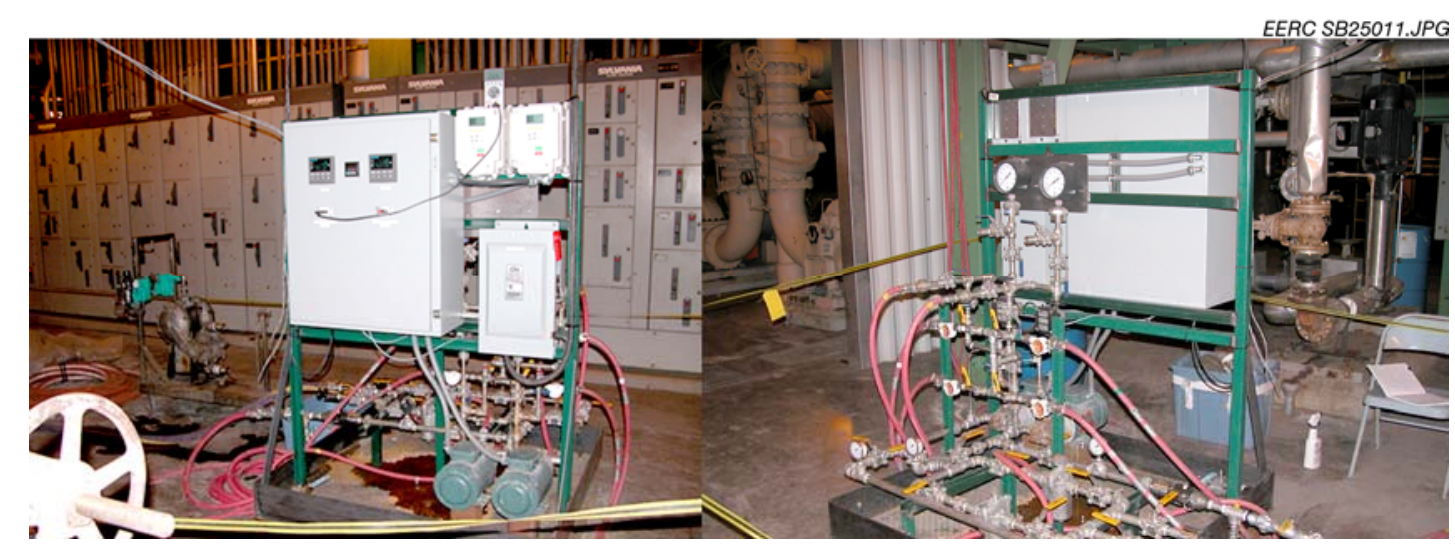

Figure 5-3. SEA pumping and metering skid.

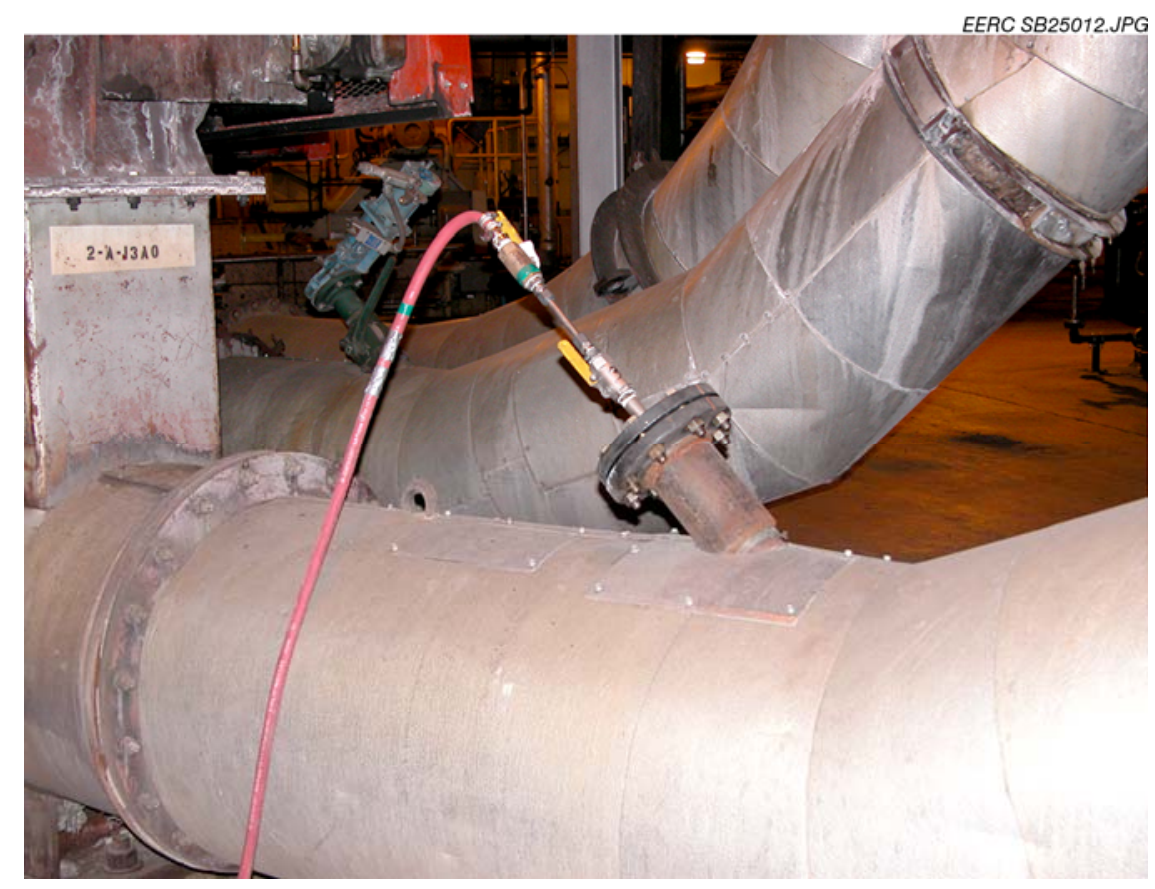

Figure 5-4. SEA injection lances shown installed at MRY Unit 2. 
$\mathrm{CaCl}_{2}$ and SEA2 were stored in 3100-gal plastic tanks adjacent to the pump skid. A 250-gal plastic tote of $\mathrm{MgCl}_{2}$ solution was also used during the parametric testing. When empty, this became available as a "reserve" tank during the long-term testing to minimize feed interruptions when transferring and mixing SEA2 solution in the large tanks. The larger tanks were interconnected and connected to the pump skid with 1.5-in.-diameter hoses and camlock connections. Valves at the tanks, pump skid, and both ends of the hoses isolated each unit and minimized spillage when hoses were connected and disconnected. The tanks were surrounded by a clay berm designed to contain potential spills and small leaks.

Considerable difficulty was experienced with the quality of the delivered $\mathrm{CaCl}_{2}$ and SEA2 solutions, as they were normally vended as drilling fluids. Foreign material such as leaves, twigs, paper fragments, and small amounts of mud, oil, and wax were encountered. These tended to produce rapid plugging of the filters (and subsequently the flowmeters) on the aqueous injection skid. The problem appeared to be exacerbated by the necessity of using fire main water for dilution. This was effectively filtered lake water which contained a mineral content more than adequate to form "scale" on the filters, flowmeters, and in the subsequent downstream hoses. It is suspected that soluble sulfates combining with calcium ion in the solutions were responsible for much of the scaling. Soaking filters and flowmeter components in commercial Limeaway bathroom cleaner was reasonably effective at removing the scale. However, the scaling would reoccur after a period of hours to a couple of days. It is recommended that future testing use much purer plant condensate water for dilution and flushing and that coarse filter traps be installed upstream of the fine skid filters.

Both $\mathrm{CaCl}_{2}$ and SEA2 solutions were delivered in 3000-gal lots by semi tanker truck. The $\mathrm{CaCl}_{2}$ solution had a specific gravity of 1.3 , so was able to be stored in a single large tank. The delivered SEA2 solution had a specific gravity of 1.6, so it was not deemed advisable to fill a single tank to its full rated capacity. Instead SEA2 shipments were split between two tanks, leaving the third available for dilution and mixing. SEA2 dilution was necessary to bring the SEA2 concentration to a level compatible with the 0.1-2.2-gal/min pumping range of the SEA skid pumps. This, combined with available tank capacity, necessitated dilution operations to be performed every 1-3 days during the long-term testing.

The dilution procedure was somewhat intricate. The dilute SEA2 inventory had to be maintained so that the dilution and mixing would occur during the daytime (07:00-18:00) when EERC personnel were available on-site. Sometime prior to the mixing, the 250 -gal reserve tank was gravity-filled from the large feed tank by cross-connecting the main feed line to a small $1 / 2$-in.-i.d. hose leading to the reserve tank. This had to be performed while the feed tank had sufficient head to transfer the desired amount to the reserve tank. When the feed tank level was nearly empty, the valve was closed, isolating the tank from the system, and feed was started from the reserve tank. The 1.5-in. hose was disconnected from the pump skid and attached to one of the tanks containing concentrated SEA2. The valves between the two tanks were opened, enabling the concentrated SEA2 to flow by gravity into the feed tank. The large tanks had level graduations in 500-gal increments. A plastic template was used to interpolate between these increments, allowing estimation of liquid content to within 10-20 gallons. The volume transferred was monitored from the level change in the concentrate and feed tanks. Of course, the desired liquid volume transferred had to be within the amount possible to gravity-feed because of 
the difference in liquid levels between the two tanks. When the transfer was complete, the concentrate tank was isolated with a closed valve; the transfer hose was detached and connected to a water line, which was used to flush the concentrated SEA2 into the feed tank. This prevented a "slug" of concentrated SEA2 of remaining in the hose when first feeding from the feed tank. Additional water to dilute the SEA2 to a density of 1.15-1.2 was introduced in the top of the feed tank. Again, the template was used to interpolate the final liquid volume required. The density of the concentrated SEA2 was found to produce persistent stratification in the tank, even though the introduced water appeared to produce significant agitation. This was not recognized during the first dilutions, resulting in changes in SEA2 concentration as the tank level decreased. MPC personnel designed an agitator consisting of a weighted tee made of 3-foot-long sections of 1-in. pipe with the base of the tee attached to a compressed air line and the ends of the tee arms crimped down. The tee was lowered to the bottom of the feed tank and the compressed air flow adjusted to a point where very vigorous bubbling occurred. The agitation continued for 2-3 hours or longer, depending on the time available. This air agitator was found to be quite effective in mixing the tank and eliminating stratification. It also was very effective in forcing all of the sludge and scale on the bottom of the tank into suspension, virtually assuring plugging of filters and flow meters in a short time after feeding from the tank began. Finally, the 1.5-in. hose was reconnected to the pump skid, the reserve tank valve was closed, and feed was restarted from the feed tank.

The pump skid provided three means of pumping control: load following, local control, and pump speed control. Load following control received a 4-20-mA plant input which was proportional to the total coal feed rate and multiplied by a logical 1 (on) or 0 (off), indicating the operating status of Cyclones 3, 4, 9, and 10. Thus loss of any of these four cyclones would stop the aqueous injection. During the parametric testing and for short periods during the long-term testing, the pump skid was operated in local control. The coal feed rate was obtained from the plant and the desired aqueous injection rate calculated and manually set on the skid controller. In both of these modes, the skid controller was set to limit pump speed to a value just above the selected pumping rate. This was necessary because of the high potential for plugging of the flowmeters. Since a plugged flowmeter would indicate no flow, the skid controller would otherwise increase the pump speed to its maximum value in an attempt to maintain the injection rate. Unchecked, as in unattended night operation, this would result in aqueous injection rates 3-4 times that desired and excessive consumption of the aqueous inventory. Ultimately, the injection control method selected was to set the pump speed to a constant value independently of the skid controller. This was done occasionally for short periods when problems occurred because of plugged flowmeters.

\subsubsection{PAC Injection System}

A PAC injection system was supplied and installed by Apogee upstream of the ESP. The PAC injection system consisted of an Apogee Portapac metering skid, blower, connecting lines, and injection lances. The Portapac system include provision for loading 900-lb supersacks of PAC, along with a discharge hopper, feed screw, blower, eductor, and discharge hose to supply carbon to the duct. PAC injection was performed at 16 locations into the ductwork upstream of the ESP, as shown in Figure 5-5. The PAC feed rate was monitored by load cells mounted on the 


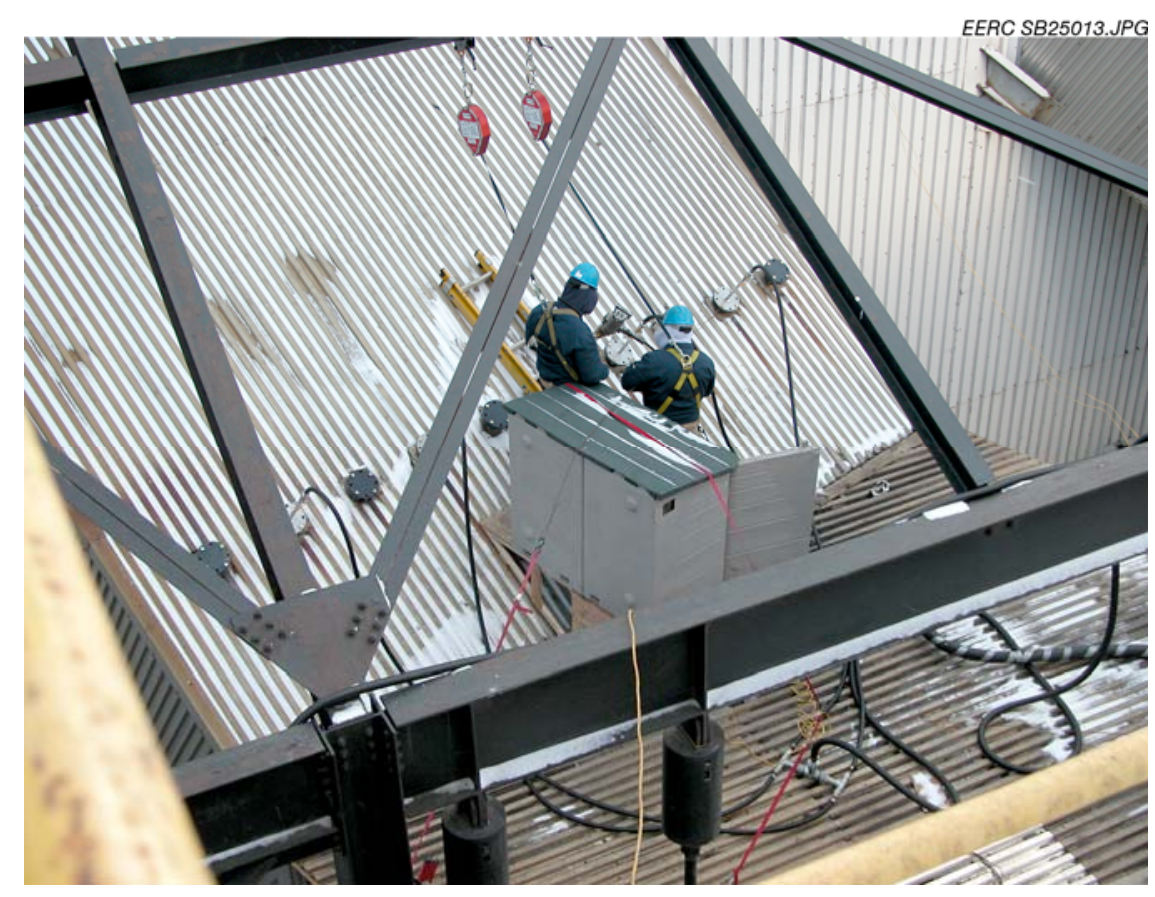

Figure 5-5. PAC injection and $\mathrm{OH}$ and $\mathrm{CMM}$ sampling locations.

portapack system, with weight change and feed rate monitored by a laptop computer. Carbon was transported through a discharge hose to distribution manifolds atop the ESP inlet ducts (approximately 90 feet above the portapack system at ground level). The carbon stream was split into two streams, with each stream then split again to feed the four ESP inlet ducts. Two more splits were made so as to feed four injection lances positioned in ports on each duct. Injection on the inboard B-side duct was on either side of the central port where the $\mathrm{OH}$ sampling was performed. Visual inspection of the $\mathrm{OH}$ filters showed no indication of the PAC being collected in these samples. This configuration resulted in PAC treatment of the entire flue gas stream for Unit 2. The control logic for the PAC system was configured to allow PAC addition to be set and controlled proportionally to the unit load in megawatts. Provisions were made to stop the PAC injection if the load fell below a certain MW level, in the case of a plant shutdown. At the injection rates used, PAC consumption was approximately one 900-lb supersack every 2 days. No problems were encountered with the PAC injection system, except for occasional PAC stoppages because of bridging in the supersacks themselves.

\subsection{Balance-of-Plant Data Collection}

\subsubsection{Plant Data}

Plant operation data from the plant control room, such as unit temperature, load, and stack CMM data, were recorded for the duration of field testing. These data were reviewed to determine if noticeable changes in plant operation occurred during testing activities. 


\subsubsection{Corrosion/Deposition Probes}

The potential corrosive effects of SEA2 and PAC injections were evaluated by installing air-cooled corrosion/deposition test probes at the economizer exit (ECM), air heater inlet (AHI), and air heater outlet (AHO) of MRY Unit 2. Two coupons for each location were fabricated by MRY personnel: a baseline coupon exposed to the normal flue gas environment for 8 weeks and a test coupon exposed to flue gas while SEA2 and PAC were being added to the coal feed for 6 weeks. No standard test method in the literature was found appropriate for corrosion testing of simulated steam tube samples in a full-scale utility boiler environment; therefore, a customized testing procedure was developed. Each corrosion/deposition probe was designed to hold an 18-in.-long, 1-in.-diameter coupon consisting of a section of stainless steel boiler tubing. To induce stress in the metal and possibly enhance corrosion, the tubing was flattened in a 2 -in. section at the midpoint to produce an oval with a minimum inside diameter of 0.5 inches. The purpose of the flattening was to introduce stress in the metal to enhance potential corrosion. Actual coupon outside diameter was $111 / 16$ in., with a 0.25 -in. wall. Reducing couplings were used to join the coupons to the probes.

The corrosion probe assembly is shown in Figure 5-6, and a picture of the coupon and cross-sectioned coupon is shown in Figure 5-7. The probe was inserted into the boiler through a 4-in. threaded pipe stub attached to the boiler wall. The threaded 4-in. pipe cap supported the probe. Welded to and extending through the pipe cap was a section of 1-in. Schedule 40 pipe. Stainless steel pipe was used for all of the probes. Additional couplings and 18-in. pipe lengths were screwed on to extend the probe length, with the test coupon held at the end. The test coupons were threaded for attachment to the corrosion probe assembly and for a pipe cap to seal the opposite end. A 0.5-in. 316 stainless steel tube spans the length of the probe. Compressed air for cooling was introduced through a pipe tee and flowed down the annulus between the tubing and probe pipe and back out of the stainless steel tubing. A gate valve at the inlet was used to regulate the airflow, and a ball valve provided on/off control. Skin temperatures of the coupons were monitored with a thermocouple extending down the stainless steel tube and that pressed against the end cap. A second thermocouple monitored exit cooling air temperature.

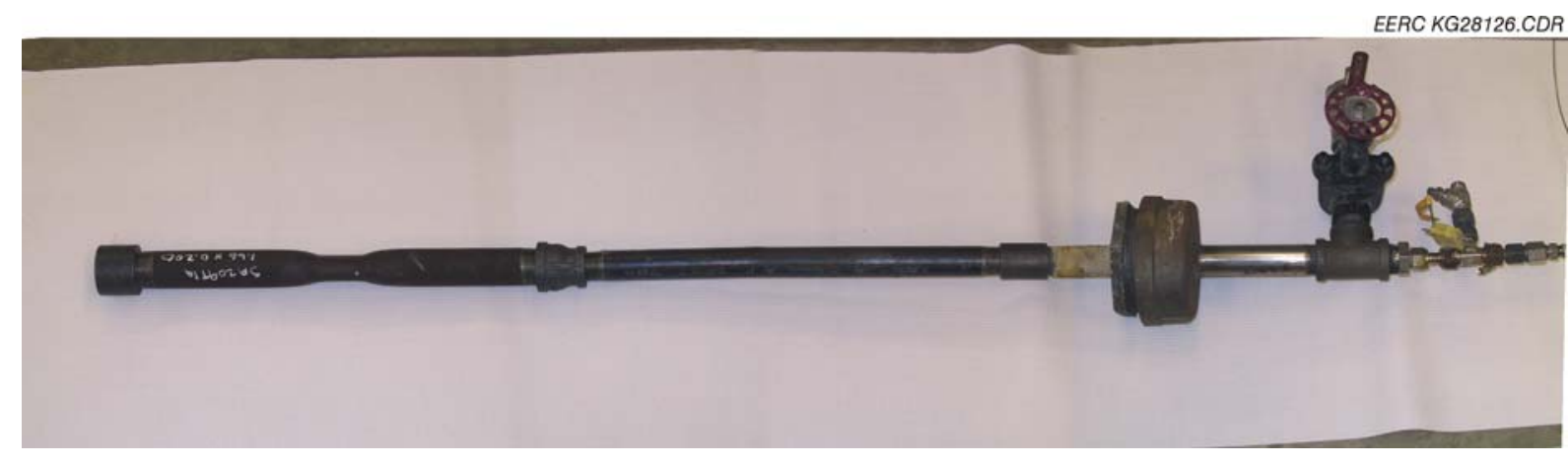

Figure 5-6. Photograph of the corrosion/deposition probe assembly. 


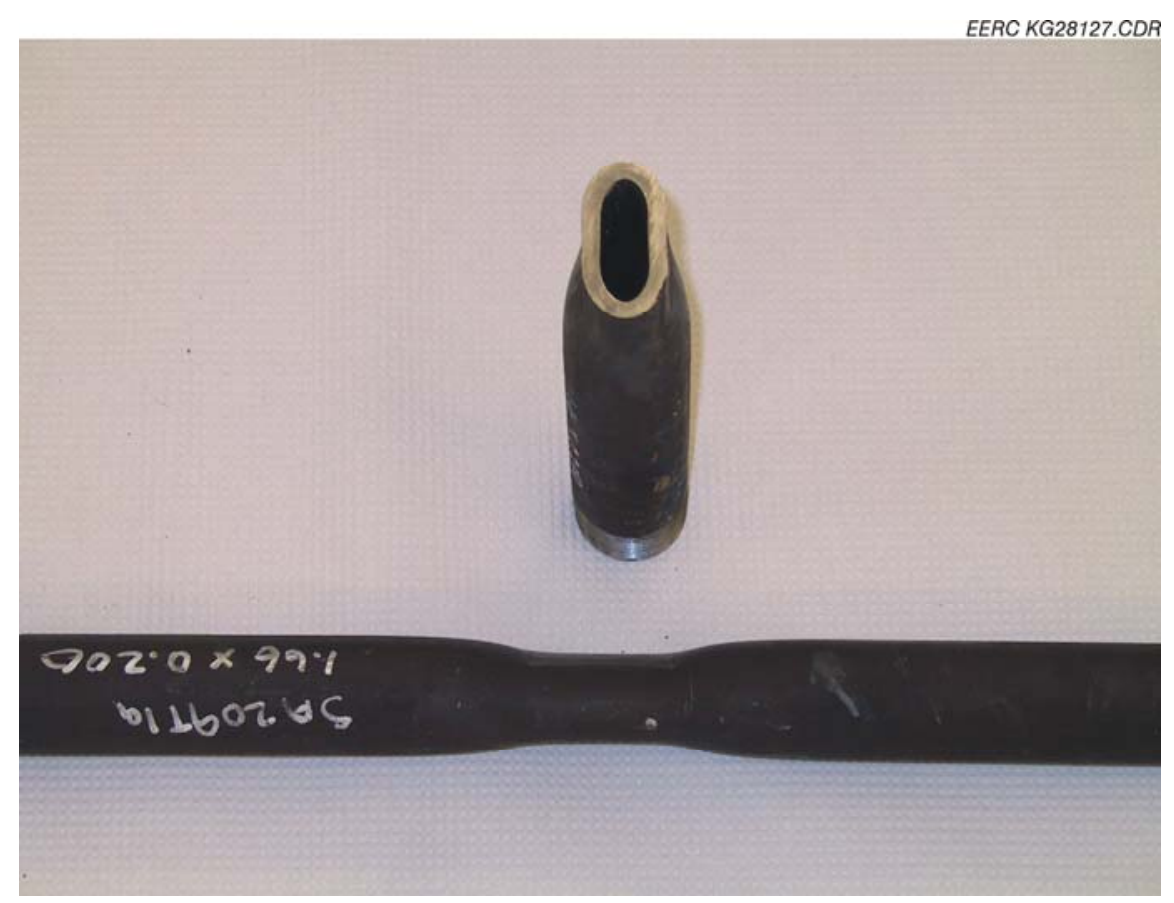

Figure 5-7. Photograph of coupon and a cross-sectioned coupon.

To preserve any ash deposit adhering to the probes, they were wrapped in plastic film and placed in cardboard tubes prior to transport. Upon arrival at the EERC, the test coupon sections of the probes were sprayed with a mixture of acetone and epoxy to affix the ash deposits during subsequent cutting. The test coupons were cross-sectioned with a metal band saw at the midpoint of the crimped area. The cutting operation was performed without lubrication to prevent contamination of the coupons. The samples were then mounted in epoxy and polished to obtain samples for scanning electron microscopy (SEM) analysis.

Six coupon samples were examined with the SEM to ascertain the degree of corrosion at the metal-metal oxide/deposit interface. Line scans were performed for each sample on one of the curved sections and flat sections. Four lines were selected at each location for quantitative point analyses for $\mathrm{Na}, \mathrm{Mg}, \mathrm{Al}, \mathrm{Si}, \mathrm{P}, \mathrm{S}, \mathrm{Cl}, \mathrm{Br}, \mathrm{K}, \mathrm{Ca}, \mathrm{Ti}, \mathrm{Cr}, \mathrm{Fe}, \mathrm{Ni}, \mathrm{Mn}$, and $\mathrm{O}$. Each line was $40 \mu \mathrm{m}$ long across the metal-metal oxide/deposit interface, and 81 point analyses were performed along the line in equal intervals between points.

\subsection{Mercury Stability in Coal Fly Ash}

The stability of $\mathrm{Hg}$ in fly ashes collected from ESP hoppers during baseline and $\mathrm{Hg}$ control technology testing conditions was evaluated. Experiments were designed to assess the potential for $\mathrm{Hg}$ mobility under controlled laboratory conditions similar to those that fly ash may be exposed to in disposal and utilization environments. 


\subsubsection{Leaching}

Leaching is the most likely mechanism of transport of constituents from disposed or utilized fly ashes contacted by water. Leaching is typically performed on fly ash to characterize it for management purposes. The leaching procedure used for these samples were the synthetic groundwater leaching procedure (SGLP) with long-term leaching (LTL) (24).

The SGLP batch-leaching procedure is a relatively simple test that follows many of the conditions of the toxicity characteristic leaching procedure (TCLP) (25) and ASTM D3987 (26). The test utilizes a 20:1 liquid-to-solid ratio, end-over-end agitation at approximately $30 \mathrm{rpm}$, and an 18-hour equilibration time were and usually employs a leaching solution consisting of water from the site, water that has been prepared in the lab similar to water likely to contact the ash, or distilled deionized water. Distilled deionized water was used in this effort. For the long-term component of this procedure, multiple bottles are set up and analyzed at different time intervals. A typical SGLP and LTL test consisting of 18-hour, 30-day, and 60-day equilibration times was performed in this effort. Although 60 days is often not long enough to have achieved complete equilibrium, it is generally long enough to determine the concentration evolution of individual parameters. The most important factor when LTL is performed is to have at least three equilibration times to determine a true trend. Leachates were filtered through $0.45-\mu \mathrm{m}$ filter paper and analyzed for total $\mathrm{Hg}$. $\mathrm{Hg}$ leachate concentrations were determined using cold-vapor atomic fluorescence (CVAFS) and CVAAS techniques.

\subsubsection{Thermal Stability}

A schematic for the controlled thermal desorption of mercury and mercury compounds was assembled and is shown schematically in Figure 5-8 The apparatus was constructed using AAS for mercury detection and included a small tube furnace and temperature controller for thermal desorption. A Hewlett Packard 3395 integrator was used for data collection. Detection of thermally desorbed mercury and mercury compounds was done in an electrically heated quartz cell operated at $800^{\circ} \mathrm{C}$. The use of a heated cell allowed detection of mercury compounds by thermally decomposing compounds to form elemental mercury, which can be detected by AA. Nitrogen gas flow was maintained at $5 \mathrm{~cm}^{3} /$ min through the AA. The temperature controller was ramped from ambient temperature to $750^{\circ} \mathrm{C}$ at a rate of $25^{\circ} \mathrm{C}$ per minute.

\section{$5.11 \mathrm{Hg}^{0}$ Oxidants and Powdered Activated Carbon}

The addition of inorganic chloride compounds such as $\mathrm{CaCl}_{2}$ and $\mathrm{MgCl}_{2}$ to coal may promote $\mathrm{Hg}^{0}$ oxidation after the coal combustion process. $\mathrm{CaCl}_{2}$ and $\mathrm{MgCl}_{2}$ were selected as chlorine-containing additives because the addition of small amounts of calcium and magnesium, $\leq 4 \mathrm{lb} /$ Macf, was expected to have little effect on ash slagging and fouling severity because of the inherently high alkaline earth metal contents of the Center Mine lignite coal. SEA2 is a proprietary $\mathrm{Hg}^{0}$ oxidizing agent effective at addition rates on the order of one-tenth of those for $\mathrm{CaCl}_{2}$. 


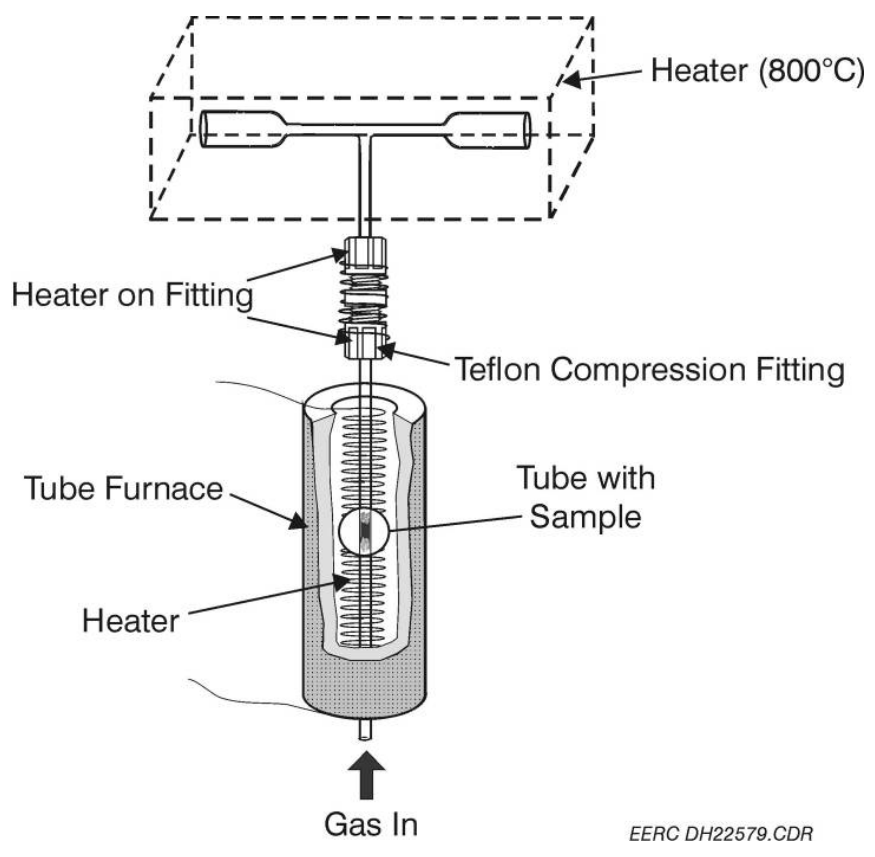

Figure 5-8. Hg thermal desorption apparatus.

The PAC injected at MRY Unit 2 was NORIT Americas Inc. DARCO ${ }^{\circledR} \mathrm{Hg}$, a lignite-based activated carbon manufactured specifically for the removal of $\mathrm{Hg}$ in coal-fired utility flue gas emission streams. According to the manufacturer, it has been proven in numerous full-scale operating facilities to be highly effective for removing gaseous $\mathrm{Hg}$. Some of the general properties of DARCO Hg are presented in Table 5-2.

Table 5-2. General Properties of NORIT Americas Inc. DARCO $\mathrm{Hg}^{1}$

\begin{tabular}{lc}
\hline Parameter & Value \\
\hline Mesh Size, $<325$ mesh $(<45 \mu \mathrm{m})$ & $>95 \%$ \\
Iodine Number & $550 \mathrm{mg} / \mathrm{g}$ \\
Sulfur & $1.2 \mathrm{wt} \%$ \\
Bulk Density & $0.51 \mathrm{~g} / \mathrm{mL}\left(32 \mathrm{lb} / \mathrm{ft}^{3}\right)$ \\
Surface Area & $600 \mathrm{~m}^{2} / \mathrm{g}$ \\
\hline${ }^{1}$ NORIT Americas Inc. Web site: www.norit-americas.com/1.2.cfm (accessed February 2006).
\end{tabular}

\subsection{RESULTS}

\subsection{Coal Analysis Results}

Coal samples were collected daily during the baseline, parametric, and long-term testing conditions. Proximate, ultimate, $\mathrm{Hg}$, and $\mathrm{Cl}$ analyses were performed on randomly selected coal samples. Average coal analysis results are summarized in Table 6-1, and individual coal analysis results are presented in Appendix D. Even though coal samples collected downstream from the coal crushers were partially dry, they are referred to as "as-received" in this report. Many of the 
original coal samples were analyzed almost a year after they were collected; therefore, their moisture contents were much less. Analyses for these relatively low-moisture coal samples are presented in Appendix D. Average results for the higher-moisture coals are presented in Table 6-1 for time periods corresponding to baseline, parametric, and monthlong testing conditions as well as for the entire sampling period. These coal analysis results were used to calculate theoretical $\mathrm{Hg}$ concentrations in the flue gas.

Presented in Table 6-2 are the elemental oxide compositions of three pulverized coals sampled from MRY Unit 2 during the long-term testing conditions. Even though the three coals are compositionally variable, especially their $\mathrm{SiO}_{2}, \mathrm{Al}_{2} \mathrm{O}_{3}, \mathrm{Fe}_{2} \mathrm{O}_{3}, \mathrm{CaO}, \mathrm{Na}_{2} \mathrm{O}$, and $\mathrm{SO}_{3}$ contents, they are characterized by relatively high alkaline-earth $(\mathrm{CaO}$ and $\mathrm{MgO})$ and alkali $\left(\mathrm{Na}_{2} \mathrm{O}\right)$ metal concentrations. Average chemical fractionation results for the three MRY coal samples are presented in Table 6-3. Average results are presented because the chemical fractionation results for all three samples were statistically similar with standard deviations of $<1 \%$. Certain elements (e.g., Si, Al, and Ti) are not included in Table 6-3 because they were not removed significantly during the extraction procedure. These insoluble elements are generally associated with the aluminosilicate (e.g., mixed clays and kaolinite $\left[\mathrm{Al}_{2} \mathrm{Si}_{2} \mathrm{O}_{5}(\mathrm{OH})_{4}\right]$ ), silicate (e.g., quartz $\left[\mathrm{SiO}_{2}\right]$ ), and oxide (e.g., rutile $\left[\mathrm{TiO}_{2}\right]$ ) mineral components of the MRY coal. About $20 \%$ of the $\mathrm{Na}$ in MRY coal was water-soluble, suggesting that it occurs dissolved in moisture or as a salt (e.g., $\mathrm{NaCl}$ and $\mathrm{NaSO}_{4}$ ). The remaining $\mathrm{Na}$ was extracted using $\mathrm{NH}_{4} \mathrm{OAc}$, suggesting a clay and/or organic association. Essentially all of the $\mathrm{Ca}$ and $\mathrm{Mg}$ in $\mathrm{MRY}$ coal were extracted using $\mathrm{NH}_{4} \mathrm{OAc}$ and $\mathrm{HCl}$, implying a clay and/or organic association.

Presented in Table 6-4 are computer-controlled scanning electron microscopy (CCSEM) of the coal minerals contained in six MRY Unit 2 coals sampled during baseline and long-term testing conditions. The mixed clays quantified in Table 6-4 also contain $\mathrm{Ca}$ and $\mathrm{Mg}$ that is ionexchangeable in $\mathrm{NH}_{4} \mathrm{OAc}$. As indicated in Table 6-4, the MRY coal contains the major mineral assemblage: quartz + kaolinite + illite + mixed clays + pyrite. Hematite $\left(\mathrm{Fe}_{2} \mathrm{O}_{3}\right)$, rutile $\left(\mathrm{TiO}_{2}\right)$, calcite $\left(\mathrm{CaCO}_{3}\right)$ and/or dolomite $\left(\mathrm{CaMg}\left[\mathrm{CO}_{3}\right]_{2}\right)$, barite $\left(\mathrm{BaSO}_{4}\right)$, and gypsum $\left(\mathrm{CaSO}_{4} \cdot 2 \mathrm{H}_{2} \mathrm{O}\right)$ are present in MRY coal as accessory minerals. The mineral concentrations in these MRY coal samples are variable, which is consistent with the variability in the three coal ash compositions presented in Table 6-2.

The large variability in MRY coal pyrite $\left(\mathrm{FeS}_{2}\right)$, and hence sulfur contents, suggests that the $\mathrm{Hg}$ contents could also be highly variable because pyrite is generally assumed to be the dominant mineral host for $\mathrm{Hg}$ in coal. Indeed, as indicated in Figure 6-1 and statistically summarized in Table 6-5, coal Hg concentrations are very variable. As shown in Figures 6-2 and 6-3, coal pyrite and $\mathrm{Hg}$ and coal sulfur and $\mathrm{Hg}$ concentrations correlate very well with correlation coefficients of 0.941 and 0.925 , respectively. An analysis of a pyrite-rich reject sample (collected on 3/16/05) from the coal crushers indicated the presence of $2.28 \mathrm{ppm} \mathrm{Hg}$. The dominance of pyrite-associated $\mathrm{Hg}$ caused a "nugget" effect in regard to sampling coal at MRY for $\mathrm{Hg}$ analyses. 
Table 6-1. Summary of MRY Unit 2 Coal Analysis Results, as-received unless otherwise noted

\begin{tabular}{|c|c|c|c|c|c|c|c|c|}
\hline \multirow[b]{2}{*}{ Parameter, Unit } & \multicolumn{2}{|c|}{ Overall } & \multicolumn{2}{|c|}{ Baseline Testing } & \multicolumn{2}{|c|}{ Parametric Testing } & \multicolumn{2}{|c|}{ Long-Term Testing } \\
\hline & Average & Std. Dev. ${ }^{1}$ & Average & Std. Dev. & Average & Std. Dev. & Average & Std. Dev. \\
\hline Mercury, ppm (dry) & 0.112 & 0.045 & 0.112 & 0.059 & 0.063 & 0.008 & 0.117 & 0.040 \\
\hline Chlorine, ppm (dry) & 13.8 & 2.5 & 14.3 & 3.1 & 11.0 & N/A & 13.5 & 2.5 \\
\hline \multicolumn{9}{|l|}{ Proximate } \\
\hline Moisture, wt $\%$ & 35.8 & 0.8 & 35.8 & 0.7 & 36.4 & $\mathrm{~N} / \mathrm{A}^{2}$ & 35.8 & 0.9 \\
\hline Volatile Matter, wt $\%$ & 27.2 & 0.8 & 28.0 & 0.5 & 28.2 & N/A & 26.8 & 0.5 \\
\hline Fixed Carbon, wt $\%$ & 29.6 & 0.9 & 28.9 & 0.9 & 28.1 & N/A & 29.9 & 0.7 \\
\hline Ash, wt $\%$ & 7.46 & 1.26 & 7.25 & 0.49 & 7.35 & N/A & 7.56 & 1.55 \\
\hline \multicolumn{9}{|l|}{ Ultimate } \\
\hline Hydrogen, wt $\%$ & 6.84 & 0.12 & 6.92 & 0.04 & 6.90 & N/A & 6.78 & 0.14 \\
\hline Carbon, wt $\%$ & 40.1 & 0.9 & 39.6 & 1.4 & 38.6 & N/A & 40.5 & 0.4 \\
\hline Nitrogen, wt $\%$ & 0.77 & 0.02 & 0.75 & 0.01 & 0.74 & N/A & 0.79 & 0.01 \\
\hline Sulfur, wt\% & 0.95 & 0.21 & 0.79 & 0.01 & 0.78 & N/A & 1.05 & 0.22 \\
\hline Oxygen, wt\% & 43.7 & 1.5 & 44.9 & 1.0 & 45.6 & N/A & 42.9 & 1.3 \\
\hline Heating Value, Btu/lb & 6768 & 212 & 6614 & 240 & 6445 & N/A & 6870 & 150 \\
\hline \multicolumn{9}{|l|}{ Calculated Parameters } \\
\hline $\mathrm{F}_{\mathrm{d}}{ }^{3}, \mathrm{dscf} / 10^{6} \mathrm{Btu}$ & 9920 & $\mathrm{NC}^{4}$ & 9982 & $\mathrm{NC}$ & 9944 & N/A & 9892 & $\mathrm{NC}$ \\
\hline Sulfur, wt $\%$ (dry) & 1.48 & 0.33 & 1.23 & 0.02 & 1.23 & N/A & 1.64 & 0.34 \\
\hline Heating Value, Btu/lb (dry) & 10542 & 330 & 10302 & 374 & 10134 & N/A & 10701 & 234 \\
\hline $\mathrm{Hg}, \mu \mathrm{g} / \mathrm{dNm}^{3}$ (flue gas & & & & 7.9 & & N/A & & 5.2 \\
\hline basis) & 14.7 & 5.9 & 15.0 & & 8.58 & & 15.2 & \\
\hline $\mathrm{Hg}, \mathrm{lb} / \mathrm{TBtu}$ (flue gas basis) & 10.6 & 4.3 & 10.9 & 5.7 & 6.22 & N/A & 10.9 & 3.7 \\
\hline
\end{tabular}

Standard deviation.

${ }^{2}$ Not applicable.

${ }^{3}$ Ratio of combustion gas volume to heat input on a dry basis.

${ }^{4}$ Not calculated.

Table 6-2. Triplicate and Average MRY Coal Ash Elemental Oxide Compositions, wt \%

\begin{tabular}{lccccc}
\hline Elemental Oxide & $4 / 12-15 / 05$ & $4 / 26-28 / 05$ & $5 / 11 / 05$ & Average & Std. Dev. \\
\hline $\mathrm{SiO}_{2}$ & 20.6 & 22.0 & 32.7 & 25.1 & 6.6 \\
$\mathrm{Al}_{2} \mathrm{O}_{3}$ & 9.45 & 11.2 & 12.2 & 11.0 & 1.4 \\
$\mathrm{TiO}_{2}$ & 0.37 & 0.64 & 0.62 & 0.54 & 0.15 \\
$\mathrm{Fe}_{2} \mathrm{O}_{3}$ & 9.35 & 6.38 & 6.05 & 7.26 & 1.82 \\
$\mathrm{CaO}$ & 17.3 & 23.5 & 14.4 & 18.4 & 4.6 \\
$\mathrm{MgO}$ & 6.29 & 7.56 & 6.07 & 6.64 & 0.80 \\
$\mathrm{Na}_{2} \mathrm{O}$ & 7.39 & 5.92 & 9.24 & 7.52 & 1.66 \\
$\mathrm{~K}_{2} \mathrm{O}$ & 0.72 & 0.60 & 1.31 & 0.88 & 0.38 \\
$\mathrm{P}_{2} \mathrm{O}_{5}$ & 0.17 & 0.09 & 0.12 & 0.13 & 0.04 \\
$\mathrm{SO}_{3}$ & 27.4 & 21.2 & 16.1 & 21.6 & 5.7 \\
$\mathrm{BaO}_{\mathrm{Total}}$ & 0.56 & 0.43 & 0.77 & 0.59 & 0.17 \\
\hline
\end{tabular}




$\begin{aligned} & \text { Table 6-3. Average MRY Coal Chemical Fractionation } \\
& \text { Results, \% removed }\end{aligned}$
\begin{tabular}{lccc}
\hline Element & $\mathrm{H}_{2} \mathrm{O}$ Soluble & $\mathrm{NH}_{4} \mathrm{OAc}$ Soluble & $\mathrm{HCl}$ Soluble \\
\hline $\mathrm{Fe}$ & $<5$ & $<5$ & 39 \\
$\mathrm{Ca}$ & $<5$ & 51 & 45 \\
$\mathrm{Mg}$ & 7 & 60 & 27 \\
$\mathrm{Na}$ & 17 & 81 & $<5$ \\
$\mathrm{~K}$ & $<5$ & 6 & $<5$ \\
\hline
\end{tabular}

Table 6-4. Quantitative MRY Unit 2 Coal Mineral Analyses, wt $\%$ on a mineral basis

\begin{tabular}{|c|c|c|c|c|c|c|c|c|}
\hline $\begin{array}{l}\text { Classification } \\
\text { Category }\end{array}$ & $3 / 18 / 05$ & $4 / 4 / 05$ & $4 / 8 / 05$ & $4 / 12-15 / 05$ & $4 / 26-28 / 05$ & $5 / 11 / 05$ & Avg. ${ }^{1}$ & $\begin{array}{l}\text { Std. } \\
\text { Dev. }\end{array}$ \\
\hline Quartz & 10.3 & 4.3 & 11.2 & 8.8 & 13.9 & 20.5 & 11.5 & 5.4 \\
\hline Hematite & 0.8 & 0.4 & $<0.1$ & 0.3 & 0.1 & 0.7 & 0.4 & 0.3 \\
\hline Rutile & 0.3 & 0.1 & 0.3 & 0.1 & 0.2 & 0.5 & 0.2 & 0.2 \\
\hline Calcite & 0.2 & $<0.1$ & $<0.1$ & 0.2 & 0.3 & 0.8 & 0.3 & 0.3 \\
\hline Kaolinite $^{2}$ & 13.8 & 3.7 & 6.7 & 5.3 & 13.3 & 8.7 & 8.6 & 4.2 \\
\hline Illite & 5.3 & 2.9 & 3.2 & 3.6 & 4.9 & 9.0 & 4.8 & 2.3 \\
\hline Mixed Clays ${ }^{3}$ & 15.1 & 6.4 & 8.2 & 11.7 & 12.7 & 13.6 & 11.3 & 3.3 \\
\hline Pyrite & 24.6 & 53.3 & 36.0 & 52.9 & 24.4 & 10.7 & 33.6 & 17.1 \\
\hline Barite & 0.4 & 0.6 & 0.9 & 0.2 & 0.5 & 1.4 & 0.7 & 0.4 \\
\hline Gypsum & 0.4 & 5.1 & 1.8 & $<0.1$ & 0.1 & 0.9 & 1.4 & 1.9 \\
\hline Others ${ }^{4}$ & 28.8 & 23.0 & 31.4 & 16.7 & 29.4 & 32.7 & 27.0 & 6.0 \\
\hline
\end{tabular}

${ }^{1}$ Average.

2 Sum of kaolinite, alumina, aluminosilicate, and silicon-rich categories presented in Appendix C.

3 Sum of montmorillonite and calcium-, sodium-, iron-, and mixed-aluminosilicate categories presented in Appendix C.

${ }^{4}$ Sum of calcium silicate, gypsum/aluminosilicate, calcium-rich, calcium-silica-rich, and unclassified categories presented in Appendix C.

\subsection{MRY Unit 2 Operation}

MRY Unit 2 operational and stack emission data are plotted in Figure 6-4. The time lines for the three test conditions are also indicated in Figure 6-4. Total Hg measurement results are lacking during late March and early May because the CMMs were not operating then. The plant operation, especially load, remained relatively consistent during the 2-month test period. 


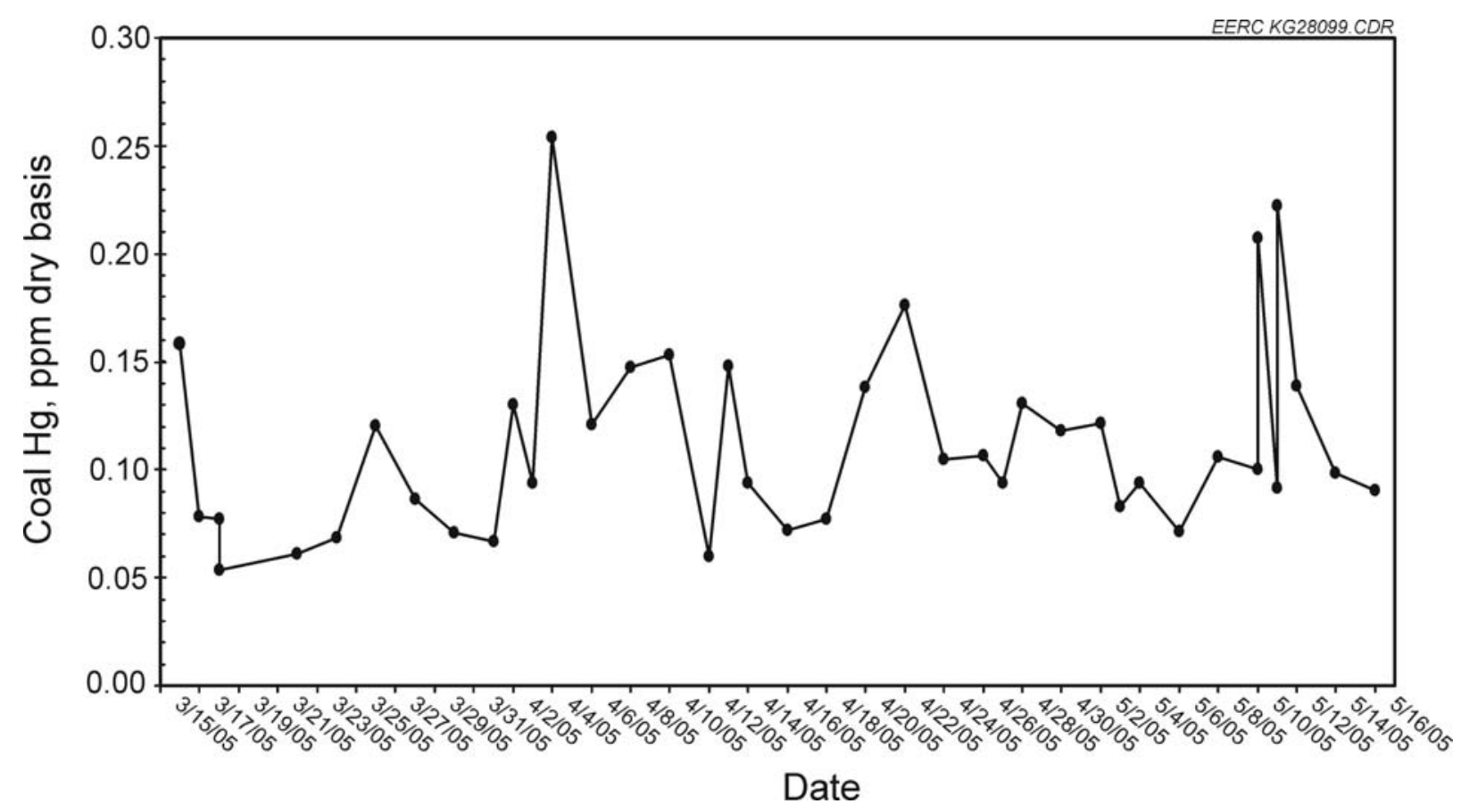

Figure 6-1. Temporal variations in MRY Unit 2 lignite Hg concentrations.

Table 6-5. Statistical Summary of MRY Unit 2 Coal Hg Analysis Results

\begin{tabular}{lcccc}
\hline & Overall & Baseline Testing & Parametric Testing & Long-Term Testing \\
\hline Mean & 0.112 & 0.112 & 0.063 & 0.117 \\
Std. Dev. & 0.045 & 0.059 & 0.008 & 0.040 \\
RSD $^{1}$ & 40.3 & 52.7 & 12.0 & 34.0 \\
$95 \%$ C.I. & 0.014 & 0.037 & 0.007 & 0.015 \\
$\mathrm{~N}^{3}$ & 40 & 10 & 4 & 27 \\
\multicolumn{2}{l}{${ }^{2}$ Relative standard deviation. } & & & \\
${ }^{2}$ Confidence interval at $95 \%$. & & & \\
\multicolumn{2}{l}{ Number of samples. }
\end{tabular}

\subsection{Baseline Testing}

$\mathrm{OH} \mathrm{Hg} \mathrm{measurements} \mathrm{were} \mathrm{performed} \mathrm{in} \mathrm{triplicate} \mathrm{to} \mathrm{quantify} \mathrm{baseline} \mathrm{Hg}$ concentrations at the ESP and wet FGD inlets and stack prior to any chemical additions or PAC injections. The average baseline $\mathrm{Hg}$ species measurement results are presented in Figure 6-5. The Hg speciation results in Figure 6-5 are very similar to those obtained in 2002 (refer to Figure 4-2). In both cases, the $\mathrm{Hg}(\mathrm{p})$ concentrations are significant at the ESP inlet probably because of a known measurement bias associated with the $\mathrm{OH}$ sampling of $\mathrm{Hg}$ in the presence of relatively high fly ash concentrations. The results obtained at the wet FGD inlet and stack that indicate $\mathrm{Hg}^{0}$ as the most abundant species are probably more representative of the actual flue gas $\mathrm{Hg}$ speciation. A 


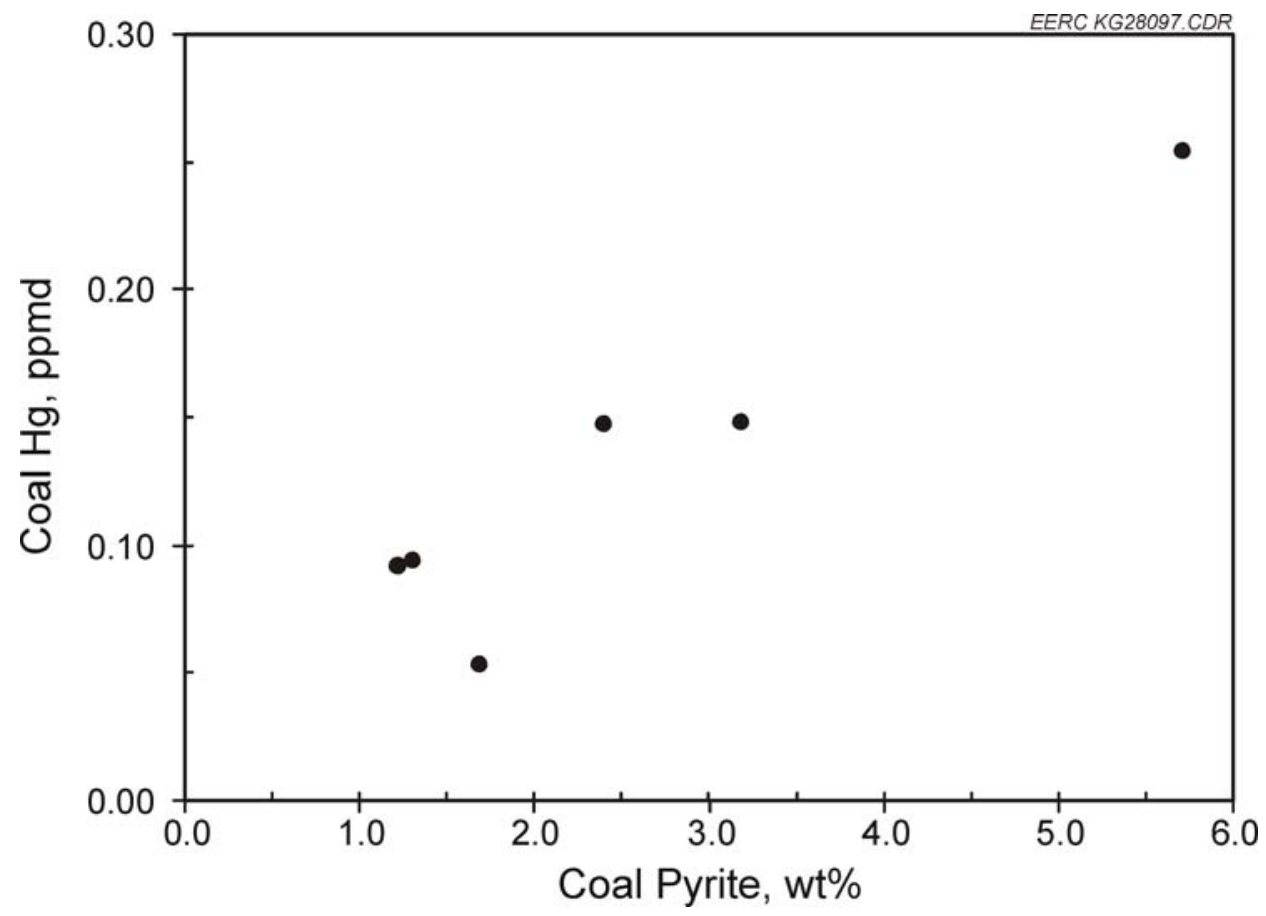

Figure 6-2. MRY Unit 2 lignite pyrite versus Hg concentrations (on a dry basis), correlation coefficient of 0.941 .

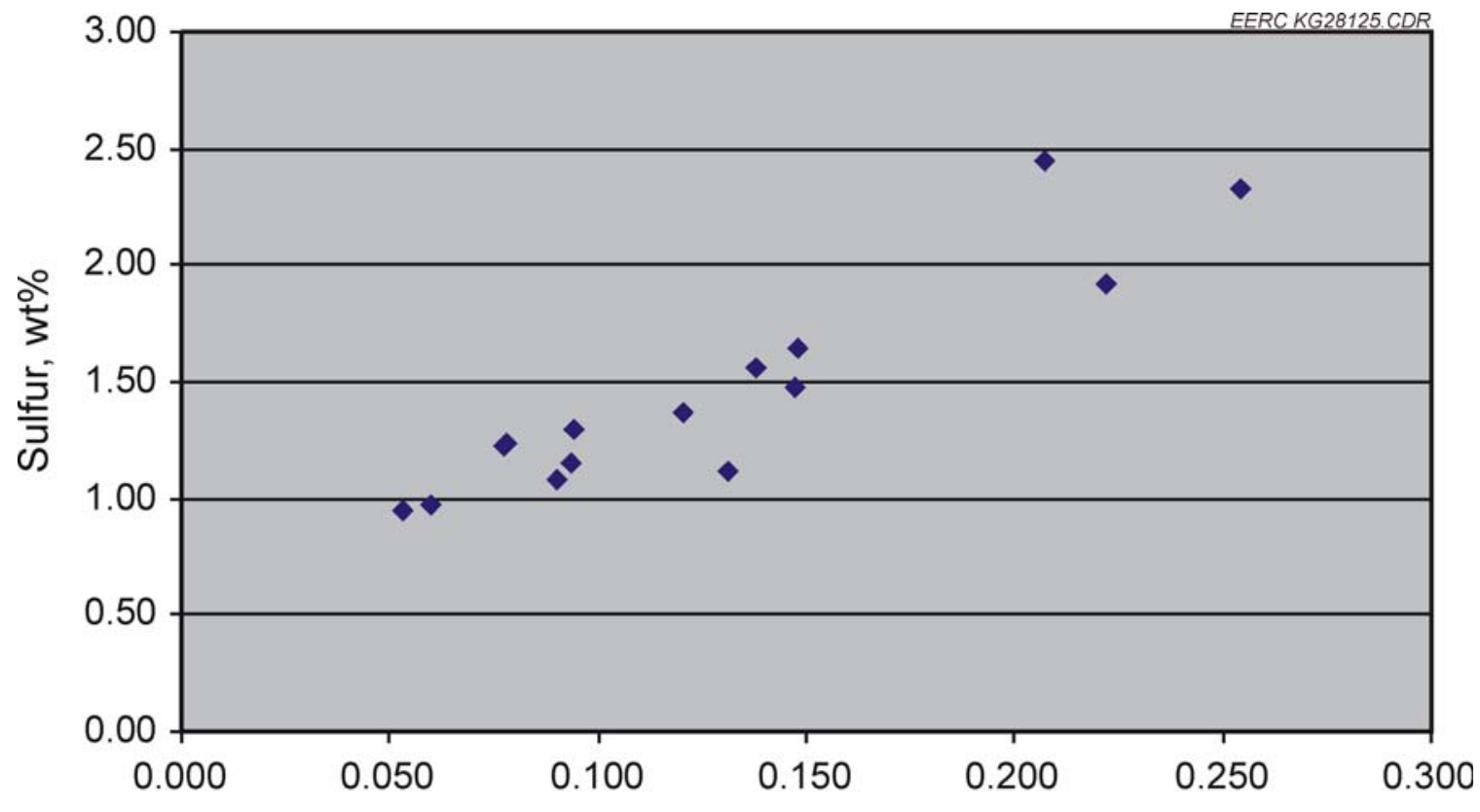

$\mathrm{Hg}, \mathrm{g} / \mathrm{g}$

Figure 6-3. MRY Unit 2 lignite $\mathrm{Hg}$ versus $\mathrm{S}$ concentrations (on a dry basis), correlation coefficient of 0.925 . 


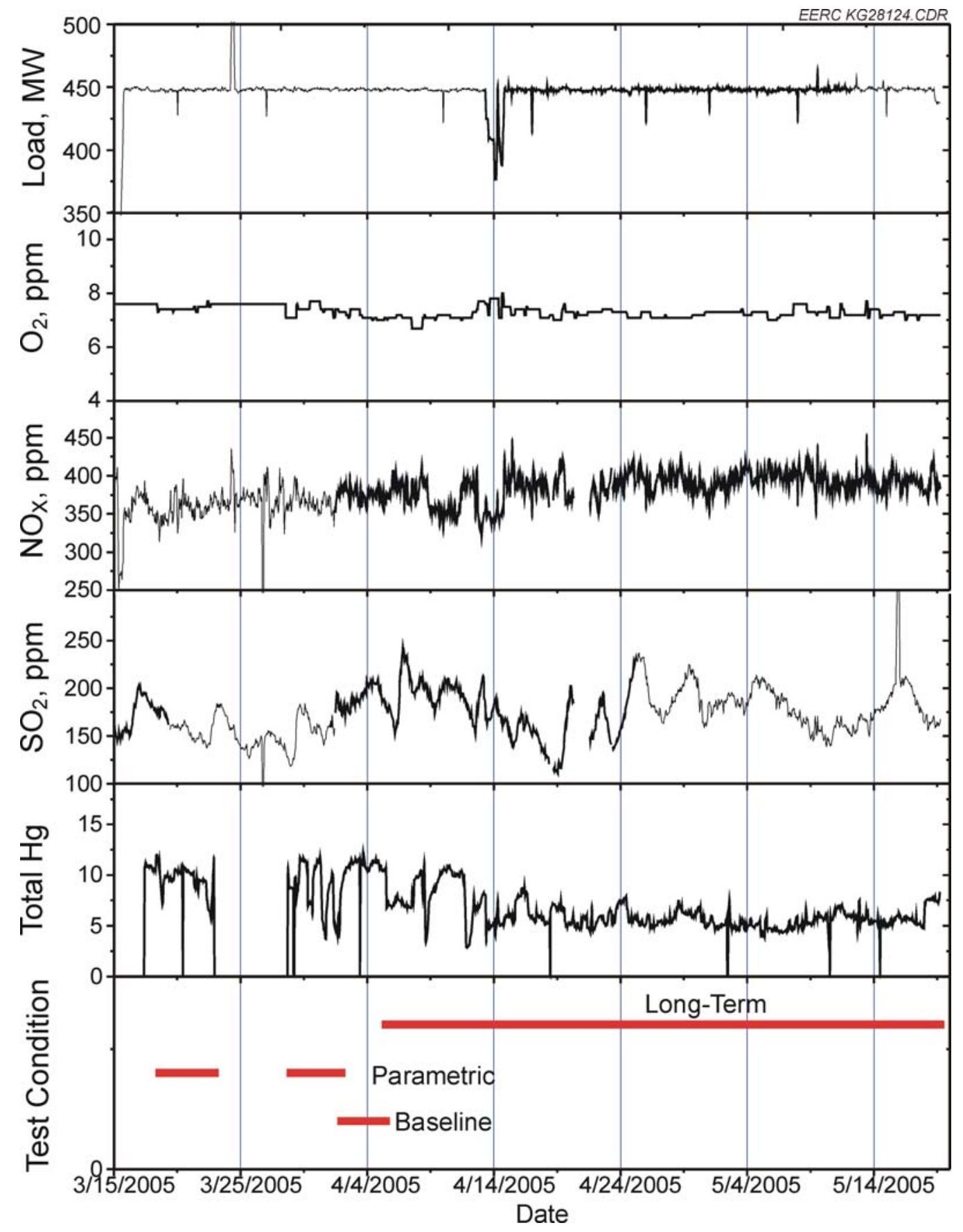

Figure 6-4. Summary of MRY unit operational and emission data. 


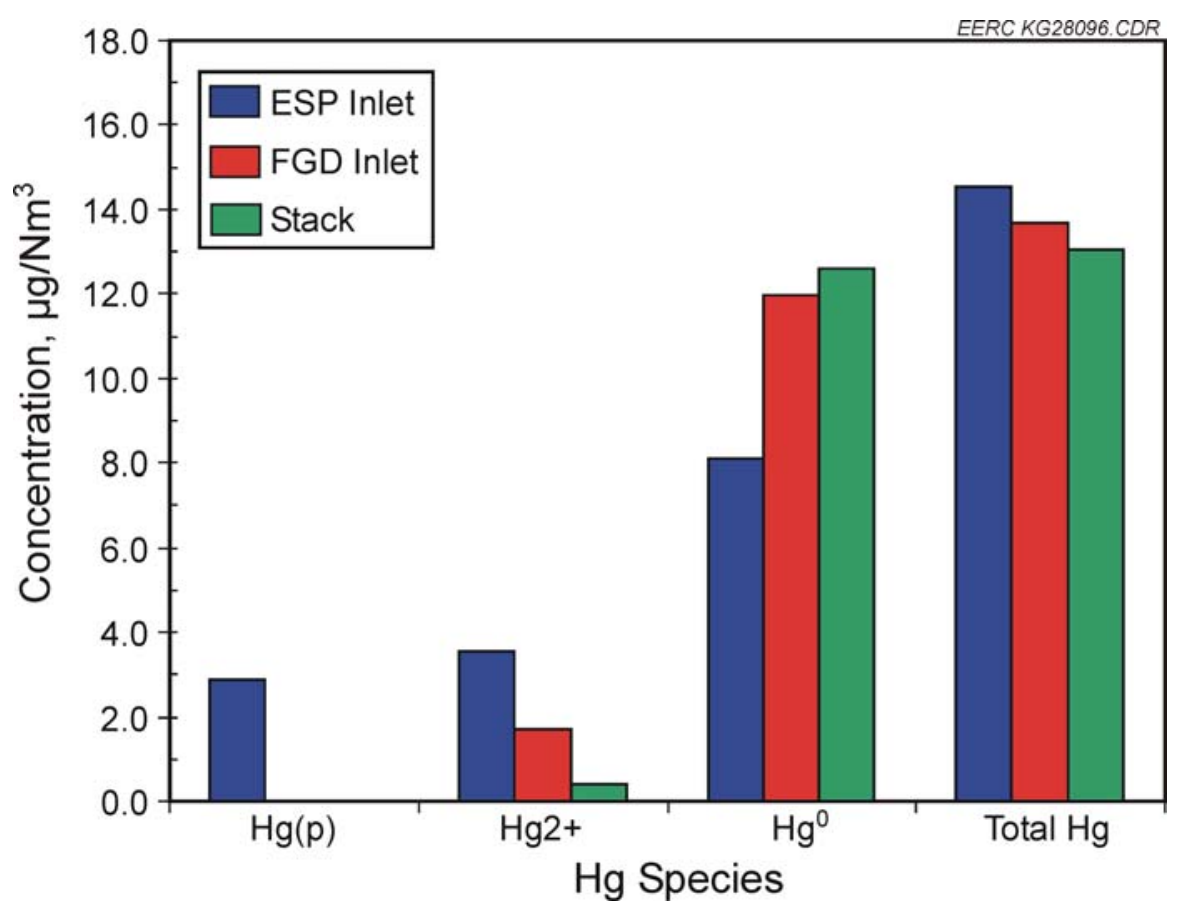

Figure 6-5. Baseline OH Hg measurement results.

total $\mathrm{Hg}$ concentration in flue gas value calculated from the average coal analysis results (Table 6-1) is also plotted in Figure 6-5. The total Hg concentration measured at the ESP inlet was only $0.5 \mu \mathrm{g} / \mathrm{dNm}^{3}$ less than the theoretical value.

Compared in Table 6-6 are average $\mathrm{OH}$ and $\mathrm{CMM}$ results that were obtained simultaneously during the baseline testing conditions. A CMM was not used at the ESP inlet because of the known $\mathrm{Hg}$ measurement interference caused by the high dust loading at such a location. The $\mathrm{OH}$ and $\mathrm{CMM}$ results obtained at the FGD inlet and stack compare favorably with relative percent differences (RPD) of $<20$. Total $\mathrm{Hg}$ concentrations at the ESP and wet FGD inlets varied from about 12 to $16 \mu \mathrm{g} / \mathrm{dNm}^{3}$, whereas at the stack concentrations were consistently at about $13 \mu \mathrm{g} / \mathrm{dNm}^{3}$, indicating that the ESP and wet FGD were very inefficient at removing $\mathrm{Hg}$ during routine power plant operations.

An EPA Method 26A sampling and analysis of MRY Unit 2 flue gas at the ESP inlet indicated that $\mathrm{HCl}$ was nondetectable $(<2 \mathrm{ppmv})$. As indicated in Table 6-1, the Center lignite coal contains very low coal chlorine concentrations, consistent with the EPA Method 26A measurement result.

Presented in Table 6-7 are duplicate $\mathrm{Hg}, \mathrm{Br}$, and $\mathrm{Cl}$ analysis results for fly ash samples collected from the ESP during baseline testing conditions on March 17, 2005. The presence of about $0.3 \mathrm{ppm} \mathrm{Hg}$ on the fly ash indicates that it has some inherent $\mathrm{Hg}$ adsorption capacity. 
Table 6-6. Comparison of $\mathrm{OH}$ and CMM Results $\left(\mu \mathrm{g} / \mathrm{dNm}^{3}\right)$ Obtained Concurrently During Baseline Testing Conditions (March 17 and 18, 2005).

\begin{tabular}{lccccccc}
\hline \multicolumn{5}{l}{} & \multicolumn{5}{c}{ Ontario Hydro } & \multicolumn{3}{c}{$\mathrm{CMM}^{1}$} \\
\hline \multicolumn{2}{l}{ Sampling Location } & $\mathrm{Hg}^{0}$ & $\mathrm{Hg}^{2+}$ & $\mathrm{Hg}(\mathrm{p})$ & Total Hg & Total Hg & $\mathrm{RPD}^{2}$ \\
& & & & & & & \\
\multirow{5}{*}{ FGD Inlet } & Average & 8.12 & 3.55 & 2.88 & 14.5 & $\mathrm{NA}^{3}$ & $\mathrm{NA}$ \\
& Std. dev. & 0.39 & 2.48 & 0.19 & 2.6 & $\mathrm{NA}$ & $\mathrm{NA}$ \\
& & & & & & & \\
\multirow{5}{*}{ Stack } & Average & 12.0 & 1.71 & $<0.1$ & 13.7 & 13.1 & $4.06 \%$ \\
& Std. dev. & 0.5 & 0.93 & $\mathrm{NA}$ & 1.4 & 0.4 & $\mathrm{NA}$ \\
& & & & & & & \\
& Average & 12.6 & 0.43 & $<0.1$ & 13.0 & 11.0 & $16.6 \%$ \\
& Std. dev. & 0.5 & 0.14 & $\mathrm{NA}$ & 0.6 & 0.2 & $\mathrm{NA}$ \\
\hline
\end{tabular}

${ }^{1}$ Average of two hours of CMM measurements.

${ }^{2}$ Relative percent difference from the average of $\mathrm{OH}$ and $\mathrm{CMM}$ measurement results.

${ }^{3}$ Not analyzed or not applicable.

Table 6-7. Duplicate Hg, Br, and Cl Analysis Results for Fly Ashes Sampled from the ESP During Baseline Testing Conditions

\begin{tabular}{lccc}
\hline Analyte, ppm & Replicate 1 & Replicate 2 & Average \\
\hline $\mathrm{Hg}$ & 0.215 & 0.323 & 0.269 \\
$\mathrm{Br}$ & $<2$ & $<2$ & $<2$ \\
$\mathrm{Cl}$ & 26 & 26 & 26 \\
\hline
\end{tabular}

Consistent with the EPA Method 26A and coal $\mathrm{Cl}$ measurements (Table 6-1), the $\mathrm{Cl}$ content of the fly ash was very low. Br was below the quantification limit, $<2 \mathrm{ppm}$, of the ion chromatography method.

\subsection{Parametric Testing}

Parametric testing at MRY Unit 2 was performed using $\mathrm{CaCl}_{2}, \mathrm{MgCl}_{2}$, and SEA2 at varying addition rates alone and in combination with PAC injections to determine the most effective conditions for achieving $\geq 55 \% \mathrm{Hg}$ capture. Compared in Table 6-8 are average $\mathrm{OH}$ and CMM results that were obtained simultaneously during the parametric testing conditions. During most of the tests, the $\mathrm{OH}$ and CMM results compared favorably with RPDs of $<20$. The coal-derived $\mathrm{Hg}$ flue gas concentration of $8.58 \mu \mathrm{g} / \mathrm{dNm}^{3}$ (Table 6-1) was biased much lower relative to the $\mathrm{OH}$ and $\mathrm{CMM}$ measurements probably because of the great variability in coal $\mathrm{Hg}$ concentrations (Figure 6-1 and Table 6-5). 
Table 6-8. Comparison of $\mathrm{OH}$ and CMM Results $\left(\mu \mathrm{g} / \mathrm{dNm}^{3}\right)$ Obtained Concurrently During Parametric Testing Conditions (March 18-April 1, 2005)

\begin{tabular}{|c|c|c|c|c|c|c|c|c|}
\hline \multirow{2}{*}{$\begin{array}{l}\text { Sampling } \\
\text { Location }\end{array}$} & \multirow[b]{2}{*}{ Date } & \multicolumn{4}{|c|}{ Ontario Hydro } & \multicolumn{2}{|c|}{$\mathrm{CMM}^{1}$} & \multirow[b]{2}{*}{$\mathrm{RPD}^{2}$} \\
\hline & & $\mathrm{Hg}^{0}$ & $\mathrm{Hg}^{2+}$ & $\mathrm{Hg}(\mathrm{p})$ & Total $\mathrm{Hg}$ & Total $\mathrm{Hg}$ & Std. Dev. & \\
\hline \multicolumn{9}{|c|}{$300 \mathrm{ppm} \mathrm{CaCl} 2$} \\
\hline ESP In & & 6.39 & 1.75 & 2.20 & 10.3 & $\mathrm{NA}^{3}$ & NA & NA \\
\hline FGD In & $3 / 19 / 05$ & 8.93 & 1.02 & $<0.1$ & 9.95 & 9.94 & 0.61 & 0.15 \\
\hline Stack & & 8.65 & 0.36 & $<0.1$ & 9.01 & 9.63 & 0.28 & 6.63 \\
\hline \multicolumn{9}{|c|}{$100 \mathrm{ppm} \mathrm{CaCl}{ }_{2}$} \\
\hline ESP In & & 8.79 & 2.35 & 2.19 & 13.3 & NA & NA & NA \\
\hline FGD In & $3 / 20 / 05$ & 10.2 & 0.70 & $<0.1$ & 10.9 & 11.5 & 0.4 & 4.98 \\
\hline Stack & & 10.1 & 0.47 & $<0.1$ & 10.5 & 10.5 & 0.2 & 0.75 \\
\hline \multicolumn{9}{|c|}{$500 \mathrm{ppm} \mathrm{CaCl}{ }_{2}$} \\
\hline ESP In & & 7.20 & 2.97 & 2.19 & 12.4 & NA & NA & NA \\
\hline FGD In & $3 / 21 / 05$ & 10.2 & 0.86 & $<0.1$ & 11.1 & 9.71 & 0.42 & 13.0 \\
\hline Stack & & 9.30 & 0.68 & $<0.1$ & 9.99 & 8.70 & 0.27 & 13.8 \\
\hline \multicolumn{9}{|c|}{$500 \mathrm{ppm} \mathrm{CaCl}{ }_{2}+0.5 \mathrm{lb} / \mathrm{Macf}$ PAC } \\
\hline ESP In & & 9.63 & 1.66 & 1.99 & 13.3 & NA & NA & NA \\
\hline FGD In & $3 / 22 / 05$ & 6.62 & 0.37 & $<0.1$ & 7.00 & 7.25 & 0.58 & 3.57 \\
\hline Stack & & 7.14 & 0.12 & $<0.1$ & 7.26 & 6.49 & 0.10 & 11.2 \\
\hline \multicolumn{9}{|c|}{25 ppm SEA2 } \\
\hline ESP In & & 2.70 & 4.90 & 10.8 & 18.4 & NA & NA & NA \\
\hline FGD In & $3 / 29 / 05$ & 7.42 & 1.31 & $<0.1$ & 8.73 & 11.1 & 0.6 & 24.0 \\
\hline Stack & & 7.98 & 1.83 & $<0.1$ & 9.81 & 8.66 & 0.29 & 12.4 \\
\hline \multicolumn{9}{|c|}{50 ppm SEA2 } \\
\hline ESP In & & 3.63 & 2.22 & 3.86 & 9.71 & NA & NA & NA \\
\hline FGD In & $3 / 30 / 05$ & 8.55 & 1.19 & $<0.1$ & 9.74 & 9.34 & 0.65 & 4.20 \\
\hline Stack & & 7.37 & 2.02 & $<0.1$ & 9.39 & 7.34 & 0.16 & 24.5 \\
\hline \multicolumn{9}{|c|}{25 ppm SEA2 + 0.25 lb/Macf PAC } \\
\hline ESP In & & 5.70 & 2.78 & 3.09 & 11.6 & NA & NA & NA \\
\hline FGD In & $3 / 31 / 05$ & 5.86 & 0.70 & $<0.1$ & 6.56 & 7.01 & 0.30 & 6.56 \\
\hline Stack & & 4.95 & 1.06 & $<0.1$ & 6.00 & 5.39 & 0.18 & 10.8 \\
\hline \multicolumn{9}{|c|}{50 ppm SEA2 + 0.25 lb/Macf PAC } \\
\hline ESP In & & 2.71 & 5.91 & 4.88 & 13.5 & NA & NA & NA \\
\hline FGD In & $4 / 1 / 05$ & 5.66 & 0.99 & $<0.1$ & 6.65 & 7.46 & 1.02 & 11.4 \\
\hline Stack & & 4.40 & 1.32 & $<0.1$ & 5.72 & 4.91 & 0.27 & 15.3 \\
\hline
\end{tabular}

\subsubsection{Effects of $\mathrm{CaCl}_{2}, \mathrm{MgCl}_{2}$, and SEA2 Additions on $\mathrm{Hg}$ Speciation and ESP- Wet FGD Capture}

Shown in Figure 6-6 are average Hg speciation results obtained during the combustion of Center lignite with $\mathrm{CaCl}_{2}$ added at 100,300 , and $500 \mathrm{ppm}$ on a dry coal basis. These results indicate that $\mathrm{Hg}^{2+}$ and $\mathrm{Hg}(\mathrm{p})$ concentrations only increased slightly with $\mathrm{CaCl}_{2}$ addition at $\leq 500 \mathrm{ppm}$. In contrast, when Center lignite and $\mathrm{CaCl}_{2}$ addition testing was performed in the 

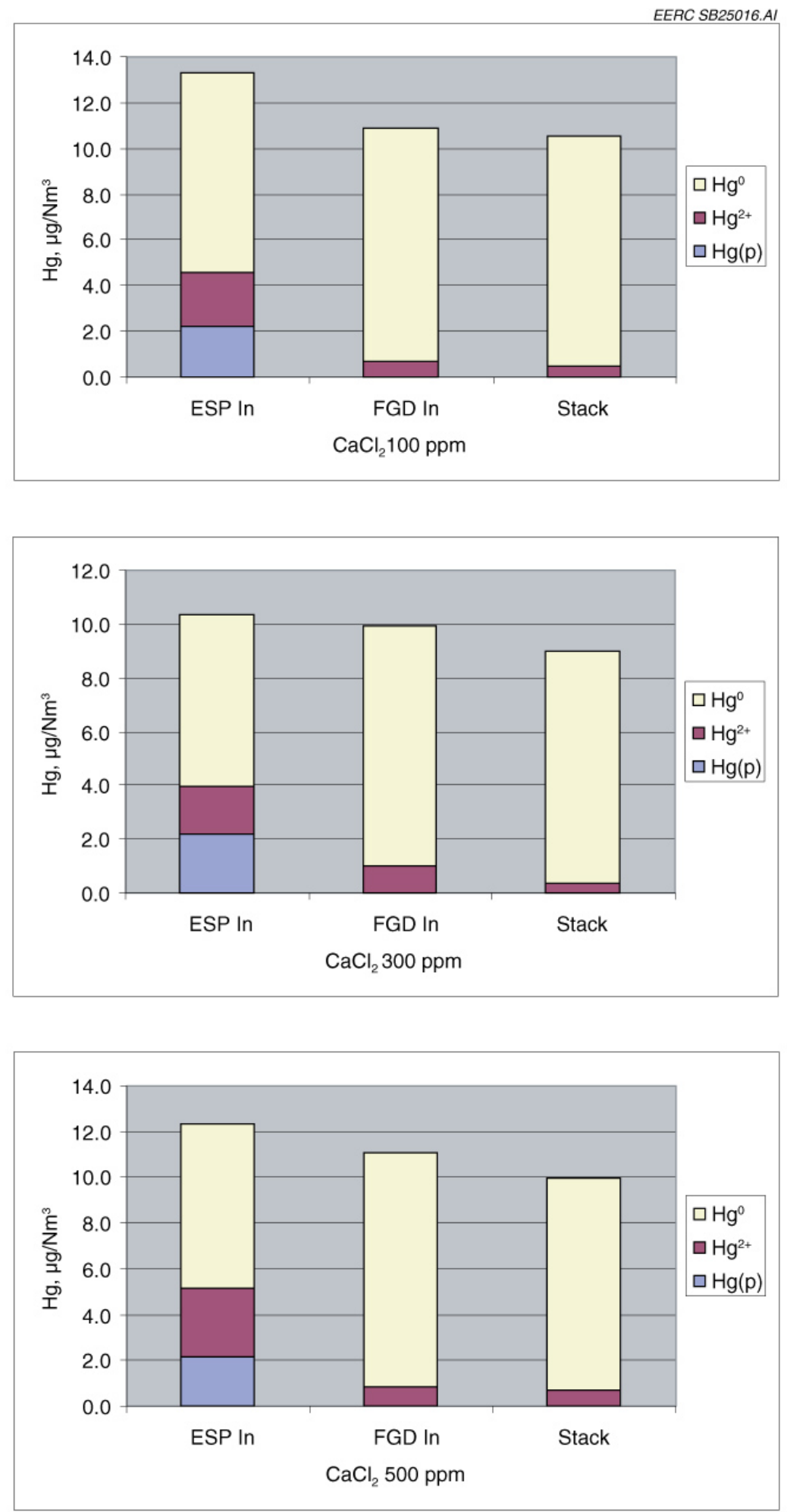

Figure 6-6. Average $\mathrm{Hg}$ speciation results for Center lignite combustion flue gases containing

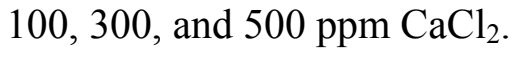


EERC pilot-scale system, the degree of $\mathrm{Hg}^{0}$ oxidation increased dramatically with $\mathrm{CaCl}_{2}$ addition (11). Apparently, differences in combustion conditions and/or coal characteristics during the pilot- and full-scale testing affected the $\mathrm{Hg}^{0}$ chlorination reaction.

Plotted in Figure 6-7 are ESP-wet FGD Hg removal efficiencies as functions of $\mathrm{MgCl}_{2}$, $\mathrm{CaCl}_{2}$, and SEA2 addition rates. An example of the CMM results used to calculate total $\mathrm{Hg}$ removal efficiencies of the ESP-wet FGD is presented in Figure 6-8. Removal efficiencies were calculated based on average stack CMM measurements obtain before, during, and after the chemical additions. $\mathrm{MgCl}_{2}$ and $\mathrm{CaCl}_{2}$ were relatively ineffective in promoting $\mathrm{Hg}^{0}$ oxidation and capture in the ESP-wet FGD. Relatively low additions of SEA2, however, significantly improved the $\mathrm{Hg}$ removal efficiency of the ESP-wet FGD, although the goal of $55 \% \mathrm{Hg}$ removal was not achieved using as much as $75 \mathrm{ppm}$ SEA2. Nearly all of the $\mathrm{Hg}$ removal occurred in the ESP suggesting that SEA2 addition promoted the conversion of $\mathrm{Hg}^{0}$ to $\mathrm{Hg}(\mathrm{p})$ which was subsequently captured in the ESP.

\subsubsection{Effects of PAC Injection and $\mathrm{CaCl}_{2}$ and SEA2 Additions on $\mathrm{Hg}$ Speciation and ESP-Wet FGD Capture}

Presented in Figure 6-9 are total Hg removal efficiencies obtained with the ESP-wet FGD during PAC injections and $\mathrm{CaCl}_{2}$ and SEA2 additions. Presented in Figures 6-10 and 6-11 are the stack $\mathrm{CMM}$ results that were used to calculate total $\mathrm{Hg}$ removal efficiencies and construct Figure 6-9. PAC injection at a $\mathrm{lb} / \mathrm{Macf}$ resulted in an ESP-wet FGD total $\mathrm{Hg}$ removal

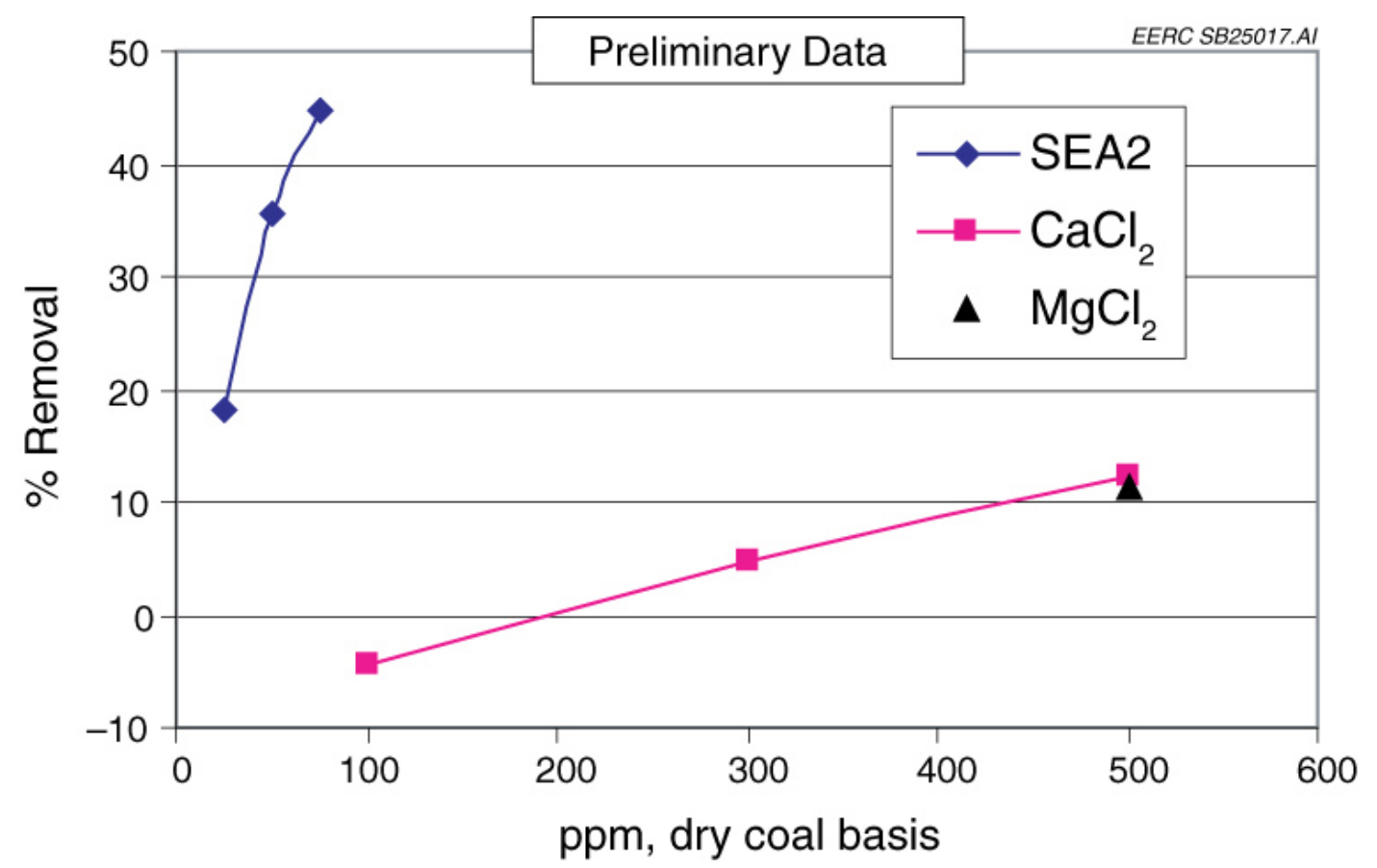

Figure 6-7. ESP-wet FGD Hg removal efficiencies during $\mathrm{CaCl}_{2}, \mathrm{MgCl}_{2}$, and SEA2 additions. 


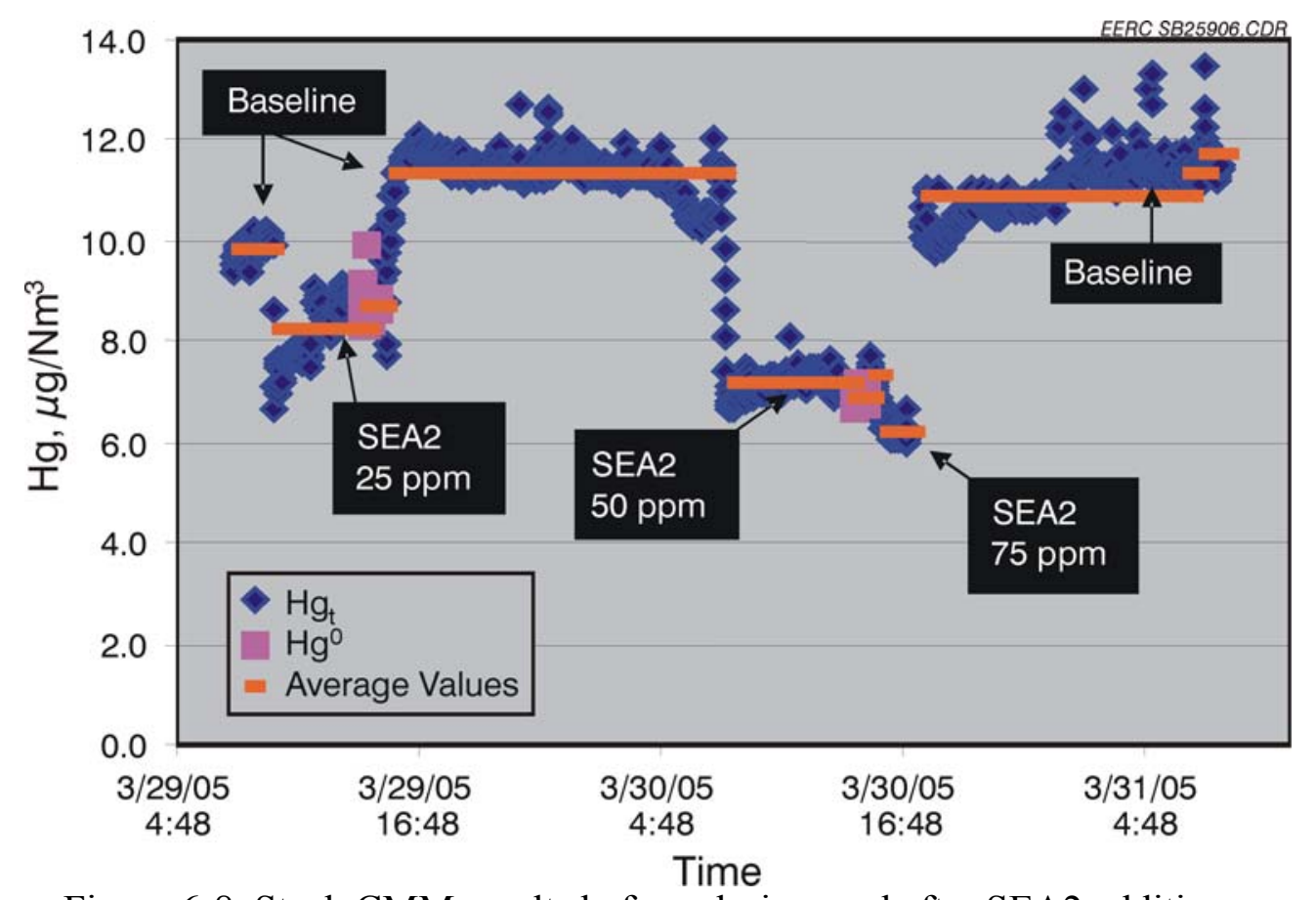

Figure 6-8. Stack CMM results before, during, and after SEA2 additions.

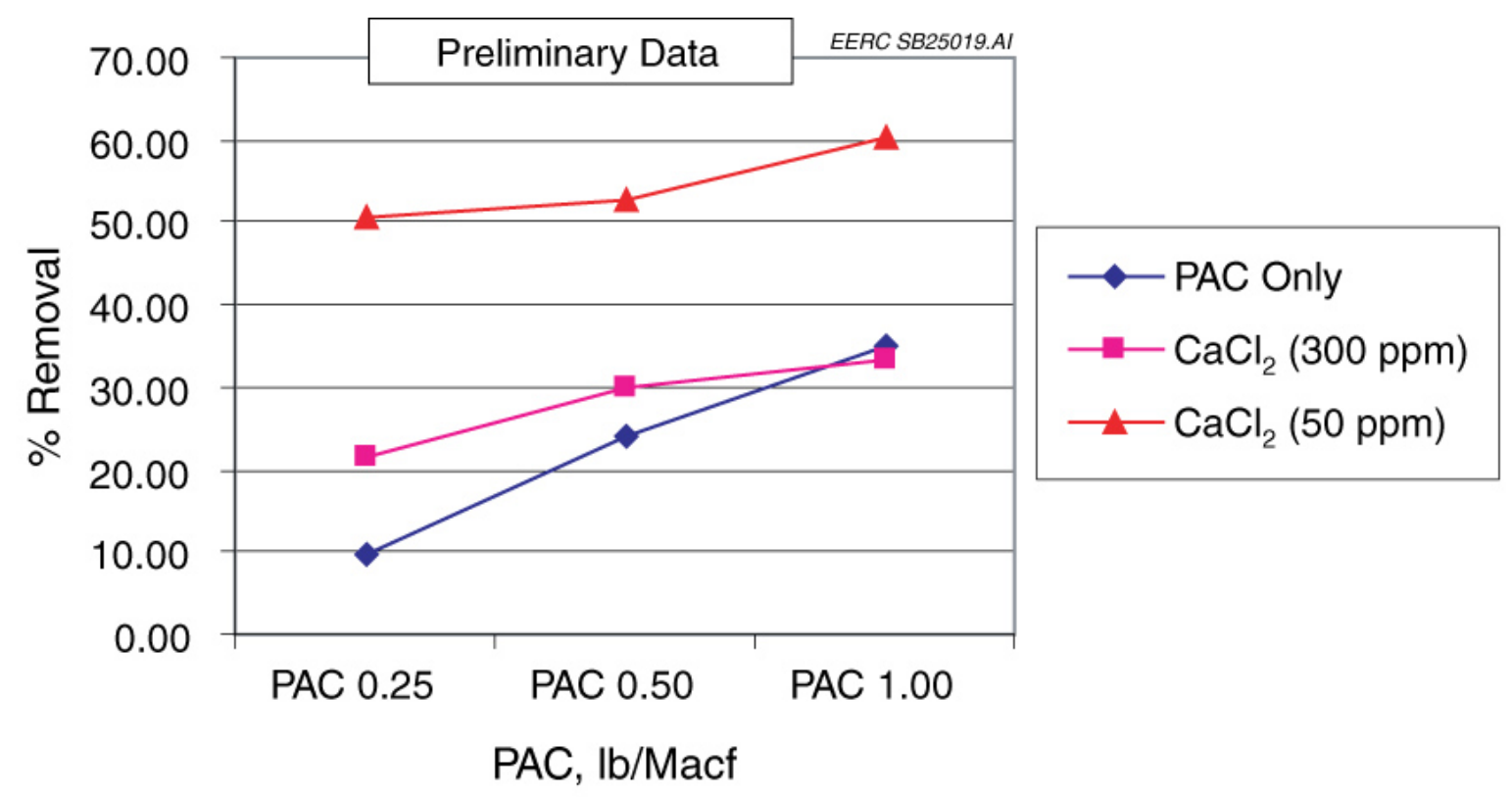

Figure 6-9. Effects of PAC injections alone and in combination with $\mathrm{CaCl}_{2}$ or $\mathrm{SEA} 2$ additions on ESP-wet FGD Hg removal efficiency. 


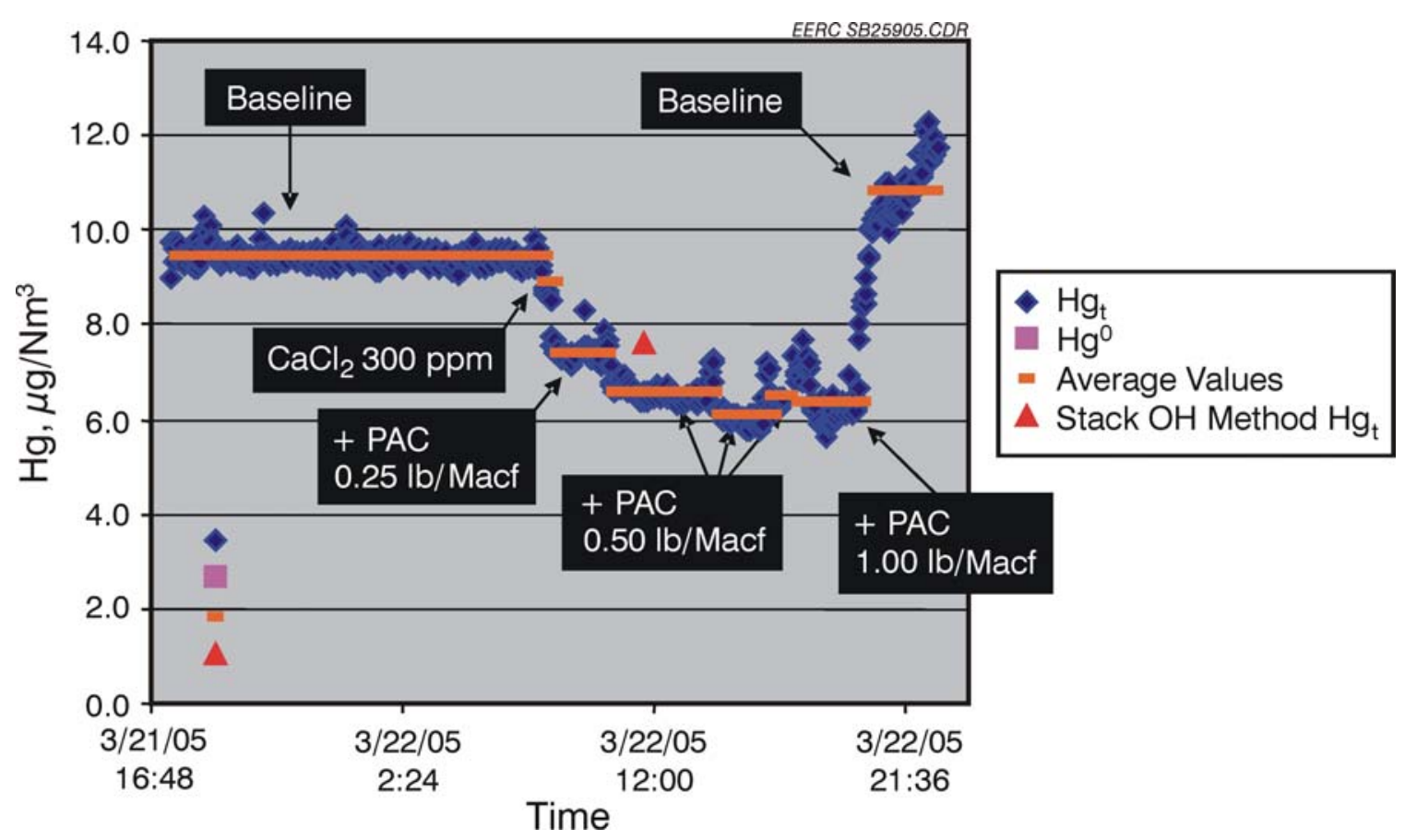

Figure 6-10. Stack CMM results obtained before, during, and after $\mathrm{PAC}$ injections and $\mathrm{CaCl}_{2}$ addition at $300 \mathrm{ppm}$.

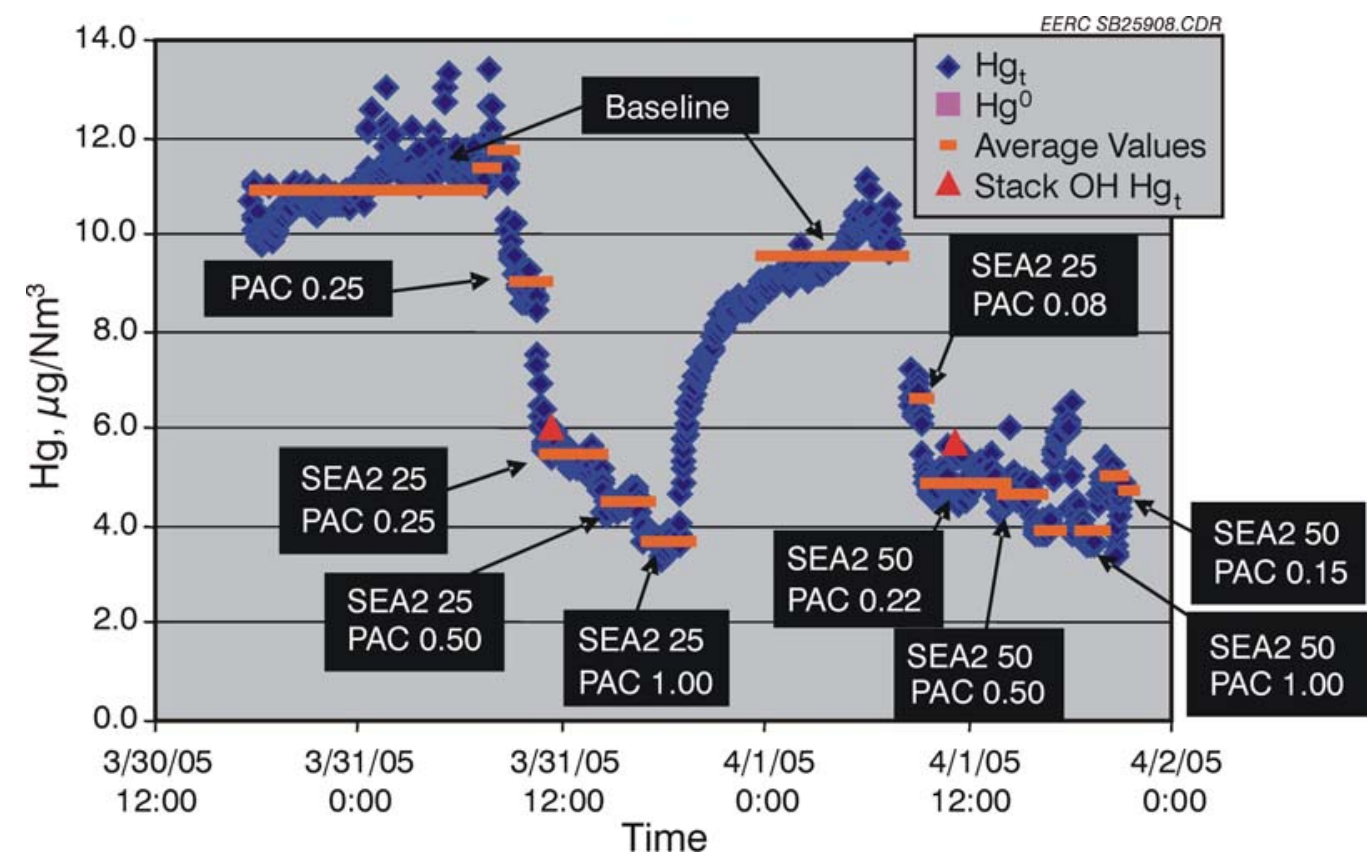

Figure 6-11. Stack CMM results obtained before, during, and after PAC injections and SEA2 additions on a $\mathrm{lb} / \mathrm{Macf}$ basis. 
efficiency of 35\%. Although not shown in Figure 6-9, PAC injection at $1.8 \mathrm{lb} / \mathrm{Macf}$ resulted in a $53 \% \mathrm{Hg}$ removal efficiency, near the 55\% goal, but impractical because of such a high injection rate. $\mathrm{CaCl}_{2}$ addition significantly improved $\mathrm{Hg}$ capture in the ESP-wet FGD at relatively low $\mathrm{PAC}$ injection rates of $0.25 \mathrm{lb} /$ Macf and $0.50 \mathrm{lb} / \mathrm{Macf}$ but not at $1.0 \mathrm{lb} / \mathrm{Macf}$. The combination of PAC injection and SEA2 addition provided the best $\mathrm{Hg}$ capture, much better than that observed with SEA2 addition alone (Figure 6-7). As indicated by the $\mathrm{OH}$ measurement results in Figure 612, nearly all of the $\mathrm{Hg}$ removal during PAC injection and SEA2 additions occurred in the ESP and primarily $\mathrm{Hg}^{0}$ exited the ESP and wet FGD. $\mathrm{Hg}$ removals of $50 \%$ or better were attainable with the addition of 50 ppm SEA2 and 0.3-0.5 lb/Macf PAC injection.
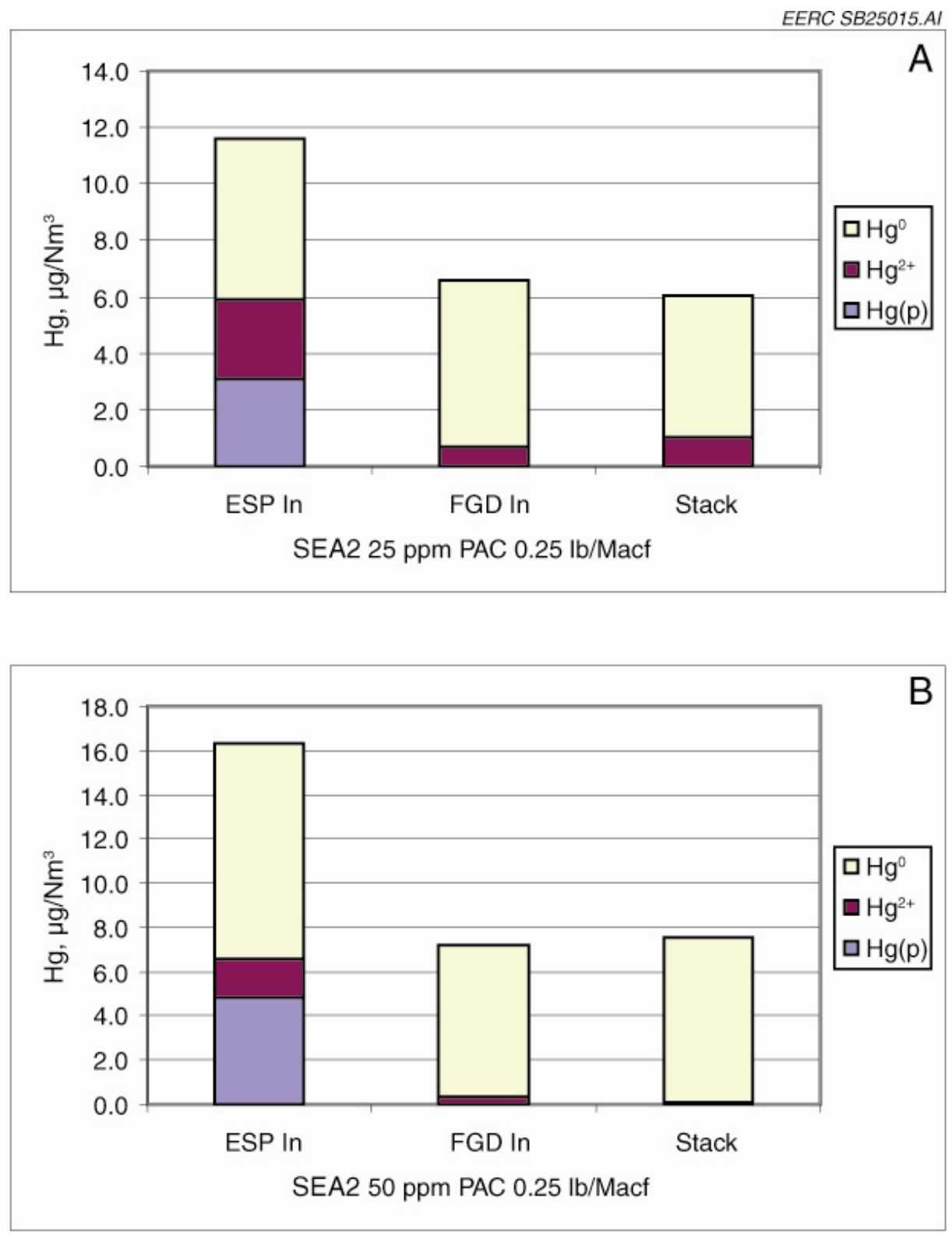

Figure 6-12. $\mathrm{OH} \mathrm{Hg} \mathrm{speciation} \mathrm{results} \mathrm{obtained} \mathrm{during} \mathrm{PAC} \mathrm{injection} \mathrm{and} \mathrm{SEA2} \mathrm{additions.}$ 


\subsection{Long-Term Testing at MRY Unit 2}

Compared in Table 6-9 are average $\mathrm{OH}$ and $\mathrm{CMM}$ results that were obtained simultaneously during the long-term testing conditions. Nine OH measurements of ESP inlet total $\mathrm{Hg}$ concentrations averaged $13.0 \mu \mathrm{g} / \mathrm{dNm}^{3}$, or $86 \%$ of the $15.2 \mu \mathrm{g} / \mathrm{dNm}^{3}$ expected based on the average coal $\mathrm{Hg}$ result in Table 6-1. Early CMM measurements of FGD inlet and stack total $\mathrm{Hg}$ concentrations did not compare very well with the $\mathrm{OH}$ results (RPDs $\approx 30$ ), but subsequent measurements compared favorably with RPDs of $<20$.

Table 6-9. Comparison of Average OH and CMM Results ( $\left.\mu \mathrm{g} / \mathrm{dNm}^{3}\right)$ Obtained Concurrently During Long-Term Testing Conditions (April 5-May 17, 2005).

\begin{tabular}{|c|c|c|c|c|c|c|c|c|c|}
\hline \multirow[b]{2}{*}{$\begin{array}{l}\text { Sampling } \\
\text { Location }\end{array}$} & \multirow[b]{2}{*}{ Dates } & \multicolumn{5}{|c|}{ Ontario Hydro $^{1}$} & \multicolumn{2}{|c|}{$\mathrm{CMM}^{2}$} & \multirow[b]{2}{*}{ RPD } \\
\hline & & $\mathrm{Hg}^{0}$ & $\mathrm{Hg}^{2+}$ & $\mathrm{Hg}(\mathrm{p})$ & Total Hg & Std. Dev. & Total Hg & $\begin{array}{l}\text { Std. } \\
\text { Dev. }\end{array}$ & \\
\hline ESP In & & 3.79 & 3.17 & 4.28 & 11.2 & 0.6 & $\mathrm{NA}^{4}$ & NA & NA \\
\hline FGD In & $4 / 12-14 / 05$ & 5.56 & 4.61 & $<0.1$ & 10.2 & 1.7 & 7.11 & 0.15 & 35.4 \\
\hline Stack & & 5.41 & 1.98 & $<0.1$ & 7.40 & 1.85 & 5.66 & 0.24 & 26.6 \\
\hline ESP In & & 3.89 & 2.41 & 8.10 & 14.4 & 0.9 & NA & NA & NA \\
\hline FGD In & $4 / 26-28 / 05$ & 5.04 & 1.01 & $<0.1$ & 6.06 & 0.39 & 5.29 & 0.46 & 13.5 \\
\hline Stack & & 5.44 & 0.83 & $<0.1$ & 6.27 & 1.22 & 5.66 & 0.12 & 10.2 \\
\hline ESP In & & 4.37 & 2.09 & 6.99 & 13.4 & 2.4 & NA & NA & NA \\
\hline FGD In & $5 / 10-11 / 05$ & 4.49 & 1.17 & $<0.1$ & 5.66 & 1.52 & 5.48 & 0.75 & 3.29 \\
\hline Stack & & 5.74 & 0.56 & $<0.1$ & 6.31 & 1.11 & 5.37 & 0.34 & 16.2 \\
\hline
\end{tabular}

The Hg removal efficiencies for the extended testing were calculated from stack CMM measurements including baseline measurements performed after the parametric testing and before the long-term testing. During April 5 through April 19, 2005, problems were encountered with stratification of the diluted SEA2 solution (a concentrated $50 \mathrm{wt} / \mathrm{wt} \%$ SEA2 aqueous solution was diluted to a nominal $15 \mathrm{wt} / \mathrm{wt} \%$ solution for injection). Dilution was required because of pump capacity and range limitations. Additional problems were encountered because of contaminants in the SEA2 solution, including small quantities of oil, sludge, and organic debris. Significant scale formation was also encountered during the extended testing period, resulting in the plugging of filters, pumps, and flowmeters. For the SEA2-only portion of the testing, this resulted in erratic SEA2 injection rates, as indicated in Figure 6-13 and, thus, fluctuations in $\mathrm{Hg}$ removal efficiencies. Air agitation of the dilute SEA2 solution for 3 to 4 hours produced a well-mixed solution, but sludge and scale formation were a recurring problem. 


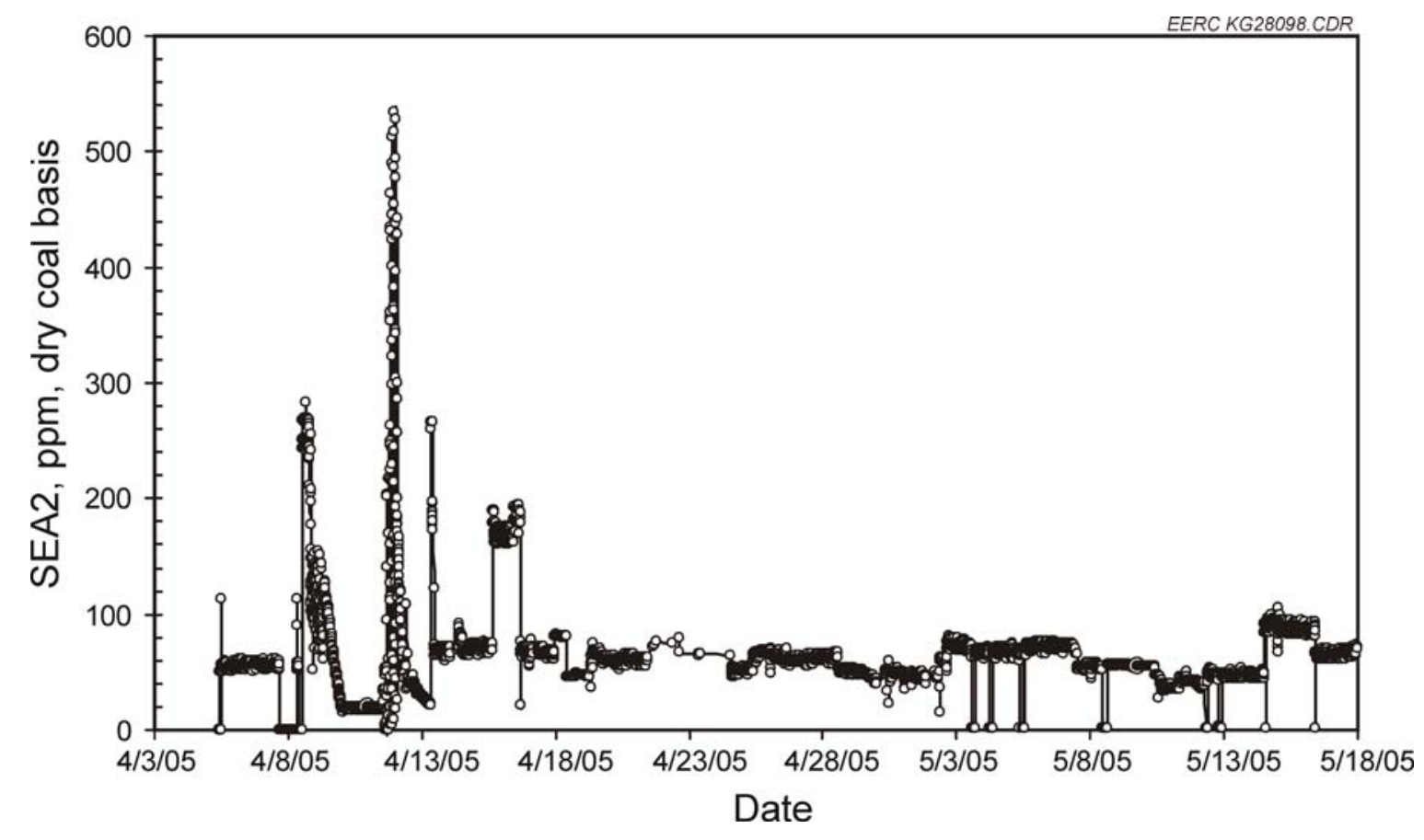

Figure 6-13. SEA2 addition rates during the long-term testing at MRY Unit 2.

The objective of the extended testing was to demonstrate that approximately $55 \% \mathrm{Hg}$ removal could be obtained over a period of a month or more. Initially, this was attempted using SEA2 addition alone at rates of 60-550 ppm (dry coal basis). The ESP-wet FGD Hg removal efficiencies for an extended period are shown in Figure 6-14. Initially, removals of $\leq 75 \%$ were attained but only at SEA2 injection rates of 300-550 ppm. Relatively high SEA2 addition rates combined with a small quantity $(0.15 \mathrm{lb} / \mathrm{Macf})$ of PAC injection were required to consistently meet the target of 55\% Hg removal. Presented in Figure 6-15 are the PAC injection rates used during the long-term testing period. The addition of SEA2 (50-100 ppm, dry coal basis) in combination with a nominal 0.15-lb/Macf PAC injection was initiated on April 19 and continued until May 18, 2005, when the supply of SEA2 was exhausted. PAC injection continued for several hours on May 19 to empty the PAC Supersack feeding the PortaPac injection system. During the SEA2 and PAC injections, the 55\% Hg removal goal was exceeded about $25 \%$ of the time, as indicated in Figure 6-16. About half of the time, the ESP-wet FGD Hg removal rate ranged from $50 \%$ to $55 \%$. 


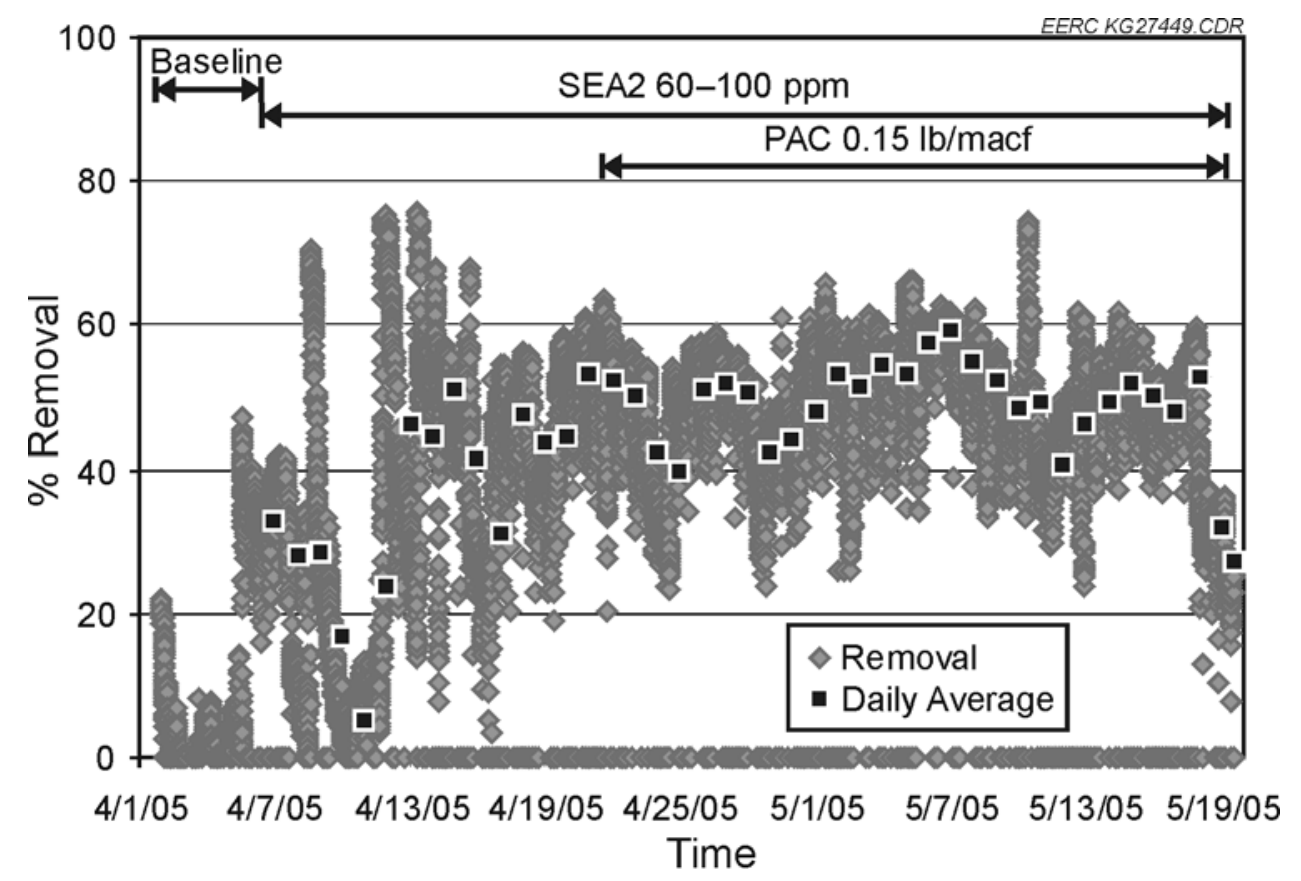

Figure 6-14. ESP-wet FGD Hg removal efficiencies during extended testing at MRY Unit 2 using SEA2 additions and SEA2 with PAC injections.

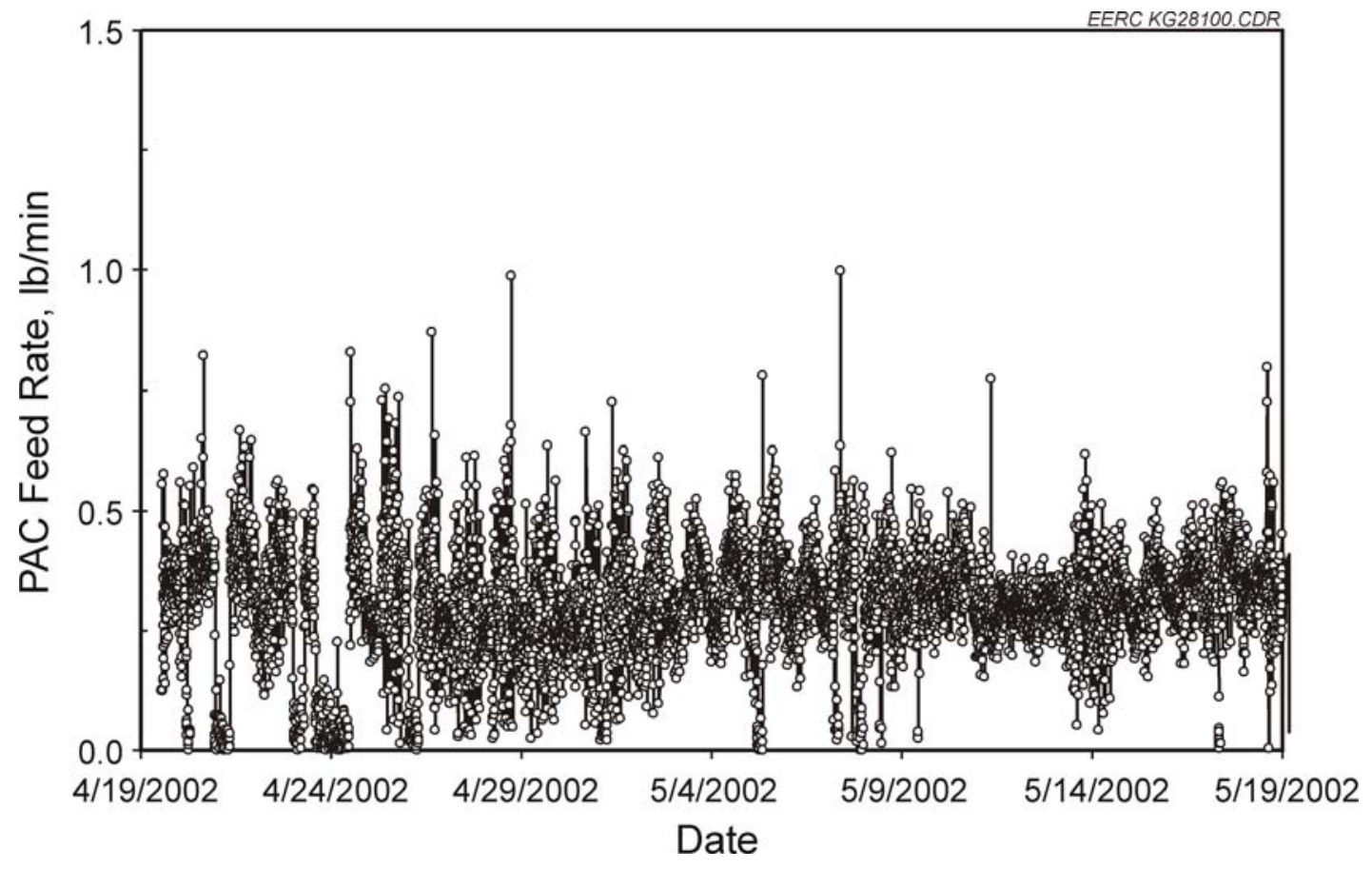

Figure 6-15. PAC injection rates during the long-term testing at MRY Unit 2. 


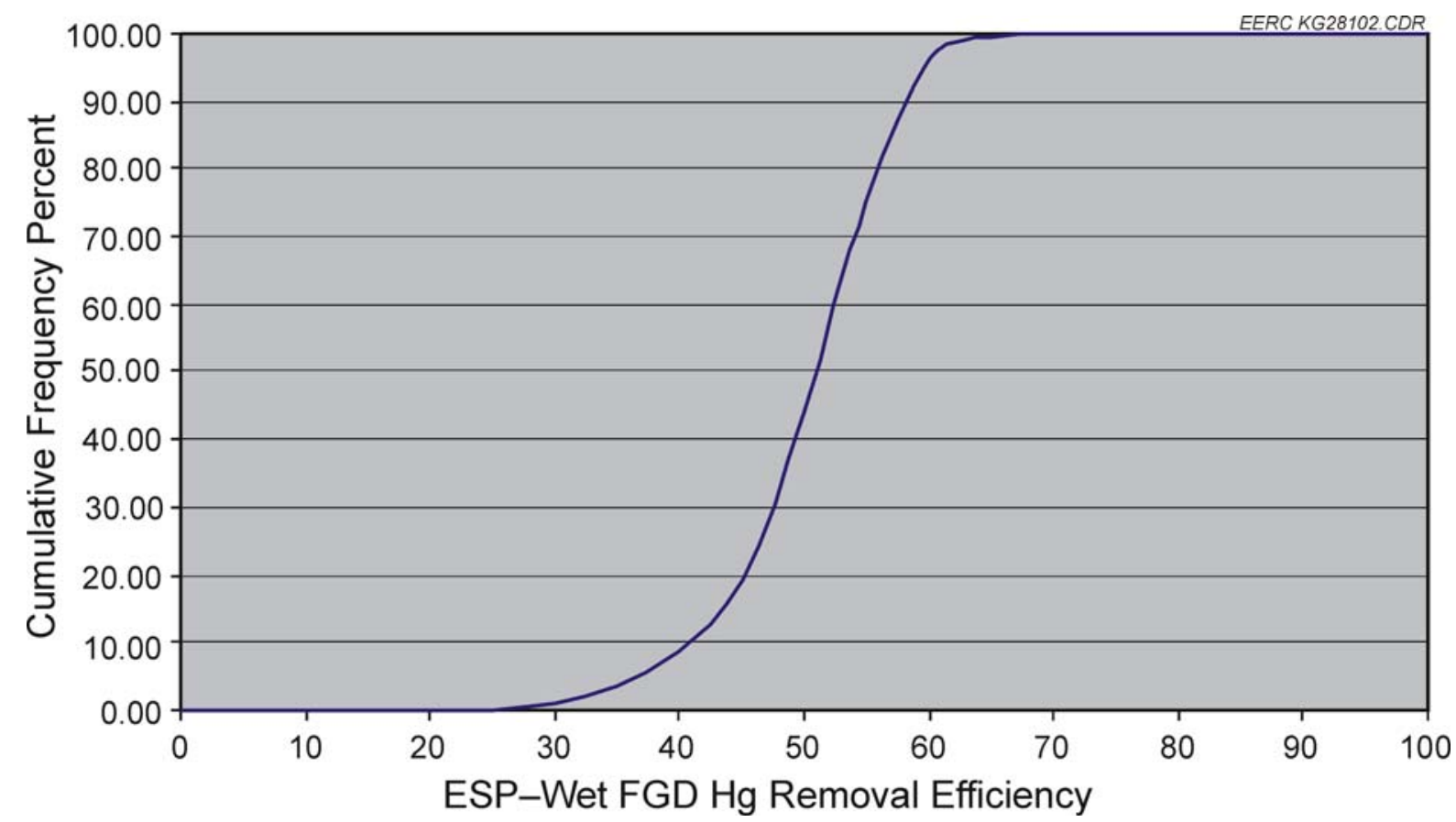

Figure 6-16. Cumulative frequency percent plot for the Hg removal efficiencies attained at MRY Unit 2 during (April 19 - May 18, 2005) SEA 2 (50-100 ppm, dry coal basis) and 0.15 lb/Macf PAC injections.

Triplicate EPA Method 26A measurements indicated that $\mathrm{HCl}$ concentrations at the ESP inlet varied widely from about 2 to 25 ppmv during the monthlong $\mathrm{Hg}$ control testing. Presented in Table 6-10 are $\mathrm{Hg}, \mathrm{Br}$, and $\mathrm{Cl}$ concentrations for fly ash samples collected from Row 1 of the ESP during SEA2 additions at 60-100 ppm and SEA2 addition combined with PAC injection $(0.15 \mathrm{lb} / \mathrm{Macf})$. The Hg results in Table 6-10 are consistent with the ESP-wet FGD Hg removal efficiencies plotted in Figure 6-13 in that $\mathrm{Hg}$ is more effectively captured in the SEA2- and PACbearing fly ash relatively to the fly ash containing SEA2 only. SEA2 addition significantly increased the $\mathrm{Br}$ content, but not $\mathrm{Cl}$, of fly ash as indicated by comparing Table 6-10 fly ash $\mathrm{Br}$ concentrations with those presented in Table 6-7 for the baseline fly ashes.

Table 6-10. Hg, Br, and Cl Analysis Results (ppm) for Fly Ashes Sampled from the ESP During SEA2 Additions and SEA2-PAC Injections

\begin{tabular}{lccc}
\hline Test Condition & SEA2 $60-100 \mathrm{ppm}$ & \multicolumn{2}{c}{ SEA2-PAC } \\
\cline { 2 - 4 } Date(s) sampled & $3 / 17 / 05$ & $4 / 26-28 / 05$ & $5 / 10-11 / 05$ \\
\hline $\mathrm{Hg}$ & 0.479 & 0.705 & 0.688 \\
$\mathrm{Br}$ & 176 & 451 & 464 \\
$\mathrm{Cl}$ & 10 & 17 & 20 \\
\hline
\end{tabular}




\subsection{BALANCE-OF-PLANT EFFECTS OF HG CONTROL TECHNOLOGIES}

\subsection{Corrosion Probe Characterization}

Baseline coupons were exposed to flue gas for 8 weeks during routine power plant operating conditions. Hg control coupons were exposed to flue gas for 6 weeks during the chemical and PAC injection testing conditions. On installation, uncooled coupon skin temperatures were approximately $800^{\circ}$ and $775^{\circ} \mathrm{F}$ at the ECM and AHI, respectively. Cooling airflows for the ECM, AHI, and AHO coupons were established to maintain coupon skin temperatures at approximately $460^{\circ}, 485^{\circ}$, and $270^{\circ} \mathrm{F}$, respectively. Temperatures were logged with a computer at 5-minute intervals during the coupon testing. Temperatures fluctuated based on flue gas temperature because the cooling airflow was not constantly being adjusted.

The baseline coupons were in the boiler from 11/18/04 16:34 to 1/17/05 13:12. A summary of the temperature data for the baseline coupon testing is given in Table 7-1. Some temperature information was not obtained because of problems with the data logger. During the period from $11 / 22 / 0410: 43$ to $11 / 24 / 0412: 08$, the compressed air supply to the AHO probe was apparently reduced or interrupted, because the coupon skin temperature was abnormally high and the exit cooling air temperature was much lower. During three brief periods between 11/30/04 and $12 / 13 / 04$, both the coupon skin temperature and exiting cooling air temperature went much lower than normal, and the coupon skin temperature approximated its cooling air temperature, indicating reduced/interrupted flue gas flow or excess cooling air to the ECM and AH probes.

The Hg control coupons were tested from $4 / 5 / 05$ to $5 / 17 / 05$. However, most of the temperature data was lost as a result of computer hard disk failure. Coupon temperature data were retained only for the period of 4/11/05 7:03 to 4/15/05 5:19 as summarized in Table 7-2. Coupon temperatures during this short period were relatively stable.

Table 7-1. Baseline Coupon Temperatures, ${ }^{\circ} \mathbf{F}$

\begin{tabular}{lccccrc}
\hline & ECM & ECM & AHI & AHI Cooling & AHO & AHO \\
& Coupon & Cooling Air & Coupon & Air & Coupon & Cooling Air \\
\hline Av & 472.2 & 235.3 & 453.3 & 250.0 & 260.9 & 158.0 \\
Min. & 66.4 & 58.7 & 66.6 & 59.1 & 55.1 & 16.3 \\
Max. & 878.3 & 353.3 & 517.5 & 307.7 & 368.7 & 209.8 \\
Std. Dev. & 97.6 & 38.2 & 73.4 & 35.5 & 65.9 & 44.3 \\
\hline
\end{tabular}

Table 7-2. Hg Control Coupon Temperatures, ${ }^{\circ} \mathrm{F}$

\begin{tabular}{lcrrrrr}
\hline & ECM & $\begin{array}{c}\text { ECM } \\
\text { Cooling Air }\end{array}$ & $\begin{array}{c}\text { AHI } \\
\text { Coupon }\end{array}$ & $\begin{array}{c}\text { AHI } \\
\text { Cooling Air }\end{array}$ & $\begin{array}{c}\text { AHO } \\
\text { Coupon }\end{array}$ & AHO Cooling Air \\
\hline Avg. & 435.7 & 266.1 & 456.0 & 264.4 & 245.3 & 127.2 \\
Min. & 414.3 & 252.7 & 430.7 & 250.0 & 220.1 & 97.4 \\
Max. & 457.0 & 281.2 & 478.7 & 276.8 & 274.6 & 138.9 \\
Std. Dev. & 8.1 & 4.9 & 8.2 & 4.7 & 11.5 & 5.0 \\
\hline
\end{tabular}




\subsubsection{Economizer Coupons}

Compared in Figure 7-1 are backscattered electron images (BSEI) of the steel-ash deposit interface for the curved and flat sections of the ECM baseline and Hg control coupons. The brightness and contrast in a BSEI is a function of average atomic number. Consequently, the brightest feature on the right side of each picture is the steel coupon, the gray area is a deposit layer, and the darkest gray area on the left side is epoxy in which the coupon section was mounted. For both the baseline and Hg control ECM coupons, a portion of the deposit occurs as closely packed spheres. The baseline coupon has a smooth surface, whereas the $\mathrm{Hg}$ control coupon has a rougher surface, indicating more extensive corrosion. On the flat coupon sections, the baseline sample has a thicker deposit layer relative to the $\mathrm{Hg}$ control coupon.

Figures 7-2 and 7-3 show results of electron microprobe line scan analyses for $\mathrm{Fe}, \mathrm{Cr}, \mathrm{Ni}$, $\mathrm{S}, \mathrm{Na}, \mathrm{K}, \mathrm{Ca}, \mathrm{Si}$, and $\mathrm{Al}$ on the $\mathrm{ECM}$ coupons. $\mathrm{Al}, \mathrm{Si}$, and $\mathrm{Ca}$ are the major elements composing the deposits on the coupons. The deposits on baseline coupons have greater $\mathrm{Al}$ and $\mathrm{Si}$ contents relative to those on the $\mathrm{Hg}$ control coupons, whereas the $\mathrm{Hg}$ control coupon deposits have much higher $\mathrm{Ca}$ contents, especially on the curved coupon section. Both the baseline and $\mathrm{Hg}$ control coupons have relatively high sulfur concentrations in the ash deposit layers. The deposit on the flat section of the $\mathrm{Hg}$ control coupon has a much higher sulfur content relative to the corresponding baseline coupon deposit. Sulfur contents for the deposits on the baseline and $\mathrm{Hg}$ control curved coupons are similar. Variations in $\mathrm{Ca}$ and $\mathrm{S}$ concentrations in Figures 7-2 and 7-3 suggest that calcium sulfate deposition increased as a result of SEA2 and PAC injections.
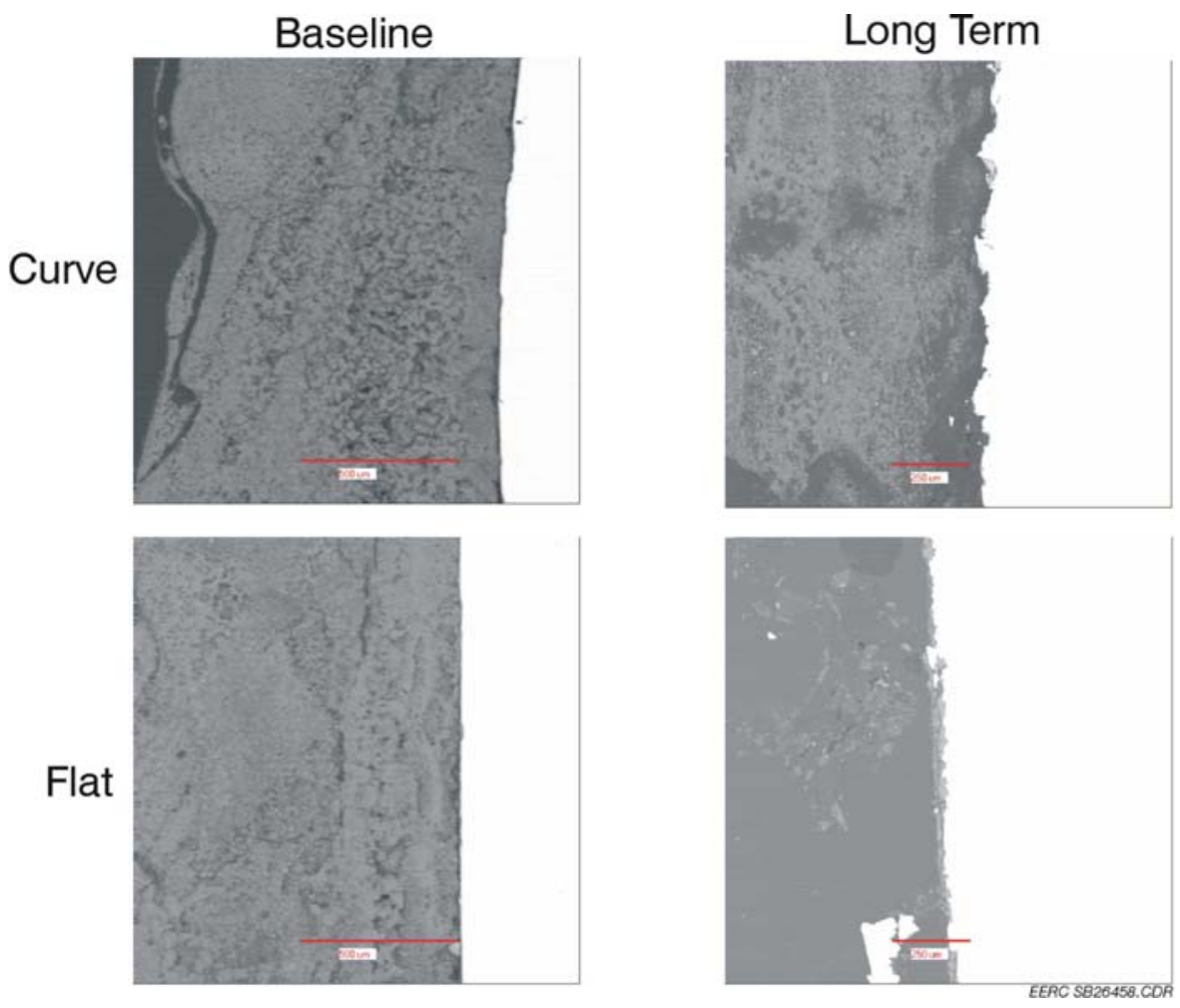

Figure 7-1. Backscattered electron image of MRY ECM coupons. 

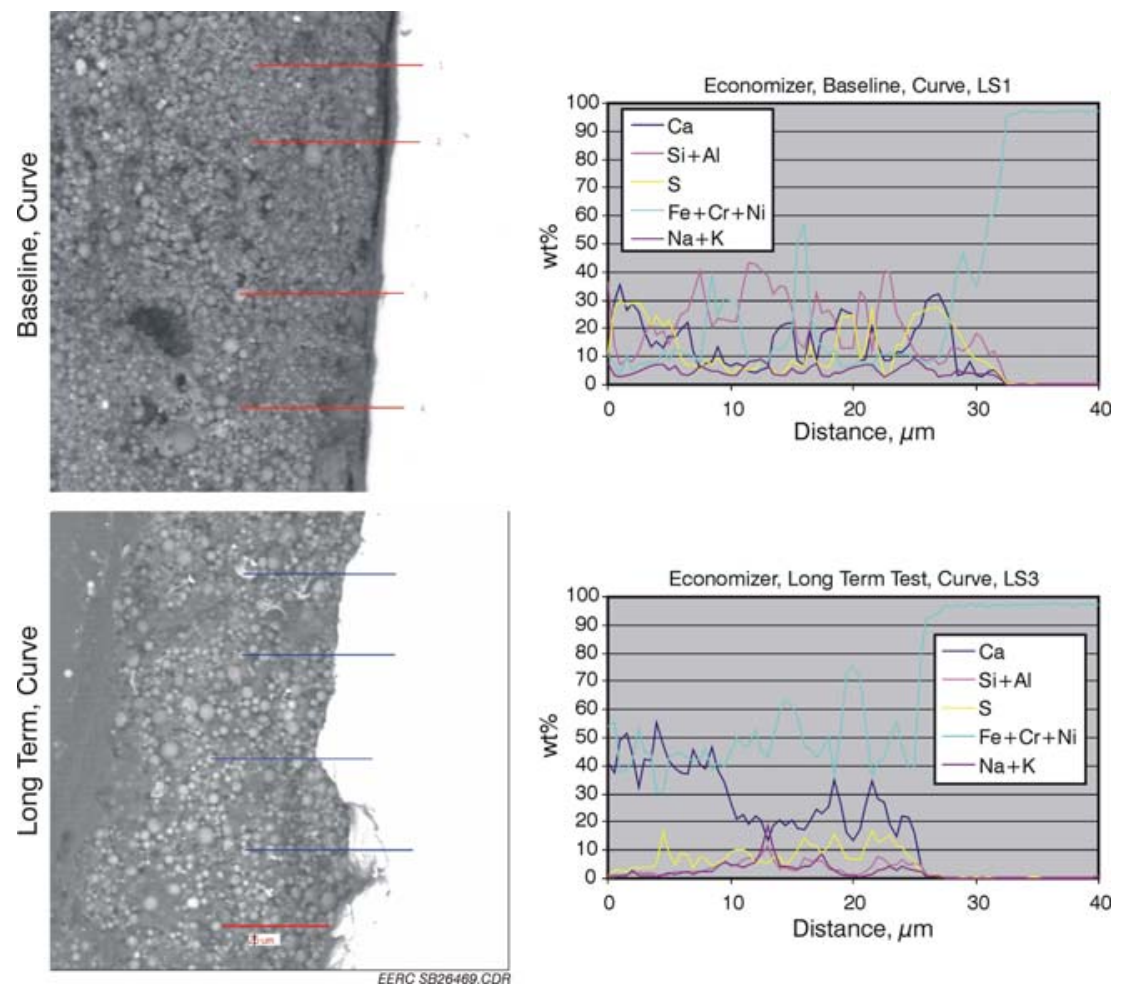

Figure 7-2. Comparison of ECM baseline and long-term coupons.
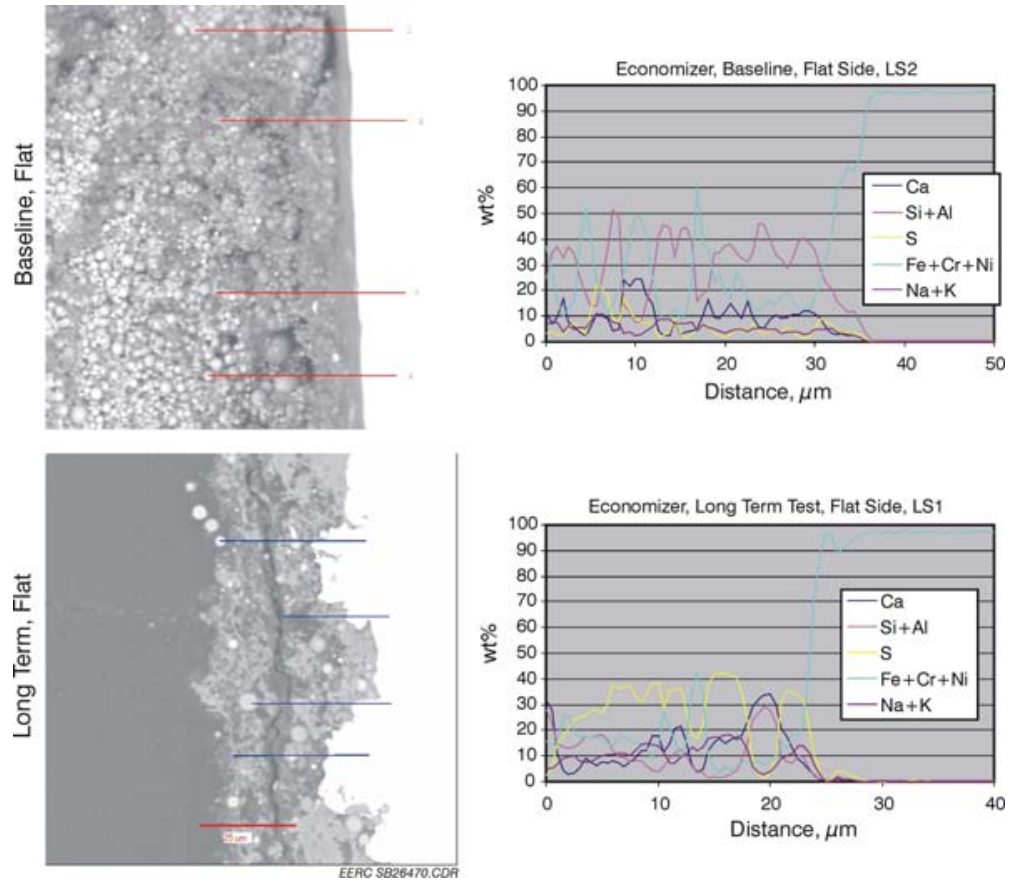

Figure 7-3. Comparison of ECM baseline and long-term coupons. 


\subsubsection{Air Heater Inlet Coupons}

The AHI baseline and $\mathrm{Hg}$ control coupon cross sections are compared in Figure 7-4. The BSEIs of the AHI coupons are similar to those of the ECM coupons shown in Figure 7-1, the baseline coupons have a smooth surface, and the $\mathrm{Hg}$ control coupons have a rougher steel surface, indicating more intensive corrosion during the SEA2 and PAC injections. The deposit layers, however, are much thinner relative to those on the ECM coupons. Deposits on the $\mathrm{Hg}$ control coupons are closely packed on the steel surface, while there is a "crack" between the deposit layer and steel surface on baseline coupons.

SEM line scan analysis results for the AHI coupons are compared in Figures 7-5 and 7-6. In general, these results are similar to those for the ECM coupons. A notable difference is that the deposits on the $\mathrm{Hg}$ control coupons have much higher $\mathrm{Na}, \mathrm{K}$, and $\mathrm{S}$ concentrations. On the flat section of the $\mathrm{Hg}$ control coupon, the deposit layer is composed mostly of $\mathrm{Na}, \mathrm{K}$, and $\mathrm{Ca}$ sulfates.

\subsubsection{Air Heater Outlet Coupons}

Figure 7-7 shows the appearance of typical areas of the steel-oxide interface for the AHO baseline and long-term coupons. The deposit layer on the baseline coupon is much thicker than that of the long-term coupon. In contrast to the ECM and AHI coupons, steel surfaces on the
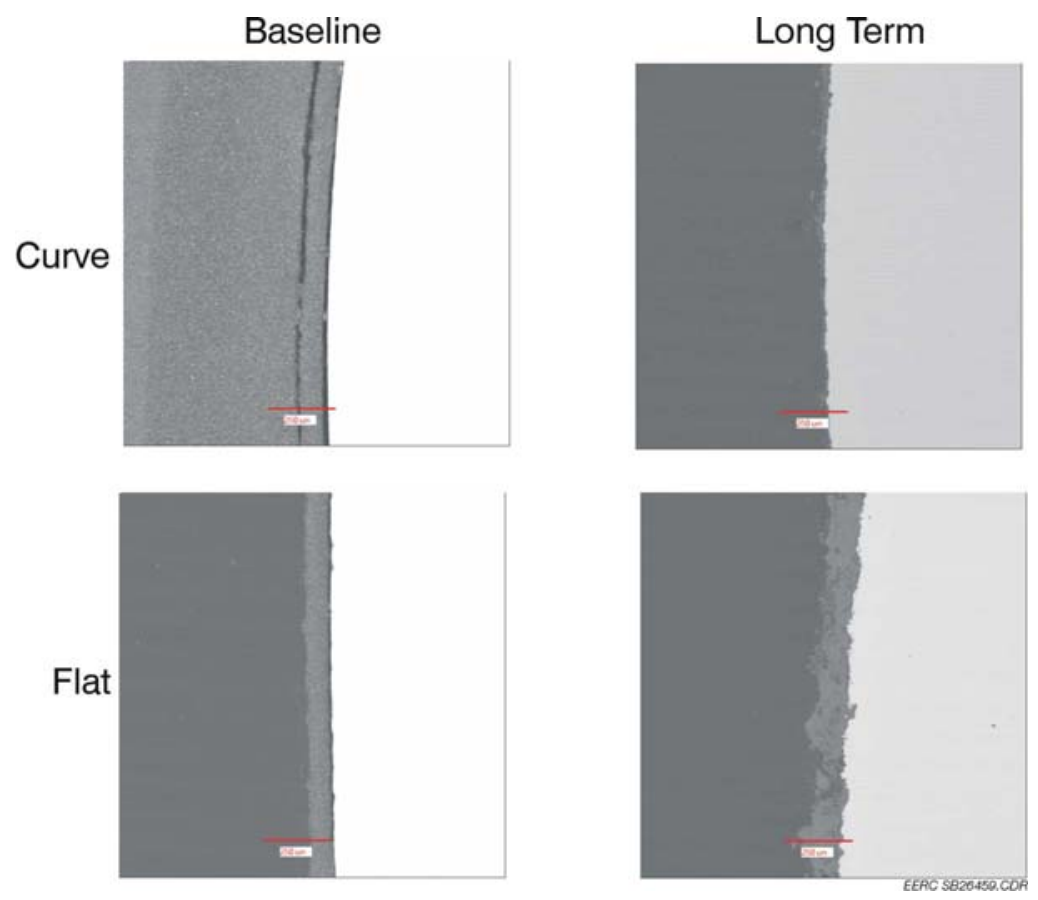

Figure 7-4. MRY AHI coupons. 

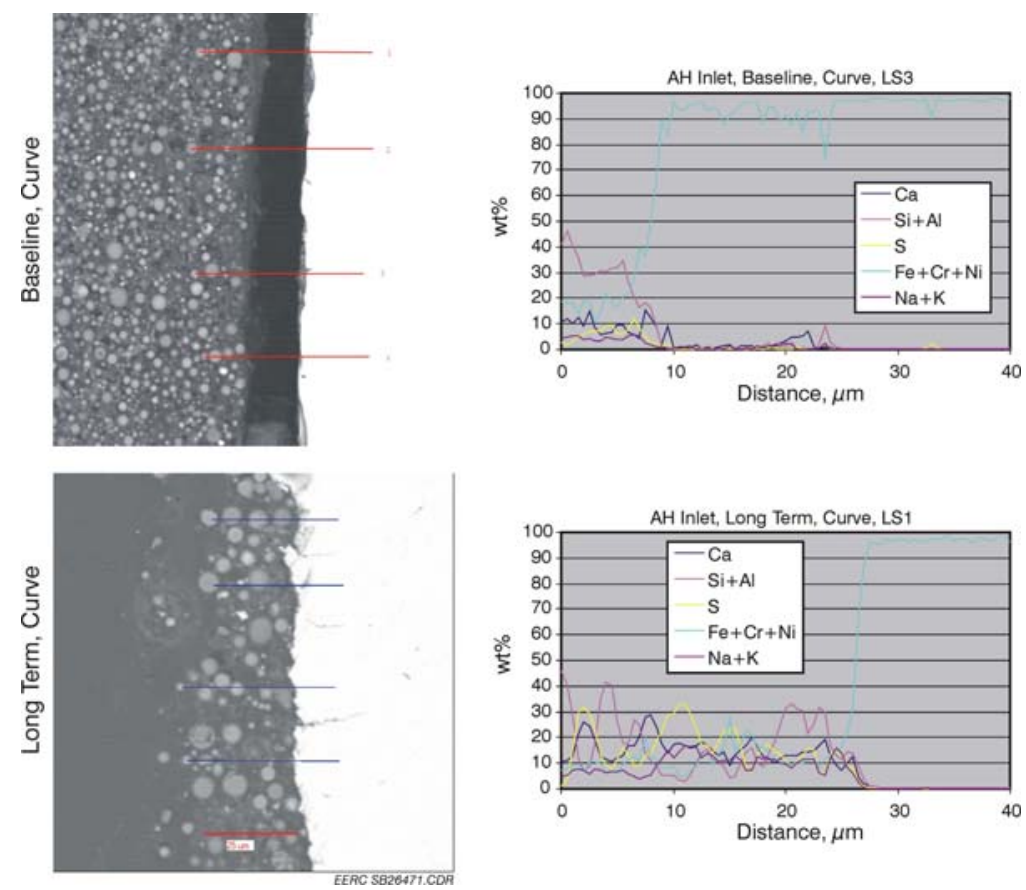

Figure 7-5. Comparison of AHI baseline and $\mathrm{Hg}$ control coupons (curved side).
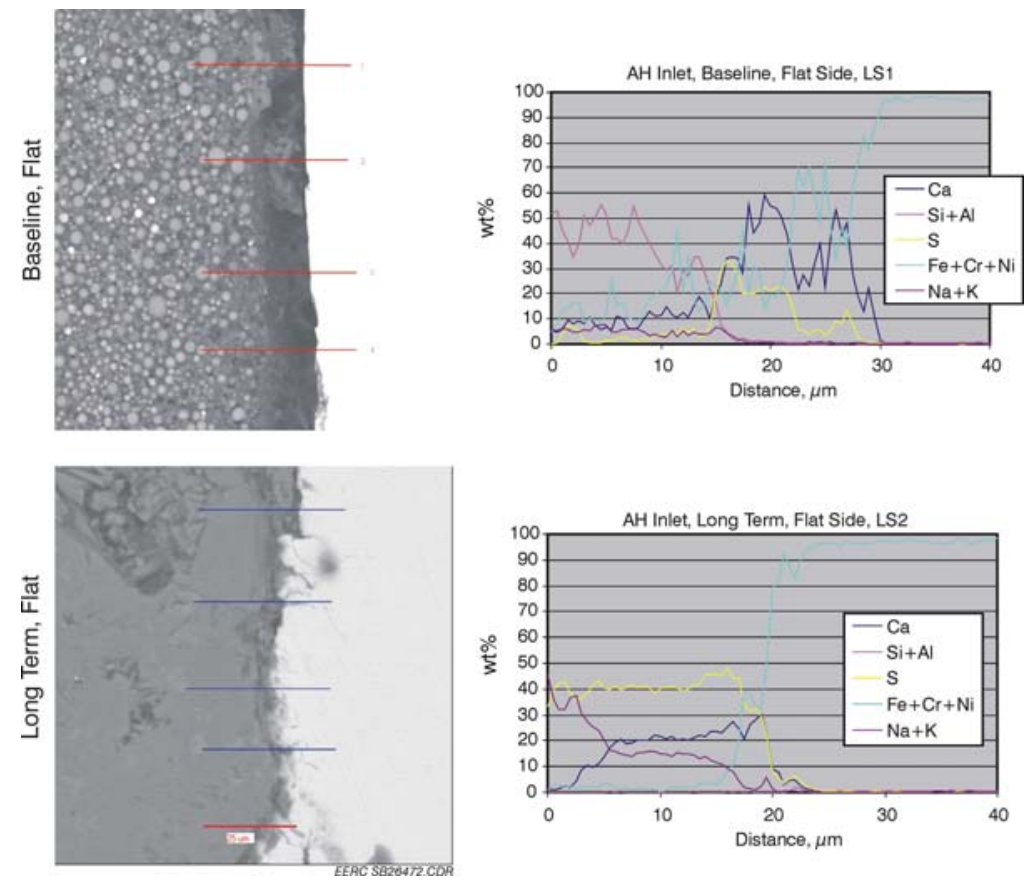

Figure 7-6. Comparison of AHI baseline and $\mathrm{Hg}$ control coupons (flat side). 

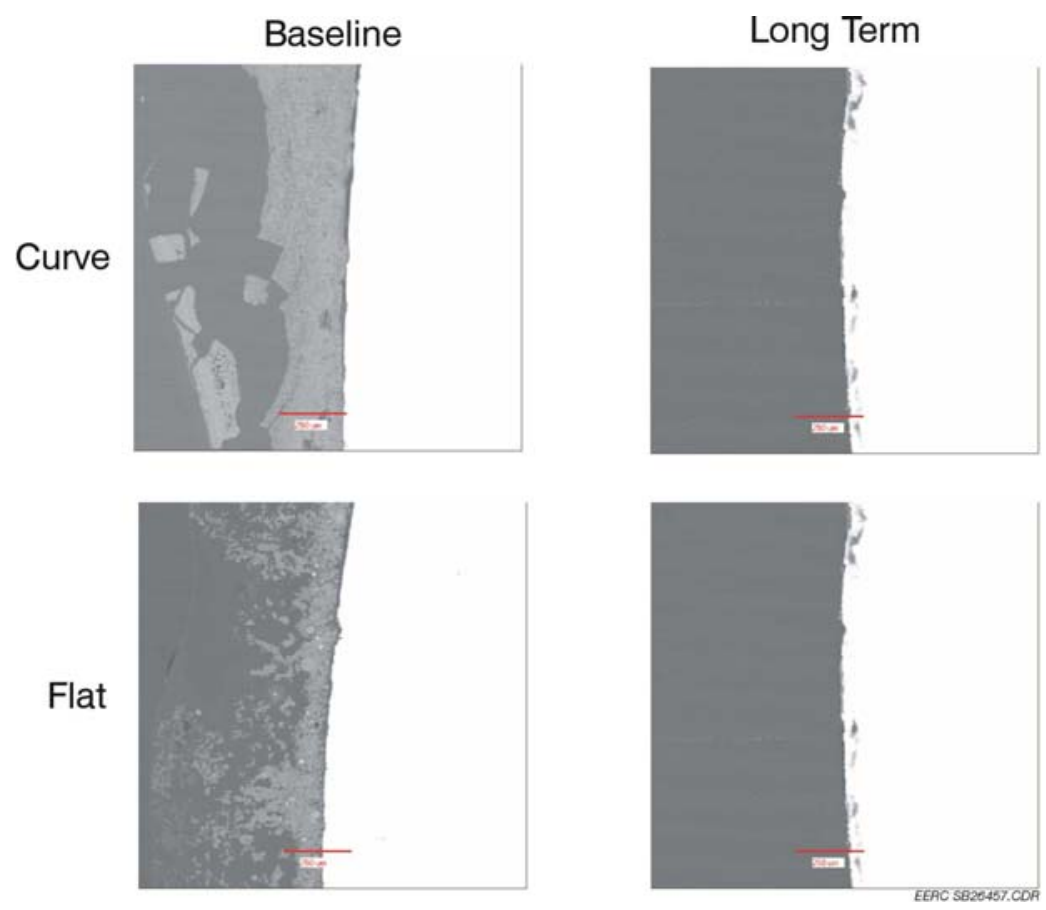

Figure 7-7. MRY AHO coupons.

AHO baseline and long-term coupons are similar. The long-term coupon steel surface is not as rough as that of the ECM and AHI long-term coupons. There is no indication of more intensive corrosion of the long-term coupon than the baseline coupon.

Electron microprobe line scan analyses for the AHO coupons are compared in Figures 7-8 and 7-9. The deposit layer on the curved section is different from that on the flat section of the same coupon. On the baseline coupon, although both the curve and flat sections have a deposit layer of aluminosilicate fly ash particles cemented by $\mathrm{Na}, \mathrm{K}$, and $\mathrm{Ca}$ sulfates, the fly ash particles on the curve are $\leq 2 \mu \mathrm{m}$ in diameter, whereas particles on the flat sections are much coarser, $\geq 30 \mu \mathrm{m}$ in diameter. On the long-term coupon, the deposit layer of the flat section is composed of fine aluminosilicate particles cemented with sodium, potassium, and calcium silicate, while the deposit on the curve is a thin layer of Sodium, potassium, and Ca sulfates.

Chemically, these results are similar to those for the ECM and AHI coupons. The deposits produced during $\mathrm{Hg}$ control testing conditions have higher $\mathrm{Na}, \mathrm{K}$, and $\mathrm{S}$ concentrations and lower $\mathrm{Al}$ and $\mathrm{Si}$ concentrations relative to the baseline deposits. On the curved coupon section, the $\mathrm{Hg}$ control coupon has higher $\mathrm{Ca}$ concentrations in the deposit layer than the baseline coupon. Apparently, SEA2 and PAC injections enhance Ca sulfate deposition on the coupon.

\subsection{Mercury Stability Analysis}

A couple of fly ash samples were collected from ESP hoppers for evaluating Hg mobility during leaching and heating experiments. Sample 05-005 was collected on March 17, 2005, 

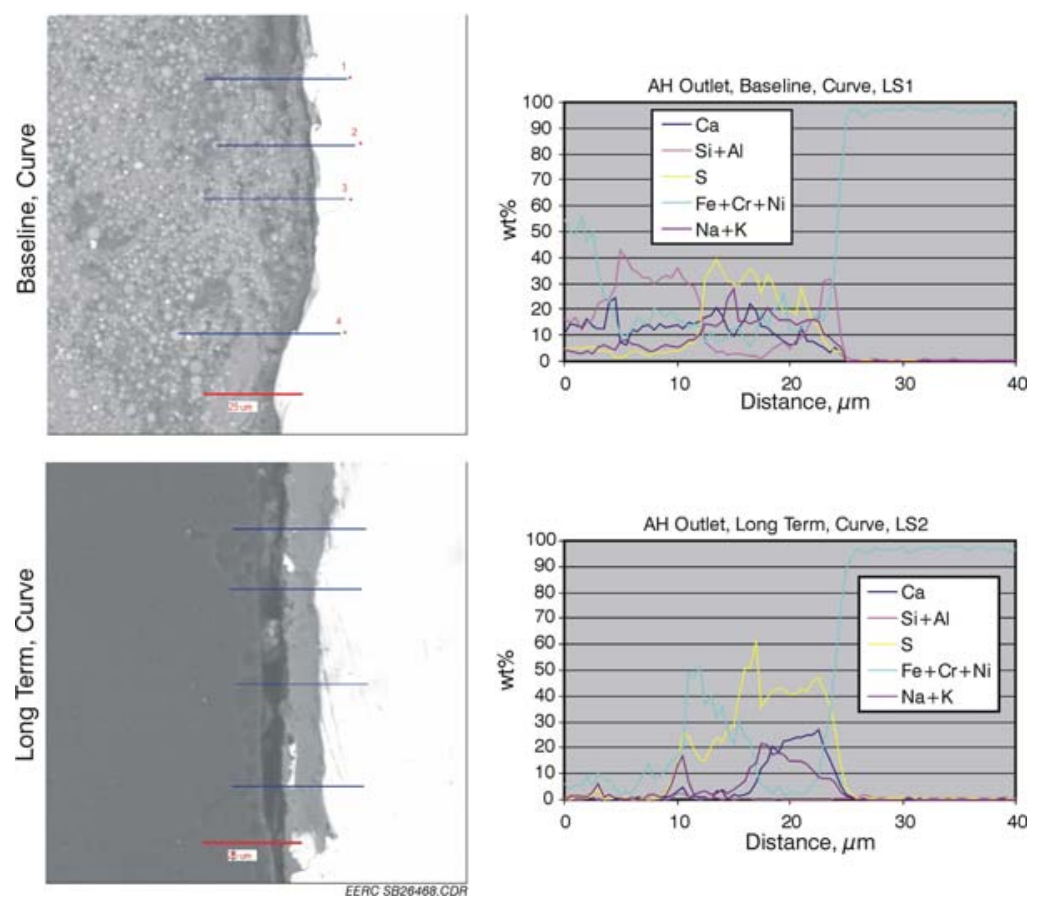

Figure 7-8. Comparison of AHO baseline and long-term coupons.
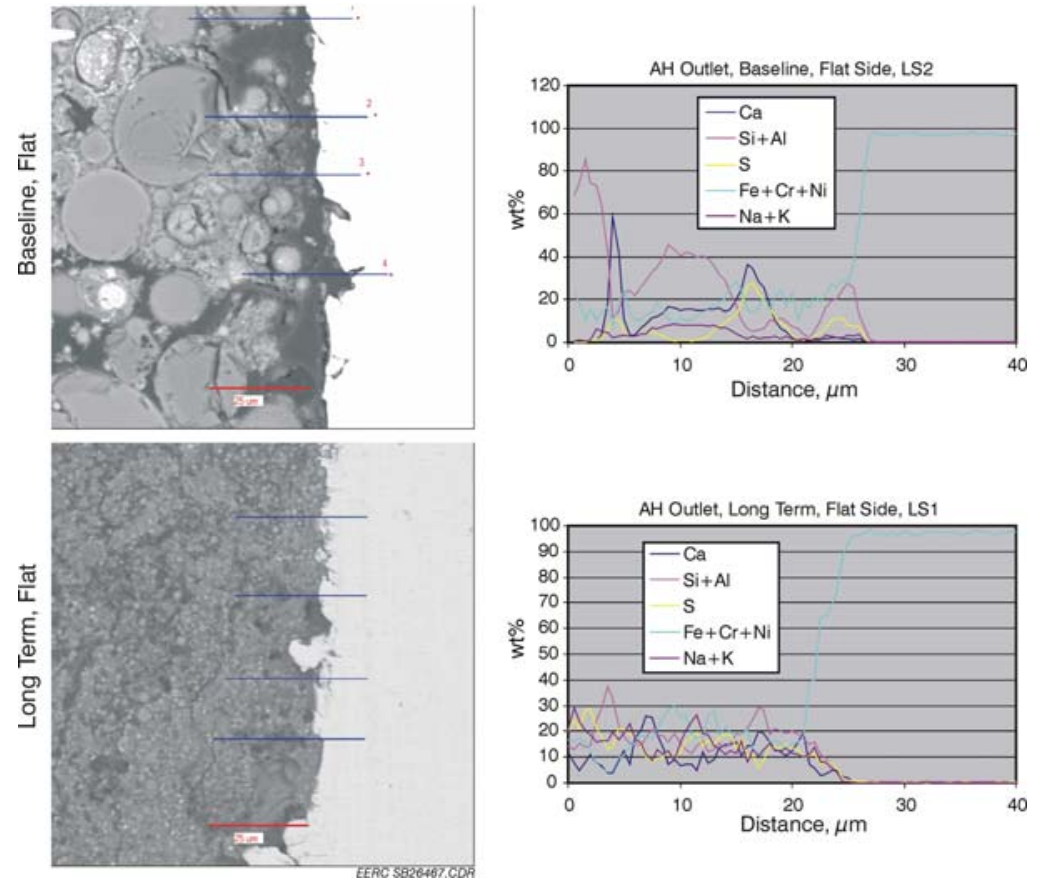

Figure 7-9. Comparison of AHO baseline and long-term coupons. 
during baseline testing conditions, whereas Sample 05-017 was collected on April 13, 2005, during $\mathrm{Hg}$ control technology testing involving SEA2 injections.

Before the leaching and thermal stability analyses were performed, the total $\mathrm{Hg}$ contents and $\mathrm{pH}$ of the fly ash samples were determined as reported in Table 7-1. As expected, the total $\mathrm{Hg}$ content of the fly ash collected during $\mathrm{Hg}$ control testing is greater than the baseline sample. The $\mathrm{pH}$ of the fly ash samples was determined using distilled water after 24 hours of stirring. The $\mathrm{pH}$ of both samples was $>10$, indicating that LTL is appropriate for evaluating the leaching profile of these samples. Coal fly ashes exhibiting a high $\mathrm{pH}$ have the potential to undergo hydration reactions that can change the leaching profile with time.

\subsubsection{Leaching Analysis}

Fly ash leaching results, consisting of final leachate $\mathrm{pH}$ and $\mathrm{Hg}$ concentrations, from using SGLP and 30- and 60-day LTL tests are compared in Tables 7-3 and 7-4. Duplicate 60-day LTL analyses were performed yielding reproducible leachate $\mathrm{Hg}$ concentrations that were less than the quantification limit of the analysis method indicating that the $\mathrm{Hg}$ in these two fly ashes was relatively insoluble.

Table 7-3. SGLP Results

\begin{tabular}{lcccc}
\hline ID No. & Testing Condition & Total $\mathrm{Hg}, \mu \mathrm{g} / \mathrm{g}$ & Initial $\mathrm{pH}$ & 24-hr $\mathrm{pH}$ \\
\hline $05-005$ & Baseline & 0.431 & 11.77 & 11.57 \\
$05-017$ & PAC and SEA2 injections & 0.717 & 12.04 & 11.77 \\
\hline
\end{tabular}

Table 7-4. Longer-Term Fly Ash Hg Leaching Results

\begin{tabular}{ccccc}
\hline & & & \multicolumn{2}{c}{ Leachate } \\
ID No. & Testing Condition & Leaching Procedure & $\mathrm{Hg}, \mu \mathrm{g} / \mathrm{L}$ & $\mathrm{pH}$ \\
\hline $05-005$ & Baseline & SGLP & $<0.01$ & 11.73 \\
$05-005$ & Baseline & 30-day LTL & $<0.01$ & 11.61 \\
$05-005$ & Baseline & 60-day LTL & $<0.01$ & 11.84 \\
$05-005$ & Baseline & 60-day LTL & $<0.01$ & 11.83 \\
$05-017$ & PAC and SEA2 injections & SGLP & $<0.01$ & 11.94 \\
$05-017$ & PAC and SEA2 injections & 30-day LTL & $<0.01$ & 11.69 \\
$05-017$ & PAC and SEA2 injections & 60-day LTL & $<0.01$ & 12.01 \\
$05-017$ & PAC and SEA2 injections & 60-day LTL & $<0.01$ & 11.99 \\
\hline
\end{tabular}

\subsubsection{Thermal Stability}

The generation of $\mathrm{Hg}$ thermal desorption curves for two fly ash samples was technically challenging. Samples of fly ash collected during baseline testing conditions were evaluated asreceived and after sieving (100 mesh) to concentrate unburned carbon in a coarser fly ash fraction. Samples of fly ash collected during the PAC and SEA2 injections were also tested asreceived. Examples of $\mathrm{Hg}$ thermal desorption curves for the fly ashes sampled during baseline and long-term $\mathrm{Hg}$ control testing conditions are presented in Figures 7-10 and 7-11, respectively. 
Both samples generally desorbed $\mathrm{Hg}$ at a peak temperature. However, the fly ash sampled during $\mathrm{PAC}$ and SEA2 injections occasionally produced an additional minor peak at $>550^{\circ} \mathrm{C}$. The average $\mathrm{Hg}$ release peak temperatures for the samples are presented in Table 7-5. $\mathrm{Hg}$ release profiles similar to those presented in Figures 7-10 and 7-11 have been reported for other coal fly ashes (29). The Hg evolved from the sieved baseline fly ash at a lower temperature relative to the corresponding as-received sample apparently because the $\mathrm{Hg}$ associated with the larger ash particles is more volatile. The $\mathrm{Hg}$ captured on fly ash during PAC and SEA2 injections was thermally more stable relative to the baseline fly ash.

$\mathrm{Hg}$ mass balance recoveries for both samples were low because a $\mathrm{Hg}$ compound had deposited on a cool area of the furnace tube $\left(\sim 200^{\circ} \mathrm{C}\right)$. $\mathrm{Hg}$ analyses of thermally desorbed samples indicated that $\mathrm{Hg}$ was below detection in the baseline fly ashes; however, a minute amount was detected in the fly ashes sampled during long-term $\mathrm{Hg}$ control testing conditions.

Table 7-5. Average Hg Thermal Desorption Results

\begin{tabular}{lccccc}
\hline Sample & Testing Condition & $\begin{array}{c}\text { Average } \\
\text { Peak, }{ }^{\circ} \mathrm{C}\end{array}$ & Std. Dev. & RSD, \% & $\mathrm{N}^{1}$ \\
\hline 05-005, both & Baseline & 353 & 30.4 & $8.6 \%$ & 7 \\
05-005, as-received & Baseline & 375 & 9.6 & $2.6 \%$ & 3 \\
05-005, sieved & Baseline & 336 & 29.8 & $8.9 \%$ & 4 \\
05-017, as-received & PAC and SEA2 & & & & \\
& Injections & 402 & 8.8 & $2.2 \%$ & 7 \\
\hline
\end{tabular}

${ }^{1}$ Number of analyses.

Run \# 1219

EERC LH27068

start

$365^{\circ} \mathrm{C}$

end of signal

Figure 7-10. Sample 05-005 example AA mercury thermal desorption curve. 


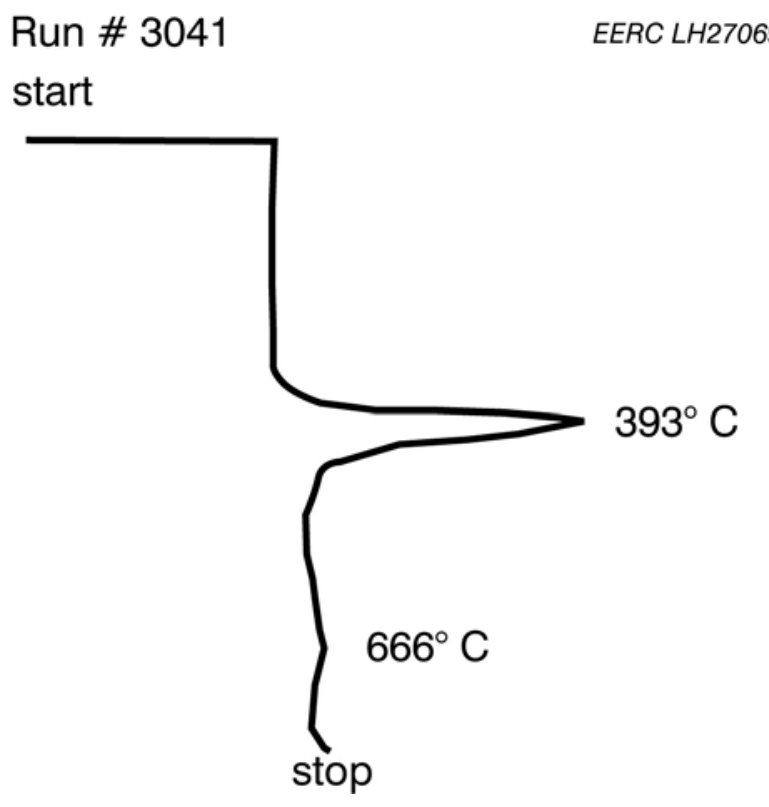

Figure 7-11. Sample 05-017 example AA mercury thermal desorption curve.

\subsection{Fly Ash Particle-Size Distributions}

This section was left blank intentionally pending results.

\subsection{ECONOMIC ANALYSIS OF MERCURY CONTROL}

\subsection{Capital Cost Estimates}

Economic evaluations of mercury control for MRY Unit 2 were performed assuming various $\mathrm{CaCl}_{2}, \mathrm{SEA} 2, \mathrm{CaCl}_{2}$ with $\mathrm{PAC}$, and SEA2 with PAC injection rates. The primary capital investments were an additive injection skid and PAC feeder. Cost estimates for these systems included the following:

- Base equipment cost

- Instrumentation and controls

- Injection lances and distribution modeling

- Shipping

- Installation costs

- Earthwork, foundation, and structural support

- Labor (general, technical, and supervisory)

- Checkout testing

- Contingency

- Taxes 


\subsubsection{PAC Feeder System}

A Portapack injection system was supplied and installed by Apogee Scientific. At the injection rates used, PAC consumption was approximately a 900-lb supersack every 2 days, which was well within the maximum capacity of the PAC system. The total estimated capital cost of the delivered PAC injection system was $\$ 974,000$. The following items were included with the PAC injection system:

- PAC storage silo and all associated equipment.

- Volumetric feeder, hopper, and associated equipment for delivery lines.

- Eductors and blowers.

- All structural steel and piping.

- Control panel and associated software and hardware.

- Injection distribution system (injection lances) and flow/distribution modeling.

- Field support services.

In addition to capital equipment provided by a vendor, site preparation and infrastructure would be required by plant personnel. The MRY plant was assumed to provide the following:

- Concrete foundations for the silo, feeders, and blowers.

- Unloading and assembly of vendor supplied equipment with support from the PAC vendor on-site technician.

- Piping to provide dry compressed air (100 psi) to the feeder and silo.

- Drainage and containment as required by the site to collect and dispose of wash-down and any other wastes generated by the PAC system.

- Electrical service including single-phase $120-\mathrm{V}$ and three-phase $480-\mathrm{V}$ power.

- Communication wiring to the plant process and data control system.

- General lighting.

- Applicable permits.

\subsubsection{Aqueous Injection Skid}

The Babcock and Wilcox (B\&W) company provided a system to inject $\mathrm{CaCl}_{2}, \mathrm{MgCl}_{2}$, and SEA2 in an aqueous form. The system consists of four skid-mounted transfer pumps, flowmeters, and controllers to enable the injection rate of the aqueous solution to be adjusted and, if necessary, follow the load through communications with the plant data collection system. The control panel received a signal from the plant, allowing the injection rate to be set and controlled proportionally to the overall coal feed rate. Each pump had a maximum capacity of 
$2.2 \mathrm{gpm}$. This skid-mounted system and three 3100 -gallon tanks were sited near the coal pipes in the basement of MRY Unit 2. The total capital cost of the SEA2 injection system was $\$ 500,000$.

Plant-required costs to install an injection skid include site preparation, foundation installation, and piping and electrical connection. The total installation cost is calculated based on using $\$ 32 / \mathrm{hr}$ for skilled labor such as operators, technicians, and electricians; $\$ 23 / \mathrm{hr}$ for general labor; and an overhead rate plus benefit rate of $42 \%$ on labor cost. Table $8-1$ presents the installation costs for the aqueous injection system.

Table 8-1. Installation Costs for aqueous injection skid

\begin{tabular}{lcc}
\hline Item & Hours & Cost, $\$$ \\
\hline Skilled Labor & 300 & 9600 \\
General Labor & 80 & 1840 \\
Concrete Pad & & 5500 \\
Supplies & & 6500 \\
Overhead & & 5260 \\
\hline Total & & 28,700 \\
\hline
\end{tabular}

\subsection{Operating and Maintenance Costs (O\&M)}

The O\&M costs are divided into variable and fixed costs. The primary variable costs are associated with purchases of $\mathrm{CaCl}_{2}, \mathrm{SEA} 2$, and PAC. The delivered cost of PAC was $\$ 0.58 / \mathrm{lb}$. The delivered cost of $\mathrm{CaCl}_{2}$ was $\$ 0.3 / \mathrm{lb}$ compared to $\$ 2.05 / \mathrm{lb}$ for SEA2. Also included in the O\&M costs are the operating labor, maintenance labor, replacement parts, and utilities. The fixed costs for installation include taxes, capital recovery, and depreciation. Additional factors, pertinent to operational costs that were used to evaluate the economic impact of mercury capture include the following:

- Economic life, 20 years

- Discount rate, $6.5 \%$

- Escalation factor, $3.5 \%$

- Depreciation rate, $5 \%$

- Overhead and benefit rate, $42 \%$ of O\&M labor costs

\subsubsection{Maintenance and Replacement Parts}

Maintenance, both routine and unscheduled, has an impact on operational costs. Typically, maintenance activities would include routing system inspection, equipment servicing based on manufacturer specifications (i.e., lubrication, calibration), and repair of equipment failure or damage. The total labor requirement for maintenance of the PAC skid has been estimated at 80 personnel days for general labor and 40 personnel days for specialized labor. Maintenance labor for the $\mathrm{CaCl}_{2}$ and SEA2 injection system has been estimated at 40 personnel days of general labor and 20 personnel days of specialized maintenance labor. The cost for replacement 
parts has been based on a percentage of the total purchase cost for the skids and is set at $2 \%$ of the total product cost (TPC) on an annual basis.

\subsubsection{Utility Costs}

The overall utility cost for the PAC and aqueous injection systems is a product of feed rate. Therefore, the energy costs are based on the maximum capacity of the equipment. Each of the two process systems contains several electrical components that contribute to the overall energy consumption. The electrical requirements for the components of the PAC skid include the following:

- Rotary valves are driven by $1 / 2-\mathrm{hp}, 480-\mathrm{V}$ motor.

- The volumetric feeder is driven by a 1-hp, 480-V motor.

- The blowers (two) are each 10-hp, 480-V.

- Miscellaneous process control and communication power are supplied by a $480-\mathrm{V}$ control center.

The utilities necessary to operate the aqueous injection skid are as follows:

- Propane or natural gas $2.5 \mathrm{~kg} / \mathrm{hr}$

- A 7-hp, 480-V blower

- Miscellaneous process control and communication power, likely provided through the PAC system

- $5 \mathrm{gal} / \mathrm{min}$ cooling water

The total power requirement on a yearly basis for the PAC skid is $25 \mathrm{~kW}$, or $195,000 \mathrm{kWh}$. For the aqueous injection skid, the total amount of propane and natural gas is $50 \mathrm{cfh}$, or $385,000 \mathrm{cf} / \mathrm{yr}$, and the yearly power requirements are $65,600 \mathrm{kWh}$. The total cooling water is $2.3 \times 10^{6} \mathrm{gal} / \mathrm{yr}$. Utility costs used for the cost analysis include the following:

- $\$ 0.045 / \mathrm{kWh}$ for electricity

- $\$ 1.042 / \mathrm{scf}$ for natural gas

- $\$ 1.00 / 1000$ gal for water

\subsection{Economic Evaluation of Mercury Control at MRY Station Unit 2}

The economic evaluation of mercury control for MRY Unit 2 was based on the operations data presented in Table 8-2. Economic analysis results for eight different mercury control technology scenarios involving $\mathrm{CaCl}_{2}, \mathrm{SEA} 2$, and PAC injections at MRY Unit 2 are presented in Table 8-3. As indicated in Table 8-3, SEA2 and a small amount of PAC injection were more cost-effective compared to $\mathrm{CaCl}_{2}$ injection. 
Table 8-2. MRY Unit 2 Operations Data

\begin{tabular}{lr}
\hline Plant Capacity, net MW & 450 \\
Capacity Factor & 0.85 \\
Flue Gas Volume, acf $/ \mathrm{min}^{\mathrm{a}}$ & $1,10,9585$ \\
Temperature of Flue Gas, ${ }^{\circ} \mathrm{F}$ & 181.2 \\
Net Unit Heat Rate, Btu/kWh & 10,137 \\
Fuel Burn Rate, ton $/ \mathrm{hr}$ & 337 \\
Excess $\mathrm{O}_{2}, \%$ volume dry basis & 4.16 \\
\hline
\end{tabular}

${ }^{\mathrm{a}}$ Volume is based on fuel burn rate.

\subsection{COSTS OF MERCURY MEASUREMENT AND REPORTING UNDER CAMR}

CAMR requires each utility ( $>25 \mathrm{MW}$ ) to continuously monitor mercury and report the results to both ensure the utility is in compliance with the rule and provide data for establishing trading criteria. Two methods are outlined in the rule to measure mercury: using continuous mercury monitors, (CMM) or sorbent traps (referred to as Appendix K). The costs are very different for these two methods. For purposes of this report, it has been assumed that the monitor purchased will be a Tekran Model 3300. For Appendix K, it has been assumed that the traps are purchased and analyzed by Frontier Geosciences at present costs. It should be noted that for Appendix K, there are very few vendors from which to purchase sampling equipment and traps and obtain sample trap analysis. It is expected that during the next 3-5 years, the cost will decrease as new methods are developed and more vendors become equipped to support this method. The costs associated with mercury measurement and reporting are listed below:

- Capital costs for mercury measurement equipment.

- If CMMs are used, there are costs associated with PS 12A (instrument setup).

- If Appendix $\mathrm{K}$ is used, there are costs associated with purchasing, replacing, and analyzing sorbent traps.

- Training costs.

- Maintenance costs including replacement parts.

- Ongoing QA/QC requirements including a yearly relative accuracy test assessment (RATA).

- Reporting costs associated with mercury measurement.

- Reporting costs associated with cap-and-trade provisions of CAMR. 
Table 8-3. Summary of Costs Associated with Mercury Control at MRY Unit 2

\begin{tabular}{|c|c|c|c|c|c|c|c|c|}
\hline & Case 1 & Case 2 & Case 3 & Case 4 & Case 5 & Case 6 & Case 7 & Case 8 \\
\hline Targeted Mercury Removal & $16 \%$ & $44 \%$ & $55 \%$ & $35 \%$ & $53 \%$ & $55 \%$ & $60 \%$ & $55 \%$ \\
\hline Test Type $^{1}$ & $\mathrm{P}$ & $\mathrm{P}$ & $\mathrm{P}$ & $\mathrm{P}$ & $\mathrm{P}$ & $\mathrm{P}$ & $\mathrm{P}$ & $\mathrm{L}$ \\
\hline $\mathrm{CaCl}_{2}$ Injection Rate, ppm & 500 & - & - & 300 & - & - & & \\
\hline SEA2 Injection Rate, ppm & - & 75 & 112 & - & 50 & 50 & 50 & 100 \\
\hline PAC Injection Rate, lb/Macf & - & - & - & 1.0 & 0.49 & 0.61 & 1.03 & 0.15 \\
\hline \multicolumn{9}{|l|}{ Capital Cost, $\$$} \\
\hline Purchased Equipment & 500,000 & 500,000 & 500,000 & $1,474,000$ & $1,474,000$ & $1,474,000$ & $1,474,000$ & $1,474,000$ \\
\hline Installation & 26,950 & 26,950 & 26,950 & 51,950 & 51,950 & 51,950 & 51,950 & 51,950 \\
\hline Indirect $^{2}$ & 90,000 & 90,000 & 90,000 & 90,000 & 90,000 & 90,000 & 90,000 & 90,000 \\
\hline Total Capital Cost & 616,950 & 616,950 & 616,950 & $1,615,950$ & $1,615,950$ & $1,615,950$ & $1,615,950$ & $1,615,950$ \\
\hline \multicolumn{9}{|l|}{ O\&M, \$/yr } \\
\hline Operating Labor & 16,000 & 16,000 & 16,000 & 48,000 & 48,000 & 48,000 & 48,000 & 48,000 \\
\hline Maintenance Labor & 79,800 & 79,800 & 79,800 & 98,040 & 98,040 & 98,040 & 98,040 & 98,040 \\
\hline Supervision Labor ${ }^{3}$ & 2400 & 2400 & 2400 & 7200 & 7200 & 7200 & 7200 & 7200 \\
\hline Replacement Parts ${ }^{4}$ & 10,000 & 10,000 & 10,000 & 29,480 & 29,480 & 29,480 & 29,480 & 29,480 \\
\hline Sorbents/Additives & 752,794 & 771,613 & $1,152,276$ & 806,311 & 688,180 & 730,736 & 879,682 & $1,082,013$ \\
\hline Utilities & 5252 & 5252 & 5252 & 14,027 & 14,027 & 14,027 & 14,027 & 14,027 \\
\hline Disposal & 0 & 0 & 0 & 7606 & 6849 & 7762 & 10,956 & 7385 \\
\hline Overhead $^{5}$ & 37,870 & 37,870 & 37,870 & 63,952 & 63,952 & 63,952 & 63,952 & 63,952 \\
\hline Taxes, Insurance, Administration ${ }^{6}$ & 30,848 & 30,848 & 30,848 & 80,798 & 80,798 & 80,798 & 80,798 & 80,798 \\
\hline Fixed Charges & 114,602 & 114,602 & 114,602 & 300,173 & 300,173 & 300,173 & 300,173 & 300,173 \\
\hline \multicolumn{9}{|l|}{ Levelized Annual Costs, $\$^{7}$} \\
\hline Total Annual Cost, $\$ / y r$ & $1,321,980$ & $1,346,764$ & $1,848,053$ & $1,758,392$ & $1,601,830$ & $1,659,074$ & $1,859,426$ & $2,121,169$ \\
\hline Total Annual Cost, \$/MWh (mills/kWh) & 0.39 & 0.40 & 0.55 & 0.52 & 0.48 & 0.50 & 0.55 & 0.63 \\
\hline Mercury Reduction (\$/lb Hg removed) & 91,568 & 14,088 & 14,496 & 17,379 & 10,445 & 10,424 & 12,834 & 16,639 \\
\hline
\end{tabular}

\footnotetext{
${ }^{1} \mathrm{P}$ - parametric, $\mathrm{L}$ - monthlong.

${ }^{2}$ Indirect charges (includes contingency) are for SEA skid only.

${ }^{3}$ Based on $15 \%$ of operating labor.

${ }^{4}$ Based on $2 \%$ of purchase equipment.

${ }^{5}$ Based on $20 \%$ of labor costs.

${ }^{6}$ Based on $3 \%$ of total capital requirements.

${ }^{7}$ The sum of the levelized operating and fixed costs.
} 


\subsection{CMM}

Based on a recent quote from Tekran, the cost of the CMM is $\$ 122,365$. The capital costs for purchasing and installing a CMM include the following:

- Sample conditioner module

- Elemental mercury calibration unit

- Inertial sampling system and probe

- Mercury analyzer

- Heated umbilical cord

- Air and water filtrations systems

- Mounting rack

- Shipping

To complete the specifications as required by PS $12 \mathrm{~A}$ and provide necessary QA/QC, a $\mathrm{CMM}$ will also require an oxidized mercury injection system. The estimated cost for the system is $\$ 35,000$ (based on projected cost for the Tekran system to be available in fall of 2006).

As part of purchase price, the vendor will provide an instrument technician to aid the plant in installing the CMM. Based on the EERC's experience, it is assumed that a minimum of 1 month of skilled labor will be required to install the CMM. Once the instrument is installed, the protocols as written in PS 12A in 40 CFR Part 60 must be completed. Although training costs are considered to be part of the O\&M costs, there is some overlap with installation costs associated with PS 12A. It is expected the vendor or hired consultants (integrators) will provide additional training and consulting support to help meet the requirements of PS 12A. The most costly part of PS $12 \mathrm{~A}$ will be doing a complete RATA. Based on the requirements stated in CAMR, a RATA consists of completing nine valid paired sets of $\mathrm{OH}$ method samples. The relative difference between the pair trains must be less than $10 \%$. The RATA cost to complete 12 paired trains (nine required plus three contingency samples) is estimated to be $\$ 55,000$. It is possible that, in the future, an instrumental reference method may be developed that could reduce this cost.

Although not considered part of this economic analysis, another potential cost item for operating CMMs is the potential need to expand the plant's CEM complex. These instruments are fairly large and at a site with multiple stacks more space may be needed.

Once the instrument has been installed and is operating (must be completed by January 1 , 2009), the plant must then obtain 12 months of valid data before it is required to begin reporting data for compliance purposes. Assuming an economic life of 10 years (although the firstgeneration compliance CMMs may be replaced earlier as it is expected that vendors will be making improvements during the first couple years of operation), the main O\&M costs associated with CMM use include the following:

- Training costs

- Utility requirements (electrical, air, argon, etc.)

- Operational and maintenance labor

- Replacement parts 
- Annual RATA

- Reporting and record keeping

A minimum of 3 weeks of training time per person will be needed to ensure an instrument technician is able to operate and perform the required maintenance and troubleshoot these instruments. A utility will need to have at least two people able to operate these instruments. Therefore, training cost will include 30 days of instrument technician time and the cost of the training which is expected to cost $\$ 100 / \mathrm{hr}$, resulting in a total training cost of $\$ 24,000$.

It is expected, especially during the first year, that a minimum of $2 \mathrm{hr} /$ day of an instrument technician's time will be needed to ensure the instrument is running properly. Further, it has been assumed that replacement part costs are $10 \%$ of purchased equipment cost, equal to $\$ 15,375$ a year.

For a CMM, the utilities required are electrical power (both to operate the instrument and to ensure the heat-traced umbilical sample line remains hot), compressed air (70-100 psi), argon (two cylinders/month), and deionized water. Table 9-1 provides the required utilities and cost to operate a Tekran with a 500-foot sampling line.

\subsection{Appendix K}

The capital costs for Appendix $\mathrm{K}$ sampling include the cost associated with purchasing the sampling box and probe. Based on a quote from Apex, the cost of a load-following unit will be $\$ 25,000$ for a dual train box. This quote includes the following:

- One consol containing duplicated sampling systems

- A dual trap heated probe and connections

- 25-foot umbilical cord and connections

- Chiller

- Software

A plant would also need to purchase a second unit so that when maintenance and calibration of the consol is being done, mercury sampling can continue. Therefore, the total capital cost would $\$ 50,000$.

In addition to the capital costs of the equipment, it is required that the sampling system be load-following; therefore, the sampling system must be tied into the plant process control and data acquisition system. This will allow the Appendix $\mathrm{K}$ controller to adjust the sample flow proportionate to the plant load. Based on discussions with Apex, it is expected that 40 hours of skilled labor (electrician) will be necessary to install and shakedown the system, and $\$ 5000$ of materials will be needed. It is assumed that once installation is complete, switching out sampling consoles will be relatively simple and would be associated with the O\&M costs of switching the sorbent traps. 
Table 9-1. Utilities Needed to Operate a Tekran CMM

\begin{tabular}{lccc}
\hline Utility & Required & Cost/Unit & Cost, \$ \\
\hline Electrical & $53,340 \mathrm{kwh}$ & $\$ 0.045 / \mathrm{kWh}$ & 2400 \\
Argon & Two cylinders $/$ month & $\$ 240 /$ cylinder & 5760 \\
Compressed Air & $80 \mathrm{psi}$ & $\$ 1250 / \mathrm{yr}$ & 1250 \\
Deionized Water & $1 \mathrm{gal} /$ day & $\$ 250 / 1000 \mathrm{gal}$ & 100 \\
\hline Total Cost & & & 9510 \\
\hline
\end{tabular}

The O\&M costs associated with Appendix K, assuming an economic life of 5 years, are as follows:

- Spiked sorbent traps and analyses

- Electrical requirements

- Training costs

- Labor to change the sorbent traps on a weekly basis

- Maintenance

- Annual RATA

- Reporting and recordkeeping

Based on the most current quote from Frontier Geosciences, the cost per spiked trap and analysis is $\$ 200(2 / 20 / 06)$. It will take one person about 8 hours a week to remove and change the traps, bag and ship them, and record the data once they are obtained. There are very little data available regarding maintenance requirements for the Appendix K sampling system, but based on previous work at the EERC with the similar EPA Method 5 systems, it is expected that, with calibration, a total of $80 \mathrm{hr}$ a year will be needed. It is assumed that replacement part costs are $10 \%$ of capital cost or $\$ 5000$ a year. The power requirements are approximately $3 \mathrm{~kW}$, or 22,860 $\mathrm{kWh}$.

Although an initial RATA certification is not necessary, Appendix $\mathrm{K}$ does have similar annual RATA requirements as is the case for a CMM installation. The cost of doing the RATA is estimated to be $\$ 55,000$.

\subsection{Reporting and Recordkeeping Requirements under CAMR}

There are essentially three types of mercury reporting required under CAMR. The first is mercury monitoring certification reporting. As part of this reporting, a mercury representative must designate and complete a certification application for each monitoring system. In addition, as part of the certification, PS 12A must be met for each monitoring system.

For ongoing mercury monitoring reporting requirements, monthly reports must be filed electronically. These reports must include all mercury measurement data and a data assessment report based on CAMR requirements. The mercury representative must also report any exceedences as required under $40 \mathrm{CFR} \S 60.7$ (a) and maintain records needed to demonstrate compliance with CAMR. 
As part of the cap-and-trade provisions of CAMR, a legally binding and federally enforceable written document (Title V) must be completed. This document must be issued by a permitting authority and must specify the mercury budget trading requirements for each source. The plant must, therefore, provide any documentation required by the permitting authority. The mercury measurement data must be provided in such a manner that would document trading allowances.

In discussions with Basin Electric they plan on hiring It is expected that utilities will require a full-time person at the corporate level especially during the early part of the rule to support PS 12A documentation completion. The representative must also directly work with the state to determine proper allowances based on the mercury budgets established for North Dakota. Finally, a recordkeeping system must be established that meets the requirements under CAMR. Basin Electric has eight units that would be required to share in this cost. The estimated costs for the two mercury-monitoring methods are compared in Table 9-2.

Table 9-2. Summary Comparison of the Total Costs for Appendix K and CMMs

\begin{tabular}{|c|c|c|}
\hline & Appendix K & CMM \\
\hline \multicolumn{3}{|l|}{ Capital Cost, $\$$} \\
\hline \multicolumn{3}{|l|}{ Purchased Equipment (PE) } \\
\hline Instrument/Console & 50,000 & $\$ 122,365$ \\
\hline Calibration Unit & 0 & 35,000 \\
\hline \multicolumn{3}{|l|}{ Installation } \\
\hline Labor & 2280 & 12,500 \\
\hline Materials & 5000 & 5000 \\
\hline Overhead & 500 & 2500 \\
\hline PS $12 \mathrm{~A}$ & 0 & 55,000 \\
\hline Total Capital Requirement & 57,780 & 232,365 \\
\hline \multicolumn{3}{|l|}{ O\&M, \$/yr } \\
\hline Training & 6400 & 24,000 \\
\hline Sorbent Traps and Analyses & 18,100 & 0 \\
\hline Operating Labor & 20,800 & 31,025 \\
\hline Maintenance Labor & 4560 & 5600 \\
\hline Supervision Labor ( $5 \%$ of labor) & 1268 & 1831 \\
\hline Replacement Parts ( $10 \%$ of PE) & 5000 & 15,735 \\
\hline Utilities & 1715 & 9510 \\
\hline Deprecation & 5000 & 15,735 \\
\hline Overhead ( $20 \%$ of labor) & 5325 & 7691 \\
\hline RATA & 55,000 & 55,000 \\
\hline Reporting and Recordkeeping & 17,700 & 17,700 \\
\hline Total Annual O\&M Costs & 140,868 & 183,827 \\
\hline
\end{tabular}




\subsection{CONCLUSIONS}

$\mathrm{Hg}$ in the lignite coal fired in MRY Unit 2 varied from 0.05 to $0.25 \mathrm{ppm}$ and averaged $0.112 \pm 0.014 \mathrm{ppm}$ (dry coal basis). Most of the $\mathrm{Hg}$ was associated with $\mathrm{Hg}$-rich (2.28 ppm) pyrite grains that ranged in concentration from about 1 to $6 \mathrm{wt} \%$ (on a coal basis). During routine power plant operations, total $\mathrm{Hg}$ concentrations at the ESP and wet FGD inlets varied from about 12 to $16 \mu \mathrm{g} / \mathrm{dNm}^{3}$, whereas at the stack, concentrations were consistently at approximately $13 \mu \mathrm{g} / \mathrm{dNm}^{3}$, indicating that the ESP and wet FGD were very inefficient at removing $\mathrm{Hg}$ primarily because $\mathrm{Hg}^{0}$ was dominant. $\mathrm{MgCl}_{2}$ and $\mathrm{CaCl}_{2}$ were relatively ineffective in promoting $\mathrm{Hg}^{0}$ oxidation and capture in an ESP-wet FGD. Relatively low additions of SEA2, however, significantly improved the Hg removal efficiency of the ESP-wet FGD, although the goal of $55 \% \mathrm{Hg}$ removal was not achieved using as much as 75 ppm SEA2 (dry coal basis). Most of the $\mathrm{Hg}$ removal occurred in the ESP, suggesting that SEA2 addition promoted the conversion of $\mathrm{Hg}^{0}$ to particulate-bound Hg. SEA2 addition (50-100 ppm, dry coal basis) combined with 0.15-lb/Macf PAC injection was performed for a month during which $\mathrm{Hg}$ removal efficiencies generally ranged from $50 \%$ to $65 \%$.

SGLP and LTL analyses of fly ash samples collected during baseline and Hg control testing conditions indicated that $\mathrm{Hg}$ was relatively insoluble. The fly ash samples collected during baseline and $\mathrm{Hg}$ control technology testing conditions at the MRY power plant released $\mathrm{Hg}$ at about $375^{\circ}$ and $400^{\circ} \mathrm{C}$, respectively. The fly ash sampled during $\mathrm{Hg}$ control technology testing also released some $\mathrm{Hg}$ at approximately $550^{\circ} \mathrm{C}$. The $\mathrm{Hg}$ captured on fly ash and PAC during SEA2 injections was thermally more stable relative to the baseline fly ash.

Economic evaluations of mercury control for MRY Unit 2 were performed assuming various $\mathrm{CaCl}_{2}, \mathrm{SEA} 2, \mathrm{CaCl}_{2}$ with $\mathrm{PAC}$, and $\mathrm{SEA} 2$ with $\mathrm{PAC}$ injection rates. The cost for maintaining a 55\% mercury removal efficiency at MRY Unit 2 using SEA2 in combination with a small amount of PAC was estimated as follows:

- Levelized annual cost: $\$ 2,121,169$

- Annual cost, $\$ / \mathrm{MWh}$ (mills/kWh): 0.63

- Cost of mercury removal, $\$ / 1 b: 16,639$

\subsection{REFERENCES}

1. Pavlish, J.H.; Sondreal, E.A.; Mann, M.D.; Olson, E.S.; Galbreath, K.C.; Laudal, D.L.; Benson, S.A. Status Review of Mercury Control Options for Coal-Fired Power Plants. Fuel Process. Technol. 2003, $82(2,3), 89-165$.

2. Sjostrom, S.; Richardson, C.; Chang, R. Evaluation of Mercury Emissions and Control Options for Great River Energy; Final Report for North Dakota Industrial Commission; June 2001. 
3. Chang, R.; Strohfus, M. The Evaluation of Chemical Additives for Mercury Emission Control at Great River Energy; Final Report for the North Dakota Industrial Commission; Jan 2003.

4. Global Mercury Assessment. United Nations Environment Program (UNEP) Chemicals: Geneva, Switzerland; Dec 2002.

5. Kilgroe, J.; Sedman, C.; Srivastava, R.; Ryan, J.; Lee, C.; Thorneloe, S. Control of Mercury Emissions from Coal-Fired Electric Utility Boilers: Interim Report Including Errata; Dated March 21, 2002; EPA-600/R-01-109; U.S. Environmental Protection Agency: Washington, DC, April 2002.

6. National Research Council. Toxicological Effects of Methylmercury; Report for U.S. Environmental Protection Agency; National Academy Press: Washington, DC, Aug 2000.

7. U.S. Environmental Protection Agency. Mercury Study Report to Congress Volume I: Executive Summary; EPA-452/R-97-003; Office of Air Quality Planning and Standards and Office of Research and Development: Dec 1997.

8. U.S. Environmental Protection Agency. A Study of Hazardous Air Pollutant Emissions from Electric Utility Steam Generating Units: Final Report to Congress; EPA-453/R-98-004a; U.S. EPA Office of Air Quality Planning and Standards, U.S. Government Printing Office: Washington, DC, Feb 1998.

9. U.S. Environmental Protection Agency. Information Collection Request; 1999.

10. Pavlish, J.H.; Holmes, M.J. Mercury Control for Lignite-Fired Power Plants Poses a Challenge. Center for Air Toxic Metals Newsletter 2002, 8 (1), 6.

11. Pavlish, J.H.; Sondreal, E.A.; Mann, M.D.; Olson, E.S.; Galbreath, K.C.; Laudal, D.L.; Benson, S.A. Status Review of Mercury Control Options for Coal-Fired Power Plants. Fuel Process. Technol. 2003, 82 (2-3), 89-165.

12. Carey, T.R.; Hargrove, O.W.; Richardson, C.F.; Chang, R.; Meserole, F.B. Factors Affecting Mercury Control in Utility Flue Gas Using Activated Carbon. J. Air Waste Manage. Assoc. 1998, 48, 1166-1174.

13. Dunham, G.E.; Olson, E.S.; Miller, S.J. Impact of Flue Gas Constituents on Carbon Sorbents. In Proceedings of the Air Quality II: Mercury, Trace Elements, and Particulate Matter Conference; McLean, VA, Sept 19-21, 2000; Paper A4-3.

14. Olson, E.S.; Sharma, R.K.; Miller, S.J.; Dunham, G.E. Identification of the Breakthrough Oxidized Mercury Species from Sorbents in Flue Gas. In Proceedings of the Specialty Conference on Mercury in the Environment; Minneapolis, MN, Sept 15-17, 1999; pp 121126. 
15. Pavlish, J.H.; Holmes, M.J.; Benson, S.A.; Crocker, C.R.; Galbreath, K.C. Mercury Control Technologies for Utilities Burning Lignite Coal, In Proceedings of Air Quality III, Mercury, Trace Elements, and Particulate Matter Conference, Sept 9-12, 2002.

16. Bustard, J.; Durham, M.; Starns, T.; Lindsey, C.; Martin, C., Schlager, R.; Bladrey, K. FullScale Evaluation of Sorbent Injection for Mercury Control on Coal-Fired Power Plants. In Proceedings of Air Quality III: Mercury, Trace Elements, and Particulate Matter Conference; Sept 9-12, 2002.

17. Sjostrom, S.; Richardson, C.; Chang, R. Evaluation of Mercury Emissions and Control Options for Great River Energy; Final Report for North Dakota Industrial Commission, June 2001.

18. Liu, W.; Vidic, R.D.; Brown, T.D. Optimization of Sulfur Impregnation Protocol for FixedBed Application of Activated Carbon-Based Sorbents for Gas-Phase Mercury Removal. Environ. Sci. Technol. 1998, 32, 531-538.

19. Ghorishi, S.B.; Kenney, R.M.; Serre, S.D.; Gullett, B.K.; Jozewicz, W.S. Development of a Cl-Impregnated Carbon for Entrained-Flow Capture of Elemental Mercury. Environ. Sci. Technol. 2002, 36, 4454-4459.

20. Dunham, G.E.; Miller, S.J.; Laudal, D.L. Investigation of Sorbent Injection for Mercury Control in Coal-Fired Boilers; Final Report for EPRI and DOE; Energy \& Environmental Research Center: Grand Forks, ND, Sept 1998.

21. Laumb, J.D.; Benson, S.A.; Olson, E. S. X-Ray Photoelectron Spectroscopy Analysis of Mercury Sorbent Surface Chemistry. In Proceedings of the Air Quality III: Mercury, Trace Elements, and Particulate Matter Conference; Arlington, VA, Sept 9-12, 2002; Energy \& Environmental Research Center: Grand Forks, ND, 2002.

22. Benson, S.A.; Olson, E.; Crocker, C.; Pavlish, J.; Holmes, M. Mercury Sorbent Testing in Simulated Low-Rank Coal Flue Gases. In Proceedings of the 6th Electric Utilities Environmental Conference; Jan 27-30, 2003.

23. Thompson, J.S.; Holmes, M.J.; Laudal, D.L. Long-Term Monitoring at North Dakota Power Plants; Final Report for the North Dakota Industrial Commission; March 2003.

24. Hassett, D.J. Synthetic Groundwater Leaching Procedure. In Encyclopedia of Environmental Analysis and Remediation; John Wiley \& Sons, Inc., 1998; pp 4797-4803.

25. U.S. Environmental Protection Agency. Method 1311, Toxicity Characteristic Leaching Procedure, Test Methods for Evaluating Solid Waste, Physical/Chemical Methods; EPA Publication SW-846, Third Edition, as amended by Updates I, II, IIB, and III, finalized in the Federal Register, June 13, 1997. 
26. American Society for Testing and Materials. Standard Method for Shake Extraction of Solid Waste with Water. In Annual Book of ASTM Standards; Section 11: Water and Environmental Technology, ASTM D3987-85, 1989.

27. Hassett, D.J.; Heebink, L.V.; Pflughoeft-Hassett, D.F.; Zacher, E.J.; Buckley, T.D.; Eylands, K.E. Mercury and Air Toxic Element Impacts of Coal Combustion By-Product Disposal and Utilization; Final Year 2 Annual Report for U.S. Department of Energy National Energy Technology Laboratory Cooperative Agreement No. DE-FC26-02NT41727; EERC Publication 2005-EERC-06-09; Energy \& Environmental Research Center: Grand Forks, ND, Jun 2005. 
APPENDIX A

\section{QUALITY ASSURANCE/QUALITY CONTROL FOR PILOT-SCALE TESTS}




\section{QUALITY ASSURANCE/QUALITY CONTROL}

Detailed quality assurance/quality control $(\mathrm{QA} / \mathrm{QC})$ procedures that were used for the flue gas sampling activities and implementation of the $\mathrm{Hg}$ control technologies at Milton $\mathrm{R}$. Young Station (MRY) are described herein. The QA/QC Plan, which provided guidelines as to how testing activities detailed in the site-specific test plan were to be performed, was adhered to during all testing, sample preparation, sample analysis, and data reduction activities.

Careful consideration was used during on-site flue gas monitoring and sampling procedures to ensure that all QA/QC requirements were met. $\mathrm{CaCl}_{2}, \mathrm{MgCl}_{2}$, and SEA2 addition and powder activated carbon (PAC) injection systems were installed, calibrated, and operated with QA/QC procedures in mind. All analytical work, performed either on-site or at Energy \& Environmental Research Center (EERC) facilities, was performed according to QA/QC guidelines. Ash and coal samples recovered by Minnkota Power Cooperative, Inc. (MPC) personnel were done so according to the QA/QC plan, as well.

\section{FLUE GAS MERCURY MEASUREMENTS}

\section{Continuous Mercury Monitoring (CMM)}

The Tekran Model 2537A atomic fluorescence-based $\mathrm{Hg}$ vapor analyzer was used in conjunction with a PS Analytical S235C400 wet-chemistry conversion unit to continuously monitor $\mathrm{Hg}^{0}$ and total $\mathrm{Hg}$ concentrations at the wet flue gas desulfurization (FGD) inlet and stack locations. The PS Analytical uses two separate liquid flow paths: one to continuously reduce $\mathrm{Hg}^{2+}$ to $\mathrm{Hg}^{0}$, resulting in a total gas-phase $\mathrm{Hg}$ sample, and the other to continuously scrub out $\mathrm{Hg}^{2+}$, resulting in an $\mathrm{Hg}^{0}$ sample. The PS Analytical also uses a Peltier thermoelectric cooler module to cool and dry the sample gases prior to analysis.

The Tekran instrument traps the $\mathrm{Hg}$ vapor from the conditioned sample onto a cartridge containing an ultrapure gold sorbent. The amalgamated $\mathrm{Hg}$ is then thermally desorbed and detected using atomic fluorescence spectrometry. A dual-cartridge design enables alternate sampling and desorption, resulting in a nearly continuous measurement of the sample stream. An automatic $\mathrm{Hg}^{0}$ permeation source was used to calibrate the instrument daily. Manual $\mathrm{Hg}^{0}$ injection calibration on both cartridges was also performed for verification. The Tekran instrument measures either total $\mathrm{Hg}$ or $\mathrm{Hg}^{0}$, with an analysis occurring approximately every 2.5 minutes.

A four-point calibration curve was then completed using matrix-matched standards. The detector response for a given standard was logged and compared to specifications to ensure the instrument was properly set up. A QC standard of a known analyte concentration was analyzed immediately after the instrument was standardized in order to verify the calibration. This QC standard was prepared from a different stock than the calibration standards. The values obtained read within $5 \%$ of the true value. After the initial QC standardization was completed, standards were run every ten samples to check the slope of the calibration curve. One in every ten samples was run in triplicate and spiked to verify analyte recovery. A QC chart was also maintained by the EERC chemist to monitor the long-term precision of the instrument. 


\section{ASTM International Method D6784-01}

The ASTM International Method D6784-01 (Ontario Hydro [OH] method) was used to monitor flue gas mercury concentrations and verify CMM measurements. $\mathrm{Hg}$ species samples were collected at the air heater $(\mathrm{AH})$ outlet and the stack at each condition, as outlined in the test plan. U.S. Environmental Protection Agency (EPA) methods to determine flue gas flow rate at both locations were used, and EPA Reference Methods 1-5 and 17 requirements for isokinetic sampling were followed. The impinger trains were weighed before and after sampling to determine flue gas moisture. The sampling trains used in-stack filtration (EPA Method 17 configuration) at all sampling locations. All analyses of the liquid samples collected using the $\mathrm{OH}$ mercury speciation method were performed by the EERC, either on-site or at a nearby location, including the field blanks and spikes.

Presampling Preparation. All data sheets, volumetric flasks, and petri dishes used for sample recovery were marked with preprinted labels to ensure proper cross-referencing. The liquid samples were recovered into premarked volumetric flasks, logged, and then analyzed onsite or at a nearby location. The stack filter samples were placed in premarked petri dishes and then taken back to the EERC, where they were analyzed. The prestack filter samples were placed in premarked containers, logged, and then analyzed on-site. The labels contained identifying data including date, time, run number, sample port location, and the name of the sampler.

Glassware and Plasticware Cleaning and Storage. All glass volumetric flasks and transfer pipets used in the preparation of analytical reagents and calibration standards were Class "A" as designated by federal specifications. Prior to being used for sampling, all glassware was washed with hot soapy water, rinsed with DI water three times, soaked in $10 \% \mathrm{~V} / \mathrm{v}$ nitric acid for a minimum of 4 hours, rinsed an additional three times with DI water, and dried. The glassware was stored in closed containers until used at the plant.

Analytical Reagents. All acids used for the analysis of mercury were trace metal-grade. Other chemicals that were used in the preparation of analytical reagents were analytical reagentgrade. The calibration standards used for instrument calibration and the QC standards used for calibration verification were purchased commercially and certified to be accurate within $\pm 0.5 \%$ and traceable to NIST standard reference materials.

Blanks and Spikes. As part of QA/QC, a field blank was associated with sampling at each location for each test condition. A field blank is a complete impinger train including all glassware and solutions that is taken to the field during sampling and exposed to ambient conditions. These sample trains were taken apart and the solutions recovered and analyzed in the same manner as those sample trains used for sampling activities. The blanks were used to verify low background levels.

As part of QA/QC, a field spike was associated with each $\mathrm{OH}$ test day. A field spike was prepared by the field manager at a level similar to the field samples. These sample trains were then taken apart, and the solution recovered and analyzed in the same manner as those sample trains used for sampling activities. The target range for recovery of a field spike is $20 \%$. 
The results of the blanks and spikes are show in Tables A-1 and A-2. With few exceptions, blanks were at or near detection limits. All of the spikes were within the $20 \%$ range required by the method. A summary of the field spike results is presented in Table A-3.

Table A-1. Results of Mercury Speciation Field Blanks at MRY

\begin{tabular}{lcccc}
\hline Date & Sample ID & $\mathrm{KCl}$ Solution, $\mu \mathrm{g} / \mathrm{L}$ & $\mathrm{H}_{2} \mathrm{O}_{2}$ Solution, $\mu \mathrm{g} / \mathrm{L}$ & $\mathrm{KMnO}_{4}$ Solution, $\mu \mathrm{g} / \mathrm{L}$ \\
\hline $3 / 17 / 05$ & MRY-4 & $<0.05$ & $<0.1$ & $<0.05$ \\
$3 / 17 / 05$ & MRY-10 & $<0.05$ & $<0.1$ & $<0.05$ \\
$3 / 18 / 05$ & MRY-15 & $<0.05$ & $<0.1$ & $<0.05$ \\
$3 / 19 / 05$ & MRY-20 & $<0.05$ & $<0.1$ & $<0.05$ \\
$3 / 20 / 05$ & MRY-25 & $<0.05$ & $<0.1$ & $<0.05$ \\
$3 / 21 / 05$ & MRY-30 & $<0.05$ & $<0.1$ & $<0.05$ \\
$3 / 29 / 05$ & MRY-40 & $<0.08$ & $<0.025$ & $<0.015$ \\
$3 / 30 / 05$ & MRY-45 & 0.029 & 0.022 & 0.084 \\
$3 / 31 / 05$ & MRY-50 & 0.088 & $<0.07$ & $<0.05$ \\
$4 / 26 / 05$ & MRY-76 & $<0.07$ & $<0.07$ & $<0.05$ \\
$4 / 27 / 05$ & MRY-82 & $<0.07$ & $<0.07$ & $<0.05$ \\
$4 / 28 / 05$ & MRY-87 & $<0.07$ & $<0.03$ & $<0.05$ \\
$5 / 10 / 05$ & MRY-92 & $<0.05$ & $<0.07$ & $<0.05$ \\
$5 / 11 / 05$ & MRY-103 & $<0.07$ & & $<0.05$
\end{tabular}

Table A-2. Results of Mercury Speciation Field Spikes at MRY

$\begin{array}{ccc}\mathrm{KCl} \text { Solution } & \mathrm{H}_{2} \mathrm{O}_{2} \text { Solution } & \mathrm{KMnO}_{4} \text { Solution } \\ \text { Spike } & & \text { Spike }\end{array}$

Measured Spike, Recovery, Measured Spike, Recovery, Measured Spike, Recovery,

\begin{tabular}{lccccccccc} 
Sample ID & Value, $\mathrm{ppb}$ & $\mathrm{ppb}$ & $\%$ & Value, $\mathrm{ppb}$ & $\mathrm{ppb}$ & $\%$ & Value, $\mathrm{ppb}$ & $\mathrm{ppb}$ & $\%$ \\
\hline MRY-5 & 5.88 & 6.00 & 98 & 5.51 & 6.00 & 92 & 6.20 & 6.00 & 103 \\
MRY-16 & 5.99 & 6.00 & 100 & 5.37 & 6.00 & 90 & 4.80 & 5.00 & 96 \\
MRY-21 & 2.94 & 3.00 & 98 & 3.73 & 4.00 & 93 & 10.2 & 10.0 & 102 \\
MRY-26 & 1.92 & 2.00 & 96 & 1.85 & 2.00 & 93 & 9.70 & 10.0 & 97 \\
MRY-31 & 2.16 & 2.00 & 108 & 1.74 & 2.00 & 87 & 5.25 & 5.00 & 105 \\
MRY-36 & 2.14 & 2.00 & 107 & 1.76 & 2.00 & 88 & 5.10 & 5.00 & 102 \\
MRY-41 & 4.00 & 4.00 & 100 & 4.20 & 4.00 & 105 & 3.99 & 4.00 & 100 \\
MRY-46 & 5.10 & 5.00 & 102 & 3.78 & 4.00 & 95 & 5.21 & 5.00 & 104 \\
MRY-51 & 3.06 & 3.00 & 105 & 2.99 & 3.00 & 100 & 6.01 & 6.00 & 100 \\
MRY-77 & 5.10 & 5.00 & 102 & 3.15 & 3.00 & 105 & 5.07 & 5.00 & 101 \\
MRY-83 & 2.06 & 2.00 & 103 & 2.13 & 2.00 & 107 & 2.07 & 2.00 & 104 \\
MRY-88 & 4.24 & 4.00 & 106 & 3.83 & 4.00 & 96 & 4.00 & 4.00 & 100 \\
MRY-93 & 4.88 & 5.00 & 98 & 2.00 & 2.00 & 100 & 9.96 & 10.0 & 100 \\
MRY-104 & 5.73 & 6.00 & 97 & 3.17 & 3.00 & 106 & 5.89 & 6.00 & 98 \\
\hline
\end{tabular}


Table A-3. Summary of Field Spikes

\begin{tabular}{llccc}
\hline & & Average & & Std. Dev. \\
$\mathrm{KCl}(\%)$ & $=$ & 101 & \pm & 4 \\
$\mathrm{H}_{2} \mathrm{O}_{2}(\%)$ & $=$ & 97 & \pm & 7 \\
$\mathrm{KMnO}_{4}(\%)$ & $=$ & 101 & \pm & 3 \\
\hline
\end{tabular}

\section{Comparison of CMM and ASTM International Method D6784-01 Analysis Results}

The ASTM International Method D6784-01 (OH method) is considered to be a reference method by EPA for evaluating the relative accuracy of CMM results. All of the $\mathrm{OH}$ samples were collected for 2 hours. Compared in Tables 6-6, 6-8, and 6-9 are CMM and $\mathrm{OH}$ total gaseous $\mathrm{Hg}$ measurement results obtained simultaneously (pp 37, 38, and 44 of the main text).

\section{COAL, ASH, SCRUBBER SLURRY, AND MISCELLANEOUS SAMPLES}

Coal, ash, and other samples were taken as outlined in the test plan. All samples were labeled with unique identifiers and descriptive notations. The majority of the samples were archived and stored by MPC personnel on-site. Samples that were taken to the EERC for analysis were in the custody of EERC personnel at all times. Once the EERC laboratory had received the samples, the sample condition was checked, and the sample was logged into the EERC system. After analyses, summarized in Table A-4, were complete, the samples were archived and stored at the EERC. Samples will be stored, at a minimum, until the end of the project.

Table A-4. Analytical Methods for Coal and Ash Samples

\begin{tabular}{ll}
\hline Analysis & Method \\
\hline Coal & \\
\hline Mercury & ASTM D6414-01 \\
Chlorine & ASTM D6721-01 \\
Proximate & ASTM D5142-02 \\
Sulfur & ASTM D5106-98 \\
Heating Value & ASTM D5865 \\
Ultimate & ASTM D5373 \\
\hline Ash & \\
\hline Mercury & ASTM D6414-01 \\
Loss on Ignition (LOI) & ASTM C311-02 \\
\hline
\end{tabular}

\section{MERCURY STABILITY}

Mercury release experiments addressed three areas: 1) direct leachability of mercury, 2) vapor release of mercury at elevated temperatures, and 3) biologically induced leachability and vapor release. For leaching, the synthetic groundwater leaching procedure (SGLP) along with long-term leaching (LTL) was used. The mercury analyses of the CCB leachate samples are performed at a laboratory using standard EPA-approved laboratory methods. Duplicate and spike analyses are performed every ten samples. A QA/QC protocol is not established at this time for 
the elevated-temperature release of mercury from CCBs. The reproducibility is about $\pm 10 \%$ both quantitatively and qualitatively.

\section{SEA ADDITION}

Aqueous $\mathrm{CaCl}_{2}, \mathrm{MgCl}_{2}$, and SEA2 were injected into the coal stream between the feeders and the pulverizers. The aqueous control panel was skid-mounted and set up on-site by MPC personnel. The aqueous solutions were transported via skid-mounted pumps. Prior to setup, the flowmeters underwent an NIST traceable multipoint calibration. Calibration verification of the aqueous feed rates was completed on-site via measurement of weight versus time. The aqueous feeder control panel received signals from the plant, allowing the injection rate to be set and controlled proportionally to coal feed rate. The aqueous injection rate was logged continuously by the plant data collection system for the duration of the test period, along with the feed rate signals from the plant. The aqueous feed rates per actual pound of coal were calculated from the actual coal data and the volumetric flow rate recorded by the plant's data collection system (DCS).

\section{PAC INJECTION}

The control panel for the PAC system was configured to allow the PAC feed rate to be established and controlled proportionally to the unit load in megawatts. Multipoint calibration of the PAC injection system was completed on-site via measurement of weight versus time. All calibration verifications fell inside the acceptance range of $\pm 15 \%$. The plant data collection system recorded the PAC system feeder screw speed for the entire test period, along with the load signal from the plant. The PAC feed rate in $\mathrm{lb} / \mathrm{Macf}$ was calculated based on the feeder screw feed, calibration data correlating feeder screw speed to pounds of carbon per hour, and flue gas flow data. 
APPENDIX B

\section{SAMPLE CALCULATIONS}


Sample calculations are included for each of the calculated parameters.

OH METHOD SAMPLING

Volume of Gas Sample

$\mathrm{Vm}(\mathrm{std}) \quad=\quad$ Volume of gas sample measured by the dry gas meter, corrected to standard conditions, dscf

$\mathrm{Vm}(\mathrm{std})(\mathrm{dscf}) \quad=\quad \frac{\mathrm{K}_{1} \times \mathrm{Vmc} \times \mathrm{Pm}}{\mathrm{Tm}+460}$

$\mathrm{Vm}(\mathrm{std}) \quad=\quad \frac{17.64 \times 45.472 \times 29.665}{104+460}=42.190 \mathrm{dscf}$

Where:

$\mathrm{K}_{1}$

$=\quad 17.64 \mathrm{R} /$ in. $\mathrm{Hg}$

$\mathrm{Vmc} \quad=\quad \mathrm{Vm} \times \mathrm{Cm}=$ Volume of gas sample as measured by dry gas meter corrected for meter calibration

$(\mathrm{Cm}=$ meter calibration coefficient $)(\mathrm{dcf})$

Pm $\quad=\quad$ Meter pressure (in. $\mathrm{Hg}$ )

$\mathrm{Tm} \quad=\quad$ Meter temperature $\left({ }^{\circ} \mathrm{F}\right)$

\section{Volume of Water Vapor}

Vw(std)

$=\quad$ Volume of water vapor in the gas sample, corrected to standard

$\mathrm{Vw}(\mathrm{std})(\mathrm{scf})$ conditions, scf

$\mathrm{Vw}(\mathrm{std})$

$=\mathrm{K}_{2} \times \mathrm{H}_{2} \mathrm{O}(\mathrm{g})$

$=0.04715 \times 137.5=6.483 \mathrm{scf}$

Where:

$\mathrm{K}_{2}$

$\mathrm{H}_{2} \mathrm{O}(\mathrm{g})$ $=\quad 0.04715 \mathrm{ft}^{3} / \mathrm{g}$

$=\quad$ Mass of liquid collected in impingers and silica gel $(\mathrm{g})$

Water Vapor in the Gas Stream

$\begin{array}{lll}\text { Bws } & = & \text { Water vapor in the gas stream, proportion by volume } \\ \text { Bws } & =\frac{\mathrm{Vw}(\mathrm{std})}{\mathrm{Vm}(\mathrm{std})+\mathrm{Vw}(\mathrm{std})} \\ \text { Bws } & =\frac{6.483}{42.190+6.483}=0.1332\end{array}$




\section{Dry Molecular Weight}

$\begin{array}{lll}\operatorname{Md} & = & \text { Dry molecular weight of stack gas, lb/lb-mole } \\ \mathrm{Md}(\mathrm{lb} / \mathrm{lb}-\mathrm{mol}) & = & 0.440 \times\left(\% \mathrm{CO}_{2}\right)+0.320 \times\left(\% \mathrm{O}_{2}\right)+0.280 \times\left(\% \mathrm{~N}_{2}+\% \mathrm{CO}\right) \\ \mathrm{Md} & = & 0.440 \times 15.9+0.320 \times 3.1+0.280 \times 81.0=30.7 \mathrm{lb} / \mathrm{lb}-\mathrm{mol}\end{array}$

Where:

$\%\left(\mathrm{CO}_{2}, \mathrm{O}_{2}, \mathrm{~N}_{2}, \mathrm{CO}\right)=\quad$ Percent $\left(\mathrm{CO}_{2}, \mathrm{O}_{2}, \mathrm{~N}_{2}, \mathrm{CO}\right)$ by volume, dry basis

\section{Molecular Weight}

Ms

Ms (lb/lb-mol)

Ms $=\quad$ Molecular weight of stack gas, wet basis, lb/lb-mol

$=\quad \mathrm{Md} \times(1-\mathrm{Bws})+18.0 \times \mathrm{Bws}$

$=\quad 30.7 \times(1-0.1332)+18.0 \times 0.1332=29.0 \mathrm{lb} / \mathrm{lb}-\mathrm{mol}$

\section{Average Stack Gas Velocity}

Vs $\quad=\quad$ Average stack gas velocity, $\mathrm{ft} / \mathrm{sec}$

$\mathrm{Vs}(\mathrm{ft} / \mathrm{sec}) \quad=\quad \mathrm{K}_{3} \times \mathrm{Cp} \times(\Delta \mathrm{p})^{1 / 2}(\mathrm{avg}) \times\left[\frac{\mathrm{Ts}+460}{\mathrm{Ps} \times \mathrm{Ms}}\right]^{1 / 2}$

$\mathrm{Vs}$

$=\quad 85.49 \times 0.84 \times 0.4472 \times\left[\frac{685+460}{30.49 \times 29.0}\right]^{1 / 2}=36.6 \mathrm{ft} / \mathrm{sec}$

Where:

$\mathrm{K}_{3}=85.49 \mathrm{ft} / \mathrm{sec} \times\left[\frac{\frac{\mathrm{lb}}{\mathrm{lb}-\text { mole }} \times \text { in. } \mathrm{Hg}}{\mathrm{R} \times \text { in. }_{2} \mathrm{O}}\right]^{1 / 2}$

$\mathrm{Cp} \quad=\quad$ Pitot tube coefficient, dimensionless

$\Delta \mathrm{p} \quad=\quad$ Velocity head of stack gas (in. Hg)

$(\Delta P)^{1 / 2}($ avg $) \quad=\quad$ Averageof the square root of $\Delta P$ values

Ts $\quad=\quad$ Stack gas temperature $\left({ }^{\circ} \mathrm{F}\right)$

Ps $\quad=\quad$ Stack pressure (in. $\mathrm{Hg}$ )

\section{Isokinetic Sampling Rate}

$\begin{array}{lll}\text { I } & = & \text { Percent of isokinetic sampling, } \% \\ \mathrm{I}(\%) & = & \frac{\mathrm{K}_{4} \times(\mathrm{Ts}+460) \times \mathrm{Vm}(\mathrm{std}) \times 144}{\mathrm{Ps} \times \mathrm{Vs} \times \mathrm{An} \times \theta \times(1-\mathrm{Bws})} \\ \mathrm{I} & =\frac{0.09450 \times(685+460) \times 42.190 \times 144}{30.49 \times 36.6 \times 0.0707 \times 90 \times(1-0.1332)}=107 \%\end{array}$


Where:

$\begin{array}{lll}\mathrm{K}_{4} & = & \frac{0.09450 \%(\mathrm{in} . \mathrm{Hg})(\mathrm{min})}{\mathrm{R} \times \mathrm{sec}} \\ \text { An } & = & \left.\text { Cross-sectional area of nozzle (in. }{ }^{2}\right) \\ \theta & = & \text { Total sampling time (min) }\end{array}$

Volume of Gas Sample Corrected to $3 \% \mathrm{O}_{2}$

$\mathrm{Vm} *(\mathrm{std}) \quad=\quad$ Volume of gas sample measured by the dry gas meter $(\mathrm{Vm}[\mathrm{std}])$,

* corrected to $3 \%$ oxygen, $\mathrm{Nm}^{3}$

$\mathrm{Vm}^{*}(\mathrm{std}) \quad \mathrm{K}_{5} \times \mathrm{Vm}(\mathrm{std}) \times \frac{21-\% \mathrm{O}_{2}}{18}$

$\mathrm{Vm} *(\mathrm{std}) \quad=\quad 0.02832 \times 42.190 \times \frac{21-3.1}{18}=1.188 \mathrm{Nm}^{3}$

Where:

$\mathrm{K}_{5}$

$=0.02832 \mathrm{~m}^{3} / \mathrm{ft}^{3}$

Mercury

$\mathrm{Hg}\left(\mu \mathrm{g} / \mathrm{Nm}^{3}\right)$

$=\frac{\mu \mathrm{g}}{\mathrm{Vm} *(\mathrm{std})}$

$\mathrm{Hg}$

$=\frac{6.99}{1.188}=5.88 \mu \mathrm{g} / \mathrm{Nm}^{3}$

Particulate $\mathrm{Hg} \quad=\quad$ Sum of mercury from filter and nozzle rinse

Oxidized $\mathrm{Hg}=\quad$ Sum of mercury from $\mathrm{KCl}$ impingers

Elemental $\mathrm{Hg}=\quad$ Sum of mercury from $\mathrm{H}_{2} \mathrm{O}_{2}$ and $\mathrm{KMnO}_{4}$ impingers

MERCURY CEMS

\section{Corrected Mercury Concentration at AHO}

$\mathrm{Hg}_{\mathrm{AHO}}=\quad$ Mercury Concentration, $3 \% \mathrm{O}_{2}$, Dry Basis, AHO Location, $\mu \mathrm{g} / \mathrm{dNm}^{3}$

$\mathrm{Hg}_{\mathrm{AHO}}\left(\mu \mathrm{g} / \mathrm{dNm}^{3}\right)=\mathrm{Hg}_{\mathrm{CEM}} \times\left(\frac{21-3}{21-\% \mathrm{O}_{2}}\right) \times\left(1-\frac{\% \mathrm{CO}_{2}}{100}\right)$

$\mathrm{Hg}_{\text {Ано }}=8.99 \times\left(\frac{21-3}{21-6}\right) \times\left(1-\frac{13}{100}\right)=9.39 \mu \mathrm{g} / \mathrm{dNm}^{3}$

Where:

$\mathrm{Hg}_{\mathrm{CEM}} \quad=\quad$ Mercury concentration measured by CEM 


\section{Corrected Mercury Concentration at Stack}

$\mathrm{Hg}_{\text {STK }}=\quad$ Mercury concentration, $3 \% \mathrm{O}_{2}$, dry basis, stack location, $\mu \mathrm{g} / \mathrm{dNm}^{3}$

$\mathrm{Hg}_{\text {STK }}\left(\mu \mathrm{g} / \mathrm{dNm}^{3}\right)=\mathrm{Hg}_{\mathrm{CEM}} \times\left(\frac{21-3}{21-\% \mathrm{O}_{2}}\right) \times\left(1+\frac{\% \mathrm{H}_{2} \mathrm{O}}{100}\right)$

$\mathrm{Hg}_{\mathrm{STK}} \quad=2.68 \times\left(\frac{21-3}{21-4.6}\right) \times\left(1+\frac{19}{100}\right)=3.50 \mu \mathrm{g} / \mathrm{dNm}^{3}$

\section{$\mathrm{CaCl}_{2}, \mathrm{MgCl}_{2}$, and SEA2 ADDITIONS}

\section{$\mathrm{CaCl}_{2}$ Concentration}

$\begin{array}{ll}\mathrm{Cl}_{(\mathrm{dry})} & =\text { Concentration of chlorine, dry basis, ppm } \\ \mathrm{Cl}_{(\mathrm{dry})}(\mathrm{ppm}) & =\frac{\% \text { solution }}{100} \times \rho \times \gamma \times \mathrm{F}_{\mathrm{SEA}} \times \frac{2 \times \mathrm{M}_{\mathrm{Br}}}{\mathrm{M}_{\mathrm{CaBr}_{2}}} \times \frac{60}{\mathrm{CF}(\mathrm{avg}) \times 2000} \times 10^{6} \\ \mathrm{Cl}_{(\mathrm{dry})} & =\frac{7.5}{100} \times 8.34 \times 1.04 \times 0.11 \times \frac{2 \times 79.91}{200.6} \times \frac{60}{214 \times 2000} \times 10^{6}=7.99 \mathrm{ppm}\end{array}$

Where:

$\begin{array}{lll}\rho & = & \text { Density of } \mathrm{H}_{2} \mathrm{O}(\mathrm{lb} / \mathrm{gal}) \\ \gamma & = & \text { Specific gravity of SEA solution, dimensionless } \\ \mathrm{F}_{\mathrm{SEA}} & = & \text { SEA feed rate }(\mathrm{lb} / \mathrm{hr}) \\ \mathrm{M}_{\mathrm{Cl}} & = & \text { Molecular weight of } \mathrm{Cl} \\ \mathrm{M}_{\mathrm{CaCl} 2} & = & \text { Molecular weight of } \mathrm{CaCl}{ }_{2} \\ \mathrm{CF}(\mathrm{avg}) & = & \text { Coal feed rate }(\mathrm{ton} / \mathrm{hr})\end{array}$

\section{SEA Injection}

$\mathrm{I}_{\mathrm{SEA}} \quad=\quad$ Amount of $\mathrm{Cl}$ injected into pulverizers, based on gas flow, lb/Macf $\mathrm{I}_{\mathrm{SEA}}$

(lb/Macf)

$$
=\frac{\mathrm{Br}_{(\mathrm{dry})}}{10^{6}} \times \frac{\mathrm{CF}(\mathrm{avg}) \times 2000}{60} \times \frac{1000 \times 528}{\mathrm{~F}_{\mathrm{S}}(\mathrm{avg}) \times\left(\mathrm{T}_{\mathrm{AHO}}+460\right)}
$$

ISEA

$$
=\frac{8.20}{10^{6}} \times \frac{214 \times 2000}{60} \times \frac{1000 \times 528}{1214.0 \times(300+460)}=0.033 \mathrm{lb} / \mathrm{Macf}
$$

Where:

$\mathrm{F}_{\mathrm{S}}(\mathrm{avg}) \quad=\quad$ Average stack gas flow $(\mathrm{kscfm})$

$\mathrm{T}_{\mathrm{AHO}} \quad=\quad$ Average $\mathrm{AHO}$ gas outlet temperature $\left({ }^{\circ} \mathrm{F}\right)$ 
PAC INJECTION

I $\quad=\quad$ Amount of PAC injected into duct, based on gas flow, lb/Macf

$\mathrm{I}_{\mathrm{PAC}}(\mathrm{lb} / \mathrm{Macf}) \quad=\quad \frac{\mathrm{F}_{\mathrm{PAC}}}{60} \times \frac{1000 \times 528}{\mathrm{~F}_{\mathrm{S}} \times\left(\mathrm{T}_{\mathrm{AHO}}+460\right)}$

$\mathrm{I}_{\mathrm{PAC}} \quad=\frac{47.8}{60} \times \frac{1000 \times 528}{1213.5 \times(300+460)}=0.46 \mathrm{lb} / \mathrm{Macf}$

Where:

$\mathrm{F}_{\mathrm{PAC}} \quad=\quad \mathrm{PAC}$ feed rate $(\mathrm{lb} / \mathrm{hr})$

$\mathrm{F}_{\mathrm{S}} \quad=\quad$ Stack gas flow $(\mathrm{kscfm})$

COAL ANALYSIS

Heat Input

$\mathrm{Fd} \quad=\quad$ Heat input of fuel, dry basis, dscf $/ 10^{6} \mathrm{Btu}$

$\mathrm{Fd}\left(\mathrm{dscf} / 10^{6} \mathrm{Btu}\right) \quad=10^{6} \times \frac{3.64 \times\left(\% \mathrm{H}_{2}\right)+1.53 \times(\% \mathrm{C})+0.57 \times(\% \mathrm{~S})+0.14 \times\left(\% \mathrm{~N}_{2}\right)-0.46 \times\left(\% \mathrm{O}_{2}\right)}{\mathrm{HV}}$

$\mathrm{Fd}\left(\mathrm{dscf} / 10^{6} \mathrm{Btu}\right) \quad=10^{6} \times \frac{3.64 \times 5.37+1.53 \times 47.32+0.57 \times 0.88+0.14 \times 0.91-0.46 \times 35.79}{8079}$

$\mathrm{Fd} \quad=9421 \mathrm{dscf} / 10^{6} \mathrm{Btu}$

Where:

$\%\left(\mathrm{H}_{2}, \mathrm{C}, \mathrm{S}, \mathrm{N}_{2}, \mathrm{O}_{2}\right)=$ Percent $\left(\mathrm{H}_{2}, \mathrm{C}, \mathrm{S}, \mathrm{N}_{2}, \mathrm{O}_{2}\right)$ by weight

$\mathrm{HV} \quad=\quad$ Heating value $(\mathrm{Btu} / \mathrm{lb})$

\section{Sulfur}

$\mathrm{S}_{(\mathrm{dry})} \quad$ Sulfur, dry basis, $\%$

$\mathrm{S}_{(\mathrm{dry})}(\%)$

$=\frac{\% \mathrm{~S}}{\left(1-\frac{\% \mathrm{H}_{2} \mathrm{O}}{100}\right)}$

$\mathrm{S}_{(\mathrm{dry})}$

$=\frac{0.88}{\left(1-\frac{20.20}{100}\right)}=1.10 \%$

\section{Heating Value}

$\mathrm{HV}_{(\mathrm{dry})} \quad=\quad$ Heating value, dry basis, $\%$ 


$$
\begin{array}{ll}
\mathrm{HV}_{(\text {dry })}(\%) & =\frac{\mathrm{HV}}{\left(1-\frac{\% \mathrm{H}_{2} \mathrm{O}}{100}\right)} \\
\mathrm{HV}_{(\text {dry })} & =\frac{8079}{\left(1-\frac{20.20}{100}\right)}=10,124 \%
\end{array}
$$

\section{Mercury, Volume Based}

$\mathrm{Hg}_{(\mathrm{FGB})} \quad=\quad \mathrm{Hg}$, flue gas basis, $\mu \mathrm{g} / \mathrm{Nm}^{3}$

$\mathrm{Hg}_{(\mathrm{FGB})}\left(\mu \mathrm{g} / \mathrm{Nm}^{3}\right)=\mathrm{Hg}_{(\text {dry })} \times 10^{6} \times\left(1-\frac{\% \mathrm{H}_{2} \mathrm{O}}{100}\right) \times 453.6 \times\left(\frac{18}{21 \times \mathrm{HV} \times \mathrm{F}_{\mathrm{d}} \times 0.02832}\right)$

$\mathrm{Hg}_{(\mathrm{FGB})}$

$=0.0534 \times 10^{6} \times\left(1-\frac{20.20}{100}\right) \times 453.6 \times\left(\frac{18}{21 \times 8079 \times 9421 \times 0.02832}\right)$

$\mathrm{Hg}_{(\mathrm{FGB})} \quad=\quad 7.69 \mu \mathrm{g} / \mathrm{dNm}^{3}$

Where:

$\mathrm{Hg}_{(\mathrm{dry})} \quad=\quad$ Mercury measured in coal, dry basis $(\mathrm{ppm})$

Mercury, Energy Based

$\mathrm{Hg}_{(\mathrm{FGB})} \quad=\quad \mathrm{Hg}$, flue gas basis, $\mathrm{lb} / \mathrm{TBtu}$

$\mathrm{Hg}_{\text {(FGB) }}(\mathrm{lb} / \mathrm{TBtu})=\frac{\mathrm{Hg}_{(\text {dry })} \times 10^{6}}{\mathrm{HV}} \times\left(1-\frac{\% \mathrm{H}_{2} \mathrm{O}}{100}\right)$

$\mathrm{Hg}_{(\mathrm{FGB})} \quad=\quad \frac{0.0534 \times 10^{6}}{8079} \times\left(1-\frac{20.20}{100}\right)=5.27 \mathrm{lb} / \mathrm{TBtu}$ 


\section{APPENDIX C}

\section{STANDARD OPERATING PROCEDURE FOR COAL/ASH MINERAL ANALYSIS BY COMPUTER-CONTROLLED SCANNING ELECTRON MICROSCOPY}




\section{Scope}

1.1 This procedure is used for sizing, chemically classifying, and quantifying the inorganic constituents in coal and coal ash using a computer-controlled scanning electron microscopy (CCSEM) technique (Lee and Kelly, 1980; Huggins and others, 1980, 1982).

\section{Summary of Method}

2.1 Coal to be analyzed is pulverized to a standard combustion grind ( $\sim 80 \%$ of the particles -200 mesh), mounted in carnauba wax, cross-sectioned, and polished. Coal ash is ultrasonically dispersed and mounted on filter paper or in epoxy resin. Ash epoxy mounts are cross-sectioned and polished. Samples are sputter-coated with carbon to minimize electron-beam charging artifacts. An automated SEM, operating in the back-scattered electron (BSE) imaging mode, is programmed to scan in a grid pattern the entire sample.

2.2 A modified version of NORAN Instruments Feature Sizing and Chemical Typing program is used to locate, size, and chemically analyze individual coal/ash mineral particles. Mineral particles are automatically detected by an increase in the BSE signal above a preset video threshold, and a binary image is created for the coal and mineral particles. Image analysis is used to determine mineral particle minimum, maximum, and average diameter; perimeter; shape factor (circularity); and whether the mineral particle is included or excluded from a coal particle. After image analysis, an energy-dispersive x-ray (EDX) spectrum $(0-10 \mathrm{keV})$ is acquired from the particle's center. Spectral regions-of-interest (ROI) are defined to measure the characteristic x-ray emission intensities of common, mineral-forming, major and minor elements $(\mathrm{Na}, \mathrm{Mg}, \mathrm{Al}, \mathrm{Si}, \mathrm{P}, \mathrm{S}, \mathrm{Cl}, \mathrm{K}, \mathrm{Ca}, \mathrm{Ti}, \mathrm{Fe}$, and $\mathrm{Ba})$. X-ray emission intensities are quantified using the atomic number and x-ray absorption and fluorescence (ZAF) correction method. X-ray quantitative data, location, size, and shape parameters for a statistically significant number of particles are collected at three magnifications ( $50 \times$ for 22 to $100 \mu \mathrm{m}, 250 \times$ for 4.6 to $22 \mu \mathrm{m}$, and $800 \times$ for $1.0-$ to 4.6- $\mu \mathrm{m}$-diameter particles) and transferred to a personal computer where they are tabulated and stored to disk for data reduction, report generation, and archival.

2.3 A particle characterization (PARTCLASS) program classifies the Feature Sizing and Chemical Typing analyses based on compositional criteria into one of 33 mineral/chemical and mineral association categories. Analyses that do not conform to any of the specified criteria are termed unclassified. The program allocates the classified particles according to average diameter based on the pixel dimension of equivalent spheres into six intervals (1.0-2.2 $\mu \mathrm{m}, 2.2-4.6 \mu \mathrm{m}, 4.6-10 \mu \mathrm{m}, 10-22 \mu \mathrm{m}, 22-46 \mu \mathrm{m}$, and 46-100 $\mu \mathrm{m})$ so that the size distribution of mineral/chemical types can be determined. The particle-diameter intervals are a geometric progression based on the cube root of ten. A geometric size distribution is used to lessen sectioning effects present in fly ash epoxy mounts that cause the measured cross-sectional diameters of the particles to be less than or equal to the maximum diameter of the particles (DeHoff and Rhines, 1968; Hurley, 1990). A report is generated that summarizes the results in a series of tables containing information on the number and proportions of minerals in their respective size intervals. Mineral weight 
percentages are calculated assuming that particle areas are proportional to volumes (e.g., point-counting method of Chayes [1950]) and mineral densities are constants (Table 1). The CCSEM analysis generates three Feature Sizing and Chemical Typing raw data files, one for each magnification that each have a ".size" extension. A PARTClass data output file and a summary report output file are archived on CD via a computer network system.

\section{Significance and Use}

3.1 Quantitative coal/ash mineral analysis and size analysis are useful in characterizing the physical and chemical properties of coal; predicting the inorganic transformations that occur during combustion; understanding the deposition, slagging, and fouling characteristics of combusted materials; and determining the potential utilization or disposal of ash by-products.

3.2 The reader is referred to Zygarlicke and Steadman (1990), Zygarlicke and others (1990), and Jones and others (1992) for additional information and examples of specific CCSEM applications.

3.3 The CCSEM analysis technique classifies inorganic particles solely by chemical composition and, therefore, cannot distinguish polymorphous minerals (e.g., quartz versus cristobalite) or crystalline from amorphous phases.

\section{Equipment}

4.1 Automated Analytical Scanning Electron Microscope - Two JEOL 5800 series SEMs equipped with a NORAN Instruments' Pioneer x-ray detector and a Voyager IV x-ray analyzer with image analysis and stage automation software.

4.2 Pulverizer - Angstrom Shatterbox equipped with tungsten carbide pulverizing vessels.

4.3 Analytical Balance, sensitive to $0.1 \mathrm{mg}$.

4.4 Slow-Speed Diamond Saw - Buehler Isomet.

4.5 Riffle Sampler.

4.6 Vacuum Oven - Lab-Line Instruments, Inc.

4.7 Filters - 0.45- $\mu \mathrm{m}$ millipore.

4.8 Carbon Coaters - Emitech, Inc. K450; SPI Vacu-Prep II, Denton Vacuum 502A Carbon Evaporator.

4.9 Polishers - Buehler Minimet; Buehler Ecomet. 
4.10 Polishing Materials - Buehler Carbimet Paper Discs (120, 180, 240, 320, 400, and 600 grit); Buehler Diamond Polishing Compound (1.0, 0.25, and $6 \mu \mathrm{m})$.

\section{Reagents}

\subsection{Carnauba Wax.}

5.2 Epoxy - Buehler Epoxide Resin.

5.3 Dispersing Agent - Coulter type B.

5.4 Purity of Reagents - Reagent-grade ethyl alcohol, toluene, and trichloro-trifluoroethane.

\section{Preparation of Coal}

6.1 Bulk coal sample is pulverized to a standard combustion grind ( $\sim 80 \%$ of the particles -200 mesh).

6.2 A representative sample is obtained by splitting.

6.3 The coal subsample is dried in a vacuum oven at $70^{\circ} \mathrm{C}$ to constant weight.

6.4 Two grams of coal is mixed with three grams of molten carnauba wax in a 1-in. (2.54-cm)diameter mold and allowed to cool under ambient conditions.

6.5 The resulting coal-carnauba pellet is cross-sectioned using a slow-speed diamond saw.

6.6 The sectioned pellet surface is polished according to ASTM Standard Practice D2797 (ASTM, 1991). The final polishing steps are performed with 6-, 1-, and 0.25- $\mu \mathrm{m}$ diamond paste.

6.7 Coal pellet is cleaned by sonication in trichloro-trifluoroethane, or in some cases, toluene is used.

6.8 The coal pellet is sputter-coated with carbon to minimize electron-beam charging artifacts.

\section{Preparation of Coal Ash}

7.1 Filter Mount - A representative sample of ash is collected on the tip of a microspatula and placed in a $10-\mathrm{mL}$ beaker. A dispersing agent (2-4 drops) and $5 \mathrm{~mL}$ of ethyl are added to the sample. The ash mixture is sonicated for 10 minutes and then filtered. The ash filter is mounted onto a carbon stub with carbon tape. 
7.2 Ash-Epoxy Mount - Three grams of ash is mixed with 5 grams of epoxy resin in a 1-in. $(2.54-\mathrm{cm})$-diameter mold and allowed to cool under ambient conditions.

7.2.1 The resulting ash-epoxy pellet is cross-sectioned using a slow-speed diamond saw.

7.2.2 The sectioned pellet surface is polished according to ASTM Standard Practice D2797 (ASTM, 1991). The final polishing steps are performed with 6-, 1-, and $0.25-\mu \mathrm{m}$ diamond paste.

7.2.3 Ash pellet is cleaned by sonication in trichloro-trifluoroethane.

7.3 The ash samples are sputter-coated with carbon to minimize electron-beam charging artifacts.

\section{Image and Data Acquisition Parameters}

8.1 The SEM is operated at an accelerating voltage of $15 \mathrm{kV}$, probe current of $1.0 \mathrm{nA}$, working distance of $21 \mathrm{~mm}$, and at magnifications of 50, 250, and 800 in the BSE imaging mode.

8.2 Analyses are performed at three magnifications of 50, 250, and 800 corresponding to particle diameter range limits of $22-100 \mu \mathrm{m}, 4.6-22 \mu \mathrm{m}$, and $1.0-4.6 \mu \mathrm{m}$, respectively, with at least 1200 particles analyzed at each magnification or until the entire sample is analyzed.

\section{Feature Sizing and Chemical Typing}

9.1 NORAN Instruments Feature Sizing and Chemical Typing program is used to locate and size coal/ash mineral particles.

9.2 Mineral particles are detected by an increase of the BSE signal above a preset BSE video signal threshold. The threshold is set manually between the brightness of coal and minerals or between the brightness of ash particles and mounting medium.

9.3 A binary image is created for the coal particles and the mineral particles and a third image for the coal plus mineral particles which is later used for an ash percent calculation. The maximum, minimum, and average diameters are determined based on the pixel dimension of the binary image, and the particle's area, perimeter, and shape factor are calculated. The particle's centroid position, $\mathrm{x}-\mathrm{y}$ coordinates, are also recorded to prevent duplication of analysis. 


\section{Energy-Dispersive X-Ray Spectrum Acquisition and Processing}

10.1 NORAN Instruments Feature Sizing and Chemical Typing program is used to chemically analyze coal/ash particles.

10.2 An EDX spectrum is acquired $(0-10 \mathrm{keV})$ for 10 seconds on the center of mass for each particle that meets the size criteria based on the pixel dimensions of an equivalent sphere.

10.3 The characteristic $\mathrm{x}$-ray intensities of the common mineral-forming major and minor elements $(\mathrm{Na}, \mathrm{Mg}, \mathrm{Al}, \mathrm{Si}, \mathrm{P}, \mathrm{S}, \mathrm{Cl}, \mathrm{K}, \mathrm{Ca}, \mathrm{Ti}, \mathrm{Fe}$, and $\mathrm{Ba}$ ) are $\mathrm{ZAF}$-corrected and the spectra are stored to a file.

\section{Feature Sizing and Chemical Typing Raw Data File Designation, Format, and Content}

11.1 Feature Sizing data files for the $50 \times, 250 \times$, and $800 \times$ analyses are designated as xxxxhi.size, xxxxmed.size, and xxxxlow.size, where $\mathrm{xxxx}$ is a sample number or some other identifying number. These files are converted to comma-delimited files (.csv) and transferred to a PC where they are put in the proper format for input to PARTCLASS. Along with each size file, a second separate file is created that contains x-ray counts for pre-defined elemental regions of interest for each spectrum. These files are designated as xxxxhi.prn, xxxxmed.prn, and xxxxlow.prn, where $\mathrm{xxxx}$ is the same descriptor as the .size files. Another .prn file is associated with each CCSEM data set which is the total number of pixels representing both mineral and coal particles for each frame. These data are used to determine the area per cent of mounting medium devoid of coal and mineral/ash particles and to calculate ash content.

11.2 Feature Sizing files contain 30 columns of data for each mineral particle analysis in the following format:

Frame, Part. \#, Area, Cumulative Number, Binary Composition, X-Coordinate, Y-Coordinate, Perimeter, Mean Projection, Maximum Projection, Minimum Projection, Circularity, Chemical Type, Figure of Merit, Quant Chi Squared, Total, Na, Mg, Al, Si, P, $\mathrm{S}, \mathrm{Cl}, \mathrm{K}, \mathrm{Ca}, \mathrm{Fe}, \mathrm{Ba}, \mathrm{Ti}$, Binary Phase 1 Area, Binary Phase 2 Area.

where:

Frame \# = Frame number corresponding to the image area that the particle was located in during analysis. Each image collected on a sample is referred to as a frame, and each frame is consecutively numbered within a data file.

Part. \# = Particle number $(1,2,3, \ldots)$ corresponding to the order in which a particle was analyzed. Each particle analyzed is assigned a consecutive number within a data file.

Area $=$ The number of pixels defining a particle times the pixel area measured in square microns $\left(\mu \mathrm{m}^{2}\right)$. 
Cumulative Number $=$ Cumulative particle number. Each particle is assigned a number in the overall analysis.

Binary Composition $=$ Included or excluded mineral grain. Two binary phases are defined, the mineral grains and the coal particles. A value of 1 is assigned to the pixels representing each phase in the binary image and all other pixels are assigned a value of 0 . A mineral grain that is excluded from the coal matrix is assigned a value of 10 in the binary composition column to indicate that the particle is present in the binary phase representing the minerals and absent in the binary phase representing the coal phase. An included mineral is designated with an 11 to indicate that both the mineral and coal phases are present at the pixel location of the corresponding spectral analysis.

$\mathrm{X}$-Coordinate and $\mathrm{Y}$-Coordinate $=\mathrm{X}$ - and $\mathrm{Y}$-coordinates for center of particle mass. Average particle pixel $\mathrm{X}$ - and $\mathrm{Y}$-coordinates. This number is recorded to prevent duplicate analysis and to locate particles on stored BSE images for additional analysis.

Perimeter $=$ Sum of the distances between centers of adjacent pixels on the particle perimeter, times pixel width, measured in $\mu \mathrm{m}$.

Mean Proj., Min. Proj., Max. Proj. $=$ Average, minimum, and maximum cross-sectional caliper dimension measured in $\mu \mathrm{m}$.

Shape $=$ Shape factor $($ circularity $)$ value calculated as $(\text { Perimeter })^{2} /($ area $\times 4 \pi)$ and is unitless.

Chemical Type $=$ The file name of the chemical type whose composition compares the best to the analyte particle's chemical composition.

Figure of Merit $=$ An indicator of the similarity between the chemical type's compositional criteria and a given particle's chemical composition.

Quant Chi Squared $=$ An indicator of the goodness of fit between the energy-dispersive reference spectra obtained on mineral standards and the analyte particle spectrum.

Total $=$ Total elemental oxide weight percent.

$\mathrm{Na}, \mathrm{Mg}, \mathrm{Al}, \mathrm{Si}, \mathrm{P}, \mathrm{S}, \mathrm{Cl}, \mathrm{K}, \mathrm{Ca}, \mathrm{Fe}, \mathrm{Ba}, \mathrm{Ti}=$ elemental oxide concentrations (wt\%).

Binary Phase 1 Area, Binary Phase 2 Area $=$ The pixel area (\%) that a given binary phase occupies in a frame.

11.3 Three separate files containing $x$-ray counting data are generated. They are labeled xxxxlow.prn, xxxxmed.prn, and xxxxhi.prn where xxxx represents the sample number. These files consist of a single column of alternating spectrum file name and total $\mathrm{x}$-ray counts for the spectrum. 
11.4 For each magnification, a Feature Sizing and Chemical Typing file is created (.csv), an x-ray counts file is created (.prn), and a total area file is created (xxxxxxxx.prn where xxxxxxxx represents the fund and sample numbers).

\subsection{Data Manipulation}

12.1 The three raw data files (.csv files), the three x-ray count files (.prn files), and the pixel area for each frame are combined using a $\mathrm{C}++$ program, MasterCCS.exe. This program combines and arranges the raw data files to a format appropriate for input to PARTCLASS, the coal/ash mineral classification program.

12.2 A column containing the total number of x-ray counts is added to the elemental analysis data for input to PARTCLASS.

X-Ray Counts $=$ Total $x$-ray counts acquired for the particle. This value is used to exclude particles that emit insufficient $\mathrm{X}$-ray counts $(<600)$ for chemical characterization.

12.3 The three Feature Sizing and Chemical Typing raw data files $(50,250$, and 800 magnification analyses), the x-ray counts files, and the \% epoxy files are formatted for input into the PARTCLASS coal/ash mineral classification program.

\subsection{Data Reduction}

13.1 A Fortran program, PARTCLASS, classifies the Feature Sizing and Chemical Typing analyses based on elemental relative intensities, relative-intensity ratios, and stoichiometric criteria into one of $33 \mathrm{mineral} / \mathrm{chemical}$ and mineral association categories (Table C-1 on p C-14).

13.2 Analyses that do not conform to any of the specified criteria are termed unclassified.

13.3 The classified particles are allocated according to average diameter into six intervals (1.0-2.2 $\mu \mathrm{m}, 2.2-4.6 \mu \mathrm{m}, 4.6-10 \mu \mathrm{m}, 10-22 \mu \mathrm{m}, 22-46 \mu \mathrm{m}, 46-100 \mu \mathrm{m})$.

\section{PARTCLASS Data and Summary Report Output File Designation, Format, Content, and Calculations}

14.1 The PARTCLASS program produces a data output file and summary report output file. The data and summary report output files are designated with a four-digit number followed by an "o" and "s", respectively, and a "prn" extension (i.e., \#\#\#\#.prn and \#\#\#\#s.prn). The PARTCLASS data file is an augmented version of the Feature Sizing and Chemical Typing data file with 21 columns of data in the following format: 
Part. \#, X-Ray Counts, Na, Mg, Al, Si, P, S, Cl, K, Ca, Fe, Ba, Ti, X-Coord., Y-Coord., Avg. Diam., Area, Shape, Frame \#, Type.

The column heading definitions are akin to the Feature Sizing and Chemical Typing data files as arranged by the MasterCCS program. The "Type" column, however, contains classification numbers corresponding to a mineral/chemical or mineral association category assigned by the PARTCLASS program (Table C-1).

14.2 The summary report file presents the manipulated data in a tabular format. An explanation of the report's content on a page-by-page basis is provided below. Some of the parameters and tables described apply only to the analysis of coal.

\subsubsection{Summary Page}

14.2.1.1 Percent Epoxy Used - Average area percent of epoxy or carnauba wax mounting medium for an analyzed coal sample. Value is estimated by summing the area of each pixel used to define the binary phases. Each frame is calculated, and an average value is calculated using all frames from all magnifications.

14.2.1.2 Total Mineral Area Analyzed at $800 \mathrm{Mag}$. - Summation of the cross-sectional areas $\left(\mu \mathrm{m}^{2}\right)$ measured at $800 \mathrm{X}$ for the 1- to $4.6-\mu \mathrm{m}$-diameter particles.

14.2.1.3 Normalized Area Analyzed at 800.0 Mag. - The total mineral area analyzed at $800 \mathrm{X}$ is normalized by multiplying by $\left(F^{1} N^{1}\right) /\left(F^{3} N^{3}\right)$ where $F^{1}$ and $F^{3}$ are the field sizes $\left(\mu \mathrm{m}^{2}\right)$ at 50X and $800 \mathrm{X}$, respectively, and $N^{1}$ and $N^{3}$ are the number of frames collected on the sample at $50 \mathrm{X}$ and $800 \mathrm{X}$, respectively. The actual sample area scanned by the electron microbeam at high magnification (800X) for the 1- to $4.6-\mu \mathrm{m}$-size particles is smaller than the sample area scanned at low magnification (50X) for the 22- to $100-\mu \mathrm{m}$-size particles. Therefore, the total mineral area analyzed at $800 \mathrm{X}$ is normalized so that the 1- to 4.6- $\mu \mathrm{m}$-size particles have equal statistical representation.

14.2.1.4 Mineral Area Analyzed 250.0 Mag. - Summation of the cross-sectional areas $\left(\mu \mathrm{m}^{2}\right)$ measured at $240 \mathrm{X}$ for the 4.6 - to $22-\mu \mathrm{m}$-diameter particles.

14.2.1.5 Normalized Area Analyzed 250.0 Mag. - The total mineral area analyzed at 250X is normalized by multiplying by $\left(F^{1} N^{1}\right) /\left(F^{2} N^{2}\right)$ where $F^{1}$ and $F^{2}$ are the field sizes $\left(\mu \mathrm{m}^{2}\right)$ at $50 \mathrm{X}$ and $250 \mathrm{X}$, respectively, and $N^{1}$ and $N^{2}$ are the number of frames collected on the sample at $50 \mathrm{X}$ and $250 \mathrm{X}$, respectively. The actual sample area scanned by the electron microbeam at intermediate magnification $(250 \mathrm{X})$ for the 4.6- to $22-\mu \mathrm{m}$-size particles is smaller than the sample area scanned at low magnification $(50 \mathrm{X})$ for the $22-$ to $100-\mu \mathrm{m}$-size particles. Therefore, the total mineral area analyzed at $250 \mathrm{X}$ is normalized so that the 4.6- to $22-\mu \mathrm{m}$-size particles have equal statistical representation. 
14.2.1.6 Total Mineral Area Analyzed at 50.0 Mag. - Summation of the crosssectional areas $\left(\mu \mathrm{m}^{2}\right)$ measured at $50 \mathrm{X}$ for the $22-$ to $100-\mu \mathrm{m}$-diameter particles.

14.2.1.7 Number of Frames at 800, 250, and 50 Mag. - Total number of frames collected on the sample at $800 \mathrm{x}, 250 \mathrm{X}$, and 50X, respectively.

14.2.1.8 Total Mineral Area on a Coal Basis - The total mineral area analyzed is expressed on a coal basis, $M_{t}^{c}$, where $M$ is the total mineral area analyzed $(M=$ normalized area analyzed at high mag. + normalized area analyzed at intermediate mag. + total mineral area analyzed at low mag.) and $C$ is the total coal area imaged $\left(\mu \mathrm{m}^{2}\right)$. $C$ is determined from:

$$
C=\frac{A(100-E)}{100}
$$

where $A$ is the total area $\left(\mu \mathrm{m}^{2}\right)$ imaged on the sample $\left(A=F^{1} N^{1}\right)$, and $E$ is the estimated area percent of mounting medium (percent epoxy used value).

14.2.1.9 Total Mineral Weight Percent on a Coal Basis - The total mineral content by weight on a coal basis, $W_{t}^{c}$, is calculated from

$$
W_{t}^{c}=\left(\frac{\sum_{j=1}^{N P} A_{j} d_{j}^{i}}{d_{c}(C-M)+\sum_{j=1}^{N P} A_{j} d_{j}^{i}}\right) 100
$$

where $A_{\mathrm{j}}$ is the area for particle $j, d_{j}^{i}$ is the density of mineral/chemical classification category $i$ (Table $\mathrm{C}-1$ ) assigned to particle $j, N P$ is the total number of particles analyzed, $C$ is the total coal area imaged, $M$ is the total mineral area analyzed, and $d_{\mathrm{c}}$ is the density of coal $\left(d_{\mathrm{c}}=1.4 \mathrm{~g} / \mathrm{cm}^{3}\right)$.

14.2.1.10 Total Number of Points Analyzed - Total number of mineral/ash particles detected and analyzed.

14.2.1.11 Number of Points under Threshold - Number of particle analyses excluded from the PARTCHAR mineral classification routine because of an insufficient $\mathrm{x}$-ray signal for chemical characterization. Particles that emit $<600$ total $\mathrm{x}$-ray counts are excluded.

14.2.1.12 Weight Percent on a Mineral Basis - The weight proportions of each mineral/chemical classification category $i$ on a mineral basis, $W_{i}^{m}$, are calculated from 


$$
W_{i}^{m}=\left(\frac{\left(A_{i} d_{i}\right)}{\sum_{j=1}^{N P} A_{j} d_{j}^{i}}\right) 100
$$

where $A_{\mathrm{i}}$ is the total area of the particles assigned to mineral/chemical classification category $i, d_{\mathrm{i}}$ is the density $\left(\mathrm{g} / \mathrm{cm}^{3}\right)$ for mineral/chemical classification category $i$ (Table $\mathrm{C}-1$ ), $A_{\mathrm{j}}$ is the area of particle $j, d_{j}^{i}$ is the density of mineral/chemical classification category $i$ assigned to particle $j$, and $N P$ is the total number of particles analyzed.

\subsubsection{Page 1}

14.2.2.1 Area in Each Size Range - Summation of the measured cross-sectional areas $\left(\mu \mathrm{m}^{2}\right)$ for each mineral/chemical and mineral association category in each diameter interval. The values for the 1- to $22-\mu \mathrm{m}$-diameter particles are not normalized.

\subsubsection{Page 2}

14.2.3.1 Normalized Area in Each Size Range - Essentially the same data as on page 1 , except that the cross-sectional areas for the 1 - to $22-\mu \mathrm{m}$-diameter particles have been normalized.

\subsubsection{Page 3}

14.2.4.1 Area Percent Mineral Basis - The total area of the particles assigned to each mineral/chemical classification category, $A_{\mathrm{i}}$ (page 2 ), is converted to area percent by:

$$
\left(\frac{A_{i}}{M}\right) 100
$$

where $M$ is the total mineral area analyzed.

\subsubsection{Page 4}

14.2.5.1 Weight Percent Mineral Basis - These data are also presented on the summary page. Refer to summary page, item 13 for an explanation.

\subsubsection{Page 5}

14.2.6.1 Mineral Area Percent Coal Basis - The area percent on a mineral basis values from page 3 are converted to a coal basis by multiplying by $(M / C)$ where $M$ is the total mineral area analyzed and $C$ is the total coal area imaged. These values are equivalent to volume percent, assuming that a representative planar section of the coal was analyzed. 


\subsubsection{Page 6}

14.2.7.1 Weight Percent Coal Basis - The weight percent of each mineral/chemical classification category $i$ on a coal basis, $W_{i}^{c}$, is determined by

$$
W_{i}^{c}=\left(\frac{A_{i} d_{i}}{d_{c}(C-M)+\sum_{j=1}^{N P} A_{j} d_{j}^{i}}\right) 100
$$

where $A_{\mathrm{i}}$ is the total area of the particles assigned to mineral/chemical classification category $i, d_{\mathrm{i}}$ is the density $\left(\mathrm{g} / \mathrm{cm}^{3}\right)$ of mineral/chemical classification category $i, A_{\mathrm{j}}$ is the area of particle $j, d_{j}^{i}$ is the density of mineral/chemical category $i$ assigned to particle $j, N P$ is the total number of particles analyzed, $C$ is the total coal area imaged, $M$ is the total mineral area analyzed, and $d_{\mathrm{c}}$ is the density of coal $\left(d_{\mathrm{c}}=1.4 \mathrm{~g} / \mathrm{cm}^{3}\right)$.

\subsubsection{Page 7}

14.2.8.1 Distribution by Percent of Each Mineral Phase - The distribution percent, $D_{\mathrm{i}}$, of mineral/chemical phase $i$ is determined by

$$
D_{i}=\left(\frac{W_{i}^{s}}{W_{i}^{t}}\right) 100
$$

where $W_{i}^{s}$ is the weight percent of mineral/chemical classification category $i$ in the average particle diameter interval $s$, and $W_{i}^{t}$ is the total weight percent of mineral/chemical classification category $i$.

\subsubsection{Page 8}

14.2.9.1 Number of Particles in Each Size Range - Actual number of particles detected and analyzed in their respective diameter intervals.

\subsubsection{Page 9}

14.2.10.1 Distribution of Mineral Phases (frequency percent) - The total number of particles analyzed for each mineral/chemical classification category (page 8) are converted to frequency percent by dividing by the total number of points analyzed and multiplying by 100 . 


\section{Precision, Bias, and Accuracy}

15.1 The evaluation of the performance characteristics of the CCSEM method has been impeded because there are no certified coal or coal ash mineral standards available, and there are only a very limited number of laboratories employing CCSEM available to perform collaborative testing.

15.2 Casuccio et al. (1990) conducted an interlaboratory coal testing study involving six laboratories to evaluate repeatability and reproducibility. The data from four of the participating were evaluated. The repeatability relative standard deviation for major minerals was $<20 \%$. The reproducibility relative standard deviation for major minerals ( $>5$ weight $\%$ on a mineral basis) was $\leq 35 \%$.

15.3 Galbreath et al. (1996) conducted an international interlaboratory evaluation of CCSEM involving six laboratories to evaluate repeatability and reproducibility. A total of five analyses were preformed by most of the laboratories on three bituminous coal samples. Repeatability relative standard deviation was $<20 \%$ for the four minerals analyzed: calcite, kaolinite, pyrite, and quartz. Reproducibility relative standard deviations $\left(\mathrm{RSD}_{\mathrm{R}}\right)$ ranged from 21 to $83 \%$. Reproducibility of the kaolinite results was the poorest, with an average $\mathrm{RSD}_{\mathrm{R}}$ of $60 \%$, and pyrite was the best, with an average $\mathrm{RSD}_{\mathrm{R}}$ of $22 \%$. The reproducibility of calcite and quartz analysis results was similar, with an average $\mathrm{RSD}_{\mathrm{R}}$ of $38 \%$ and $36 \%$, respectively. Although pyrite content was determined the most precisely, normative mineral calculations indicated that the results were overbalanced.

15.4 Statistical Quality Control - Analytical bias and precision are evaluated on a continuous basis by periodically analyzing the Pittsburgh No. 8 and Illinois No. 6 coals from the Argonne Premium Coal Sample Program (Vorres, 1989). The Pittsburgh No. 8 coal was analyzed ten times, and the Illinois No. 6 coal was analyzed four times over an 8-month period (March through October 1992) to establish quality control charts. The relative standard deviation for major minerals ( $>5$ weight $\%$ on a mineral basis) was $<20 \%$; the relative standard deviation for minor minerals ( $1-5$ weight $\%$ on a mineral basis) was $<40 \%$; and the relative standard deviation for trace minerals ( $<1$ weight $\%$ on a mineral basis) was $50 \%$.

15.4 Qualitative crystalline phase analysis data, obtained by x-ray powder diffraction, are referred to for confirmation of CCSEM phase identifications whenever possible.

\section{Referenced Documents}

American Society for Testing and Materials (ASTM). Standard Practice for Preparing Coal Samples for Microscopical Analysis by Reflected Light (D2797), Annual Book of ASTM Standards; 1991, Vol. 5.05, pp 308-311.

Casuccio, G.S.; Gruelich, F.A.; Hamburg, G.; Huggins, F.E.; Nissen, D.A.;Vleeskens, J.M. Coal Mineral Analysis: A Check on Interlaboratory Agreement. Scanning Microscopy 1990, 4 (2), 227-236. 
Chayes, F. On the Bias of Grain-Size Measurements Made in Thin Section. Journal of Geology 1950, 58, 156-160.

DeHoff, R.T.; Rhines, F.N. Quantitative Microscopy; Materials Science and Engineering Series, McGraw-Hill Book Company, 1968; 422 p.

Galbreath, K.; Zygarlicke, C.; Casuccio, G.; Moore, T.; Gottlieb, P.; Agron-Olshina, N.; Huffman, G.; Shah, A.; Yang, N.; Vleeskens, J.; Hamburg, G. Collaborative Study of Quantitative Coal Mineral Analysis Using Computer-Controlled Scanning Electron Microscopy. Fuel 1996, 75 (4), 424-430.

Huggins, F.E.; Kosmack, D.A.; Huffman, G.P.; Lee, R.J. Coal Mineralogies by SEM Automatic Image Analysis. Scanning Electron Microscopy 1980, I, 531-540.

Huggins, F.E.; Huffman, G.P.; Lee, R.J. Scanning Electron Microscope-Based Automated Image Analysis (SEM-AIA) and Mössbauer Spectroscopy: Quantitative Characterization of Coal Minerals. In Coal and Coal Products: Analytical Characterization Techniques; Fuller, E.L., Jr., Ed.; American Chemical Society Symposium Series 205; 1982; Chapter 12, pp. 239-258.

Hurley, J.P. A Pilot-Scale Study of the Formation of Ash During Pulverized Low-Rank Coal Combustion; University of North Dakota, Ph.D. Dissertation, 1990; 247 p.

Jones, M.L.; Kalmanovitch, D.P.; Steadman, E.N.; Zygarlicke, C.J.; Benson, S.A. Application of SEM Techniques to the Characterization of Coal and Coal Ash Products. In Advances in Coal Spectroscopy; Meuzelaar, M.L.C., Ed.; Plenum Publishing Corp.: New York, 1992; Chapter 1, pp. 1-27.

Lee, R.J.; Kelly, J.F. Overview of SEM-Based Automated Image Analysis. Scanning Electron Microscopy. 1980, I, 303-310.

Vorres, K.S. Users Handbook for the Argonne Premium Coal Sample Program; Argonne National Laboratory, 1989; $64 \mathrm{p}$.

Zygarlicke, C.J.; Steadman, E.N. Advanced SEM Techniques to Characterize Coal Minerals. Scanning Microscopy 1990, 4 (3), 579-590.

Zygarlicke, C.J.; Steadman, E.N.; Benson, S.A. Studies of Transformations of Inorganic Constituents in a Texas Lignite During Combustion. Prog. Energy Combust. Sci. 1990, 16, 195-204. 


\begin{tabular}{|c|c|c|c|}
\hline $\begin{array}{l}\text { Classification } \\
\text { Number }\end{array}$ & $\begin{array}{c}\text { Mineral/Chemical \& } \\
\text { Mineral Association } \\
\text { Categories } \\
\end{array}$ & $\begin{array}{l}\text { Density } \\
\left(\mathrm{g} / \mathrm{cm}^{3}\right)\end{array}$ & $\begin{array}{c}\text { Compositional Criteria } \\
\text { (percent relative } \\
\text { x-ray intensity) }\end{array}$ \\
\hline 1 & Quartz & 2.65 & $\mathrm{Al} \leq 5, \mathrm{Si} \geq 80$ \\
\hline 2 & Iron Oxide & 5.30 & $\begin{array}{l}\mathrm{Mg} \leq 5, \mathrm{Al} \leq 5, \mathrm{Si}<10, \mathrm{~S} \leq 5, \\
\mathrm{Fe} \geq 80\end{array}$ \\
\hline 3 & Periclase & 3.61 & $\mathrm{Mg} \geq 80, \mathrm{Ca} \leq 5$ \\
\hline 4 & Rutile & 4.90 & $\mathrm{~S} \leq 5, \mathrm{Ti}+\mathrm{Ba} \geq 80$ \\
\hline 5 & Alumina & 4.00 & $\mathrm{Al} \geq 80$ \\
\hline 6 & Calcite & 2.80 & $\begin{array}{l}\mathrm{Mg} \leq 5, \mathrm{Al} \leq 5, \mathrm{Si} \leq 5, \mathrm{P} \leq 5 \\
\mathrm{~S}<10, \mathrm{Ca} \geq 80, \mathrm{Ti} \leq 5, \mathrm{Ba} \leq 5\end{array}$ \\
\hline 7 & Dolomite & 2.86 & $\mathrm{Mg}>5, \mathrm{Ca}>10, \mathrm{Ca}+\mathrm{Mg} \geq 80$ \\
\hline 8 & Ankerite & 3.00 & $\begin{array}{l}\mathrm{Mg}<\mathrm{Fe}, \mathrm{S}<15, \mathrm{Ca}>20 \\
\mathrm{Fe}>20, \mathrm{Ca}+\mathrm{Mg}+\mathrm{Fe} \geq 80\end{array}$ \\
\hline 9 & Kaolinite & 2.65 & $\begin{array}{l}\mathrm{Na} \leq 5, \mathrm{Al}+\mathrm{Si} \geq 80, \mathrm{~K} \leq 5, \mathrm{Ca} \leq 5, \\
0.8<\mathrm{Si} / \mathrm{Al}<1.5, \mathrm{Fe} \leq 5\end{array}$ \\
\hline 10 & Montmorillonite & 2.50 & $\begin{array}{l}\mathrm{Na} \leq 5, \mathrm{Al}+\mathrm{Si} \geq 80, \mathrm{~K} \leq 5, \mathrm{Ca} \leq 5, \\
1.5<\mathrm{Si} / \mathrm{Al}<2.5, \mathrm{Fe} \leq 5\end{array}$ \\
\hline 11 & K-Al Silicate & 2.60 & $\begin{array}{l}\mathrm{Na} \leq 5, \mathrm{Al} \geq 15, \mathrm{Si}>20, \mathrm{~K}>5, \\
\mathrm{~K}+\mathrm{Al}+\mathrm{Si} \geq 80, \mathrm{Ca} \leq 5, \mathrm{Fe} \leq 5\end{array}$ \\
\hline 12 & Fe-Al Silicate & 2.80 & $\begin{array}{l}\mathrm{Na} \leq 5, \mathrm{Al} \geq 15, \mathrm{Si}>20, \mathrm{~S} \leq 5 \\
\mathrm{~K} \leq 5, \mathrm{Ca} \leq 5, \mathrm{Fe}>5 \\
\mathrm{Fe}+\mathrm{Al}+\mathrm{Si} \geq 80\end{array}$ \\
\hline 13 & Ca-Al Silicate & 2.65 & $\begin{array}{l}\mathrm{Na} \leq 5, \mathrm{Al} \geq 15, \mathrm{Si}>20, \mathrm{~S} \leq 5 \\
\mathrm{~K} \leq 5, \mathrm{Ca} \geq 5, \mathrm{Ca}+\mathrm{Al}+\mathrm{Si} \geq 80 \\
\mathrm{Fe} \leq 5\end{array}$ \\
\hline 14 & Na-Al Silicate & 2.60 & $\begin{array}{l}\mathrm{Na} \geq 5, \mathrm{Al} \geq 15, \mathrm{Si}>20 \\
\mathrm{Na}+\mathrm{Al}+\mathrm{Si} \geq 80, \mathrm{~S} \leq 5, \mathrm{~K} \leq 5, \\
\mathrm{Ca} \leq 5, \mathrm{Fe} \leq 5\end{array}$ \\
\hline 15 & Aluminosilicate & 2.65 & $\begin{array}{l}\mathrm{Na} \leq 5, \mathrm{Al}>20, \mathrm{Si}>20, \\
\mathrm{Si}+\mathrm{Al} \geq 80, \mathrm{~K} \leq 5, \mathrm{Ca} \leq 5, \mathrm{Fe} \leq 5\end{array}$ \\
\hline 16 & Mixed Silicate & 2.65 & $\begin{array}{l}\mathrm{Na}<10, \mathrm{Al}>20, \mathrm{Si}>20, \mathrm{~S} \leq 5 \\
\mathrm{~K}<10, \mathrm{Ca}<10, \mathrm{Fe}<10, \\
\mathrm{Na}+\mathrm{Al}+\mathrm{Si}+\mathrm{K}+\mathrm{Ca}+\mathrm{Fe} \$ 80\end{array}$ \\
\hline 17 & Fe Silicate & 4.40 & $\begin{array}{l}\mathrm{Na} \leq 5, \mathrm{Al} \leq 5, \mathrm{Si}>20, \mathrm{~S} \leq 5, \\
\mathrm{~K} \leq 5, \mathrm{Ca} \leq 5, \mathrm{Fe}>10, \mathrm{Fe}+\mathrm{Si} \geq 80\end{array}$ \\
\hline
\end{tabular}




\begin{tabular}{|c|c|c|c|}
\hline $\begin{array}{l}\text { Classification } \\
\text { Number }\end{array}$ & $\begin{array}{c}\text { Mineral/Chemical \& } \\
\text { Mineral Association } \\
\text { Categories }\end{array}$ & $\begin{array}{l}\text { Density } \\
\left(\mathrm{g} / \mathrm{cm}^{3}\right)\end{array}$ & $\begin{array}{c}\text { Compositional Criteria } \\
\text { (percent relative } \\
\text { x-ray intensity) }\end{array}$ \\
\hline 18 & Ca Silicate & 3.09 & $\begin{array}{l}\mathrm{Na} \leq 5, \mathrm{Al} \leq 5, \mathrm{Si}>20, \mathrm{~S} \leq 5 \\
\mathrm{~K} \leq 5, \mathrm{Ca}>10, \mathrm{Ca}+\mathrm{Si} \geq 80 \\
\mathrm{Fe} \leq 5\end{array}$ \\
\hline 19 & Ca Aluminate & 2.80 & $\begin{array}{l}\mathrm{Al}>15, \mathrm{Si} \leq 5, \mathrm{P} \leq 5, \mathrm{~S} \leq 5, \\
\mathrm{Ca}>20, \mathrm{Ca}+\mathrm{Al} \geq 80\end{array}$ \\
\hline 20 & Pyrite & 5.00 & $\begin{array}{l}\mathrm{S}>40, \mathrm{Ca}<10, \mathrm{Fe} \geq 15, \mathrm{Ba}<5 \\
\mathrm{Fe} / \mathrm{S} \leq 0.7, \mathrm{Fe}+\mathrm{S} \geq 80\end{array}$ \\
\hline 21 & Pyrrhotite & 4.60 & $\begin{array}{l}\mathrm{S}>20, \mathrm{Ca}<10, \mathrm{Fe} \geq 20, \mathrm{Ba}<5, \\
0.7<\mathrm{Fe} / \mathrm{S}<1.5, \mathrm{Fe}+\mathrm{S} \geq 80\end{array}$ \\
\hline 22 & Oxidized Pyrrhotite & 5.30 & $\begin{array}{l}\mathrm{S}>5, \mathrm{Ca}<10, \mathrm{Fe}>40, \mathrm{Ba}<5, \\
\mathrm{Fe} / \mathrm{S} \geq 1.5, \mathrm{Fe}+\mathrm{S}>80\end{array}$ \\
\hline 23 & Gypsum & 2.50 & $\begin{array}{l}\mathrm{Si}<10, \mathrm{~S}>20, \mathrm{Ca}>20, \\
\mathrm{Ca}+\mathrm{S} \geq 80, \mathrm{Ti}<10, \mathrm{Ba}<10\end{array}$ \\
\hline 24 & Barite & 4.50 & $\begin{array}{l}\mathrm{S}>20, \mathrm{Ca} \leq 5, \mathrm{Fe}<10, \mathrm{Ba} \\
+\mathrm{Ti}>20, \mathrm{Ba}+\mathrm{S}+\mathrm{Ti} \geq 80\end{array}$ \\
\hline 25 & Apatite & 3.20 & $\begin{array}{l}\mathrm{Al} \leq 5, \mathrm{P} \$ 20, \mathrm{~S} \leq 5, \mathrm{Ca} \$ 20 \\
\mathrm{Ca}+\mathrm{P} \geq 80\end{array}$ \\
\hline 26 & Ca-Al-P & 2.80 & $\begin{array}{l}\mathrm{Al}>10, \mathrm{Si} \leq 5, \mathrm{P}>10, \mathrm{~S} \leq 5, \\
\mathrm{Ca}>10, \mathrm{Al}+\mathrm{P}+\mathrm{Ca} \geq 80\end{array}$ \\
\hline 27 & $\mathrm{KCl}$ & 1.99 & $\mathrm{~K} \geq 30, \mathrm{Cl} \geq 30, \mathrm{~K}+\mathrm{Cl} \geq 80$ \\
\hline 28 & Gypsum/Barite & 3.50 & $\begin{array}{l}\mathrm{S}>20, \mathrm{Ca}>5, \mathrm{Ti}>5, \mathrm{Fe} \leq 5, \\
\mathrm{Ba}>5, \mathrm{~S}+\mathrm{Ca}+\mathrm{Ti}+\mathrm{Ba} \geq 80\end{array}$ \\
\hline 29 & Gypsum/Al Silicate & 2.60 & $\begin{array}{l}\mathrm{Al}>5, \mathrm{Si}>5, \mathrm{~S}>5, \mathrm{Ca}>5, \\
\mathrm{Al}+\mathrm{Si}+\mathrm{S}+\mathrm{Ca} \geq 80\end{array}$ \\
\hline 30 & Si Rich & 2.65 & $65 \leq \mathrm{Si}<80$ \\
\hline 31 & Ca Rich & 2.60 & $\mathrm{Al}<15,65 \leq \mathrm{Ca}<80$ \\
\hline 32 & Ca-Si Rich & 2.60 & $\mathrm{Si} \geq 20, \mathrm{Ca} \geq 20, \mathrm{Si}+\mathrm{Ca} \geq 80$ \\
\hline 33 & Unknown & 2.70 & Unclassified Compositions \\
\hline
\end{tabular}


APPENDIX D

COAL AND ASH DATA 
Table D-1. Coal Analysis Results for Samples Obtained During Baseline Testing, as-received unless otherwise noted

\begin{tabular}{|c|c|c|c|c|c|c|c|c|}
\hline Sample ID: & 060715 & 060716 & 060717 & 050648 & 050649 & 060189 & & \\
\hline Date: & $3 / 18 / 05$ & $3 / 26 / 05$ & $4 / 4 / 05$ & $3 / 17 / 05$ & $3 / 18 / 05$ & $4 / 2-4 / 4 / 05$ & & \\
\hline Time: & $14: 00$ & $14: 00$ & $15: 00$ & $11: 00$ & $14: 00$ & & Average & Std. Dev. \\
\hline Chlorine, ppm (dry) & 13.0 & 12.0 & 12.0 & 17.0 & 11.0 & 15.0 & 13.3 & 2.3 \\
\hline \multicolumn{9}{|l|}{ Proximate } \\
\hline Moisture, wt $\%$ & 17.3 & 16.0 & 24.4 & 35.1 & 36.4 & 36.0 & 27.5 & 9.5 \\
\hline Fixed Carbon, wt\% & 39.6 & 39.1 & 33.8 & 29.8 & 28.1 & 28.9 & 33.2 & 5.2 \\
\hline $\mathrm{Ash}, \mathrm{wt} \%$ & 8.36 & 8.89 & 9.80 & 6.72 & 7.35 & 7.69 & 8.14 & 1.11 \\
\hline \multicolumn{9}{|l|}{ Ultimate } \\
\hline Hydrogen, wt $\%$ & 5.58 & 5.44 & 6.01 & 6.95 & 6.90 & $\mathrm{NA}^{1}$ & 6.18 & 0.72 \\
\hline Carbon, wt $\%$ & 50.9 & 51.0 & 45.2 & 40.6 & 38.6 & NA & 45.3 & 5.7 \\
\hline Heating Value, Btu/lb & 8824 & 8816 & 8122 & 6784 & 6445 & NA & 7798 & 1124 \\
\hline
\end{tabular}

${ }^{1}$ Not analyzed. 
Table D-2. MRY Coal Hg, Cl, Proximate, and Ultimate Analysis

Results

\begin{tabular}{lc}
\hline Sample ID & 050649 \\
\hline Date: & $3 / 18 / 05$ \\
Time: & $14: 00$ \\
\hline Mercury, ppm (dry) & 0.063 \\
Chlorine, ppm (dry) & 11.00 \\
Proximate & \\
Moisture, wt $\%$ & 36.40 \\
Volatile Matter, wt $\%$ & 28.18 \\
Fixed Carbon, wt $\%$ & 7.35 \\
Ash, wt $\%$ & 6.90 \\
Ultimate & \\
Hydrogen, wt $\%$ & 6.90 \\
Carbon, wt $\%$ & 38.59 \\
Nitrogen, wt $\%$ & 0.74 \\
Sulfur, wt $\%$ & 0.78 \\
Oxygen, wt $\%$ & 45.63 \\
Heating Value, Btu/lb & 6445 \\
\hline
\end{tabular}


Table D-3. Coal Analysis Results During Long-Term Testing, as-received unless otherwise noted

\begin{tabular}{|c|c|c|c|c|c|c|c|c|c|c|c|c|c|c|c|}
\hline Sample ID: & 060718 & 060719 & 060720 & 060721 & 060722 & 060723 & 060724 & 060098 & 060099 & 060100 & 060190 & 060191 & 060192 & & \\
\hline Date & $4 / 8 / 05$ & $4 / 12 / 05$ & $4 / 20 / 05$ & $4 / 28 / 05$ & $5 / 4 / 05$ & $5 / 10 / 05$ & $5 / 16 / 05$ & $\begin{array}{l}4 / 12- \\
4 / 15 / 05 \\
\end{array}$ & $\begin{array}{l}4 / 26- \\
4 / 28 / 05 \\
\end{array}$ & $\begin{array}{l}5 / 10- \\
5 / 11 / 05 \\
\end{array}$ & $\begin{array}{l}5 / 3- \\
5 / 4 / 05 \\
\end{array}$ & $5 / 10 / 05$ & $5 / 11 / 05$ & Average & $\begin{array}{l}\text { Std. } \\
\text { Dev. }\end{array}$ \\
\hline Time & $13: 30$ & 13:00 & $14: 00$ & $13: 40$ & $13: 20$ & $14: 00$ & 13:00 & & & & & 14:00 & & & \\
\hline Mercury, ppm (dry) & 0.147 & 0.060 & 0.138 & 0.131 & 0.094 & 0.207 & 0.090 & 0.148 & 0.0941 & 0.222 & 0.0828 & 0.100 & 0.0918 & 0.124 & 0.049 \\
\hline Chlorine, ppm (dry) & 13.0 & 10.0 & 13.0 & 11.0 & 14.0 & 10.0 & 13.0 & 12.6 & 9.60 & 12.9 & 17.0 & 14.0 & 15.0 & 12.7 & 3.1 \\
\hline \multicolumn{16}{|l|}{ Proximate } \\
\hline Moisture, wt $\%$ & 24.00 & 24.20 & 23.80 & 21.10 & 23.10 & 20.70 & 21.60 & 35.30 & 35.80 & 34.20 & 36.60 & 35.90 & 36.80 & 28.700 & 6.916 \\
\hline Volatile Matter, wt $\%$ & 31.69 & 32.86 & 31.39 & 33.30 & 31.80 & 33.30 & 32.55 & 27.38 & 26.63 & 26.97 & 27.29 & 26.02 & 26.42 & 29.815 & 2.992 \\
\hline Fixed Carbon, wt $\%$ & 35.09 & 36.69 & 34.25 & 36.66 & 35.08 & 35.39 & 35.78 & 30.05 & 30.71 & 28.92 & 29.96 & 29.12 & 30.57 & 32.944 & 3.048 \\
\hline Ash, wt $\%$ & 9.22 & 6.25 & 10.56 & 8.94 & 10.02 & 10.61 & 10.07 & 7.28 & 6.85 & 9.92 & 6.15 & 8.97 & 6.21 & 8.542 & 1.743 \\
\hline \multicolumn{16}{|l|}{ Ultimate } \\
\hline Hydrogen, wt $\%$ & 5.98 & 6.08 & 5.93 & 5.61 & 5.90 & 5.58 & 5.85 & 6.85 & 6.88 & 6.63 & NA & NA & NA & 6.129 & 0.483 \\
\hline Carbon, wt $\%$ & 45.76 & 46.79 & 44.77 & 46.66 & 45.82 & 46.22 & 46.82 & 40.85 & 40.63 & 39.98 & NA & NA & NA & 44.429 & 2.797 \\
\hline Nitrogen, wt $\%$ & 0.90 & 0.93 & 0.90 & 0.99 & 0.93 & 0.94 & 0.96 & 0.80 & 0.78 & 0.79 & NA & NA & NA & 0.892 & 0.075 \\
\hline Sulfur, wt $\%$ & 1.12 & 0.74 & 1.19 & 0.88 & 0.89 & 1.94 & 0.85 & 1.06 & 0.83 & 1.26 & NA & NA & NA & 1.076 & 0.348 \\
\hline Oxygen, wt $\%$ & 37.02 & 39.22 & 36.66 & 36.93 & 36.44 & 34.72 & 35.45 & 43.18 & 44.04 & 41.42 & NA & NA & NA & 38.508 & 3.292 \\
\hline Heating Value, Btu/lb & 8128 & 8230 & 7966 & 8044 & 8108 & 8097 & 8273 & 6923 & 6987 & 6702 & NA & NA & NA & 7745 & 613 \\
\hline
\end{tabular}


APPENDIX B

\section{MERCURY CONTROL FIELD TESTING AT MONTICELLO STEAM ELECTRIC STATION}




\section{APPENDIX B}

\section{MERCURY CONTROL FIELD TESTING AT MONTICELLO STEAM ELECTRIC STATION}




\title{
MERCURY CONTROL FIELD TESTING AT MONTICELLO STEAM ELECTRIC STATION
}

\author{
Draft Site Report
}

(For the period of September 26, 2003, through March 31, 2007)

Prepared for:

AAD Document Control

U.S. Department of Energy

National Energy Technology Laboratory

3610 Collins Ferry Road, B26-269

PO Box 880 Mail Stop C04

Morgantown, WV 26507-0880

Cooperative Agreement No. DE-FC26-03NT41991

Performance Monitor: Mr. Andrew O'Palko

Prepared by:

Katherine Dombrowski

Carl Richardson

URS Corporation 9400 Amberglen Blvd.

Austin, TX 78729

Steven A. Benson Michael J. Holmes Donald P. McCollor Jill M. Mackenzie Charlene R. Crocker Lingbu Kong

Kevin C. Galbreath

Energy \& Environmental Research Center University of North Dakota 15 North 23rd Street, Stop 9018

Grand Forks, ND 58202-9018

November 2006 


\section{DISCLAIMER}

This report was prepared as an account of work sponsored by an agency of the United States Government. Neither the United States Government, nor any agency thereof, nor any of their employees makes any warranty, express or implied, or assumes any legal liability or responsibility for the accuracy, completeness, or usefulness of any information, apparatus, product, or process disclosed or represents that its use would not infringe privately owned rights. Reference herein to any specific commercial product, process, or service by trade name, trademark, manufacturer, or otherwise does not necessarily constitute or imply its endorsement, recommendation, or favoring by the United States Government or any agency thereof. The views and opinions of authors expressed herein do not necessarily state or reflect those of the United States Government or any agency thereof.

This report is available to the public from the National Technical Information Service, U.S. Department of Commerce, 5285 Port Royal Road, Springfield, VA 22161; phone orders are accepted at (703) 487-4650.

\section{DOE DISCLAIMER}

This report was prepared with the support of the U.S. Department of Energy (DOE) National Energy Technology Laboratory Cooperative Agreement No. DE-FC26-03NT41991. However, any opinions, findings, conclusions, or recommendations expressed herein are those of the authors and do not necessarily reflect the views of DOE.

This report was prepared by the Energy \& Environmental Research Center (EERC), an agency of the University of North Dakota, as an account of work sponsored by DOE; Apogee; the Babcock \& Wilcox Company, Inc.; Basin Electric Power Cooperative; BNI Coal, Ltd.; Dakota Westmoreland Corporation; Electric Power Research Institute; Great River Energy; Minnkota Power Cooperative, Inc.; Montana-Dakota Utilities Company; North American Coal Corporation; North Dakota Industrial Commission; Otter Tail Power Company; SaskPower; TXU Corporation; and URS Corporation.

\section{EERC DISCLAIMER}

LEGAL NOTICE This research report was prepared by the Energy \& Environmental Research Center (EERC), an agency of the University of North Dakota, as an account of work sponsored by U.S. Department of Energy. Because of the research nature of the work performed, neither the EERC nor any of its employees makes any warranty, express or implied, or assumes any legal liability or responsibility for the accuracy, completeness, or usefulness of any information, apparatus, product, or process disclosed, or represents that its use would not infringe privately owned rights. Reference herein to any specific commercial product, process, or service by trade name, trademark, manufacturer, or otherwise does not necessarily constitute or imply its endorsement or recommendation by the EERC. 


\section{ACKNOWLEDGMENTS}

The EERC's project manager and principal investigators are grateful to the following organizations for their support, technical advice, and assistance in completing this draft site report:

- U.S. Department of Energy National Energy Technology Laboratory

- Apogee

- Babcock \& Wilcox Company, Inc.

- Basin Electric Power Cooperative

- BNI Coal, Ltd.

- Dakota Westmoreland Corporation

- Electric Power Research Institute

- Great River Energy

- Minnkota Power Cooperative, Inc.

- Montana-Dakota Utilities Company

- North American Coal Corporation

- North Dakota Industrial Commission

- Otter Tail Power Company

- SaskPower

- TXU Energy

- URS Corporation 


\section{TABLE OF CONTENTS}

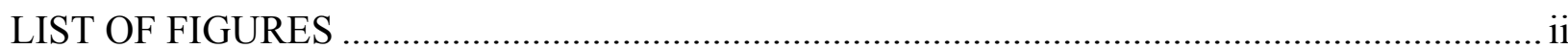

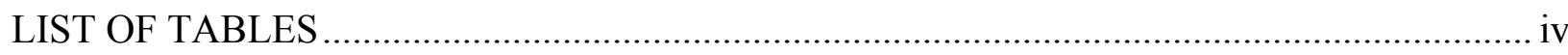

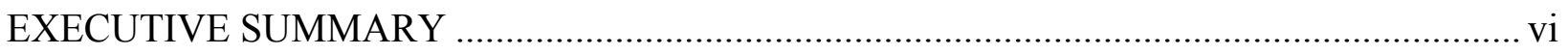

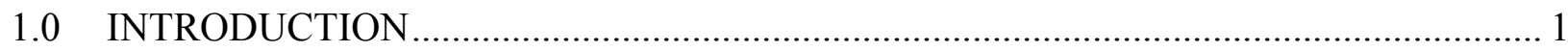

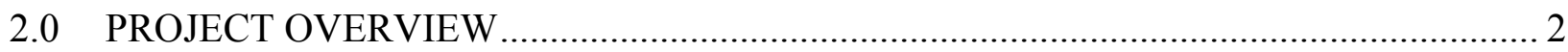

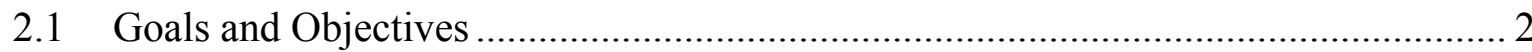

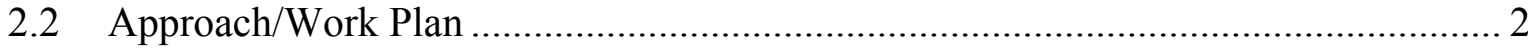

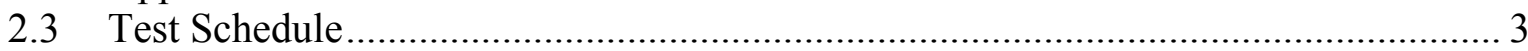

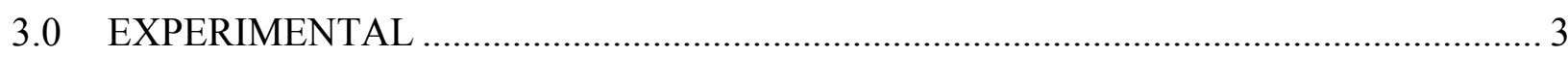

3.1 Systems Operation and Monitoring ………………............................................. 3

3.1.1 Halogen Addition Method ..................................................................... 3

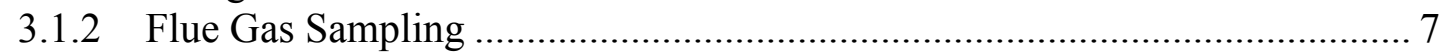

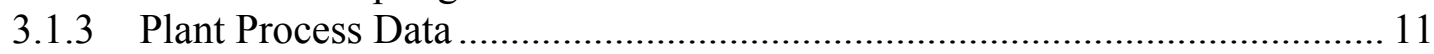

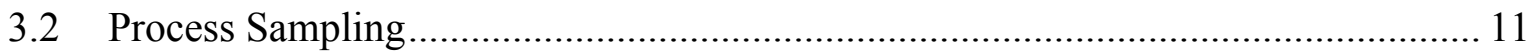

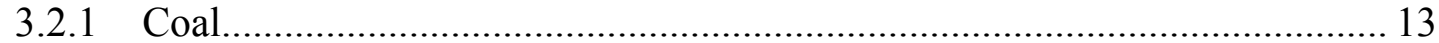

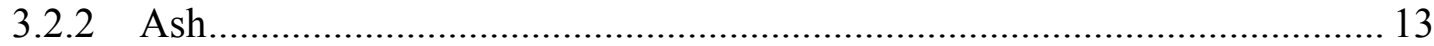

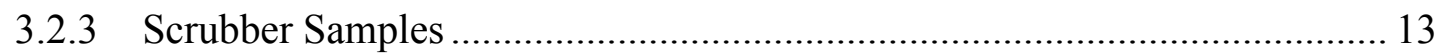

3.2.4 Limestone and Makeup Water....................................................................... 14

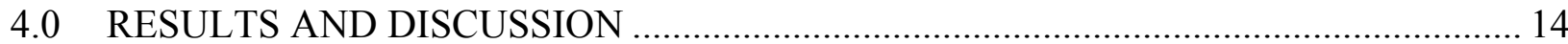

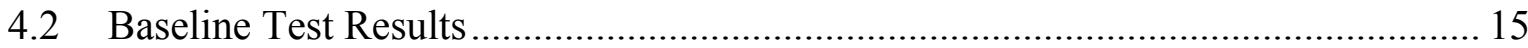

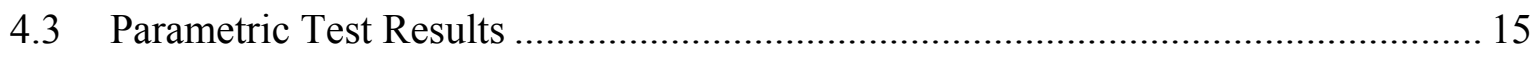

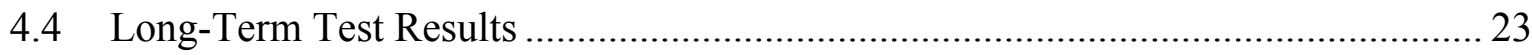

4.4.1 Evaluation of Actual $\mathrm{CaBr}_{2}$ Injection Rates ............................................. 23

4.4.2 Summary of Mercury Data from Long-Term Injection Test No. 1.............. 28

4.4.3 Summary of Mercury Data from Long-Term Injection Test No. 2 2.............. 32

4.5 MoSES Chemical Injection Analytical Summary ………………………………...... 38

4.5.1 Comparison of Coal and Fly Ash Mercury to SCEM Data............................ 38

4.5.2 Analysis of FGD By-Products................................................................... 47

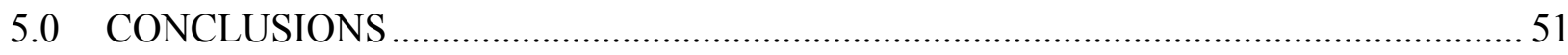

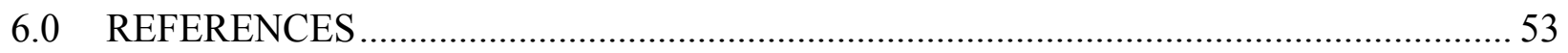

Continued. . . 


\section{TABLE OF CONTENTS (continued)}

\section{SAMPLE DATES AND TIMES FOR FLUE GAS SAMPLES AND PROCESS \\ SAMPLES AT MONTICELLO SES UNIT 3}

Appendix A

SCEM DATA ANALYSIS METHODOLOGY FOR MONTICELLO SES UNIT 3 ..Appendix B

METHOD 26 RESULTS Appendix C

MATERIAL BALANCE CALCULATIONS Appendix D

\section{LIST OF FIGURES}

2-1 Schematic of MoSES Unit 3 configuration............................................................... 3

3-1 Chemical storage tanks and pump skid for MoSES Unit 3 tests................................... 6

3-2 Stock feeder deck (top) and insertion of halogen feed line into top of stock feeder for

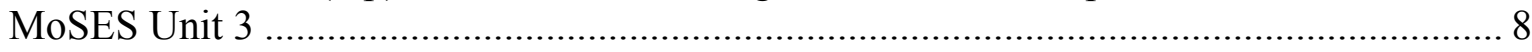

3-3 MoSES coal handling system layout................................................................... 9

3-4 Schematic of the EPRI semicontinuous mercury analyzer used to measure mercury in situ during the MoSES Unit 3 tests ................................................................... 11

3-5 Hopper diagram for Unit 3 B-side ESP ........................................................... 14

4-1 Baseline mercury SCEM data measured prior to parametric mercury control injection tests at MoSES Unit 3

4-2 Baseline mercury SCEM data measured prior to the first set of long-term mercury control injection tests at MoSES Unit 3 .....

4-3 Baseline mercury SCEM data measured prior to the second set of long-term mercury control injection tests at MoSES Unit 3 .....

4-4 SCEM concentrations measured during $\mathrm{CaCl}_{2}$ parametric injection tests ...................... 19

4-5 SCEM concentrations measured during $\mathrm{CaBr}_{2}$ parametric injection tests ...................... 19

4-6 Percent oxidized mercury present at ESP inlet and outlet for $\mathrm{CaCl}_{2}$ parametric injection tests

Continued. . . 


\section{LIST OF FIGURES (continued)}

4-7 Percent oxidized mercury present at ESP inlet and outlet for $\mathrm{CaBr}_{2}$ parametric injection tests.....

4-8 Mercury removal across the ESP and FGD for $\mathrm{CaCl}_{2}$ during parametric injection tests at MoSES.

4-9 Mercury removal across the ESP and FGD for $\mathrm{CaBr}_{2}$ during parametric injection tests at MoSES

4-10 Actual additive injection rate of $\mathrm{CaBr}_{2}$ and $\mathrm{M} 26$ measurements during first 2-week long-term test period at MoSES

4-11 Actual additive injection rate of $\mathrm{CaBr}_{2}$ and $\mathrm{M} 26$ measurements during second 2-week long-term test period at MoSES

4-12 Hourly averaged total mercury concentration from SCEM data collected during $\mathrm{CaBr}_{2}$ injection at approximately $55 \mathrm{ppm} \mathrm{Br}$ equivalent in the dry coal, first 2-week long-term test at MoSES

4-13 ESP inlet total and elemental mercury concentrations measured during $\mathrm{CaBr}_{2}$ injection at approximately $55 \mathrm{ppm} \mathrm{Br}$ equivalent in the dry coal, first 2-week long-term test at MoSES

4-14 ESP outlet total and elemental mercury concentrations measured during $\mathrm{CaBr}_{2}$ injection at approximately $55 \mathrm{ppm} \mathrm{Br}$ equivalent in the dry coal, first 2-week long-term test at MoSES

4-15 FGD outlet total and elemental mercury concentrations measured during $\mathrm{CaBr}_{2}$ injection at approximately 55 ppm Br equivalent in the dry coal, first 2-week long-term test at MoSES

4-16 Effect of coal blend on oxidation and removal of flue gas mercury during long-term test no. 1

4-17 Comparison of scrubber inlet elemental mercury concentration to scrubber outlet total mercury concentration during the first long-term $\mathrm{CaBr}_{2}$ injection test at MoSES...... 33

4-18 Comparison of Appendix K data with SCEM data 34

Continued. . . 


\section{LIST OF FIGURES (continued)}

4-19 Hourly averaged SCEM data collected during the second long-term $\mathrm{CaBr}_{2}$ injection test at MoSES

4-20 ESP inlet total and elemental mercury concentrations measured during the second long-term $\mathrm{CaBr}_{2}$ injection test at MoSES 35

4-21 ESP outlet total and elemental mercury concentrations measured during the second long-term $\mathrm{CaBr}_{2}$ injection test at MoSES 35

4-22 FGD outlet total and elemental mercury concentrations measured during the second long-term $\mathrm{CaBr}_{2}$ injection test at MoSES.

4-23 Comparison of ESP outlet elemental mercury concentrations to scrubber outlet total mercury concentrations during the second long-term $\mathrm{CaBr}_{2}$ injection test at MoSES

4-24 Coal mercury concentrations measured during test program

4-25 Comparison of ESP inlet vapor phase mercury (as measured by SCEM) to coal mercury concentration.

4-26 Mercury concentration of fly ash during baseline and first continuous-injection test ....... 45

4-27 Mercury concentration of fly ash during baseline and second continuous-injection test ... 45

4-28 Ratio of mercury content in ash collected (g/hr) to mercury content in coal-fired (g/hr)... 47

4-29 Shift in mercury content of FGD by-product from solid to liquid phase during second long-term injection test

4-30 Measured bromide concentration of FGD liquor

\section{LIST OF TABLES}

2-1 Dates of Key Phases of Completed Test Program ........................................................ 4

2-2 Executed Test Schedule for Parametric Tests at MoSES Unit 3.................................. 4

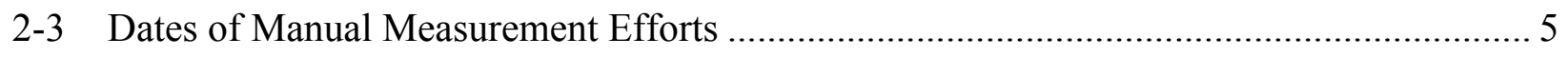

Continued. . . 


\section{LIST OF TABLES (continued)}

3-1 Frequency of Flue Gas Sampling Methods at MoSES Unit 3...................................... 9

3-2 Process Data Collected at MoSES ............................................................................. 12

3-3 Target Analytes for Solid and Liquid Process Samples ............................................. 12

4-1 Comparison of Measured Flue Gas $\mathrm{HCl}$ Concentrations to Theoretical Predictions for

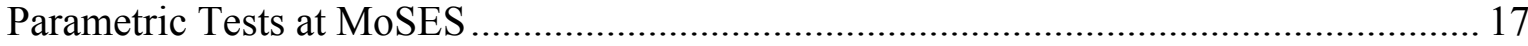

4-2 Comparison of Measured Flue Gas HBr Concentrations to Theoretical Predictions for Parametric Tests at MoSES ................................................................................... 18

4-3 Average Mercury Concentrations During Parametric Injection Tests at MoSES............. 20

4-4 Percent Oxidation of Mercury at ESP Inlet and Outlet Measured During Parametric

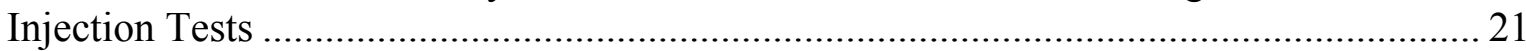

4-5 Comparison of Measured Flue Gas HBr Concentrations to Theoretical Predictions for MoSES Long-Term Tests.

4-6 Method 26A Measurement Results from the MoSES Long-Term Injection Test at $55 \mathrm{ppm} \mathrm{Br}$ Equivalent in the Coal (all results expressed as ppm, dry, 3\% $\mathrm{O}_{2}$ )

4-7 Appendix K Measurements at Unit 3 Stack During Long-Term Test No. 1.................... 33

4-8 Average FGD Outlet Mercury Concentrations Measured by SCEM During the Long-Term Injection Tests at MoSES

4-9 Ratio of Oxidized Mercury in Flue Gas to Average Coal Mercury Content During the Long-Term Injection Tests ............................................................................... 38

4-10 Unit 1 - Texas Lignite Coal Analyses for Long-Term Injection Test ............................ 39

4-11 Unit 1 - PRB Coal Analyses for Long-Term Injection Test......................................... 40

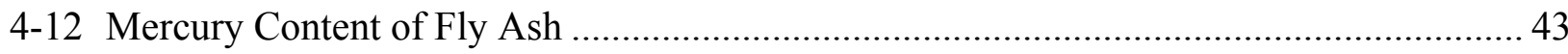

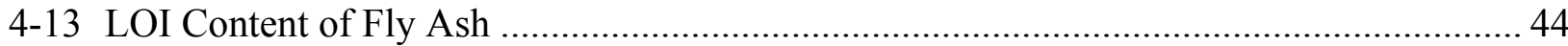

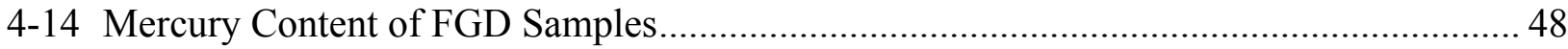

4-15 Results from Analysis of FGD Solids and Liquors ................................................. 50

4-16 Fly Ash Bromide Concentrations .......................................................................... 51 


\section{MERCURY CONTROL FIELD TESTING AT MONTICELLO STEAM ELECTRIC STATION}

\section{EXECUTIVE SUMMARY}

TXU's Monticello Steam Electric Station (MoSES) Unit 3 was one of two units to be tested as part of a project primarily funded by U.S. Department of Energy entitled "Large-Scale Mercury Control Technology Testing for Lignite-Fired Utilities - Oxidation Systems For Wet FGD". The overall project goal was to cost-effectively oxidize most of the $\mathrm{Hg}^{0}$ in lignitic combustion flue gases into a more soluble and reactive inorganic mercuric compound $\left(\mathrm{Hg}^{2+}\right)$ that could subsequently be captured in an electrostatic precipitator (ESP) and/or wet flue gas desulfurization (FGD) system. MoSES Unit 3 is a 793-MW unit that fires a 50/50 blend of Texas lignite and Powder River Basin (PRB) coals. The unit is equipped with an ESP and limestone forced-oxidation spray tower FGD system for $\mathrm{SO}_{2}$ control. Baseline flue gas mercury measurements indicated that the ESP outlet flue gas typically contains about $25 \% \mathrm{Hg}^{2+}$ and $75 \% \mathrm{Hg}^{0}$, with a total $\mathrm{Hg}$ concentration of about $20 \mu \mathrm{g} / \mathrm{dNm}^{3}$.

A test program was carried out at MoSES in Fall 2005 to evaluate the furnace injection of halogen materials as a means of oxidizing the flue gas mercury so that it could be removed in a downstream wet scrubber. The program consisted of three parts: 1) baseline measurements to quantify the mercury concentrations and mercury removal across the system, 2) a set of parametric tests to compare the performance of furnace injection of two halogen salts $\left(\mathrm{CaCl}_{2}\right.$ and $\mathrm{CaBr}_{2}$ ), and 3) two 2-week continuous injection tests to evaluate the variability and balance-ofplant impacts associated with furnace halogen injection. Flue gas mercury measurements were made primarily with Electric Power Research Institute (EPRI) semicontinuous mercury monitors (SCEM's).

During baseline measurements, no removal of mercury was measured with the CMMs and the Ontario Hydro $(\mathrm{OH})$ method across the ESP. On average for the course of the long-term test program, coal mercury concentrations correlated well with ESP inlet mercury concentrations measured by the CMM. The mercury content of the baseline fly ash represented less than $20 \%$ of the coal mercury content. Both the coal and ash results corroborate the flue gas determination of a small amount of mercury removal upstream of the ESP and no removal across the ESP. The coal mercury concentration of the PRB coal ranged from 0.04 to $0.09 \mathrm{ppm}$ dry. The coal mercury concentration of the Texas lignite was highly variable, ranging from 0.17 to 0.36 ppm dry. Likewise, the ESP inlet mercury concentrations ranged over a wide span (15 to $30 \mu \mathrm{g} / \mathrm{dNm}^{3}$ at $3 \% \mathrm{O}_{2}$ ) during the course of the test program. The baseline flue gas typically contained $10 \%-40 \%$ oxidized mercury. The measured mercury oxidation was typical of that measured at other plants burning Texas lignite/PRB blends.

Parametric tests conducted with two halogen salts demonstrated that it was possible to increase the oxidation of mercury in the flue gas and to simultaneously increase mercury removal by the FGD scrubber. Calcium chloride provided only nominal improvements in mercury oxidation even at the highest tested injection rate of $800 \mathrm{ppm} \mathrm{Cl}$ in the coal. The calcium chloride was not observed to be capable of sustaining the mercury oxidation necessary for the project's mercury removal target of $55 \%$. In contrast, parametric tests with calcium bromide 
demonstrated up to $78 \%$ oxidation at an injection rate of $200 \mathrm{ppm} \mathrm{Br}$ in the coal. Based on these parametric test results, calcium bromide was selected for an evaluation in two 2-week continuous-injection tests.

The first of these tests was conducted at an average injection rate of $55 \mathrm{ppm} \mathrm{Br}$ in the coal. This injection rate achieved an average 67\% mercury oxidation at the scrubber inlet, and the average removal of mercury across the scrubber was $65 \%$. These values represent averages over a 2-week injection test; however, it was observed with the CMMs that the scrubber outlet total mercury concentration steadily increased over the test period. These results were confirmed with Appendix $\mathrm{K}$ measurements. Therefore, a higher injection rate was evaluated in the second 2-week injection test.

For the second 2-week injection test, the calcium bromide injection rate was increased to an average $113 \mathrm{ppm} \mathrm{Br}$ in the coal. Over the course of the 10 days at this injection rate, the mercury at the ESP inlet was on average $85 \%$ oxidized. The removal of vapor-phase mercury across the system averaged $86 \%$ for the entire test period. With the exception of a few brief periods, an injection rate of $113 \mathrm{ppm} \mathrm{Br}$ was sufficient to consistently maintain scrubber outlet mercury concentrations below $5 \mu \mathrm{g} / \mathrm{dNm}^{3}$ (at $3 \% \mathrm{O}_{2}$ ).

It should be noted that all of the reported mercury oxidation and removal values were based on the average coal mercury concentration for the respective test periods. The scrubber inlet total vapor-phase mercury measurements made by CMM were biased low during bromide injection, as determined from a comparison of CMM data to coal and ash mercury data. The presence of bromine in the flue gas can oxidize mercury in the wet solutions that pretreat the gas for the CMM. The scrubber inlet elemental mercury measurements did not appear to be subject to a negative bias, as these values agreed well with the scrubber outlet total mercury concentrations. The scrubber outlet mercury data are not subject to the bromine bias because bromine is removed by the FGD scrubber.

The furnace injection of calcium bromide did not result in increased mercury removal by the fly ash. The oxidized mercury was removed by the FGD scrubber, as expected. During baseline and the first week of each long-term injection test, the mercury partitioned to the FGD solids; however, during the second week of each test, the mercury transitioned to the liquor phase. At an injection rate of $113 \mathrm{ppm} \mathrm{Br}$ in the coal, over $85 \%$ of the mercury in the FGD by-product was contained in the liquor.

These two 2-week furnace injection tests were not long enough to evaluate the balance-ofplant effects. A unit inspection conducted after the test program did not indicate any brominerelated corrosion; however, the test period was too short for an adequate corrosion evaluation. The effect of increased bromine concentration in the FGD liquor on FGD performance and corrosion of FGD materials of construction needs to be determined. Duct corrosion and air heater plugging also need to be evaluated in a longer-term test. Finally, the effect of increased bromine concentrations on the marketability of the coal combustion by-products must be addressed. 


\section{MERCURY CONTROL FIELD TESTING AT MONTICELLO STEAM ELECTRIC STATION}

\subsection{INTRODUCTION}

The Energy \& Environmental Research Center (EERC) is leading a consortium involving URS Group, Apogee, Babcock \& Wilcox Company, Inc. (B\&W), U.S. Department of Energy (DOE) National Energy Technology Laboratory (NETL), Electric Power Research Institute (EPRI), North Dakota Industrial Commission (NDIC), and SaskPower, as well as a Mercury Task Force consisting of Basin Electric Power Cooperative; BNI Coal, Ltd.; Dakota Westmoreland Corporation; Great River Energy; Minnkota Power Cooperative, Inc. (MPC); Montana-Dakota Utilities Company; North American Coal Corporation; Otter Tail Power Company; and TXU Energy (TXU) to evaluate cost-effective approaches for capturing the mercury $(\mathrm{Hg})$ occurring in lignitic combustion flue gases using a cold-side electrostatic precipitator (ESP) and/or wet flue gas desulfurization (FGD) system. This project was developed in response to the U.S. Environmental Protection Agency (EPA) decision to regulate $\mathrm{Hg}$ from utility power plants and a DOE solicitation requesting additional data on the performance of $\mathrm{Hg}$ control technologies for lignite facilities. EPA based its decision on health effects, emissions, and scientific data. U.S. power plants burning lignite generally release greater proportions of elemental mercury $\left(\mathrm{Hg}^{0}\right)$ than those burning bituminous coals. $\mathrm{Hg}^{0}$ is the most difficult chemical species of $\mathrm{Hg}$ to remove from flue gas and, therefore, requires an innovative $\mathrm{Hg}$ control approach.

The overall project goal was to cost-effectively oxidize most of the $\mathrm{Hg}^{0}$ in lignitic combustion flue gases into a more soluble and reactive inorganic mercuric compound $\left(\mathrm{Hg}^{2+}\right)$ that could subsequently be captured in an ESP and/or wet FGD system. $\mathrm{Hg}^{0}$ oxidation processes have been demonstrated using pilot-scale and short-term full-scale tests (1-3). Longer-term full-scale testing is required to further demonstrate and optimize $\mathrm{Hg}^{0}$ oxidation technologies. The applicability of this $\mathrm{Hg}$ control approach is expected to increase with the demand for FGD systems in the United States and Canada.

TXU Monticello Steam Electric Station (MoSES) Unit 3 near Mt. Pleasant, Texas, is one of two host sites for field testing as part of a project entitled "Large-Scale Mercury Control Technology Testing for Lignite-Fired Utilities - Oxidation Systems for Wet FGD”. URS Group is leading the test program at this site and is working in collaboration with the EERC and EPRI. The EERC is leading testing at the other site, Minnkota Power Cooperative's Milton R. Young Station Unit 2 near Center, North Dakota. An ESP and wet FGD are used at MoSES for controlling particulate and sulfur dioxide $\left(\mathrm{SO}_{2}\right)$ emissions, respectively. The $\mathrm{Hg}$ removal technology investigated at MoSES involved adding two halogenated calcium compounds, calcium chloride $\left(\mathrm{CaCl}_{2}\right)$ and calcium bromide $\left(\mathrm{CaBr}_{2}\right)$, to the coal feed for enhancing $\mathrm{Hg}$ capture in the ESP and/or wet FGD. The technical work on this project involves $\mathrm{Hg}$ measurements upstream and downstream of ESP and wet FGD units before and during chemical additions, determining the $\mathrm{Hg}$ removal efficiencies of ESP and wet FGD units, quantifying the balance-of-plant impacts of the control technologies, and facilitating technology commercialization. 


\subsection{PROJECT OVERVIEW}

In response to a DOE solicitation calling for additional data on the performance of $\mathrm{Hg}$ control technologies for lignite facilities, a consortium was developed to perform the research described herein. The objective was to evaluate potentially cost-effective $\mathrm{Hg}$ control technology options by using existing emission control equipment. Three primary technologies were identified for field testing: 1) in situ $\mathrm{Hg}$ sorbent enhancement of powder activated carbon (PAC), 2) injection of treated PACs, and 3) $\mathrm{Hg}^{0}$ oxidation upstream of a wet or dry scrubber. This report focuses on the work performed at MoSES Unit 3, in which $\mathrm{Hg}^{0}$ oxidation upstream of a wet scrubber was investigated.

\subsection{Goals and Objectives}

The goal of testing at MoSES Unit 3 was to evaluate furnace injection of two halogencontaining salts for $\mathrm{Hg}$ oxidation and control. To meet this goal, the following scope of work was performed at MoSES Unit 3:

- Baseline Hg speciation and removal were measured

- $\mathrm{Hg}$ oxidation resulting from the furnace injection of two halogen salts $\left(\mathrm{CaCl}_{2}\right.$ and $\mathrm{CaBr}_{2}$ ) was measured

- Halogen injection rates were optimized for target $\mathrm{Hg}$ removals of at least $55 \%$

- Two 2-week continuous injection tests were performed with $\mathrm{CaBr}_{2}$

- The variability of $\mathrm{Hg}$ removal and emissions was evaluated while the control technology was applied

- Data were collected to support the economic evaluation of the technology.

\subsection{Approach/Work Plan}

TXU's MoSES Unit 3 fires a blend of approximately 50\% Texas lignite and 50\% subbituminous coal from the Powder River Basin (PRB) and is rated at 793 MW. Figure 2-1 illustrates the Unit 3 configuration. Unit 3 has a horizontally opposed, pulverized coal boiler with low-NO $\mathrm{NO}_{\mathrm{X}}$ burners. A cold-side ESP (design SCA of $452 \mathrm{ft}^{2} / \mathrm{kacfm}$ ) is used for particulate control, and a limestone forced oxidation spray tower FGD system is used for $\mathrm{SO}_{2}$ control. Three spray absorbers achieve about $90 \% \mathrm{SO}_{2}$ removal on the flue gas treated. About $50 \%$ of the flue gas is bypassed. The ESP outlet flue gas generally contains about $25 \% \mathrm{Hg}^{+2}$ and $75 \% \mathrm{Hg}^{0}$, with total $\mathrm{Hg}$ concentrations of about $20 \mu \mathrm{g} / \mathrm{Nm}^{3}$.

Halogen salts were introduced to the boiler via a metered salt solution that was sprayed onto the coal as it fell off the weigh belt and into the pulverizers. EPRI semicontinuous mercury analyzers measured the resulting changes in flue gas mercury concentration and speciation. Other gas-sampling measurements included the Ontario Hydro $(\mathrm{OH})$ method and the sorbent tube method for flue gas mercury concentrations and Methods 26 and 26A for flue gas halogen concentrations. Process samples, such as coal, fly ash, and FGD by-products, were collected for analysis. Appendix A summarizes the sample times for the collected flue gas and plant process samples. Plant process data were also collected. These data were used to evaluate the balance-of- 


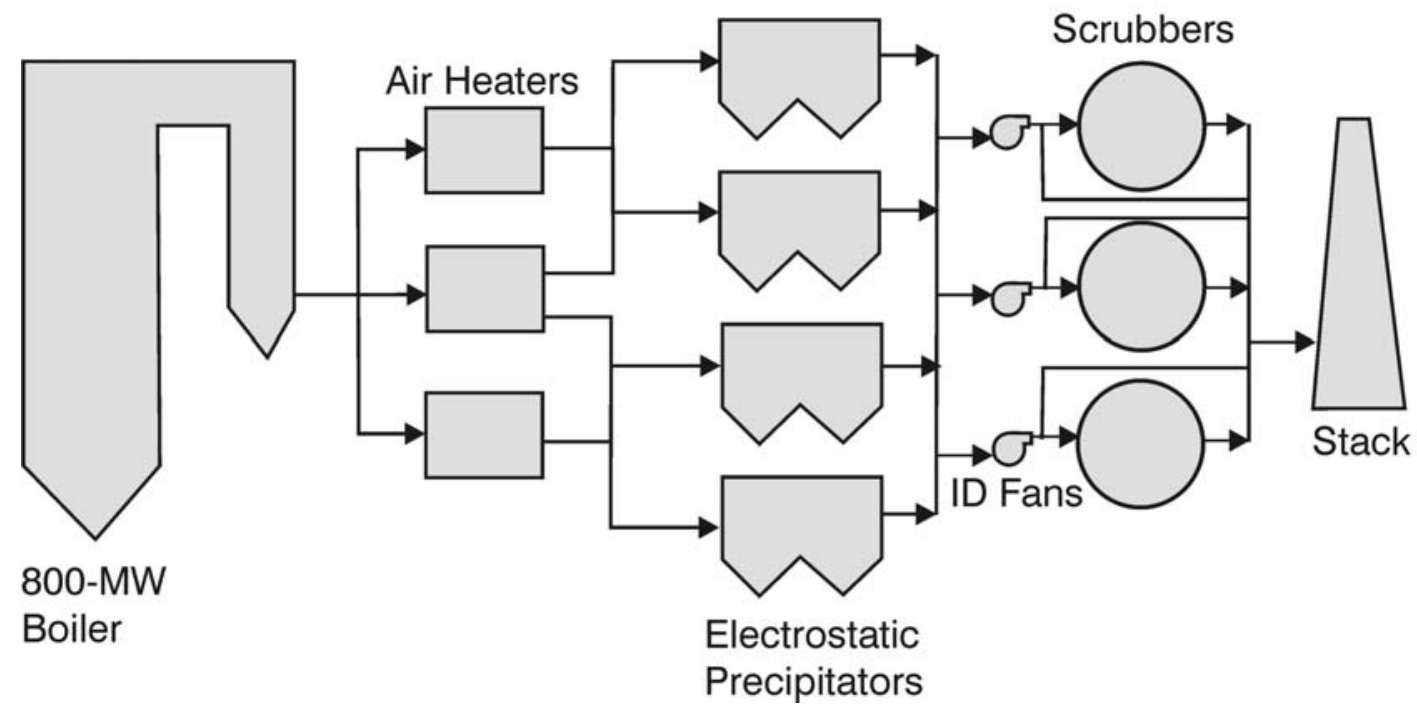

Figure 2-1. Schematic of MoSES Unit 3 configuration.

plant impacts of halogen addition. The data were also used to perform an economic evaluation of the process for mercury control.

\subsection{Test Schedule}

The test program duration was approximately 2 months. Table 2-1 provides the dates of the key phases of the test program. Mercury semicontinuous emission monitor (SCEM) measurements were made during all the key phases of the test program. Table 2-2 summarizes the test schedule for the parametric tests, indicating the times at which each injection rate was tested. Table 2-3 provides the dates of other manual sampling methods that were performed at Monticello Unit 3, including the $\mathrm{OH}$ method, Method 26, and Appendix K method. A detailed table with specific sample times for all gas characterization methods and process samples is provided in Appendix A.

\subsection{EXPERIMENTAL}

\subsection{Systems Operation and Monitoring}

\subsubsection{Halogen Addition Method}

There are three possible ways to add a halogenated material to the boiler: 1) add dry salt to the coal, 2) spray salt solution onto the coal, and 3) inject salt solution directly into the boiler. The method selected for these tests was spraying the salt solution onto the coal. This method was chosen because the spray solution can be applied to the coal as it enters the pulverizers, thereby limiting the time between salt application and boiler entrance to a few seconds. By treating 
Table 2-4. Dates of Key Phases of Completed Test Program

\begin{tabular}{|c|c|c|}
\hline Start Date/Time & End Date/Time & Test Activity \\
\hline $10 / 24 / 05$ & $10 / 26 / 05$ & Baseline measurements \\
\hline $10 / 27 / 05$ & $10 / 28 / 05$ & $\mathrm{CaCl}_{2}$ parametric tests \\
\hline $10 / 29 / 05$ & $10 / 30 / 05$ & $\mathrm{CaBr}_{2}$ parametric tests \\
\hline $11 / 1 / 0517: 00$ & $11 / 5 / 0512: 15$ & Baseline measurements \\
\hline $11 / 5 / 0512: 15$ & $11 / 18 / 0518: 50$ & $\begin{array}{l}\mathrm{CaBr}_{2} \text { continuous injection test } \\
\text { (average rate of } 55 \mathrm{ppm} \mathrm{AR}^{1} \text { in coal) }\end{array}$ \\
\hline 11/18/05 18:50 & $11 / 19 / 058: 45$ & Baseline measurements \\
\hline $11 / 19 / 05$ & $11 / 28 / 05$ & $\begin{array}{l}\text { Break between first and second } \mathrm{CaBr}_{2} \\
\text { continuous injection tests }\end{array}$ \\
\hline 11/28/05 17:00 & $12 / 2 / 0511: 10$ & Baseline measurements \\
\hline 12/2/05 11:10 & 12/12/05 11:39 & $\begin{array}{l}\mathrm{CaBr}_{2} \text { continuous injection test } \\
\text { (average rate of } 113 \mathrm{ppm} \text { in coal) }\end{array}$ \\
\hline 12/12/05 11:39 & $12 / 13 / 052: 00$ & $\begin{array}{l}\mathrm{CaBr}_{2} \text { continuous injection test } \\
\text { (average rate of } 193 \mathrm{ppm} \text { in coal) }\end{array}$ \\
\hline $12 / 13 / 052: 00$ & $12 / 14 / 0514: 20$ & $\begin{array}{l}\mathrm{CaBr}_{2} \text { continuous injection test } \\
\text { (average rate of } 330 \mathrm{ppm} \text { in coal) }\end{array}$ \\
\hline $12 / 14 / 0514: 20$ & $12 / 15 / 0514: 44$ & Baseline measurements \\
\hline $12 / 15 / 0514: 44$ & $12 / 16 / 0514: 37$ & Iodide parametric tests \\
\hline
\end{tabular}

Table 2-5. Executed Test Schedule for Parametric Tests at MoSES Unit 3

\begin{tabular}{|c|c|c|c|}
\hline $\begin{array}{l}\text { Start } \\
\text { Date/Time }\end{array}$ & End Date/Time & Test Activity & $\begin{array}{c}\text { Targeted Injection Rate, } \\
\text { ppm AR in the coal }\end{array}$ \\
\hline $10 / 24 / 05$ & $10 / 27 / 0512: 55$ & Baseline & 0 \\
\hline $10 / 27 / 0512: 55$ & 10/27/05 17:05 & $\mathrm{CaCl}_{2}$ injection & 600 \\
\hline 10/27/05 17:05 & 10/28/05 10:29 & Baseline & 0 \\
\hline $10 / 28 / 0510: 29$ & 10/28/05 14:00 & $\mathrm{CaCl}_{2}$ injection & 400 \\
\hline 10/28/05 14:00 & 10/28/05 18:02 & $\mathrm{CaCl}_{2}$ injection & 800 \\
\hline 10/28/05 18:02 & $10 / 29 / 0510: 39$ & Baseline & 0 \\
\hline 10/29/05 10:39 & 10/29/05 14:40 & $\mathrm{CaBr}_{2}$ injection & 100 \\
\hline $10 / 29 / 0514: 40$ & 10/29/05 18:00 & $\mathrm{CaBr}_{2}$ injection & 200 \\
\hline 10/29/05 18:00 & 10/30/05 12:00 & Baseline & 0 \\
\hline 10/30/05 12:00 & 10/30/05 15:27 & $\mathrm{CaBr}_{2}$ injection & 12 \\
\hline $10 / 30 / 0515: 27$ & 10/30/05 16:14 & $\mathrm{CaBr}_{2}$ injection & 50 \\
\hline 10/30/05 16:14 & 10/30/05 18:20 & $\mathrm{CaBr}_{2}$ injection & 100 \\
\hline 10/30/05 18:20 & 10/30/05 19:10 & $\mathrm{CaBr}_{2}$ injection & 200 \\
\hline
\end{tabular}


Table 2-6. Dates of Manual Measurement Efforts

\begin{tabular}{lcc}
\hline Date* & Test Activity & Sample Locations \\
\hline $10 / 25 / 05$ & OH method, set 1 & ESP inlet, ESP outlet \\
$10 / 26 / 05$ & OH method, set 2 & ESP inlet, ESP outlet \\
$11 / 16 / 05$ & OH method, set 3 & ESP inlet, FGD outlet \\
$11 / 17 / 05$ & M26A & ESP inlet, FGD outlet \\
Periodically Through & M26 & ESP inlet \\
Entire Test Program & Appendix K (performed by & Stack \\
$11 / 8 / 05-11 / 11 / 05$ & TXU) & Stack \\
11/14/05-11/18/05 & Appendix K (performed by & TXU) \\
Periodically Through & Modified sorbent tube method & ESP inlet, FGD outlet \\
Entire Test Program & & \\
* Specific sample times for individual runs can be found in Appendix A.
\end{tabular}

pulverizers that serviced the front and back of the furnace, the entire boiler should have been treated with the halogen material. Completely uniform distribution of the halogen material in the furnace cannot be guaranteed because not all of the pulverizers were treated. The halogen solution was not applied to the coal as it was bunkered (in which case all of the coal would have been treated) because of practical/economic limitations associated with this short-term test.

The dry addition method was not chosen for various reasons. At MoSES, the dry addition method might have been applied at the coal handling yard, in which case up to 6 hours would have elapsed between addition of the salt material and injection into the boiler. This time delay would have made on-the-fly changes to the salt injection rate infeasible. Alternatively, the dry coal might have been added to the furnace pipes as the coal enters the furnace. However, this method of application would entail pneumatic transport of the salt, which can be difficult with the deliquescent materials.

The spraying of halogen material directly into the boiler was not chosen. In previous EPRIfunded testing, it has been difficult to feed salt solution into the boiler for prolonged periods of time without plugging the injection lances. The salt spray from the lances has a tendency to blow back onto the lances and plate onto them. For the 2-week continuous-injection tests, the boiler addition method appeared too risky.

Liquid salt injection equipment for the Monticello chemical injection tests included chemical holding tanks, a pump skid, hose, and injection lances. The salt solution was stored in plastic holding tanks, photographed in Figure 3-1. Four double-walled tanks were used for this project, each holding approximately 2500 gal.

The injection skid (Figure 3-1), consisting of two pumps and all associated flow indication/control equipment, was provided by DOE. The physical dimensions of the skid were $80 \mathrm{in}$. long by $60 \mathrm{in}$. wide by $75 \mathrm{in}$. high, with a weight of $1800 \mathrm{lb}$. Each pump had a capacity of 0.1 to $2.2 \mathrm{gal} / \mathrm{min}$ at a maximum pressure of approximately $80 \mathrm{psi}$. The power requirements for the pump skid were 480 volt, 3 phase. 

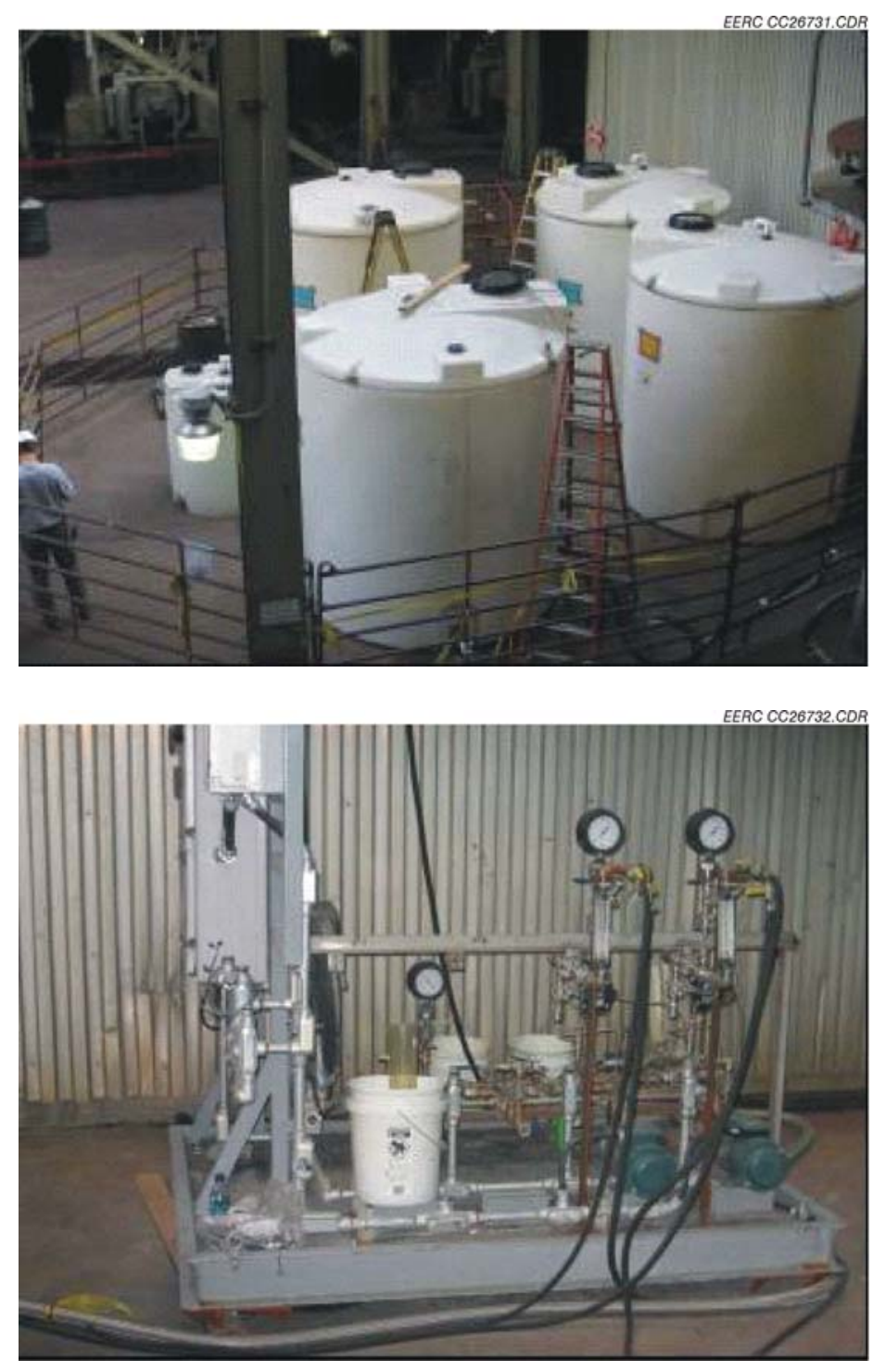

Figure 3-1. Chemical storage tanks and pump skid for MoSES Unit 3 tests.

The control system for the pump skid contained a signal generator producing a 4-20 ma signal that corresponded to the desired ppm feed rate. A second 4-20 ma signal was obtained from the plant computer that corresponded to the coal feed rate for the unit. A programmable logic controller (PLC) compared the two signals and generated a signal to control the variable frequency drives for the pumps to maintain a constant additive to the coal feed rate. A flowmeter at the pump outlet provided feedback to the PLC as to the actual flow rate. In addition, a rotameter was installed for each pump outlet to provide visual and quantitative verification of the fluid flow rate.

Injection skid data logged by the plant's data logger included the flow rates for each pump and the coal feed rates for each pulverizer (other unit process data are discussed later in this section). The following injection skid data were logged periodically by the URS process 
engineer: flow rates measured by the rotameters and positive displacement flowmeter, tank level, and other parameters that were related to the maintenance of the injection skid. Samples of the injected salt solution were taken daily so that they could be analyzed for halogen concentration. These measured values were used in conjunction with the salt flow rate to determine the amount of halogen added to the furnace.

The salt solution was pumped through a hose to the stock feeder, as shown in Figure 3-2, for the pulverizer. The stock feeder was located at approximately 60 feet elevation. The liquid exited via a stainless steel tube inserted into the top of the stock feeder (Figure 4-2) and fell onto the coal in the stock feeder as the coal fell off the weigh belt. The coal and salt solution mixed together in the pulverizer and then traveled through the fuel pipes to the furnace.

Figure 3-3 shows the coal feeding system for the furnace, from the coal bunkers to the furnace fuel pipes. The front side of the furnace has five burner elevations, labeled A, B, C, D, and $\mathrm{E}$. The back side of the furnace has five corresponding elevations, labeled $\mathrm{K}, \mathrm{J}, \mathrm{H}, \mathrm{G}$, and $\mathrm{F}$. Each elevation on each side is served by its own coal bunker, stock feeder, and pulverizer.

The stock feeder was located between the coal bunker and the pulverizer. The residence time of the coal from the stock feeder to the furnace was only a few seconds. Good mixing of the salt solution and the coal was achieved in the pulverizer. Each pulverizer feeds seven fuel pipes that span the width of the furnace. The pulverizers are located on the north and south sides of the furnace. Pulverizers on the south side of the furnace feed both the back and front sides of the furnace; likewise for the north side.

The stock feeders used in this test program were chosen for their proximity to each other; that is, all stock feeders were situated on the south side of the furnace. The stock feeders were also chosen to ensure that the salt was applied to coal being fed to both the back and front walls of the furnace. The salt was sprayed as a liquid onto the coal into stock feeders B, D, F and $\mathrm{H}$ for the parametric tests. For the long-term tests, because of the small amount of solution to be pumped, only feeders B and $\mathrm{H}$ were used. Despite the selection of coal feeders to ensure that the entire flue gas was treated with halogen, the halogen concentration over the furnace flue gas may have been less evenly distributed in comparison to an addition method in which bromide was added to all of the coal feeders.

\subsubsection{Flue Gas Sampling}

An integral part to this test program was the collection and analysis of gas, solid, and liquid samples. Flue gas mercury concentrations (total and elemental mercury) were measured at the ESP inlet, ESP outlet, and FGD outlet using EPRI SCEMs. Flue gas mercury concentrations were also made with the $\mathrm{OH}$ method, Appendix $\mathrm{K}$ method, and a modified sorbent tube method at various times in the test program. Flue gas halogen concentrations $(\mathrm{HCl}$ and $\mathrm{HBr})$ were measured with Method 26 (mini-impinger method) at the ESP inlet and with Method 26A at the FGD outlet. 

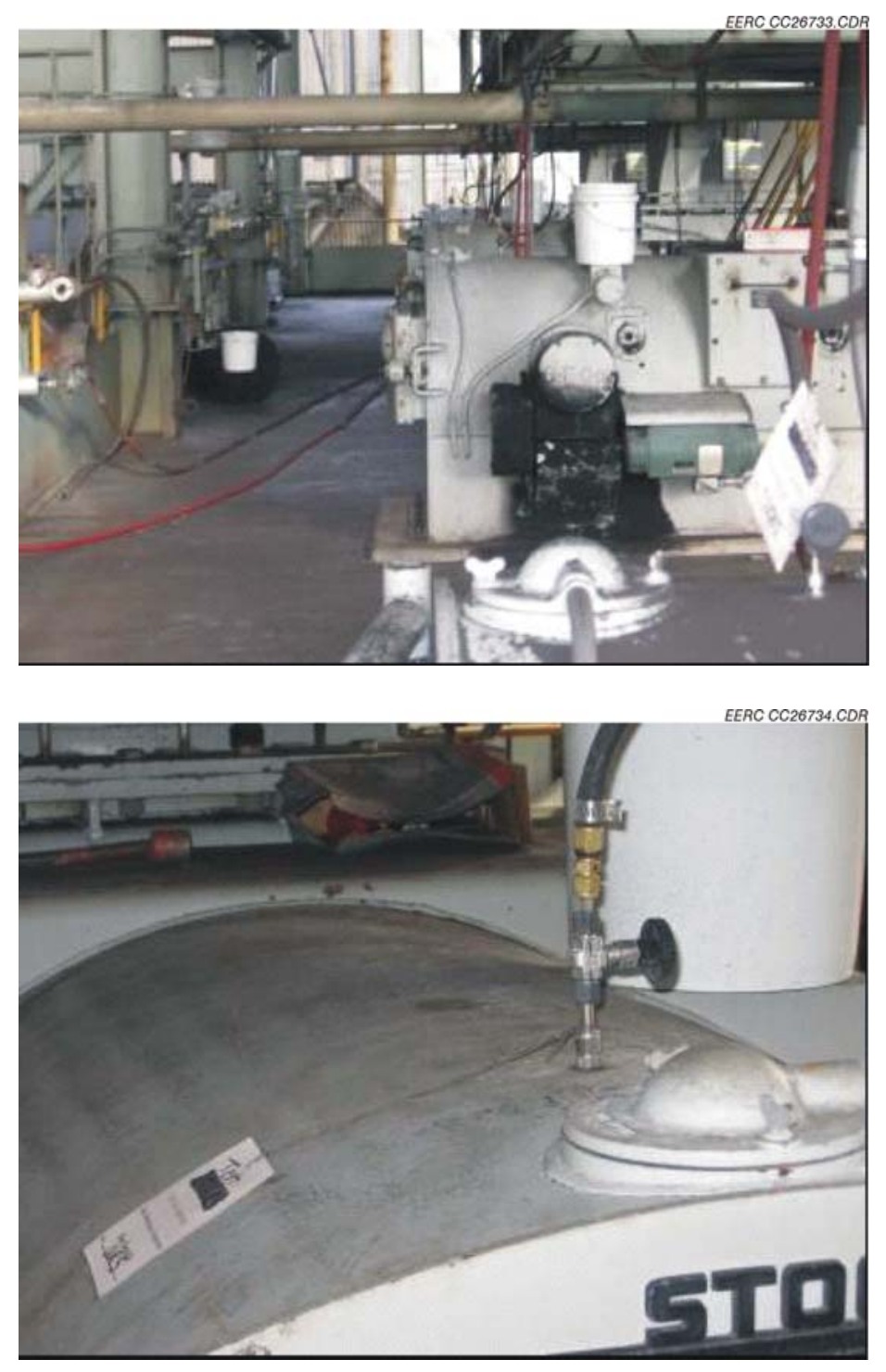

Figure 3-2. Stock feeder deck (top) and insertion of halogen feed line into top of stock feeder for MoSES Unit 3.

Table 3-1 indicates the frequency with which the flue gas sampling occurred. Appendix A summarizes the specific dates and times for each flue gas sample that was collected. The $\mathrm{OH}$ method, Appendix K method, and Methods 26 and 26A are standard methods. The quantitative limitations associated with Methods 26 and 26A are described below. The SCEM mercury analyzer is an experimental method developed by EPRI and described below. 


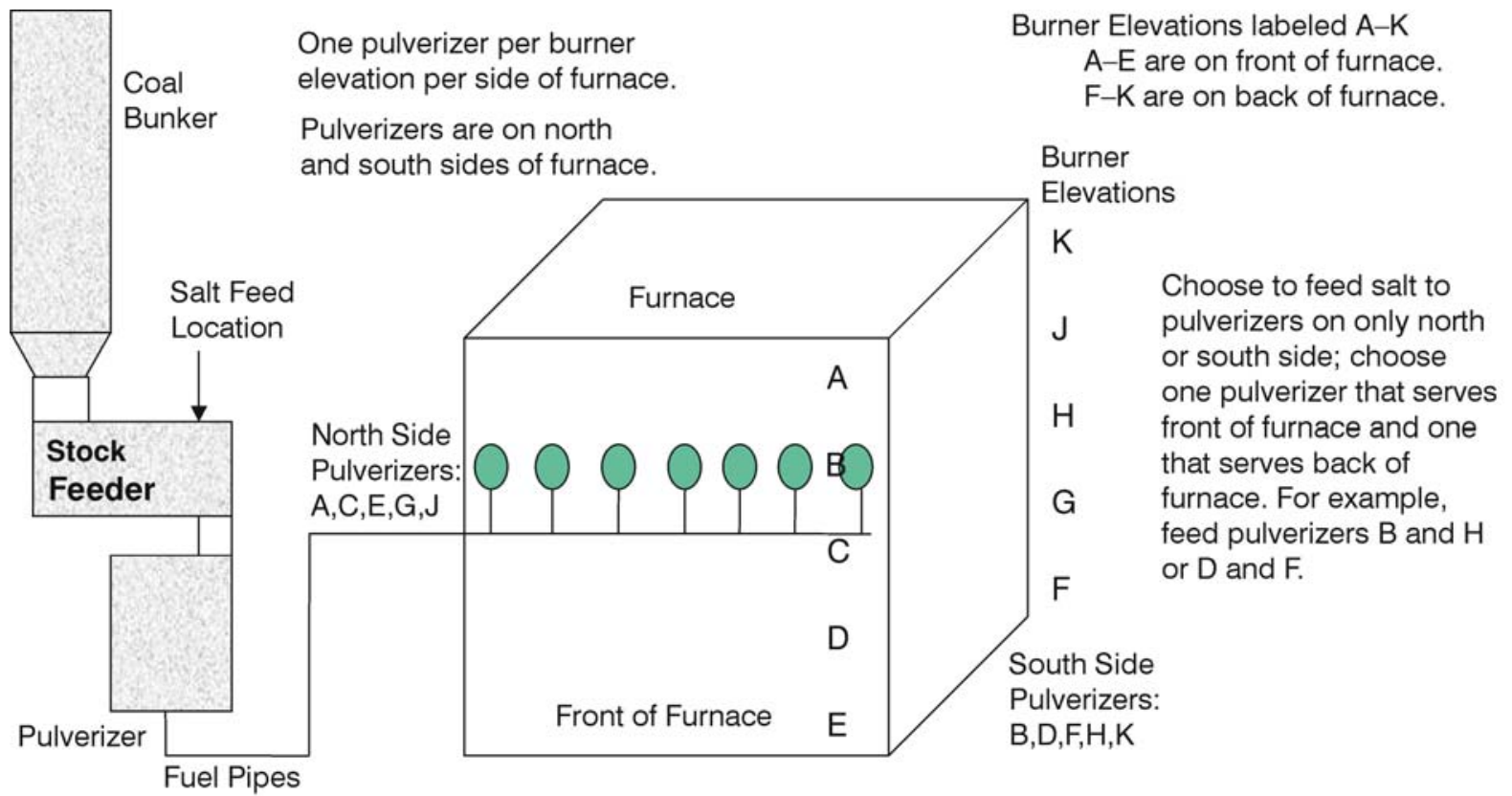

EERC KG27958.CDR

Figure 3-3. MoSES coal handling system layout.

Table 3-4. Frequency of Flue Gas Sampling Methods at MoSES Unit 3

\begin{tabular}{lccc}
\hline Flue Gas Sampling & Sampling & \multicolumn{2}{c}{ Frequency of Measurement } \\
Method & Location & Parametric Tests & Long-Term Tests \\
\hline Mercury SCEM & ESP inlet, & Semicontinuous & Semicontinuous \\
& ESP outlet, & & \\
Scrubber outlet & ESP inlet & Two sets during BL & One set of three \\
$\begin{array}{l}\text { OH Method } \\
\text { OH Method }\end{array}$ & ESP outlet & Two sets during BL & None \\
OH Method & FGD outlet & None & One set of three \\
$\begin{array}{l}\text { Method 26A } \\
\text { Method 26 }\end{array}$ & FGD outlet & One set of three \\
ESP inlet & Once per injection & Twice per day \\
$\begin{array}{l}\text { Appendix K } \\
\text { Modified Sorbent }\end{array}$ & rate & Periodic \\
Tube Method & ESP inlet & None & Periodic \\
Modified Sorbent & FGD outlet & None & Periodic \\
Tube Method & & & \\
\hline
\end{tabular}




\subsubsection{Methods 26 and 26A}

Flue gas samples were collected using EPA Method 26 (Determination of hydrogen halide $[\mathrm{HX}]$ and halogen $\left[\mathrm{X}_{2}\right]$ emissions from stationary sources) during baseline and halogen injection testing to evaluate halogen concentrations. These measurements were made to verify the amount of halogen added to the flue gas. Flue gas samples for Method 26 were obtained at the ESP inlet location as a single-point measurement, nonisokinetically, and with mini-impingers. Flue gas samples for Method 26A were obtained at the FGD outlet location as an isokinetic traverse with large impingers. The impinger solutions were analyzed for halogen by ion chromatograph at the URS Austin laboratories.

In Methods 26 and 26A, the hydrogen halides are solubilized in an acidic solution, while the halogens pass through to be captured in an alkaline solution. Methods 26 and 26A have not been validated for flue gas measurements below $20 \mathrm{ppm}$ halide; furthermore, a negative bias has been demonstrated in the quantification of the $\mathrm{X}_{2}$ (with a corresponding positive bias for the quantification of the hydrogen halide). In the presence of certain flue gas components $\left(\mathrm{SO}_{2}, \mathrm{NO}_{\mathrm{x}}\right)$, a significant fraction of the $\mathrm{X}_{2}$ is captured in the acidic solution (4). While this bias affects the halogen speciation data, it does not affect the measurement of total halogen $\left(\mathrm{HX}+\mathrm{X}_{2}\right)$ in the flue gas. Therefore, the total halogen concentration is provided for this report.

\subsubsection{Mercury SCEMs}

Flue gas vapor-phase mercury analyses were made using EPRI semicontinuous analyzers depicted in Figure 3-4. At each sample location, a sample of the flue gas was extracted at a single point from the duct and then drawn through an inertial gas separation (IGS) filter to remove particulate matter. This IGS filter consists of a heated stainless steel tube lined with sintered material. A secondary sample stream is pulled across the sintered metal filter and then is directed through the mercury analyzer at a rate of approximately $1-2 \mathrm{~L} / \mathrm{min}$ thus providing near real-time feedback during the various test conditions. The analyzer consists of a cold-vapor atomic absorption spectrometer (CVAAS) coupled with a gold amalgamation system (Au-CVAAS). Since the Au-CVAAS measures mercury by using the distinct lines of the UV absorption characteristics of elemental mercury, the nonelemental fraction is converted to elemental mercury prior to analysis using a chilled reduction solution of acidified stannous chloride. Several impingers containing alkaline solutions are placed downstream of the reducing impingers to remove acidic components from the flue gas; elemental mercury is quantitatively transferred through these impingers. Gas exiting the impingers flows through a gold amalgamation column where the mercury in the gas is adsorbed $\left(<60^{\circ} \mathrm{C}\right)$. After adsorbing onto the gold for a fixed period of time (typically 1 to $6 \mathrm{~min}$ ), the concentrated mercury is thermally desorbed $\left(>400^{\circ} \mathrm{C}\right)$ in nitrogen or air, and flows as a vapor stream to a CVAAS for analysis.

Therefore, the total flue gas mercury concentration is measured semicontinuously with a 1-6 minute sample time followed by a 2-min analytical period.

To measure elemental mercury only, an impinger containing either $1 \mathrm{M}$ potassium chloride $(\mathrm{KCl})$ or $1 \mathrm{M}$ Tris Hydroxymethyl (aminomethane) and ethylenediaminetetraacetic acid (EDTA) 


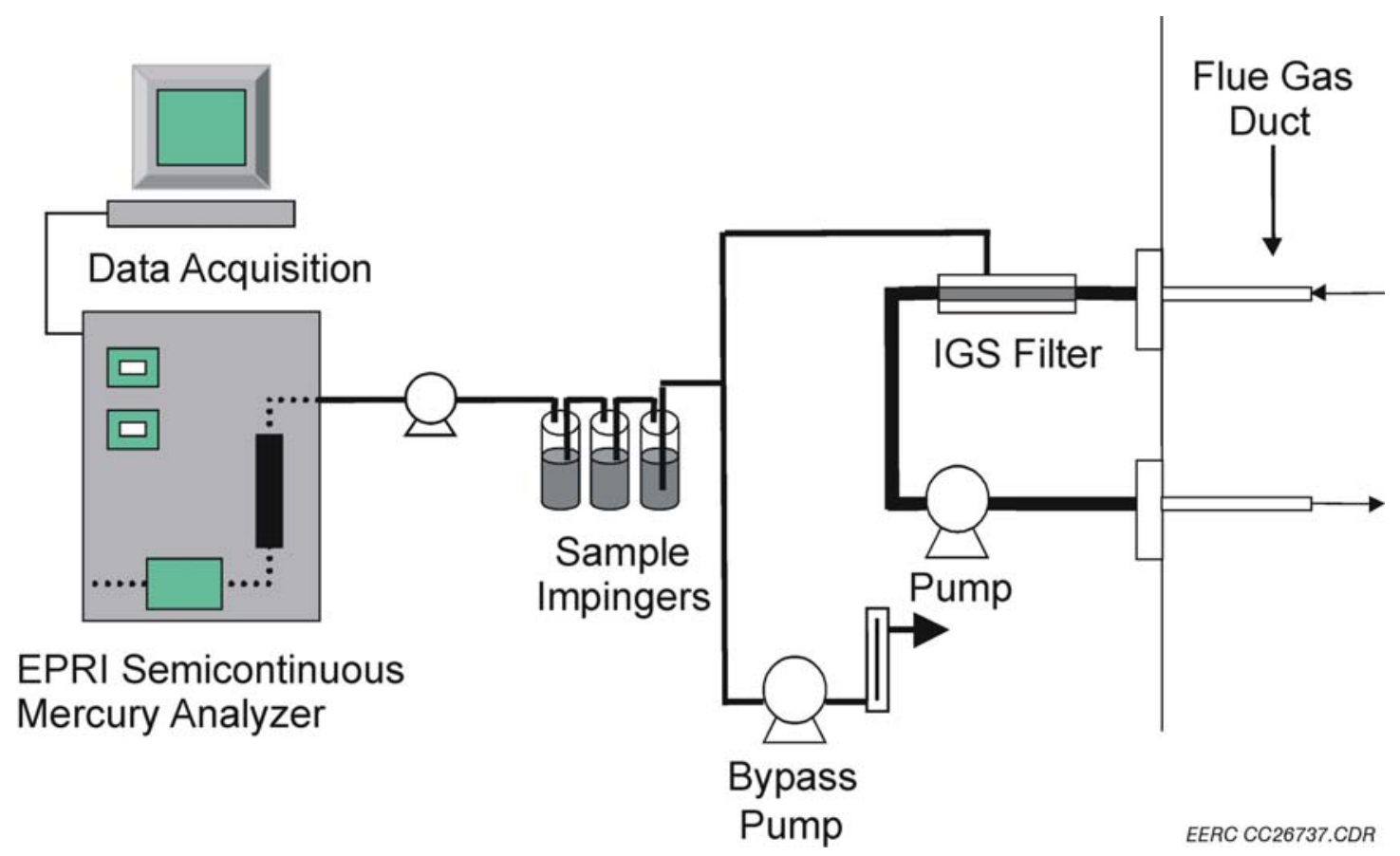

Figure 3-4. Schematic of the EPRI semicontinuous mercury analyzer used to measure mercury in situ during the MoSES Unit 3 tests.

is placed upstream of the alkaline solution impingers to capture oxidized mercury. Oxidized forms of mercury are subsequently captured and maintained in the $\mathrm{KCl}$ or Tris impingers while elemental mercury passes through to the gold amalgamation system. Comparison of "total" and "elemental" mercury measurements yields the extent of mercury oxidation in the flue gas. Appendix B describes how vapor-phase mercury concentrations are calculated from the data recorded by the SCEMs.

\subsubsection{Plant Process Data}

Process data typically archived by the plant were monitored to determine if any correlation exists between changes in mercury concentration with measured plant operation. The process data were used to determine any balance-of-plant effects, such as air heater plugging or ESP operation. Process data collected by the plant are summarized in Table 3-2. URS engineers coordinated with plant personnel to retrieve the necessary historical plant operating data files.

\subsection{Process Sampling}

Process samples included coal, ESP ash, FGD slurry, FGD makeup water, limestone, and the injected salt reagent solution. Care was taken to obtain representative samples of the process samples. URS was responsible for obtaining all of these process samples, except for coal samples that were gathered by the unit operators. The target analytes for each process sample are listed in Table 3-3. Appendix A lists the dates and times for all process samples that were collected. Not 
Table 3-5. Process Data Collected at MoSES

\begin{tabular}{ll}
\hline Parameter & Sample/Signal/Test \\
\hline Coal & Plant signals: \\
& - Coal feed rate, ton/hr \\
& - Heating value of coal being bunkered \\
\hline Unit Operation & Plant signals: \\
& - Boiler load, gross $\mathrm{MW}$ \\
& - Heat rate, gross Btu/kwh \\
& - Temperature, and pressure \\
& - Furnace $\mathrm{O}_{2}$ \\
\hline Temperatures & Plant signal at air heater inlet, air heater outlet, ESP \\
& outlet \\
\hline Air Heater Operations & Air heater pressure drops, in. $\mathrm{H}_{2} \mathrm{O}$ for gas and air sides \\
\hline ESP Operations & Plant data: \\
& - ESP power, current, voltage by field \\
& - Sparking data \\
& - Ammonia conditioning flow rate \\
& Plant data: \\
& - pH \\
& - SO ${ }_{2}$ inlet concentrations \\
& - SO ${ }_{2}$ removal \\
& - Reagent flow rate \\
& - Slurry density \\
& - ME flow rate \\
& - ME delta P \\
& - Oxidation air flow \\
& - Blowdown rate \\
& - Makeup water flow \\
& - Inlet pressure \\
& Plant signals: \\
& - NO $(\mathrm{CEM})$ \\
& - SO $($ CEM) \\
& - Opacity \\
& - Flow rate \\
\hline Stack Data &
\end{tabular}

Table 3-6. Target Analytes for Solid and Liquid Process Samples

\begin{tabular}{lc}
\hline Process Sample & Target Analytes \\
\hline Texas Lignite Coal & $\mathrm{Hg}$, halogens, ultimate/proximate \\
PRB Coal & $\mathrm{Hg}$, halogens, ultimate/proximate \\
ESP Ash & $\mathrm{LOI}, \mathrm{Hg}$, halogens \\
FGD Solids & $\mathrm{Hg}, \mathrm{wt}^{2}$ solids, $\%$ inerts, $\mathrm{Ca}^{2+}, \mathrm{Mg}^{2+}, \mathrm{SO}_{3}{ }^{2-}, \mathrm{SO}_{4}{ }^{2-}, \mathrm{CO}_{3}{ }^{2-}, \mathrm{Br}^{2-} \mathrm{SO}_{4}{ }^{2-}, \mathrm{CO}_{3}{ }^{2-}, \mathrm{Cl}, \mathrm{Br}, \mathrm{Ca}^{2+}, \mathrm{Mg}^{2+}, \mathrm{Na}^{+}$ \\
FGD Liquors & $\mathrm{Hg}, \mathrm{SO}_{3}{ }^{2}, \mathrm{purity}$ \\
Limestone & $\mathrm{Hg}$ \\
Makeup Water & $\mathrm{Hg}$ \\
\hline
\end{tabular}


all collected samples were analyzed; rather, periodic samples were selected to represent the operation of the process across the duration of the test program. The sample collection method and sample frequency were specific to each process sample type.

\subsubsection{Coal}

The PRB and Texas lignite coals were sampled and analyzed separately. At Monticello, the only location available for segregated coal samples is at the coal belt in the coal feed yard, which is approximately 6 hours upstream of the furnace. Coal samples were collected once per day. The coal samples were analyzed in URS' Austin laboratories for mercury and halogen content. The coal was digested by ASTM 4208 and analyzed for halogens by Method 300. Coal mercury contents were determined in triplicate using ASTM 3684 digestion and CVAAS analysis. Hg and $\mathrm{Cl} / \mathrm{Br}$ concentrations were reported as $\mu \mathrm{g} / \mathrm{g}$ on a dry basis. The ultimate/proximate parameters were determined by a subcontracted laboratory (Commercial Testing and Engineering).

\subsubsection{Ash}

Fly ash was collected and analyzed by hopper from the Unit 3 B-side ESP, which was the ESP across which flue gas mercury measurements were made. Figure 3-5 shows the hopper layout for the B-side ESP on Unit 3. There are five rows of hoppers in the ESP; however, ash samples were collected only from the first two rows (Hoppers B-1 through B-12). The final three rows of the ESP did not yield an appreciable amount of ash for collection.

During the parametric tests, ash samples were collected at the end of each injection test period. The ESP hoppers are continually emptied at Monticello, so the ash collected at the end of the injection test period was representative of the ash collected by the ESP during the test period. During the continuous-injection tests, ash samples were gathered once per day.

The fly ash samples were analyzed in URS' Austin laboratories for LOI, mercury, and halogen content. Fly ash mercury concentrations were determined using ASTM 3684 digestion and CVAAS analysis. Hg concentrations were reported as $\mu \mathrm{g} / \mathrm{g}$ on a dry basis. Bromine in the ash was extracted with the Synthetic Precipitation Leaching Procedure (SPLP, EPA Method 1312) and analyzed with ion chromatography.

\subsubsection{Scrubber Samples}

Scrubber samples were taken by URS personnel from the exit of the slurry recirculation pump on the $\mathrm{C}$ scrubber module on Unit 3. The FGD sampling included a slurry to be filtered for mercury analysis of solids and liquid. The sample was filtered on-site within an hour of collection to ensure that the mercury did not repartition between the solid and liquid phases. A full set of diluted filtrates (DFs) was taken each day. DFs are used to preserve the liquid sample for analysis of $\mathrm{SO}_{3}{ }^{2-}, \mathrm{SO}_{4}{ }^{2-}, \mathrm{CO}_{3}{ }^{2-}$, halogens, $\mathrm{Ca}^{2+}, \mathrm{Mg}^{2+}$, and $\mathrm{Na}^{+}$. A slurry sample was taken each day and filtered off-site at URS-Austin for weight \% solids and cations and anions in the solids $\left(\mathrm{Ca}^{2+}, \mathrm{Mg}^{2+}, \mathrm{SO}_{3}{ }^{2-}, \mathrm{SO}_{4}{ }^{2-}\right.$, and $\left.\mathrm{CO}_{3}{ }^{2-}\right)$. All scrubber analyses were performed in URS' Austin laboratories. 


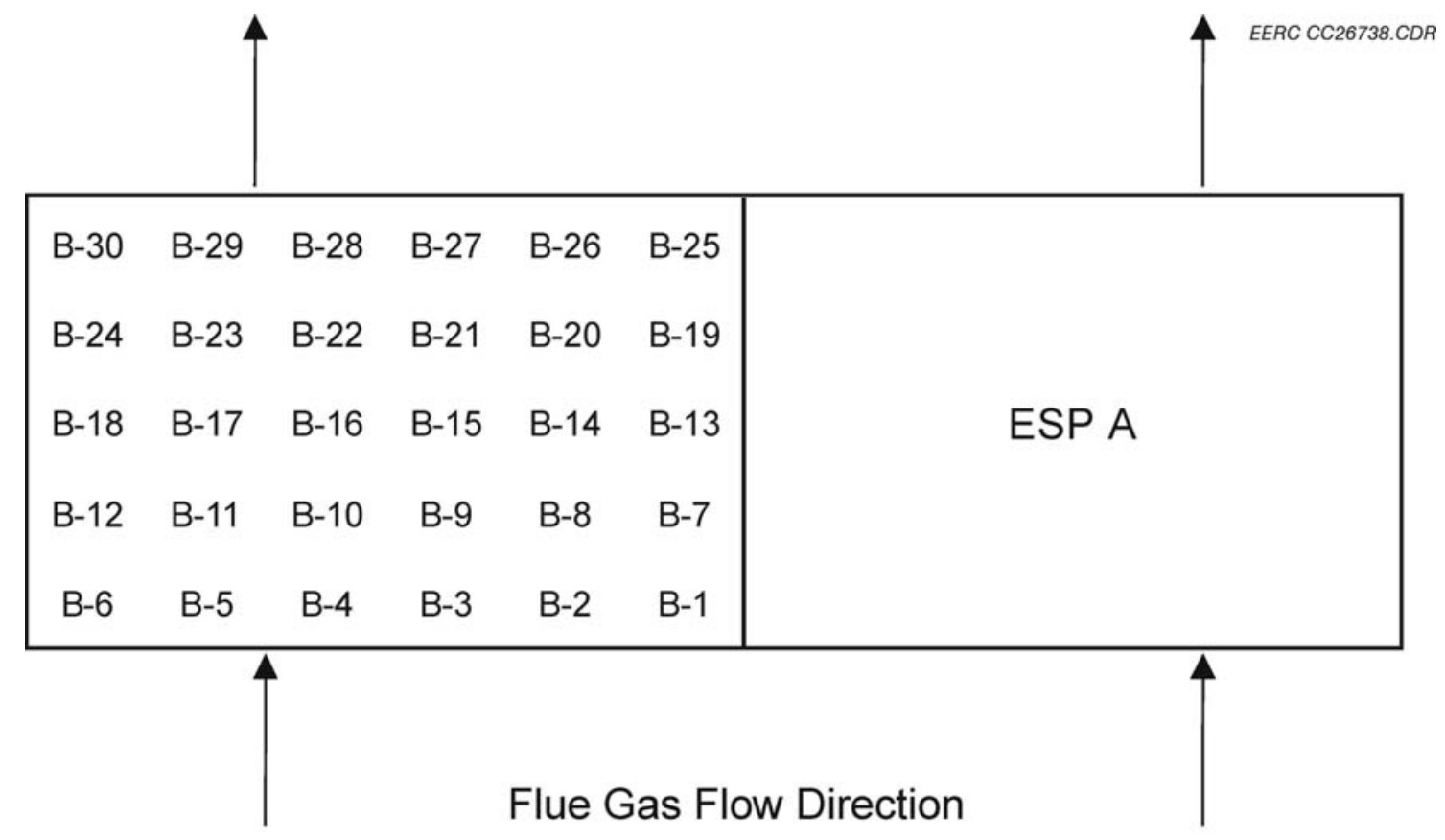

Figure 3-5. Hopper diagram for Unit 3 B-side ESP

The scrubber was sampled during the baseline periods of operation and once per day during the long-term tests. The scrubber was not sampled during the parametric injection test periods, as these test periods were too short in comparison to the residence time of the slurry in the scrubber. Therefore, it would not have been possible to obtain representative slurry samples during the parametric tests.

\subsubsection{Limestone and Makeup Water}

The limestone reagent feed and makeup water were sampled once during the test program.

\subsection{RESULTS AND DISCUSSION}

Full-scale boiler halogen injection tests were performed at MoSES Unit 3 to evaluate mercury oxidation and removal across a cold-side ESP/wet FGD system in a Texas lignitederived flue gas stream. Short-term parametric tests were followed by two 2-week continuousinjection tests. Parametric tests evaluated $\mathrm{CaCl}_{2}$ and $\mathrm{CaBr}_{2}$. Based on the results, $\mathrm{CaBr}_{2}$ was selected for the long-term tests. The long-term tests were executed as two 2-week periods of $\mathrm{CaBr}_{2}$ injection. Baseline measurements were made prior to the start of each long-term period. In the first 2-week period, the target injection rate was $50 \mathrm{ppm} \mathrm{Br}$ equivalent in the dry coal; for the second 2-week period, the primary target injection rate was $100 \mathrm{ppm} \mathrm{Br}$ equivalent in the dry coal. 


\subsection{Baseline Test Results}

Baseline flue gas mercury measurements were made during three distinct periods in the test program. These baseline periods are as follows:

- October 24, 19:50, through October 27, 12:55. These are the days prior to the parametric tests. Data for this time period are shown in Figure 4-1.

- November 1, 17:00, through November 5, 12:15. These are the days prior to the first long-term injection test. Data for this time period are shown in Figure 4-2.

- November 28, 17:00, through December 2, 11:10. These are the days prior to the second long-term injection test. Data for this time period are shown in Figure 4-3.

The total gas-phase mercury concentration was highly variable at MoSES Unit 3, with the baseline ESP inlet total mercury concentration ranging between 10 and $50 \mu \mathrm{g} / \mathrm{Nm}^{3}$; however, the concentrations were typically between 15 and $30 \mu \mathrm{g} / \mathrm{Nm}^{3}$ over the course of the baseline test days. The ESP inlet and outlet mercury was typically present as $10 \%-40 \%$ oxidized mercury; however, oxidized mercury levels as high as 55\% were observed December 1-2, 2005. Calculated baseline mercury removal across the ESP ranged from $-10 \%$ to $10 \%$; therefore, removal of mercury across the ESP was negligible overall. The removal of mercury across the ESP/FGD system was equivalent to the mercury removal across the FGD since there was no mercury removal across the ESP. Mercury removal across the FGD ranged from 10\% to 60\% over the course of the baseline testing; however, the mercury removal across the ESP/FGD system was more typically $10 \%-40 \%$. The measured mercury removal across the FGD agreed well with the ESP outlet oxidation.

The baseline $\mathrm{HCl} / \mathrm{Cl}_{2}$ and $\mathrm{HBr} / \mathrm{Br}_{2}$ concentrations were measured with Method 26 during various baseline periods. Results from individual runs are summarized in Appendix $\mathrm{C}$. Method $26 / 26 \mathrm{~A}$ has a negative bias associated with the quantification of $\mathrm{Cl}_{2} / \mathrm{Br}_{2}$ and a correspondingly positive bias associated with $\mathrm{HCl} / \mathrm{HBr}$. Therefore, halogen concentrations are presented as total halogen, expressed as $\mathrm{HCl}$ or $\mathrm{HBr}$. The baseline $\mathrm{HCl}$ concentration ranged from 1.2 to $5.2 \mathrm{ppm}$ and averaged $3.0 \mathrm{ppm}$. The baseline $\mathrm{HBr}$ concentration averaged $0.09 \mathrm{ppm}$.

\subsection{Parametric Test Results}

Two salt solutions were evaluated in parametric tests: $\mathrm{CaCl}_{2}$ and $\mathrm{CaBr}_{2}$. Each salt solution was tested at multiple injection rates over 2-day periods. Flue gas mercury concentrations were monitored continuously with mercury SCEMs at the ESP inlet, ESP outlet, and FGD outlet. Method 26 measurements were made at the ESP inlet during each parametric test condition to verify the amount of halogen species present in the flue gas.

Tables 4-1 and 4-2 show the measured flue gas $\mathrm{HCl} / \mathrm{Cl}_{2}$ and $\mathrm{HBr} / \mathrm{Br}_{2}$ concentrations during the parametric test periods. The data presented are the average of multiple runs conducted at each test condition (data for individual runs are listed in Appendix C). The measured $\mathrm{Cl}_{2}$ and $\mathrm{Br}_{2}$ concentrations were less than the detection limits of 0.07 and $0.01 \mathrm{ppm}$, respectively. 


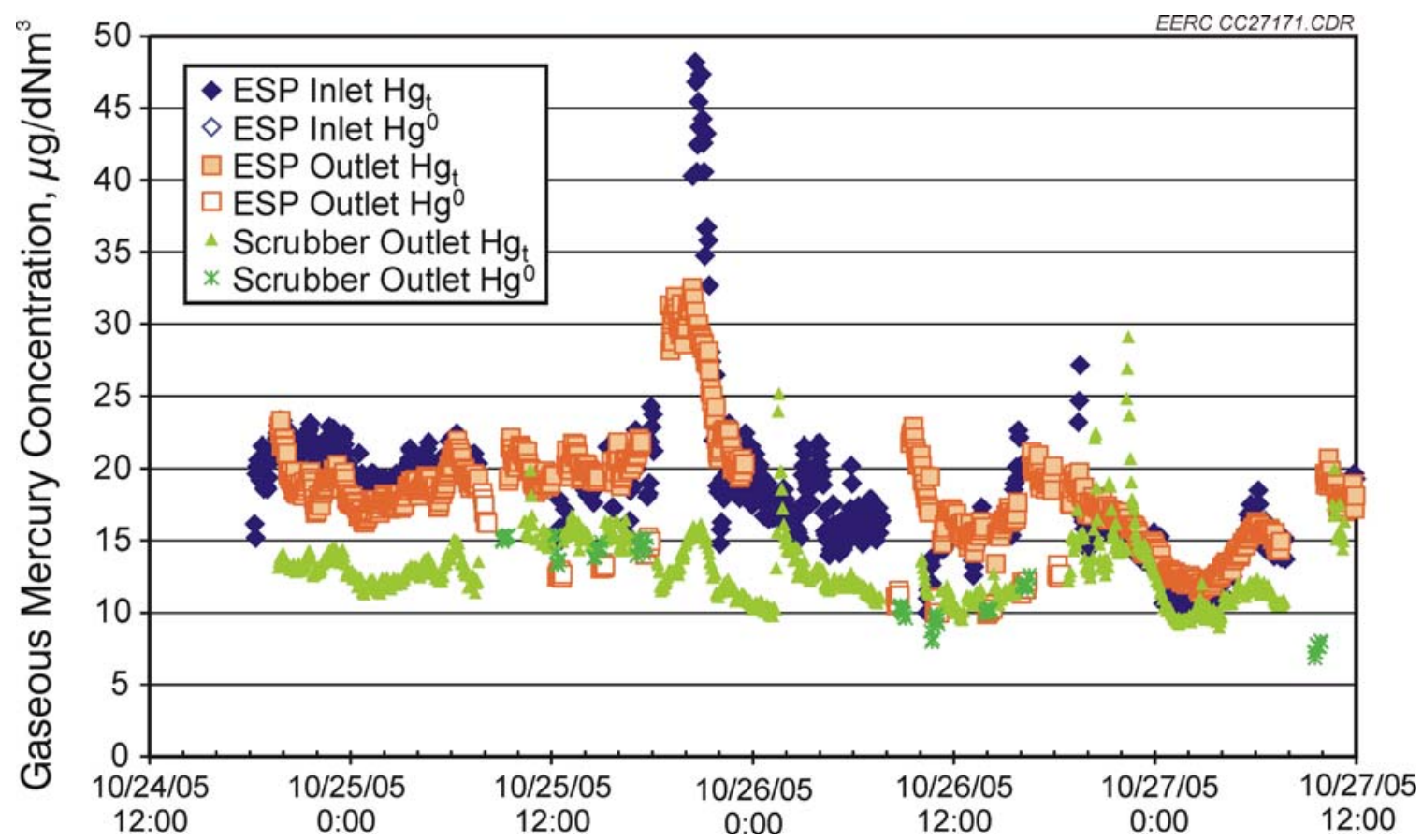

Figure 4-1. Baseline mercury SCEM data measured prior to parametric mercury control injection tests at MoSES Unit 3.

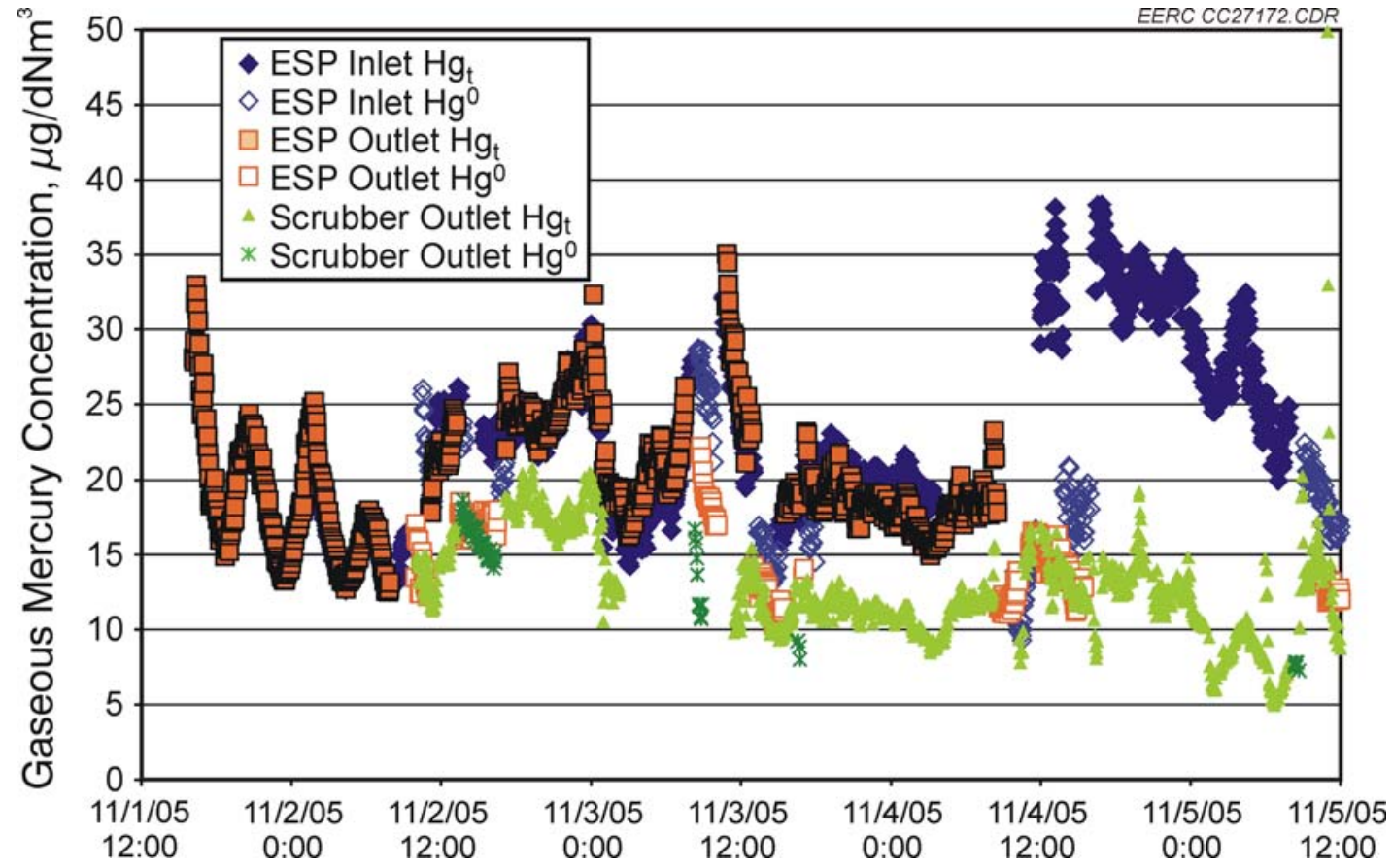

Figure 4-2. Baseline mercury SCEM data measured prior to the first set of long-term mercury control injection tests at MoSES Unit 3. 


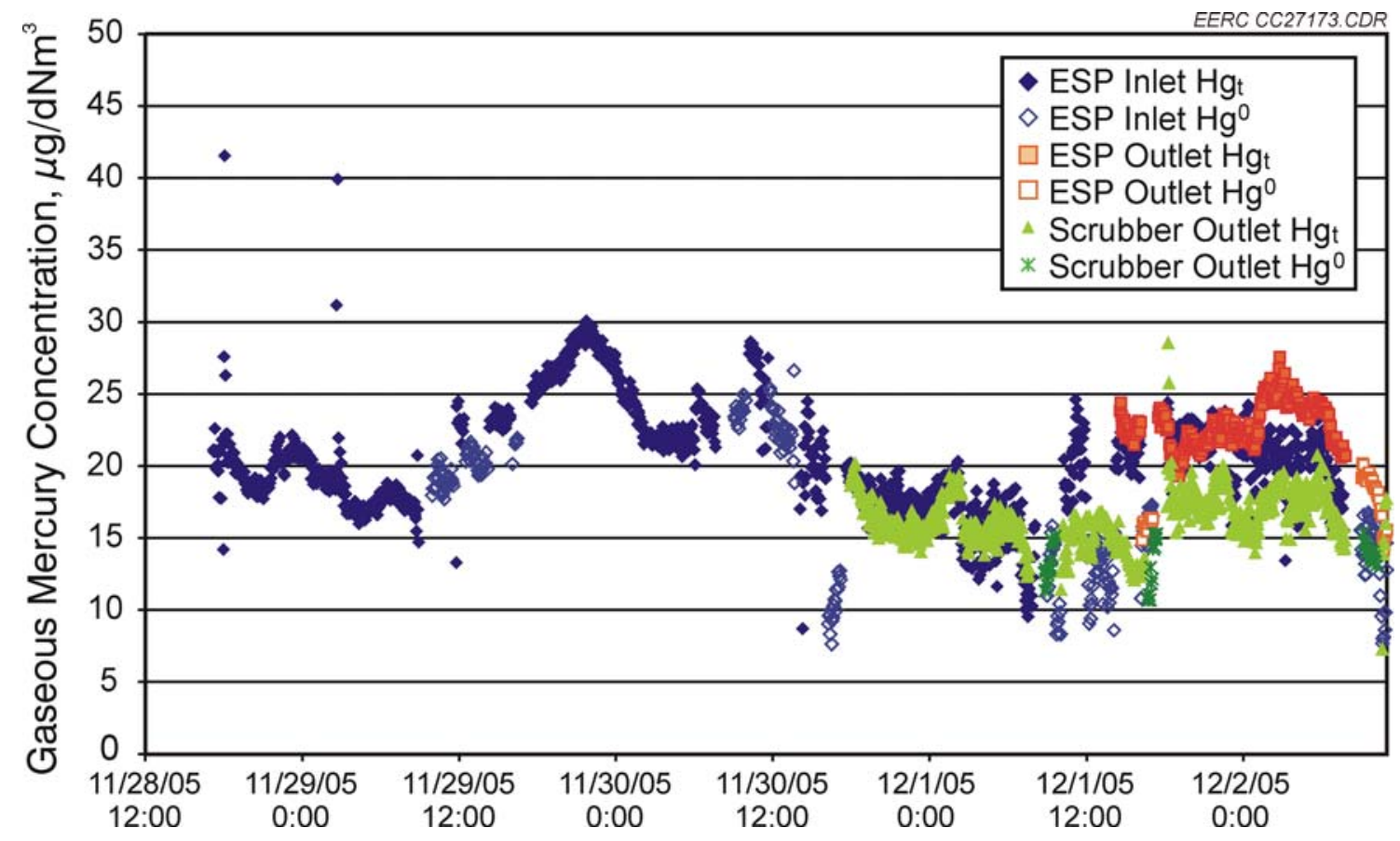

Figure 4-3. Baseline mercury SCEM data measured prior to the second set of long-term mercury control injection tests at MoSES Unit 3.

Table 4-1. Comparison of Measured Flue Gas HCI Concentrations to Theoretical Predictions for Parametric Tests at MoSES

\begin{tabular}{lccc}
\hline $\begin{array}{l}\text { Average } \\
\text { Injection Rate, } \\
\text { pm equivalent } \\
\text { in dry coal }\end{array}$ & $\begin{array}{c}\text { Average M26 } \\
\text { Measurement of } \\
\text { Flue Gas HCl, ppm, } \\
\text { dry, 3\% O }\end{array}$ & $\begin{array}{c}\text { Theoretical Chloride } \\
\text { Concentration, as HCl, } \\
\text { ppm, dry, 3\% O }\end{array}$ & $\begin{array}{c}\text { Measured/ } \\
\text { Theoretical, } \\
\%\end{array}$ \\
\hline 400 & 33.0 & 37 & 89 \\
600 & 52.1 & 55 & 95 \\
800 & 63.0 & 73 & 86 \\
\hline
\end{tabular}

The theoretical flue gas halogen (as HX) concentrations shown in Tables 4-1 and 4-2 were computed from the actual halogen injection rate and an estimated flue gas flow rate. The flue gas flow rate was estimated from an EPA Method 19 F-factor calculation, which agreed within $8 \%$ of the stack CEM flow measurements. For the theoretical calculation, it was assumed that all of the injected halogen (X) converted to HX in the flue gas. The calculation of the theoretical HX concentration included the baseline measurement of HX. 


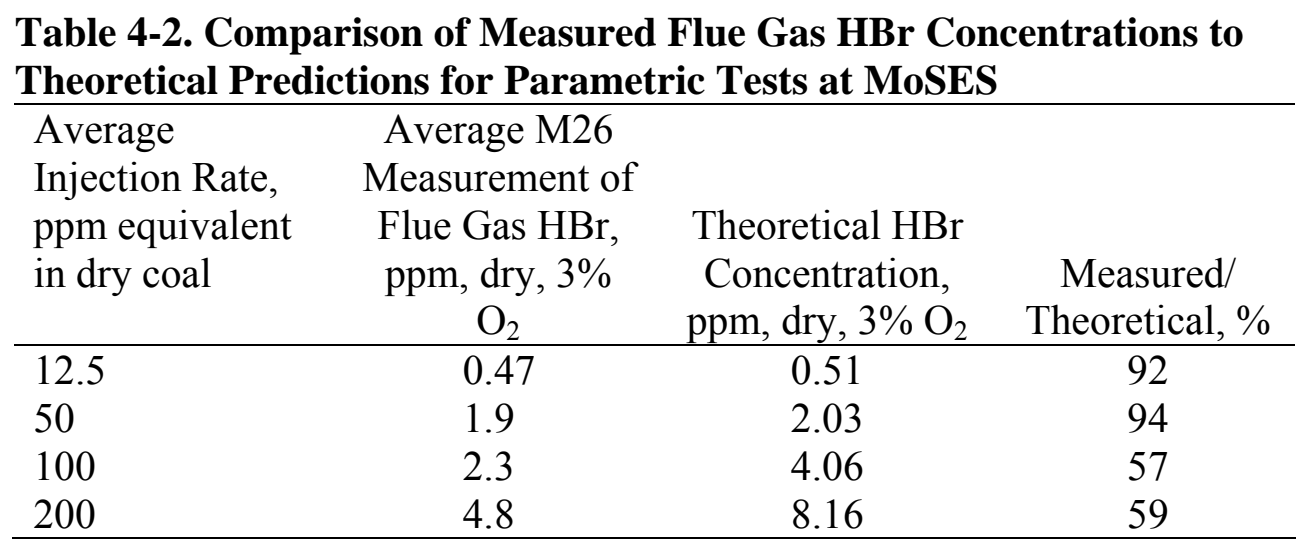

The measured flue gas $\mathrm{HCl}$ concentration correlates well with theoretical predictions, with the measured flue gas $\mathrm{HCl}$ concentration ranging from $86 \%$ to $95 \%$ of theoretical. For the $\mathrm{CaBr}_{2}$ tests, the measured $\mathrm{HBr}$ concentrations were closest to the theoretical concentrations at the lowest injection rates of 12.5 and $50 \mathrm{ppm} \mathrm{Br}$ equivalent in the coal (dry basis). At the higher injection rates of 100 and $200 \mathrm{ppm} \mathrm{Br}$ equivalent in the coal, the flue gas $\mathrm{HBr}$ concentration is approximately $60 \%$ of the theoretical value. This same trend of comparison between the measured to theoretical $\mathrm{HBr}$ concentrations was seen in the 2-week continuous tests.

The measured SCEM data are shown in Figures 4-4 and 4-5 for the $\mathrm{CaCl}_{2}$ and $\mathrm{CaBr}_{2}$ tests, respectively. In general, each injection rate was maintained for at least 2 hours. Once the flue gas mercury concentrations steadied out, the injection rate was changed. For each injection rate, an average of the measured steady-state mercury concentrations was taken. Table 4-3 presents these average concentrations. As can be seen in Figures 4-4 and 4-5, the total $\mathrm{Hg}$ concentrations measured at the ESP inlet and ESP outlet decreased during $\mathrm{CaBr}_{2}$ injection. This decrease in total mercury concentration was not observed during $\mathrm{CaCl}_{2}$ injection. It was later observed from the long-term test data that the presence of bromide in the flue gas likely caused a negative bias in the measurement of total mercury in the flue gas. This bias does not exist at the scrubber outlet because the scrubber removes the flue gas bromine. No biases in elemental mercury concentration measurements were observed upstream of the scrubber. The bias in total mercury concentration in the presence of bromine is explored in detail in the discussion of the long-term injection results. In the long-term data analysis, test-average coal mercury values were used in place of the scrubber inlet total vapor-phase mercury concentrations measured by the SCEMs. This option was not available for the parametric data analysis, as it was difficult to obtain single daily coal samples that were representative of the flue gas condition. Therefore, for these parametric tests, the total vapor-phase mercury concentration data are still presented for the $\mathrm{CaBr}_{2}$ injection, but they are flagged as having a possible negative bias. All mercury removal and oxidation values calculated from the total mercury concentration may likewise be biased low.

While Figure 4-5 presents all of the scrubber outlet mercury concentration data that were measured by the SCEM, only limited scrubber outlet data were used in the calculation of mercury removal for the parametric $\mathrm{CaBr}_{2}$ tests. Significant problems were initially encountered 


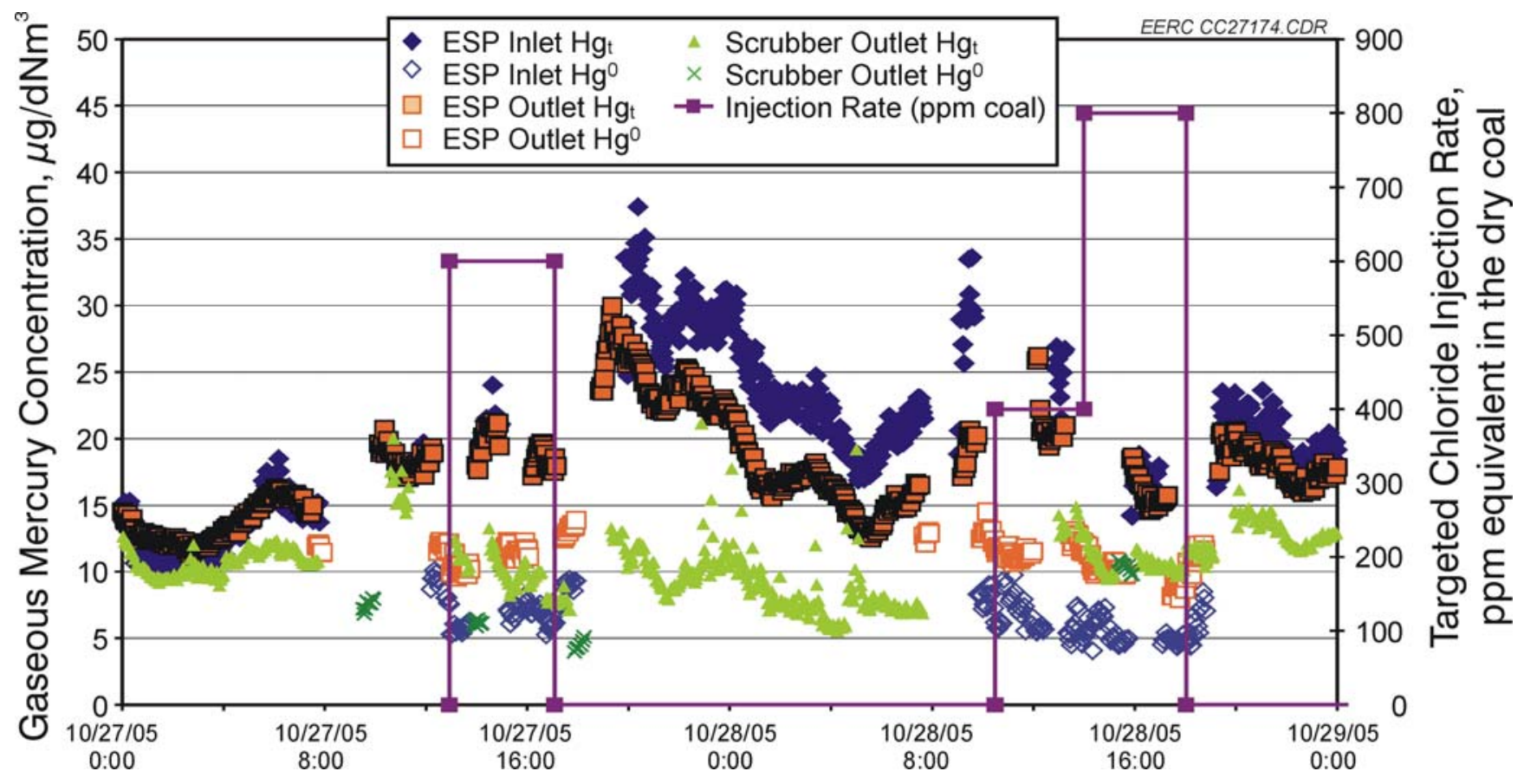

Figure 4-4. SCEM concentrations measured during $\mathrm{CaCl}_{2}$ parametric injection tests.

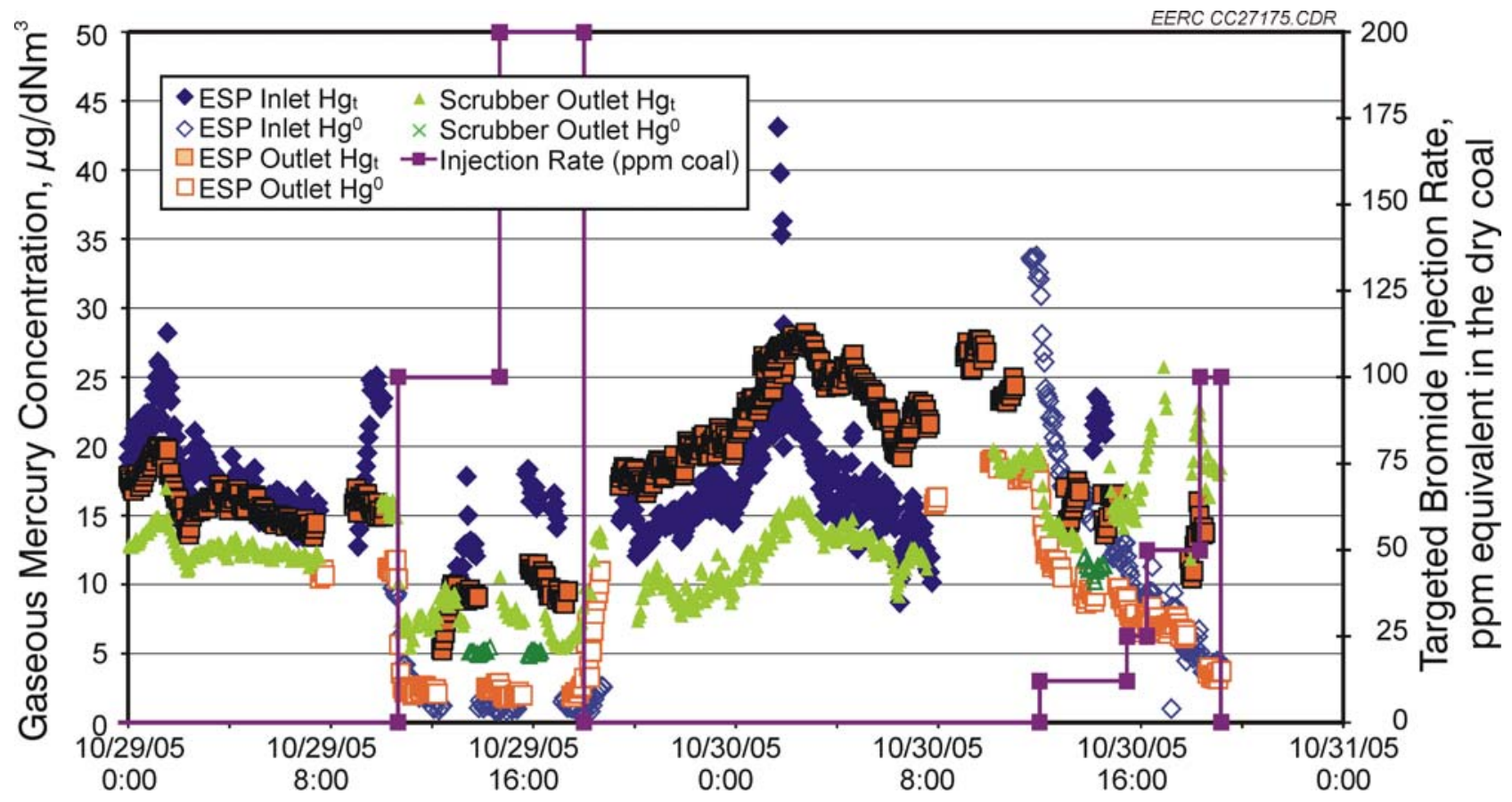

Figure 4-5. SCEM concentrations measured during $\mathrm{CaBr}_{2}$ parametric injection tests. 
Table 4-3. Average Mercury Concentrations During Parametric Injection Tests at MoSES

\begin{tabular}{|c|c|c|c|c|c|c|c|}
\hline \multirow[b]{2}{*}{ Chemical } & \multirow{2}{*}{$\begin{array}{c}\text { Targeted } \\
\text { Injection Rate, } \\
\text { ppm X in coal }\end{array}$} & \multicolumn{2}{|c|}{ ESP Inlet } & \multicolumn{2}{|c|}{ ESP Outlet } & \multicolumn{2}{|c|}{ Scrubber Outlet } \\
\hline & & Hg Total & $\mathrm{Hg}^{01}$ & Hg Total & $\mathrm{Hg}^{0}$ & Hg Total & $\mathrm{Hg}^{0}$ \\
\hline Baseline & 0 & 19.3 & 9.3 & 18.4 & 11.9 & 16.2 & NA \\
\hline $\mathrm{CaCl}_{2}$ & 600 & 21.1 & 6.8 & 19.6 & 11.0 & 10.2 & 6.2 \\
\hline Baseline & 0 & 28.2 & 7.9 & 19.3 & 12.7 & $\mathrm{NA}^{2}$ & NA \\
\hline $\mathrm{CaCl}_{2}$ & 400 & 25.0 & 7.0 & 21.0 & 11.6 & 13.6 & NA \\
\hline $\mathrm{CaCl}_{2}$ & 800 & 17.0 & 5.3 & 16.0 & 9.8 & 10.4 & 10.4 \\
\hline Baseline & 0 & 20.7 & 9.5 & 15.8 & 11.2 & 15.6 & NA \\
\hline $\mathrm{CaBr}_{2}$ & 100 & $12.0^{4}$ & 1.3 & $8.7^{4}$ & 2.4 & 8.1 & 5.1 \\
\hline $\mathrm{CaBr}_{2}$ & 200 & $16.1^{4}$ & 1.1 & $10.1^{4}$ & 2.2 & 6.3 & 5.1 \\
\hline Baseline & 0 & NA & 33.3 & 23.8 & 18.3 & 18.9 & NA \\
\hline $\mathrm{CaBr}_{2}$ & 12 & $21.9^{4}$ & 15.9 & $15.6^{4}$ & 9.9 & 14.3 & 11.2 \\
\hline $\mathrm{CaBr}_{2}$ & 50 & NA & 8.8 & NA & 7.1 & 16.9 & NA \\
\hline $\mathrm{CaBr}_{2}$ & 100 & NA & 6.4 & $12.5^{4}$ & 6.9 & $\mathrm{D}^{3}$ & NA \\
\hline $\mathrm{CaBr}_{2}$ & 200 & NA & 4.2 & NA & 3.4 & $\mathrm{D}^{3}$ & NA \\
\hline
\end{tabular}

${ }^{1}$ ESP inlet $\mathrm{Hg}^{0}$ values are biased low (oxidation biased high) because of sampling problem.

${ }^{2} \mathrm{NA}=$ Not available because the value either was not measured or did not pass QC.

${ }^{3} \mathrm{D}=$ Deleted data because scrubber outlet probe received a slug of FGD slurry and caused increased measured mercury concentrations.

${ }^{4}$ Total Hg concentrations at ESP inlet and ESP outlet during calcium bromide injection tests may be biased low.

while the gas was sampled at the scrubber outlet because the only available sampling ports were directly above the scrubber exit. As the mist-laden flue gas exited the scrubber and was sampled by the mercury extraction probe, large volumes of slurry would occasionally get pulled into the extraction probe (despite having a nozzle on the probe tip that was pointed in the opposite direction of flue gas flow). As the slurry was heated by the probe, the mercury in the slurry offgassed and was sampled by the SCEM, producing a positive bias in the scrubber outlet mercury concentrations. As the test program progressed, methods were devised to minimize this positive bias. These methods included 1) the use of a dual extraction loop, 2) decreasing the heating on the extraction probe to prevent spray-drying any captured slurry, and 3) daily preventive cleaning of the extraction probe. While these methods did not eliminate the problem, they reduced the occurrence of positively biased data at the FGD outlet. However, many of these techniques were not employed until the completion of the parametric test program.

The percentage of mercury present as oxidized mercury was calculated at the ESP inlet and ESP outlet locations. Table 4-4 shows these results. Figures 4-6 and 4-7 plot the mercury oxidation results for $\mathrm{CaCl}_{2}$ and $\mathrm{CaBr}_{2}$ injection, respectively.

For the first test days during parametric testing, the oxidation of mercury at the ESP inlet was significantly higher than at the ESP outlet. At the ESP inlet, the baseline oxidation was between $54 \%$ and $71 \%$, while the ESP outlet oxidation was between $29 \%$ and $25 \%$. The ESP inlet oxidation percentages were significantly higher than what was measured during all the other 
Table 4-4. Percent Oxidation of Mercury at ESP Inlet and Outlet Measured During Parametric Injection Tests

\begin{tabular}{|c|c|c|c|c|}
\hline Test Day & Chemical & $\begin{array}{c}\text { Targeted } \\
\text { Injection Rate, } \\
\text { ppm X in coal }\end{array}$ & $\begin{array}{l}\text { Hg Oxidation } \\
\text { at ESP Inlet }{ }^{\mathrm{b}}, \%\end{array}$ & $\begin{array}{l}\text { Hg Oxidation } \\
\text { at ESP Outlet, \% }\end{array}$ \\
\hline \multirow[t]{2}{*}{1} & Baseline & 0 & 52 & 35 \\
\hline & $\mathrm{CaCl}_{2}$ & 600 & 68 & 44 \\
\hline \multirow[t]{3}{*}{2} & Baseline & 0 & 72 & 34 \\
\hline & $\mathrm{CaCl}_{2}$ & 400 & 72 & 45 \\
\hline & $\mathrm{CaCl}_{2}$ & 800 & 69 & 39 \\
\hline \multirow[t]{3}{*}{3} & Baseline & 0 & 54 & 29 \\
\hline & $\mathrm{CaBr}_{2}$ & 100 & $89^{c}$ & $72^{\mathrm{c}}$ \\
\hline & $\mathrm{CaBr}_{2}$ & 200 & $93^{c}$ & $78^{\mathrm{c}}$ \\
\hline \multirow[t]{5}{*}{4} & Baseline & 0 & NA & 23 \\
\hline & $\mathrm{CaBr}_{2}$ & 12 & $27^{\mathrm{c}}$ & $37^{\mathrm{c}}$ \\
\hline & $\mathrm{CaBr}_{2}$ & 50 & $60^{a, c}$ & $50^{\mathrm{a}, \mathrm{c}}$ \\
\hline & $\mathrm{CaBr}_{2}$ & 100 & $71^{\mathrm{a}, \mathrm{c}}$ & $45^{\mathrm{c}}$ \\
\hline & $\mathrm{CaBr}_{2}$ & 200 & $81^{\mathrm{a}, \mathrm{c}}$ & $73^{a, c}$ \\
\hline
\end{tabular}

${ }^{\mathrm{a}}$ Total gas-phase mercury concentration was not available for these runs; therefore, percent oxidation was based on average total gas-phase mercury concentration measured during either the previous or following test.

${ }^{b}$ Percent mercury oxidation at the ESP inlet may be biased high because of problem with sampling extraction loop at ESP inlet.

${ }^{c}$ The percent oxidation measured at ESP inlet and outlet during calcium bromide injection tests may be biased low because of negative bias in measurement of total vapor-phase mercury concentrations with SCEMs in the presence of bromine.

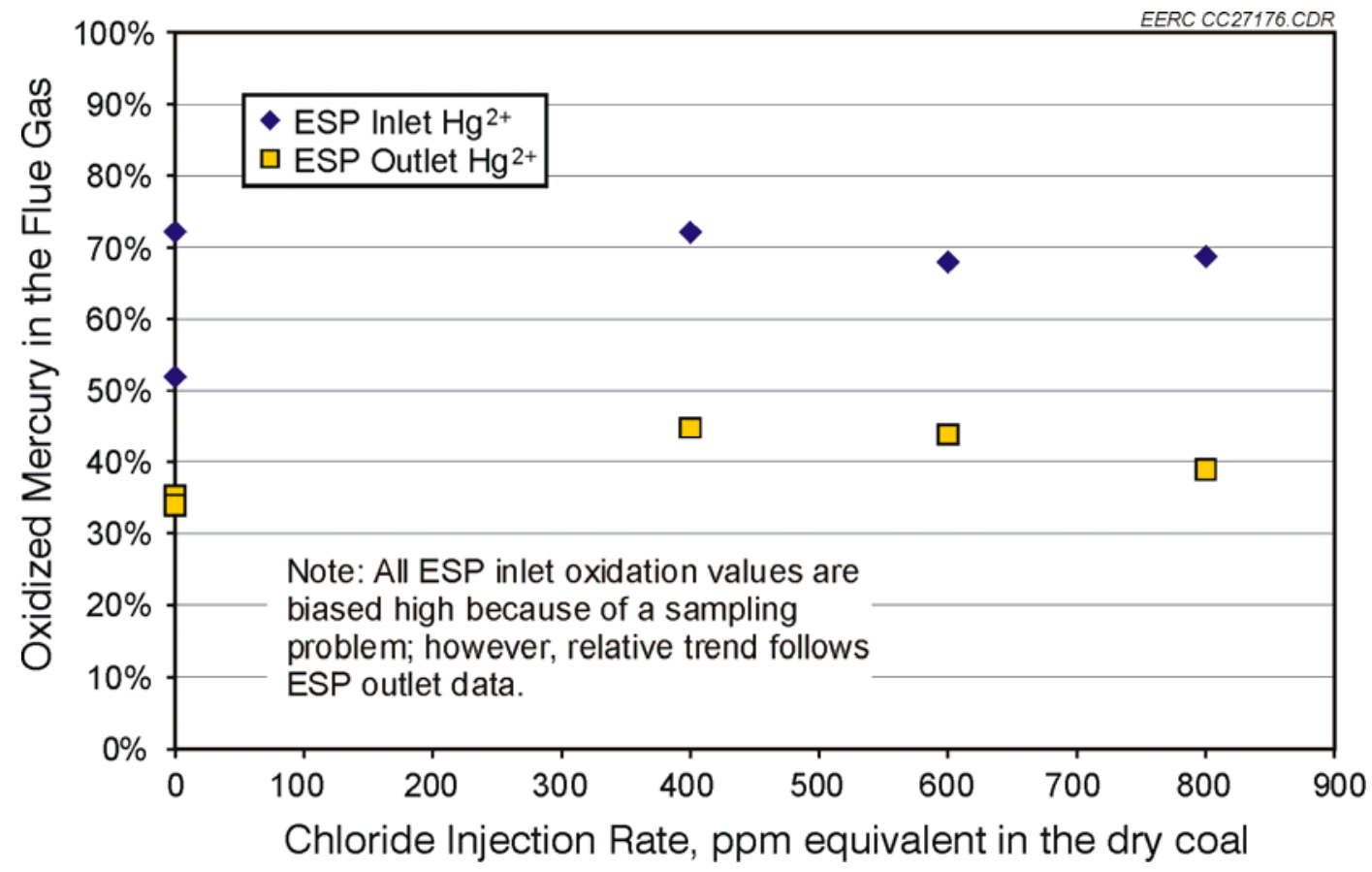

Figure 4-6. Percent oxidized mercury present at ESP inlet and outlet for $\mathrm{CaCl}_{2}$ parametric injection tests. 


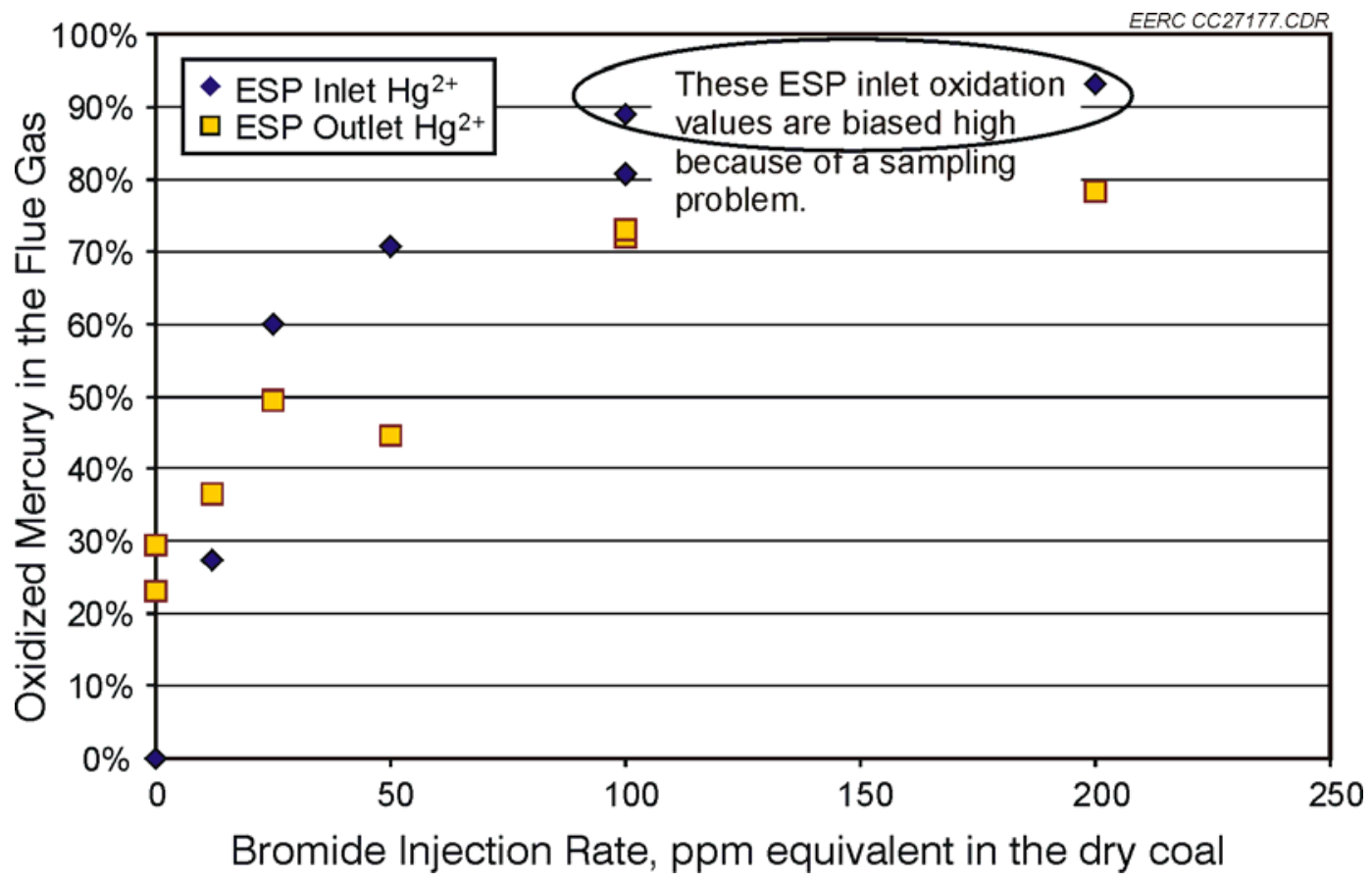

Figure 4-7. Percent oxidized mercury present at ESP inlet and outlet for $\mathrm{CaBr}_{2}$ parametric injection tests.

baseline measurement periods, when it was typically between $10 \%$ and $40 \%$. The IGS filter at the ESP inlet was replaced at the beginning of the fourth day of parametric testing; an increase in the elemental mercury concentration (and decrease in oxidation) measured at the ESP inlet was observed following IGS filter replacement; therefore, it is believed that the IGS filter was oxidizing a portion of the mercury in the sampled flue gas. While the oxidation values at the ESP inlet are biased high for the first three test days of parametric testing, these values do show the same performance trends as the ESP outlet data for the two halogenated chemicals.

The parametric $\mathrm{CaCl}_{2}$ tests showed only a nominal increase in mercury oxidation at the ESP inlet and ESP outlet locations. The gas-phase mercury at the ESP outlet reached a maximum of $45 \%$ oxidation at an injection rate of $400 \mathrm{ppm} \mathrm{Cl}$ equivalent in the dry coal as compared to a baseline oxidation of $35 \%$. The oxidation of mercury at both the ESP inlet and ESP outlet locations did not increase with injection rates above $400 \mathrm{ppm} \mathrm{Cl}$ equivalent in the coal. In contrast, the injection of $\mathrm{CaBr}_{2}$ resulted in up to $72 \%$ oxidation of the mercury at the ESP outlet at an injection rate of $100 \mathrm{ppm} \mathrm{Br}$ equivalent in the dry coal. The breaking point for the performance curve appears to be around $100 \mathrm{ppm} \mathrm{Br}$ equivalent in the coal. Increasing the injection rate to $200 \mathrm{ppm} \mathrm{Br}$ increased the oxidation from $72 \%$ up to only $78 \%$.

The bromide addition in this test program was limited to only two of the stock feeders. The feeders were chosen to treat both the front and back sides of the furnace and each feeder supplied fuel pipes that spanned the width of the furnace wall. Despite these efforts to ensure that the entire flue gas was treated with bromide, the bromide concentration over the boiler flue gas might have been less evenly distributed in comparison to addition of bromide to all of the coal 
feeders. Therefore, the "break point" as observed here may not be applicable to other conditions, as has been shown in some applications in which the entire coal stream was treated with bromide (5). The parametric chloride addition results from this test program may also have been impacted in a similar manner if nonuniform distribution existed.

Figures 4-8 and 4-9 show the percentage of mercury removal across the ESP and the FGD for the $\mathrm{CaCl}_{2}$ and $\mathrm{CaBr}_{2}$ injection tests, respectively. The baseline mercury removal across the ESP was approximately $20 \%$ during these test days, but was typically $0 \%$ during all other baseline periods in the test program. Neither the $\mathrm{CaCl}_{2}$ nor the $\mathrm{CaBr}_{2}$ resulted in an increase in mercury removal across the ESP.

The mercury removal across the FGD increased from $12 \%$ at baseline to approximately $45 \%$ during the $\mathrm{CaCl}_{2}$ injection tests. These results agree well with the measured $45 \%$ oxidation of mercury at the FGD inlet (ESP outlet). Because of sampling problems (described above) at the FGD outlet during the $\mathrm{CaBr}_{2}$ parametric test days, the FGD outlet data were invalidated. Therefore, the parametric test results were inconclusive in regards to the effect of $\mathrm{CaBr}_{2}$ on mercury removal by the FGD scrubber. However, the effect of $\mathrm{CaBr}_{2}$ on mercury removal across the FGD is well documented in the long-term testing.

Because of the sampling problems at the FGD outlet during the $\mathrm{CaBr}_{2}$ injection tests, it was not possible to compare the effect of halogen identity on net flue gas mercury removal across the ESP/FGD system. The parametric tests for the $\mathrm{CaCl}_{2}$ showed that $\mathrm{CaCl}_{2}$ did not achieve the oxidation needed to meet the mercury removal target of $55 \%$ for the project. Conversely, $\mathrm{CaBr}_{2}$ was shown capable of achieving high mercury oxidation that might be sufficient to achieve the mercury removal goals for the project; therefore, $\mathrm{CaBr}_{2}$ was selected for the long-term tests. For the first 2-week continuous-injection test, an injection rate of $50 \mathrm{ppm} \mathrm{Br}$ equivalent in the coal was selected. Based on the parametric oxidation results, this injection rate appeared capable of achieving the mercury removal target of $55 \%$.

\subsection{Long-Term Test Results}

Two longer-term, continuous-injection tests were executed as part of this test program. In the first 2-week continuous test, $\mathrm{CaBr}_{2}$ was injected at a target injection rate of $50 \mathrm{ppm} \mathrm{Br}$ equivalent in the dry coal. In the second 2-week test, $\mathrm{CaBr}_{2}$ was injected at a target injection rate of $100 \mathrm{ppm} \mathrm{Br}$ equivalent in the coal. At the end of the second 2-week test, the injection rate was further increased in an attempt to achieve higher mercury oxidation and removal rates.

\subsubsection{Evaluation of Actual $\mathrm{CaBr}_{2}$ Injection Rates}

During the $\mathrm{CaBr}_{2}$ injection tests, the approximate targeted injection rate was maintained by monitoring the coal feed rate and the solution pump rate and by using measurements of the solution density to estimate the bromide content of the solution. The pumped $\mathrm{CaBr}_{2}$ solution was collected daily during the test program. At the conclusion of the long-term tests, these solution samples were analyzed in URS' Austin laboratory with ion chromatography for the true bromide content. The true bromide content was used in conjunction with the solution density and coal 


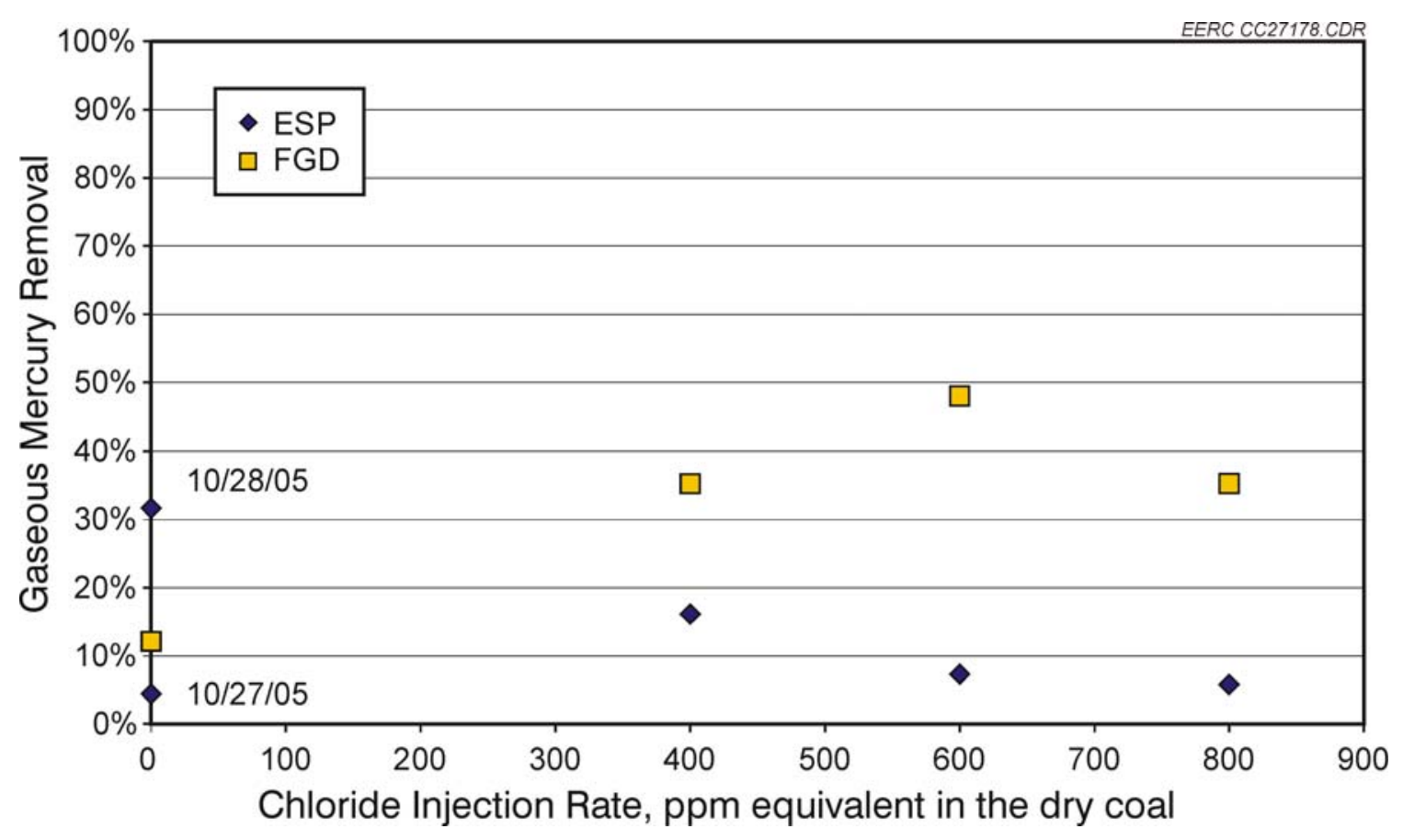

Figure 4-8. Mercury removal across the ESP and $\mathrm{FGD}$ for $\mathrm{CaCl}_{2}$ during parametric injection tests at MoSES.

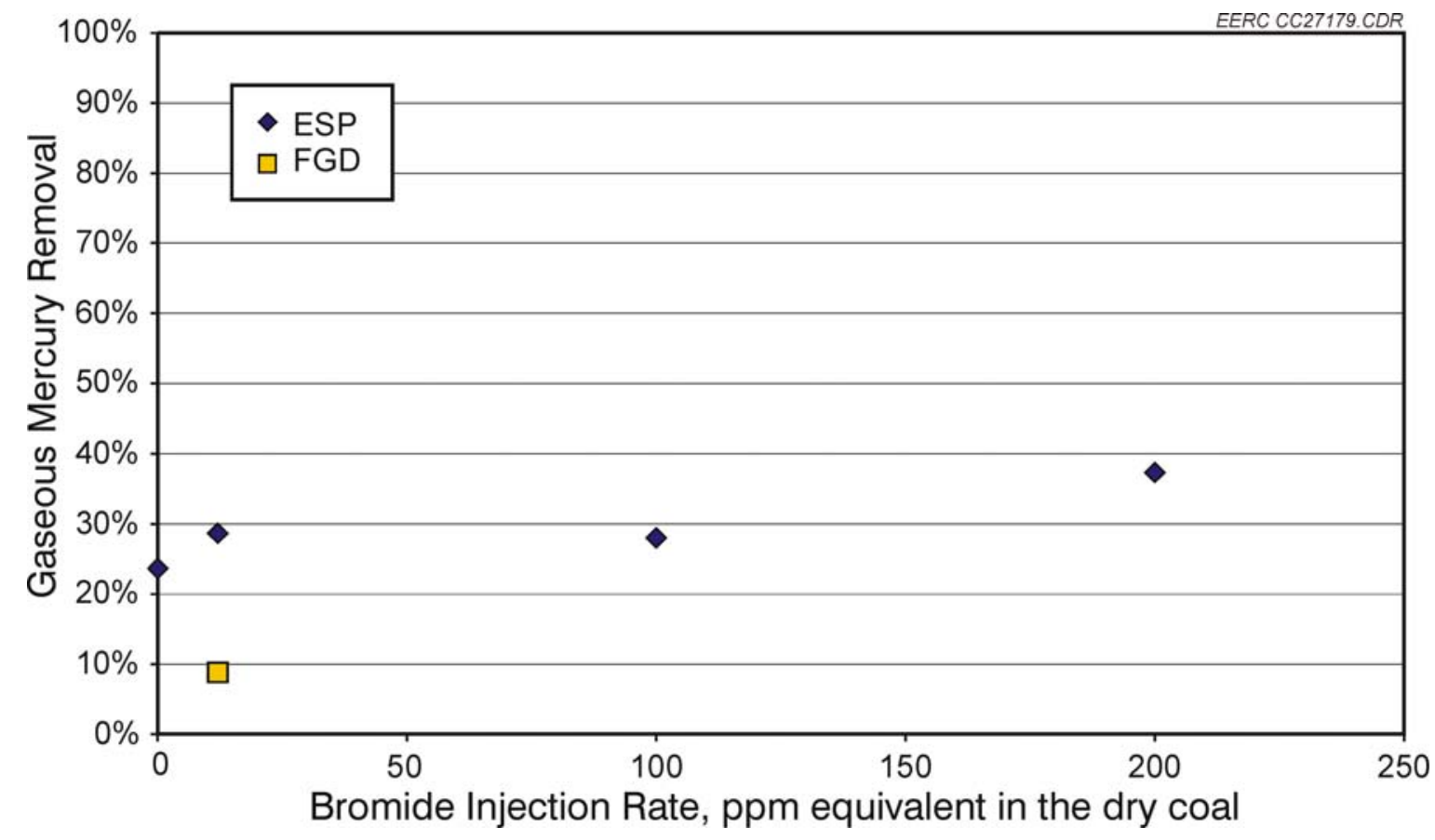

Figure 4-9. Mercury removal across the ESP and FGD for $\mathrm{CaBr}_{2}$ during parametric injection tests at MoSES. 
feed rate (from plant data) to calculate the actual injection rates maintained during the test program. In addition, flue gas halogen concentrations were monitored daily at the ESP inlet using Method 26.

Overall, the calculated injection rates, as presented in Figure 4-10, were slightly higher than the target injection rate of $50 \mathrm{ppm} \mathrm{Br}$ equivalent in the dry coal for the first 2-week test period. Over the course of the 2-week test period, the actual injection rate was an average $55 \mathrm{ppm} \mathrm{Br}$ equivalent in the coal. Because of fluctuations in the $\mathrm{CaBr}_{2}$ pump response to the changing load and pulverizer speeds, the injection rate temporarily reached as low as $45 \mathrm{ppm}$ and as high as 90 ppm during the test period.

Figure 4-10 also shows the results of daily Method 26 monitoring of flue gas bromide concentrations made daily during the test period (complete results are tabulated in Appendix C). During baseline (no $\mathrm{CaBr}_{2}$ injection), the flue gas $\mathrm{HBr}$ content was less than 0.09 ppm (dry, $3 \% \mathrm{O}_{2}$ ). As noted in the description of $\mathrm{M} 26$, the method has a negative bias for the quantification of $\mathrm{Br}_{2}$ and a corresponding positive bias for $\mathrm{HBr}$. Results are reported for total $\mathrm{Br}$ as $\mathrm{HBr}$, but in reality some portion of the bromine may be present in flue gas as $\mathrm{Br}_{2}$. The $\mathrm{HBr}$ concentration of the flue gas averaged $1.7 \mathrm{ppm}\left(\mathrm{dry}, 3 \% \mathrm{O}_{2}\right)$ over the course of the first 2-week injection test period. Because of the fluctuations in the feed rate, the $\mathrm{HBr}$ concentration went as high as 2.3 and as low as $1.3 \mathrm{ppm}$.

The target injection rate for the second 2-week test period was initially $100 \mathrm{ppm} \mathrm{Br}$ equivalent in the coal. The injection rate was increased toward the end of the test period in an attempt to realize higher oxidation and removal rates of mercury. The actual injection rate is shown in Figure 4-11. Over the course of the 2-week test period (December 2-12, 2005), the actual injection rate averaged $113 \mathrm{ppm} \mathrm{Br}$ equivalent in the coal. The injection rate ranged from as low as $97 \mathrm{ppm}$ to as high as $158 \mathrm{ppm}$. On December 12, the injection rate was increased to $193 \mathrm{ppm} \mathrm{Br}$, and on December 13, the injection rate was further increased to an injection rate of $330 \mathrm{ppm} \mathrm{Br}$ equivalent in the coal.

Results of daily Method 26 measurements of flue gas bromide/bromine concentrations are also shown in Figure 4-11 (results for individual runs are tabulated in Appendix $\mathrm{C}$ ). $\mathrm{The}_{\mathrm{Br}}$ concentration of the flue gas was less than the detection limit of $0.02 \mathrm{ppm}$ during all of the longterm test periods. During baseline (no $\mathrm{CaBr}_{2}$ injection), the flue gas $\mathrm{HBr}$ content was less than $0.06 \mathrm{ppm}$ (dry, corrected to $3 \% \mathrm{O}_{2}$ ). The $\mathrm{HBr}$ concentration of the flue gas averaged $3.0 \mathrm{ppm}$ (dry, 3\% $\mathrm{O}_{2}$ ) during the period when the average injection rate was $113 \mathrm{ppm} \mathrm{Br}$ equivalent in the coal. When the injection rate was increased to $193 \mathrm{ppm} \mathrm{Br}$ equivalent in the coal, the flue gas $\mathrm{HBr}$ concentration increased to $5.2 \mathrm{ppm}$; when the injection rate was further increased to $330 \mathrm{ppm} \mathrm{Br}$ equivalent in the coal, the flue gas $\mathrm{HBr}$ concentration increased to $7.6 \mathrm{ppm}$.

The theoretical flue gas $\mathrm{HBr}$ concentration was computed from the actual $\mathrm{CaBr}_{2}$ injection rate and the flue gas flow rate. The flue gas flow rate was estimated from an EPA Method 19 F-factor calculation. For the theoretical calculation, it was assumed that all of the injected bromide converts to flue gas $\mathrm{HBr}$. Table 4-5 compares the average Method 26 measurement of 


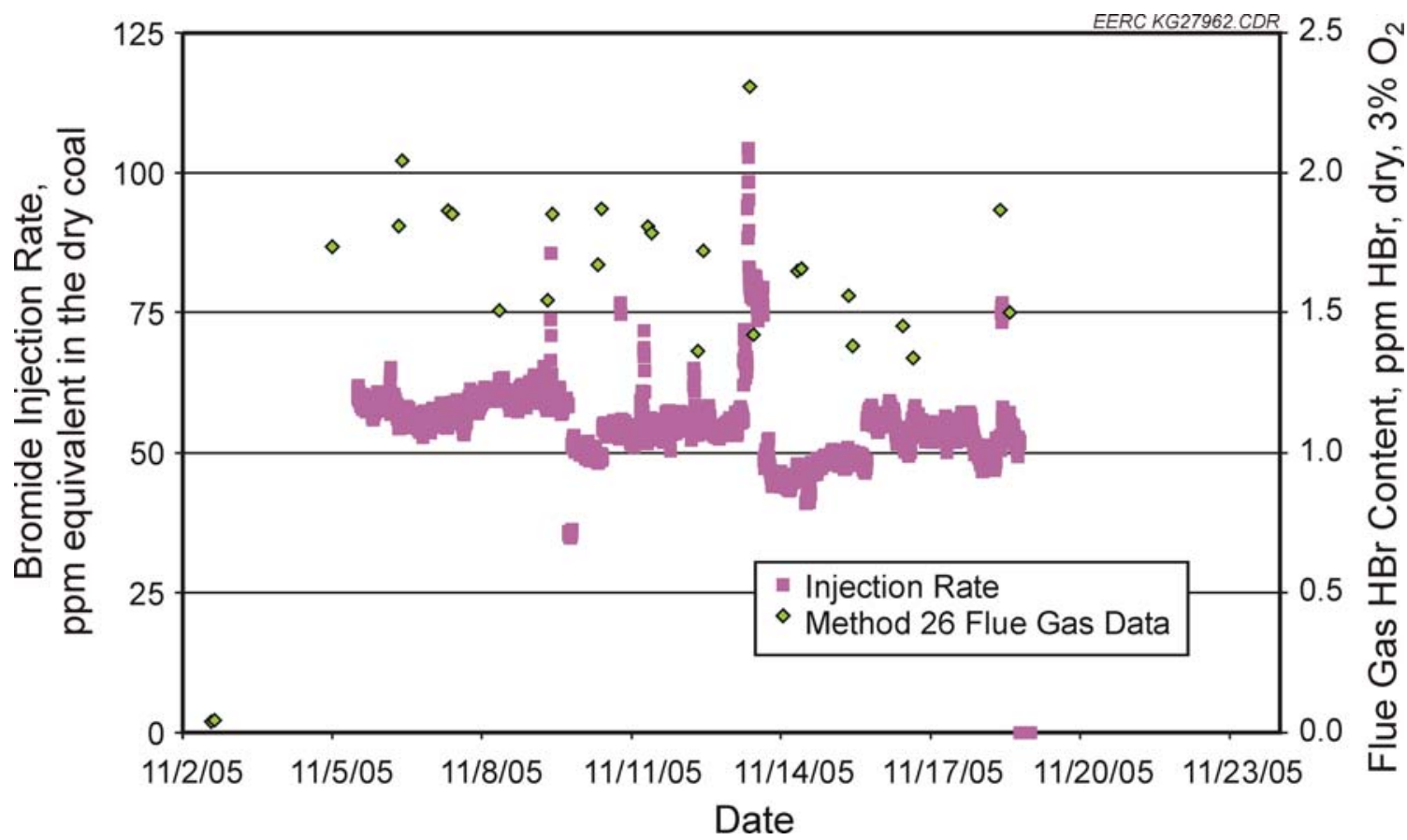

Figure 4-10. Actual additive injection rate of $\mathrm{CaBr}_{2}$ and $\mathrm{M} 26$ measurements during first 2-week long-term test period at MoSES.

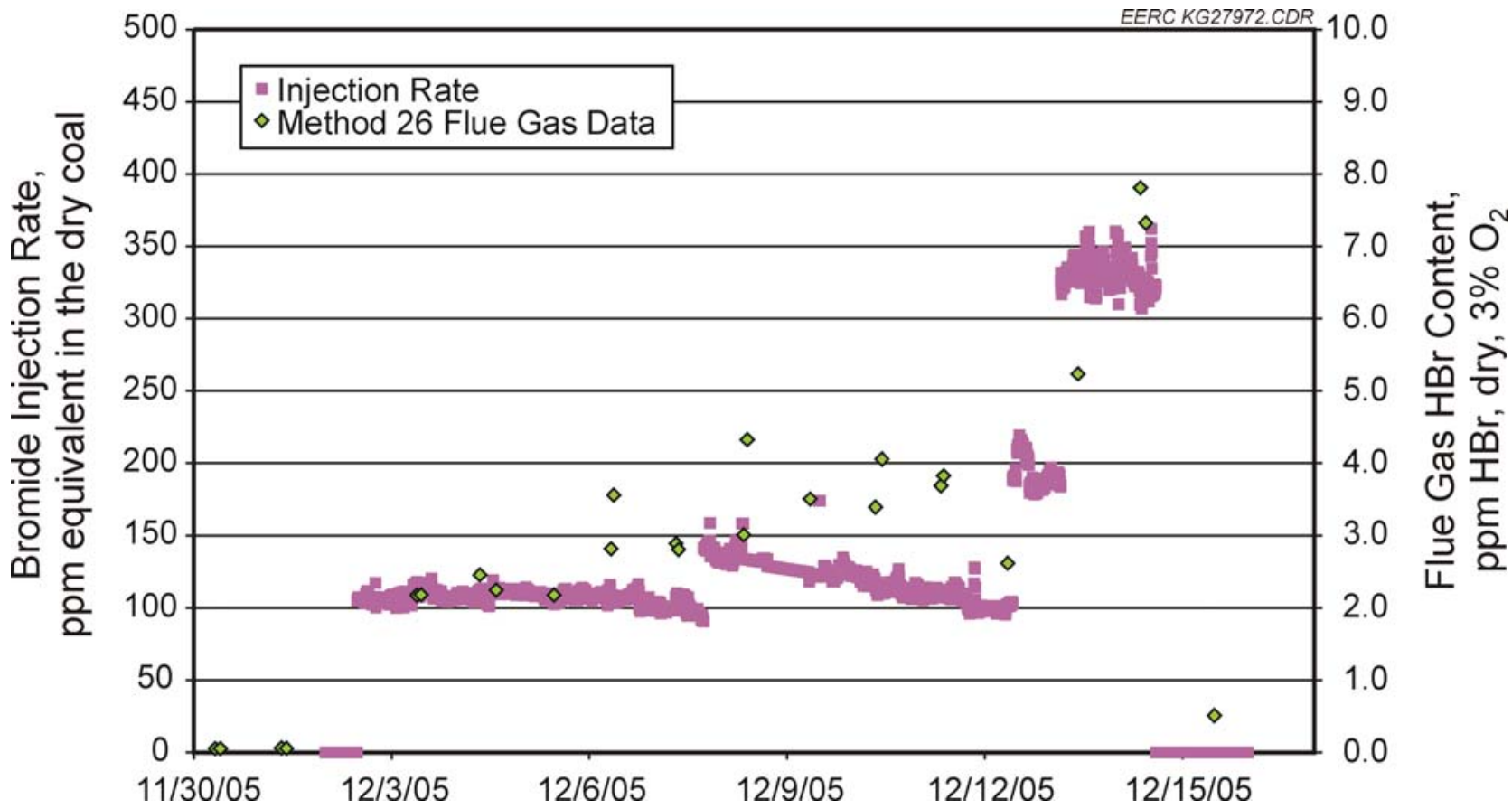

Figure 4-11. Actual additive injection rate of $\mathrm{CaBr}_{2}$ and $\mathrm{M} 26$ measurements during second 2-week long-term test period at MoSES. 


\begin{tabular}{|c|c|c|c|}
\hline $\begin{array}{l}\text { Average Injection } \\
\text { Rate, ppm } \mathrm{Br} \\
\text { equivalent in dry coal }\end{array}$ & $\begin{array}{l}\text { Average M26 } \\
\text { Measurement of } \\
\text { Flue Gas } \mathrm{HBr} \text {, } \\
\text { ppm, dry, } 3 \% \mathrm{O}_{2}\end{array}$ & $\begin{array}{l}\text { Theoretical } \mathrm{HBr} \\
\text { Concentration, } \\
\text { ppm, dry, } 3 \% \mathrm{O}_{2}\end{array}$ & Measured/Theoretical, \% \\
\hline 55 & 1.7 & 2.2 & 77 \\
\hline 113 & 3.0 & 4.6 & 65 \\
\hline 193 & 5.2 & 7.8 & 66 \\
\hline 330 & 7.6 & 13.4 & 57 \\
\hline
\end{tabular}

flue gas $\mathrm{HBr}$ content to the theoretical prediction. The measured flue gas $\mathrm{HBr}$ concentration correlated relatively well with theoretical predictions. At the lowest injection rate, the measured concentration was $77 \%$ of the theoretical concentration. As the injection rate increases, the measured concentration decreased to only $57 \%$ of the theoretical concentration.

While most flue gas halogen monitoring was carried out nonisokinetically with the Method 26 mini-impinger method, one set of Method 26A samples was collected during 1 day of the injection test at $55 \mathrm{ppm} \mathrm{Br}$ equivalent in the coal. An isokinetic, full-traverse Method 26A was conducted at the ESP inlet and an isokinetic, single-point Method 26A was conducted at the scrubber outlet locations. The results are summarized in Table 4-6. At the ESP inlet, the flue gas chlorine and bromine concentrations were below the detection limit of the method. The flue gas $\mathrm{HBr}$ concentration was $1.85 \mathrm{ppm} \mathrm{HBr}\left(\right.$ dry, $\left.3 \% \mathrm{O}_{2}\right)$, which agreed well with the average flue gas $\mathrm{HBr}$ concentration measured with the nonisokinetic Method 26. The flue gas $\mathrm{HCl}$ concentration measured by Method 26A was $1.5 \mathrm{ppm} \mathrm{HCl}$, which was within the range of $\mathrm{HCl}$ concentrations measured with Method 26.

\begin{tabular}{|c|c|c|c|c|c|}
\hline Condition & $\begin{array}{l}\text { Location/ } \\
\text { Run No. }\end{array}$ & Date & Start Time & $\mathrm{HCl}$ & $\mathrm{HBr}$ \\
\hline $55 \mathrm{ppm} \mathrm{Br}$ & ESP Inlet 1 & $11 / 16 / 05$ & $8: 32$ & 1.56 & 1.84 \\
\hline $55 \mathrm{ppm} \mathrm{Br}$ & ESP Inlet 2 & $11 / 16 / 05$ & $10: 30$ & 1.40 & 1.87 \\
\hline \multirow[t]{2}{*}{$55 \mathrm{ppm} \mathrm{Br}$} & ESP Inlet 3 & $11 / 16 / 05$ & $12: 25$ & 1.46 & 1.86 \\
\hline & ESP Inlet & & AVERAGE & 1.49 & 1.86 \\
\hline
\end{tabular}

The Method 26A data at the scrubber outlet were problematic. The scrubber outlet Method 26A measurements were made in the same row of ports that the OH and SCEM measurements were made. As already discussed in regard to the SCEM measurements, these ports were located directly above the scrubber exit, and FGD slurry was frequently accidentally pulled into the sample probes. Therefore, scrubber slurry contaminated the sample train at the FGD outlet, biasing the results high. 
Both $\mathrm{HCl}$ and $\mathrm{HBr}$ should be scrubbed with nearly $100 \%$ efficiency by the FGD scrubber. Therefore, the expected scrubber outlet $\mathrm{HCl}$ and $\mathrm{HBr}$ concentrations should be close to zero. However, these Method 26A measurements indicated an average of $15.8 \mathrm{ppm} \mathrm{HCl}$ at the scrubber outlet, which is ten times higher than the inlet $\mathrm{HCl}$ concentration. The average Method $26 \mathrm{~A} \mathrm{HBr}$ concentration at the scrubber outlet was $0.9 \mathrm{ppm} \mathrm{HBr}$, which indicated that only $50 \%$ of the $\mathrm{HBr}$ was scrubbed. These Method 26A measurements are unrealistic; therefore, the results have been voided and are not reported in Table 4-6.

\subsubsection{Summary of Mercury Data from Long-Term Injection Test No. 1}

Figure 4-12 shows the SCEM total mercury concentrations measured at the ESP inlet, ESP outlet, and FGD outlet over the course of the first 2-week continuous injection test. Figures 4-13 through 4-15 show hourly averages of the total and elemental mercury concentrations measured at each of the three locations.

As noted in the discussion of the parametric test results, there was a negative bias in the measurement of total vapor phase mercury upstream of the scrubber. This bias was caused by the presence of bromine in the flue gas. The bias was not confirmed until after the test program was completed and coal and ash mercury concentrations were available for data analysis. This bias is explored further at the end of this report, when the coal and ash mercury results are presented. For the long-term tests, the total vapor phase mercury concentrations are presented in Figures 4-12, 4-13, and 4-14, with the caveat that the values are likely biased low at the scrubber inlet.

This bias does not exist at the scrubber outlet because the scrubber removes the flue gas bromine; therefore, the total mercury concentrations at the scrubber outlet should be reliable. Because the scrubber inlet elemental mercury concentrations matched well with the scrubber outlet total mercury concentrations, it is believed that the scrubber inlet elemental mercury concentrations were not subject to the measurement bias.

In the long-term data analysis, test-average coal mercury values were used in place of the scrubber inlet total vapor-phase mercury concentrations measured by the SCEMs. The average coal mercury concentration for each entire test period was compared to the average SCEM data for the entire test period. Calculations were not made for individual days because of the difficulty in obtaining single coal samples that were representative of the flue gas mercury concentration. The coal mercury data were coupled with the inlet elemental mercury data to determine average mercury oxidation during the long-term injection test periods. Using this methodology, the vapor-phase mercury at the scrubber inlet was on average $67 \%$ oxidized at an injection rate of $55 \mathrm{ppm} \mathrm{Br}$ in the coal.

The weight fraction of Texas lignite coal fired by Unit 3 varied over the course of the first long-term test, ranging from 47 to $69 \%$. Figure 4-16 plots the percent oxidation of mercury at the ESP outlet and the percent removal of vapor-phase mercury across the FGD versus the weight fraction of Texas lignite fired. For the range of coal blends tested, there is no clear relationship between mercury oxidation/removal and the fraction of Texas lignite in the coal blend. 


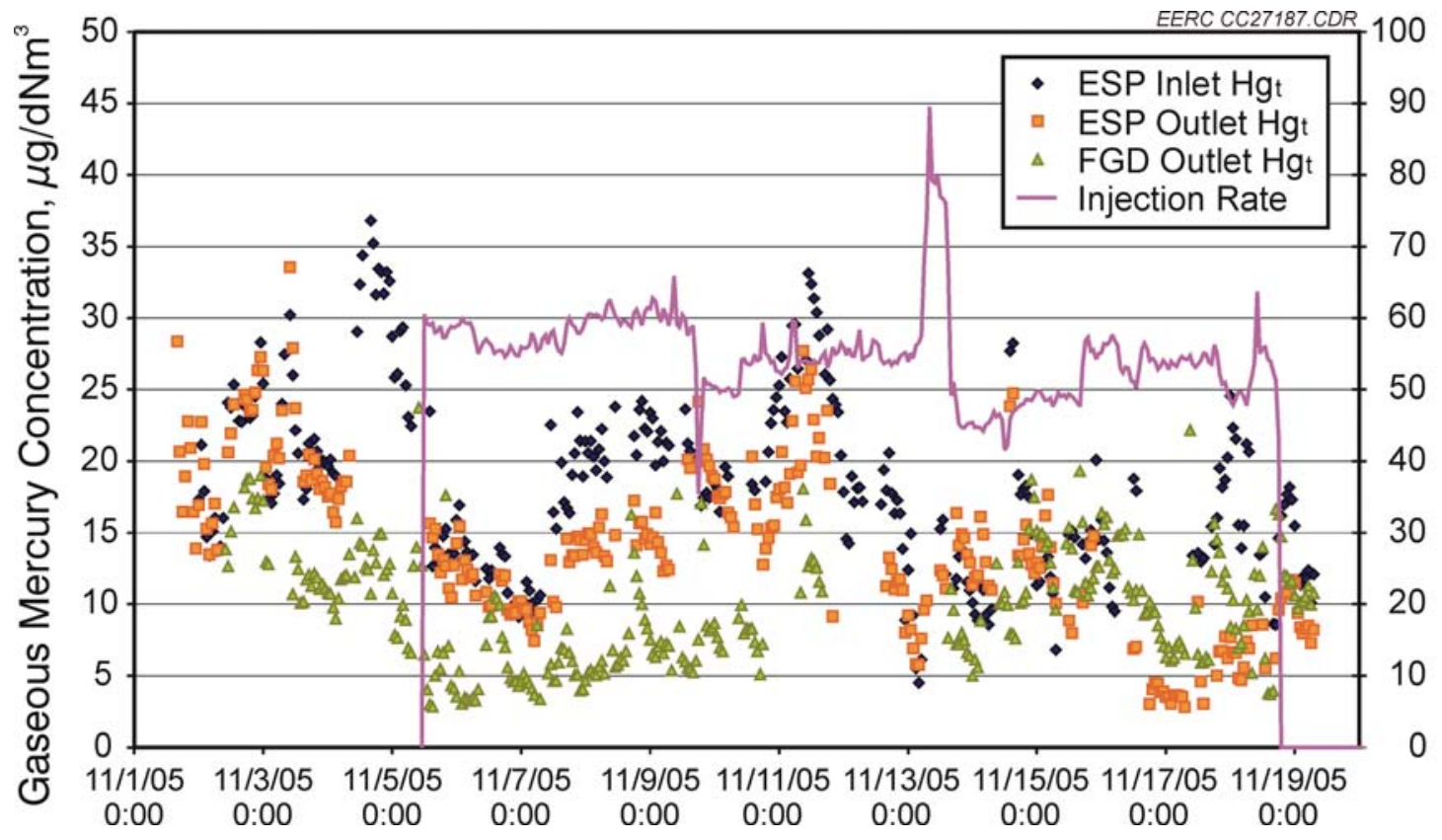

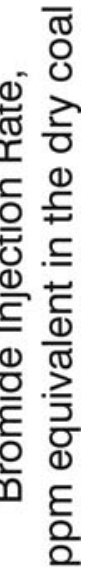

Figure 4-12. Hourly averaged total mercury concentration from SCEM data collected during $\mathrm{CaBr}_{2}$ injection at approximately $55 \mathrm{ppm} \mathrm{Br}$ equivalent in the dry coal, first 2-week long-term test at MoSES.

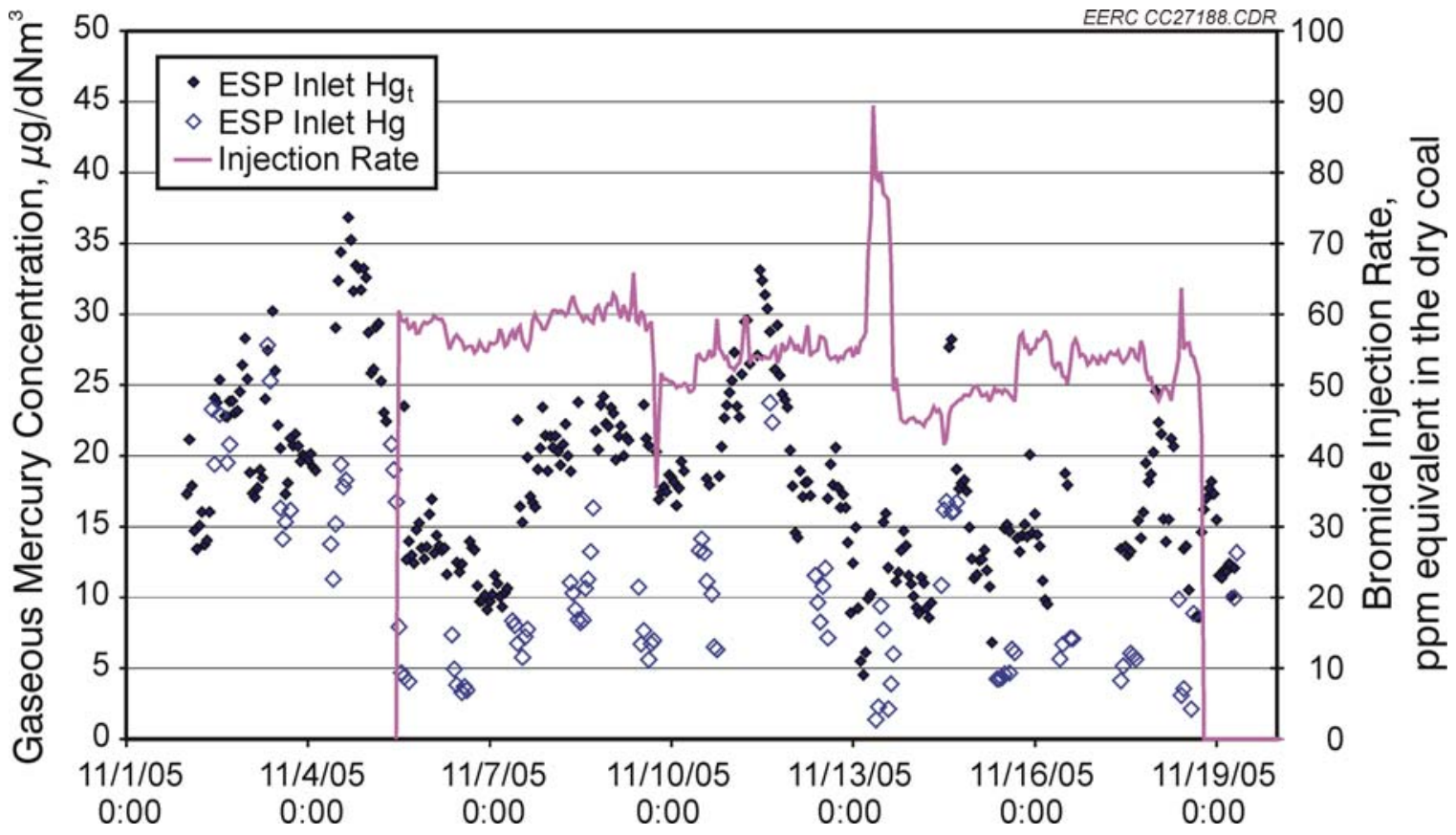

Figure 4-13. ESP inlet total and elemental mercury concentrations measured during $\mathrm{CaBr}_{2}$ injection at approximately $55 \mathrm{ppm} \mathrm{Br}$ equivalent in the dry coal, first 2-week long-term test at MoSES. 


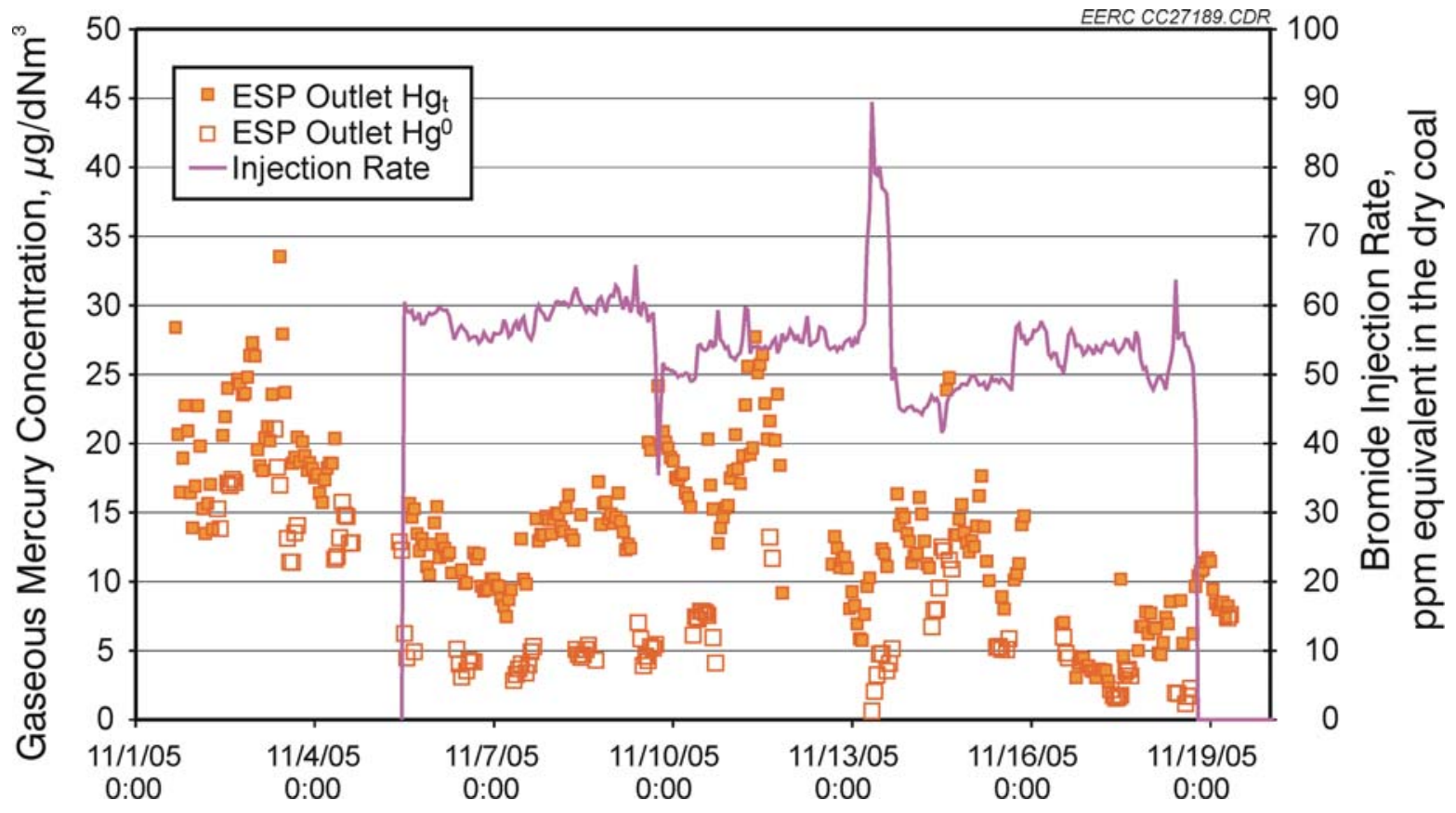

Figure 4-14. ESP outlet total and elemental mercury concentrations measured during $\mathrm{CaBr}_{2}$ injection at approximately $55 \mathrm{ppm} \mathrm{Br}$ equivalent in the dry coal, first 2-week long-term test at MoSES.

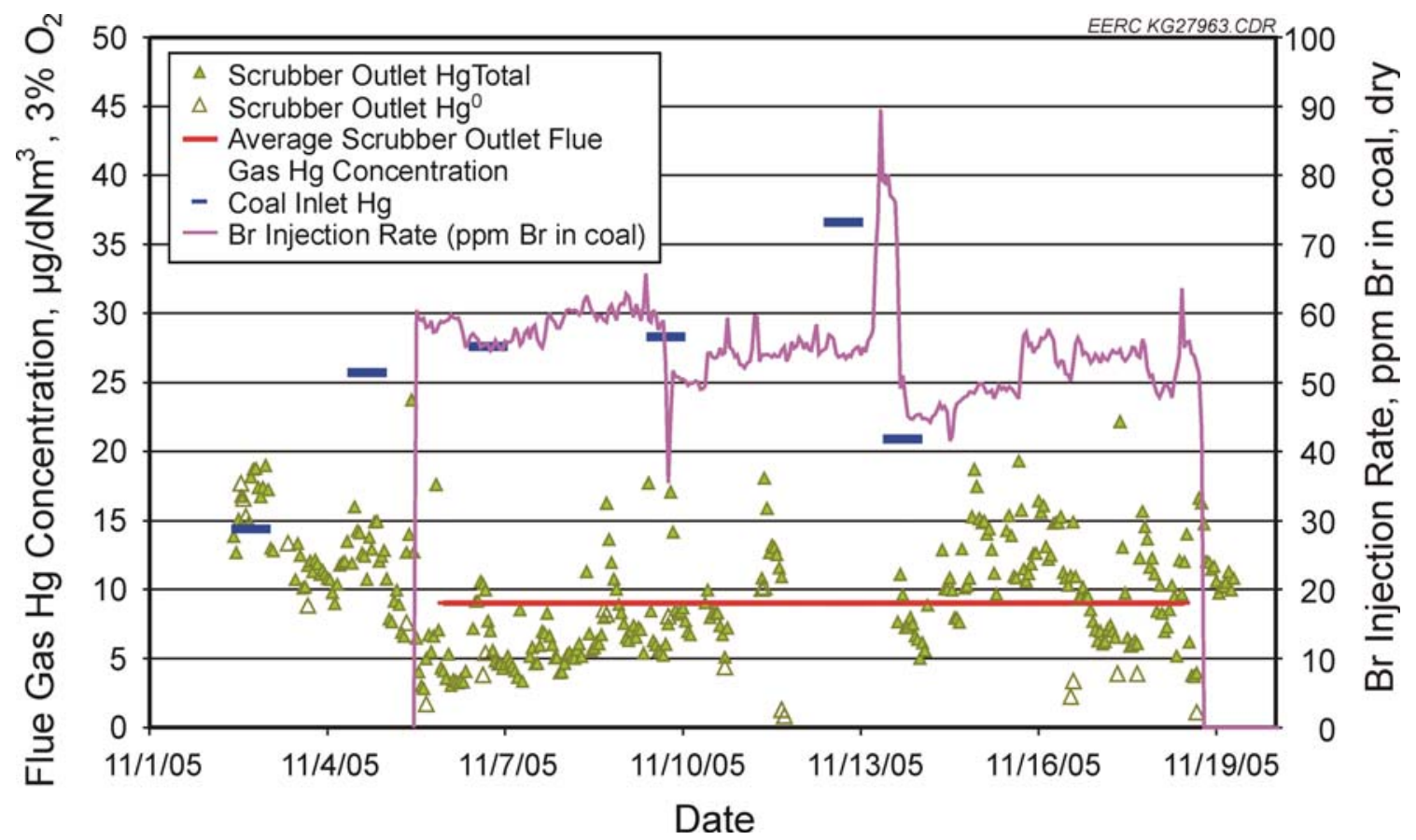

Figure 4-15. FGD outlet total and elemental mercury concentrations measured during $\mathrm{CaBr}_{2}$ injection at approximately $55 \mathrm{ppm} \mathrm{Br}$ equivalent in the dry coal, first 2-week long-term test at MoSES. 


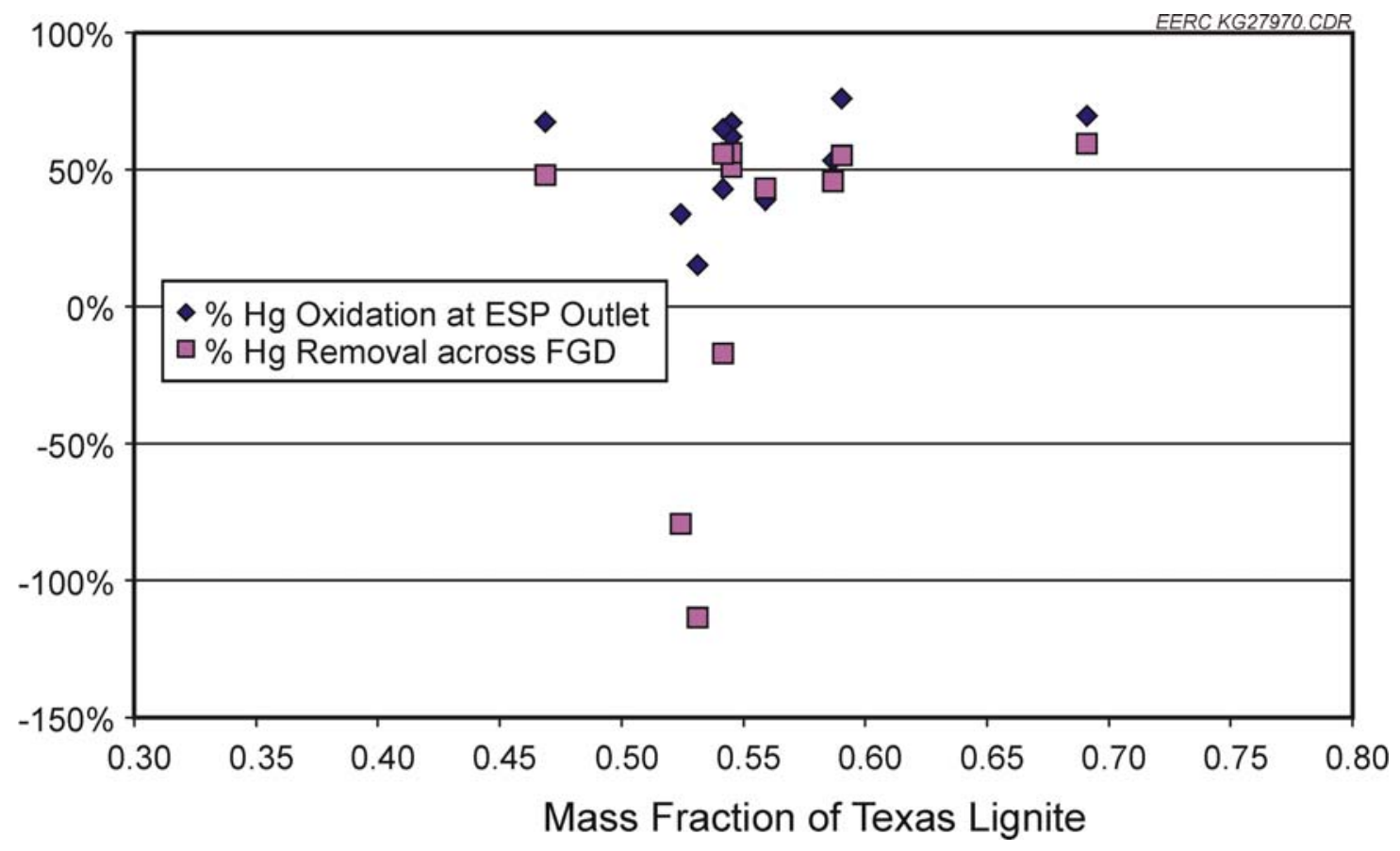

Figure 4-16. Effect of coal blend on oxidation and removal of flue gas mercury during long-term test no. 1.

The average coal mercury data were coupled with the average scrubber outlet mercury concentration to quantify the overall mercury removal obtained during the long-term injection test period. Using this methodology, the vapor-phase mercury removal for the system was $65 \%$ at an injection rate of $55 \mathrm{ppm} \mathrm{Br}$ in the coal. However, over the two-week test period at this injection rate, the scrubber outlet total mercury steadily increased, indicating that this removal rate was not sustained over the test period.

Prior to the start of the injection test, the scrubber inlet elemental mercury concentration and the scrubber outlet total mercury concentration ranged from 10 to $20 \mu \mathrm{g} / \mathrm{dNm}^{3}\left(3 \% \mathrm{O}_{2}\right)$. During the first day of the injection test, the ESP inlet and ESP outlet elemental mercury concentrations decreased significantly, and the scrubber outlet mercury concentration decreased to $3-7 \mu \mathrm{g} / \mathrm{Nm}^{3}$. On the following 6 days, the scrubber outlet mercury concentration steadily increased to approximately $12 \mu \mathrm{g} / \mathrm{Nm}^{3}$ however, the ESP inlet concentration also increased during this time period. On November 11, 2005, the scrubber C module (which is the module on which SCEM measurements were being made) was taken out of service for 2 days. The scrubber $\mathrm{C}$ module was placed back in service on November 13. During the first 2 days back in service, the scrubber outlet mercury concentration steadily increased from 5 to $12 \mu \mathrm{g} / \mathrm{Nm}^{3}$. For the remainder of the test period (November 15 to 18), the scrubber outlet mercury concentrations remained in this range.

A possibility for this phenomenon could be a positive bias in the scrubber outlet extraction system, caused by the vaporization of mercury in the FGD slurry accidentally captured in the extraction loop. However, the scrubber outlet extraction loop was kept under constant 
supervision, cleaning, and maintenance during this test program. Typically, when the scrubber outlet mercury concentrations were biased high, the biased period lasted for a finite period of time on the order of a few to several hours. In this case, the elevated scrubber concentrations were maintained for several days, despite cleaning of the scrubber extraction loop.

Figure 4-17 compares the scrubber outlet total mercury concentration to the scrubber inlet (ESP outlet) elemental mercury concentration. In a situation with complete removal of oxidized mercury and no mercury reemissions across the scrubber, these two values should be equal. Figure 4-17 shows that the values are equivalent for the baseline period prior to the injection test and for the first half of the injection test (through November 14, 2005). After that period, the scrubber outlet total mercury concentration was, at times, more than double the scrubber inlet elemental mercury concentration.

Appendix K measurements were made at the stack during the first long-term injection test. The results are provided in Table 4-7. The stack flue gas is composed of approximately $60 \%$ gas that is treated by the FGD scrubber and $40 \%$ gas that bypasses the FGD scrubber. To compare the SCEM data to the Appendix K data, a composite stack SCEM concentration was calculated as follows:

\section{Composite stack SCEM Hg $=0.6 \times$ Scrubber Outlet SCEM + 0.4 $\times$ ESP Outlet Hg SCEM}

The composite stack concentration was alternatively calculated with the ESP inlet (rather than ESP outlet) mercury concentration from the SCEM. Figure 4-18 shows a comparison of both of these methodologies to the Appendix K data. All three data sets show the same trend in the concentration over the course of the test program. The composite concentration calculated from the ESP inlet data matches very well with the Appendix K data. All seven runs were within $\pm 20 \%$ of each other, with five of the seven runs within $\pm 7 \%$ of each other. When the ESP outlet SCEM data are used to calculate the composite stack concentration, the composite stack data are within $-5 \%$ to $-35 \%$ of the Appendix $\mathrm{K}$ data. The agreement between the Appendix $\mathrm{K}$ and SCEM data indicate that elevated mercury concentrations measured by the SCEM at the scrubber outlet may have been real and not the result of a sampling artifact.

Based on a preliminary evaluation of these data made immediately following the conclusion of the first 2-week injection test, the project team elected to conduct the second 2-week injection test at double the $\mathrm{CaBr}_{2}$ injection rate. The results for the second 2-week injection test are presented in the next subsection.

\subsubsection{Summary of Mercury Data from Long-Term Injection Test No. 2}

The second long-term mercury control test involved $\mathrm{CaBr}_{2}$ injection at an average $113 \mathrm{ppm}$ $\mathrm{Br}$ equivalent in dry coal. Figure 4-19 shows the hourly averages of the SCEM total mercury concentrations measured at the ESP inlet, ESP outlet, and FGD outlet over the course of the second 2-week continuous-injection test. Figures 4-20 through 4-22 show the total and elemental mercury concentrations measured at each of the three locations. As noted with the parametric and long-term tests, there was a negative bias in the measurement of total mercury 


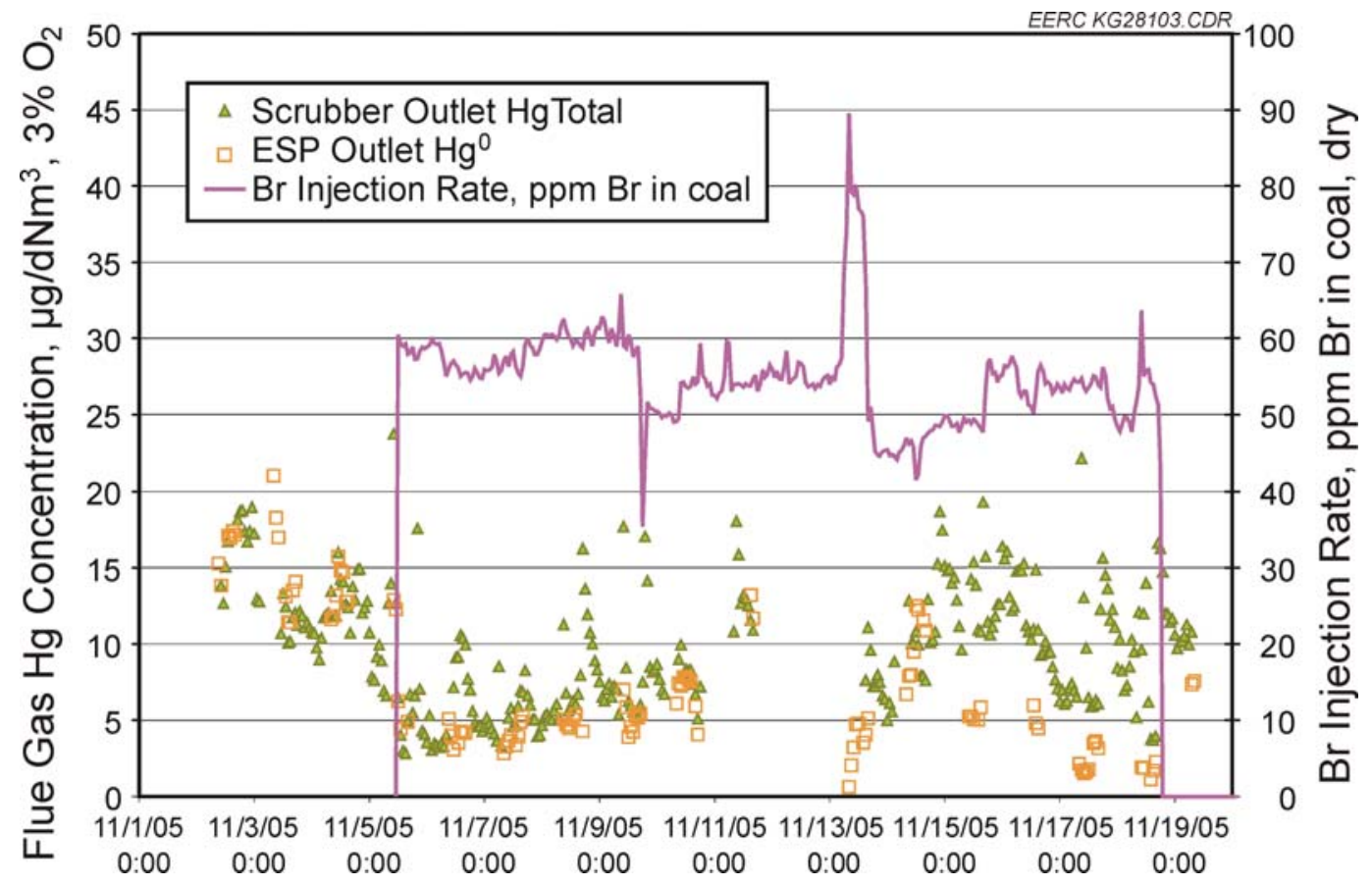

Figure 4-17. Comparison of scrubber inlet elemental mercury concentration to scrubber outlet total mercury concentration during the first long-term $\mathrm{CaBr}_{2}$ injection test at MoSES.

Table 4-7. Appendix K Measurements at Unit 3 Stack During Long-Term Test No. 1 Condition Date Start Time End Time Stack Flue Gas Hg Concentration

\begin{tabular}{llllr} 
& & & & $\left(\mu \mathrm{g} / \mathrm{dNm}^{3}\right.$ at \\
\hline $55 \mathrm{ppm}$ & $11 / 08 / 05$ & $09: 45$ & $13: 45$ & 9.6 \\
$55 \mathrm{ppm}$ & $11 / 08 / 05$ & $09: 45$ & $13: 45$ & 9.5 \\
$55 \mathrm{ppm}$ & $11 / 09 / 05$ & $13: 06$ & $17: 06$ & 14.5 \\
$55 \mathrm{ppm}$ & $11 / 09 / 05$ & $13: 06$ & $17: 06$ & 12.6 \\
$55 \mathrm{ppm}$ & $11 / 11 / 05$ & $10: 35$ & $14: 35$ & 21.2 \\
$55 \mathrm{ppm}$ & $11 / 11 / 05$ & $10: 35$ & $14: 35$ & 18.9 \\
$55 \mathrm{ppm}$ & $11 / 14 / 05$ & $13: 50$ & $17: 50$ & 15.4 \\
$55 \mathrm{ppm}$ & $11 / 14 / 05$ & $13: 50$ & $17: 50$ & 14.8 \\
$55 \mathrm{ppm}$ & $11 / 16 / 05$ & $08: 07$ & $12: 07$ & 14.4 \\
$55 \mathrm{ppm}$ & $11 / 16 / 05$ & $08: 07$ & $12: 07$ & 13.6 \\
$55 \mathrm{ppm}$ & $11 / 16 / 05$ & $12: 41$ & $16: 41$ & 15.5 \\
$55 \mathrm{ppm}$ & $11 / 16 / 05$ & $12: 41$ & $16: 41$ & 13.9 \\
$55 \mathrm{ppm}$ & $11 / 17 / 05$ & $11: 35$ & $15: 35$ & 10.0 \\
$55 \mathrm{ppm}$ & $11 / 17 / 05$ & $11: 35$ & $15: 35$ & 9.0 \\
$55 \mathrm{ppm}$ & $11 / 18 / 05$ & $08: 28$ & $12: 28$ & 13.8 \\
$55 \mathrm{ppm}$ & $11 / 18 / 05$ & $08: 28$ & $12: 28$ & 14.6 \\
\hline
\end{tabular}

* Oxygen concentrations were not originally reported with Appendix $\mathrm{K}$ measurements. Assumed 7\% $\mathrm{O}_{2}$ concentration on the stack, based on a weighted average of $\mathrm{O}_{2}$ concentrations measured by EPRI SCEMs at the ESP outlet and FGD outlet. 


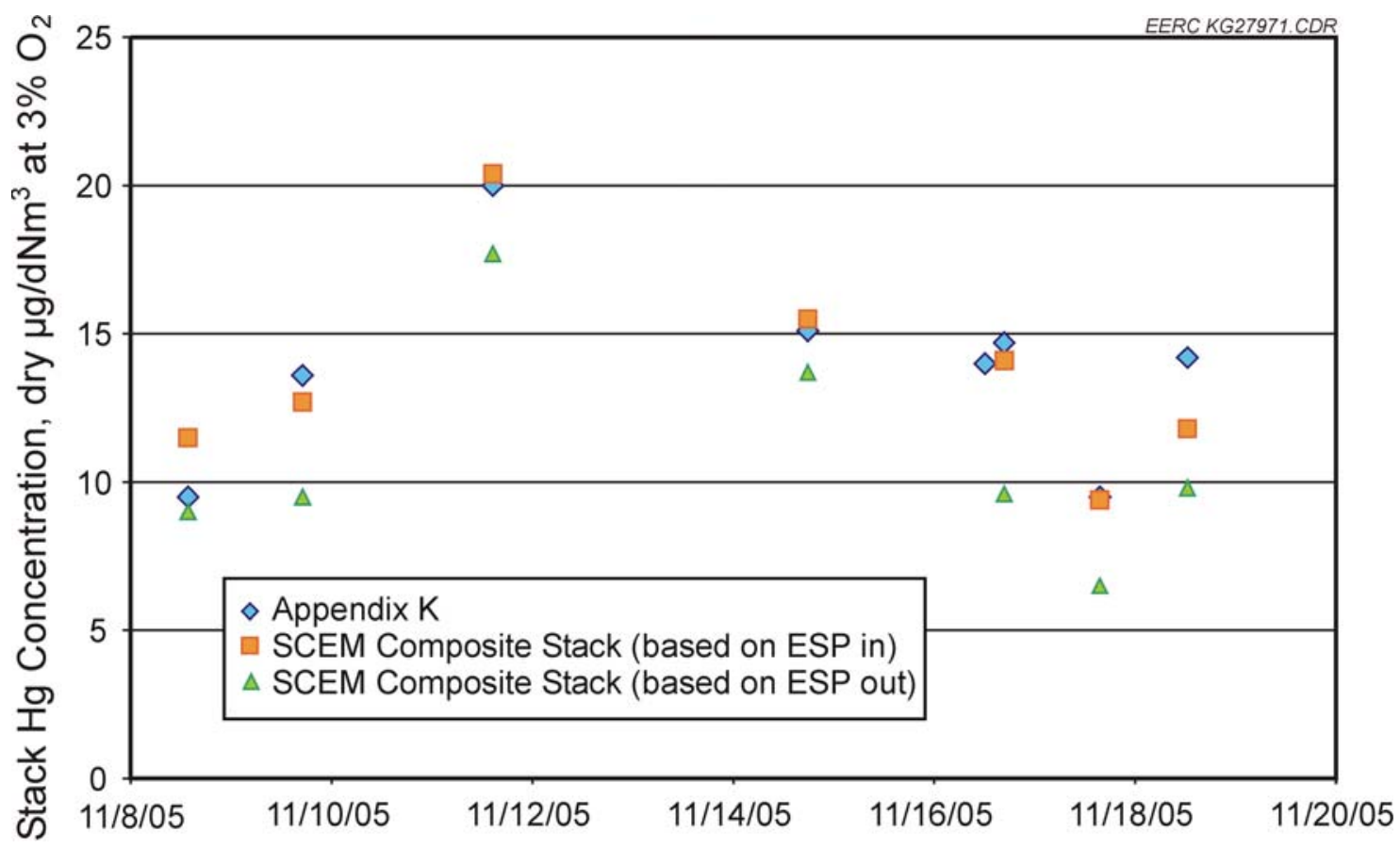

Figure 4-18. Comparison of Appendix K data with SCEM data.

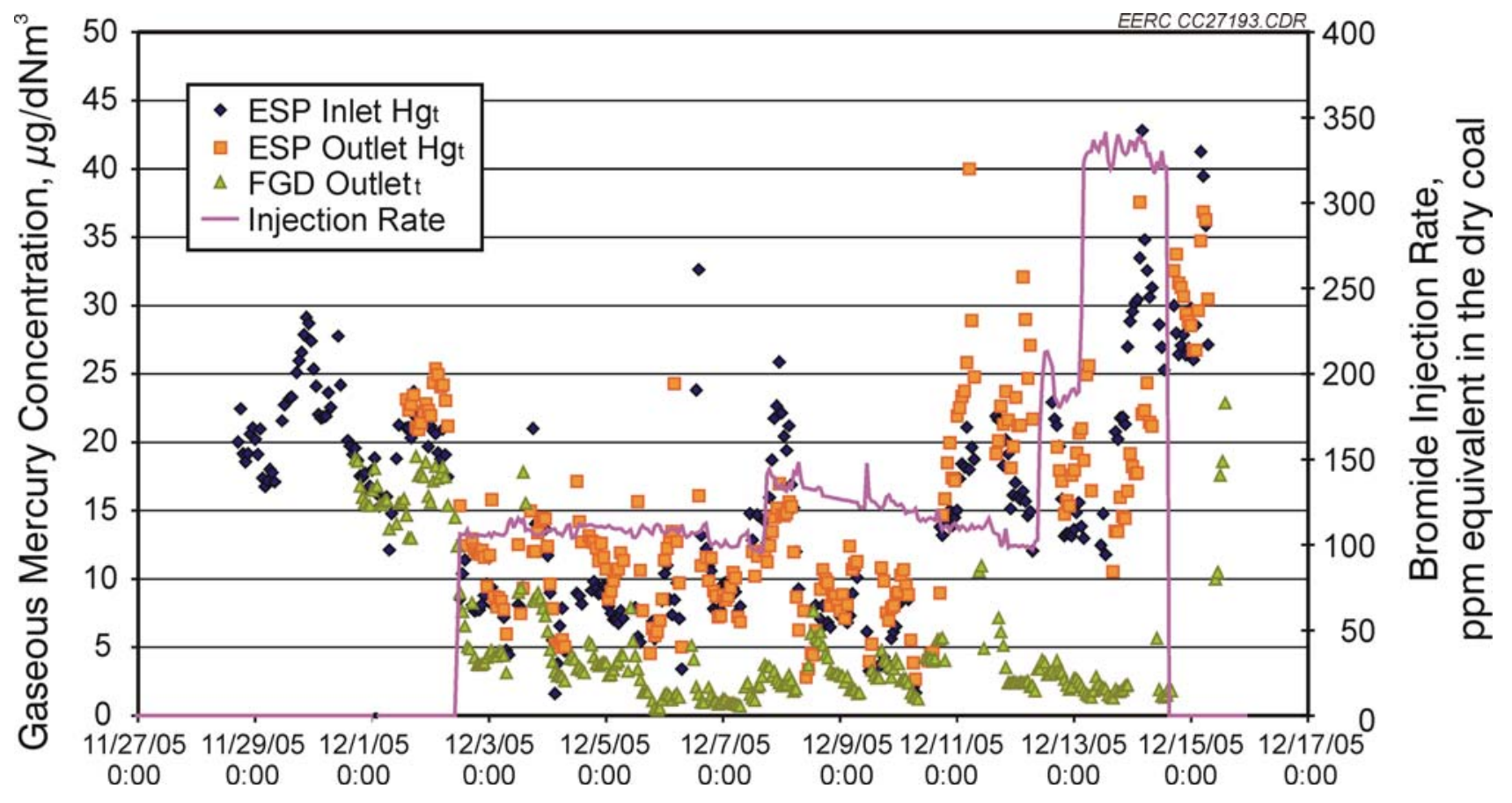

Figure 4-19. Hourly averaged SCEM data collected during the second long-term $\mathrm{CaBr}_{2}$ injection test at MoSES. 


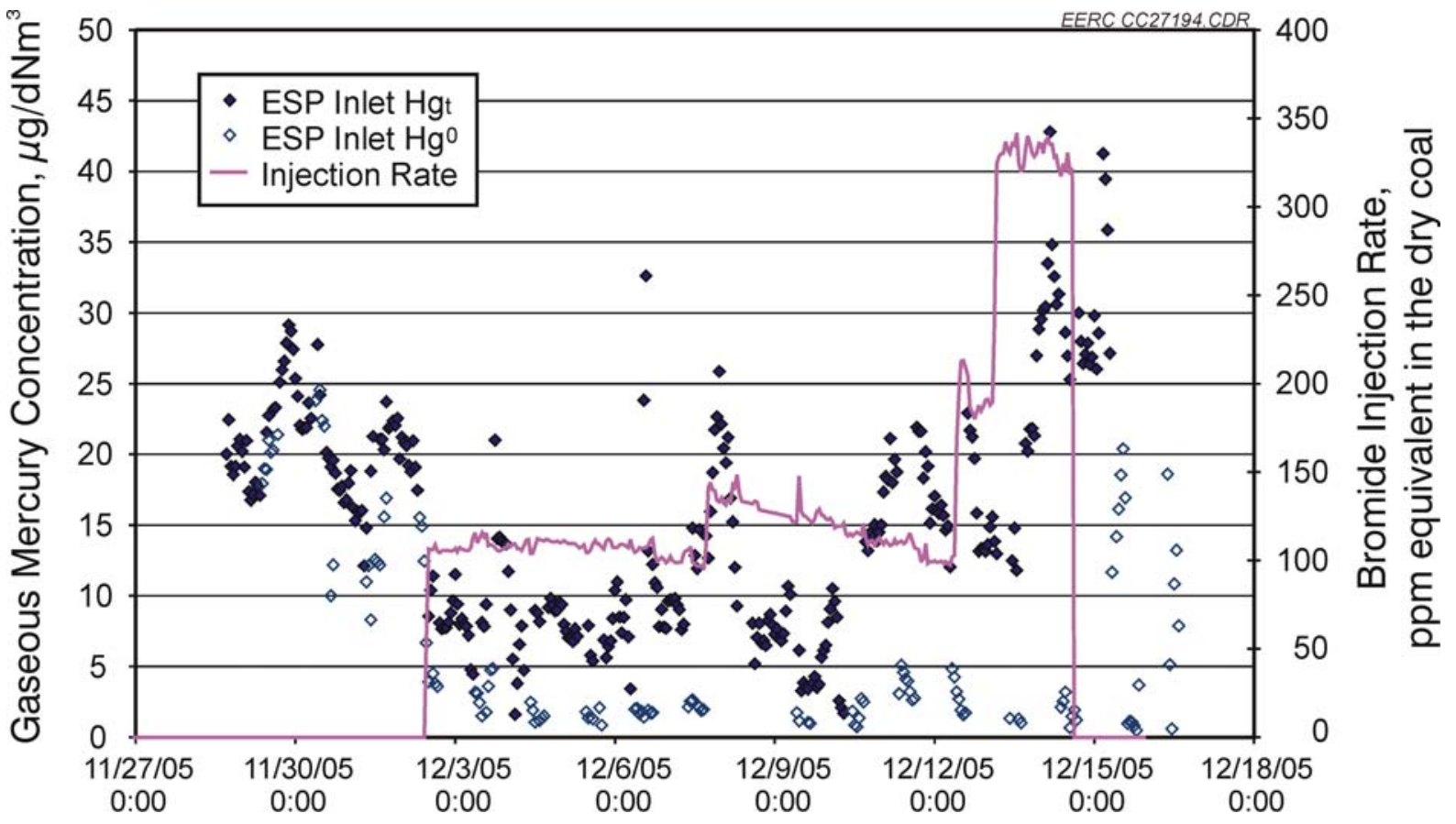

Figure 4-20. ESP inlet total and elemental mercury concentrations measured during the second long-term $\mathrm{CaBr}_{2}$ injection test at MoSES.

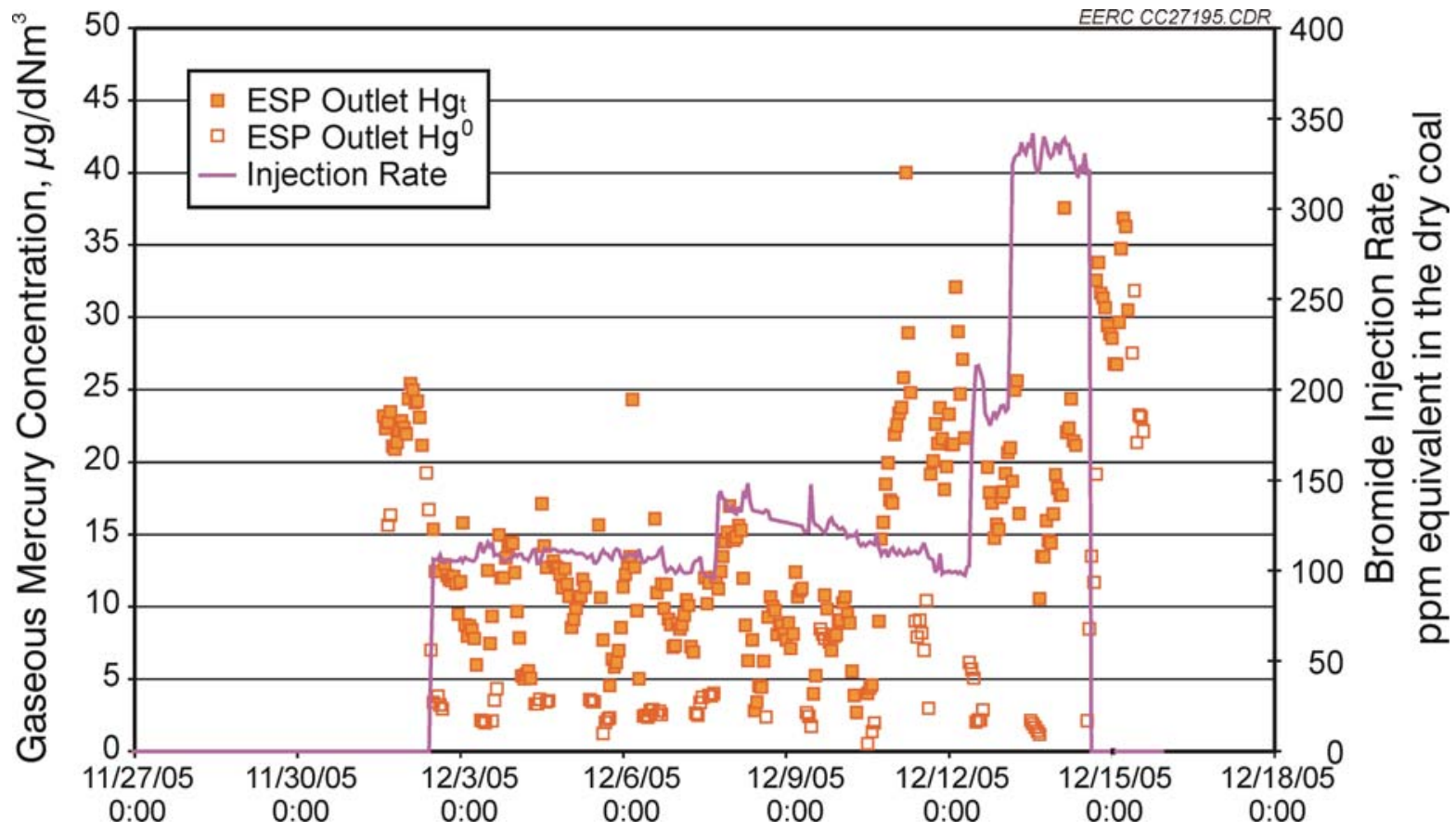

Figure 4-21. ESP outlet total and elemental mercury concentrations measured during the second long-term $\mathrm{CaBr}_{2}$ injection test at MoSES. 


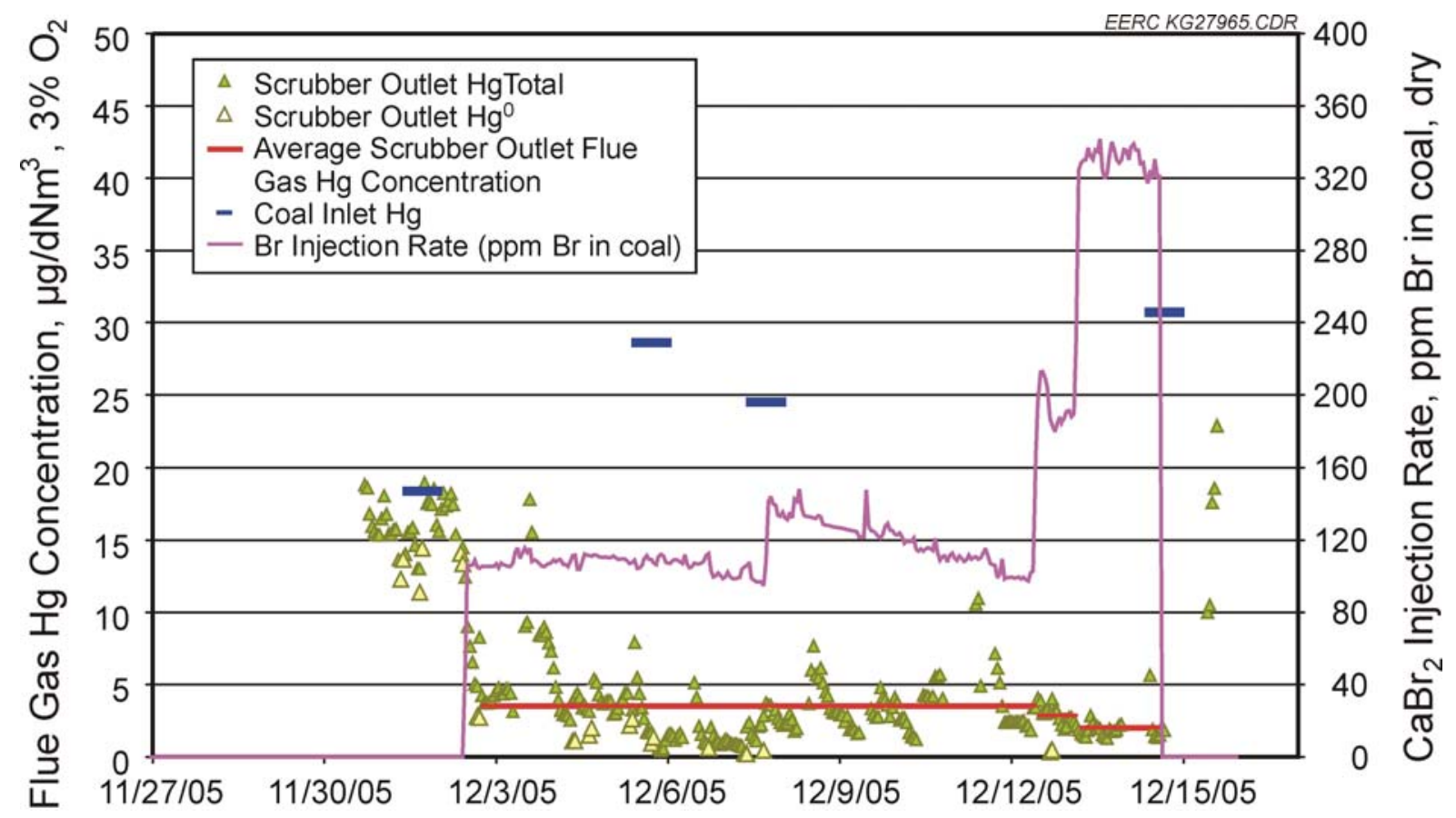

Figure 4-22. FGD outlet total and elemental mercury concentrations measured during the second long-term $\mathrm{CaBr}_{2}$ injection test at MoSES.

concentrations at the ESP inlet and ESP outlet when bromine was present in the flue gas. The discussion of the first long-term injection test contains details on how this bias was accounted for in the presentation of the results.

Prior to the start of the injection test, the ESP outlet elemental mercury concentrations and the scrubber outlet total mercury concentrations ranged from 12 to $19 \mu \mathrm{g} / \mathrm{dNm}^{3}\left(3 \% \mathrm{O}_{2}\right)$. During the first day of the injection test, the ESP inlet and ESP outlet elemental mercury concentrations decreased significantly, and the scrubber outlet mercury concentration decreased to $4 \mu \mathrm{g} / \mathrm{Nm}^{3}$. During the next 10 days of the injection test, in which the injection rate averaged $113 \mathrm{ppm} \mathrm{Br}$ equivalent in the coal, the scrubber outlet mercury concentration ranged from 0.5 to $11 \mu \mathrm{g} / \mathrm{Nm}^{3}$. However, the scrubber outlet mercury concentration was typically less than $5 \mu \mathrm{g} / \mathrm{Nm}^{3}$; only during short periods of a few hours did the scrubber outlet mercury concentration exceed $5 \mu \mathrm{g} / \mathrm{Nm}^{3}$. A 1-day test showed that increasing the injection rate to $193 \mathrm{ppm} \mathrm{Br}$ equivalent in the coal resulted in the scrubber outlet concentration being maintained below $4 \mu \mathrm{g} / \mathrm{Nm}^{3}$. The injection rate was increased to $330 \mathrm{ppm} \mathrm{Br}$ equivalent in the coal, and the scrubber outlet mercury concentration was maintained below $3 \mu \mathrm{g} / \mathrm{Nm}^{3}$ for the 2-day duration of this injection rate. Figure 4-23 compares the scrubber outlet elemental mercury concentration to the scrubber outlet total mercury concentration. Throughout the 2 -week test period, the two values are nearly equivalent, indicating little to no mercury reemissions. The average FGD outlet mercury concentrations measured during each test period are summarized in Table 4-8. 


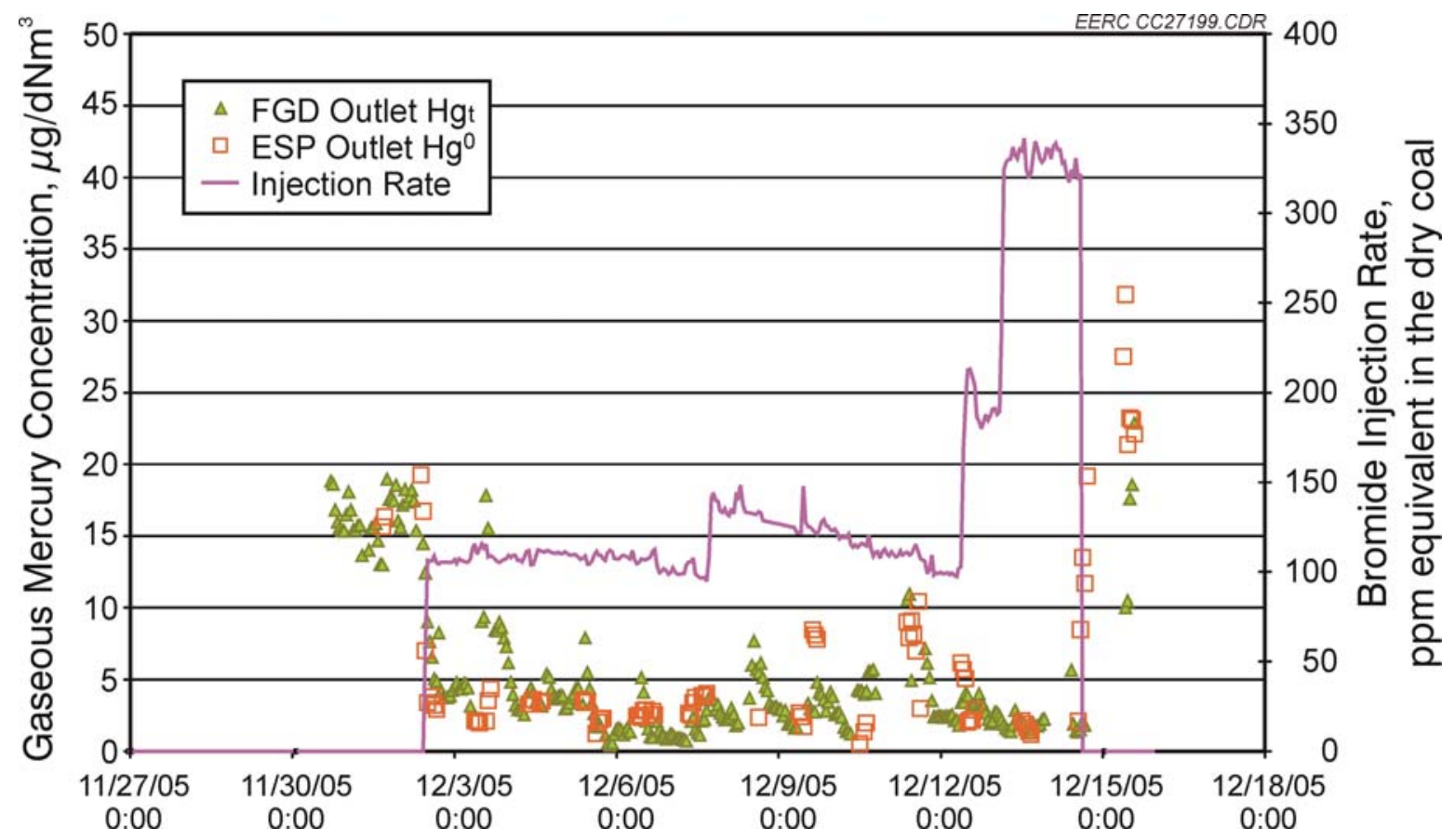

Figure 4-23. Comparison of ESP outlet elemental mercury concentrations to scrubber outlet total mercury concentrations during the second long-term $\mathrm{CaBr}_{2}$ injection test at MoSES.

Table 4-8. Average FGD Outlet Mercury Concentrations Measured by SCEM During the Long-Term Injection

Tests at MoSES

\begin{tabular}{|c|c|}
\hline $\begin{array}{l}\mathrm{CaBr}_{2} \text { Injection Rate, } \\
\text { ppm, dry, } 3 \% \mathrm{O}_{2}\end{array}$ & $\begin{array}{c}\text { Average FGD Outlet } \mathrm{Hg} \\
\text { Concentration, } \mu \mathrm{g} / \mathrm{dNm}^{3}, 3 \% \mathrm{O}_{2}\end{array}$ \\
\hline 55 & 9.0 \\
\hline 113 & 3.5 \\
\hline 193 & 2.9 \\
\hline 330 & 2.0 \\
\hline
\end{tabular}

The average oxidation of mercury during each tested injection rate is shown in Table 4-9. All oxidation percentages are calculated as the oxidized mercury concentration at the scrubber inlet averaged over the test period divided by the coal mercury concentration. At an injection rate of $55 \mathrm{ppm} \mathrm{Br}$ in the coal (first long-term test), the mercury in the scrubber inlet flue gas was $67 \%$ oxidized. At an injection rate of $113 \mathrm{ppm} \mathrm{Br}$ equivalent in the coal, the oxidation of mercury at the ESP inlet was an average $85 \%$. Increasing the injection rate to $193 \mathrm{ppm} \mathrm{Br}$ equivalent in the coal resulted in a slightly higher oxidation percentage of 91\%. Further increasing the $\mathrm{CaBr}_{2}$ injection rate to $330 \mathrm{ppm}$ in the coal did not result in significantly higher oxidation of mercury. 


\begin{tabular}{|c|c|c|}
\hline $\begin{array}{l}\mathrm{CaBr}_{2} \text { Injection Rate, } \\
\text { ppm } \mathrm{Br} \text { in the coal }\end{array}$ & $\begin{array}{c}\% \text { Oxidation of } \\
\mathrm{Hg} \text { at Scrubber } \\
\text { Inlet }\end{array}$ & $\begin{array}{l}\% \text { Removal of } \mathrm{Hg} \text { at } \\
\text { Scrubber Outlet } \\
\text { (compared to coal } \mathrm{Hg} \text { ) }\end{array}$ \\
\hline 55 & $67 \%$ & $65 \%$ \\
\hline 113 & $85 \%$ & $86 \%$ \\
\hline 193 & $91 \%$ & $89 \%$ \\
\hline 330 & $93 \%$ & $92 \%$ \\
\hline
\end{tabular}

The removal of mercury across the system (computed as average scrubber outlet total mercury concentration compared to coal mercury concentration) is also shown in Table 4-9. The oxidation of mercury at the scrubber inlet compares very favorably with the removal of mercury across the scrubber. At an injection rate of $113 \mathrm{ppm} \mathrm{Br}$ in the coal, $86 \%$ of the coal mercury was removed by the system. Tripling the bromide injection rate resulted in mercury removals just over $90 \%$.

\subsection{MoSES Chemical Injection Analytical Summary}

This section presents an analysis of the mercury and bromine analytical data gathered from the coal, fly ash, and FGD by-products. Several material balances are calculated with these data, the details of which can be found in Appendix D.

\subsubsection{Comparison of Coal and Fly Ash Mercury to SCEM Data}

Samples of the Texas lignite and PRB coal were collected daily throughout the test program. Selected coal samples were analyzed for mercury, bromide, chloride, and ultimate/proximate parameters. The analysis results for the Texas lignite and PRB coals are summarized in Tables 4-10 and 4-11, respectively. The mercury content for each coal reported in Tables 4-10 and 4-11 was calculated from an average of triplicate analyses performed in URS' Austin laboratories. Figure 4-24 shows the variation in the mercury concentration of each coal over the test program. The concentration of mercury in the PRB coal was fairly consistent between 0.04 and $0.09 \mathrm{ppm}$, with the exception of one day in which the mercury concentration was $0.26 \mathrm{ppm}(12 / 9 / 05)$. When this day is excluded, the average mercury concentration of the PRB coal during the test program was $0.07 \pm 0.01 \mathrm{ppm}$. The mercury concentration in the Texas lignite ranged from 0.17 to $0.71 \mathrm{ppm}$ (dry). The measured value of $0.71 \mathrm{ppm}$ was twice as high as the next highest mercury concentration measured in the Texas lignite samples. Excluding this value, the average Texas lignite mercury concentration was $0.26 \pm 0.06 \mathrm{ppm}$.

A comparison of the mercury content of the coal sampled to the flue gas mercury concentrations at the ESP inlet should provide an indication of how much mercury is removed upstream of the ESP by the fly ash. The ESP inlet vapor-phase mercury concentrations measured by the SCEM were averaged for a single day. The daily coal sample mercury concentrations were combined with the coal-specific F-factors to determine the equivalent flue gas mercury 
Table 4-10. Unit 1 - Texas Lignite Coal Analyses for Long-Term Injection Test

\begin{tabular}{|c|c|c|c|c|c|c|c|c|c|c|c|c|c|c|c|c|c|}
\hline Date in 2005 & $10 / 28$ & $11 / 2$ & $11 / 3$ & $11 / 4$ & $11 / 6$ & $11 / 9$ & $11 / 12$ & $11 / 13$ & $11 / 17$ & $12 / 1$ & $12 / 2$ & $12 / 3$ & $12 / 5$ & $12 / 7$ & $12 / 9$ & $12 / 11$ & $12 / 14$ \\
\hline Sample Time & $7: 50$ & $10: 55$ & $11: 50$ & $10: 35$ & $7: 30$ & NA & NA & NA & $7: 00$ & day & day & day & $13: 20$ & $8: 00$ & NA & NA & $14: 30$ \\
\hline Coal Type & TxL & TxL & $\mathrm{TxL}$ & TxL & TxL & TxL & TxL & TxL & TxL* & TxL & TxL* & TxL & $\mathrm{TxL}$ & TxL & TxL* & TxL & TxL \\
\hline \multicolumn{18}{|l|}{$\begin{array}{r}\text { Proximate, } \\
\text { wt } \% \text { AR }\end{array}$} \\
\hline Moisture & 32.44 & 29.57 & 30.25 & 31.44 & 30.37 & 31.33 & 32.14 & 31.6 & & 31.06 & & 34.22 & 33.01 & 30.93 & & 28.14 & 31.82 \\
\hline Ash & 11.21 & 17.12 & 10.37 & 12.54 & 17.99 & 16.82 & 14.33 & 14 & & 18.41 & & 7.98 & 13.53 & 15.76 & & 23.94 & 19.57 \\
\hline Volatile Matter & 28.4 & & & & 27.4 & & & 28.32 & & 27.26 & & & & & & 26.95 & \\
\hline Fixed Carbon & 27.95 & & & & 24.24 & & & 26.08 & & 23.27 & & & & & & 20.97 & \\
\hline \multicolumn{18}{|l|}{$\begin{array}{l}\text { Ultimate, } \\
\text { wt } \% \text { AR }\end{array}$} \\
\hline Sulfur & 0.49 & 0.49 & 0.34 & 0.48 & 0.4 & 0.44 & 0.45 & 0.45 & & 0.45 & & 0.48 & 0.54 & 0.45 & & 0.42 & 0.51 \\
\hline Carbon & 40.79 & & & & 37.19 & & & 38.95 & & 36.46 & & & & & & 34.87 & \\
\hline Hydrogen & 3.03 & & & & 2.88 & & & 3.02 & & 2.88 & & & & & & 2.71 & \\
\hline Nitrogen & 0.63 & & & & 0.61 & & & 0.7 & & 0.61 & & & & & & 0.54 & \\
\hline Oxygen & 11.41 & & & & 10.56 & & & 11.28 & & 10.13 & & & & & & 9.38 & \\
\hline $\begin{array}{l}\text { Heating Value HHV } \\
(\mathrm{Btu} / \mathrm{lb}, \mathrm{AR})\end{array}$ & 7011 & 6560 & 7469 & 6972 & 6424 & 6410 & 6603 & 6763 & & 6326 & & 7194 & 6638 & 6685 & & 5957 & 6012 \\
\hline $\begin{array}{l}\text { M19 F-factor } \\
(\mathrm{dscf} / \mathrm{MMBtu} \\
\left.\text { at } 0 \% \mathrm{O}_{2}\right)\end{array}$ & 9778 & & & & 9782 & & & 9722 & & 9793 & & & & & & 9941 & \\
\hline $\begin{array}{l}\text { Mercury } \\
(\mu \mathrm{g} / \mathrm{g}, \mathrm{dry})\end{array}$ & 0.315 & 0.174 & 0.172 & 0.271 & 0.289 & 0.292 & 0.370 & 0.246 & & 0.168 & & 0.250 & 0.276 & 0.254 & & 0.706 & 0.361 \\
\hline $\begin{array}{l}\text { Mercury } \\
(\mathrm{lb} / \mathrm{TBtu})\end{array}$ & 30.35 & & 16.08 & & 31.28 & 31.26 & & 24.83 & & 18.31 & & & 27.85 & & & 85.14 & 40.97 \\
\hline $\begin{array}{l}\text { Chloride } \\
(\mu \mathrm{g} / \mathrm{g}, \text { dry })\end{array}$ & 27 & & $<25$ & & $<25$ & $<25$ & & 32 & & 40 & & & 54 & & & 26 & \\
\hline $\begin{array}{l}\text { Bromide } \\
(\mu \mathrm{g} / \mathrm{g}, \text { dry })\end{array}$ & $<10$ & & $<10$ & & $<10$ & $<10$ & & $<10$ & & $<10$ & & & $<10$ & & & $<10$ & \\
\hline
\end{tabular}

* Analysis of sample (based on heating value and ash content) revealed that it was PRB coal, not Texas lignite. 
Table 4-11. Unit 1 - PRB Coal Analyses for Long-Term Injection Test

\begin{tabular}{|c|c|c|c|c|c|c|c|c|c|c|c|c|c|c|c|c|c|}
\hline Date in 2005 & $10 / 28$ & $11 / 2$ & $11 / 3$ & $11 / 4$ & $11 / 6$ & $11 / 9$ & $11 / 12$ & 11/13 & $11 / 17$ & $12 / 1$ & $12 / 2$ & $12 / 3$ & $12 / 5$ & $12 / 7$ & $12 / 9$ & $12 / 11$ & $12 / 14$ \\
\hline Sample Time & $8: 40$ & $10: 55$ & $9: 15$ & $10: 35$ & $8: 50$ & NA & NA & NA & $8: 30$ & day & day & day & 1320 & $10: 00$ & NA & NA & $12: 00$ \\
\hline Coal Type & PRB & PRB & PRB & PRB & PRB & PRB & PRB & PRB & PRB & PRB & PRB & PRB* & PRB & PRB & PRB & PRB & PRB \\
\hline \multicolumn{18}{|l|}{ Proximate, wt $\%$ AR } \\
\hline Moisture & 30.31 & 30.14 & 29.5 & 30.79 & 31.01 & 30.54 & 30.99 & 30.45 & 30.19 & 28.23 & 29.54 & & 29.66 & 28.09 & 27.59 & 30.67 & 31.11 \\
\hline Ash & 5.94 & 5.48 & 5.48 & 4.49 & 4.95 & 4.83 & 6.03 & 4.44 & 5.01 & 4.92 & 4.69 & & 4.37 & 5.19 & 7.16 & 5.27 & 5.75 \\
\hline Volatile Matter & 29.71 & & & & 29.39 & & & 29.68 & & 31.52 & & & & & & 29.71 & \\
\hline Fixed Carbon & 34.04 & & & & 34.65 & & & 35.43 & & 35.33 & & & & & & 34.35 & \\
\hline \multicolumn{18}{|l|}{ Ultimate, wt \% AR } \\
\hline Sulfur & 0.41 & 0.33 & 0.36 & 0.31 & 0.34 & 0.35 & 0.34 & 0.28 & 0.31 & 0.37 & 0.39 & & 0.31 & 0.37 & 0.40 & 0.38 & 0.36 \\
\hline Carbon & 46.78 & & & & 46.68 & & & 47.92 & & 49.41 & & & & & & 47.05 & \\
\hline Hydrogen & 3.34 & & & & 3.35 & & & 3.42 & & 3.59 & & & & & & 3.36 & \\
\hline Nitrogen & 0.6 & & & & 0.57 & & & 0.6 & & 0.62 & & & & & & 0.61 & \\
\hline Oxygen & 12.62 & & & & 13.10 & & & 12.89 & & 12.86 & & & & & & 12.66 & \\
\hline $\begin{array}{l}\text { Heating Value HHV } \\
\text { (Btu/lb,AR) }\end{array}$ & 8084 & 8070 & 8264 & 8134 & 8046 & 8201 & 7953 & 8275 & 8187 & 8626 & 8274 & & 8363 & 8385 & 8236 & 7804 & 8043 \\
\hline $\begin{array}{l}\text { Mercury } \\
\qquad(\mu \mathrm{g} / \mathrm{g}, \text { dry })\end{array}$ & 0.088 & 0.046 & 0.070 & 0.053 & 0.086 & 0.063 & 0.052 & 0.054 & 0.082 & 0.078 & 0.066 & & 0.075 & 0.064 & 0.261 & 0.080 & 0.067 \\
\hline \multicolumn{18}{|l|}{ M19 F-factor } \\
\hline $\begin{array}{l}(\mathrm{dscf} / \mathrm{MMBtu} \text { at } \\
\left.0 \% \mathrm{O}_{2}\right)\end{array}$ & 9679 & & & & 9677 & & & 9677 & & 9628 & & & & & & 10084 & \\
\hline Mercury (lb/TBtu) & 7.58 & & 5.93 & & 7.37 & 5.36 & & 4.56 & 6.98 & 6.45 & & & 6.33 & & & 7.12 & 5.75 \\
\hline Chloride ( $\mu \mathrm{g} / \mathrm{g}$, dry) & $<25$ & & $<25$ & & $<25$ & $<25$ & & $<25$ & & $<25$ & & & $<25$ & & & $<25$ & \\
\hline Bromide $(\mu \mathrm{g} / \mathrm{g}$, dry $)$ & $<10$ & & $<10$ & & $<10$ & $<10$ & & $<10$ & & $<10$ & & & $<10$ & & & $<10$ & \\
\hline
\end{tabular}

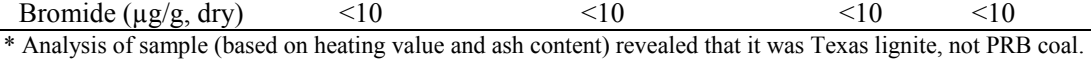




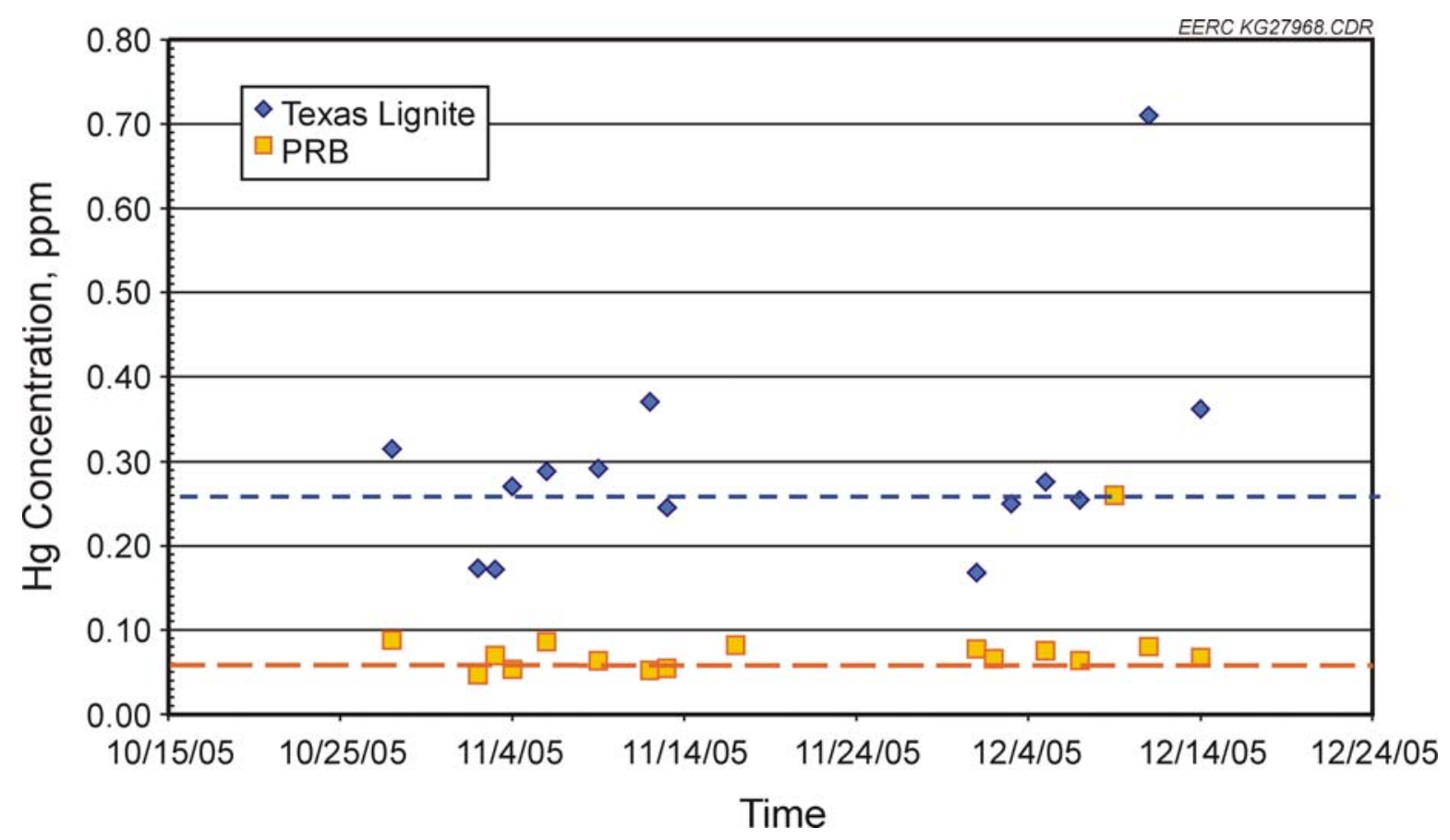

Figure 4-24. Coal mercury concentrations measured during test program.

concentration (expressed on the same basis as the SCEM as $\mu \mathrm{g} / \mathrm{dNm}^{3}$ at $3 \% \mathrm{O}_{2}$ ). As Monticello fires both PRB and Texas lignite coals, the coal-derived mercury concentrations were weighted based on the fraction of each coal fired. These fractions were determined from an analyzer at the plant that monitors the heating value of the coal being loaded into the bunkers and by assuming that each coal was loaded at an equal mass rate.

Figure 4-25 plots the vapor-phase ESP inlet mercury concentrations versus the coalderived flue gas mercury concentrations. Datum points that fall along the unity line indicate little mercury removal upstream of the ESP. All five baseline days represented on this plot fall either on the unity line or slightly above it, indicating no baseline removal of mercury upstream of the ESP. Averaging these five baseline test days, the ESP inlet gas-phase mercury concentration represented $116 \%$ of the coal mercury.

Points that fall below the unity line in Figure 4-25 indicate that not all of the mercury in the coal was accounted for in the flue gas at the ESP inlet. Of the nine datum points that represent days of calcium bromide injection, only one falls on the unity line. The remaining eight points fall well below the unity line, indicating that either the calcium bromide injection caused mercury to be removed by the ash prior to the ESP or the presence of bromide in the gas caused a sampling bias with the SCEM analyzer. On average, the ESP inlet gas-phase mercury concentration represented:

- $54 \%$ of the coal mercury during the $55 \mathrm{ppm} \mathrm{Br}$ test (average of 4 days).

- $36 \%$ of the coal mercury during the $113 \mathrm{ppm} \mathrm{Br}$ test (average of 3 days).

- $96 \%$ of the coal mercury during the $330 \mathrm{ppm} \mathrm{Br}$ test (average of 1 day). 


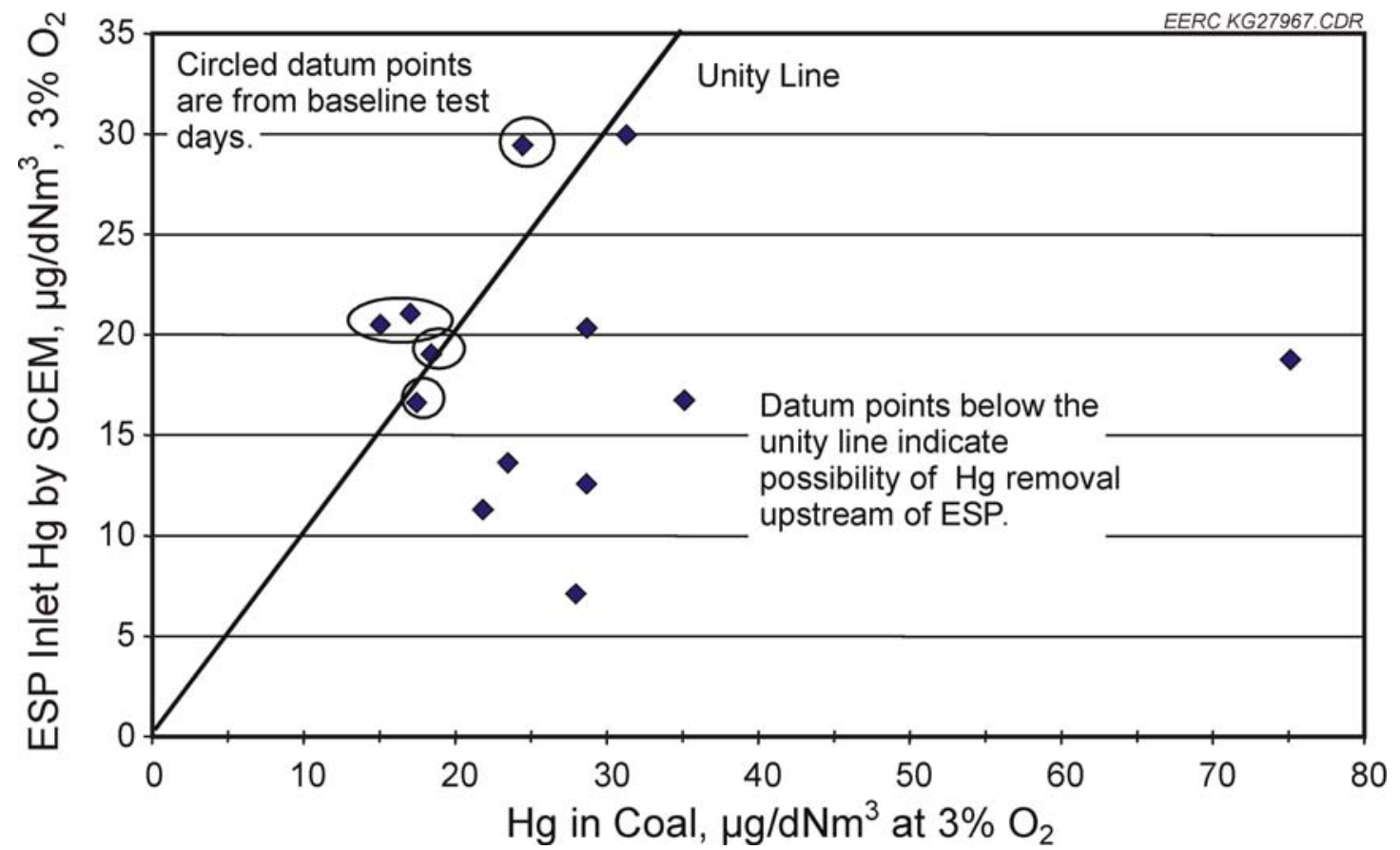

Figure 4-25. Comparison of ESP inlet vapor phase mercury (as measured by SCEM) to coal mercury concentration.

If the SCEM data are correct, then on average during the $55 \mathrm{ppm} \mathrm{Br}$ injection test, $46 \%$ of the coal mercury was removed from the flue gas upstream of the ESP. When the injection rate was increased to $113 \mathrm{ppm} \mathrm{Br}$, on average $64 \%$ of the coal mercury was removed from the flue gas upstream of the ESP. However, when the injection rate was increased to $330 \mathrm{ppm} \mathrm{Br}$, no mercury removal was observed upstream of the ESP.

The ash mercury contents were analyzed to determine if the injection of calcium bromide caused an increase in mercury partitioning to the fly ash. Ash samples were collected by hopper from the first two fields of the ESP on a daily basis. Selected ash samples were analyzed for mercury and LOI content, as summarized in Tables 4-12 and 4-13, respectively. For each day, the average mercury and LOI content was calculated for Field 1 and Field 2.

Figures 4-26 and 4-27 show the mercury concentration of the composite fly ash samples for the two long-term injection tests. Each plots shows the baseline (no injection) ash data as well as the ash mercury concentrations collected during injection. The average mercury concentration of the first field baseline ash collected during the baseline period prior to the first continuous-injection test was $0.214 \mu \mathrm{g} / \mathrm{g}$. During the first injection test (55 ppm Br in the coal), the average first field ash mercury concentration increased to $0.328 \mu \mathrm{g} / \mathrm{g}$. Likewise, the second field ash mercury concentration also increased during the calcium bromide injection test. 
Table 4-12. Mercury Content of Fly Ash

\begin{tabular}{|c|c|c|c|c|c|c|c|c|c|}
\hline Date & Time & Field & Row 1 & Row 2 & Row 3 & Row 4 & Row 5 & Row 6 & Average \\
\hline \multirow{2}{*}{$10 / 25 / 05$} & $13: 00$ & 1 & & 0.155 & & 0.325 & 0.340 & 0.287 & 0.277 \\
\hline & & 2 & & & & 0.566 & & & 0.566 \\
\hline \multirow[t]{2}{*}{$10 / 26 / 05$} & $15: 30$ & 1 & & 0.125 & 0.162 & 0.290 & & 0.235 & 0.203 \\
\hline & & 2 & & & & 0.572 & 0.471 & 0.477 & 0.507 \\
\hline \multirow[t]{2}{*}{$11 / 04 / 05$} & $17: 00$ & 1 & 0.113 & 0.088 & & 0.217 & 0.214 & 0.174 & 0.161 \\
\hline & & 2 & & 0.215 & & 0.438 & 0.415 & 0.445 & 0.378 \\
\hline \multirow[t]{2}{*}{$11 / 06 / 05$} & $15: 00$ & 1 & 0.280 & 0.231 & & 0.493 & 0.451 & 0.430 & 0.377 \\
\hline & & 2 & & 0.444 & & 0.859 & 0.793 & 0.679 & 0.694 \\
\hline \multirow[t]{2}{*}{$11 / 09 / 05$} & $14: 30$ & 1 & 0.218 & 0.170 & & 0.405 & 0.370 & 0.370 & 0.307 \\
\hline & & 2 & 0.303 & 0.341 & & & 0.698 & 0.724 & 0.517 \\
\hline \multirow[t]{2}{*}{$11 / 11 / 05$} & $15: 30$ & 1 & 0.157 & 0.140 & & 0.264 & 0.263 & 0.246 & 0.214 \\
\hline & & 2 & 0.235 & 0.239 & & & 0.462 & 0.481 & 0.354 \\
\hline \multirow[t]{2}{*}{$11 / 12 / 05$} & $17: 00$ & 1 & 0.194 & 0.139 & & 0.380 & 0.333 & 0.357 & 0.281 \\
\hline & & 2 & 0.319 & 0.364 & & & 0.583 & 0.628 & 0.474 \\
\hline \multirow[t]{2}{*}{$11 / 13 / 05$} & $16: 45$ & 1 & 0.308 & 0.257 & & 0.482 & 0.506 & 0.441 & 0.399 \\
\hline & & 2 & 0.447 & 0.464 & & & 0.844 & 0.966 & 0.68 \\
\hline \multirow[t]{2}{*}{$11 / 15 / 05$} & $14: 00$ & 1 & 0.312 & 0.261 & & 0.491 & 0.462 & 0.418 & 0.389 \\
\hline & & 2 & 0.510 & 0.577 & & & 0.766 & 0.835 & 0.672 \\
\hline \multirow[t]{2}{*}{$11 / 17 / 05$} & $11: 50$ & 1 & 0.304 & 0.212 & & 0.392 & 0.379 & 0.347 & 0.327 \\
\hline & & 2 & 0.542 & 0.482 & & & 0.719 & 0.710 & 0.613 \\
\hline \multirow[t]{2}{*}{$11 / 29 / 05$} & 14:05 & 1 & 0.110 & 0.070 & & & 0.051 & & 0.077 \\
\hline & & 2 & 0.118 & 0.110 & & & 0.087 & 0.100 & 0.104 \\
\hline \multirow[t]{2}{*}{$12 / 01 / 05$} & $14: 00$ & 1 & 0.153 & 0.133 & & 0.244 & 0.233 & 0.211 & 0.195 \\
\hline & & 2 & 0.182 & 0.265 & & & 0.403 & 0.377 & 0.307 \\
\hline \multirow[t]{2}{*}{$12 / 02 / 05$} & $14: 30$ & 1 & 0.189 & 0.175 & & 0.321 & 0.317 & 0.316 & 0.264 \\
\hline & & 2 & 0.353 & 0.363 & & & 0.539 & 0.603 & 0.465 \\
\hline \multirow[t]{2}{*}{$12 / 06 / 05$} & $13: 35$ & 1 & 0.256 & 0.217 & & 0.522 & 0.510 & 0.556 & 0.412 \\
\hline & & 2 & 0.370 & 0.430 & & & 0.922 & 0.762 & 0.621 \\
\hline \multirow[t]{2}{*}{$12 / 05 / 05$} & $15: 30$ & 1 & 0.254 & 0.166 & & 0.531 & 0.493 & 0.411 & 0.371 \\
\hline & & 2 & 0.383 & 0.456 & & & 0.877 & 0.907 & 0.656 \\
\hline \multirow[t]{2}{*}{$12 / 07 / 05$} & $15: 00$ & 1 & 0.202 & 0.216 & & 0.472 & 0.482 & 0.304 & 0.335 \\
\hline & & 2 & 0.460 & 0.399 & & & 0.963 & 0.913 & 0.684 \\
\hline \multirow[t]{2}{*}{$12 / 09 / 05$} & $11: 00$ & 1 & 0.274 & 0.212 & & 0.306 & 0.312 & & 0.276 \\
\hline & & 2 & 0.444 & 0.414 & & & 0.546 & 0.488 & 0.473 \\
\hline \multirow[t]{2}{*}{$12 / 11 / 05$} & $11: 15$ & 1 & 0.251 & 0.203 & & 0.326 & 0.325 & & 0.276 \\
\hline & & 2 & 0.352 & 0.355 & & & 0.484 & 0.462 & 0.413 \\
\hline \multirow[t]{2}{*}{$12 / 13 / 05$} & $14: 45$ & 1 & 0.356 & 0.306 & & 0.439 & 0.452 & 0.467 & 0.404 \\
\hline & & 2 & 0.546 & 0.574 & & & 0.662 & 0.699 & 0.62 \\
\hline $12 / 14 / 05$ & $14: 25$ & 2 & 0.483 & 0.511 & & & 0.508 & 0.516 & 0.505 \\
\hline
\end{tabular}


Table 4-13. LOI Content of Fly Ash

\begin{tabular}{|c|c|c|c|c|c|c|c|c|c|}
\hline Date & Time & Field & Row 1 & Row 2 & Row 3 & Row 4 & Row 5 & Row 6 & Average \\
\hline \multirow[t]{2}{*}{$10 / 25 / 05$} & $13: 00$ & 1 & & 0.34 & & 0.16 & 0.12 & 0.13 & 0.19 \\
\hline & & 2 & & & & 0.20 & & & 0.2 \\
\hline \multirow[t]{2}{*}{$10 / 26 / 05$} & $15: 30$ & 1 & & 0.38 & 0.22 & 0.22 & & 0.14 & 0.24 \\
\hline & & 2 & & & & 0.30 & 0.23 & 0.29 & 0.27 \\
\hline \multirow[t]{2}{*}{$11 / 04 / 05$} & $17: 00$ & 1 & 0.11 & 0.18 & & 0.15 & 0.12 & 0.16 & 0.14 \\
\hline & & 2 & & 0.19 & & 0.15 & 0.21 & 0.10 & 0.16 \\
\hline \multirow[t]{2}{*}{$11 / 06 / 05$} & $15: 00$ & 1 & 0.12 & 0.29 & & 0.16 & 0.32 & 0.18 & 0.21 \\
\hline & & 2 & & 0.13 & & 0.20 & 0.19 & 0.19 & 0.18 \\
\hline \multirow[t]{2}{*}{$11 / 09 / 05$} & $14: 30$ & 1 & 0.09 & 0.21 & & 0.13 & 0.25 & 0.13 & 0.16 \\
\hline & & 2 & 0.11 & 0.12 & & & 0.13 & 0.10 & 0.12 \\
\hline \multirow[t]{2}{*}{$11 / 11 / 05$} & $15: 30$ & 1 & 0.20 & 0.24 & & 0.27 & 0.24 & 0.32 & 0.25 \\
\hline & & 2 & 0.22 & 0.21 & & & 0.22 & 0.25 & 0.23 \\
\hline \multirow[t]{2}{*}{$11 / 12 / 05$} & $17: 00$ & 1 & 0.18 & 0.27 & & 0.16 & 0.31 & 0.13 & 0.21 \\
\hline & & 2 & 0.17 & 0.17 & & & 0.14 & 0.11 & 0.15 \\
\hline \multirow[t]{2}{*}{$11 / 13 / 05$} & $16: 45$ & 1 & 0.25 & 0.35 & & 0.32 & 0.25 & 0.12 & 0.26 \\
\hline & & 2 & 0.13 & 0.22 & & & 0.17 & 0.10 & 0.16 \\
\hline \multirow[t]{2}{*}{$11 / 15 / 05$} & $14: 00$ & 1 & 0.08 & 0.20 & & 0.20 & 0.29 & 0.27 & 0.21 \\
\hline & & 2 & 0.27 & 0.22 & & & 0.16 & 0.28 & 0.23 \\
\hline \multirow[t]{2}{*}{$11 / 17 / 05$} & $11: 50$ & 1 & 0.14 & 0.25 & & 0.35 & 0.19 & 0.22 & 0.23 \\
\hline & & 2 & 0.15 & 0.22 & & & 0.15 & 0.20 & 0.18 \\
\hline \multirow[t]{2}{*}{$12 / 01 / 05$} & $14: 00$ & 1 & 0.05 & 0.12 & & 0.12 & 0.07 & 0.11 & 0.09 \\
\hline & & 2 & 0.05 & 0.14 & & & 0.11 & 0.07 & 0.09 \\
\hline \multirow[t]{2}{*}{$12 / 02 / 05$} & $14: 30$ & 1 & 0.09 & 0.22 & & 0.15 & 0.25 & 0.09 & 0.16 \\
\hline & & 2 & 0.10 & 0.10 & & & 0.11 & 0.14 & 0.11 \\
\hline \multirow[t]{2}{*}{$12 / 06 / 05$} & $13: 35$ & 1 & 0.15 & 0.28 & & 0.26 & 0.20 & 0.09 & 0.2 \\
\hline & & 2 & 0.12 & 0.14 & & & 0.17 & 0.10 & 0.13 \\
\hline \multirow[t]{2}{*}{$12 / 05 / 05$} & $15: 30$ & 1 & 0.15 & 0.36 & & 0.27 & 0.15 & 0.24 & 0.23 \\
\hline & & 2 & 0.12 & 0.16 & & & 0.19 & 0.23 & 0.18 \\
\hline \multirow[t]{2}{*}{$12 / 07 / 05$} & $15: 00$ & 1 & 0.10 & 0.11 & & 0.13 & 0.20 & 0.10 & 0.13 \\
\hline & & 2 & 0.09 & 0.13 & & & 0.12 & 0.09 & 0.11 \\
\hline \multirow[t]{2}{*}{$12 / 09 / 05$} & $11: 00$ & 1 & 0.08 & 0.27 & & 0.17 & 0.17 & & 0.17 \\
\hline & & 2 & 0.08 & 0.13 & & & 0.13 & 0.09 & 0.11 \\
\hline \multirow[t]{2}{*}{$12 / 11 / 05$} & $11: 15$ & 1 & 0.13 & 0.08 & & 0.14 & 0.10 & & 0.11 \\
\hline & & 2 & 0.09 & 0.09 & & & 0.05 & 0.07 & 0.08 \\
\hline \multirow[t]{2}{*}{$12 / 13 / 05$} & $14: 45$ & 1 & 0.04 & 0.16 & & 0.11 & 0.11 & 0.05 & 0.09 \\
\hline & & 2 & 0.08 & 0.07 & & & 0.05 & 0.05 & 0.06 \\
\hline $12 / 14 / 05$ & $14: 25$ & 2 & 0.04 & 0.06 & & & 0.03 & 0.04 & 0.04 \\
\hline
\end{tabular}




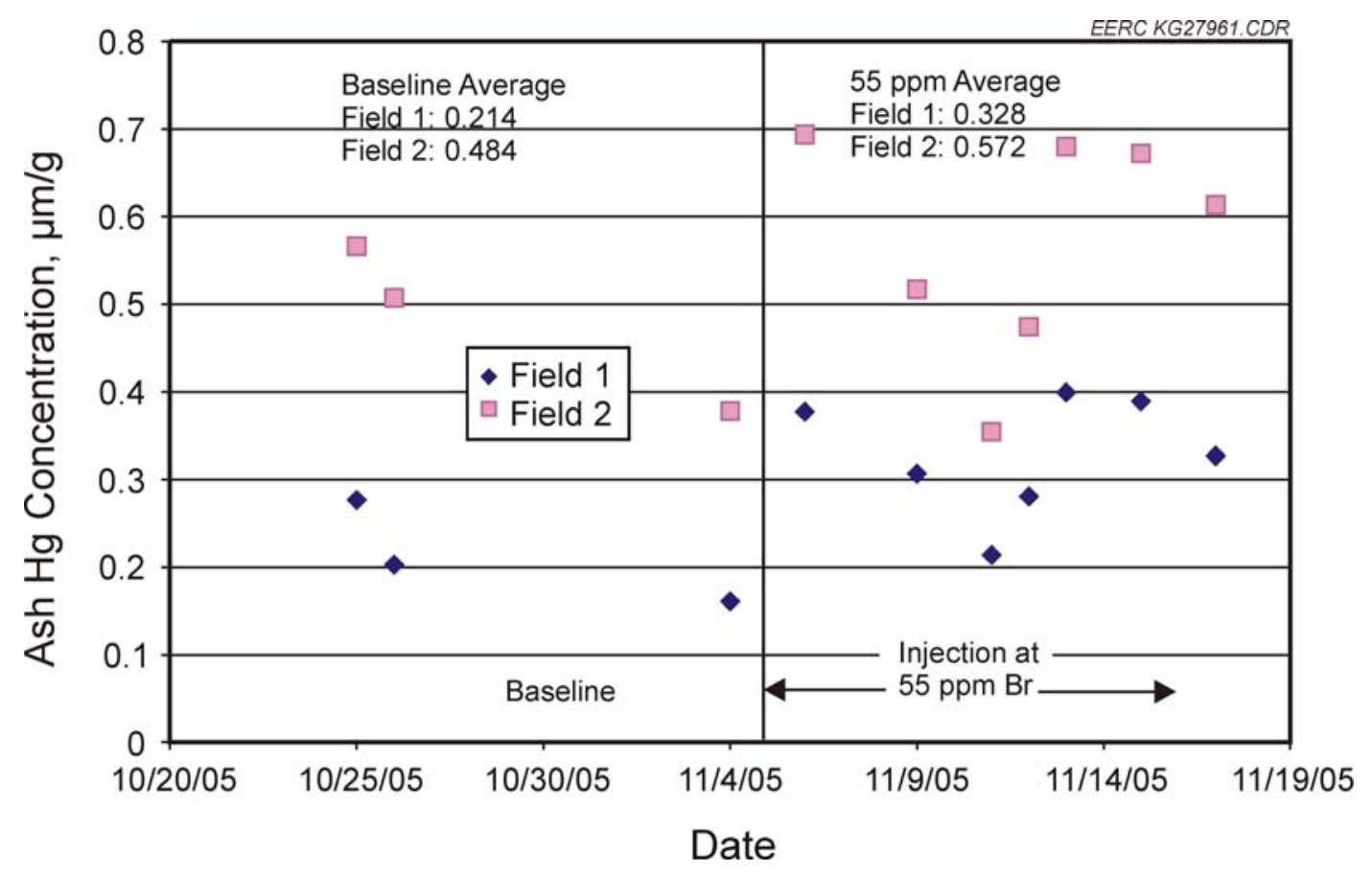

Figure 4-26. Mercury concentration of fly ash during baseline and first continuous-injection test.

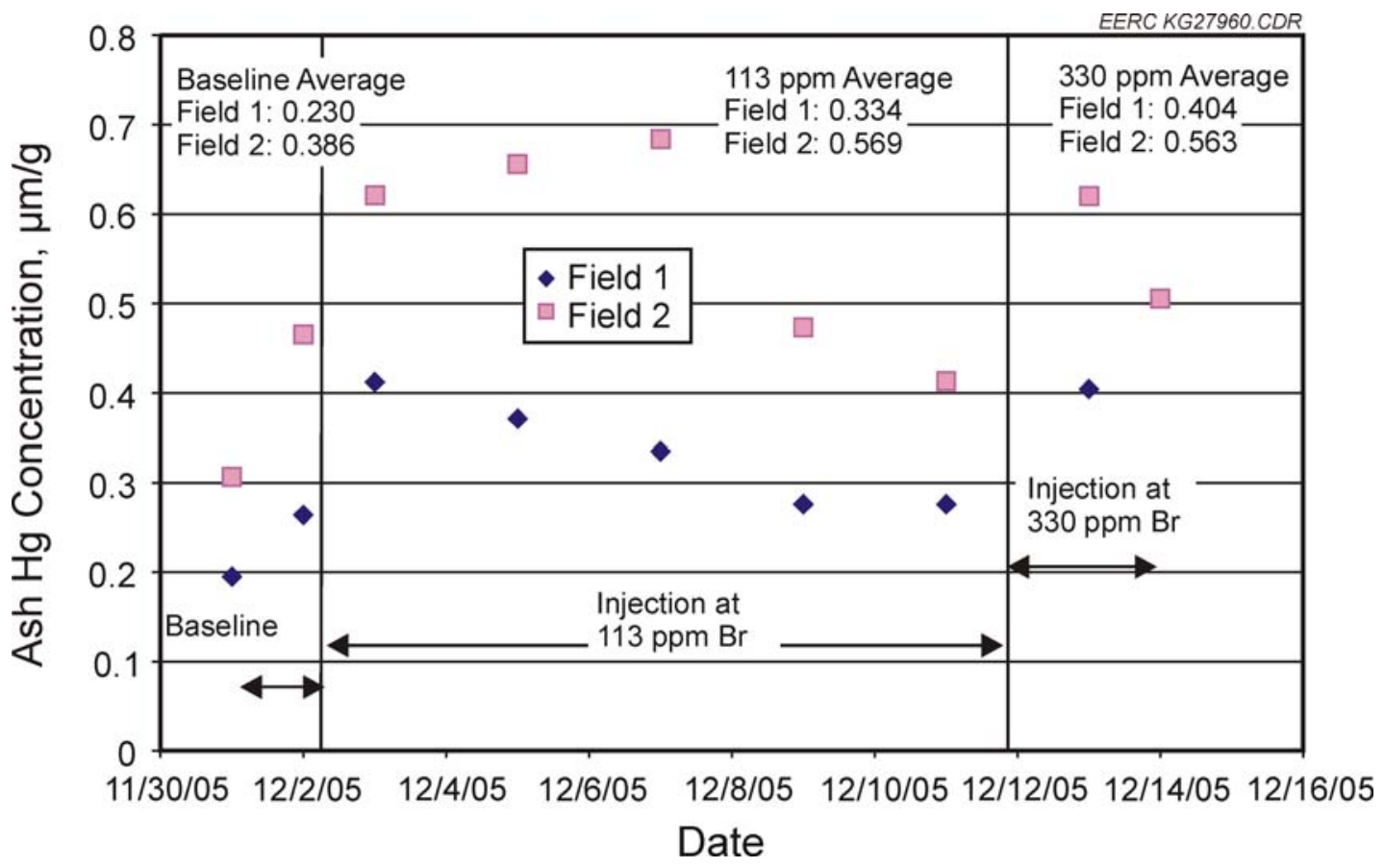

Figure 4-27. Mercury concentration of fly ash during baseline and second continuous-injection test. 
The average mercury concentration of the first field baseline ash collected during the baseline period prior to the second continuous injection test $(0.230 \mu \mathrm{g} / \mathrm{g})$ was similar to the first baseline period $(0.214 \mu \mathrm{g} / \mathrm{g})$. During the second injection test (113 ppm $\mathrm{Br}$ in the coal), the average first field ash mercury concentration increased to $0.334 \mu \mathrm{g} / \mathrm{g}$. Likewise, the second field ash mercury concentration also increased during the calcium bromide injection test.

Figure 4-28 shows the ratio of the mercury leaving the system with the fly ash compared to the mercury entering the system with the coal. A value of $0 \%$ indicates no removal of mercury by the ash, and a value of $100 \%$ indicates total removal of mercury by the fly ash. For the baseline day just prior to the $55 \mathrm{ppm} \mathrm{Br}$ test, the ash mercury represented $12 \%$ of the coal mercury, indicating little native removal. During the $55 \mathrm{ppm} \mathrm{Br}$ test, 4 days of coal and ash data indicate that an average $25 \%$ of the coal mercury was removed with the fly ash. These data indicate a slight increase in mercury removal by the fly ash during calcium bromide injection; however, the ash data do not indicate as high a mercury removal as the gas-phase SCEM data, which had indicated an average of $46 \%$ mercury removal by the fly ash.

For the baseline day just prior to the $113 \mathrm{ppm}$ Br test, the ash mercury represented $22 \%$ of the coal mercury. During the $113 \mathrm{ppm} \mathrm{Br}$ test, the three days of coal and ash data indicate that an average $22 \%$ of the coal mercury was removed with the fly ash. Similarly for the $330 \mathrm{ppm} \mathrm{Br}$ test, $22 \%$ of the coal mercury was removed with the fly ash. The injection of calcium bromide during this second long-term test did not result in an increase in mercury removal by the fly ash. These results are in contradiction to the flue gas data for the $113 \mathrm{ppm} \mathrm{Br}$ test, which showed $64 \%$ of the mercury being removed prior to the ESP. The percentage of mercury removed by the fly ash during this second long-term test is comparable to the percentage of mercury removed during the first long-term test. It is possible that the baseline ash/coal ratio of $12 \%$ measured just prior to the first long-term test is a low outlier and that, indeed, the removal of mercury by the fly ash did not increase during the 55 ppm Br injection test.

The comparison of the ESP inlet vapor-phase data and the ash mercury data to the coal mercury data indicate a contradiction. The ESP inlet vapor-phase mercury data for the $55 \mathrm{ppm}$ and $113 \mathrm{ppm} \mathrm{Br}$ injection tests indicate appreciable (46\% and 64\%, respectively) removal of mercury upstream of the ESP, while the ash mercury data indicate little additional removal of mercury with the bromine injection process. Kanefke et al. (6) have observed a negative measurement bias by SCEMs (such as the EPRI SCEMs in this project) using a stannous chloride solution for the reduction of oxidized mercury. Kanefke et al. (6) showed that in the presence of $6 \mathrm{ppmv} \mathrm{Br}$, the measured total vapor-phase mercury concentrations were biased by as much as $20 \%$. In the presence of $30 \mathrm{ppmv} \mathrm{Br}$, the measured total vapor-phase mercury concentrations were biased by as much as $50 \%$.

Analysis of the gas-phase mercury concentrations measured by the SCEMs and the coal and ash mercury data indicate that there was a bromine-related negative bias associated with the measurement of total vapor-phase mercury upstream of the scrubber. Such a bias does not appear to exist for the measurement of elemental mercury upstream of the scrubber, as the scrubber inlet elemental mercury concentrations agree well with the scrubber outlet total mercury concentrations. For the purposes of calculating the oxidation of mercury and the removal of 


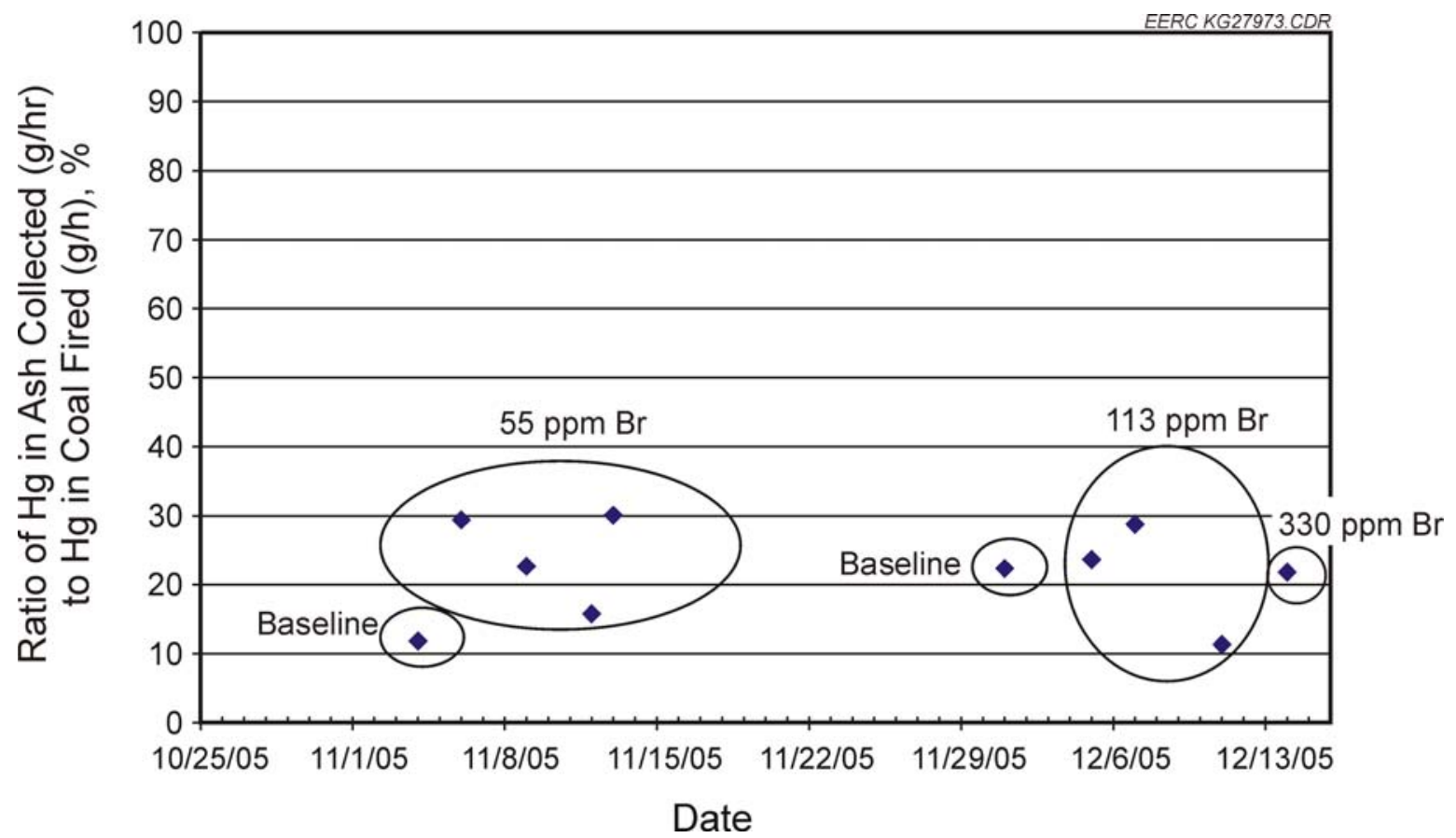

Figure 4-28. Ratio of mercury content in ash collected $(\mathrm{g} / \mathrm{hr})$ to mercury content in coal fired $(\mathrm{g} / \mathrm{hr})$.

mercury by the system, average coal mercury values were used in place of the SCEM total mercury data at the scrubber inlet.

\subsubsection{Analysis of FGD By-Products}

A sample of the FGD slurry was filtered daily on-site and preserved for mercury analysis off-site at URS' Austin laboratories. The mercury concentrations in the FGD solids and liquors are summarized in Table 4-14. The baseline mercury concentration of the FGD solids ranged from 1.50 to $3.16 \mathrm{ppm}$, and the baseline mercury concentration of the FGD liquor was $3.22 \mathrm{ppb}$. Greater than $98 \%$ of the mercury in the FGD slurry was contained in the FGD solids.

For both the $55 \mathrm{ppm}$ and $113 \mathrm{ppm} \mathrm{Br}$ injection tests, the first week of $\mathrm{CaBr}_{2}$ injection did not appear to affect either the liquor or solids mercury concentrations. In the second week of testing, the mercury concentration of the liquor increased by two orders of magnitude, while the mercury concentration of the solids decreased by one order of magnitude. These data indicate that the partitioning of the mercury in the FGD by-products shifts from the solid to the liquor phase. At the conclusion of the $55 \mathrm{ppm} \mathrm{Br}$ injection test, approximately half of the mercury in the FGD slurry was contained in the liquor; at the end of the $113 \mathrm{ppm} \mathrm{Br}$ test, over $85 \%$ of the mercury in the FGD slurry was contained in the liquor. The increase in mercury concentration of the liquor is a step change that occurs after approximately one week of injection, perhaps indicating that there is some sort of threshold that must be overcome. This sudden increase 
Table 4-14. Mercury Content of FGD Samples

\begin{tabular}{lcccc}
\hline Condition & Date & Time & $\begin{array}{c}\text { Hg in FGD } \\
\text { liquor }(\mu \mathrm{g} / \mathrm{L})\end{array}$ & $\begin{array}{c}\text { Hg in FGD } \\
\text { solid }(\mu \mathrm{g} / \mathrm{g})\end{array}$ \\
\hline Baseline & $11 / 3 / 05$ & $16: 30$ & 3.93 & 1.50 \\
Baseline & $11 / 4 / 05$ & $16: 48$ & 3.22 & 3.16 \\
$55 \mathrm{ppm} \mathrm{Br}$ & $11 / 6 / 05$ & $\mathrm{NA}$ & 2.11 & 3.24 \\
$55 \mathrm{ppm} \mathrm{Br}$ & $11 / 9 / 05$ & $14: 15$ & 4.08 & 2.51 \\
$55 \mathrm{ppm} \mathrm{Br}$ & $11 / 11 / 05$ & $15: 30$ & 2.83 & 2.83 \\
$55 \mathrm{ppm} \mathrm{Br}$ & $11 / 13 / 05$ & $16: 00$ & 3.13 & 3.61 \\
$55 \mathrm{ppm} \mathrm{Br}$ & $11 / 15 / 05$ & $11: 37$ & 111 & Not available \\
$55 \mathrm{ppm} \mathrm{Br}$ & $11 / 17 / 05$ & $15: 40$ & 163 & 1.48 \\
$\mathrm{Baseline}$ & $12 / 2 / 05$ & $10: 10$ & $50.2 *$ & 2.46 \\
$113 \mathrm{ppm} \mathrm{Br}$ & $12 / 5 / 05$ & $16: 45$ & 6.87 & 3.21 \\
$113 \mathrm{ppm} \mathrm{Br}$ & $12 / 7 / 05$ & $13: 08$ & 4.38 & 3.30 \\
$113 \mathrm{ppm} \mathrm{Br}$ & $12 / 9 / 05$ & $15: 45$ & 262 & 0.89 \\
$113 \mathrm{ppm} \mathrm{Br}$ & $12 / 11 / 05$ & $10: 20$ & 455 & 0.48 \\
$330 \mathrm{ppm} \mathrm{Br}$ & $12 / 13 / 05$ & $15: 15$ & Not available & 0.38 \\
$330 \mathrm{ppm} \mathrm{Br}$ & $12 / 14 / 05$ & $14: 40$ & 417 & 0.33 \\
\hline
\end{tabular}

* This value appears to be an outlier for baseline scrubber liquor mercury concentration.

occurred after 10 days of injection at $55 \mathrm{ppm} \mathrm{Br}$ and after only 7 days of injection at $113 \mathrm{ppm} \mathrm{Br}$. Figure 4-29 plots the change in mercury content of the FGD solids and liquor for the long-term test at $113 \mathrm{ppm} \mathrm{Br}$.

Table 4-15 presents the chemical analysis of the FGD liquors and solids collected during the two long-term injection tests. The sulfite concentration of the liquor was below the detection limit of $4 \mathrm{ppm}$. The chloride concentration of the liquor ranged between 2000 and $3500 \mathrm{ppm}$. Baseline bromide concentrations were much lower, ranging between 27 and $35 \mathrm{ppm}$. The bromide concentration of the liquor increased during the calcium bromide injection tests as indicated in Figure 4-30. After two weeks of injection at $55 \mathrm{ppm} \mathrm{Br}$ in the coal, the bromine concentration of the FGD liquor reached a steady value of $55 \mathrm{ppm}$. After approximately ten days of injection at $113 \mathrm{ppm} \mathrm{Br}$ in the coal, the bromine concentration of the FGD liquor reached a steady $110 \mathrm{ppm}$. The increase in bromine concentration in the FGD liquor represented approximately $8 \%$ of the bromine injected into the furnace.

Long-term furnace chemical injection of calcium bromide did not result in an increase in the bromine concentration of the FGD solids from baseline values. Baseline FGD solids bromine concentrations were $10 \mathrm{ppm}$ or less; the bromine concentrations of the FGD solids during chemical injection ranged from 8 to $19 \mathrm{ppm}$.

During the long-term calcium bromide injection test, the maximum bromide concentrations reached in the liquor were less than $10 \%$ of the chloride concentration; however, the bromide species is more reactive the chloride species, with respect to mercury complexation. This test program was not long enough to evaluate the effect of the elevated bromide concentration on the 


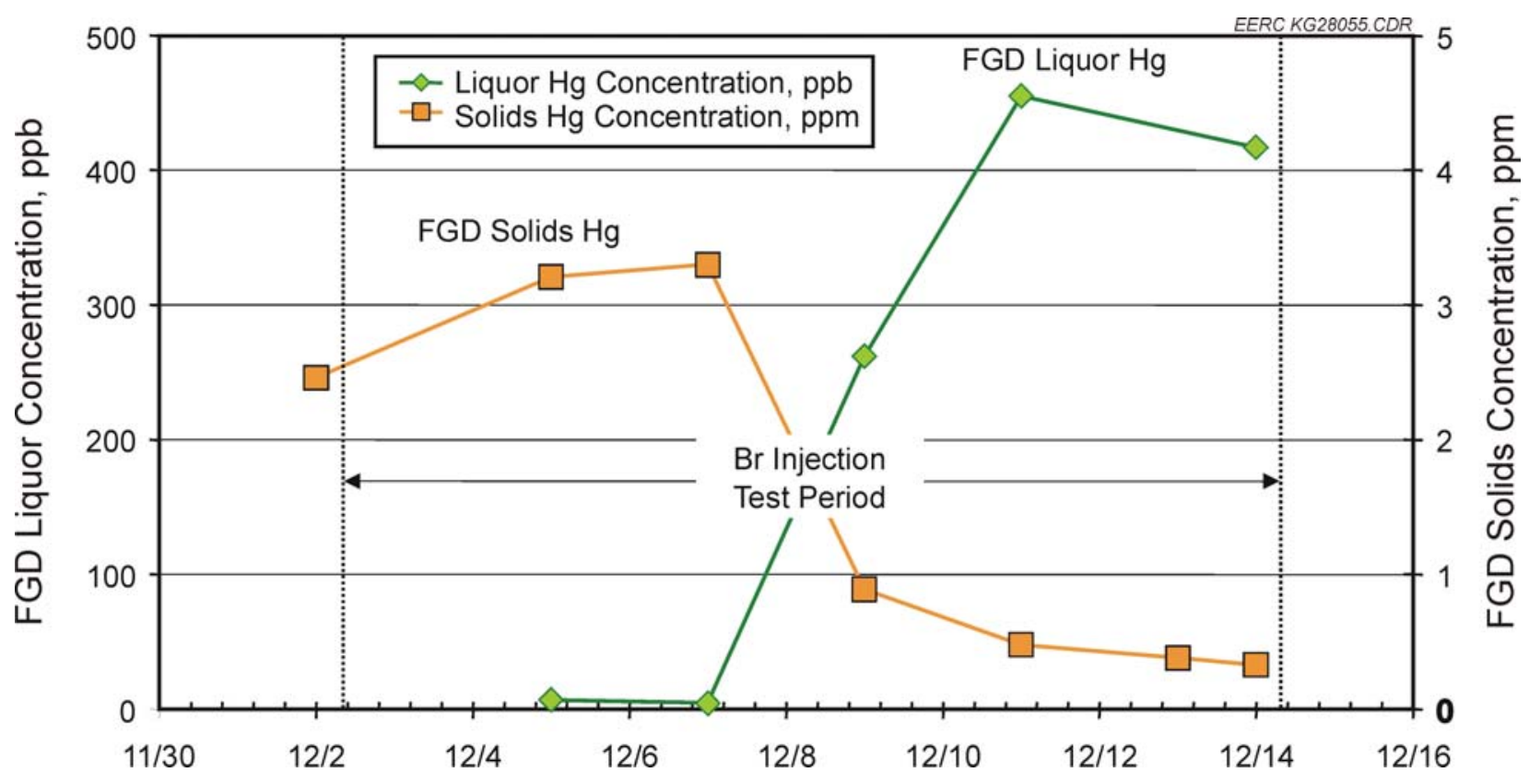

Figure 4-29. Shift in mercury content of FGD by-product from solid to liquid phase during second long-term injection test.

rate of corrosion of the materials of construction for the FGD scrubber. Monticello Unit 3 was inspected during a plant outage that followed four months after the long-term calcium bromide tests. There were no abnormal signs of corrosion observed.

Selected ash samples were analyzed for bromine content, as summarized in Table 4-16. The bromine in the ash was extracted with the SPLP (EPA Method 1312) and analyzed with ion chromatography. During baseline, the bromine content of the ash was $<1 \mathrm{ppm}$. During the $55 \mathrm{ppm} \mathrm{Br}$ injection test, the bromine content of the fly ash was just over $3 \mathrm{ppm}$. At the $113 \mathrm{ppm}$ $\mathrm{Br}$ injection rate, the bromine content of the fly ash was measured at 3.5 and $5.0 \mathrm{ppm}$ for two different test days. The bromine content of the fly ash increased to $7.0 \mathrm{ppm}$ at the $330 \mathrm{ppm}$ injection rate. For all ash samples analyzed, the bromide content of the fly ash represented less than $0.5 \%$ of the bromide injected into the furnace.

A mass balance on the bromine does not close for this system. Of the bromine injected into the furnace, approximately $8 \%$ was found in the FGD liquor, none was found in the FGD solids, and less than $0.5 \%$ was found in the ash. It is unclear why the other $90 \%$ of the injected bromine did not show up in the FGD liquor. A possible sample bias in the measurement of bromine in the FGD liquor is being investigated. 
Table 4-15. Results from Analysis of FGD Solids and Liquors

\begin{tabular}{|c|c|c|c|c|c|c|c|c|c|c|}
\hline DATE & $11 / 4 / 05$ & $11 / 9 / 05$ & $11 / 13 / 05$ & $11 / 15 / 05$ & $11 / 17 / 05$ & $12 / 2 / 05$ & $12 / 5 / 05$ & $12 / 7 / 05$ & $12 / 11 / 05$ & $12 / 14 / 05$ \\
\hline TIME & $16: 45$ & $14: 20$ & $16: 15$ & $11: 37$ & $15: 40$ & 10:10 & $16: 45$ & 13:08 & $10: 20$ & 14:40 \\
\hline CONDITION & Baseline & $55 \mathrm{ppm} \mathrm{Br}$ & $55 \mathrm{ppm} \mathrm{Br}$ & $55 \mathrm{ppm} \mathrm{Br}$ & $55 \mathrm{ppm} \mathrm{Br}$ & Baseline & 113 ppm Br & $113 \mathrm{ppm} \mathrm{Br}$ & $113 \mathrm{ppm} \mathrm{Br}$ & $330 \mathrm{ppm} \mathrm{Br}$ \\
\hline $\mathrm{PH}$ & 5.62 & 5.72 & 5.62 & 5.76 & 5.7 & 5.6 & 5.73 & 5.79 & 5.7 & 5.74 \\
\hline TEMP, C & 56.2 & 60.1 & 55 & 58.9 & 53.8 & 56.8 & 57.2 & 57.2 & 57.6 & 57.8 \\
\hline \multicolumn{11}{|l|}{ Liquids Summary } \\
\hline $\mathrm{Ca}, \mathrm{mg} / \mathrm{L}$ & 667 & 651 & 676 & 736 & 674 & 646 & 641 & 644 & 674 & 642 \\
\hline $\mathrm{Mg}, \mathrm{mg} / \mathrm{L}$ & 2500 & 2569 & 2040 & 1945 & 1683 & 2293 & 2240 & 2538 & 1651 & 2037 \\
\hline $\mathrm{Na}, \mathrm{mg} / \mathrm{L}$ & 1889 & 1895 & 1540 & 1448 & 1219 & 1549 & 1591 & 1768 & 1195 & 1403 \\
\hline $\mathrm{Cl}, \mathrm{mg} / \mathrm{L}$ & 3441 & 3542 & 2815 & 2888 & 2381 & 3055 & 2775 & 3332 & 2118 & 2680 \\
\hline $\mathrm{Br}, \mathrm{mg} / \mathrm{L}$ & 35 & 37 & 41 & 55 & 55 & 27 & 72 & 102 & 109 & 145 \\
\hline $\mathrm{CO} 3, \mathrm{mg} / \mathrm{L}$ & 21 & 31 & 23 & 19 & 21 & 23 & 23 & 21 & 28 & 20 \\
\hline $\mathrm{SO} 3, \mathrm{mg} / \mathrm{L}$ & $<3$ & $<3$ & $<3$ & $<3$ & $<2$ & $<2$ & $<4$ & $<2$ & $<2$ & $<2$ \\
\hline $\mathrm{SO} 4, \mathrm{mg} / \mathrm{L}$ & 9960 & 10373 & 8447 & 8383 & 7314 & 8833 & 8970 & 9748 & 6815 & 7863 \\
\hline \multicolumn{11}{|l|}{ Solids Summary } \\
\hline $\mathrm{Ca}, \mathrm{mg} / \mathrm{g}$ & 228 & 225 & 228 & 228 & 228 & 225 & 221 & 223 & 230 & 228 \\
\hline $\mathrm{Mg}, \mathrm{mg} / \mathrm{g}$ & 1.03 & 0.53 & 0.64 & 0.66 & 0.46 & 0.38 & 0.33 & 0.36 & 0.28 & 0.29 \\
\hline $\mathrm{Br}, \mathrm{mg} / \mathrm{g}$ & 13 & 8 & $<10$ & 9 & 9 & $<10$ & $<10$ & $<10$ & 19 & 13 \\
\hline $\mathrm{SO} 3, \mathrm{mg} / \mathrm{g}$ & 0.00 & 0.26 & 0.26 & 0.53 & 0.67 & 0.27 & 0.27 & 0.27 & 0.00 & 0.00 \\
\hline $\mathrm{SO} 4, \mathrm{mg} / \mathrm{g}$ & 538 & 542 & 543 & 538 & 548 & 543 & 546 & 541 & 543 & 542 \\
\hline $\mathrm{CO} 3, \mathrm{mg} / \mathrm{g}$ & 0.30 & 0.14 & 1.35 & 4.95 & 0.30 & 1.51 & 1.30 & 1.76 & 1.06 & 1.64 \\
\hline INERTS, wt $\%$ & 1.4 & 1.08 & 1.42 & 1.39 & 1.07 & 1 & 0.8 & 0.91 & 1.11 & 0.96 \\
\hline SOLIDS, wt $\%$ & 6.2 & 12.9 & 8.9 & 12.1 & 12.8 & 13.3 & 13.2 & 14.0 & 14.5 & 8.9 \\
\hline OXIDATION, \% & 100 & 99.9 & 99.9 & 99.9 & 99.9 & 99.9 & 99.9 & 99.9 & 100 & 100 \\
\hline
\end{tabular}




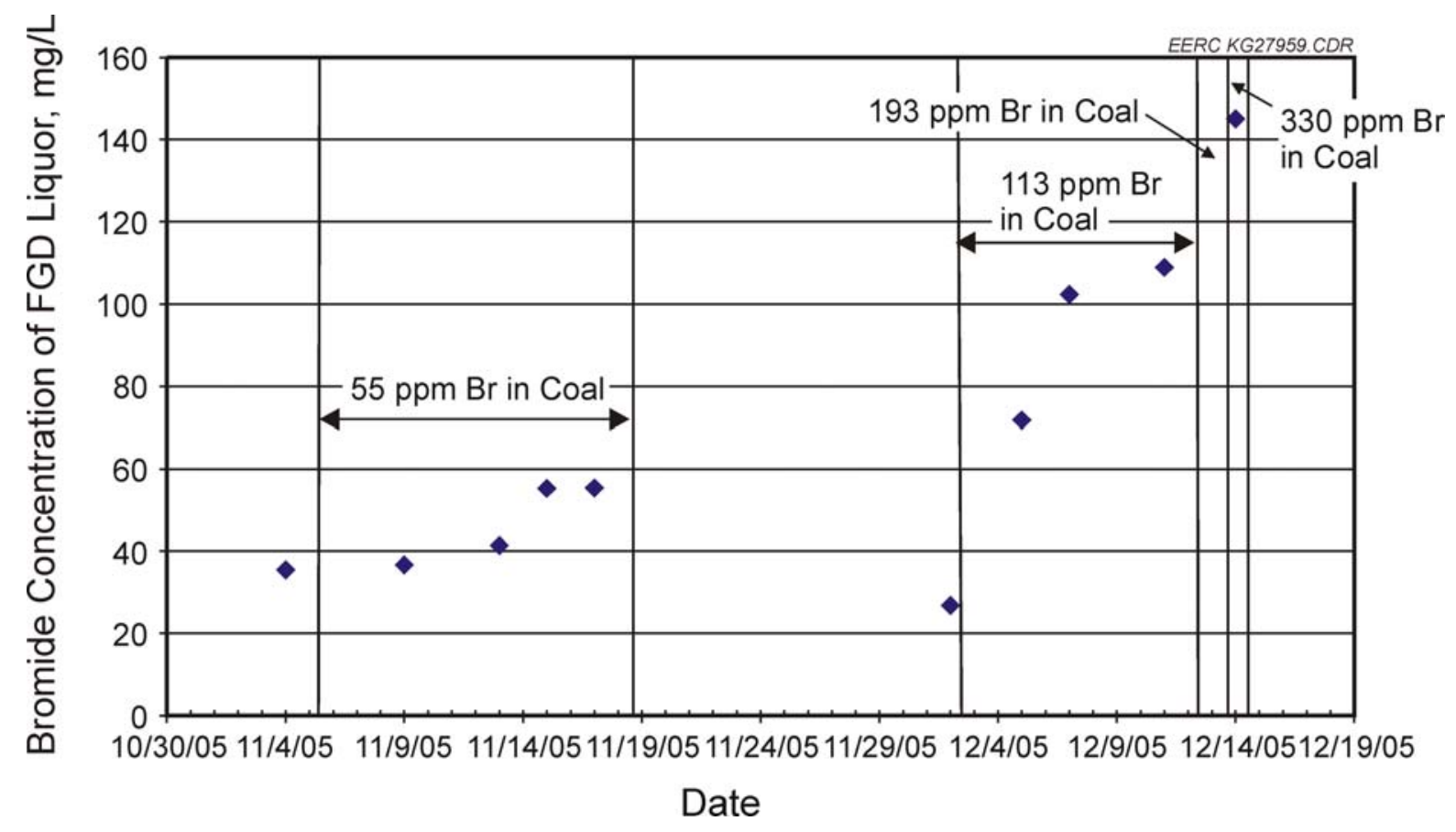

Figure 4-30. Measured bromide concentration of FGD liquor.

Table 4-16. Fly Ash Bromide Concentrations

\begin{tabular}{cccccc}
\hline Condition & Date & Time & Composite of Hoppers & Field & $\begin{array}{c}\text { Br in Ash } \\
(\boldsymbol{\mu g} / \mathbf{g})\end{array}$ \\
\hline Baseline & $11 / 4 / 2005$ & $17: 00$ & $1,2,4,5,6$ & 1 & $<1$ \\
Baseline & $12 / 1 / 2005$ & $14: 00$ & $1,2,4,5,6$ & 1 & $<1$ \\
$55 \mathrm{ppm} \mathrm{Br}$ & $11 / 9 / 2005$ & $14: 30$ & $1,2,4,5,6$ & 1 & 2.25 \\
$55 \mathrm{ppm} \mathrm{Br}$ & $11 / 13 / 2005$ & $16: 45$ & $1,2,4,5,6$ & 1 & 3.10 \\
$55 \mathrm{ppm} \mathrm{Br}$ & $11 / 17 / 2005$ & $11: 50$ & $1,2,4,5,6$ & 1 & 3.20 \\
$55 \mathrm{ppm} \mathrm{Br}$ & $11 / 17 / 2005$ & $11: 50$ & $7,8,11,12$ & 2 & 4.46 \\
$113 \mathrm{ppm} \mathrm{Br}$ & $12 / 9 / 2005$ & $11: 00$ & $1,2,4,5$ & 1 & 5.03 \\
$113 \mathrm{ppm} \mathrm{Br}$ & $12 / 11 / 2005$ & $11: 15$ & $1,2,4,5$ & 1 & 3.54 \\
$113 \mathrm{ppm} \mathrm{Br}$ & $12 / 11 / 2005$ & $11: 15$ & $7,8,11,12$ & 2 & 3.71 \\
$330 \mathrm{ppm} \mathrm{Br}$ & $12 / 13 / 2005$ & $14: 45$ & $1,2,4,5,6$ & 1 & 6.98 \\
\hline
\end{tabular}

\subsection{CONCLUSIONS}

TXU's Monticello Steam Electric Station Unit 3 was one of two units to be tested as part of a project primarily funded by DOE entitled "Large-Scale Mercury Control Technology Testing for Lignite-Fired Utilities - Oxidation Systems for Wet FGD." The overall project goal was to cost-effectively oxidize most of the $\mathrm{Hg}^{0}$ in lignitic combustion flue gases into a more soluble and reactive inorganic mercuric compound $\left(\mathrm{Hg}^{2+}\right)$ that could subsequently be captured in an ESP and/or wet FGD system. MoSES Unit 3 is a 793-MW unit that fires a 50/50 blend of 
Texas lignite and PRB coals. The unit is equipped with an ESP and limestone forced-oxidation spray tower FGD system for $\mathrm{SO}_{2}$ control. Baseline flue gas mercury measurements indicated that the ESP outlet flue gas typically contains about $25 \% \mathrm{Hg}^{2+}$ and $75 \% \mathrm{Hg}^{0}$, with a total $\mathrm{Hg}$ concentration of about $20 \mu \mathrm{g} / \mathrm{dNm}^{3}$.

A test program was carried out at MoSES in Fall 2005 to evaluate the furnace injection of halogen materials as a means of oxidizing the flue gas mercury so that it could be removed in a downstream wet scrubber. The program consisted of three parts: 1) baseline measurements to quantify the mercury concentrations and mercury removal across the system, 2) a set of parametric tests to compare the performance of furnace injection of two halogen salts $\left(\mathrm{CaCl}_{2}\right.$ and $\mathrm{CaBr}_{2}$ ), and 3) two 2-week continuous-injection tests to evaluate the variability and balance-ofplant impacts associated with furnace halogen injection. Flue gas mercury measurements were made primarily with EPRI semicontinuous mercury monitors (CMMs).

During baseline measurements, no removal of mercury was measured with the CMMs and the OH method across the ESP. On average for the course of the long-term test program, coal mercury concentrations correlated well with ESP inlet mercury concentrations measured by the CMM. The mercury content of the baseline fly ash represented less than $20 \%$ of the coal mercury content. Both the coal and ash results corroborate the flue gas determination of a small amount of mercury removal upstream of the ESP and no removal across the ESP. The coal mercury concentration of the PRB coal ranged from 0.04 to $0.09 \mathrm{ppm}$ dry. The coal mercury concentration of the Texas lignite was highly variable, ranging from 0.17 to $0.36 \mathrm{ppm}$ dry. Likewise, the ESP inlet mercury concentrations ranged over a wide span (15 to $30 \mu \mathrm{g} / \mathrm{dNm}^{3}$ at $3 \% \mathrm{O}_{2}$ ) during the course of the test program. The baseline flue gas typically contained $10 \%-40 \%$ oxidized mercury. The measured mercury oxidation was typical of that measured at other plants burning Texas lignite/PRB blends.

Parametric tests conducted with two halogen salts demonstrated that it was possible to increase the oxidation of mercury in the flue gas and to simultaneously increase mercury removal by the FGD scrubber. Calcium chloride provided only nominal improvements in mercury oxidation even at the highest tested injection rate of $800 \mathrm{ppm} \mathrm{Cl}$ in the coal. The calcium chloride was not observed to be capable of sustaining the mercury oxidation necessary for the project's mercury removal target of 55\%. In contrast, parametric tests with calcium bromide demonstrated up to $78 \%$ oxidation at injection rate of $200 \mathrm{ppm} \mathrm{Br}$ in the coal. Based on these parametric test results, calcium bromide was selected for an evaluation in two 2-week continuous-injection tests.

The first of these tests was conducted at an average injection rate of $55 \mathrm{ppm} \mathrm{Br}$ in the coal. This injection rate achieved an average $67 \%$ mercury oxidation at the scrubber inlet, and the average removal of mercury across the scrubber was $65 \%$. These values represent averages over a 2-week injection test; however, it was observed with the CMMs that the scrubber outlet total mercury concentration steadily increased over the test period. These results were confirmed with Appendix K measurements. Therefore, a higher injection rate was evaluated in the second 2-week injection test. 
For the second 2-week injection test, the calcium bromide injection rate was increased to an average $113 \mathrm{ppm} \mathrm{Br}$ in the coal. Over the course of the ten days at this injection rate, the mercury at the ESP inlet was on average $85 \%$ oxidized. The removal of vapor-phase mercury across the system averaged $86 \%$ for the entire test period. With the exception of a few brief periods, an injection rate of $113 \mathrm{ppm} \mathrm{Br}$ was sufficient to consistently maintain scrubber outlet mercury concentrations below $5 \mu \mathrm{g} / \mathrm{dNm}^{3}$ (at $3 \% \mathrm{O}_{2}$ ).

It should be noted that all of the reported mercury oxidation and removal values were based on the average coal mercury concentration for the respective test periods. The scrubber inlet total vapor-phase mercury measurements made by CMM were biased low during bromide injection, as determined from a comparison of CMM data to coal and ash mercury data. The presence of bromine in the flue gas can oxidize mercury in the wet solutions that pretreat the gas for the CMM. The scrubber inlet elemental mercury measurements did not appear to be subject to a negative bias, as these values agreed well with the scrubber outlet total mercury concentrations. The scrubber outlet mercury data are not subject to the bromine bias because bromine is removed by the FGD scrubber.

The furnace injection of calcium bromide did not result in increased mercury removal by the fly ash. The oxidized mercury was removed by the FGD scrubber, as expected. During baseline and the first week of each long-term injection test, the mercury partitioned to the FGD solids; however, during the second week of each test, the mercury transitioned to the liquor phase. At an injection rate of $113 \mathrm{ppm} \mathrm{Br}$ in the coal, over $85 \%$ of the mercury in the FGD by-product was contained in the liquor.

These two 2-week furnace injection tests were not long enough to evaluate the balance-ofplant effects. A unit inspection conducted after the test program did not indicate any brominerelated corrosion; however, the test period was too short for an adequate corrosion evaluation. The effect of increased bromine concentration in the FGD liquor on FGD performance and corrosion of FGD materials of construction needs to be determined. Duct corrosion and air heater plugging also need to be evaluated in a longer-term test. Finally, the effect of increased bromine concentrations on the marketability of the coal combustion by-products must be addressed.

\subsection{REFERENCES}

1. Pavlish, J.H.; Sondreal, E.A.; Mann, M.D.; Olson, E.S.; Galbreath, K.C.; Laudal, D.L.; Benson, S.A. Status Review of Mercury Control Options for Coal-Fired Power Plants. Fuel Process. Technol. 2003, 82 (2, 3), 89-165.

2. Sjostrom, S.; Richardson, C.; Chang, R. Evaluation of Mercury Emissions and Control Options for Great River Energy; Final Report for North Dakota Industrial Commission; Energy \& Environmental Research Center: Grand Forks, ND, June 2001.

3. Chang, R.; Strohfus, M. The Evaluation of Chemical Additives for Mercury Emission Control at Great River Energy; Final Report for the North Dakota Industrial Commission; Energy \& Environmental Research Center: Grand Forks, ND, Jan 2003. 
4. Sun, J.Q.; Crocker, C.R.; Lillemoen, C.M. The Effect of Coal Combustion Flue Gas Components on Low-Level Chlorine Speciation Using EPA Method 26A. J. Air Waste Manage. Assoc. 2000, 50, 936-940.

5. Vosteen, B. et al. Bromine-Enhanced Mercury Abatement from Combustion Flue Gases Recent Industrial Applications and Laboratory Research. GBPowerTech 2006, 86, 70-75.

6. Kanefke, R. et al. Rauchgasreinigung - Abscheidung von Quecksilber und sonstigen Schwermetallen, Aerosolen, Dioxinen und Furanen Haus der Technik, 09 February 2006. 


\section{APPENDIX A}

\section{SAMPLE DATES AND TIMES FOR FLUE GAS SAMPLES AND PROCESS SAMPLES AT MONTICELLO SES UNIT 3}




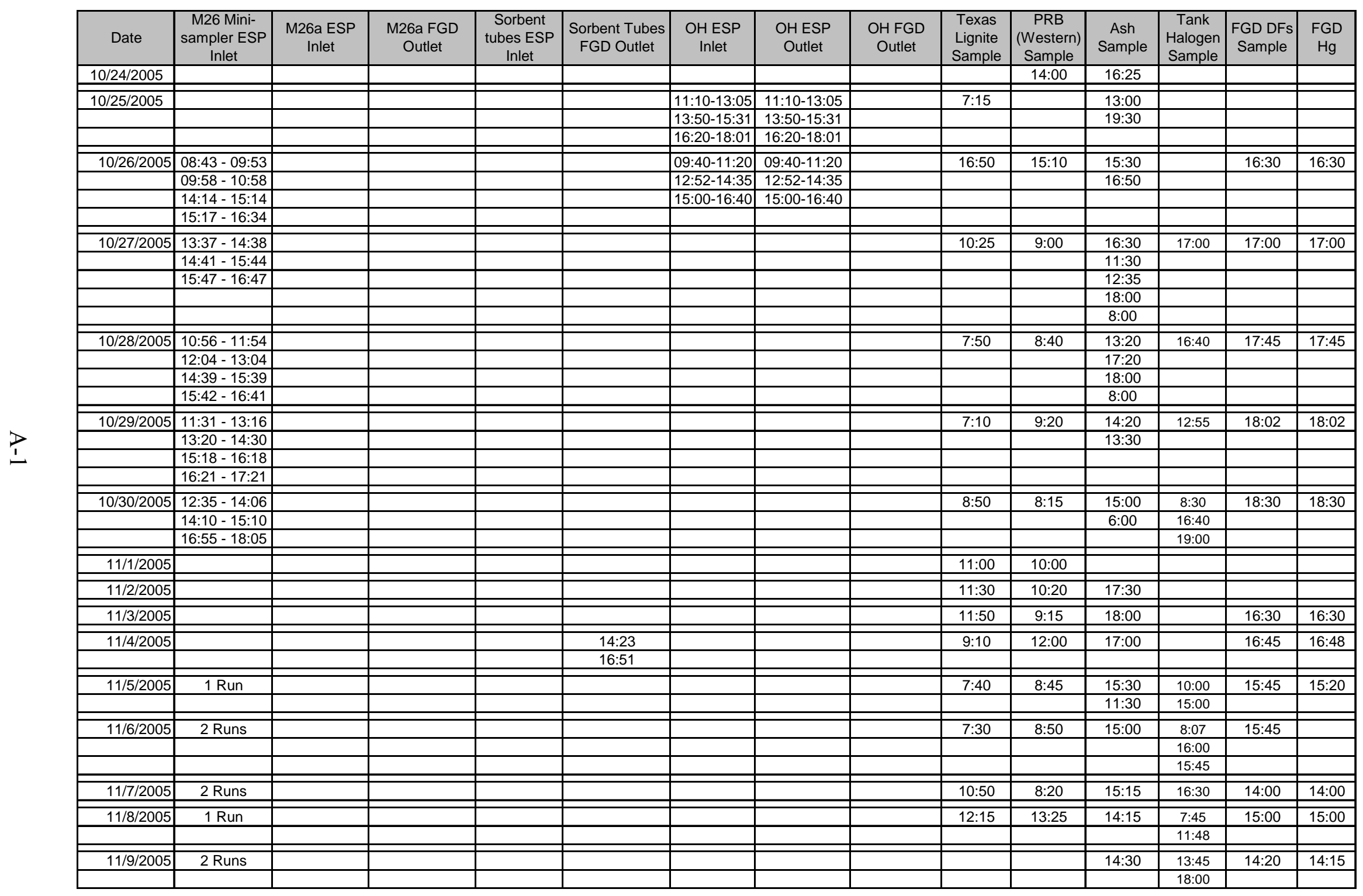




\begin{tabular}{|c|c|c|c|c|c|c|c|c|c|c|c|c|c|c|}
\hline Date & \begin{tabular}{|c|}
$\begin{array}{c}\text { M26 Mini- } \\
\text { sampler ESP } \\
\text { Inlet }\end{array}$ \\
\end{tabular} & $\begin{array}{l}\text { M26a ESP } \\
\text { Inlet }\end{array}$ & $\begin{array}{c}\text { M26a FGD } \\
\text { Outlet }\end{array}$ & $\begin{array}{c}\text { Sorbent } \\
\text { tubes ESP } \\
\text { Inlet } \\
\end{array}$ & $\begin{array}{l}\text { Sorbent Tubes } \\
\text { FGD Outlet }\end{array}$ & $\begin{array}{c}\text { OH ESP } \\
\text { Inlet }\end{array}$ & $\begin{array}{c}\text { OH ESP } \\
\text { Outlet }\end{array}$ & $\begin{array}{c}\text { OH FGD } \\
\text { Outlet }\end{array}$ & $\begin{array}{l}\text { Texas } \\
\text { Lignite } \\
\text { Sample }\end{array}$ & \begin{tabular}{|c|} 
PRB \\
(Western) \\
Sample \\
\end{tabular} & $\begin{array}{l}\text { Ash } \\
\text { Sample }\end{array}$ & \begin{tabular}{|c|} 
Tank \\
Halogen \\
Sample \\
\end{tabular} & $\begin{array}{c}\text { FGD DFs } \\
\text { Sample }\end{array}$ & $\begin{array}{c}\mathrm{FGD} \\
\mathrm{Hg}\end{array}$ \\
\hline $11 / 10 / 2005$ & 3 Runs & & & $15: 16$ & 11:00 & & & & & & $15: 30$ & & $14: 45$ & \\
\hline & & & & & 14:30 & & & & & & & & & \\
\hline $11 / 11 / 2005$ & 2 Runs & & & 14:04 & & & & & & $17: 00$ & $15: 30$ & 10:40 & $15: 35$ & $15: 30$ \\
\hline & & & & & & & & & & & & $10: 35$ & & \\
\hline $11 / 12 / 2005$ & 2 Runs & & & $15: 49$ & & & & & & & $17: 00$ & $12: 30$ & & \\
\hline & & & & & & & & & & & & 9:30 & & \\
\hline $11 / 13 / 2005$ & 2 Runs & & & & & & & & & & $16: 45$ & $12: 35$ & $16: 15$ & $16: 00$ \\
\hline & & & & & & & & & & & & $10: 15$ & & \\
\hline & & & & & & & & & & & & 9:00 & & \\
\hline $11 / 14 / 2005$ & 9:55 & & & 14:11 & 14:17 & & & & $8: 15$ & $14: 00$ & 15:00 & No Time & $15: 30$ & $15: 35$ \\
\hline & & & & $\begin{array}{l}14: 17 \\
10: 53\end{array}$ & 10:53 & & & & & & & & & \\
\hline $11 / 15 / 2005$ & 2 Runs & & & & & & & & & $7: 00$ & $14: 00$ & 11:00 & $11: 37$ & $11: 37$ \\
\hline & & & & & & & & & & & & $15: 15$ & & \\
\hline $11 / 16 / 2005$ & 2 Runs & 8:32-10:09 & 8:32-10:02 & & & $10: 40-12: 22$ & & $10: 40-12: 10$ & $13: 00$ & $7: 00$ & $13: 45$ & 14:15 & 19:15 & $19: 15$ \\
\hline & & $10: 30-12: 06$ & $10: 30-12: 00$ & & & 13:07-14:43 & & $13: 07-14: 37$ & & & & $16: 00$ & & \\
\hline & & $12: 25-14: 02$ & 12:25-13:55 & & & $15: 12-16: 50$ & & $15: 12-16: 42$ & & & & & & \\
\hline $11 / 17 / 2005$ & & & & & & & & & $7: 00$ & $8: 30$ & $11: 50$ & $13: 45$ & $15: 40$ & $15: 40$ \\
\hline $11 / 18 / 2005$ & 2 Runs & & & & & & & & 9:00 & $7: 30$ & 11:25 & & $14: 30$ & $14: 30$ \\
\hline $11 / 29 / 2005$ & $8: 46$ & & & & & & & & days & days & $14: 05$ & $16: 30$ & & \\
\hline $11 / 30 / 2005$ & 4 Runs & & & $14: 17$ & & & & & & & $16: 30$ & & & 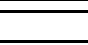 \\
\hline $12 / 1 / 2005$ & 4 Runs & & & $14: 22$ & & & & & days & days & 14:00 & $15: 15$ & & \\
\hline & & & & & & & & & & & & $15: 45$ & & \\
\hline $12 / 2 / 2005$ & & & & & & & & & days & days & $14: 30$ & 18:00 & $10: 10$ & $10: 10$ \\
\hline & & & & & & & & & & & & & & $15: 50$ \\
\hline $12 / 3 / 2005$ & 4 Runs & & & & & & & & days & days & $13: 35$ & & $15: 50$ & \\
\hline$\overline{12 / 4 / 2005}$ & $8: 12$ & & & & & & & & 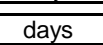 & 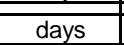 & 11:30 & 11:00 & 111:00 & $\overline{111: 00}$ \\
\hline & $14: 07$ & & & & & & & & & & & $7: 30$ & & \\
\hline & & & & & & & & & & & & $9: 45$ & & \\
\hline $12 / 5 / 2005$ & $11: 15$ & & & & & & & & $15: 00$ & $13: 20$ & $15: 30$ & $20: 00$ & $16: 45$ & $16: 45$ \\
\hline $12 / 6 / 2005$ & $7: 54$ & & & & & & & & $114: 50$ & $\overline{113: 20}$ & $\overline{15: 30}$ & $\begin{array}{c}8: 00 \\
\end{array}$ & $114: 59$ & $\overline{114: 00}$ \\
\hline & $8: 45$ & & & & & & & & & & & $18: 00$ & & \\
\hline & & & & & & & & & & & & $\begin{array}{l}15: 00 \\
12: 15\end{array}$ & & - \\
\hline $12 / 7 / 2005$ & $7: 35$ & & & 13:02 & $13: 02$ & & & & $8: 00$ & 10:00 & $15: 00$ & 12.15 & $13: 08$ & $13: 08$ \\
\hline & $8: 33$ & & & $10: 25$ & $10: 25$ & & & & & & & $15: 30$ & & \\
\hline & & & & 12:01 & & & & & & & & & & \\
\hline $12 / 8 / 2005$ & $8: 18$ & & & & & & & & $14: 50$ & $12: 20$ & 16:00 & $16: 35$ & $15: 28$ & \\
\hline & & & & & & & & & & & & $15: 55$ & 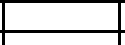 & - \\
\hline & & & & & & & & & & & & $15: 45$ & & \\
\hline
\end{tabular}


APPENDIX B

\section{SCEM DATA ANALYSIS METHODOLOGY FOR MONTICELLO SES UNIT 3}




\section{SCEM DATA ANALYSIS METHODOLOGY FOR MONTICELLO SES UNIT 3}

The mercury semicontinuous emission monitors (SCEMs) use a gold amalgamation column coupled with a cold-vapor atomic absorption (CVAA). The flue gas is conditioned to remove the acid gas constituents (which can harm the gold's ability to adsorb mercury). It is also conditioned either to convert all the mercury to the elemental phase or to remove the oxidized mercury, leaving just the elemental phase. The CVAA can only detect the elemental form of mercury.

A measured flow rate of conditioned flue gas is passed over the gold amalgamation column for a fixed period of time. The flow rate is measured by a mass flowmeter. The flowmeter is calibrated to generate flow rates in the units of normal cubic meters $\left(\mathrm{Nm}^{3}\right)$, where normal means the gas flow has been corrected to $32^{\circ} \mathrm{F}\left(0^{\circ} \mathrm{C}\right)$.

As the flue gas passes over the gold, the mercury in the flue gas adsorbs to the gold. Once a measured quantity of flue gas has passed over the gold, the gold is heated to desorb the mercury. This desorbed mercury is detected by the CVAA. The size of the peak generated by the CVAA correlates to a mass of mercury, as determined by a calibration curve. To produce the mercury concentration in $\mu \mathrm{g} / \mathrm{Nm}^{3}$, the mass of mercury is divided by the volume of flue gas sampled.

These mercury measurements are initially calculated at the actual $\mathrm{O}_{2}$ concentration in the duct. For each mercury concentration, an oxygen concentration is measured. The mercury data are corrected to a $3 \% \mathrm{O}_{2}$ basis in order to account for dilution effects from location to location. The calculation for conversion to $3 \% \mathrm{O}_{2}$ is:

$$
\mathrm{Hg}\left[\mu \mathrm{g} / \mathrm{Nm}^{3} \text { at } 3 \% \mathrm{O}_{2}\right]=\mathrm{Hg}\left[\mu \mathrm{g} / \mathrm{Nm}^{3} \text { at } \mathrm{x} \% \mathrm{O}_{2}\right] \times(20.9-3) /(20.9-\mathrm{x})
$$

where $\mathrm{x}$ represents the actual $\mathrm{O}_{2}$ concentration measured.

Each mercury SCEM produces a datum point every 3 to 7 minutes, depending on the sample time needed to collect a detectable amount of mercury on the gold. The sample time increases as the flue gas mercury concentration decreases.

\section{Methodology for Data Analysis of Parametric Results}

A parametric test condition consists of an oxidation enhancement agent type and an injection rate. Mercury SCEMs were employed at the electrostatic precipitator (ESP) inlet, ESP outlet, and flue gas desulfurization (FGD) outlet locations. An average mercury concentration was calculated for each location at each test condition. Each test condition typically lasted from 2 to 3 hours. During each test period, flue gas mercury concentrations were measured by the SCEMs. The test period was run long enough for the mercury concentrations to reach a steady state. At each location the steady-state data were averaged to generate an average mercury concentration for the test condition. Mercury removals across the ESP, FGD, and ESP/FGD system were calculated for each injection rate using these average mercury concentrations. 


\section{Methodology for Data Analysis of Long-Term Results}

The long-term halogen injection test was run for two 2-week periods. Over this time period, mercury SCEM data were collected every 3 to 7 minutes at the ESP inlet, ESP outlet, and FGD outlet locations. Because of the huge volume of data, the mercury concentrations were reduced to 1-hour averages. These 1-hour averages were used for the plots in this report, and for calculations of percent removal across the ESP and FGD. 
APPENDIX C

\section{METHOD 26 RESULTS}




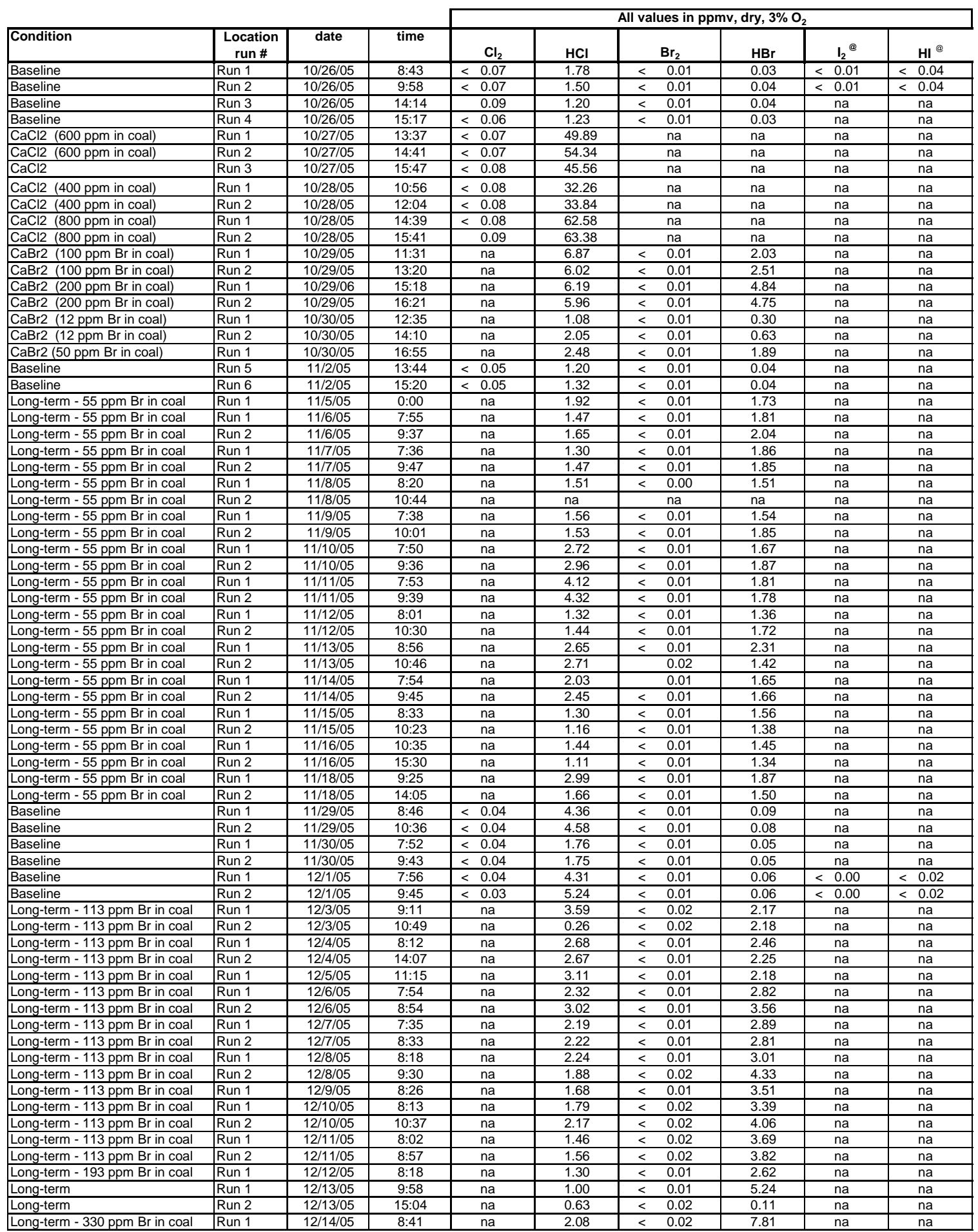


APPENDIX D

\section{MATERIAL BALANCE CALCULATIONS}




\section{MATERIAL BALANCE CALCULATIONS}

Mass balances for mercury were computed for Unit 3 to evaluate the consistency of the SCEM results with the ash, coal, and FGD mercury concentrations. These balances were also used to determine how much mercury was captured by the fly ash as a result of the calcium bromide injection process. As the combustion by-products were not analyzed for mercury on every test day, material balances were computed only for days on which coal, ash, and vapor phase $\mathrm{Hg}$ data existed. Material balances were computed for each of 11 test days between November 2 and December 14, 2005.

The system for the boiler/ESP system is shown in Figure D-1. The basis for determining the mercury content of each stream in the system is now described.

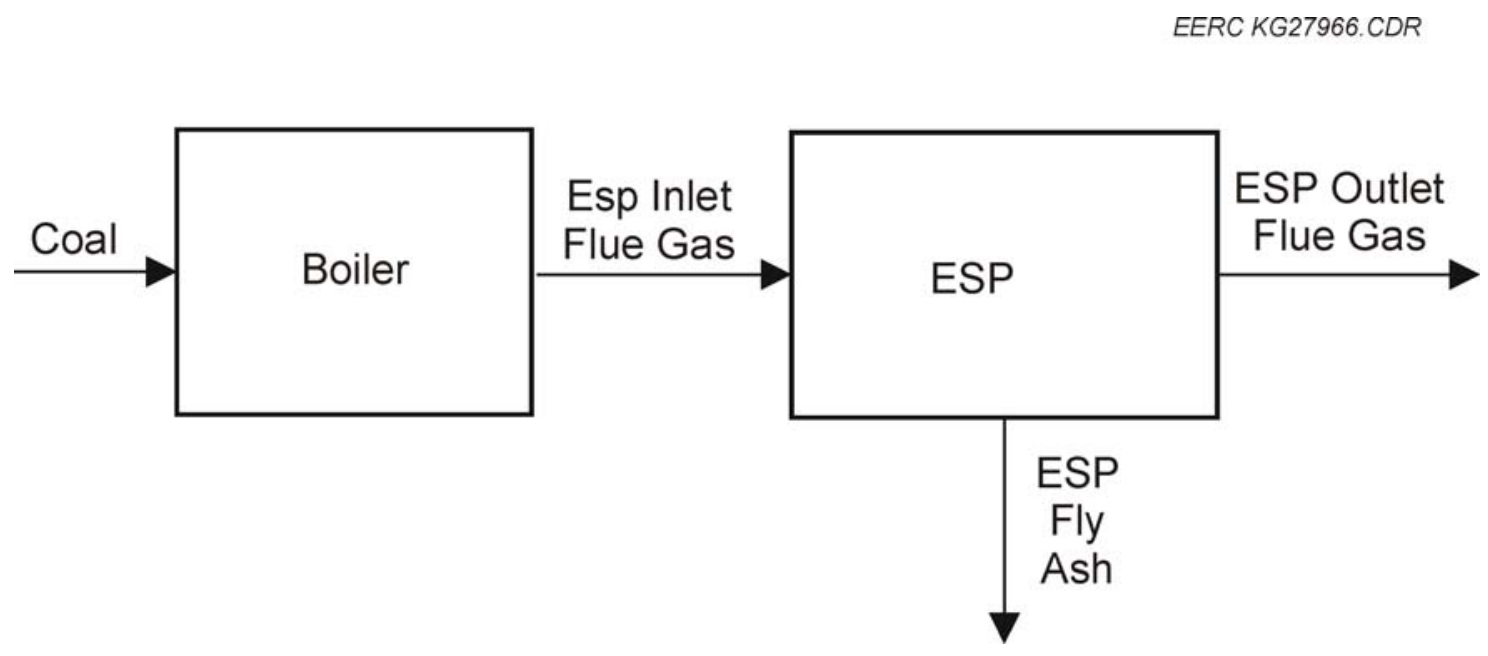

Figure D-1. Components of system mercury balance.

\section{COAL MERCURY}

Monticello Unit 3 fires a blend of PRB and Texas lignite. The mercury content of the inlet coal stream was calculated as:
Coal $_{\mathrm{Hg}}=\left[\left(\right.\right.$ Fraction $\left._{\mathrm{TxL}}\right) \times\left(\mathrm{Hg}_{\mathrm{TxL}}\right)+\left(1-\right.$ Fraction $\left.\left._{\mathrm{TxL}}\right) \times\left(\mathrm{Hg}_{\mathrm{PRB}}\right)\right] \times$ Coal flow $\times(2000 \mathrm{lb} /$ ton $) \times$ $(454 \mathrm{~g} / \mathrm{lb}) /\left(10^{6} \mu \mathrm{g} / \mathrm{g}\right)$

where,

$\mathrm{Coal}_{\mathrm{Hg}}=$ the rate of $\mathrm{Hg}$ entering the system with the coal in $\mathrm{g} / \mathrm{hr}$

Fraction $_{\mathrm{TxL}}=$ the weight fraction of coal fed as Texas lignite

Coal flow $=$ the coal feed rate in tons of dry coal per hour

$\mathrm{Hg}_{\mathrm{TxL}}=$ the mercury content of the Texas lignite in $\mu \mathrm{g} \mathrm{Hg} / \mathrm{g}$ dry coal

$\mathrm{Hg}_{\mathrm{PRB}}=$ the mercury content of the PRB in $\mu \mathrm{g} \mathrm{Hg} / \mathrm{g}$ dry coal 
The coal feed rate in ton/hour was taken from the plant data logger. An average $30 \%$ moisture in the coal was assumed for the purposes of calculating the dry coal feed rate. This assumption is very consistent with the composition analysis results from the two coal types.

The weight fraction of coal fired as Texas lignite was determined from averaging plant data for a 12-hour span around the time the coal was sampled. Monticello Unit 3 has equipment that monitors the Btu/lb content of the coal as it is being loaded into the silos. As Texas lignite and PRB coals have significantly different heating values, it is possible to determine from the on-line heating value data when each coal was being loaded into the silos. It was assumed that both the PRB and Texas lignite were loaded at the same mass feed rate. On some days, the Btu analyzer was not working. In these cases, the fraction of coal loaded as Texas lignite was estimated from the nearest available data.

\section{ASH MERCURY}

Ash was collected on a daily basis from each hopper in the first two fields of the ESP. Because so little ash is collected in downstream fields and the hoppers at Monticello are continually being cleared, it was not possible to take ash samples from the downstream fields. Each hopper sample was analyzed separately. For a given sample time, the measured mercury content from each hopper in the first field was averaged to give a first field average mercury content. The same computation was performed with the second field samples. It was then assumed that $70 \%$ of the collected fly ash was collected in the first field, and $30 \%$ was collected in the second field.

The amount of mercury leaving the system through the fly ash was computed as:

$$
\begin{gathered}
\mathrm{Ash}_{\mathrm{Hg}}=\mathrm{Hg}_{\mathrm{Ash}} \times \text { Coal flow } \times \text { Coal ash } /(1-\text { Moisture }) \times(2000 \mathrm{lb} / \text { ton }) \times(454 \mathrm{~g} / \mathrm{lb}) \times \text { Fraction fly } \\
\text { ash } \times \text { Fraction captured } /\left(10^{6} \mu \mathrm{g} / \mathrm{g}\right)
\end{gathered}
$$

where,

$\mathrm{Ash}_{\mathrm{Hg}}=$ the rate of $\mathrm{Hg}$ leaving the system with the fly ash in $\mathrm{g} / \mathrm{hr}$

$\mathrm{Hg}_{\mathrm{Ash}}=$ the concentration of mercury in the composited ash sample in $\mu \mathrm{g} / \mathrm{g}$, computed as described above

Coal ash $=$ the fraction of ash in the as-received coal, weighted by coal type

Moisture $=$ the fraction of moisture in the as-received coal

Fraction fly ash $=$ the fraction of coal ash that becomes fly ash, assumed as $71 \%$ per engineer at Monticello

Fraction Captured $=$ the fraction of fly ash that is captured in the ESP, assumed as $99 \%$.

\section{Vapor-Phase Mercury}

The mercury in the ESP inlet gas stream was calculated as

ESP Inlet Hg $=\mathrm{Hg}_{\text {ESPIn }} \times$ Flue gas flow rate $\times(60 \mathrm{~min} / \mathrm{hr}) /\left(1 \times 10^{6} \mu \mathrm{g} / \mathrm{g}\right)$ 
where,

ESP Inlet ${ }_{\mathrm{Hg}}=$ the rate of mercury entering the ESP in the flue gas in $\mathrm{g} / \mathrm{hr}$

$\mathrm{Hg}_{\mathrm{ESPI}}=$ the concentration of mercury in the ESP inlet flue gas as measured by the SCEM, in $\mu \mathrm{g} / \mathrm{Nm}^{3}$, dry, $3 \% \mathrm{O}_{2}$

Flue gas flow rate $=$ the flue gas flow rate in $\mathrm{Nm}^{3} / \mathrm{min}$, dry, $3 \% \mathrm{O}_{2}$

The mercury in the ESP outlet gas stream was calculated from an analogous equation. The concentrations used in these equations corresponded to a time 9 hours after the day's coal was sampled. The coal was sampled as it was being loaded to the coal silos, at which point the coal is 8 to 10 hours from being fired.

The stack CEM flow rate is on an actual flow basis that includes moisture. Because the moisture content of the flue gas is not known for all days on which the mercury balance was computed, the calculated flue gas flow rate was used instead. The flue gas flow rate was calculated from the load, heat rate, and composite F-factor. The load and heat rate were taken from plant data at a time 9 hours after the day's coal was sampled. The composite F-factor was computed with the average F-factors calculated from the ultimate/proximate analyses for lignite and bituminous coals, weighted for the Btu fraction of each coal type. The Btu fraction was computed from the weight fraction of Texas lignite (described above) and the heating value of the coal sampled. The heating value used in the balance was determined by the subcontracting laboratory, SGS, not from the plant's Btu analyzer.

\section{Mercury in FGD Byproducts}

The mercury balance across the FGD scrubber was computed on a lb/MMBtu basis. The predicted amount of mercury in the gypsum was calculated from the vapor-phase mercury removal across the FGD (as measured by the SCEMs) and the amount of gypsum produced. This calculation assumed that all of the mercury partitioned to the FGD solid (gypsum) phase. This value was compared to the measured gypsum mercury concentrations.

The predicted gypsum mercury content was calculated as

$$
\mathrm{Hg}_{\text {gypsum,predicted }}=\mathrm{Hg} \text { removal by FGD/Gypsum produced } \times 10^{6}
$$

where,

$\mathrm{Hg}_{\text {gypsum,predicted }}=$ the predicted mercury content of the gypsum, in $\mu \mathrm{g} / \mathrm{g}$ (dry basis) $\mathrm{Hg}$ removal by FGD = the mercury removed by FGD system, in $\mathrm{lb} \mathrm{Hg} / \mathrm{MMBtu}$ fired Gypsum produced $=$ the amount of gypsum produced on a lb gypsum/MMBtu basis

The mercury removal by the FGD was computed on a $\mathrm{lb} \mathrm{Hg} / \mathrm{MMBtu}$ basis with the following equation

$\mathrm{Hg}$ removal by $\mathrm{FGD}=\left(\mathrm{Hg}_{\mathrm{FGDout}}-\mathrm{Hg}_{\text {ESPout }}\right) \times \mathrm{F}$-factor $/\left(35.3 \mathrm{ft}^{3} / \mathrm{m}^{3}\right) \times(492 \mathrm{R} / 528 \mathrm{R}) /$

$$
\left(10^{6} \mu \mathrm{g} / \mathrm{g}\right) /(454 \mathrm{~g} / \mathrm{lb})
$$


where

$\mathrm{Hg}_{\mathrm{FGDout}}=$ the concentration of mercury in the FGD outlet flue gas as measured by the $\mathrm{SCEM}$, in $\mu \mathrm{g} / \mathrm{Nm}^{3}$, dry, $3 \% \mathrm{O}_{2}$

$\mathrm{Hg}_{\mathrm{ESPout}}=$ the concentration of mercury in the ESP outlet flue gas as measured by the $\mathrm{SCEM}$, in $\mu \mathrm{g} / \mathrm{Nm}^{3}$, dry, $3 \% \mathrm{O}_{2}$

$\mathrm{F}$-factor $=$ the standard $\mathrm{F}$-factor for the fuel blend, based on average coal analyses, in dry std $\mathrm{ft}^{3} / \mathrm{MMBtu}$ at 3\% $\mathrm{O}_{2}$ (approximately $11410 \mathrm{dsft}^{3} / \mathrm{MMBtu}$ at 3\% $\mathrm{O}_{2}$ for MoSES U3)

The amount of gypsum produced by the FGD was calculated from the FGD inlet $\mathrm{SO}_{2}$ concentration and the $\mathrm{SO}_{2}$ removal, as recorded by the plant data logger. The equation is as follows:

Gypsum produced $=\mathrm{SO}_{2}{ }^{\text {inlet }} \times \mathrm{SO}_{2}$ removal $/ 100 \times 172.1 \mathrm{lb}$ gypsum $/ 64 \mathrm{lb} \mathrm{SO}$ removed where,

$\mathrm{SO}_{2}{ }^{\text {inlet }}=$ the $\mathrm{SO}_{2}$ concentration in the FGD inlet flue gas, on a lb $\mathrm{SO}_{2} / \mathrm{MMBtu}$ basis

$\mathrm{SO}_{2}$ removal $=$ the percent of $\mathrm{SO}_{2}$ removed by the FGD scrubber (assuming that all flue gas is treated by the FGD scrubber)

The value $\mathrm{SO}_{2}{ }^{\text {inlet }}$ was calculated from the daily coal sulfur analyses of the two coal types and the Btu fraction of each coal fired. The equation was

$$
\mathrm{SO}_{2}{ }^{\text {inlet }}=\text { BtuFraction }_{\mathrm{TxL}} \times \mathrm{S}_{\mathrm{TxL}}+\left(1-\text { BtuFraction }_{\mathrm{TxL}}\right) \times \mathrm{S}_{\mathrm{PRB}}
$$

where,

BtuFraction $_{\mathrm{TxL}}=$ the fraction of coal fired as Texas lignite, on a Btu basis

$\mathrm{S}_{\mathrm{TxL}}=$ the sulfur content of the daily Texas lignite coal sample, in $\mathrm{lb} \mathrm{SO}_{2} / \mathrm{MMBtu}$

$\mathrm{S}_{\mathrm{PRB}}=$ the sulfur content of the daily PRB coal sample, in $\mathrm{lb} \mathrm{SO}_{2} / \mathrm{MMBtu}$

The sulfur content of the coal sample was calculated from the weight percent sulfur value and the heating value of the sample.

\section{Bromine in FGD Byproducts}

The predicted bromine concentration of the FGD by-products was calculated on a $\mathrm{lb}$ $\mathrm{Br} / \mathrm{MMBtu}$ basis.

The theoretical bromine concentration of the FGD liquor was calculated as

$$
\mathrm{Br}_{\mathrm{FGDliquor}, \text { theoretical }}=\left(\mathrm{Br}_{\text {injected }} / \text { Liquor }_{\text {Generated }} \times 10^{6}\right)-\mathrm{Br}_{\mathrm{FGDliquor}, \text { baseline }}
$$


where,

$\mathrm{Br}_{\mathrm{FGDliquor} \text {,theoretical }}=$ the predicted $\mathrm{Br}$ concentration of the liquor, assuming that all of the injected bromine partitions to the FGD liquor, in $\mu \mathrm{g} / \mathrm{g}$, dry basis

$\mathrm{Br}_{\text {injected }}=$ the bromine injected into furnace in $\mathrm{lb} \mathrm{Br} / \mathrm{MMBtu}$

Liquor $_{\text {Generated }}=$ the amount of FGD liquor on a lb/MMBtu basis

$\mathrm{Br}_{\mathrm{FGDliquor}, \text { baseline }}=$ the baseline bromine concentration of the FGD liquor

The amount of bromine injected into the furnace was calculated as

$\mathrm{Br}_{\text {injected }}=\mathrm{Br}_{\text {Furnace }} /$ Coal flow $\times(1-$ Moisture $) /(2000 \mathrm{lb} /$ ton $) \times\left(10^{6} \mathrm{Btu} / \mathrm{MMBtu}\right) \times\left(\right.$ Fraction $_{\mathrm{TxL}} \times$ $\mathrm{HV}_{\mathrm{TxL}}+\left(1-\right.$ Fraction $\left.\left._{\mathrm{TxL}}\right) \times \mathrm{HV}_{\mathrm{PRB}}\right)$

where,

$\mathrm{Br}_{\text {Furnace }}=$ the amount of bromine injected into the furnace, as calculated from pump skid

data on $\mathrm{lb} \mathrm{Br} / \mathrm{hr}$ basis

$\mathrm{HV}_{\mathrm{TxL}}=$ the heating value of the daily Texas lignite coal sample

$\mathrm{HV}_{\mathrm{PRB}}=$ the heating value of the daily PRB coal sample

The FGD liquor amount was calculated as:

Liquor $_{\text {Generated }}=$ Gypsum produced $\times 100 / \mathrm{FGD}_{\mathrm{wt} \% \text { solids }} \times\left(1-\mathrm{FGD}_{\mathrm{wt} \% \text { solids }} / 100\right)$

where,

$\mathrm{FGD}_{\mathrm{wt} \% \text { solids }}=$ the weight percent solids of the FGD slurry. 
Table D-1. Mass Balance Calculations for Long-term Test

Monticello Unit 3 Long-Term Test \#1
\begin{tabular}{|l|r|}
\hline fraction coal ash reporting as fly ash & 0.71 \\
\hline fraction fly ash captured in ESP & 0.99 \\
\hline$\%$ Ash collected in Field 1 & 0.7 \\
\hline$\%$ Ash collected in Field 2 & 0.3 \\
\hline
\end{tabular}

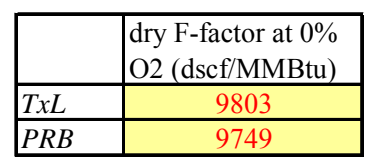

\section{Entered Values:}

\begin{tabular}{|c|c|c|c|c|c|c|c|c|c|}
\hline Date in 2005 & & $11 / 2$ & $11 / 3$ & $11 / 4$ & $11 / 6$ & $11 / 9$ & $11 / 12$ & $11 / 13$ & $11 / 17$ \\
\hline Time Coal Sampled $(*=$ estimated $)$ & & $10: 55$ & & $10: 35$ & $8: 10$ & $8: 00^{*}$ & $8: 00$ & $8: 00^{*}$ & $7: 45$ \\
\hline Time Coal should hit Furnace & & $19: 55$ & & $19: 35$ & $17: 10$ & $17: 00$ & $17: 00$ & $17: 00$ & $16: 45$ \\
\hline Load, Gross at time Coal hit Furnace & MW (gross) & 844 & & 825 & 823 & 816 & 805 & 822 & 848 \\
\hline Time Ash Sampled & & $17: 30$ & & $17: 00$ & $15: 00$ & $14: 30$ & $17: 00$ & $16: 45$ & $11: 50$ \\
\hline Load, Gross at time Ash Sampled & \begin{tabular}{|c}
$\mathrm{MW}$ (gross) \\
\end{tabular} & 845.4 & & 828.8 & 823.7 & 818.4 & 805.4 & 817.1 & 852.7 \\
\hline Hg ESP Inlet by SCEM & $\mu \mathrm{g} / \mathrm{Nm} 3$, dry, $3 \% \mathrm{O} 2$ & 23.01 & & 33.45 & 13.5 & 20.28 & 20.57 & 11.76 & 16.01 \\
\hline Hg ESP Outlet by SCEM & $\mu \mathrm{g} / \mathrm{Nm} 3$, dry, $3 \% \mathrm{O} 2$ & 23.51 & & 28.9 & 11.66 & 24.16 & 13.26 & 16.37 & 4.99 \\
\hline Scrubber Outlet Hg by SCEM & $\mu \mathrm{g} / \mathrm{Nm} 3$, dry, $3 \% \mathrm{O} 2$ & 18.77 & & 14.88 & 7.71 & 7.52 & 13.18 & 7.24 & 14.52 \\
\hline Gross Heat Rate & Btu/kW-h & 10676 & & 10640 & 10607 & 10663 & 10624 & 10642 & 10653 \\
\hline Fraction Texas Lignite by Wt. & wt. Fraction & 0.46 & & 0.57 & 0.55 & 0.59 & 0.61 & 0.54 & 0.52 \\
\hline \begin{tabular}{|l|} 
Texas Lignite $\mathrm{Hg}$ \\
\end{tabular} & $\mu \mathrm{g} / \mathrm{g}$, dry & 0.174 & 0.172 & 0.271 & 0.289 & 0.292 & 0.370 & 0.246 & \#N/A \\
\hline Texas Lignite Ash & $\mathrm{wt} \%$, as recd & 17.1 & & 12.5 & 18.0 & 16.8 & 14.3 & 14.0 & $\# \mathrm{~N} / \mathrm{A}$ \\
\hline Texas Lignite Moisture & $\mathrm{wt} \%$ & 29.6 & & 31.4 & 30.4 & 31.3 & 32.1 & 31.6 & $\# \mathrm{~N} / \mathrm{A}$ \\
\hline Texas Lignite Heating Value & $\mathrm{Btu} / \mathrm{lb}$, as recd & 6560 & & 6972 & 6424 & 6410 & 6603 & 6763 & $\# \mathrm{~N} / \mathrm{A}$ \\
\hline Texas Lignite Sulfur & wt $\%$, as recd & 0.49 & 0.34 & 0.48 & 0.4 & 0.44 & 0.45 & 0.45 & $\# \mathrm{~N} / \mathrm{A}$ \\
\hline PRB Hg & $\mu \mathrm{g} / \mathrm{g}, \mathrm{dry}$ & 0.047 & 0.070 & 0.053 & 0.086 & 0.063 & 0.052 & 0.054 & 0.082 \\
\hline PRB Ash & $\mathrm{wt} \%$, as recd & 5.5 & & 4.5 & 5.0 & 4.8 & 6.0 & 4.4 & 5.0 \\
\hline PRB Moisture & $\mathrm{wt} \%$ & 30.1 & & 30.8 & 31.0 & 30.5 & 31.0 & 30.5 & 30.2 \\
\hline PRB Heating Value & $\mathrm{Btu} / \mathrm{lb}$, as recd & 8070 & & 8134 & 8046 & 8201 & 7953 & 8275 & 8187 \\
\hline PRB Sulfur & $\mathrm{wt} \%$, as recd & 0.33 & 0.36 & 0.31 & 0.34 & 0.35 & 0.34 & 0.28 & 0.31 \\
\hline Ash Br Concentration (Field \#1) & $\mu \mathrm{g} / \mathrm{g}$ & \#N/A & & \#N/A & \#N/A & 2.25 & \#N/A & 3.1 & 3.2 \\
\hline Composite Ash Hg (from URS lab) & $\mu \mathrm{g} / \mathrm{g}$ & \#N/A & & 0.226 & 0.472 & 0.370 & 0.339 & 0.483 & 0.413 \\
\hline Ash Hg Concentrations (Field \#1) & $\mu \mathrm{g} / \mathrm{g}$ & $\# \mathrm{~N} / \mathrm{A}$ & & 0.161 & 0.377 & 0.307 & 0.281 & 0.399 & 0.327 \\
\hline Ash Hg Concentrations (Field \#2) & $\mu \mathrm{g} / \mathrm{g}$ & $\# \mathrm{~N} / \mathrm{A}$ & & 0.378 & 0.694 & 0.517 & 0.474 & 0.680 & 0.613 \\
\hline$\%$ SO2 Removal by Scrubber (excluding bypass) & $\%$ & 85.0 & 84.5 & 83.8 & 85.7 & 85.4 & 93.8 & 90.1 & 90.5 \\
\hline FGD weight $\%$ solids & wt $\%$ & $\# \mathrm{~N} / \mathrm{A}$ & 12.9 & 6.2 & $\# \mathrm{~N} / \mathrm{A}$ & 12.86 & $\# \mathrm{~N} / \mathrm{A}$ & 8.86 & 12.76 \\
\hline Gpysum purity & $\%$ & $\# \mathrm{~N} / \mathrm{A}$ & 99.0 & 96.5 & $\# \mathrm{~N} / \mathrm{A}$ & 97.1 & $\# \mathrm{~N} / \mathrm{A}$ & 97.2 & 98.2 \\
\hline FGD solids Hg concentration & $\mu \mathrm{g} \mathrm{Hg} / \mathrm{g}$ gypsum & $\# \mathrm{~N} / \mathrm{A}$ & 1.50 & 3.16 & 3.24 & 3.24 & $\# \mathrm{~N} / \mathrm{A}$ & 3.61 & 1.48 \\
\hline FGD liquor $\mathrm{Hg}$ concentration & $(\mu \mathrm{g} / \mathrm{L})$ & $\# \mathrm{~N} / \mathrm{A}$ & 3.93 & 3.22 & 2.11 & 4.08 & $\# \mathrm{~N} / \mathrm{A}$ & 3.13 & 163 \\
\hline FGD liquor $\mathrm{Br}$ concentration & $(\mathrm{mg} / \mathrm{L})$ & $\# \mathrm{~N} / \mathrm{A}$ & $\# \mathrm{~N} / \mathrm{A}$ & 35 & \#N/A & 37 & $\# \mathrm{~N} / \mathrm{A}$ & 41 & 55 \\
\hline FGD solids $\mathrm{Br}$ concentration & $(\mathrm{mg} / \mathrm{kg})$ & & & 13 & & 8 & & 10 & 9 \\
\hline
\end{tabular}

\#1. FGD solids Br concentration

$(\mathrm{mg} / \mathrm{kg})$ 


\begin{tabular}{|c|c|c|c|c|c|c|c|c|}
\hline Date in 2005 & $11 / 2$ & $11 / 3$ & $11 / 4$ & $11 / 6$ & $11 / 9$ & $11 / 12$ & $11 / 13$ & $11 / 17$ \\
\hline Time Coal Sampled & $10: 55$ & & $10: 35$ & $8: 10$ & $8: 00$ & $8: 00$ & $8: 00$ & $7: 45$ \\
\hline
\end{tabular}

\section{Weighted average coal values:}

\begin{tabular}{|c|c|c|c|c|c|c|c|c|}
\hline wtd $\mathrm{Hg}$ & wt $\%$, dry & 0.105 & 0.176 & 0.197 & 0.197 & 0.244 & 0.157 & \#N/A \\
\hline wtd ash & $\mathrm{wt} \%$, as recd & 10.78 & 9.07 & 12.06 & 11.90 & 11.08 & 9.62 & $\# \mathrm{~N} / \mathrm{A}$ \\
\hline wtd moisture & $\mathrm{wt} \%$ & 29.9 & 31.2 & 30.7 & 31.0 & 31.7 & 31.1 & $\# \mathrm{~N} / \mathrm{A}$ \\
\hline wtd Btu & $\mathrm{Btu} / \mathrm{lb}$, as recd & 7383 & 7473 & 7162 & 7144 & 7132 & 7455 & \#N/A \\
\hline
\end{tabular}

\section{Calculated Values:}

\begin{tabular}{|c|c|c|c|c|c|c|c|c|}
\hline Fraction Texas Lignite by Btu & Btu Fraction & 0.40 & 0.53 & 0.49 & 0.53 & 0.56 & 0.49 & $\# \mathrm{~N} / \mathrm{A}$ \\
\hline Composite F-factor & dscf/MMBtu at 3\% O2 & 11408 & 11416 & 11414 & 11416 & 11418 & 11414 & \#N/A \\
\hline Gas flow rate (from load, heat rate, and F-Factor) & dscfm at $3 \% \mathrm{O} 2$ & 1713361 & \#\#\#\#\# & 1660721 & 1656064 & \#\#\#\#\# & 1663649 & \#N/A \\
\hline Gas flow rate (from load, heat rate, and F-Factor) & $\mathrm{dNm} 3 / \mathrm{min}$ at $3 \% \mathrm{O} 2$ & 45228 & 44090 & 43838 & 43715 & 42981 & 43916 & \#N/A \\
\hline Coal feed rate (calculated from load and heat rate) & ton/hr (dry) & 428 & 404 & 422 & 421 & 410 & 405 & $\# \mathrm{~N} / \mathrm{A}$ \\
\hline Coal feed rate (from plant data) & ton/hr (dry) & 414 & 424 & 408 & 413 & 424 & 385 & 404 \\
\hline Ash production rate & $\mathrm{lb} / \mathrm{hr}$ & 89444 & 78537 & 99733 & 100175 & 96649 & 75551 & \#N/A \\
\hline $\mathrm{Br}$ feed rate from injection pumps & $\mathrm{lb} / \mathrm{hr}$ & 0 & 0 & 45 & 49 & 45 & 45 & 45 \\
\hline Bromide Rate in ash & $\mathrm{lb} / \mathrm{hr}$ & \#N/A & \#N/A & \#N/A & 0.23 & \#N/A & 0.23 & \#N/A \\
\hline $\mathrm{Hg}$ Concentration from Coal & $\mu \mathrm{g} / \mathrm{dNm} 3$ at $3 \% \mathrm{O} 2$ & 14.4 & 25.7 & 27.6 & 28.3 & 36.6 & 20.9 & \#N/A \\
\hline Mercury Rate in Coal & $\mathrm{g} / \mathrm{h}$ & 39.2 & 68.0 & 72.7 & 74.2 & 94.4 & 55.2 & $\# \mathrm{~N} / \mathrm{A}$ \\
\hline Mercury Rate in Ash & $\mathrm{g} / \mathrm{h}$ & \#N/A & 8.1 & 21.4 & 16.8 & 14.9 & 16.6 & \#N/A \\
\hline Mercury Rate in ESP Inlet Flue Gas SCEM & $\mathrm{g} / \mathrm{h}$ & 62.4 & 88.5 & 35.5 & 53.2 & 53.0 & 31.0 & $\# \mathrm{~N} / \mathrm{A}$ \\
\hline Mercury Rate in ESP Outlet Flue Gas SCEM & $\mathrm{g} / \mathrm{h}$ & 63.8 & 76.5 & 30.7 & 63.4 & 34.2 & 43.1 & \#N/A \\
\hline Mercury Rate in Scrubber Outlet Flue Gas SCEM & $\mathrm{g} / \mathrm{h}$ & 50.9 & 39.4 & 20.3 & 19.7 & 34.0 & 19.1 & \#N/A \\
\hline Scrubber inlet $\mathrm{SO} 2$ concentration (based on coal) & lb SO2/MMBtu & 1.09 & 1.09 & 1.04 & 1.13 & 1.14 & 1.00 & \#N/A \\
\hline Hg removed by scrubber (inlet - outlet Hg by SCEM) & $\mu \mathrm{g} \mathrm{Hg}$ removed/MMBtu & 1427 & 4225 & 1190 & 5015 & 24 & 2751 & $\# \mathrm{~N} / \mathrm{A}$ \\
\hline Amount of gypsum formed & lb gypsum/MMBtu & 2.49 & 2.45 & 2.40 & 2.59 & 2.88 & 2.42 & \#N/A \\
\hline Predicted Hg in Gypsum (if all Hg in gypsum) & $\mu \mathrm{g} \mathrm{Hg} / \mathrm{g}$ gypsum & 1.26 & 3.79 & 1.09 & 4.26 & 0.02 & 2.51 & \#N/A \\
\hline Predicted $\mathrm{Hg}$ in Liquor (if all $\mathrm{Hg}$ in liquor) & $\mu \mathrm{g} \mathrm{Hg} / \mathrm{g}$ liquor & \#N/A & 113.85 & \#N/A & 285.57 & \#N/A & 110.56 & \#N/A \\
\hline Ash Hg / Coal Hg & $\%$ & \#N/A & $12 \%$ & $29 \%$ & $23 \%$ & $16 \%$ & $30 \%$ & \#N/A \\
\hline 1- (Hg in Scrubbed Gas / Coal Hg) & $\%$ & $-30 \%$ & $42 \%$ & $72 \%$ & $73 \%$ & $64 \%$ & $65 \%$ & \#N/A \\
\hline Measured Hg / Predicted Hg in Gypsum & $\%$ & \#N/A & $83 \%$ & $296 \%$ & $76 \%$ & \#N/A & $144 \%$ & \#N/A \\
\hline Measured $\mathrm{Hg}$ / Predicted $\mathrm{Hg}$ in Liquor & $\%$ & \#N/A & $3 \%$ & \#N/A & $1 \%$ & $\# \mathrm{~N} / \mathrm{A}$ & $3 \%$ & $\# \mathrm{~N} / \mathrm{A}$ \\
\hline
\end{tabular}

Measured Hg / Predicted Hg in Liquor

\begin{tabular}{l|l|l|l|l|l|l|l|l|}
$\%$ & \#N/A & 1.7 & 1.5 & \#N/A & 0.8 & \#N/A & 0.9 & 43.0 \\
\hline
\end{tabular}

\begin{tabular}{|c|c|c|c|c|c|c|c|c|c|}
\hline Br injected into furnace & lb Br/MMBtu & 0 & 0 & 0 & 0.0074 & 0.0082 & 0.0077 & 0.0075 & \#N/A \\
\hline Br increase in FGD liquor & $\mathrm{lb} \mathrm{Br} / \mathrm{MMBtu}$ & & & & $\# \mathrm{~N} / \mathrm{A}$ & 0.0001 & $\# \mathrm{~N} / \mathrm{A}$ & 0.0002 & $\# \mathrm{~N} / \mathrm{A}$ \\
\hline$\%$ of injected $\mathrm{Br}$ found in liquor & $\%$ & & & & \#N/A & 1.1 & \#N/A & 3.0 & \#N/A \\
\hline Br increase in FGD solids & $\mathrm{lb} \mathrm{Br} / \mathrm{MMBtu}$ & & & & \#N/A & 0.0000 & \#N/A & 0.0000 & \#N/A \\
\hline$\%$ of injected $\mathrm{Br}$ found in FGD solids & $\%$ & & & & \#N/A & 0.1512 & \#N/A & 0.1178 & \#N/A \\
\hline
\end{tabular}


Table D-2. Mass Balance Calculations for Long-term Test

Monticello Unit 3 Long-Term Test \#2
\begin{tabular}{|l|r|}
\hline fraction coal ash reporting as fly ash & 0.71 \\
\hline fraction fly ash captured in ESP & 0.99 \\
\hline$\%$ Ash collected in Field 1 & 0.7 \\
\hline$\%$ Ash collected in Field 2 & 0.3 \\
\hline
\end{tabular}

\section{Entered Values:}

\begin{tabular}{|c|c|c|c|c|c|c|c|c|c|}
\hline Date in 2005 & & $11 / 29$ & $12 / 1$ & $12 / 2$ & $12 / 5$ & $12 / 7$ & $12 / 9$ & $12 / 11$ & $12 / 14$ \\
\hline Time Coal Sampled $(*=$ estimated $)$ & & $14: 00$ & $14: 00^{*}$ & $14: 00$ & $14: 10$ & 9:00 & $14: 00$ & $14: 00^{*}$ & $13: 15$ \\
\hline Time Coal should hit Furnace & & $23: 00$ & $23: 00$ & $23: 00$ & $23: 10$ & $18: 00$ & $23: 00$ & $23: 00$ & $22: 15$ \\
\hline Load, Gross at time Coal hit Furnace & MW (gross) & 505 & 783 & 813 & 847 & 847 & 847 & 841 & 846 \\
\hline Time Ash Sampled & & $14: 05$ & $14: 00$ & $13: 30$ & $15: 30$ & $15: 00$ & $11: 00$ & $11: 15$ & $14: 25$ \\
\hline Load, Gross at time Ash Sampled & MW (gross) & 504.9 & 850.0 & 842.1 & 841.9 & 834.9 & 842.5 & 836.9 & $\mathrm{n} / \mathrm{a}$ \\
\hline Hg ESP Inlet by SCEM & $\mu \mathrm{g} / \mathrm{Nm} 3$, dry, $3 \% \mathrm{O} 2$ & 27.4 & 19.7 & 9.7 & 8.4 & 12.7 & 6.5 & 16.1 & 26.4 \\
\hline Hg ESP Outlet by SCEM & $\mu \mathrm{g} / \mathrm{Nm} 3$, dry, $3 \% \mathrm{O} 2$ & 23.14 & 22.3 & 9.5 & 8.5 & 11.3 & 8.9 & 19.7 & 29.4 \\
\hline Scrubber Outlet Hg by SCEM & $\mu \mathrm{g} / \mathrm{Nm} 3$, dry, $3 \% \mathrm{O} 2$ & 15.98 & 16.1 & 4.3 & 1.2 & 3.6 & 4.1 & 2.4 & 2.25 \\
\hline Gross Heat Rate & Btu/kW-h & 10455 & 10511 & 10613 & 10713 & 10676 & 10636 & 10660 & 10700 \\
\hline Fraction Texas Lignite by Wt. & wt. Fraction & 0.41 & 0.57 & 0.51 & 0.63 & 0.55 & 0.53 & 0.62 & 0.50 \\
\hline Texas Lignite $\mathrm{Hg}$ & $\mu \mathrm{g} / \mathrm{g}, \mathrm{dry}$ & \#N/A & 0.168 & \#N/A & 0.276 & 0.254 & \#N/A & $\# \mathrm{~N} / \mathrm{A}$ & 0.361 \\
\hline Texas Lignite Ash & wt $\%$, as recd & $\# \mathrm{~N} / \mathrm{A}$ & 18.4 & $\# \mathrm{~N} / \mathrm{A}$ & 13.5 & 15.8 & $\# \mathrm{~N} / \mathrm{A}$ & 23.9 & 19.6 \\
\hline Texas Lignite Moisture & $\mathrm{wt} \%$ & \#N/A & 31.1 & \#N/A & 33.0 & 30.9 & \#N/A & 28.1 & 31.8 \\
\hline Texas Lignite Heating Value & $\mathrm{Btu} / \mathrm{lb}$, as recd & \#N/A & 6326 & $\# \mathrm{~N} / \mathrm{A}$ & 6638 & 6685 & \#N/A & 5957 & 6012 \\
\hline Texas Lignite Sulfur & wt $\%$, as recd & \#N/A & 0.45 & \#N/A & 0.54 & 0.45 & \#N/A & 0.42 & 0.51 \\
\hline PRB Hg & $\mu \mathrm{g} / \mathrm{g}$, dry & 0.037 & 0.078 & 0.066 & 0.075 & 0.064 & $\# \mathrm{~N} / \mathrm{A}$ & 0.080 & 0.067 \\
\hline PRB Ash & $\mathrm{wt} \%$, as recd & \#N/A & 4.9 & 4.7 & 4.4 & 5.2 & 7.2 & 5.3 & 5.8 \\
\hline PRB Moisture & $\mathrm{wt} \%$ & $\# \mathrm{~N} / \mathrm{A}$ & 28.2 & 29.5 & 29.7 & 28.1 & 27.6 & 30.7 & 31.1 \\
\hline PRB Heating Value & Btu/lb, as recd & $\# \mathrm{~N} / \mathrm{A}$ & 8626 & 8274 & 8363 & 8385 & 8236 & 7804 & 8043 \\
\hline PRB Sulfur & $\mathrm{wt} \%$, as recd & \#N/A & 0.37 & 0.39 & 0.31 & 0.37 & 0.4 & 0.38 & 0.36 \\
\hline Ash Br Concentration (Field \#1) & $\mu \mathrm{g} / \mathrm{g}$ & \#N/A & \#N/A & \#N/A & \#N/A & \#N/A & 5.03 & 3.54 & 6.98 \\
\hline Composite Ash Hg (from URS lab) & $\mu \mathrm{g} / \mathrm{g}$ & 0.085 & 0.229 & 0.324 & 0.457 & 0.440 & 0.335 & 0.317 & 0.360 \\
\hline Ash Hg Concentrations (Field \#1) & $\mu \mathrm{g} / \mathrm{g}$ & 0.077 & 0.195 & 0.264 & 0.371 & 0.335 & 0.276 & 0.276 & 0.297 \\
\hline Ash Hg Concentrations (Field \#2) & $\mu \mathrm{g} / \mathrm{g}$ & 0.104 & 0.307 & 0.465 & 0.656 & 0.684 & 0.473 & 0.413 & 0.505 \\
\hline$\%$ SO2 Removal by Scrubber (excluding bypass) & $\%$ & 62.6 & 88.6 & 88.4 & 88.7 & 87.5 & 85.5 & 85.5 & 85.5 \\
\hline FGD weight $\%$ solids & wt $\%$ & $\# \mathrm{~N} / \mathrm{A}$ & \#N/A & 13.29 & 13.15 & 14.03 & \#N/A & 14.51 & 8.94 \\
\hline Gpysum purity & $\%$ & \#N/A & \#N/A & 97.3 & 97.8 & 96.9 & $\# \mathrm{~N} / \mathrm{A}$ & 97.3 & 97.0 \\
\hline FGD solids $\mathrm{Hg}$ concentration & $\mathrm{ppm}$ & \#N/A & \#N/A & 2.46 & 3.21 & 3.30 & 0.89 & 0.48 & 0.33 \\
\hline FGD liquor $\mathrm{Hg}$ concentration & $(\mu \mathrm{g} / \mathrm{L})$ & $\# \mathrm{~N} / \mathrm{A}$ & $\# \mathrm{~N} / \mathrm{A}$ & 6.87 & 6.87 & 4.38 & 262 & 455 & 417 \\
\hline FGD liquor $\mathrm{Br}$ concentration & $(\mathrm{mg} / \mathrm{L})$ & $\# \mathrm{~N} / \mathrm{A}$ & \#N/A & 27 & 72 & 102 & $\# \mathrm{~N} / \mathrm{A}$ & 109 & 145 \\
\hline FGD solids $\mathrm{Br}$ concentration & $(\mathrm{mg} / \mathrm{kg})$ & & & 10 & 10 & & & 19 & 13 \\
\hline
\end{tabular}

\#2. FGD solids Br concentration 


\begin{tabular}{|c|c|c|c|c|c|c|c|c|c|}
\hline Date in 2005 & & $11 / 29$ & $12 / 1$ & $12 / 2$ & $12 / 5$ & $12 / 7$ & $12 / 9$ & $12 / 11$ & $12 / 14$ \\
\hline Time Coal Sampled & & 14:00 & 14:00 & 14:00 & $14: 10$ & 9:00 & 14:00 & 14:00 & $13: 15$ \\
\hline \multicolumn{10}{|l|}{ Weighted average coal values: } \\
\hline wtd $\mathrm{Hg}$ & $\mathrm{wt} \%$, dry & $\# \mathrm{~N} / \mathrm{A}$ & 0.128 & $\# \mathrm{~N} / \mathrm{A}$ & 0.198 & 0.166 & $\# \mathrm{~N} / \mathrm{A}$ & $\# \mathrm{~N} / \mathrm{A}$ & 0.213 \\
\hline wtd ash & $\mathrm{wt} \%$, as recd & $\# \mathrm{~N} / \mathrm{A}$ & 12.56 & $\# \mathrm{~N} / \mathrm{A}$ & 10.10 & 10.95 & $\# \mathrm{~N} / \mathrm{A}$ & 16.75 & 12.66 \\
\hline wtd moisture & $\mathrm{wt} \%$ & $\# \mathrm{~N} / \mathrm{A}$ & 29.8 & $\# \mathrm{~N} / \mathrm{A}$ & 31.8 & 29.6 & $\# \mathrm{~N} / \mathrm{A}$ & 29.1 & 31.5 \\
\hline wtd Btu & Btu/lb, as recd & $\# \mathrm{~N} / \mathrm{A}$ & 7324 & $\# \mathrm{~N} / \mathrm{A}$ & 7285 & 7459 & $\# \mathrm{~N} / \mathrm{A}$ & 6668 & 7028 \\
\hline \multicolumn{10}{|l|}{ Calculated Values: } \\
\hline Fraction Texas Lignite by Btu & Btu Fraction & $\# \mathrm{~N} / \mathrm{A}$ & 0.49 & $\# \mathrm{~N} / \mathrm{A}$ & 0.57 & 0.49 & $\# \mathrm{~N} / \mathrm{A}$ & 0.55 & 0.43 \\
\hline Composite F-factor & dscf/MMBtu at $3 \%$ O2 & $\# \mathrm{~N} / \mathrm{A}$ & 11414 & $\# \mathrm{~N} / \mathrm{A}$ & 11419 & 11414 & $\# \mathrm{~N} / \mathrm{A}$ & 11418 & 11410 \\
\hline Gas flow rate (from load, heat rate, and F-Factor) & dscfm at $3 \% \mathrm{O} 2$ & $\# \mathrm{~N} / \mathrm{A}$ & \#\#\#\#\# & $\# \mathrm{~N} / \mathrm{A}$ & 1726426 & \#\#\#\#\# & $\# \mathrm{~N} / \mathrm{A}$ & 1706226 & \#\#\#\#\# \\
\hline Gas flow rate (from load, heat rate, and F-Factor) & $\mathrm{dNm} 3 / \mathrm{min}$ at $3 \% \mathrm{O} 2$ & $\# \mathrm{~N} / \mathrm{A}$ & 41344 & $\# \mathrm{~N} / \mathrm{A}$ & 45573 & 45396 & \#N/A & 45039 & 45440 \\
\hline Coal feed rate (calculated from load and heat rate) & ton $/$ hr $($ dry $)$ & $\# \mathrm{~N} / \mathrm{A}$ & 395 & $\# \mathrm{~N} / \mathrm{A}$ & 426 & 427 & $\# \mathrm{~N} / \mathrm{A}$ & 475 & 442 \\
\hline Coal feed rate (from plant data) & ton $/$ hr (dry) & 262 & 391 & 414 & 430 & 439 & 404 & 433 & 431 \\
\hline Ash production rate & $\mathrm{lb} / \mathrm{hr}$ & $\# \mathrm{~N} / \mathrm{A}$ & 98353 & $\# \mathrm{~N} / \mathrm{A}$ & 89417 & 96048 & $\# \mathrm{~N} / \mathrm{A}$ & 143853 & 111924 \\
\hline \multirow[t]{2}{*}{ Br feed rate from injection pumps } & $\mathrm{lb} / \mathrm{hr}$ & 0 & 0 & 0 & 100 & 100 & 103 & 95 & 275 \\
\hline & & & & & & & & & \\
\hline Bromide Rate in ash & $\mathrm{lb} / \mathrm{hr}$ & $\# \mathrm{~N} / \mathrm{A}$ & $\# \mathrm{~N} / \mathrm{A}$ & $\# \mathrm{~N} / \mathrm{A}$ & $\# \mathrm{~N} / \mathrm{A}$ & $\# \mathrm{~N} / \mathrm{A}$ & $\# \mathrm{~N} / \mathrm{A}$ & 0.51 & 0.78 \\
\hline Hg Concentration from Coal & $\mu \mathrm{g} / \mathrm{dNm} 3$ at $3 \% \mathrm{O} 2$ & $\# \mathrm{~N} / \mathrm{A}$ & 18.4 & $\# \mathrm{~N} / \mathrm{A}$ & 28.6 & 24.5 & $\# \mathrm{~N} / \mathrm{A}$ & $\# \mathrm{~N} / \mathrm{A}$ & 30.7 \\
\hline Mercury Rate in Coal & $\mathrm{g} / \mathrm{h}$ & $\# \mathrm{~N} / \mathrm{A}$ & 45.7 & $\# \mathrm{~N} / \mathrm{A}$ & 78.3 & 66.7 & $\# \mathrm{~N} / \mathrm{A}$ & $\# \mathrm{~N} / \mathrm{A}$ & 83.8 \\
\hline Mercury Rate in Ash & $\mathrm{g} / \mathrm{h}$ & $\# \mathrm{~N} / \mathrm{A}$ & 10.2 & $\# \mathrm{~N} / \mathrm{A}$ & 18.5 & 19.2 & $\# \mathrm{~N} / \mathrm{A}$ & 20.7 & 18.3 \\
\hline Mercury Rate in ESP Inlet Flue Gas SCEM & $\mathrm{g} / \mathrm{h}$ & $\# \mathrm{~N} / \mathrm{A}$ & $\# \mathrm{~N} / \mathrm{A}$ & $\# \mathrm{~N} / \mathrm{A}$ & \#N/A & $\# \mathrm{~N} / \mathrm{A}$ & $\# \mathrm{~N} / \mathrm{A}$ & $\#$ N/A & $\# \mathrm{~N} / \mathrm{A}$ \\
\hline Mercury Rate in ESP Outlet Flue Gas SCEM & $\mathrm{g} / \mathrm{h}$ & $\# \mathrm{~N} / \mathrm{A}$ & 55.3 & $\# \mathrm{~N} / \mathrm{A}$ & 23.2 & 30.8 & $\# \mathrm{~N} / \mathrm{A}$ & 53.2 & 80.2 \\
\hline Mercury Rate in Scrubber Outlet Flue Gas SCEM & $\mathrm{g} / \mathrm{h}$ & $\# \mathrm{~N} / \mathrm{A}$ & 39.9 & $\# \mathrm{~N} / \mathrm{A}$ & 3.3 & 9.8 & $\# \mathrm{~N} / \mathrm{A}$ & 6.5 & 6.1 \\
\hline Scrubber inlet SO2 concentration (based on coal) & lb SO2/MMBtu & $\# \mathrm{~N} / \mathrm{A}$ & & $\# \mathrm{~N} / \mathrm{A}$ & 1.25 & 1.11 & $\# \mathrm{~N} / \mathrm{A}$ & 1.21 & 1.24 \\
\hline Hg removed by scrubber (inlet - outlet Hg by SCEN & ug Hg removed/MMBtu & $\# \mathrm{~N} / \mathrm{A}$ & & $\# \mathrm{~N} / \mathrm{A}$ & 2200 & 2320 & $\# \mathrm{~N} / \mathrm{A}$ & 5214 & 8177 \\
\hline Amount of gypsum formed & lb gypsum/MMBtu & $\# \mathrm{~N} / \mathrm{A}$ & & $\# \mathrm{~N} / \mathrm{A}$ & 2.97 & 2.61 & $\# \mathrm{~N} / \mathrm{A}$ & 2.79 & 2.85 \\
\hline Predicted Hg in Gypsum (if all Hg in gypsum) & $\mu \mathrm{g} \mathrm{Hg} / \mathrm{g}$ gypsum & $\# \mathrm{~N} / \mathrm{A}$ & & $\# \mathrm{~N} / \mathrm{A}$ & 1.63 & 1.96 & $\# \mathrm{~N} / \mathrm{A}$ & 4.12 & 6.33 \\
\hline \multirow[t]{2}{*}{ Predicted $\mathrm{Hg}$ in Liquor (if all $\mathrm{Hg}$ in liquor) } & $\mu \mathrm{g} \mathrm{Hg} / \mathrm{g}$ liquor & $\# \mathrm{~N} / \mathrm{A}$ & \#DIV/0! & $\# \mathrm{~N} / \mathrm{A}$ & 112.13 & 145.08 & $\# \mathrm{~N} / \mathrm{A}$ & 317.18 & 282.05 \\
\hline & & & & & & & & & \\
\hline Ash Hg / Coal Hg & $\%$ & $\mathrm{\# N/ \textrm {A }}$ & $22 \%$ & $\mathrm{\# N/ \textrm {A }}$ & $24 \%$ & $29 \%$ & $\# \mathrm{~N} / \mathrm{A}$ & $\# \mathrm{~N} / \mathrm{A}$ & $22 \%$ \\
\hline 1- ( $\mathrm{Hg}$ in Scrubbed Gas / Coal Hg) & $\%$ & $\# \mathrm{~N} / \mathrm{A}$ & $13 \%$ & $\# \mathrm{~N} / \mathrm{A}$ & $96 \%$ & $85 \%$ & $\# \mathrm{~N} / \mathrm{A}$ & $\# \mathrm{~N} / \mathrm{A}$ & $93 \%$ \\
\hline Measured Hg / Predicted Hg in Gypsum & $\%$ & $\# \mathrm{~N} / \mathrm{A}$ & $\# \mathrm{~N} / \mathrm{A}$ & $\# \mathrm{~N} / \mathrm{A}$ & $197 \%$ & $169 \%$ & $\# \mathrm{~N} / \mathrm{A}$ & $12 \%$ & $5 \%$ \\
\hline Measured Hg / Predicted Hg in Liquor & $\%$ & $\# \mathrm{~N} / \mathrm{A}$ & $\# \mathrm{~N} / \mathrm{A}$ & $\# \mathrm{~N} / \mathrm{A}$ & $6 \%$ & $3 \%$ & $\# \mathrm{~N} / \mathrm{A}$ & $143 \%$ & $148 \%$ \\
\hline$\%$ of $\mathrm{Hg}$ in liquor & $\%$ & $\# \mathrm{~N} / \mathrm{A}$ & $\# \mathrm{~N} / \mathrm{A}$ & 1.8 & 1.4 & 0.8 & $\# \mathrm{~N} / \mathrm{A}$ & 84.8 & 92.8 \\
\hline Drinioct into firen & th Pr/MMRtt & & & & 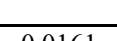 & & & & \\
\hline Br injected into furnace & lb Br/MMBtu & 0 & 0 & & 0.0101 & 0.0157 & \#N/A & 0.0150 & 0.0443 \\
\hline $\begin{array}{l}\mathrm{Br} \text { increase in FGD liquor } \\
\% \text { of injected } \mathrm{Br} \text { in liquor }\end{array}$ & $\frac{\mathrm{lb} \mathrm{Br} / \mathrm{MMBBtu}}{\%}$ & & & & $\frac{0.008}{4.9}$ & $\frac{0.0011}{7.1}$ & $\frac{\# \mathrm{~N} / \mathrm{A}}{\# \mathrm{~N} / \mathrm{A}}$ & $\frac{0.0013}{8.4}$ & $\frac{0.0033}{7.4}$ \\
\hline Predicted Br increase in FGD solids & & & & & 0.0000 & 0.0000 & $\# \mathrm{~N} / \mathrm{A}$ & 0.0000 & 0.0000 \\
\hline$\%$ of injected $\mathrm{Br}$ found in FGD solids & $\%$ & & & & 0.1745 & 0.2380 & $\# \mathrm{~N} / \mathrm{A}$ & 0.2944 & 0.0833 \\
\hline
\end{tabular}

